ISSN: 1806-8405

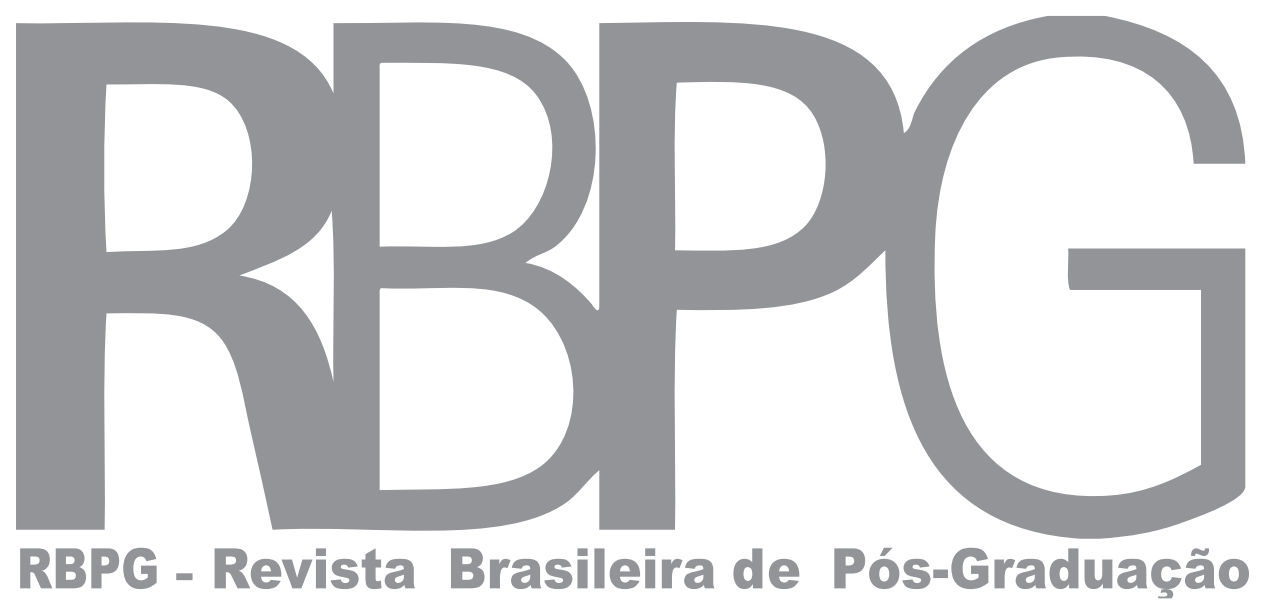


RBPG . Revista Brasileira de Pós-Graduação

Volume 10, número 21, Outubro de 2013

A RBPG . Revista Brasileira de Pós-Graduação, editada pela Fundação Coordenação de Aperfeiçoamento de Pessoal de Nivel Superior (Capes), é uma publicação técnico-científica que se define como um veículo de difusão e debate de ideias, estudos e relatos de experiências sobre a pós-graduação. É também um espaço aberto à comunidade acadêmica para manifestar-se sobre temas relacionados com a formação de recursos humanos de alto nível. Divulga documentos oficiais de políticas para a educação superior, estudos e dados sobre a pós-graduação, discussões e comunicados de interesse da comunidade acadêmica e científica. Os artigos da RBPG estão indexados nos seguintes serviços e/ou publicações (the articles of RBPG are abstracted and indexed in): Academic Search Alumni Edition, Academic Search Complete, Academic Search Elite, Academic Search Premier, Fonte Academica, TOC Premier.

NOTA: Todos os artigos assinados são de responsabilidade exclusiva de seus autores, não refletindo, necessariamente, a opinião desta Agência. Permitida a reprodução total ou parcial, desde que citada a fonte.

\section{Conselho Editorial}

Ana Lúcia Gazzola - UFMG

Carlos Ivan Simonsen Leal - FGV

Carlos Roberto Jamil Cury - UFMG

Cézar Zucco - UFSC

Eloi de Souza Garcia - Inmetro

Robert Evan Verhine - Ufba

\section{Comitê Científico}

Abílio Afonso Baeta Neves - UFRGS

Adalberto Luis Val - Inpa

Amado Luiz Cervo - UnB

Antônio Carlos Lessa - UnB

Benamy Turkienicz - UFRGS

Boaventura de Sousa Santos - Universidade de Coimbra

Eduardo H. Charreau - ANCEFN (Argentina)

Fábio Rubio Scarano - UFRJ

Hebe Vessuri - IVIC (Venezuela)

Heitor Gurgulino de Souza - Unilegis

Hélgio Trindade - Unila

Jair de Jesus Mari - Unifesp

Jesús Julio Castro Lamas - MES (Cuba)

Liovando Marciano da Costa - UFV

Lourival Domingos Possani Postay - Unam

Luiz Edson Fachin - UFPR

Pedro Dolabella Portella - BAM (Berlim, Alemanha)

Pierre Jaisson - Cofecub (França)

Thomas Maack - Cornell University (Nova York, EUA)

Vahan Agopyan - USP

Comissão de análise e julgamento de artigos sobre a pós-graduação brasileira e o desenvolvimento sustentável

Consultar página 901

\section{Pareceristas ad hoc}

Consultar página 903

\section{Editora}

Daniella Maria Barandier Toscano

\section{Apoio Editorial \\ Miriam Monteiro Carvalho \\ Lucineide Antunes Lourenço}

Distribuição e Cadastro de Assinaturas

Astrogildo Brasil

\section{Projeto Gráfico}

Igor Escalante Casenote

Diagramação

Helkton Gomes

Impressão

Neo Gráfica e Editora LTDA

Revisão

Neo Gráfica e Editora LTDA

\section{Periodicidade}

Trimestral

Tiragem

2.000 exemplares

ISSN: 1806-8405

RBPG, v. 10, n. 21, p. 414, outubro de 2013

\section{Endereço para correspondência}

Capes - Coordenação de Aperfeiçoamento de Pessoal de Nivel Superior

Setor Bancário Norte, Qd. 2, Bloco L, Lt. 06

CEP: 70040-020 - Brasília, DF

Caixa Postal 250

E-mail: rbpg@capes.gov.br

URL: http://www2.capes.gov.br/rbpg/

RBPG . Revista Brasileira de Pós-Graduação / v. 10, n. 21 (outubro, 2013) Brasília, Capes, 2013 Trimestral 


\section{Sumário}

Apresentação.

Nota Editorial

Editorial

501

\section{Debates}

Desenvolvimento sustentável, interdisciplinaridade e Ciências Ambientais 509

Arlindo Philippi Junior, Maria do Carmo Sobral, Valdir Fernandes e Carlos Alberto Cioce Sampaio

Os desafios do tema sustentabilidade no ensino da pós-graduação 537

Tadeu Fabrício Malheiros, Mario Alejandro Pérez, Carlos Alberto Cioce Sampaio e Christian Henríquez Zuñiga

A inserção da Química Verde nos programas de pós-graduação em Química do Brasil: tendências e perspectivas 557

Vânia Gomes Zuin

Múltiplos saberes da diversidade em rede: conexões interculturais no debate da inclusão digital na perspectiva dos povos da floresta 577

Ricardo Damasceno Moura

Desenvolvimento sustentável e algumas vulnerabilidades geradas pelo não atendimento de necessidades básicas 601

Wilma de Assis e Maria Elisa Zanella

\section{Experiências}

A experiência do Prodema na pós-graduação brasileira: ciência para a sustentabilidade na UFC 633

Laudemira Silva Rabelo, Melca Silva Rabelo, George Satander Sá Freire, Vládia Ponto Vidal de Oliveira e Patrícia Verônica Pinheiro Sales Lima 
Sustentabilidade e interdisciplinaridade: inovações e desafios dos programas de pós-graduação em Ambiente e Sociedade. 0 caso do Centro de Desenvolvimento Sustentável da Universidade de Brasília 665

Elimar Pinheiro do Nascimento, Mauricio Amazonas e Andréa Vilhena

Comprometimento e alinhamento da pós-graduação da PUC-Rio com o desenvolvimento sustentável

Maurício Nogueira Frota e Fabrício Casarejos Lopes Luiz

Aprendizagem colaborativa, transdisciplinaridade e gestão socioambiental na Amazônia: abordagens para a construção de conhecimento entre academia e sociedade.

Simone Athayde, Wendy-Lin Bartels, Robert Buschbacher e Rosane Duarte Rosa

Seluchinesk

A pós-graduação e a sustentabilidade do abastecimento de comunidades ribeirinhas na Amazônia por meio de água de chuva: da concepção à ação

Nircele da Silva Leal Veloso, Cristiane da Costa Gonçalves, Ronaldo Lopes Rodrigues Mendes, Mário Vasconcellos Sobrinho, Tony Carlos Dias da Costa e Dênio Ramam de Carvalho Oliveira

Inovação e sustentabilidade na indústria da construção: um exercício de ensino no PPGFAU/UnB 795

Raquel Naves Blumenschein, Katia Broeto Miller e Maria Vitoria Ferrari Tomé

\section{Estudos}

Legislação e política ambiental no Brasil: as possibilidades do desenvolvimento sustentável e os riscos do retrocesso ambiental 829

Rodrigo Machado Vilani

As políticas públicas para a agricultura familiar brasileira em clima semiárido: do combate à convivência

Daniel Alves Campelo

Siglas, Termos e Expressões 889

Conselho Editorial

Comitê Científico 896

Comissão de Análise. 901

Pareceristas ad hoc..... 903

Documentos 904

Normas para Colaborações 905 


\section{Apresentação}

Por ocasião da realização da Rio+20 - Conferência das Nações Unidas sobre o Desenvolvimento Sustentável e da celebração do sexagésimo aniversário da fundação, a Capes lançou o livro Contribuição da pós-graduação brasileira para o desenvolvimento sustentável: Capes na Rio+20 com o objetivo de registrar avanços da pós-graduação brasileira sobre a temática do desenvolvimento sustentável.

Em face da relevância do tema, e dando sequência ao esforço de apoiar a reflexão acerca da conjugação harmônica de processos que levem ao desenvolvimento do País, com base nos princípios de viabilidade econômica, justiça social, equilíbrio ambiental e respeito a valores culturais da sociedade, a Capes publica a presente edição da Revista Brasileira de Pós-Graduação (RBPG).

Cabe salientar que, ao tempo em que promove a qualidade na formação de recursos humanos de alto nível e estimula o avanço sobre as fronteiras da ciência, tecnologia e inovação, a Capes abre espaços para a reflexão da pós-graduação a respeito dos desafios presentes na grande agenda do desenvolvimento brasileiro. A questão ambiental, em particular, justamente por se situar na convergência das demandas socioeconômicas com as perspectivas de afirmação de um modelo de desenvolvimento sustentável, tem sido particularmente valorizada ao longo dos últimos anos. Em 2011, foi estabelecida a área de Ciências Ambientais na estrutura do Sistema Nacional de Avaliação da Pós-Graduação, sob responsabilidade da Diretoria de Avaliação, dando visibilidade e revestindo de relevância estratégica temas que se inscrevem nessa grande agenda, como desenvolvimento, planejamento, gestão, uso de tecnologias e educação para a ciência. A título de ilustração, somente a área de Ciências Ambientais conta hoje com 37 cursos de mestrado, seis de doutorado e 25 programas com mestrado e doutorado, mostrando o acerto na criação de nova área na Capes. A criação dessa área, inclusive, traduz a valorização crescente, nos diversos programas da Capes, do enfoque multidisciplinar e interdisciplinar na pós-graduação brasileira. 
Atenta à necessidade do fomento à pesquisa científicotecnológica e à inovação, assim como à formação de quadros qualificados voltados aos desafios presentes e futuros de temas como energia, produção de alimentos, qualidade de vida nas metrópoles, água e recursos hídricos, entre tantos outros, a Capes igualmente apoia a realização de projetos de pesquisa por meio do financiamento de ações como o Programa Ciências do Mar e Programa Pró-Amazônia: Biodiversidade e Sustentabilidade. Ao longo da Rio+20, a fundação firmou parceria com a Vale, que permitiu o estabelecimento do Prêmio Vale-Capes de Ciência e Sustentabilidade. A premiação reconhece as melhores teses de doutorado e dissertações de mestrado que busquem soluções inovadoras para questões como a redução de consumo de água; eficiência energética; redução, o reaproveitamento e a reciclagem de resíduos sólidos.

Em outra ponta, na promoção da articulação entre a pósgraduação e a educação básica, a Capes tem incentivado ainda a criação de mestrados profissionais com o objetivo de qualificar professores das redes públicas de ensino fundamental e médio em todo o Brasil. A exemplo do Programa de Mestrado Profissional em Matemática em Rede Nacional (Profmat) - primeiro curso de formação continuada stricto sensu aprovado no formato semipresencial -, estão em construção outras propostas voltadas a essa modalidade de pós-graduação, inclusive para a criação de um mestrado profissional em rede nacional na área de Ciências Ambientais, com vistas à qualificação de professores para questões socioambientais. Por meio desses programas e de outras iniciativas dirigidas aos professores da educação básica, espera-se estimular e disseminar o conhecimento, a pesquisa e o interesse sobre essa agenda o mais cedo possível, de preferência já nas salas de aula.

Ao fim, agradeço, em nome da Capes, a disponibilidade e a dedicação de todos aqueles que trabalharam para a publicação deste número, principalmente, dos autores, dos avaliadores e dos membros da comissão de análise e julgamento de artigos.

Jorge Almeida Guimarães

Presidente 


\section{Nota Editorial}

Em resposta ao Edital $n^{\circ}$ 036/2012/CAPES, 43 artigos foram submetidos para análise. Após todo o processo de avaliação das colaborações, que envolveu 75 consultores de diversas áreas do conhecimento, apresentamos este número temático da Revista Brasileira de Pós-Graduação (RBPG), que contém 13 artigos sobre a pós-graduação e o desenvolvimento sustentável.

Em face da agenda que a temática impõe, optamos nessa edição por exibir imagens que remetem a tópicos presentes na Rio+20 - Conferência das Nações Unidas sobre o Desenvolvimento Sustentável. São eles: água, energia, mobilidade, produção sustentável de alimentos e proteção ambiental.

Os professores Arlindo Philippi Junior e Maria do Carmo Martins Sobral, organizadores deste projeto, assinam o editorial desta revista.

Daniella Maria Barandier Toscano

Editora 


\section{Editorial}

Desde o gradual reconhecimento em termos globais da relevância da questão ambiental, a partir de meados da década de 1960, a temática da sustentabilidade ganhou importância em todo o planeta. Esse movimento pode ser definido como uma crescente demanda de institucionalização das questões ambientais na sociedade como um todo.

Marcos do processo de institucionalização foram as conferências internacionais promovidas pelas Nações Unidas sobre meio ambiente, como a de Estocolmo, 1972, a Rio-92 e, mais recentemente, a Rio+20, que impulsionaram a institucionalização nas esferas governamentais, da sociedade civil e do mercado nos diversos países.

Esse processo se materializou em ações de gestão, arcabouço legal e aparato institucional e se constituiu também como área de conhecimento e campo específico de pesquisa que vem permeando diversas áreas.

Nesse contexto, há crescentes esforços no sentido de vencer os inúmeros desafios que se apresentam para o estabelecimento de um padrão de desenvolvimento em bases sustentáveis. A Conferência sobre Desenvolvimento Sustentável e Meio Ambiente, a Rio+20, foi parte reconhecida desses esforços, que se somam a diversos outros, como aqueles no campo da pesquisa na temática ambiental, sobretudo considerando a sua natureza interdisciplinar.

Ao mesmo tempo em que as disciplinas devem avançar na consolidação de seus métodos, temáticas como a das questões ambientais e do desenvolvimento sustentável, de natureza complexa e transversal, impulsionam a troca de saberes e a necessidade eminente de colaboração.

Em 2012, a Capes lançou o Edital n 036 com o objetivo de chamar artigos para esta edição da Revista Brasileira de Pós-Graduação (RBPG), que trata da pós-graduação e de suas associações com princípios 
do desenvolvimento sustentável. Diante da efervescência e atualidade da temática, e de seus desafios, este número especial da RBPG traz 13 artigos que abordam o tema, especialmente considerando sua transversalidade e suas interdisciplinaridades, por meio de debates, experiências e estudos de caso.

Abrindo a edição e a seção Debates, em Desenvolvimento Sustentável, Interdisciplinaridade e Ciências Ambientais, Philippi Jr. et al. apresentam o debate sobre interdisciplinaridade na pesquisa e na pós-graduação, com foco nas ciências ambientais. É colocada em discussão a institucionalização da interdisciplinaridade e das ciências ambientais na pós-graduação brasileira, evidenciando alguns desafios e caminhos para um futuro próximo.

No segundo artigo, Os desafios do tema sustentabilidade no ensino da pós-graduação, Malheiros et al. trazem elementos relativos aos desafios de implementar pesquisa e ensino sobre sustentabilidade no contexto da pós-graduação no Brasil, sugerindo, assim, características aplicadas aos currículos e à perspectiva dos programas de pósgraduação no trato das questões relativas à sustentabilidade. Pela indissociabilidade dos temas inseridos na sustentabilidade, os autores destacam sua natureza interdisciplinar e seu papel enquanto mudança de valores.

No terceiro artigo, A inserção da Química Verde nos programas de pós-graduação em Química do Brasil: tendências e perspectivas, Zuin aborda formas pelas quais os princípios da Química Verde têm sido inseridos nos programas brasileiros de pós-graduação em Química. Considerando a importância do tema para a sustentabilidade, o artigo evidencia a existência de um processo com disciplinas, grupos, linhas e projetos de pesquisa que podem contribuir significativamente para repensar as formas de geração de materiais e instituir processos verdes.

No quarto artigo, Múltiplos saberes da diversidade em rede: conexões interculturais no debate da inclusão digital na perspectiva dos povos da floresta, Moura apresenta análise relativa à inclusão digital no espaço amazônico, tendo em vista que as políticas públicas de inclusão digital não se estendem para essas populações; portanto, advoga-se 
pela sua inclusão, levando em conta o reconhecimento de suas culturas e o direito ao exercício da cidadania.

Completando a seção Debates, em Desenvolvimento sustentável e algumas vulnerabilidades geradas pelo não atendimento de necessidades básicas, Assis e Zanella abordam as vulnerabilidades individuais e sociais possiveis de serem geradas pelo não atendimento de necessidades humanas. As autoras defendem a importância de abordagens econômicas considerarem e aproximarem-se da complexidade, por meio de indicadores de sustentabilidade e de valores humanos, abordando o contexto de transição de um modelo de desenvolvimento considerado insustentável para outro, sustentável.

Ao abrir a seção Experiências, Rabelo et al. assinam o sexto artigo, intitulado A experiência do Prodema na pós-graduação brasileira: ciência para a sustentabilidade na UFC, em que são apresentadas as contribuições do Programa de Pós-Graduação em Desenvolvimento e Meio Ambiente da Universidade Federal do Ceará para a formação de profissionais e cientistas abertos ao trabalho interdisciplinar em contextos complexos, frente às questões relacionadas ao desenvolvimento sustentável.

No artigo Sustentabilidade e Interdisciplinaridade: inovações e desafios dos programas de pós-graduação em Ambiente e Sociedade. O caso do Centro de Desenvolvimento Sustentável da Universidade de Brasília, Nascimento, Amazonas e Vilhena apresentam a experiência do Centro de Desenvolvimento Sustentável da Universidade de Brasília (CDS / UnB), evidenciando inovações e desafios desse centro, que construiu sua identidade no binômio sustentabilidade e interdisciplinaridade.

Com o artigo Comprometimento e alinhamento da pósgraduação da PUC-Rio com o desenvolvimento sustentável, Frota e Luiz refletem sobre a experiência da Pontifícia Universidade Católica do Rio de Janeiro (PUC-Rio) com o desenvolvimento sustentável, em consonância com as recomendações das conferências das Nações Unidas sobre esse aspecto. Apontam que a construção de comprometimento com relação ao tema ocorre por meio de ação integrada da universidade e discorrem sobre uma experiência relacionada a um programa de pós-graduação 
da instituição.

Aprendizagem colaborativa, transdisciplinaridade e gestão socioambiental na Amazônia: abordagens para a construção de conhecimento entre academia e sociedade, de Athayde et al., reflete sobre duas experiências na formação de líderes para a gestão socioambiental colaborativa na Amazônia, envolvendo a perspectiva interdisciplinar quando integra teorias e métodos de diferentes disciplinas e a perspectiva transdisciplinar quando aproveita experiências de gestão participativa e aprendizagem colaborativa envolvendo academia e sociedade, integrando perspectivas e conhecimentos de diferentes atores sociais.

Em seguida, em A pós-graduação e a sustentabilidade do abastecimento de comunidades ribeirinhas na Amazônia por meio de água de chuva: da concepção à ação, Veloso et al. dão sequência à necessária discussão sobre a integração entre academia e sociedade, por meio de experiência integradora de dois programas de pós-graduação na implementação de alternativas de aproveitamento da água da chuva para fins potáveis, visando contribuir para a sustentabilidade do abastecimento local.

Fechando a seção de Experiências, em Inovação e sustentabilidade na indústria da construção: um exercício de ensino no PPG/FAUUnB, Blumenschein, Miller e Tomé apresentam os resultados do desenvolvimento da ferramenta Cais (Concepção e Análise em Inovação e Sustentabilidade) para a estruturação do raciocínio e análise de projetos, para que gerem resultados em sinergia com a inovação e sustentabilidade da indústria da construção.

Abrindo a seção Estudos, em Legislação e política ambiental no Brasil: as possibilidades do desenvolvimento sustentável e os riscos do retrocesso ambiental, Vilani traz análise da apropriação do ideal de desenvolvimento sustentável, enquanto compromisso intergeracional firmado pelas principais leis ambientais federais, assim como pela Constituição Federal brasileira.

Completando a edição, o artigo de Campelo, As políticas públicas 
para a agricultura familiar brasileira em clima semiárido: do combate à convivência, discute as ideologias das políticas públicas de combate à seca, realizadas no início do século XX, comparando-as com as políticas de convivência com o clima semiárido, que trazem uma nova configuração de estratégia para a sustentabilidade do desenvolvimento local.

Por fim, cumpre ressaltar que a experiência da pós-graduação brasileira apresenta grande amplitude, destacando-se que os artigos publicados nesta edição da RBPG representam apenas uma pequena amostra da riqueza dessa experiência nas diversas áreas do conhecimento, que têm se debruçado e atuado na temática do desenvolvimento do País em bases sustentáveis.

Arlindo Philippi Jre Maria do Carmo Martins Sobral 


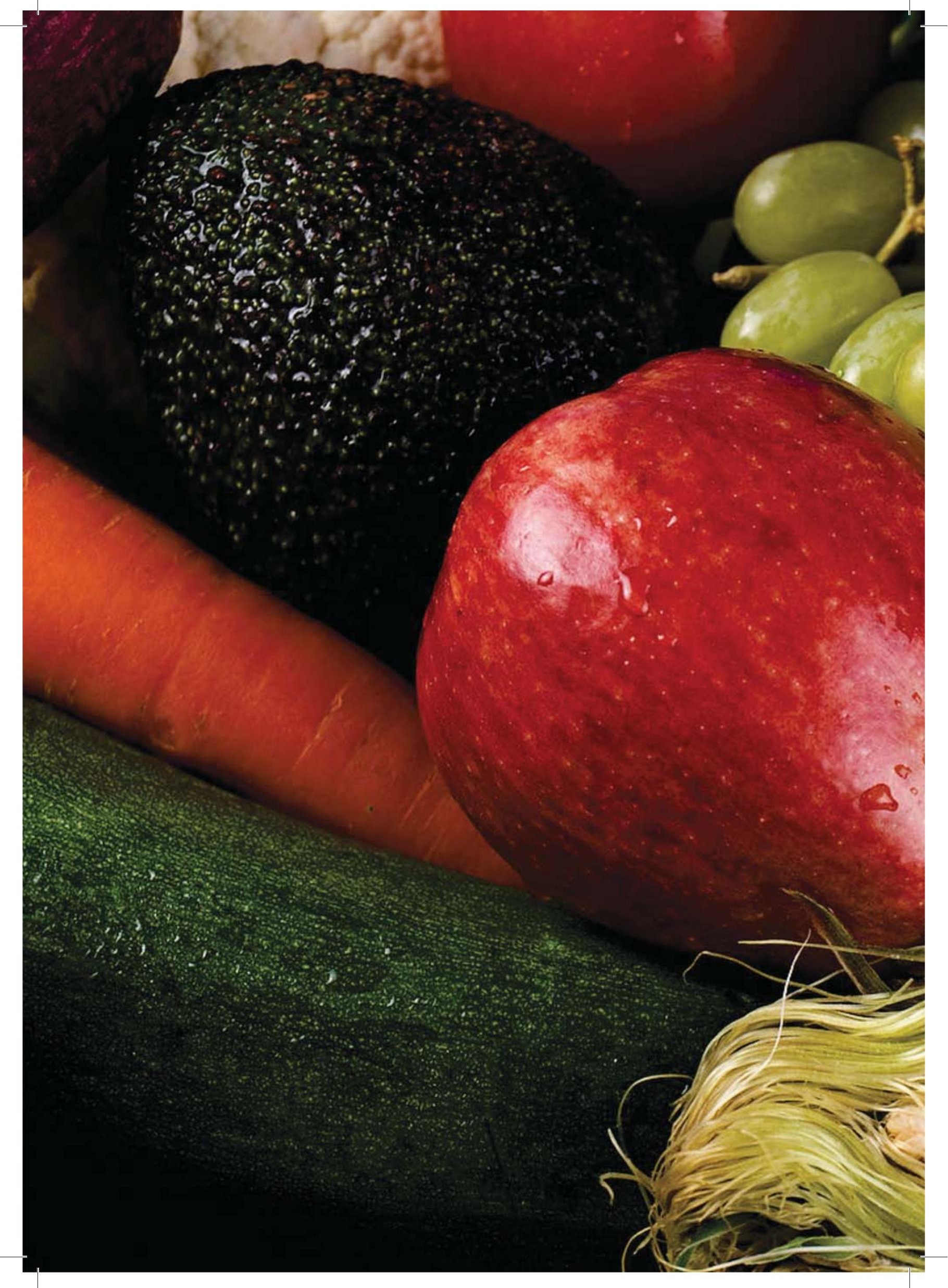




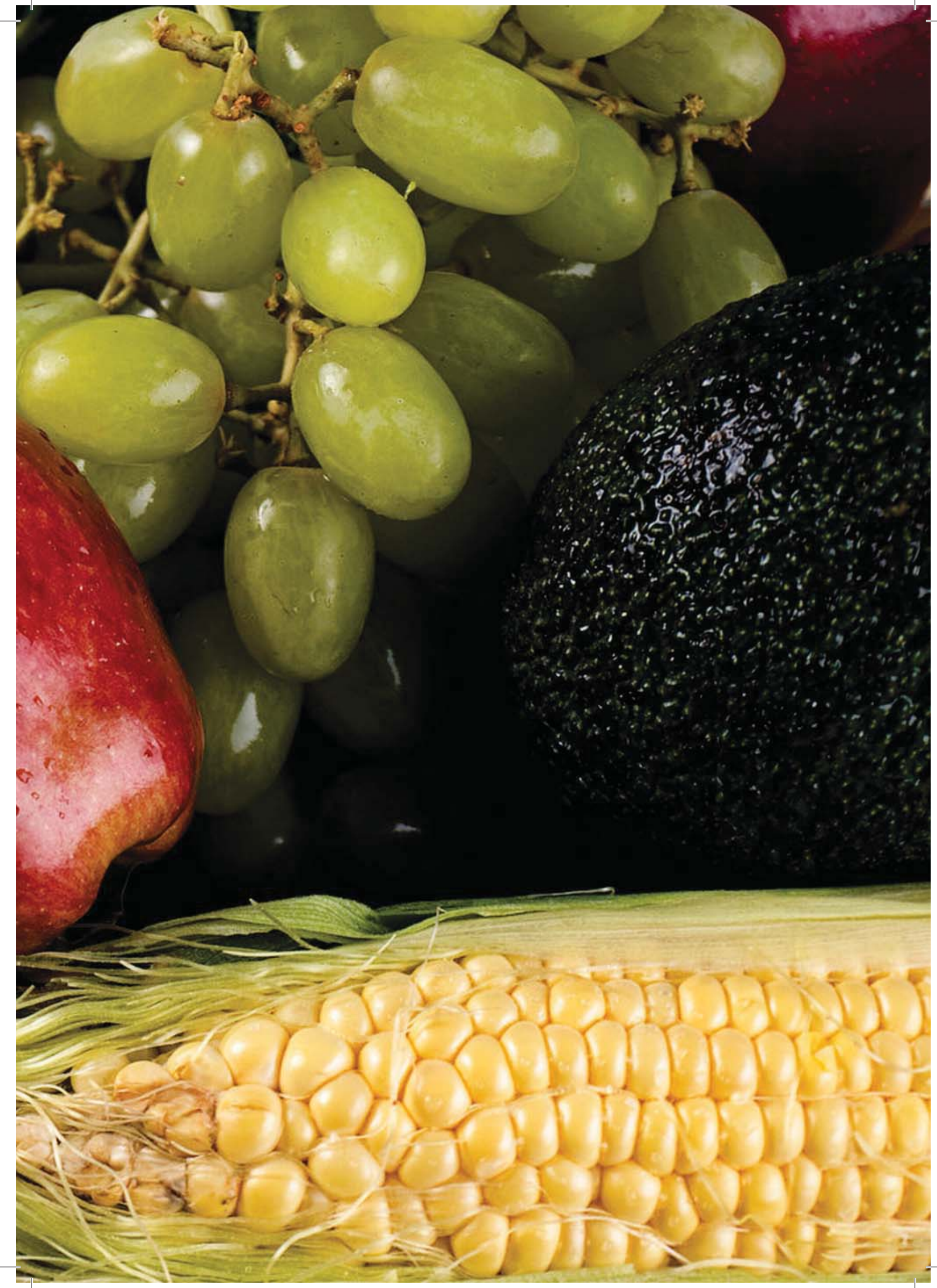




\section{Desenvolvimento sustentável, interdisciplinaridade e Ciências Ambientais}

\section{Sustainable development, Interdisciplinary and Environmental Sciences}

\section{Desarrollo sostenible, interdisciplinaridad y Ciencias Ambientales}

Arlindo Philippi Jr., doutor em Saúde Pública e professor titular da Universidade de São Paulo (USP). Endereço: Av. Dr. Arnaldo, 715. CEP: 01246-904 - São Paulo, SP. Telefone: (11) 3061-7117/ 7118. E-mail:aphij@usp.br.

Maria do Carmo Sobral, doutora em Planejamento Ambiental, pósdoutora no Instituto de Tecnologia Ambiental pela Universidade Técnica de Berlim e professora da Universidade Federal de Pernambuco (UFPe). Endereço: Departamento de Engenharia Civil da UFPE, Rua Acadêmico Helio Ramos, s/n - Cidade Universitária. CEP: 21010-470 - Recife, PE. Telefone: (81) 2126-8744. E-mail: msobral@ufpe.br.

Valdir Fernandes, doutor em Engenharia Ambiental pela Universidade Federal de Santa Catarina, pós-doutor em Saúde Ambiental pela USP e professor da Universidade Positivo (UP). Endereço: Av. Prof. Pedro Viriato Parigot de Souza, 5300. CEP: 81280-330 - Curitiba, PR. Telefone: (41) 3317-3460. E-mail: vfernandes@up.edu.br.

Carlos Alberto Cioce Sampaio, doutor em Engenharia da Produção pela Universidade Federal de Santa Catarina, pós-doutor em Ecossocioeconomia pela Universidade Austral do Chile e professor da Universidade Federal do Paraná (UFPR). Endereço: Programa de Pós-Graduação em Gestão Urbana, Escola de Arquitetura e Design, $2^{\circ}$ andar - Pontifícia Universidade Católica do Paraná. Rua Imaculada Conceição, 1155 - Prado Velho. CEP: 80215-901 
- Curitiba, PR. Telefone: (41) 3024-5284. E-mail: carlos.cioce@ gmail.com.

\section{Resumo}

O tema deste artigo insere-se no debate sobre interdisciplinaridade na pesquisa e na pós-graduação, com foco nas ciências ambientais. Tem por objetivo apresentar discussão acerca da institucionalização da interdisciplinaridade e das Ciências Ambientais na pós-graduação brasileira, a partir da vivência dos autores, de análise documental e pesquisa bibliográfica. A partir dos dados da evolução da pós-graduação brasileira, apresenta-se a institucionalização e discutese a prática interdisciplinar na pesquisa de pós-graduação em Ciências Ambientais, evidenciando caminhos e desafios para um futuro próximo.

Palavras-chave: Desenvolvimento Sustentável. Interdisciplinaridade. Ciências Ambientais. Pós-Graduação. Pesquisa Integrada.

\section{Abstract}

This article addresses the debate concerning interdisciplinarity in research as well as in graduate study in Brazil, with a focus on the environmental sciences. It aims at presenting a discussion about the institutionalization of interdisciplinarity and graduate study in the environmental sciences, based on the experience of the authors, documental analyses and bibliography evaluation. Using data about the evolution of graduate study in Brazil, it discusses the perspectives and challenges that will be faced by the environment sciences in the near future.

Keywords: sustainable development, interdisciplinarity; environmental sciences; graduate study; integrated research. 


\section{Resumen}

El tema de este artículo es parte del debate sobre la interdisciplinariedad en la investigación y el posgrado, con un enfoque en las Ciencias Ambientales. Tiene como objetivo presentar las discusiones acerca de la institucionalización de la interdisciplinariedad y de las Ciencias Ambientales en cursos de posgrado brasileños, teniendo en cuenta la experiencia de los autores, el análisis documental y la revisión de la literatura. Con base en los datos de la evolución del posgrado brasileño, se presenta la institucionalización y se discute la práctica interdisciplinaria en la investigación del posgrado en Ciencias Ambientales, mostrando caminos y desafíos para el futuro próximo.

Palabras clave: Desarrollo Sostenible. Interdisciplinariedad. Ciencias Ambientales. Posgrado. Investigación Integrada.

\section{Introdução: a questão ambiental e o desenvolvimento sustentável}

A preocupação com o desenvolvimento sustentável evoluiu a partir da percepção da sociedade de que os recursos naturais são finitos, acentuando-se na década de 70 com a crise do petróleo, que até então era encarado por muitos como abundante e inesgotável. A crise acabou por gerar sérios danos econômicos, causando recessão, inflação e desemprego em vários países, e suscitou questionamentos a respeito dos modelos de desenvolvimento adotados.

Crescentes reflexões sobre acidentes ambientais ocorridos e a necessidade de revisão de paradigmas então vigentes estimularam países e a comunidade internacional a desenvolver ações conjuntas. A Conferência das Nações Unidas sobre Meio Ambiente e Desenvolvimento, conhecida como Rio 92, foi um marco na universalização da temática ambiental, quando foi marcado o direito das pessoas de viverem em um meio ambiente com a qualidade que permita uma vida com dignidade e bem-estar (PNUMA, 2002).

O conceito 'desenvolvimento sustentável' consolidou-se na Rio 92 como um processo de transformação em que a exploração dos 
recursos, a direção dos investimentos, a orientação do desenvolvimento tecnológico e a mudança institucional se harmonizam, a fim de atender às necessidades e aspirações humanas presentes e futuras (CMMAD, 1991).

O surgimento da expressão desenvolvimento sustentável está atrelado tanto ao despertar humano quanto ao limite dos recursos naturais disponíveis no planeta Terra, assegurando o acesso às condições básicas de saúde e educação e o respeito aos costumes, às tradições e à legitimidade das instituições. Tudo isso dentro de uma perspectiva de interligação em redes de caráter local, regional, nacional e internacional.

Movimentos internacionais das últimas décadas trouxeram gradualmente à tona a questão do desenvolvimento sustentável e reconheceram também que a solução da problemática socioambiental implica necessariamente mudanças profundas na organização do conhecimento. Tal envergadura de proposta pressupõe reorganizar formatos de pesquisa e ensino, que demandam visão sistêmica da realidade e ações e métodos de caráter interdisciplinar. Essas mudanças já se fazem presentes em centros acadêmicos e institutos de pesquisa, como também na prática diária de várias instituições de setores governamentais e não governamentais.

Ainda nesse enfoque, outro aspecto da complexidade inerente a essa temática é que o paradigma de desenvolvimento leva a um duplo imperativo ético: a solidariedade sincrônica com a geração atual e a solidariedade diacrônica com as gerações futuras (SACHS, 2002). Assim, os aspectos culturais emergem do campo social tendo um papel distinto e de integração no desenvolvimento sustentável, em que a cultura é definida de forma ampla como sendo o complexo das questões de distinção espiritual, material, intelectual e emocional que caracteriza uma sociedade ou grupo social. Incluindo não somente artes e literatura, mas modos de viver, direitos fundamentais do ser humano, sistema de valores, tradições e crenças (UNESCO, 1995). A sustentabilidade do desenvolvimento demanda, então, valorização e proteção desse capital cultural, tendo como base de sustentação a proteção dos ecossistemas e dos recursos naturais. 
Esse entendimento amplo da questão ambiental e suas várias interfaces com as dimensões da sustentabilidade impulsionaram, na segunda metade do século passado, movimentos importantes, leis e arranjos institucionais para tratar e efetivar as novas relações desse cenário emergente.

A Política Nacional de Meio Ambiente, estabelecida pela Lei Federal $n^{\circ}$ 6.938/1981, conceitua meio ambiente como "o conjunto de condições, leis, influências e interações de ordem física, química e biológica que permite, abriga e rege a vida sob todas as formas”. Esse é um conceito jurídico indeterminado e, como tal, de amplo conteúdo. A implementação dessa política requer ações governamentais que assegurem a gestão dos recursos ambientais, entendida como o ato de administrar, dirigir ou reger os ecossistemas em que se insere o homem, individual e socialmente, em um processo de interação entre as atividades que exerce, buscando a proteção dos recursos naturais e das características essenciais do entorno, de acordo com padrões de qualidade (PHILIPPI JR.; ROMÉRO; BRUNA, 2004).

Um dos importantes instrumentos estabelecidos pela Política Nacional de Meio Ambiente é a Avaliação de Impactos Ambientais, que vem contribuindo para a solução ou minimização de conflitos entre o desenvolvimento econômico e a conservação ambiental. São instrumentos que envolvem multiplicidade de disciplinas, de áreas de conhecimento diversas (exatas, humanas, médicas e biológicas), e que necessariamente devem ser integradas, de forma interdisciplinar, em um objetivo comum, que é analisar a viabilidade ambiental de políticas, planos, programas e projetos de empreendimentos significativamente impactantes, sejam eles de natureza pública ou privada, possibilitando a minimização dos impactos provocados e o estabelecimento de medidas mitigadoras e compensatórias.

Registra-se também a inserção da dimensão ambiental em várias esferas, como a construção de amplo aparato institucional e extenso marco legal. Exemplo disso tem sido o tratamento de disciplinas transversais de educação ambiental e a proposição do Sistema Nacional de Educação Ambiental (Sisnea), que visa dar organicidade ao conjunto 
de ações de educação ambiental no Brasil, relacionando-se com outros sistemas de gestão.

No plano da educação superior e de ciência e tecnologia, a questão ambiental também despertou interesse desde cedo. Várias disciplinas passaram a se debruçar sobre a questão ambiental, estudando aspectos técnicos, tecnológicos, comportamentais, de planejamento, de gestão e de educação associados a questões variadas, como tratamento e prevenção dos efeitos de atividades poluidoras, planejamento e uso de recursos naturais, descarte de resíduos, uso e ocupação do solo, uso e conservação da água, poluição atmosférica, entre tantos outros aspectos amplos ou específicos que passaram a fazer parte das agendas de pesquisa (RAYNAUT; ZANONI, 2011).

De acordo com Jollivet e Pavé (2000, p. 56), em nível internacional "as pesquisas sobre meio ambiente emergiram de uma dupla interrogação: a primeira de origem científica e a segunda de origem social”. A origem científica, mais antiga, provém do esforço de apreensão da natureza, enquanto a origem social, mais recente, surge enquanto problema de pesquisa transversal ao modelo disciplinar. Essa transversalidade remete a duas questões fundamentais: uma relativa ao objeto e outra, como consequência da primeira, de natureza epistemológica e metodológica de estudo do objeto. A que se refere ao objeto diz respeito ao que se entende por meio ambiente e, diante dos impactos gerados pelas atividades antrópicas nesse meio, o que se entende por problemas ambientais. As de fundo epistemológico e metodológico referem-se a como é tratado o objeto, se é compreensível apenas por meio de estudos disciplinares isolados ou se remete necessariamente a um campo específico de natureza multidisciplinar que envolve análises de caráter interdisciplinar. Partindo dessas duas questões, é possível tomar ciência da dificuldade que é compreender o meio ambiente e, consequentemente, a problemática que envolve os impactos antrópicos e a conservação e destruição da natureza ante as dinâmicas sociais, como objeto científico, principalmente a partir de sua origem e contexto de desenvolvimento socioeconômico (BERKES, 2005).

No que se refere ao objeto meio ambiente ou à problemática ambiental, fazendo um resgate histórico recente, pode-se dizer que 
tal tema emerge na década de 1960 com a tomada de consciência dos problemas ambientais, quando começou a tornar-se conhecido, seja por meio do enfrentamento de problemas práticos de pequenas e grandes proporções no dia a dia, seja pela retórica ambientalista. Os primeiros questionamentos sobre a degradação ambiental, ligando-a ao crescimento populacional, econômico e aos sistemas produtivos, dão-se a partir do relatório Limites do Crescimento (1968), publicado pelo chamado Clube de Roma, em que se alertava para os perigos do crescimento ilimitado".

Com os eventos do início da década de 1970, como a já mencionada crise do petróleo, que anunciava um eminente colapso energético e dos recursos naturais, cresceu notavelmente a percepção sobre os problemas ambientais. A discussão superou o âmbito dos ambientalistas e tornou-se um tema cada vez mais debatido pela sociedade, bem como por organismos oficiais, como as Nações Unidas e suas conferências internacionais.

Todavia, a discussão não se limitou aos órgãos oficiais. Inúmeros fóruns paralelos (os chamados Fóruns Globais e, mais recentemente, os Fóruns Sociais Mundiais) foram realizados, de forma que a discussão extrapolou o âmbito oficial, chegando até a sociedade civil organizada, ao mesmo tempo em que extrapolou também a discussão puramente ambiental. A questão ambiental aparece como a expressão de uma crise muito maior que permeia todos os aspectos das sociedades. Os fóruns - principalmente a partir do Fórum Global do Rio em 1992 - passaram a funcionar como espaço de discussão, em que se pode apresentar e constatar a multidimensionalidade das crises deflagradas pela questão ambiental. Os problemas sociais, culturais, políticos, econômicos, de gênero e étnicos tomam parte da discussão na busca de soluções. Mais recentemente, conforme expresso na abertura do Fórum Social Mundial em Porto Alegre (2003), os fóruns têm por objetivo ser espaços abertos para reflexão, cujo objetivo é o debate democrático de ideias, a formulação de propostas, a troca livre de experiências e a articulação para ações de entidades e movimentos da sociedade civil.

A problemática ambiental emergiu, então, como fenômeno social e político na diversidade de representações no contexto das primeiras
Esse relatório é também conhecido como Relatório Meadows. Encomendado pelo Clube de Roma em 1968, foi elaborado pelos técnicos do MIT (Massachussets Institute of Technology), sob a coordenação de Donella Meadows, Jorgen Randers e Denis Meadows. 
conferências e fóruns (HOGAN; VIEIRA, 1992; VIEIRA; BERKES; SIEXAS, 2005), ao mesmo tempo em que foram as conferências e os fóruns que primeiro deram legitimidade e oxigenaram o tema, de forma a tornar o meio ambiente e a questão ambiental campo de pesquisa. É, portanto, um campo de pesquisa que nasceu da emergência de uma realidade empírica em nível global, que ganha espaço na institucionalidade de vários países. A problemática ambiental surge como realidade social, política e institucional, impulsionando e sendo impulsionada pela pesquisa científica, pelo contexto internacional, pelas instituições supranacionais e pelos movimentos sociais e ambientalistas, surgidos a partir dos anos de 1960.

Passado praticamente meio século da emergência da problemática socioambiental, pode-se dizer, alinhando-se com Vieira (2001), que, por um lado, continua-se a tratá-la como um efeito colateral ou incômodo a ser contornado:

\footnotetext{
Transcorridas quase três décadas desde a realização da Conferência de Estocolmo, em 1972, não seria um exagero afirmar que continuamos a lidar com a crise socioambiental como se ela representasse apenas uma perturbação intempestiva, uma espécie de ruído de fundo a ser tratado de forma reativa e fragmentada [...]. Isto nos leva a admitir que, no plano das mudanças efetivas de comportamento, a crise socioambiental constitui um item ainda marginal da agenda de preocupações cotidianas da maior parte da população do planeta (p. 9).
}

Por outro lado, diante dos riscos de sua simplificação, ocasionada principalmente pela excessiva compartimentação disciplinar, cresce uma corrente de formadores de opinião que insistem no caráter interdependente da interseção de problemas sociais e ambientais, bem como de seu pluralismo de visões. Nesse sentido, Vieira (2001) afirma que "o desafio crucial reside, antes, numa ruptura drástica com todas as representações da questão ambiental herdeiras do reducionismo economicista e da tecnociência burocratizada” (p. 9). Ou seja, as suas afirmações sugerem que a complexidade da problemática ambiental não se restringe à destruição da natureza. Visão compartilhada por outros pesquisadores como Morin (2010), Serres (1990), Berkes (2005), Sachs (1986), Leff (2001) e Dansereau (1999), que apontam para essa interdependência. 
Nessa perspectiva, o conceito de problemática ambiental, como retrato de um amplo espectro que vai desde problemas locais, como a poluição de um rio por efluentes de uma empresa até as condições insalubres e de miséria dos grandes centros urbanos (GARCíA, 1994), emerge como uma problemática socioambiental, resultado da forma como a sociedade, nos seus vários setores, relaciona-se com a natureza (FERNANDES; SAMPAIO, 2008). Ela surge como uma problemática econômica, tecnológica, social, institucional e cultural (LEIS, 1999; VIEIRA, 2009).

No mesmo sentido, conforme ratifica Leff (2001, p. 111), o conceito de problemática ambiental é, consequentemente, um conceito ligado de maneira direta às atividades sociais: "A questão ambiental é uma problemática de caráter eminentemente social: esta foi gerada e está atravessada por um conjunto de processos sociais”. Ela emerge, ainda, continua Leff, “como uma problemática social de desenvolvimento, propondo a necessidade de normatizar um conjunto de processos de produção e de consumo que, sujeitos à racionalidade econômica e à lógica do mercado, degradam o ambiente e a qualidade de vida” (Ibidem, p. 130). Toda a gama de processos de destruição ecológica não está desconectada da degradação socioambiental, que vai da perda de fertilização dos solos à marginalização social (GARCíA, 1994).

Segundo Leff (2001), os problemas socioambientais só existem em decorrência das formas de apropriações do mundo e da natureza a partir das relações sociais e de poder, que se materializam por meio da economia, da política, da ciência, da religião e assim por diante. 0 desafio da atualidade está em compreender a complexidade embutida na dinâmica dos sistemas socioambientais e de sua articulação com a biosfera (VIEIRA, 2001).

Por esse motivo, esses autores (VIEIRA, 1992; LEFF, 2001; SACHS, 1993) adotam a expressão problemática socioambiental, privilegiando uma visão de interdependência entre sociedade e natureza, que, segundo Davidson-Hunt e Berkes (2003), afasta-se da dicotomia natureza e sociedade para voltar-se para como os processos ligam a natureza e a sociedade, em diferentes escalas espaciais e temporais. Trata-se de uma 
estratégia eminentemente interdisciplinar que enfoca o relacionamento dos seres humanos entre si e com o meio ambiente. É a problemática ambiental a partir da interação de processos sociais e ecológicos em uma perspectiva que procura integrar homem e natureza e superar as dicotomias, privilegiando uma visão sistêmica e complexa; portanto, uma discussão acerca da problemática ambiental compreendida a partir das relações entre os processos cultural/sociedade e natural/natureza. Essa abordagem difere de outras teorias de corte cartesiano, positivista, iluminista e pragmatista, que mantiveram a separação entre a natureza e a sociedade, embora tenham fornecido modelos sofisticados de como a natureza e a sociedade se articulam e se influenciam. Trata-se de procurar fornecer a sustentação para a aproximação interdisciplinar, enfatizando que os sistemas são caracterizados por processos nãolineares e por equilíbrios múltiplos (MORIN, 2010). Em vez da estabilidade, a imprevisibilidade em relação à mudança do sistema (PRIGOGINE; STENGERS, 1984). Além disso, trata-se de uma perspectiva que inclui o homem como parte da natureza em vez da dicotomia homem versus natureza (DAVIDSON-HUNT e BERKES, 2003).

Nessa perspectiva, a pesquisa sobre a problemática socioambiental diz respeito, fundamentalmente, ao reconhecimento da relação de interdependência entre sociedade e natureza. Consequentemente, é, por definição, um estudo que requer um enfoque interdisciplinar do relacionamento e da interdependência entre seres humanos e natureza. Os problemas ambientais emergem a partir da interação de processos sociais e ecológicos e podem ser examinados dentro de um contexto de parâmetros sociais e ambientais, assim como espaciais e temporais. Trata-se de uma problemática que constitui um campo de pesquisa aglutinador de inúmeras disciplinas, implicando pesquisas interdisciplinares. A pesquisa ambiental se revela não como um tema novo, mas como uma aglutinação de temas antigos já abordados amplamente pelas disciplinas especializadas, envolvendo a análise de processos biológicos, físicos, químicos, hidrológicos, entre outros, que estão relacionados aos problemas econômicos e sociais mediados pela ciência e tecnologia. É novo, porém, porque implica simultaneamente um enfoque totalizante e sistêmico, no sentido de 
englobar disciplinas já existentes, como também implica a articulação e redefinição dessas mesmas disciplinas (PHILIPPI JR.; TUCCI; HOGAN, 2000).

A sua construção enquanto objeto da pesquisa científica tem exigido a coordenação e integração de diversos campos do conhecimento científico (AíMOLA, 2002). Conforme afirma Leis (1999), a complexa interrelação dos problemas ambientais com a economia, com a política e com a cultura em geral sugere que a problemática ambiental compreende um amplo espectro de niveis de conhecimentos e de práticas que incluem as ciências naturais e humanas, a tecnologia, a cultura e a filosofia em sentido amplo. Essa complexidade obriga os cientistas a colocarem suas análises no contexto de uma profunda transformação cultural que faça convergir as ciências naturais e as tecnológicas com as sociais.

Nesse mesmo sentido, a problemática ambiental implica que todo conjunto de disciplinas, tanto das ciências naturais e tecnológicas como das sociais, internalize um saber ambiental, para que se possa efetivamente construir um conhecimento capaz de "captar a multicausalidade e as relações de interdependência dos processos de ordem natural e social que determinam as mudanças socioambientais" (LEFF, 2001, p. 109). A internalização desse saber deve resultar, por sua vez, em um pensamento complexo e uma metodologia de pesquisa interdisciplinar, bem como uma "epistemologia capaz de fundamentar as transformações do conhecimento, induzidas pela questão ambiental” (Ibidem). Só assim é possivel restabelecer a conexão entre o social e o natural, que historicamente foi minimizada pelas pesquisas e que, mais recentemente, tem se limitado a internalizar normas ecológicas e tecnológicas às teorias e às políticas econômicas, deixando à margem a análise do conflito social e o terreno estratégico do político que atravessam o campo ambiental (LEFF, 2001).

A intermediação desse processo se dá principalmente por meio do que Habermas (1994) considerou em sua análise como sendo uma "racionalidade científica", ligada à institucionalização do "progresso científico", responsável pelas mudanças de paradigma, segundo a concepção de Thomas Kuhni. Nesse sentido, a problemática 
socioambiental, no contexto da construção das ciências ambientais (ABRAMOVAY, 2002), traz um amplo processo de transformação do saber e uma crítica aos modelos de racionalidade científica, induzindo à construção de um saber de natureza interdisciplinar que se contrapõe à fragmentação e adequação do objeto às dinâmicas das disciplinas; portanto, as disciplinas devem se adequar a esse novo campo, que demanda pesquisas integradas, interdisciplinares.

O meio ambiente enquanto campo de pesquisa implica, portanto, a discussão acerca da fragmentação do conhecimento e da necessidade de ruptura do modelo disciplinar em favor de um modelo mais integrativo. De acordo com Leff (2001), o “saber ambiental” está ainda em um processo de construção e não se constitui em um conhecimento acabado, nem homogêneo, já que depende absolutamente do contexto ecológico, sociocultural e econômico que, por sua vez, está em constante transformação. No contexto das ciências ambientais, torna-se fundamental, portanto, a prática da interdisciplinaridade. Diante disso, o objetivo deste artigo é discutir alguns aspectos e caminhos dessa prática, orientada para os princípios da sustentabilidade, particularmente tendo em vista o contexto de programas de pós-graduação.

\section{Criação da área de Ciências Ambientais no Sistema Nacional de Pós- Graduação}

Atualmente, segundo dados da Capes e do CNPq, para cada 100 mil habitantes, o Brasil tem 65 pesquisadores, enquanto na Europa esse número é de cerca de 1670, nos EUA, 1270, no Japão, 740, e na China, 665. São números que demonstram que o Brasil dispõe ainda de pouca massa crítica, comparativamente a esses países. Além disso, essas mesmas fontes dão conta de que o País forma mais de 10 mil doutores por ano, e, embora esse dado signifique um aumento de $600 \%$ em relação ao início da década de 1990, em países desenvolvidos esse número fica entre 30 mil e 45 mil doutores. Portanto, há uma defasagem não só na comparação com os grandes centros mundiais, como também em relação às demandas que o País enfrenta, considerando as várias crises que assolam as comunidades. 
Importante mencionar também que, em 2011, havia no Brasil 3.397 programas de pós-graduação responsáveis por 5.080 cursos. Desses, 2.925 em nivel de mestrado, 1.738 em nivel de doutorado e 417 mestrados profissionais. 0 número de alunos desses programas, em 2010, era de cerca de 173 mil matriculados, sendo que mais de um terço deles (aproximadamente 67 mil) contava com bolsas dos sistemas Capes e CNPq, sendo 41 mil de mestrado acadêmico e 26 mil de doutorado. 0 número de professores ligados aos programas de pósgraduação, em 2009, era de 57.270. No contexto do Sistema Nacional de Pós-Graduação, que possui um sistema de acompanhamento, avaliação e credenciamento de programas realizados pela Capes, existiam, em 2012, 48 áreas de conhecimento que avaliavam a totalidade dos cursos de pós-graduação stricto sensu do País (CAPES, 2011b; 2011c).

Devido às suas características, foi criada pela Capes a Área Interdisciplinar, que em 2010 reunia 249 programas credenciados, com 312 cursos, distribuídos em quatro câmaras: (i) Meio Ambiente e Agrárias; (ii) Ciências Sociais Aplicadas e Humanidades; (iii) Engenharia, Tecnologia e Gestão; e (iv) Ciências Biológicas e de Saúde. A Área Interdisciplinar é também uma das áreas da Capes com maior demanda de propostas, o que, associado aos critérios rigorosos de avaliação da área, representa uma dificuldade maior para receber a recomendação para aprovar um curso. Além dos critérios que normalmente caracterizam uma boa proposta em áreas disciplinares, nessa área deve-se levar em conta a característica interdisciplinar estabelecida para o desenvolvimento de pesquisa e formação de pessoas. A formação de pessoas e a produção de conhecimento esperados devem refletir concepção e método de trabalho interdisciplinar (CAPES, 2011b; 2011c).

Esses números e critérios demonstram uma efervescência interdisciplinar na comunidade acadêmica. E isso não só no Brasil. Seguramente, a complexidade das questões que se colocam ao mundo contemporâneo tem levado pesquisadores a ver que tais questões não podem mais ser tratadas apenas no âmbito disciplinar e que para a obtenção de respostas que possam ser mais efetivas e duradouras são necessários conhecimentos de variadas áreas. 
Daí surge com naturalidade a efervescência da interdisciplinaridade, como concepção, processo e forma de produzir conhecimentos, impulsionada pela necessidade de interligar saberes e ampliar a cooperação técnico-científica, algo que docentes e pesquisadores que atuam de modo interdisciplinar passam a incorporar em suas práticas. Compartilhar informações passa a ser algo inerente ao processo em que não há como avançar sem compartilhá-las reciprocamente entre os diversos enfoques disciplinares, como elementos de base para que exista a interdisciplinaridade.

\section{A institucionalização das Ciências Ambientais no Brasil}

No bojo da efervescência interdisciplinar, foi criada em 2011 pela Capes a CACiAmb (Coordenação de Área de Ciências Ambientais), como área de acreditação para programas de pós-graduação (Portaria 81, de 06 de junho de 2011). Segundo o Documento de Área de Ciências Ambientais (CAPES, 2011a), essa área foi composta inicialmente por cursos de pósgraduação relacionados à temática ambiental, existentes na CAlnter (Coordenação de Área Interdisciplinar); portanto, já com histórico de pesquisa, uma vez que a CAlnter completou 10 anos de existência no ano de 2010. O surgimento dessa temática, enquanto campo de pesquisa e área de conhecimento, constitui parte do processo de institucionalização da questão ambiental na própria sociedade como um todo.

Ainda segundo a Capes (2011a), a Área de Ciências Ambientais tem como data simbólica de sua criação em 2011 o Dia do Meio Ambiente, 5 de junho, a partir de proposta discutida e formulada por grupo de trabalho criado para essa missão, constituído por membros e consultores da Área Interdisciplinar.

A criação da CACiAmb no contexto do Sistema Nacional de Avaliação da Pós-Graduação da Capes decorre da necessidade de se dar conta da complexidade dos problemas ambientais com visão multiinterdisciplinar, face à indissociabilidade entre sistemas antrópicos e naturais que emergem no mundo contemporâneo, muitas vezes 
decorrentes do próprio avanço do conhecimento científico e tecnológico baseado em construção do saber notadamente disciplinar (CAPES, 2011a).

Atualmente, a CACiAmb é formada por 67 programas, que abrangem 84 cursos. Serão adicionados 10 novos programas de pósgraduação aprovados pelo Conselho Técnico Científico da Educação Superior da Capes (CTC-ES), englobando 13 cursos, com previsão de início em 2013.

A distribuição de cursos por conceito corresponde a $46 \%$ com nota três, 38\% com nota quatro, $13 \%$ com nota cinco e $2 \%$ com nota seis. Quando se detalha por curso, há predominância (92\%) de conceito três nos mestrado profissionais; $54 \%$ dos mestrados acadêmicos possuem conceito três, $35 \%$ são quatro, $8 \%$ são cinco e $2 \%$ são seis. Com base nesses dados, verifica-se espaço e condições para investir na ampliação do número de doutorados e na melhoria de conceitos.

O escopo e as características de natureza transversal das linhas de pesquisa dos cursos da CACiAmb formam um universo amplo de temas composto por expressões básicas que podem ser agrupadas segundo suas identidades. A análise desses agrupamentos permite destacar expressões básicas como: Desenvolvimento + Meio Ambiente, com frequência de 58\%; Recursos Naturais + Ecologia, com 36\%; Gestão + Planejamento + Políticas Públicas, com 40\%; e Tecnologia + Modelagem, com 57\%. Entre os programas aprovados em 2011, há predominância das expressões básicas de Tecnologia e de Gestão, o que é um acréscimo respectivamente de $5 \%$ e $4 \%$ na frequência de ambos. Tal análise permite observar a existência de balanceamento de temas entre as linhas de pesquisa, o que caracteriza a interdisciplinaridade em ciências ambientais.

Quanto à distribuição de cursos da CACiAmb por regiões brasileiras, configura-se o seguinte panorama: 18\% no Sul, 31\% no Sudeste, $13 \%$ no Centro- Oeste, $25 \%$ no Nordeste e $12 \%$ no Norte. Se considerados os programas aprovados em 2012, há incremento de 3\% no Centro-Oeste e diminuição de $2 \%$ no Nordeste. 
Os 77 cursos da CACiAmb são ministrados por 54 Instituições de Ensino Superior (IES), distribuídos em 23 dos 27 estados brasileiros, uma vez que Acre, Alagoas, Amapá e Rondônia ainda não apresentam cursos na área. Há um predomínio de IES públicas (81\%), com destaque para as federais, com $63 \%$. Com as propostas novas aprovadas, há acréscimo de $2 \%$ nas privadas e $4 \%$ nas públicas estaduais. Existe tendência de incremento do número de cursos na área com potencial maior para sua expansão nas regiões Centro-Oeste e Norte, bem como em áreas fronteiriças.

\section{A prática da interdisciplinaridade}

A prática da interdisciplinaridade, mais do que em qualquer outra época, coloca-se como necessidade emergente. Basta pensar nas questões ambientais envolvendo mudanças climáticas ou na recente crise financeira mundial. São crises globais que precisam de respostas que certamente não virão meramente de tratamento disciplinar.

A receita para o enfrentamento de tais crises passa, portanto, por estratégias que epistemologicamente possam ser colocadas em novas bases. Estratégias que permitam a variadas áreas do conhecimento se debruçarem sobre suas próprias atuações, ao mesmo tempo em que sejam reconhecidos pela comunidade científica os saberes existentes na sociedade.

Cada disciplina representa e possui uma forma de conhecimento, baseada em um método próprio, que deve ser respeitado e valorizado pelos participantes de um estudo com áreas convergentes, possibilitando a concepção de metodologia integrada, incorporando os elementos considerados positivos de cada uma das disciplinas. Nessa circunstância, quem adentra a interdisciplinaridade tem que estar aberto a revisar seus paradigmas e implica deixar o conforto disciplinar de sua atuação. Na pesquisa em Ciências Ambientais, tomando como perspectiva a interdisciplinaridade, esse conforto é colocado à prova, inclusive porque a posição disciplinar consolidada continua sendo altamente respeitada, mas possivelmente demande relativizações. Os docentes e 
pesquisadores que atuam interdisciplinarmente em Ciências Ambientais poderão ser eventualmente demandados por maior tempo para preparar um projeto e para obter respostas, tendo em vista a necessidade de mais discussões, maior diálogo e, principalmente, o entendimento da melhor maneira de levar os conhecimentos assim produzidos à comunidade científica, com linguagem comum construída a partir dos participantes do trabalho. Esse é sempre um caminho de pioneiros. Mesmo tendo sido praticado há muito tempo, a humanidade foi levada, em um período mais recente da História, a um processo de especialização, por vezes excessiva, que passa a não dar mais resposta compatível com os desafios da vida moderna, sobretudo em temáticas complexas como a ambiental.

No que se refere aos aspectos organizacionais, cabe mencionar que uma pesquisa ou um programa de pós-graduação poderá ter em sua formulação o conjunto de disciplinas que for considerado necessário pelo grupo proponente, porém, sem a preocupação de ter todas as disciplinas representadas. Aqui devem ser considerados os riscos de se ter um grupo inicialmente muito grande que poderá ser a origem de problemas para se trabalhar. A equipe poderá ser gradualmente aumentada, incorporando novas disciplinas, à medida que aumenta a familiaridade do grupo com os métodos de trabalho científico em bases interdisciplinares.

Formada a equipe, o passo seguinte é o trabalho de coordenação baseado no reconhecimento da liderança. Em programas ou grupos que atuam interdisciplinarmente em temáticas ambientais, é indispensável que os vários profissionais envolvidos reconheçam em seu coordenador uma figura de liderança científica, destacando-se a importância dessa liderança para o bom andamento dos trabalhos.

Ainda sobre os aspectos organizacionais, é importante trabalhar para o desenvolvimento de uma escrita interdisciplinar, adequada a cada programa ou grupo. A convergência de conhecimentos sobre questões ambientais requer processos de discussão de caráter mais abrangente, que impõem reflexões vistas por diferentes ângulos. Tão importante quanto a objetividade da engenharia deve ser a reflexão das ciências sociais. A riqueza desse processo de interação é o que eventualmente possa ser descuidado nas pesquisas disciplinares, uma vez que é da 
discussão, da reflexão e dos momentos de interação que de fato emerge o conhecimento de caráter interdisciplinar. Não é por acaso que a interdisciplinaridade é entendida essencialmente como uma forma ativa para processos de inovação. É a inovação que surge quando diferentes perspectivas se somam e revelam muito mais nuances da temática estudada do que a simples soma de perspectivas. É nesse sentido que a interdisciplinaridade é identificada como uma necessidade das ciências ambientais.

Como em qualquer projeto de pesquisa, em Ciências Ambientais parte-se da identificação do problema a ser estudado, a partir do qual podem ser estabelecidos os conceitos e as competências necessários para entendê-lo. A fase seguinte deve ser necessariamente de reflexão, discussão, embate, no sentido de fazer emergir a diversidade de perspectivas. A convergência torna-se possível a partir da diversidade, uma vez que ela seja revelada. Do contrário, corre-se o risco de se construir uma interdisciplinaridade frágil baseada na superficialidade de posições veladas.

A partir da evidência das diferenças, é possível o tratamento das perspectivas disciplinares em relação aos conceitos tratados, conduzindo-se para o estabelecimento das meta-perspectivas, a partir das quais busca-se organizar a informação e sintetizar os conflitos identificados entre os diferentes campos de conhecimento reunidos no trabalho. Ao final dessa trajetória, pode-se fazer a identificação do problema de pesquisa em termos operacionais, podendo-se iniciar o trabalho de pesquisa propriamente dito, com coleta de dados, bibliografia e todos os demais elementos, incluindo a construção do modelo de análise a ser adotado. A análise interdisciplinar, entretanto, retroalimenta-se não somente da relação com os dados e elementos teóricos-conceituais das questões ambientais, mas também envolve a tensão entre as várias perspectivas disciplinares e suas respectivas contribuições, avaliando e reavaliando o aprendizado de forma a construir os resultados, buscando eliminar ou aproximar lacunas remanescentes nas fronteiras dessas disciplinas, no sentido de produzir o conhecimento integrador acerca da compreensão e resolução de problemas ambientais. 


\section{Interdisciplinares em Ciências Ambientais}

É pressuposto da interdisciplinaridade o conhecimento disciplinar sólido, sem o qual não há como desenvolver ensino e pesquisa interdisciplinares de qualidade. Assim é que a interdisciplinaridade em Ciências Ambientais pode dar origem a programas e projetos que conduzam a resultados diferentes em comparação a pesquisas disciplinares, dependendo da formação de suas equipes. Ou seja, a realização de trabalhos em bases interdisciplinares na temática ambiental pode assumir caminhos variados; porém, esses caminhos devem ser claramente demarcados por aqueles que pretendem trabalhar dessa forma.

Enquanto estudos disciplinares podem ser relativamente simples, devido à existência de profissionais com mesma formação, linguagem comum e, muitas vezes, com perspectivas teóricometodológicas similares, na interdisciplinaridade, o ponto de partida é construir entendimento, com o estabelecimento de domínio linguístico comum sobre as questões ambientais em pauta, por parte daqueles que farão parte do processo, o que provavelmente demandará tempo maior. É exigido dos docentes e pesquisadores o exercício de sair da zona de conforto de suas disciplinas para buscar o entendimento a partir da perspectiva de outras disciplinas. Esse exercício visa maximizar naturalmente a contribuição de cada disciplina na compreensão e resolução de problemas ambientais, pois se dará não apenas a partir de sua própria visão de mundo, mas considerando também a visão de mundo de outras disciplinas.

Nesse contexto, considerando-se o Sistema Nacional de PósGraduação brasileiro, torna-se interessante caracterizar a diferenciação entre um programa de pós-graduação interdisciplinar e um programa de pós-graduação disciplinar. A multidisciplinaridade constitui-se na agregação, por meio de uma coordenação, de diferentes áreas do conhecimento em torno de um ou mais temas, em que cada área ainda preserva sua metodologia e independência, não sendo necessária obrigatoriamente a cooperação entre disciplinas. 
Na interdisciplinaridade, por sua vez, o envolvimento dos participantes torna-se mais profundo, gerando consequências mais amplas. Pressupõe a convergência de duas ou mais áreas do conhecimento, pertencentes ou não à mesma classe, que contribua para o avanço das fronteiras da ciência e tecnologia, transfira métodos de uma área para outra, gerando novos conhecimentos ou novas disciplinas. A biotecnologia, a nanotecnologia e as Ciências Ambientais são exemplos de novos campos de conhecimento que surgem da própria prática interdisciplinar, ensejada por questões complexas e concretas. A interdisciplinaridade emerge como um processo em construção para cada grupo, e o ensino e a pesquisa terão suas conformações diferenciadas em relação aos elementos que vão constituir o objeto e as equipes de pesquisa.

\section{Considerações finais: alguns desafios}

Há que se considerar que o processo de gradual incorporação de práticas interdisciplinares por grupos de pesquisa e por programas de pós-graduação encontra espaço cada vez maior e demanda por ações cada vez mais afirmativas para sua adoção, tendo em vista os desafios que se colocam em relação tanto aos problemas de caráter socioambiental como à urgência da adoção de princípios associados aos interesses do desenvolvimento do País em bases sustentáveis.

Nesse contexto, emergem de forma bastante nítida as perspectivas de consolidação da área de Ciências Ambientais como importante e relevante fator para o desenvolvimento de pesquisa e ensino de pós-graduação voltados aos interesses de uma sociedade mais justa e solidária e direcionados à obtenção de elementos de sustentabilidade que conduzam efetivamente à melhoria das condições ambientais e de vida das comunidades, com base nas diferentes complexidades, variadas regiões e distintas demandas.

Seguramente alicerçado no Sistema Nacional de Avaliação da Pós-Graduação, o desenvolvimento de ensino e pesquisa de qualidade será alicerçado por processos, concepções e métodos interdisciplinares, 
oferecendo melhores condições para a gradual incorporação aos conhecimentos assim produzidos de mecanismos, instrumentos e processos baseados em princípios da sustentabilidade.

A consolidação dessas bases envolve diretrizes e ações a serem realizadas em todo o País, que envolvem: o mapeamento das universidades com potencial para a implementação de novos programas; o estabelecimento de plano estratégico para o próximo triênio, visando a indução de programas ambientais nas várias regiões do País, de modo a contribuir para o maior equilíbrio regional, com base nos resultados da Avaliação Trienal 2010/2012; o fomento à criação de programas e pesquisas que foquem aspectos ambientais relevantes e estratégicos, tais como mudanças climáticas, impactos de novas fronteiras de desenvolvimento agrícola, impactos do desenvolvimento de energias alternativas, economia ecológica, avaliação ambiental estratégica, entre outros; a promoção de parcerias com setores públicos e privados; a articulação junto aos órgãos de fomento para promover projetos de pesquisa em Ciências Ambientais por meio de editais que privilegiem o enfoque interdisciplinar e a aplicação de princípios da sustentabilidade; a consolidação da avaliação continuada dos programas de pós-graduação da área por meio de reuniões nacionais na Capes, reuniões regionais descentralizadas e ampliação das visitas de acompanhamento; o estímulo à criação de novos arranjos institucionais contemplando redes de pesquisa, associações, parcerias nacionais e internacionais e dupla titulação entre IES brasileiras e internacionais; e o fomento à internacionalização por meio de intercâmbio acadêmico-científico com universidades estrangeiras, dando-se especial atenção às da America Latina e África.

Cabe sempre relembrar a questão relacionada ao para que se faz pesquisa e para quem é gerado o conhecimento. É necessário ter consciência de por que filosoficamente aquilo é feito e a quem ou ao que está servindo. Essa reflexão deve ser inerente ao se fazer pesquisa interdisciplinar.

Dentre as contribuições desse fazer da interdisciplinaridade está a reavaliação de valores em relação à ciência e tecnologia na busca 
de uma atitude ética em relação às implicações dos conhecimentos obtidos e seus avanços, bem como no que se refere à formação de pesquisadores e profissionais com ênfase humanista à docência e à pesquisa. Cabe ressaltar mais uma vez que a interdisciplinaridade é concepção, é processo, é forma de conhecimento e de trabalho, que pode ser aplicada com naturalidade nas várias áreas disciplinares.

Dessa forma, há que se considerar que a interdisciplinaridade terá espaço gradualmente maior no ensino, na pesquisa e extensão, fazendo com que Ciência, Tecnologia \& Inovação cresçam em qualidade e alcancem maior maturidade. A comunidade científica brasileira tem demonstrado empenho na busca do aperfeiçoamento e da qualidade de seus programas, o que deverá contribuir para a formação de profissionais, pesquisadores e docentes com novo perfil e qualidade, que respondam aos desafios colocados pelo País com relação ao seu desenvolvimento em bases sustentáveis.

Recebido 25/11/2012

Aprovado 25/07/2013

\section{Notas Explicativas}

i Nesse modelo, Kuhn (1996, p. 13) define paradigma como “as realizações científicas universalmente reconhecidas que, durante algum tempo, fornecem problemas e soluções modelares para uma comunidade de praticantes de uma ciência”. A noção de paradigma de Kuhn, segundo Morin (2010), é uma espécie de revolucionismo que se contrapõe ao evolucionismo teórico de Popper. Kuhn diferencia o que chama de ciência normal, quando o paradigma dominante ainda dá conta dos fenômenos existentes, e ciência extraordinária, quando o paradigma dominante não dá mais conta de responder aos novos fenômenos. 


\section{Referências bibliográficas}

ABRAMOVAY, R. (Org.). Construindo a ciência ambiental. São Paulo: Annablume: Fapesp, 2002.

AíMOLA, L. Uma introdução à ciência ambiental: Complexidade sócioambiental, auto-organização e interdisciplinaridade. In: ABRAMOVAY, R. (Org.). Construindo a ciência ambiental. São Paulo: Annablume: Fapesp, 2002. p. 151-173.

BERKES, F. Conexões institucionais transescalares. In: VIEIRA, P. H. F.; BERKES, F.; SIEXAS, C. S. Gestão integrada e participativa de recursos naturais: conceitos, métodos e experiências. Florianópolis: Secco/Aped, 2005.

CAPES - Coordenação de Aperfeiçoamento de Pessoal de Nivel Superior. Documento de Área de Ciências Ambientais. Brasília: Capes, $2011 \mathrm{a}$.

Plano Nacional de Pós-Graduação. v. I. Brasília: Capes, 2011b.

Plano Nacional de Pós-Graduação. v. Il. Brasília: Capes, 2011c.

CMMAD - Comissão Mundial sobre Meio Ambiente e Desenvolvimento. Nosso futuro comum. Rio de Janeiro: Fundação Getúlio Vargas, 1991.

DANSEREAU, P. Uma preparação ética para a mudança global: prospecção ecológica e prescrição moral. In: VIEIRA, P. F.; RIBEIRO, M. A. (Orgs.). Ecologia humana, ética e educação. A mensagem de Pierre Dansereau. Florianópolis: Aped, 1999. p. 299-370.

DAVIDSON-HUNT, I. J.; BERKES, F. Nature and society through the lens of resilience: toward a human-in-ecosystem perspective. In: BERKES, F.; COLDING, J.; FOLKE, C. (Eds.). Navigating social-ecological systems. Building resilience for complexity and change. Cambridge: Cambridge University Press, 2003. p. 53-82. 
FERNANDES, V.; SAMPAIO C. A. C. Problemática ambiental ou problemática socioambiental? A natureza da relação sociedade/meio ambiente. Desenvolvimento e Meio Ambiente (UFPR), v. 18, p. 87-94, 2008.

GARCíA, R. Interdisciplinariedad y sistemas complejos. In: LEFF, E. (Org.). Ciencias sociales y formación ambiental. Barcelona: Gedisa, 1994. p. 85-125.

HABERMAS, J. Teoría de la acción comunicativa: complementos y estudios previos. Madri: Cátedra/Teorema, 1994.

HOGAN, D. J.; VIEIRA, P. F. (Orgs.). Dilemas socioambientais e desenvolvimento sustentável. Campinas: Unicamp, 1992.

JOLLIVET, M.; PAVÉ, A. O meio ambiente: questões e perspectivas para a pesquisa. In: VIEIRA, P. F.; WEBER, J. (Orgs.). Gestão de recursos naturais renováveis e desenvolvimento. Novos desafios para a pesquisa ambiental. São Paulo: Cortez, 2000. p. 51-112.

KUHN, T. S. A estrutura das revoluções científicas. São Paulo: Perspectiva, 1996.

LEFF, E. Epistemologia Ambiental. São Paulo: Cortez, 2001.

LEIS, H. R. A Modernidade Insustentável. As críticas do ambientalismo à sociedade contemporânea. Petrópolis/Florianópolis: Vozes/UFSC, 1999.

MORIN, E. Ciência com consciência. Rio de Janeiro: Bertrand Brasil, 2010.

PHILIPPI JR., A; ROMÉRO, M. de A.; BRUNA, G. C. Curso de gestão ambiental. Barueri: Manole, 2004.

PHILIPPI JR., A.; TUCCI, C. E. M.; HOGAN, R. Interdisciplinaridade em Ciências Ambientais. Navegantes. São Paulo: Signus Editora, 2000.

PNUMA - Programa de las Naciones Unidas para el Medio Ambiente. Global Environment Outlook 3 (GEO-3): Past, Present and Future 
Perspectives. Londres: 2002. Disponivel em: <http://www.unep.org/ geo/geo3/>. Acesso em: 13 agosto 2009.

PRIGOGINE, I.; STENGERS, I. A nova aliança. Brasília: Ed. UnB, 1984.

RAYNAUT, C.; ZANONI, M. Reflexões sobre princípios de uma prática interdisciplinar na pesquisa e no ensino superior. In: PHILIPPI JR., A. \& SILVA NETO, A. J. Interdisciplinaridade em ciência, tecnologia \& inovação. Barueri: Manole, 2011.

SACHS, I. Espaços, tempos e estratégias do desenvolvimento. São Paulo: Vértice, 1986.

Estratégias de transição para o século XXI: desenvolvimento e meio ambiente. São Paulo: Studio Nobel: Fundap, 1993.

Caminhos para o desenvolvimento sustentável. 2 ed. Rio de Janeiro: Garamond, 2002.

SERRES, M. O Contrato Natural. Lisboa: Instituto PIAGET, 1990.

UNESCO. Culture and development: an ambivalent alliance. In: RUIJTER, A.; TIJSSEN, L. V. V (Eds.). Culture Dynamics in Development Processes... Holanda: Netherlands National Commission for UNESCO, 1995.

VIEIRA, P. H. F. A problemática ambiental e as ciências sociais no Brasil. In: HOGAN, D. J.; VIEIRA, P. F. (Orgs.). Dilemas socioambientais e desenvolvimento sustentável. Campinas: Unicamp, 1992.

Apresentação. In: LEFF, E. Epistemologia Ambiental. São Paulo: Cortez, 2001. p. 09-15.

Políticas ambientais no Brasil: do preservacionismo ao desenvolvimento sustentável. Política \& Sociedade, v. 1, p. 25-73, 2009.

VIEIRA, P. H. F.; BERKES, F.; SIEXAS, C. S. Gestão integrada e participativa de recursos naturais: conceitos, métodos e experiências. Florianópolis: Secco/Aped, 2005. 


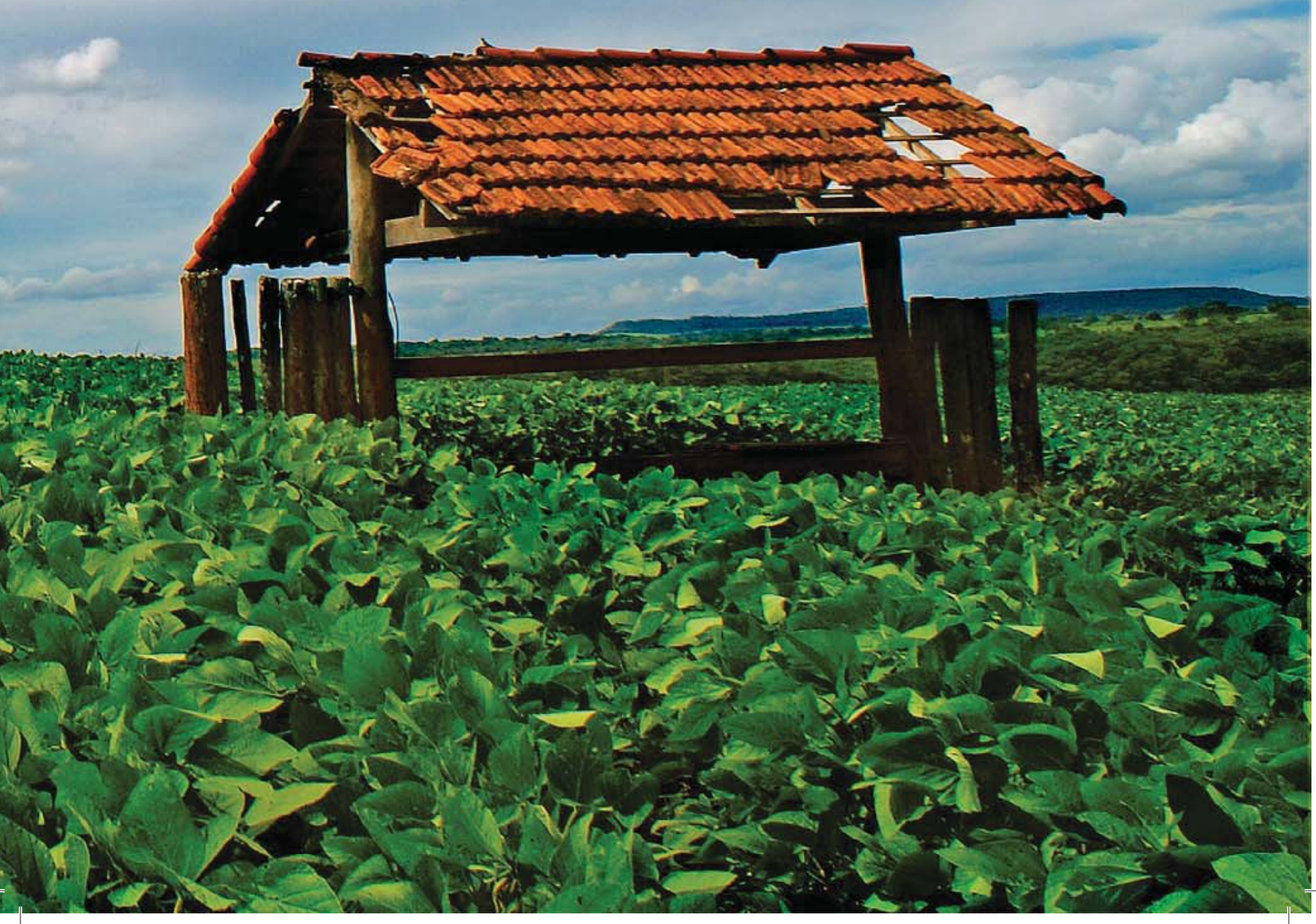




\section{Os desafios do tema sustentabilidade no ensino da pós- graduação}

\section{The challenges of the sustainability theme in graduate programs education}

\section{Los retos del tema de la sostenibilidad en la enseñanza del posgrado}

Tadeu Fabrício Malheiros, doutor em Saúde Pública e professor na Escola de Engenharia de São Carlos da Universidade de São Paulo. Endereço: Av. Trabalhador São-Carlense, 400. CEP: 13566-590 São Carlos, SP. Telelefone (16) 3373-9534. E-mail: tmalheiros@ usp.br.

Mario Alejandro Pérez, doutor em Economia Ecológica e professor na Universidad del Valle (Cali, Colômbia). Endereço: Calle 13, n 100-00, edif. 341 - Cali, Colombia. Telefone: (0057 016) 3373-8262. E-mail:mario.perez@correounivalle.edu.co.

Carlos Alberto Cioce Sampaio, doutor em Engenharia da Produção pela Universidade Federal de Santa Catarina, pós-doutor em Ecossocioeconomia pela Universidade Austral do Chile e professor da Universidade Federal do Paraná (UFPR). Endereço: Programa de Pós-Graduação em Gestão Urbana, Escola de Arquitetura e Design, $2^{\circ}$ andar - Pontifícia Universidade Católica do Paraná. Rua Imaculada Conceição, 1155 - Prado Velho. CEP: 80215-901 - Curitiba, PR. Telefone: (41) 3024-5284. E-mail: carlos.cioce@ gmail.com.

Christian Henríquez Zuñiga, doutor em Ciências Humanas e professor e pesquisador no Centro de Estudios Ambientales, Universidad Austral de Chile (UACh). Endereço: Casa 4 ${ }^{a}$, Campus Isla Teja, Universidad Austral de Chile, Valdivia. Telefone: (0056 62) 221-915. E-mail: christianhen@gmail.com. 


\section{Resumo}

As universidades estão convocadas a focalizar na sustentabilidade. Frente a esse desafio, o objetivo do presente artigo é identificar e discutir elementos essenciais para a implementação do tema sustentabilidade nos programas de pós-graduação nas universidades brasileiras. 0 artigo aplica, então, um conjunto de características que serve como um primeiro esboço de pontos-chave. Quanto ao currículo, devem ser tratados os diferentes aspectos dos meios biótico, físico, químico, cultural e socioeconômico. Quanto ao modus operandi, o programa deve ser interdisciplinar, olhando questões críticas de interface e indissociabilidade dos temas inseridos na sustentabilidade. Para construir um alinhamento e uma coerência com o tema, é necessário operacionalizar progressivamente visão, valores e princípios presentes nesse paradigma.

Palavras-chave: Sustentabilidade. Programas de Pós-Graduação. Currículos.

\section{Abstract}

Universities are called upon to focus on sustainability. Facing this challenge, the aim of this paper is to identify and discuss key elements for implementing the sustainability issue in graduate programs in Brazilian universities. The paper, then, applies a set of characteristics that work as key points for the framework of a first draft. As for the curriculum of the programs, different biotic, physical, chemical, cultural and socioeconomic aspects should be treated. As for the graduate program modus operandi, it should be interdisciplinary, looking at critical issues of interface within themes related to sustainability. To build alignment and coherence with the theme, it is necessary to progressively make operational the vision, values and principles that are present in this paradigm.

Keywords: Sustainability. Graduate Programs. Curricula. 


\section{Resumen}

Las universidades han sido convocadas a centrarse en la sostenibilidad. Frente a este reto, el objetivo de este trabajo es identificar y analizar los elementos clave para la aplicación del tema de la sostenibilidad en los programas de postgrado de las universidades brasileñas. Este artículo se utiliza, por lo tanto, de un conjunto de características que sirven como un primer borrador de los puntos clave. En cuanto al plan de estudios, se deben tratar de los diferentes aspectos de los medios blótico, físico, químico, cultural y socioeconómico. En cuanto al modus operandi, el programa debe ser interdisciplinario, analizando cuestiones críticas de la interfaz y la inseparabilidad de los temas incluidos en la sostenibilidad. Para garantizar la alineación y la coherencia con el tema, es necesario poner en práctica progresivamente la visión, los valores y principios que son parte de este paradigma.

Palabras clave: Sostenibilidad. Programas de Posgrado. Planes de Estudio.

\section{Introdução}

Na segunda metade do século XX, o mundo viveu importantes mudanças; atualmente, a sociedade percebe e cobra maior participação nas decisões políticas, a questão ambiental está mais presente nos discursos do governo, do setor empresarial e da sociedade civil e há um crescente reconhecimento da urgência de ações de redução da pobreza e das taxas de consumo de recursos naturais (PHILIPPI JR; MALHEIROS, 2012; DUARTE; MALHEIROS, 2012; VEIGA, 2010).

Nesse contexto, em 2012, o Brasil foi novamente sede da Conferência das Nações Unidas para o Desenvolvimento Sustentável (Rio+20), que resultou em um documento final focado em políticas e práticas para medir a implementação do desenvolvimento sustentável. O documento O Futuro que Queremos destaca a erradicação da pobreza como um dos principais desafios atuais na construção do desenvolvimento sustentável e reafirma a urgência de inserir a questão 
da sustentabilidade como eixo central de ação em todos os níveis de governança, colocando esforços na integração das dimensões e no reconhecimento das interfaces (ONU, 2012; UNEP, 2012; WWF, 2012). Entre os objetivos maiores do desenvolvimento sustentável estão a redução das grandes desigualdades socioeconômicas, o respeito à sociodiversidade, as mudanças dos padrões insustentáveis de produção e consumo, apontando para satisfazer necessidades humanas fundamentais, e a proteção e gestão da base de recursos naturais, como pilares da resiliência em face a novos e futuros desafios.

Nesse, como em outros eventos, o desenvolvimento sustentável, isto é, o estado da relação entre a disponibilidade e gestão de recursos, de modo que os sistemas socioeconômicos e ecológicos tenham perspectivas de continuidade, é o cerne da questão (MAX-NEEF, 2012). Desde que o desenvolvimento sustentável foi descrito pela Comissão Brundtland (CMMAD, 1988) como aquele que atende às necessidades do presente sem comprometer a capacidade das gerações futuras de terem suas necessidades atendidas, há crescente consenso sobre o que deve ser incluído na avaliação da sustentabilidade. São eles: i) a integração dos aspectos institucional, social, econômico, cultural, espacial e ambiental, e a interdependência e indissociabilidade entre eles; ii) as consequências das ações passadas e as implicações para pensar o presente e o futuro; iii) a existência de incertezas relacionadas com o resultado de nossas ações no presente e a necessidade de atuar com cautela; iv) o envolvimento de atores da sociedade; e v) considerações de equidade geracional (intra e inter) (GASPARATOS; EL-HARAM; HORNER, 2008; GASPARATOS, 2010; VEIGA, 2010; DUARTE et al., 2013; GIBSON et al., 2005).

Isso implica que os estudos e as pesquisas sobre a sustentabilidade dos sistemas sociais e ecológicos não podem ser feitos de forma reducionista e disciplinar, mas devem ser abordados de forma integral e interdisciplinar. Isso porque as sociedades humanas e seu desenvolvimento influenciam os sistemas ecológicos, que, por sua vez, afetam os padrões de desenvolvimento das sociedades.

Assim, o desafio da sustentabilidade não é apenas um problema para a gestão e implementação de políticas eficazes. É também 
desafio e convite para o desenvolvimento do conhecimento integrado interdisciplinar e intercultural e para a investigação que motive ação, desenvolvimento tecnológico e processos de educação nas instituições de ensino e, em especial, nas universidades.

Universidades em todo o mundo e, em particular, na América Latina, como centros de produção de conhecimento e protagonistas de ações em ensino, pesquisa e extensão, vêm sendo convocadas, então, a ampliar as pesquisas e a oferta acadêmica na área de sustentabilidade, bem como a adotar diretrizes mais sustentáveis na gestão de seus campi universitários, isto é, transitando do discurso para a ação.

Dessa maneira, instituições de educação superior já não são vistas somente como fonte única de conhecimento disciplinar e formação de profissionais que integrarão a sociedade e contribuirão para seu progresso econômico. Mas, sim, também como um dos importantes atores para oferecer exemplos de projetos sustentáveis, tendo como fator central a educação como ferramenta indutora de mudanças positivas de caráter coletivo e que estimulem sua emancipação. Nesse mesmo contexto, não se pode esquecer que as universidades têm papel fundamental no sucesso dessas políticas de sustentabilidade e são ator-chave, junto com os atores políticos e econômicos, para garantir o desenvolvimento sustentável.

Portanto, esse cenário de forte demanda da sociedade por capital humano preparado e capaz de enfrentar os desafios da complexidade da sustentabilidade amplia o papel e a importância das universidades como um dos pilares de operacionalização e consolidação do próprio conceito de desenvolvimento sustentável. Também é preciso ter em mente que as universidades são instituições que geram opinião pública e paradigmas metodológicos para a governança do progresso social e da proteção dos recursos naturais (AGUIRRE, 2007).

Dentro da discusão do papel das universidades na promoção e no desenvolvimento de temas socioambientais, aparecem várias perspectivas que envolvem sua própia missão:

- Ampliar a oferta acadêmica dirigida para a formação de profissionais com perfis para colocar em prática na sua vida profissional a sustentabilidade; 
- Desenvolver projetos de pesquisa que abordem os temas de sustentabilidade;

- Promover atividades de extensão que trabalhem os temas junto à comunidade, ao governo e ao setor empresarial; e

- Repensar currículos que incorporem interfaces das dimensões da sustentabilidade nos programas acadêmicos.

Neste ano de 2013, quase três décadas após a apresentação do conceito de desenvolvimento sustentável (CMMAD, 1988), estes são os desafios que ainda são postos às universidades: contextualizar, desenvolver e colocar em prática o tema da sustentabilidade dentro da sua missão.

Frente a esses desafios, o objetivo do presente artigo é identificar e discutir os elementos essenciais para a implementação do tema sustentabilidade nos programas de pós-graduação nas universidades brasileiras. As etapas metodológicas utilizadas foram: identificar os programas de pós-graduação inscritos na Capes; e examinar nesses programas a relação com o tema da sustentabilidade e a visão interdisciplinar estabelecida. Isso possibilitou ter um panorama mais preciso do objeto de análise. A partir das experiências dos autores que trabalham em diferentes programas de pós-graduação em diferentes universidades brasileiras e na América Latina, analizou-se o conteúdo programático desses programas, sobretudo de vertente acadêmica, evidenciando-se ou não a pertinência e coerência quanto ao tema do desenvolvimento sustentável.

\section{Os programas de pós-graduação no Brasil}

No âmbito dos programas de pós-graduação stricto sensu reconhecidos pelo sistema Capes, atualizados em outubro de 2012, observa-se um número significativo de programas e cursos - doutorado e mestrado acadêmico e profissional - que sugerem, mesmo que genericamente, temas correlacionados com a sustentabilidade, conforme demonstra a obra Capes na Rio+20(CAPES, 2012a), que traz a contribuição da pós-graduação brasileira para o desenvolvimento sustentável. 
Entre as grandes áreas, sinaliza-se a multidisciplinar, que compreende, entre outras, as áreas da Biotecnologia, com 43 programas e 64 cursos, de Ciências Ambientais, com 72 programas e 89 cursos, e a Interdisciplinar, com 249 programas e 312 cursos, conforme destacado na Tabela 1.

Tabela 1. Mestrados/doutorados reconhecidos da grande área multidisciplinar

\begin{tabular}{|l|c|c|c|c|c|c|c|c|c|}
\hline \multicolumn{10}{|c|}{ GRANDE ÁREA: MULTIDISCIPLINAR } \\
\hline ÁREA DE AVALIAÇÃo & \multicolumn{3}{c|}{$\begin{array}{c}\text { Programas e cursos de } \\
\text { pós-graduação }\end{array}$} & \multicolumn{3}{|c|}{$\begin{array}{c}\text { Totais de cursos de } \\
\text { pós-graduação }\end{array}$} \\
\hline & Total & M & D & F & M/D & Total & M & D & F \\
\hline Biotecnologia & 43 & 13 & 3 & 6 & 21 & 64 & 34 & 24 & 6 \\
\hline $\begin{array}{l}\text { Ciências } \\
\text { Ambientais }\end{array}$ & 72 & 31 & 7 & 17 & 17 & 89 & 48 & 24 & 17 \\
\hline Interdisciplinar & 249 & 110 & 5 & 71 & 63 & 312 & 173 & 68 & 71 \\
\hline
\end{tabular}

Fonte: CAPES, 2012

Obs.: $\mathrm{M}=$ Mestrado; $\mathrm{D}$ = Doutorado; $\mathrm{F}$ = Mestrado Profissional.

A criação da grande área multidisciplinar no âmbito da Capes sinaliza uma resposta político-institucional de reconhecimento do crescente número de programas de pós-graduação que incorporam mais de um tema-chave em seus currículos, de forma a melhor responder pelos desafios da complexidade dos problemas e das potencialidades frente a um mundo em permanente mudança. Da mesma forma, a grande área multidisciplinar segue ampliando o seu número de programas, bem como se atualizando para atender ao paradigma do desenvolvimento sustentável. A comissão da área Interdisciplinar e, mais recentemente, a de Ciências Ambientais reconhecem que

\footnotetext{
a natureza complexa da problemática sócio-ambiental demanda diálogos entre disciplinas próximas e entre disciplinas de áreas diferentes, bem como entre saberes disciplinares e saberes não disciplinares da sociedade e das culturas, dependendo do nível de complexidade do fenômeno a ser tratado. Diante disso, desafios teóricos e metodológicos colocam-se para diferentes campos da ciência e da tecnologia (CAPES, 2012b).
}

Da mesma forma, o documento de área da Comissão da área de Ciências Ambientais reforça a complexidade inerente ao tema do desenvolvimento socioambiental e que tem um aspecto ético a 
ser abordado relativo às demandas da geração atual e às janelas de oportunidades para as gerações futuras. Destaca que a

sustentabilidade do desenvolvimento demanda, então, a valorização e proteção deste patrimônio cultural, tendo como base de sustentação a proteção dos ecossistemas e dos recursos naturais. Assim, a problemática ambiental é, ao mesmo tempo, um desafio ético, político, legal, econômico, de gestão e técnico (CAPES, 2012c).

Apesar de só mais recentemente o termo sustentabilidade estar presente no nome de alguns programas de pós-graduação, como os recém-criados Programa de Pós-Graduação em Sustentabilidade em nível de mestrado e doutorado acadêmicos da Escola de Artes, Ciências e Humanidades da Universidade de São Paulo e Programa de Pós-Graduação em nível de mestrado profissional em Ambiente, Saúde e Sustentabilidade da Faculdade de Saúde Pública da Universidade de São Paulo, o tema sustentabilidade tem integrado linhas de pesquisa, disciplinas e projetos em vários programas de pós-graduação em diversas universidades brasileiras.

Assim, entendendo que a ideia por trás do conceito de sustentabilidade é a promoção da melhoria e a manutenção da qualidade de vida e da qualidade ambiental, observa-se que essa abordagem é bastante abrangente, inclusive reunindo o presente e o futuro quanto ao bem-estar econômico, social e ambiental. Isso significa que adotar a sustentabilidade como enfoque em atividades da pós-graduação traz implicações para o seu conteúdo e para seu modus operandi.

Quanto ao conteúdo, devem ser tratados os diferentes aspectos dos meios biótico, físico, químico, cultural e socioeconômico. Quanto ao seu funcionamento, deve ser desenhado e operacionalizado de maneira a trabalhar de forma interdisciplinar, buscar integração temática, olhando questões críticas de interface dos temas inseridos na sustentabilidade. A priorização de diálogos com os diferentes atores na arena dos processos de construção de sustentabilidade, nas suas diferentes escalas, é também peça-chave na operacionalização de programas de pós-graduação em sustentabilidade. Ou seja, identificar e criar canais de credibilidade, além de aproximar-se deles, junto a tomadores de decisão em instituições governamentais, no setor privado e em lideranças 
da sociedade civil, entre outros, exige dos grupos de pesquisa maior flexibilidade e, principalmente, coragem, pois, ao deixarem seus portos seguros - laboratórios e salas de pesquisa -, devem então incorporar novas ferramentas aos seus métodos e procedimentos científicos; da mesma forma, rotinas, tempos e a duração das pesquisas serão permanentemente testados.

\section{Necessidade de restruturação curricular}

A maneira como se podem produzir mudanças educativas em diferentes contextos favoreceu o desenvolvimento de paradigmas como o modelo de investigação e desenvolvimento, que surge das relações estabelecidas entre teoria e prática de maneira dialética; o modelo de interação social, que envolve ativamente os participantes, tanto na concretização como no processo de análise e na construção das propostas que se deseja impulsionar; além do modelo de resolução de problemas, que interpreta a mudança desde o ponto vista dos envolvidos no estudo e no processo da transformação que se pretende realizar, de acordo com estudos/diagnósticos do contexto que deem resposta às necessidades sentidas pelas comunidades.

Esses três processos estão intimamente articulados e são os que devem conformar o enfoque conceitual e metodológico para uma construção curricular sobre o tema da sustentabilidade nas pósgraduações. Nas últimas décadas, geraram-se mudanças substanciais na educação e, portanto, no currículo. Essas mudanças respondem, sobretudo, aos resultados das investigações que, nos diferentes níveis do sistema educativo, vinham sendo realizadas, não por mandato legal, mas sim na permanente necessidade de se atualizar, incorporando novas concepções filosóficas, sociológicas, pedagógicas, psicológicas e científicas que procuram visões integrais das relações do ser humano consigo mesmo, com a comunidade, a natureza, a ciência e o conhecimento.

No campo da sustentabilidade e, especificamente, na pósgraduação associada ao tema, requer-se passar do currículo como um 
acúmulo de matérias para trabalhar ao redor de núcleos problemáticos. Esses núcleos devem emergir da análise realizada sobre as realidades e os contextos das necessidades humanas locais, regionais e nacionais, considerando também a incidência da globalização nos chamados núcleos problemáticos, o que permite concretizar a construção de currículos efetivamente interdisciplinares, incorporando a perspectiva da teoria crítica do curriculum. A teoria crítica implica uma forma de racionalidade diferente da concepção tecnicista ou pragmática que assumem algumas correntes.

A teoria crítica do currículo tem como eixo central o raciocínio dialético. Diferente da lógica analítica ou lógica do entendimento, a lógica dialética aprofunda as análises das relações entre as partes dentro de totalidades maiores, amplas e extensas, produzindo assim um conhecimento mais profundo do que o entendimento analítico. 0 raciocínio dialético trata de superar os simples dualismos e os problemas de entendimento que surgem a partir deles e assim avançar em soluções integradas, favorecendo a aproximação do ensino e da pesquisa com a vida real.

Por sua vez, sob a perspectiva do currículo em processo, ele se adequa de forma permanente na medida em que vão se desenvolvendo experiências investigativas próprias e apropriadas ao território e muda a realidade cultural; a programação curricular não se concebe como repetição dos mesmos conteúdos ano após ano, mas trata de trabalhar desde o diagnóstico até a solução de problemas concretos, que se convertem em facilitadores da aprendizagem a partir da pesquisa-ação que gera sua abordagem. Para trabalhar e abordar esses aspectos, requer-se trabalhar por problemas e projetos que permitam, por meio de seminários de integração e autoavaliação, construir espaços de encontro de estudantes e professores das diferentes ênfases dos programas de pós-graduação.

\section{Elementos para a mudança}

Visando ampliar a inserção do tema da sustentabilidade nos programas de pós-graduação, no que se refere, portanto, ao conteúdo 
e modus operandi, é possível elencar um conjunto de características e aspectos, conforme ilustrado no Quadro 1. Essas características servem como um primeiro esboço de pontos-chave a serem observados na criação, gestão e avaliação de programas de pós-graduação. Quanto mais a questão da sustentabilidade estiver presente e explícita nos objetivos e nas áreas de concentração do programa, maior atenção deverá ser dada aos aspectos destacados no Quadro 1.

Em termos das características a serem consideradas no conteúdo curricular de programas de pós-graduação, destacam-se as de visão multitemática e de pespectiva ecossistêmica, que procura ser ponto de encontro para diversas disciplinas na identificação de problemas que devem ser abordados em equipes de trabalho. Outra característica a ser considerada é a incorporação de temas e temáticas emergentes, isto é, comprender a sustentabilidade como um campo disciplinar em disputa e que não existe enfoque melhor que estudá-la partindo da integração dos conhecimentos, repensando modelos anteriores e prospectando novos alinhados à realidade da complexidade atual.

Do ponto de vista do modus operandi, há que se destacar a interdisciplinaridade como método de construção de conhecimento que parte de uma problemática complexa que inter-relaciona o tripé ensino, pesquisa e extensão e que vai além de compreendê-la; coloca esforços no sentido de resolvê-la. É preciso criar ambiente propício ao estudo de novos campos de conhecimento que, até então, não se faziam necessários ou que surgiram de conexões de disciplinas e seus desdobramentos que ainda não existiam. A inter se dá principalmente ao longo do processo.

Outra característica é ampliar a participação de partes interessadas. Para tanto, é preciso estimular a participação de atores (governo, empresas, sociedade civil) no desenvolvimento das pesquisas, ampliando o debate e uma maior incorporação dos discursos e das percepções no próprio processo da pesquisa. Deve-se incentivar planos, estratégias e ações conjuntos formalizados em arranjos institucionais.

A transparência se traduz de forma que, ao longo da execução das pesquisas, devem ser disponibilizados espaços para consulta pública 
e para fortalecer e informar a sociedade; também é recomendável a publicação no site do projeto dos balanços e estados de resultado da contabilidade do projeto. É fundamental traduzir o processo e o resultado em produto compreensivel pelos diferentes atores e partes interessadas, ampliando a credibilidade e utilidade das pesquisas e dos produtos.

Outra característica é a intergeracional, cujo enfoque de gênero e interculturalidade deve envolver interesses intergeracionais, tais como crianças, jovens, adultos e idosos. Assim, incorporar no processo de pesquisa interesses a partir da perspectiva de gênero e da perspectiva intercultural também se alinha à ideia de sustentabilidade.

A sexta característica é o enfoque inter e transdisciplinar como prática e ação concreta de integração das diversas disciplinas; para tanto, é preciso desenhar processos de ensino que estimulem um suporte à construção dos projetos interdisciplinares. Deve-se garantir que os conteúdos estejam coordenados intra e interdisciplinarmente rumo à transdisciplina. O conteúdo pode ser similar, mas o formato de ensino deve levar à integração e à visão crítica. Também deve garantir que se encontrem e discutam os diferentes conceitos e pontos de vista dos professores, alunos e das partes interessadas. Uma estratégia integradora é o desenvolvimento de projetos aplicados para resolver problemas que permitam integrar diferentes disciplinas.

Por sua vez, a característica acompanhamento da implementação da pesquisa e do projeto de aprendizagem aponta que os projetos devem permitir, além de gerar processos de aprendizagem para os atores envolvidos, também dar continuidade a um ciclo de projeto de mais longo prazo, que não termine na operação, mas sim na avaliação e no seguimento. Do mesmo modo, deve-se estabelecer um processo de melhoria contínua, baseado na prática de aprendizagem.

Outra característica é a construção de projetos coletivos e estruturantes, que permitem aglutinar ao redor de um projeto de investigação específico uma série de professores, pesquisadores e estudantes para que trabalhem ao redor desse tema, gerando economias de escala e sinergia que favorecem potencilizar a pesquisa-ação. 
A última característica, síntese de resultados, refere-se a buscar ações que somem para um mesmo objetivo. Dessa forma, é preciso construir projetos e grupos que foquem problemas comuns, mas com estratégia de somar. Destacam-se como exemplos a construção de redes de pesquisa, projetos temáticos ou mesmo os macro programas temáticos que vêm sendo incentivados por agências de fomento de pesquisa, como o Biota-Fapesp, no tema de biodiversidade, e o BioenFapesp, no tema de bioenergia.

\section{Quadro 1. Características e aspectos para fortalecer o planejamento e a gestão de programas de pós-graduação visando a inserção do tema sustentabilidade}

\begin{tabular}{|c|c|c|}
\hline \multicolumn{2}{|r|}{ Características } & Aspectos-chave \\
\hline \multirow[b]{2}{*}{ 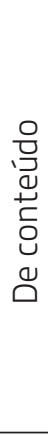 } & $\begin{array}{l}\text { 1. Multitemático e } \\
\text { visão ecossistêmica }\end{array}$ & $\begin{array}{l}\text { Integrar temas de diversas disciplinas, indo } \\
\text { além da abordagem reducionista para a visão } \\
\text { de indissociabilidade. }\end{array}$ \\
\hline & $\begin{array}{l}\text { 2. Consideração de } \\
\text { temas emergentes }\end{array}$ & $\begin{array}{l}\text { Incorporação de novas premissas em } \\
\text { sustentabilidade e sua discução e atuação } \\
\text { prática frente aos desafios da resiliência e } \\
\text { de incertezas que se sustentam, em uma } \\
\text { perspectiva intercultural, de governança, } \\
\text { irreversibilidade, ciência pós-normal, entre } \\
\text { outros. }\end{array}$ \\
\hline \multirow{6}{*}{ 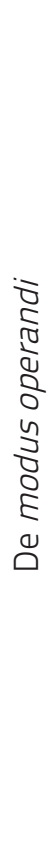 } & 3. Interdisciplinaridade & $\begin{array}{l}\text { Várias disciplinas trabalhando com base em um } \\
\text { problema complexo, desde a indissocioabilidade } \\
\text { do ensino-pesquisa-extensão. }\end{array}$ \\
\hline & $\begin{array}{l}\text { 4. Ampliar participação } \\
\text { de atores (governo, } \\
\text { empresas, sociedade } \\
\text { civil) }\end{array}$ & $\begin{array}{l}\text { Estimular a participação de atores e de arranjos } \\
\text { institucionais. }\end{array}$ \\
\hline & 5. Transparência & $\begin{array}{l}\text { Claridade nas tomadas de decisões e no uso } \\
\text { dos recursos designados para o projeto. }\end{array}$ \\
\hline & $\begin{array}{l}\text { 6.Intergeracional, } \\
\text { enfoque de gênero e } \\
\text { interculturalidade }\end{array}$ & $\begin{array}{l}\text { Integração de pontos de vista de diversas } \\
\text { gerações e culturas, relevando a perspectiva } \\
\text { de gênero. }\end{array}$ \\
\hline & $\begin{array}{l}\text { 7. Enfoque inter e } \\
\text { transdisciplinar }\end{array}$ & $\begin{array}{l}\text { Círculos interdisciplinares que incorporem } \\
\text { problemas complexos e abordagens inter e } \\
\text { transdisciplinares. }\end{array}$ \\
\hline & $\begin{array}{l}\text { 8. Acompanhamento } \\
\text { da implementação da } \\
\text { pesquisa e do projeto } \\
\text { de aprendizagem }\end{array}$ & $\begin{array}{l}\text { Possibilitar financiamento para um processo } \\
\text { maior e estimular projetos e financiamento } \\
\text { adequado para trabalhar ensino-pesquisa- } \\
\text { extensão no longo prazo. }\end{array}$ \\
\hline
\end{tabular}




\begin{tabular}{|c|c|c|}
\hline $\begin{array}{l}\frac{1}{\pi} \\
\frac{\pi}{2}\end{array}$ & $\begin{array}{l}\text { 9. Construção de } \\
\text { projetos coletivos e } \\
\text { estruturantes }\end{array}$ & $\begin{array}{l}\text { Do ponto de vista dos arranjos institucionais, } \\
\text { construir objetivos consensuados. }\end{array}$ \\
\hline 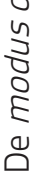 & $\begin{array}{l}\text { 10. Síntese de } \\
\text { resultados - projetos } \\
\text { complementares nas } \\
\text { soluções }\end{array}$ & $\begin{array}{l}\text { Trabalhar na perspectiva de projetos que } \\
\text { somem resultados na busca de problemas- } \\
\text { chave. }\end{array}$ \\
\hline
\end{tabular}

\section{Considerações finais}

Conforme dito anteriormente, a emergência do tema sustentabilidade requer sua inserção de forma transversal nos programas de pós-graduação, mesmo que ainda seja realizada de maneira gradual, mas que seja ajustada às especificidades de cada área e programa. Assim, os programas privilegiam que os produtos gerados promovam o enfoque do desenvolvimento sustentável e almejam as metas estabelecidas pelo Plano Nacional de Pós-Graduação Brasileira.

Em síntese, com relação aos parâmetros, para que os programas de pós-graduação sejam mais pertinentes e coerentes com o tema da sustentabilidade, é necessário atentar para os seguintes elementos: visão ecossistêmica; perspectiva interdisciplinar; participação de atores; enfoque de gênero, intercultural e intergeneracional; e novas metodologias de aprendizagem, que promovam a construção de projetos coletivos e estruturantes a partir de problemáticas socioambientais.

Recebido 25/11/2012 Aprovado 25/07/2013

\section{Referências bibliográficas}

AGUIRRE, D. Educación Superior Colombiana y Medio Ambiente. In: SÁENZ, O. (Org.). Las Ciencias Ambientales: Una Nueva Área Del Conocimiento. Bogotá: Red Colombiana de Formación Ambiental (Rcfa), 2007. 
CAPES - COORDENAÇÃO DE APERFEIÇOAMENTO DE PESSOAL DE NÍVEL SUPERIOR. Grande Área multidisciplinar. 2012a. Disponível em: <http:/ / conteudoweb.capes.gov.br/conteudoweb/ProjetoRelacaoCursosServle t?acao=pesquisarArea\&codigoGrandeArea $=90000005 \&$ descricaoGrand eArea=MULTIDISCIPLINAR+> . Acesso em: 17 nov. 2012.

Documento de área - Interdisciplinar. 2012b. Disponivel em: <http://www.capes.gov.br/images/stories/download/avaliacao/ INTER03ago10.pdf>. Acesso em: 17 out. 2012.

Documento de área - Ciências ambientais. 2012c. Disponível em: <http://www.capes.gov.br/images/stories/download/avaliacao/49. camb_DOCUMENTO_REA.pdf>. Acesso em: 17 out. 2012.

CMMAD - COMISSÃO MUNDIAL SOBRE MEIO AMBIENTE E DESENVOLVIMENTO. Nosso futuro comum. Rio de Janeiro: Ed. FGV, 1988.

DUARTE, C. G.; MALHEIROS, T. F. Qualidade ambiental e o setor sucroenergético: análise de iniciativas. In: FIGUEIREDO, F. E. L. (Org.). Relatório de qualidade ambiental - 2012 do estado de São Paulo. v. 1. São Paulo: SMA-SP, 2012. p. 196-216.

DUARTE, C. G.; et al. Sustainability assessment of sugarcane-ethanol production in Brazil: A case study of a sugarcane mill in São Paulo state. Ecological Indicators, v. 30, p. 119-129, 2013.

GASPARATOS, A. Embedded value systems in sustainability evaluation tools and their implication. Journal of Environmental Management, $v$. 91, n. 8, p. 1613-1622, 2010.

GASPARATOS, A.; EL-HARAM, M.; HORNER, M. A critical review of reductionist approaches for assessing the progress towards sustainability. Environmental Impact Assessment Review, v. 28, n. 4-5, p. $286311,2008$.

GIBSON, R. B. et al. Sustainability Assessment: Criteria, Processes and Applications. London: Earthscan, 2005. 
MAX-NEEF, M. Desenvolvimento à escala humana. Blumenau: Edifurb, 2012.

ONU - ORGANIZAÇÃO DAS NAÇÕES UNIDAS. The future we want. Outcome document adopted at RIO+20. Washington (DC): ONU, 2012. Disponivel em: <http://www.un.org/en/sustainablefuture/>. Acesso em: 24 set. 2013.

PHILIPP JR, A.; MALHEIROS, T. F. Indicadores de sustentabilidade e gestão ambiental. Barueri: Manole; 2012.

UNEP - UNITED NATIONS ENVIRONMENTAL PROGRAMME. Realizing the future we want for all - Report to the Secretary-General. New York: UNEP, 2012.

VEIGA, J. E. Sustentabilidade: a legitimação de um novo valor. São Paulo: Editora SENAC São Paulo, 2010.

WWF - WORLD WIDE FUND FOR NATURE. Living Planet Report 2012 - Special edition - On the road to Rio+20. Gland, Switzerland: WWF, 2012. Disponivel em: <http://wwf.panda.org/about_our_earth/all_ publications/living_planet_report/2012_Ipr/>. Acesso em: 20 out. 2012. 


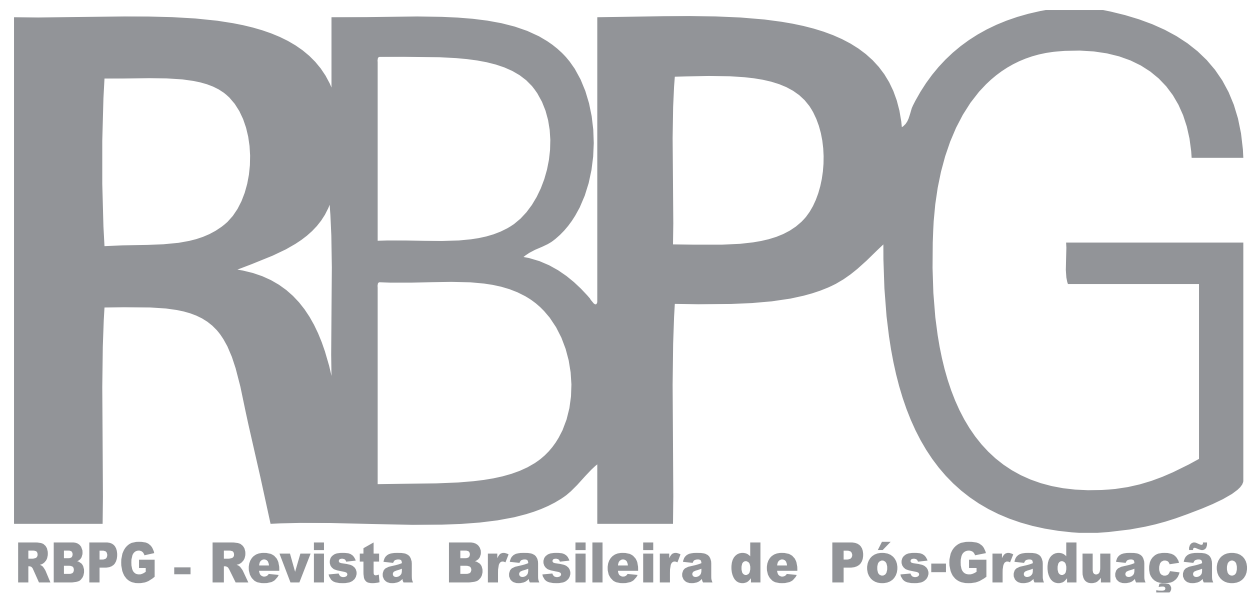




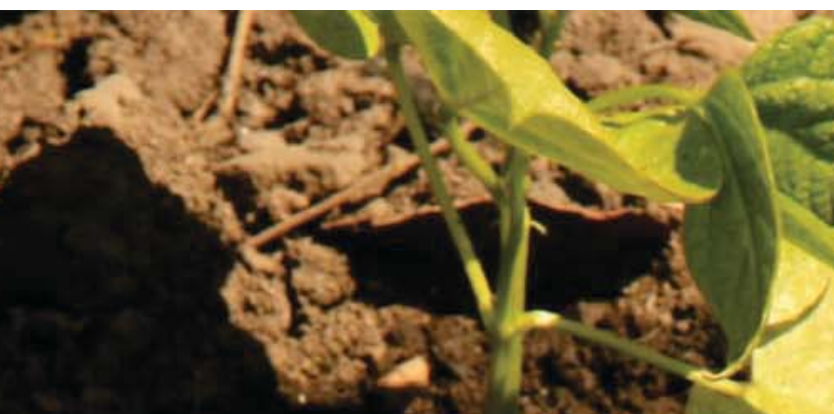

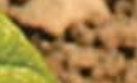

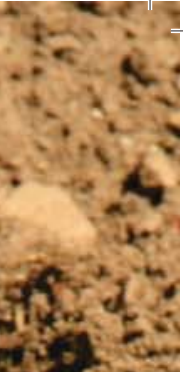
entis:
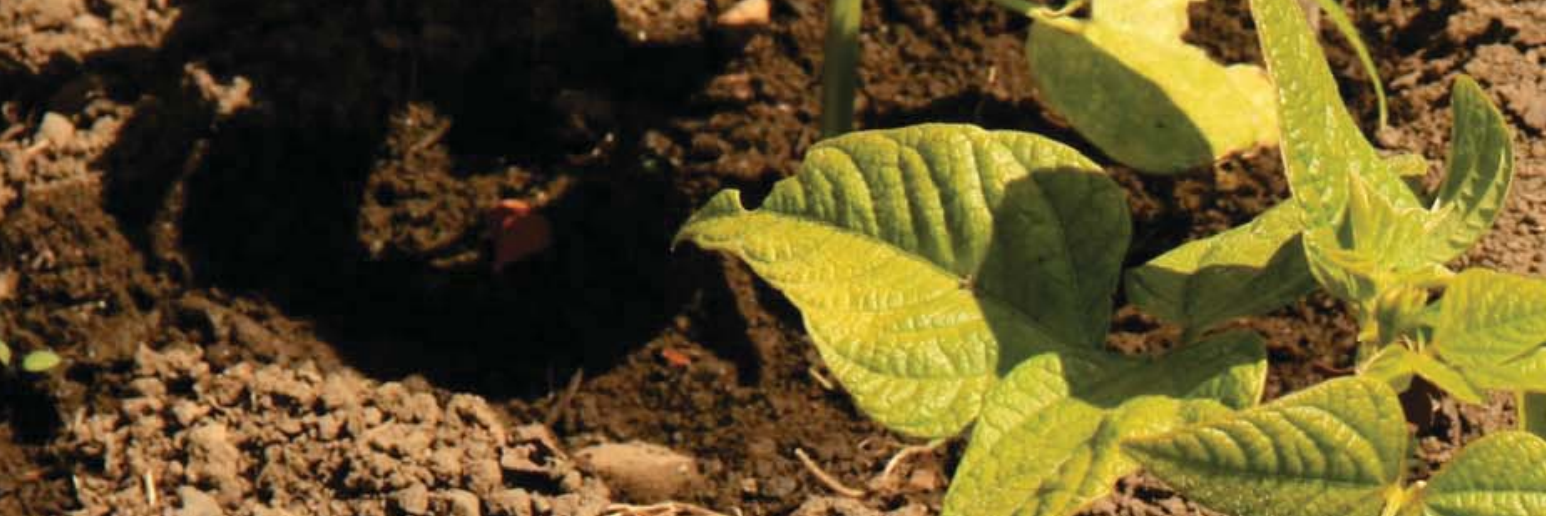

\section{2}

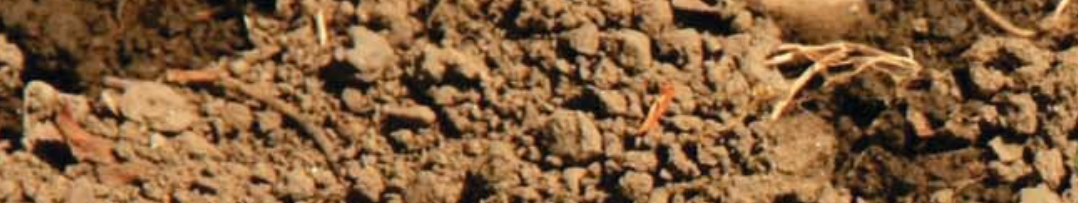

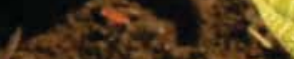

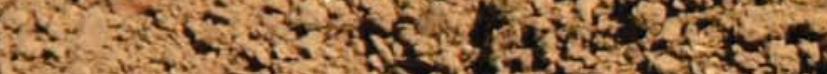
$4 x^{2}+x^{2}=$

Asing

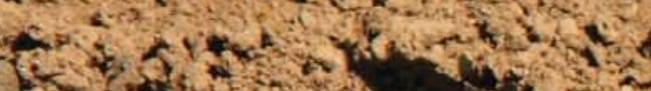

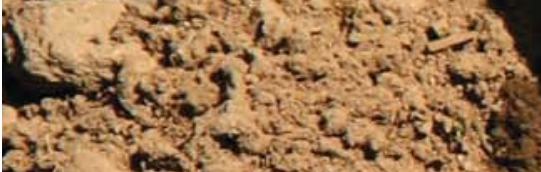

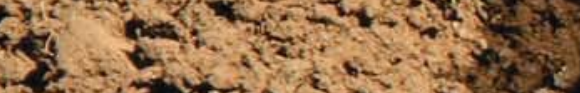

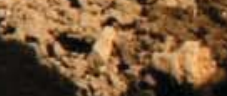
3 is thinge

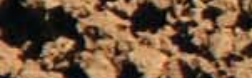

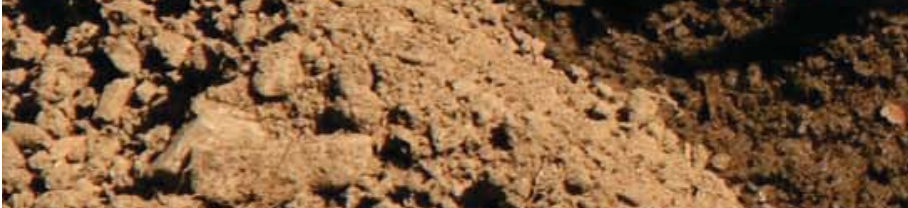

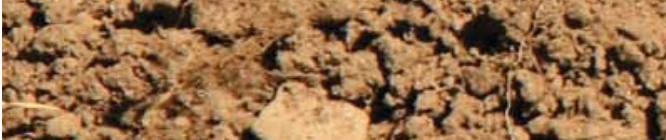

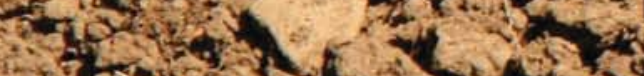

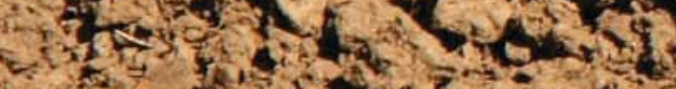
E.

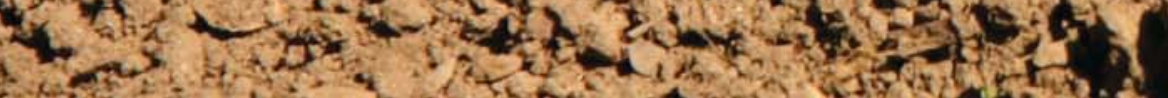

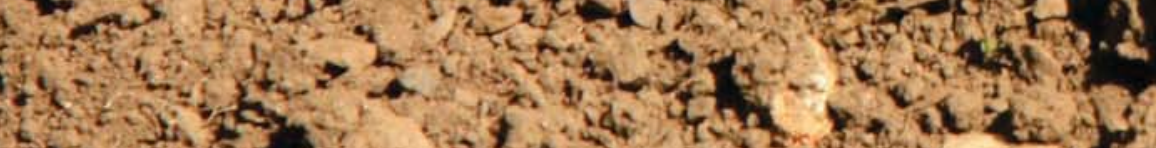

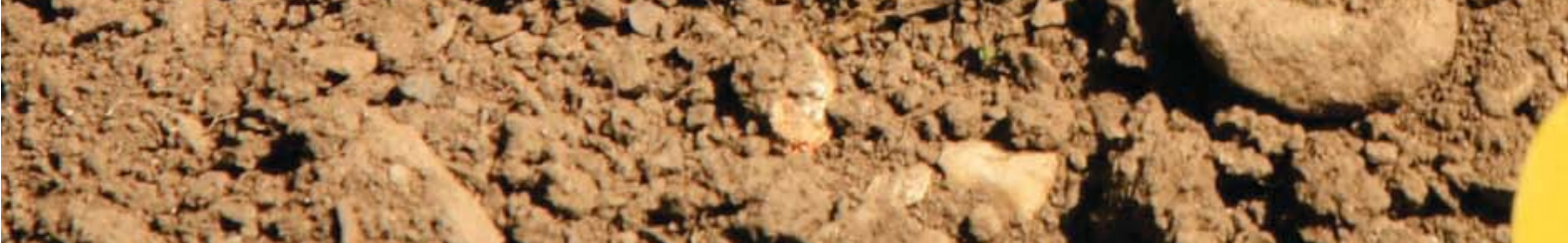

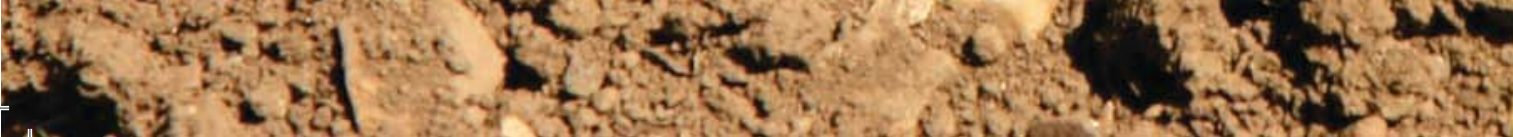


$x^{2}=1$

C.

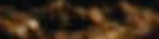

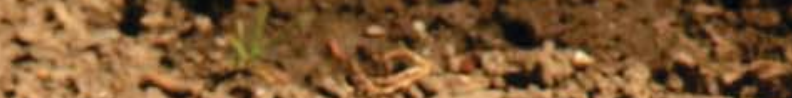

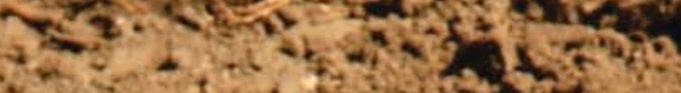

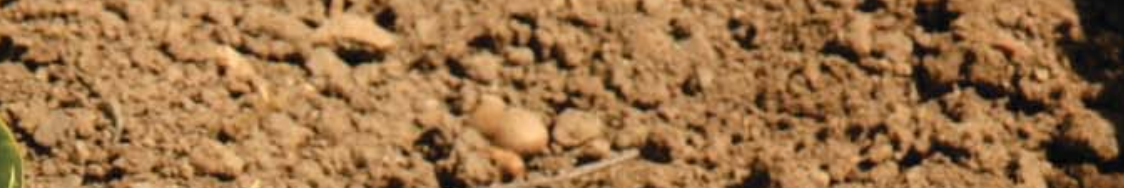

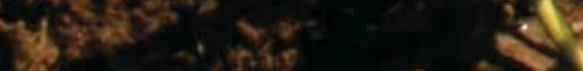

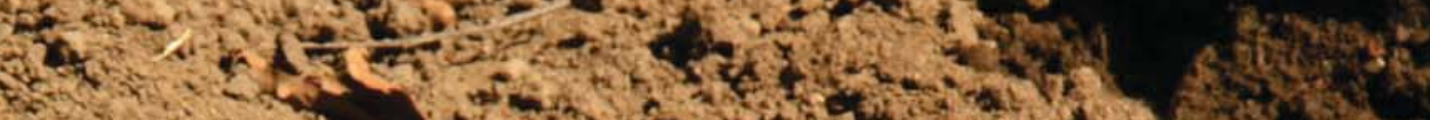

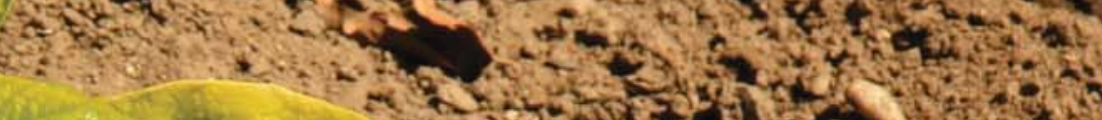

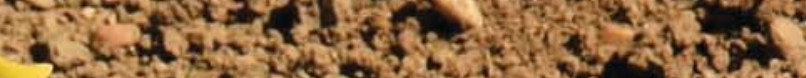

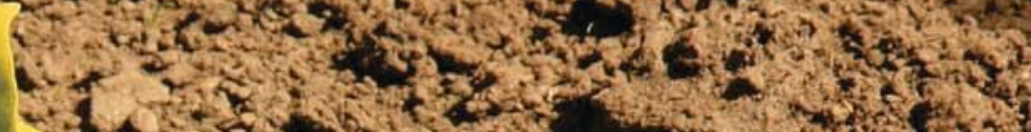

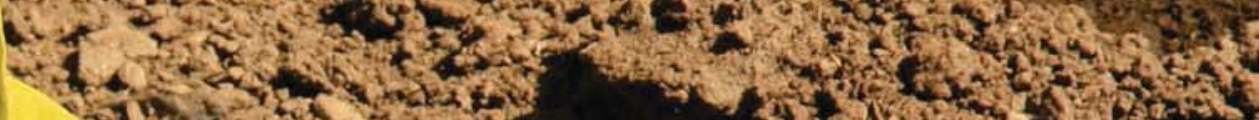
नy

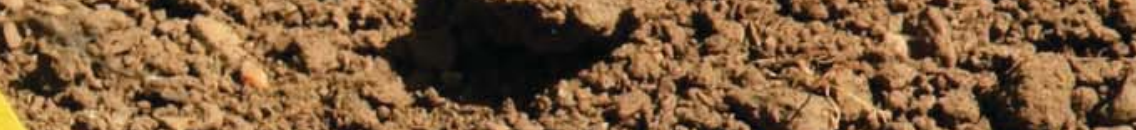

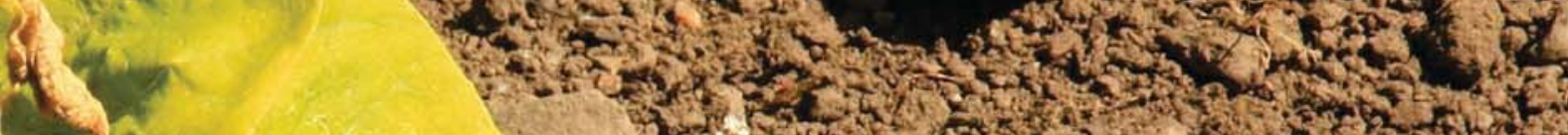
3.

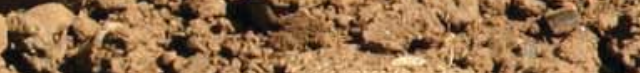

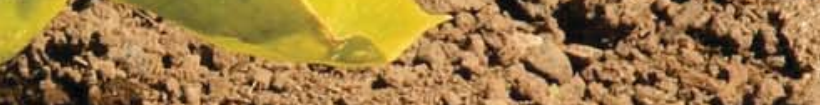
Whit

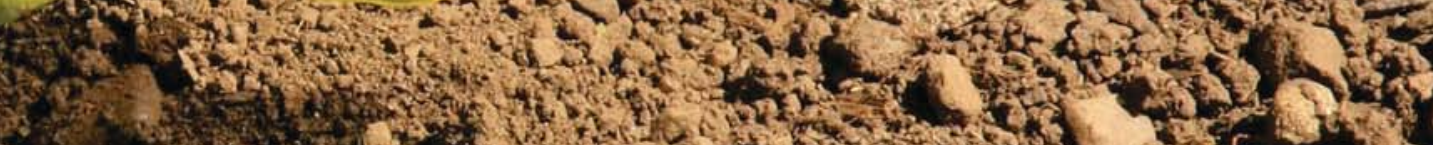

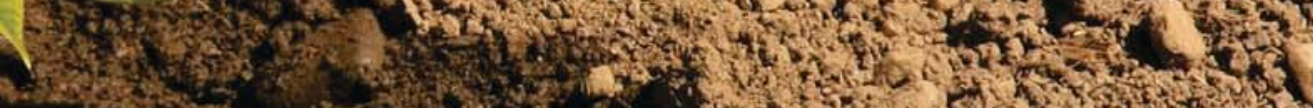

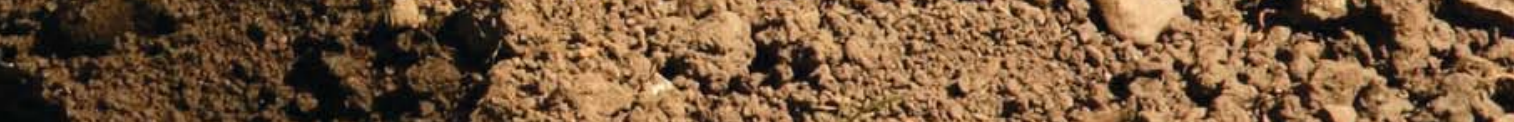

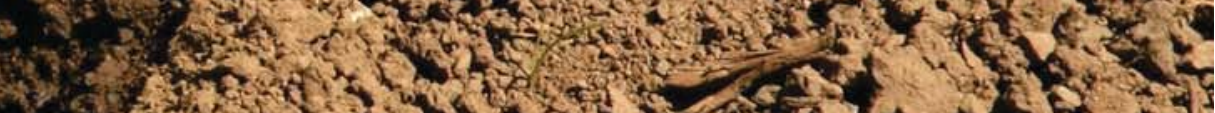

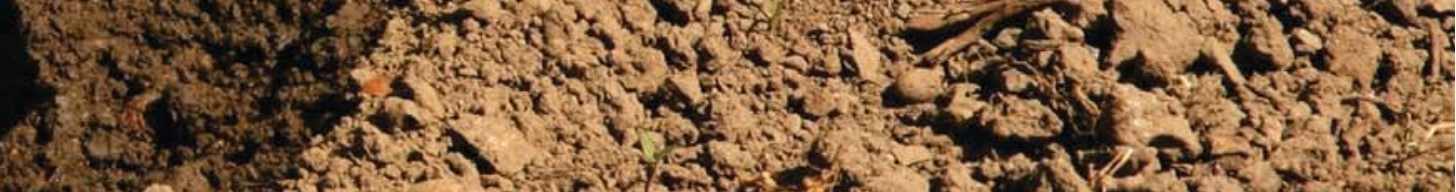

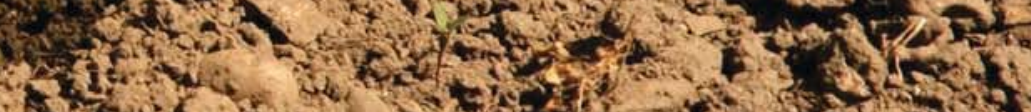

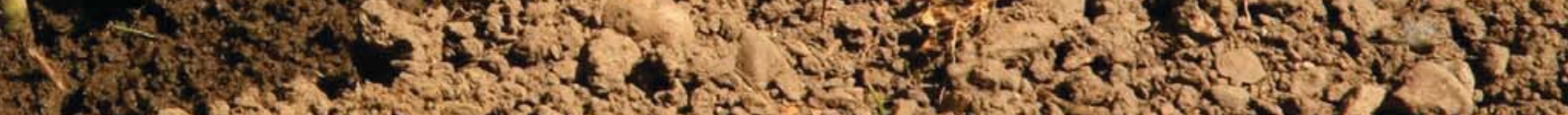

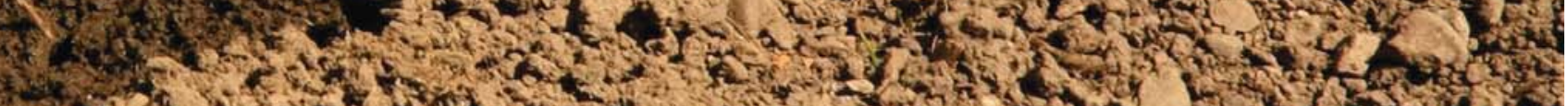

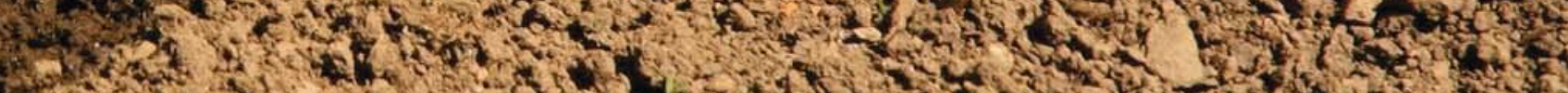

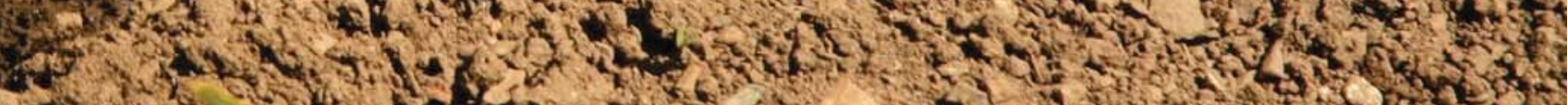

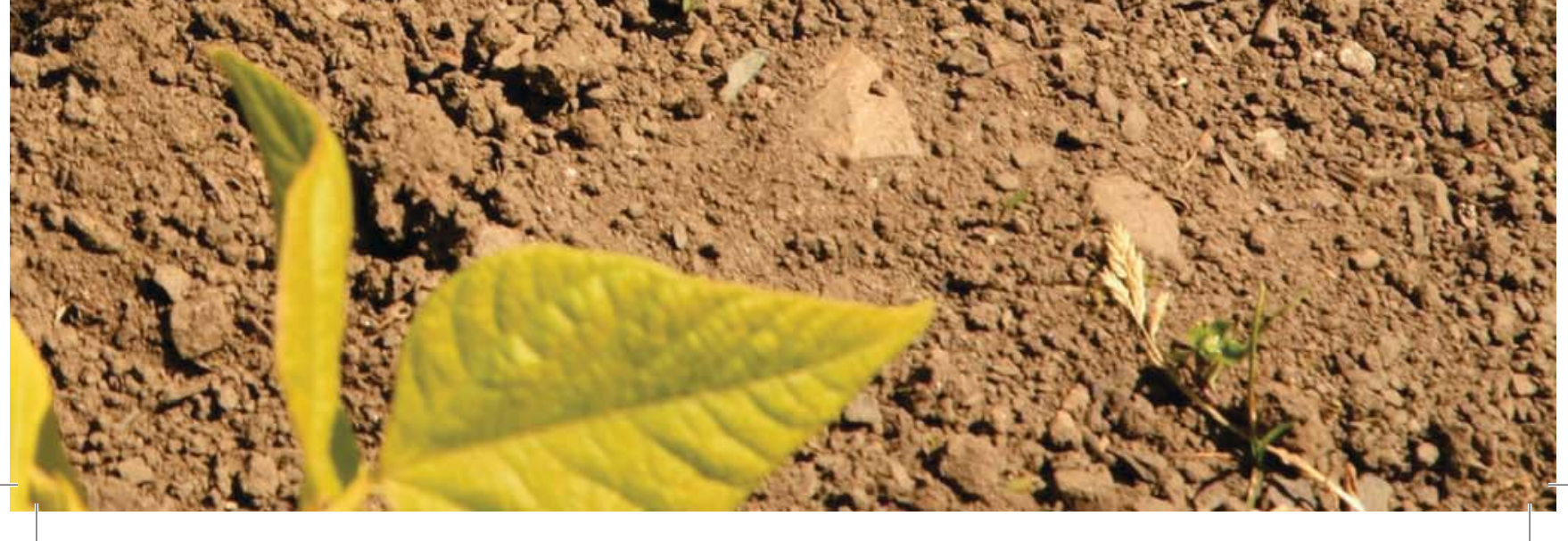




\section{A inserção da Química Verde nos programas de pós-graduação em Química do Brasil: tendências e perspectivas}

The inclusion of green chemistry in post-graduate programs in Chemistry in Brazil: tendencies and perspectives

\section{La inserción de la Química Verde en los programas de posgrado en Química en Brasil: tendencias y perspectivas}

Vânia Gomes Zuin, doutora em Ciências e em Educação pela Universidade de São Paulo (USP), professora da Universidade Federal de São Carlos (UFSCAR) e coordenadora brasileira do projeto Sustainable Education and Environmental Development (SEED) in Latin America. Endereço: Rodovia Washington Luís (SP-310), km 235. CEP: 13565-905 - São Carlos, SP. Telefone: (16) 3351-8096. E-mail:vaniaz@ufscar.br.

\section{Resumo}

Este artigo tem como meta investigar as formas pelas quais os princípios da Química Verde têm sido inseridos nos programas de pósgraduação em Química brasileiros. Parte da premissa de que, diante dos atuais desafios que tocam à produção de conhecimentos e formação de recursos humanos voltados à sustentabilidade socioambiental, fazse necessário refletir sobre os temas, as propostas, as potencialidades e os limites relacionados à Química Verde que ocorrem nos cursos ofertados por mais de 40 programas de pós-graduação em Química do País. Observa-se que a quase totalidade desses programas apresenta disciplinas, grupos, linhas e projetos de pesquisa para o desenvolvimento, a análise e a formação que permitem repensar as formas de geração de materiais e processos verdes no contexto acadêmico brasileiro contemporâneo. 
Palavras-chave: Química Verde. Pós-Graduação em Química. Ciência, Tecnologia e Inovação (CT\&I). Sustentabilidade.

\section{Abstract}

This article aims at investigating ways in which the principles of Green Chemistry are included in Brazilian Graduate Programs in Chemistry. Part of the premise is: when facing today's challenges concerning the production of knowledge and the formation of human resources focused on social and environmental sustainability, it has become necessary to reflect on topics, proposals, potentialities and limits related to Green Chemistry, which occur in the courses offered in over 40 Graduate Programs in Chemistry in the country. In almost all of these programs it is possible to observe that they include disciplines, groups, research lines and projects for development, analysis and formation which permit a rethinking of ways of creating green materials and processes in the contemporary Brazilian academic context.

Keywords: Green Chemistry. Graduate Programs in Chemistry. Science, Technology and Innovation (ScT\&I). Sustainability.

\section{Resumen}

Este artículo tiene como objetivo investigar las formas mediante las cuales los principios de la Química Verde se están insertando en los programas brasileños de posgrado en Química. Se supone que, dados los retos actuales que afectan la producción de conocimientos y la formación de recursos humanos centrados en la sostenibilidad socioambiental, es necesario reflexionar sobre los temas, las propuestas, las potencialidades y los límites relacionados a la Química Verde que ocurren en los cursos ofrecidos por más de 40 programas de posgrado en Química de Brasil. Se observa que casi la totalidad de estos programas presenta asignaturas, grupos, líneas y proyectos de investigación para el desenvolvimiento, análisis y la formación que 
permitan repensar las formas de generación de materiales y procesos ecológicos dentro del contexto académico brasileño contemporáneo.

Palabras clave: Química Verde. Posgrado en Química. Ciencia, Tecnología e Innovación (CT\&I). Sostenibilidad.

\section{Introdução}

Nos dias atuais, a construção de caminhos em direção à sustentabilidade é reconhecidamente permeada de obstáculos, muito em função dos riscos existentes, com destaque para os ambientais. Os modelos de desenvolvimento sociossustentável podem ser compreendidos como processos que têm como restrições mais importantes a exploração dos recursos naturais, a orientação científica e tecnológica e os marcos institucionais, com ênfase aos "aspectos qualitativos, notadamente os relacionados com a eqüidade, o uso de recursos - em particular da energia - e a geração de resíduos e contaminantes” (JACOBI, 2003, p. 195; JACOBI; GUNTHER; GIATTI, 2012).

Nesse sentido, durante o século $X X$, pode-se afirmar que a Química mudou significativamente as formas como vivemos, seja devido aos medicamentos, materiais para vestuário, alimentos, à moradia, aos combustiveis para os mais diversos equipamentos, além de uma miríade de outros produtos tidos como essenciais. Entretanto, ainda hoje o processo produtivo - e suas externalidades - é visto também como um empreendimento que pode causar malefícios, haja vista os desastres ambientais ocorridos em todo o mundo, como os de Seveso (Itália, 1976), Bhopal (Índia, 1984) e Toulouse (França, 2001), entre outros (LACANSTER, 2010).

Dadas as demandas contemporâneas em todo o globo, especialmente aquelas relacionadas às questões socioambientais, fazse necessário refletir sobre formas mais adequadas para a produção de conhecimentos científicos e tecnológicos que reduzam ou eliminem a geração de resíduos e efluentes tóxicos. Nesse contexto, insere-se o movimento conhecido como Química Sustentável, benign by design 
ou Química Verde, iniciado com maior ênfase nos anos noventa do século XX, principalmente nos Estados Unidos, na Inglaterra e na Itália. Esse movimento pode ser compreendido como "o uso de uma série de princípios que reduzem ou eliminam a utilização e a geração de substâncias nocivas em seu desenho, manufatura e aplicação” (ANASTAS; WARNER, 1998, p. 11) e objetiva a redução do risco por meio, idealmente, da eliminação do perigo associado às substâncias químicas tóxicas, em vez da restrição de exposição a elas. Dito de outra forma: em vez de se utilizar a abordagem histórica de controlar as concentrações ou emissões de uma substância particular, a Química Verde pretende modificar a natureza intrínseca das substâncias, que seriam então incapazes de causar poluição, tornando desnecessárias as remedições dos impactos ambientais frequentemente observados atualmente (CORREA; ZUIN, 2009; CORREA et al., 2013).

Os 12 princípios propostos por Anastas e Warner (1998) e que balizam as ações no bojo da Química Verde são: 1) prevenção (deve-se prevenir a geração de resíduos em vez de tratá-los); 2) economia de átomos (devem ser planejados métodos sintéticos de modo a maximizar a incorporação de todos os materiais usados no produto final); 3) reações com compostos de menor toxicidade (devem ser planejados métodos que utilizem ou gerem substâncias que possuem pequena ou nula toxicidade); 4) desenvolvimento de compostos seguros (deve-se reduzir ou eliminar a toxicidade sem prejuízo da eficácia); 5) diminuição do uso de solventes e auxiliares (devem ser revistas todas as etapas para a manufatura e o uso de substâncias químicas); 6) eficiência energética (devem ser minimizadas as necessidades energéticas nas transformações químicas); 7) uso de substâncias renováveis (devem ser utilizadas matérias-primas renováveis em detrimento das não renováveis); 8) evitar a formação de derivados (deve ser evitado o uso de reagentes bloqueadores, de proteção ou desproteção, modificadores temporários nos processos químicos e físicos); 9) catálise (devem ser utilizados reagentes catalíticos tão seletivos quanto possível nas transformações químicas); 10) desenvolvimento de substâncias degradáveis (devem ser projetados produtos que cumprem a sua função e não persistem no ambiente, degradando-se em materiais inócuos); 11) análise em tempo real para a prevenção da poluição 
(devem ser estabelecidas metodologias analíticas que possibilitem evitar a formação de substâncias tóxicas em um processo químico); e 12) química segura para a prevenção de acidentes (deve ser planejado o uso de substâncias que minimizem o potencial de explosões, vazamentos, incêndios, etc.).

O movimento da Química Verde tem se ampliado nos últimos anos, envolvendo as principais sociedades de Química mundiais, como a International Union of Pure and Applied Chemistry (IUPAC), que procura estabelecer diretrizes e metas voltadas ao desenvolvimento da Química Verde em todo o mundo (HÖFER, 2009; JESSOP, 2011). No Brasil, a Química Verde tem alcançado maior projeção principalmente no setor industrial, mas também nas universidades e nos demais órgãos governamentais. Desde meados de 2000, várias instituições de ensino, pesquisa, associações profissionais e empresas da área de Química e das Engenharias têm promovido eventos para a difusão da Química Verde. Em 2004, o livro “Green Chemistry in Latin-America” foi publicado como resultado de um projeto apoiado pela IUPAC (TUNDO; ROSSI, 2004).

Em 2007 houve também a criação da Rede Brasileira de Química Verde, que tem como meta atuar institucionalmente de modo a promover inovações científicas e tecnológicas para empresas nacionais, com o apoio da comunidade científica e das agências governamentais, o que incluiu o estabelecimento da Escola Brasileira de Química Verde. Em 2009 e 2010 houve as primeiras publicações de livros voltados à Química Verde com ênfase nos temas, nas pesquisas e potencialidades encontradas no País, caso da obra "Química Verde: fundamentos e aplicações", que recebeu o 52 prêmio Jabuti de Bronze na categoria "Ciências Exatas, Tecnologia e Informática” da Câmara Brasileira do Livro (CORREA; ZUIN, 2009), e do livro "Química Verde no Brasil: 2010-2030”, editado pelo Centro de Gestão e Estudos Estratégicos (CGEE), que apresentou os seguintes temas prioritários: biorrefinarias, pelas rotas termoquímica e bioquímica; alcoolquímica; oleoquímica; sucroquímica; fotoquímica; conversão de CO2; bioprodutos, bioprocessos e biocombustiveis; energias alternativas, que inclui outros eixos transversais como catálise, modelagem e escalonamento de processos (CGEE, 2010). 
Em 2012 o Brasil sediou a Conferência das Nações Unidas sobre Desenvolvimento Sustentável (Rio+20), a partir da qual foi engendrado o documento “O futuro que queremos", que defende, entre várias proposições, o desenvolvimento sustentável para a erradicação da pobreza em todos os níveis. Como parte da programação da Rio+20, o CGEE promoveu nove painéis, sendo um relacionado à discussão da Química Verde e aos desafios para o desenvolvimento sustentável. Aspectos semelhantes relacionados ao aumento de pesquisas que busquem fontes de energia renováveis e processos limpos na área de Química também foram discutidos no livro “Contribuição da pósgraduação brasileira para o desenvolvimento sustentável: Capes na Rio+20”, publicado pela Fundação Coordenação de Aperfeiçoamento de Pessoal de Nivel Superior (Capes), que teve como principal objetivo apresentar os avanços da pós-graduação brasileira na Rio+20 (BRASIL, 2012).

Ainda em 2012, fruto do projeto Sustainable Education and Environmental Development (SEED) in Latin America apoiado pela IUPAC, foi realizada a $4^{\text {th }}$ International IUPAC Conference on Green Chemistry (4 ${ }^{\text {th }}$ ICGC), em Foz do Iguaçu, Brasil, sob os auspícios da IUPAC e da Sociedade Brasileira de Química (SBQ). A conferência contou com um número superior a 600 participantes provenientes de mais de 45 países, representantes dos setores acadêmico, industrial, governamental e não governamental, que discutiram os recentes avanços e as perspectivas futuras no campo da Química Verde tanto no Brasil quanto no exterior. A programação da $4^{\text {th }}$ ICGC incluiu minicursos, palestras plenárias, palestras técnicas/empresas, apresentações de trabalhos orais e de pôsteres, além de mesas-redondas.

Objetivando aprofundar as discussões nas mesas-redondas da 4th ICGC, algumas questões orientadoras comuns foram enviadas aos seus componentes, caso da mesa intitulada Perspectives on Green Chemistry: the role of the Brazilian research funding agencies, integrada por representantes das principais agências de fomento à pesquisa científica e tecnológica e à formação de pesquisadores do Brasil (como a Capes; o Conselho Nacional de Desenvolvimento Científico e Tecnológico, CNPq; e a Fundação de Amparo à Pesquisa do Estado 
do Rio de Janeiro, Faperj). A fim de verificar os alcances da Química Verde no contexto da pós-graduação em Química do País, as questões orientadoras das discussões realizadas na $4^{\text {th }}$ ICGC foram ampliadas e encaminhadas a todos os coordenadores dos cursos de mestrado profissional, mestrado e doutorado acadêmicos da área de Química do País. Dessa maneira, as respostas apresentadas e debatidas na $4^{\text {th }}$ ICGC proporcionam a elaboração do objetivo deste artigo: compreender a natureza e as formas pelas quais a Química Verde se insere nos programas de pós-graduação em Química do Brasil, além de vislumbrar os principais desafios, potencialidades e limites desse movimento verde na área no contexto acadêmico brasileiro atual.

\section{Delineamento do levantamento e análise dos dados}

Hoje, a área de Química possui 61 programas de pós-graduação recomendados pela Capes, totalizando 96 cursos, sendo 57 cursos de mestrado acadêmico, 37 cursos de doutorado e dois de mestrado profissional, presentes em praticamente todos os estados brasileiros (BRASIL, 2012). Os programas mais antigos encontram-se consolidados e apoiam vários outros cursos, especialmente nas regiões Centro-Oeste e Norte do País, sendo um dos principais desafios da área avançar na consolidação dos cursos nessas regiões. É possível também observar que os "docentes credenciados na área atuam em todas as subáreas da Química e com uma forte interação com áreas afins (Médicas, Física, Agronomia, Biologia, Biotecnologia, Bioquímica, Materiais, Engenharias, Ensino, etc.). Essa multi- e interdisciplinaridade fica evidenciada na diversidade e qualidade da produção científica” (BRASIL, 2012, p. 106). Além do significativo número de artigos publicados (superior a 10 mil, a maior parte em revistas internacionais), o "avanço tecnológico da área pode ser medido pelo número de patentes depositadas - 272 durante o triênio 2007-2009, correspondendo a um aumento de 55\% em relação ao triênio anterior. Embora a maior parte dos mestres e doutores formados na área de Química” seja absorvida pela academia, cerca de 20-25\% "foram incorporados pelos setores não acadêmicos público e privado. A área está consolidada internacionalmente, sendo uma das áreas que mais cresce em termos de citações/artigos no Brasil” (BRASIL, 2012, p. 106). 
Vários são os temas de pesquisa na área de Química que se relacionamaos princípios da Química Verde: o desenvolvimento de novos materiais, aproveitamento de produtos vegetais, os biocombustíveis (biodiesel e etanol), a produção de hidrogênio, células a combustível, aditivos e antioxidantes para biocombustíveis, cujo aumento nos últimos cinco anos pode ser explicado em função das demandas e dos incentivos na busca por fontes renováveis e processos verdes. A Faperj lançou o Edital N²7/2012 (Apoio à Pesquisa Científica e Tecnológica em Química Verde - 2012), que teve como objetivo incentivar o desenvolvimento e a inovação de produtos e processos químicos ecologicamente corretos. As diretrizes que balizaram o Edital $N^{\circ}$ 27/2012 basearam-se na obra “Química Verde no Brasil: 2010-2030” (CGEE, 2010), e os projetos aprovados focam majoritariamente síntese orgânica, seguido por biomassa e biocatálise (CORREA et al., 2013). Outras ações indutoras, sem que sejam diretamente denominadas de Química Verde, foram também oportunizadas por outras agências de fomento à pesquisa juntamente com empresas. O programa da Fundação de Amparo à Pesquisa do Estado de São Paulo (Fapesp) voltado à Bioenergia (BIOEN) tem também como meta estimular e articular atividades de pesquisa e desenvolvimento utilizando laboratórios acadêmicos e industriais para promover o avanço do conhecimento e sua aplicação em áreas relacionadas à produção de bioenergia no Brasil.

As demais agências e órgãos, além de incentivar as pesquisas em ciência, tecnologia e inovação nessa direção, têm procurado compreender de que maneira a Química Verde se desenvolve no Brasil. Assim, em função da realização da $4^{\text {th }}$ ICGC, questões formuladas pela sua comissão científica que tinham como meta mapear as formas pelas quais a Química Verde se insere em várias instituições, no Brasil e no mundo, foram encaminhadas aos seus respectivos representantes. Dessa forma, os coordenadores dos programas de pós-graduação em Química do País receberam questões encaminhadas pela coordenação da área de Química da Capes, sob a responsabilidade do prof. Dr. Luiz Carlos Dias, cujos principais resultados foram apresentados na mesaredonda Perspectives on Green Chemistry: the role of the Brazilian 
research funding agencies, da $4^{\text {th }}$ ICGC. As perguntas são listadas a seguir e a análise das respostas é discutida no presente artigo.

1. O tema Química Verde é incluído de alguma forma em seu programa e instituição?

2. Quais são os benefícios e as dificuldades para sua implementação? (Como você avalia a sua execução?)

3. Há propostas para a inserção de disciplinas de graduação ou pós-graduação, seminários, workshops, simpósios?

4. Há propostas para a contratação de docentes com linhas de pesquisa em Química Verde?

5. Quais são as perspectivas futuras ou os planos concretos de sua instituição, a fim de promover a inclusão do tema Química Verde?

6. Comentários que considerar pertinentes, não abordados nas perguntas acima.

Dos 61 coordenadores dos programas de pós-graduação em Química do País, 45 responderam o questionário. Por meio da análise de conteúdo, as respostas foram estudadas, considerando o escrito como ponto de partida para a identificação do conteúdo manifesto (FRANCO, 2007). As categorias estabelecidas se relacionam à ideia principal das perguntas, a saber: institucionalização da Química Verde; potencialidades e limitações da Química Verde; e perspectivas para o estabelecimento e a permanência da Química Verde.

\section{O status quo da Química Verde nos programas de pós-graduação em Química brasileiros}

O conceito de desenvolvimento sustentável se espraia cada vez mais nos programas de pós-graduação brasileiros. Criado em 1980, tal conceito esteve presente na denominada Agenda 21 Global, um documento aprovado por mais de 170 países que participaram da Conferência das Nações Unidas sobre o Meio Ambiente e Desenvolvimento, ocorrida no Rio de Janeiro em 1992, a chamada Rio 92. As principais premissas que compõem esse conceito são as seguintes: 
[...] perspectiva de longo prazo, capacidade de suporte dos ecossistemas, responsabilidade intergerações, princípio da precaução, bem-estar comunitário e participativo, idéias de cooperação, conservação e justiça, bem como concepção de que sustentabilidade comporta várias dimensões, assegurando no mínimo inter-relação da ecológica, econômica e social (BRASIL, 2012, p.11-12).

Essas premissas, que estruturam as bases do conceito de desenvolvimento sustentável, determinaram o engendramento de várias correntes científico- epistemológicas simpáticas a uma postura antipredatória dos chamados recursos naturais. Dentre tais correntes, destaca-se a Química Verde, na área de Química, Engenharias e campos correlatos. Por meio da análise das respostas de coordenadores/ pesquisadores de mais de $73 \%$ dos programas de pós-graduação em Química existentes no País, pode-se observar a forma como a temática da Química Verde amealha cada vez mais espaço tanto nas disciplinas quanto no ethos de tais programas.

Nas respostas à questão "O tema Química Verde é incluído de alguma forma em seu programa e instituição?”, 95\% dos entrevistados asseveraram que a temática da Química Verde se encontra organicamente vinculada às disciplinas dos respectivos programas, o que corrobora para a institucionalização desse movimento:

O mesmo tema é abordado na disciplina de Química do Ar, Água e Solo oferecida no programa de pós-graduação (PPGQ5).

No PPGQ temos a disciplina eletiva: "Química Verde e Sustentável". Além disto, o nosso grupo de pesquisa [...] trabalha visando o desenvolvimento de metodologias verdes e a utilização de recursos renováveis em sintese. 0 que permite que os alunos apliquem os princípios da Química Verde ainda na graduação através dos programas de Iniciação Científica (PPGQ2).

Graduação: Curso Bacharelado em Química Ambiental (Noturno). PósGraduação: Disciplina Química Verde, Linhas de Pesquisa "Química Ambiental" e "Química Verde" com ao menos uma dezena de docentes envolvidos. Curso de Inverno: Química Verde com a participação de cerca de 50 alunos de todo país (PPGQ8).

É interessante observar o modo como os docentes e pesquisadores dos programas de pós-graduação em Química 
enfatizaram a presença da Química Verde em suas disciplinas, pesquisas e seus cursos, seja direta ou indiretamente. A presença maciça dos pressupostos da Química Verde necessita ser compreendida no contexto de que a preocupação com as consequências ambientais decorrentes do descarte de resíduos químicos, por exemplo, afeta, muitas vezes de forma irremediável, a vida como um todo. Já na segunda questão feita aos coordenadores/pesquisadores, "Quais são os benefícios e dificuldades para a implementação da Química Verde?”, as respostas evidenciaram que muitos consideram evidentes as potencialidades, mas a formação que possibilite o tratamento adequado de temas ligados à Química Verde é hoje um dos principais limitantes para a sua inserção nas instituições:

Os principais benefícios estão na multidisciplinaridade, na grande perspectiva de inovação tecnológica, na atratividade perante a iniciativa privada e órgãos de fomento, na grande visibilidade dos projetos realizados em seu âmbito e na complementaridade de esforços para o desenvolvimento de projetos que realmente poderão fazer a diferença para o futuro da humanidade (PPGQ11).

Os temas relacionados à Química Verde são atuais e despertam grande interesse dos estudantes. Os conhecimentos na área contribuem para uma formação mais ampla e para o desenvolvimento de projetos de pesquisa alinhados com a preocupação com o meio ambiente e com a sustentabilidade. As dificuldades estão mais relacionadas à disponibilidade de professores que atuam em temas centrais da Química Verde em oferecer disciplinas focadas na nesta temática. Em geral, a temática Química Verde está diluída nas disciplinas ministradas em nossos PPG (PPGQ16).

(Os benefícios incluem a) Diminuição da quantidade de resíduos gerados nos laboratórios de graduação e, já há alguns anos, eliminação do uso de reagentes perigosos e poluentes como sais de chumbo e solução sulfocrômica; Coleta seletiva do lixo; Destino final adequado via empresas especializadas em tratamento de resíduos químicos. Dificuldades: Limitações financeiras para dar o devido destino ao lixo comum e aos resíduos dos laboratórios; Formação deficiente dos funcionários responsáveis pelos laboratórios; Conscientização da comunidade em relação à importância do tema; Destinação final de alguns materiais coletados seletivamente, como os vidros dos reagentes (PPGQ20).

Uma vez que (...) não há docentes com formação específica em Química Verde, seria importante uma atualização da temática para os docentes, o que poderia promover uma mudança na atitude e, consequentemente, na formação dos acadêmicos (PPGQ15). 
De forma geral, todos os entrevistados concordaram que as principais benesses à inserção da Química Verde em seus programas se referem à disseminação de uma preocupação formativa, ou seja, ao incentivo do recrudescimento do processo de conscientização da relevância de se refletir sobre o empreendimento científico e os destinos dos resíduos químicos, de tal modo que se desenvolvam resistências quanto a uma perspectiva química instrumentalizada e imediatista (ZUIN, 2011). Trata-se, portanto, do incentivo à presença de uma mentalidade que considera decisiva a história da geração e do descarte de rejeitos, pois se sabe que considerar tal história significa também lidar com a história das relações e produções humanas. Interessante notar que as ênfases atribuídas a tais mentalidades e à formação ilustram a dificuldade de se encontrar profissionais cujas pesquisas estejam direta e explicitamente vinculadas à Química Verde, o que representa mais um reforço à necessidade de que já na graduação os princípios da Química Verde estejam presentes nas respectivas estruturas curriculares. Destaca-se que, dos poucos respondentes que detalharam as maneiras pelas quais a execução dos princípios da Química Verde é avaliada, a procura ou interesse pelas atividades propostas por parte da comunidade acadêmica foi considerada um dos melhores critérios de avaliação.

Na questão sobre as perspectivas futuras ou planos concretos da instituição a fim de promover a inclusão do tema Química Verde, que significa identificar as perspectivas para o estabelecimento e a permanência desse movimento, destacaram-se os seguintes depoimentos:

Os docentes do Departamento de Química já desenvolvem suas pesquisas praticando a Química Verde, tanto nos laboratórios de graduação quanto nos de pesquisa. O principal objetivo é manter o planejamento de modo a não permitir que os novos ingressantes do Departamento, tanto alunos como docentes deixem de praticar os princípios da Química Verde. Neste sentido, Seminários e disciplinas serão programadas para serem ministradas regularmente no Programa (PPGQ25).

A universidade criou em 2012 um grupo chamado (universidade federal) Sustentável, sendo criada uma comissão para discutir e aprimorar as questões relacionadas à Química Verde. O departamento de química possui um representante nessa comissão (PPGQ20). 
Já há grupos de pesquisa atuando em diferentes frentes do envelope "Química Verde”. Os concursos para preencher vagas docentes visam captar pesquisadores em várias áreas que o (instituto) considera estratégicas e muitas delas permeiam o tema Química Verde (PPGQ25).

A perspectiva futura será incluir o tema por meio de cursos, workshops e palestras visando não só os alunos, mas também os professores (PPGQ25).

Muitos dos programas de pós-graduação que participaram dessa pesquisa observaram que a presença da Química Verde em suas disciplinas já é uma realidade inconteste. Mas há que se destacar o fato de que tanto as futuras contratações de docentes quanto a contínua preocupação de que os alunos também se interessem pela discussão de seus pressupostos são incentivadas por meio da ampla maioria dos entrevistados. Os comentários adicionais encaminhados pelos entrevistados permitiram compreender outras dimensões que tocam ao objeto deste artigo. Por exemplo, que ações individuais de docentes que participam de outras instituições ou programas de pós-graduação possibilitaram a criação de programas nos quais as pesquisas em Química Verde encontram um lócus específico:

Há um grupo de docentes (...) que está organizando uma Escola Brasileira de Química Verde (EBQV). (...). Criamos uma Rede Brasileira de Química Verde, que tem como uma das finalidades o oferecimento de cursos específicos para estudantes e profissionais da química. 0 mestrado profissional (...) em Engenharia Petroquímica e de Biocombustiveis, do qual sou docente permanente, já está implementando uma ênfase em QV (Química Verde). No (instituto) acho que não existe uma ação formal, mas há gente daqui envolvida em ações multinstitucionais (PPGQ43).

O fato de as perguntas terem sido encaminhadas a todas as coordenações dos programas de pós-graduação em Química do Brasil, cuja primeira intencionalidade era subsidiar as discussões nas mesas-redondas da $4^{\text {th }}$ ICGC, promoveu reflexões acerca da inserção dos princípios da Química Verde nas suas atividades presentes e futuras, seja na pesquisa, no ensino, na extensão e gestão. Podese asseverar que, em certo sentido, o questionamento também contribuiu para induzir um aprofundamento acerca das motivações, dos temas e das práticas que se relacionam às pesquisas voltadas 
para o desenvolvimento de materiais e procedimentos científicos e tecnológicos menos impactantes ao ambiente no campo da Química:

Neste sentido, as proposições nos dão o direcionamento para requerer junto à administração uma estrutura física e até de cursos de graduação e pós-graduação que prepare os alunos, técnicos e docentes para atuarem na questão ambiental. Ao mesmo tempo o questionário nos alerta para que possamos ampliar nossas ações relativas ao tema da Química Verde no PPGQ (PPGQ13).

Houve relatos a respeito da dificuldade em se definir o significado da Química Verde, que foi enfrentada por meio da solicitação a todo corpo docente para que pensasse sobre os questionamentos colocados:

Desta experiência ficou claro que o tema de fato é muito abrangente. É um tema transversal e muitos de nossos docentes se interessam por ele, talvez até mesmo em decorrência de suas linhas de pesquisas e seus desdobramentos. É importante que muitas das iniciativas de nossos docentes referentes a este tema não são visíveis sob este rótulo "Química Verde”. É certo de que são ações espontâneas e motivadas pela percepção e consciência e interesse do docente. O tema é relevante e é uma questão de "educação em química”, mas exige conscientização de toda a comunidade para ele. No nosso entender, essa é uma área importante e de futuro, entretanto ela exige cuidados que não costumamos tomar, principalmente quando estamos pressionados pelos resultados (PPGQ35).

Evidencia-se, não apenas nesse depoimento, a demanda por um caráter formativo cultural que, para os entrevistados, urge entrar em todas as instituições acadêmicas. A inserção da Química Verde necessita ir além dos rótulos, já que as demandas atuais e vindouras nos exigem a revisão crítica constante dos objetivos, princípios e das implicações que norteiam a geração de resultados, produtos e processos que se pretendem verdes.

\section{Considerações finais}

A Química Verde se torna cada vez mais presente nos programas de pós-graduação em Química do Brasil. Seja direta ou 
indiretamente, suas premissas conquistam os espaços acadêmicos de tal maneira que se dissemina um ethos afeito à necessidade de que a sociossustentabilidade não se refira apenas a um rótulo que possa ser utilizado na perspectiva somente protocolar de algumas ações, mas sim que seja organicamente assimilada e materializada pelos professores e pesquisadores em Química de nosso País. A discussão sobre os produtos e processos verdes torna-se não só premente, como também decisiva, em tempos em que tanto resíduos quanto seres humanos parecem ser descartáveis, na medida em que não mais são considerados como produtivos. Se a maldição do progresso irrefreável é a regressão irrefreável (ADORNO; HORKHEIMER, 1986), isso não significa que esse seja o destino inexorável dos seres humanos e do ambiente, pois as atuais regressões são construções humanas e, como tais, passíveis de serem modificadas.

Por meio da análise das respostas dos coordenadores/ pesquisadores dos programas de pós-graduação em Química do País, destacou-se fundamentalmente a preocupação com a dimensão educacional/formativa cultural dos docentes e alunos. Seguindo essa linha de raciocínio, há que se enfatizar o fato de que vários dos entrevistados afirmaram que nas contratações futuras de docentes e técnicos de laboratórios os princípios da Química Verde sejam considerados como pontos relevantes nos curricula de ambos.

Definitivamente, tal preocupação não é obra do acaso, pois a conscientização de que os recursos naturais não podem ser predatoriamente utilizados reverbera também na constatação de que os serem humanos que os usam os ressignificam e também precisam deixar de se relacionar predatoriamente. Os pressupostos básicos da Química Verde, na medida em que questionam formas de regressão, referendam a veracidade e a importância central de tal premissa.

Recebido 25/11/2012

Aprovado 30/07/2013

\section{Agradecimentos}

À Capes, ao CNPQ e à Fapesp pelo apoio recebido. 


\section{Referências bibliográficas}

ADORNO, T. W.; HORKHEIMER, M. Dialética do Esclarecimento: fragmentos filosóficos. Tradução de Guido Antonio de Almeida. Rio de Janeiro: Jorge Zahar Editor, 1986.

ANASTAS, P. T.; WARNER, J. C. Green Chemistry: theory and practice. New York: Oxford University Press, 1998.

BRASIL. Ministério da Educação: Coordenação de Aperfeiçoamento de Pessoal de Nivel Superior. Contribuição da pós-graduação brasileira para o desenvolvimento sustentável: Capes na Rio+20. Brasília: Capes, 2012.

CCGE - Centro de Gestão e Estudos Estratégicos. Química verde no Brasil: 2010-2030. Brasília: Centro de Gestão e Estudos Estratégicos, 2010.

CORREA, A. G.; et al. Green Chemistry in Brazil. Pure and Applied Chemistry, v. 85, n. 8, p. 1643-1653, 2013.

CORREA, A. G.; ZUIN, V. G. (Orgs.) Química Verde: fundamentos e aplicações. 1. ed. São Carlos: EDUFSCar, 2009.

FRANCO, M. L. P. B. Análise de Conteúdo. Brasília: Liber, 2007.

HÖFER, R. Sustainable solutions for modern economies. Cambridge: RSC, 2009.

JACOBI, P. R. Educação ambiental, cidadania e sustentabilidade. Cadernos de Pesquisa, v. 118, p. 189-205, 2003.

JACOBI, P. R.; GUNTHER, W. R.; GIATTI, L. L. Agenda 21 e Governança. Estudos Avançados, v. 26, p. 331-340, 2012.

JESSOP, P. Preface to the 3rd International Conference on Green Chemistry (ICGC-3). Pure and Applied Chemistry, v. 83, n. 7, p. 1343$1343,2011$. 
LACANSTER, M. F. Green Chemistry: an introductory text. Cambridge: RSC, 2010.

TUNDO, P.; ROSSI, R. H. (Eds). Quimica Verde en Latinoamerica. In: Green Chemistry Series. v. 11. Venice: Italy, 2004.

ZUIN, V. G. A inserção da dimensão ambiental na formação de professores de Química. 1. ed. Campinas: Átomo, 2011. 


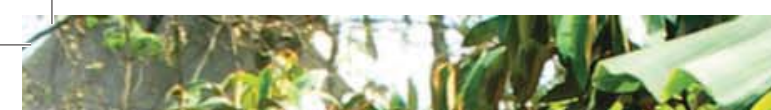
a then the

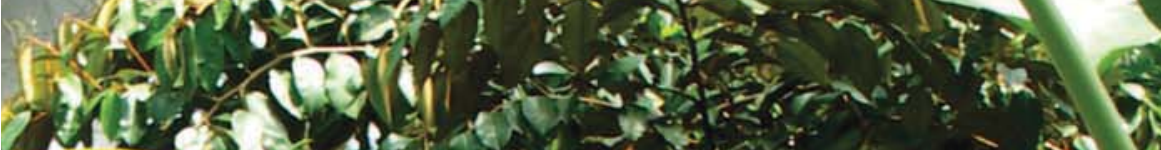

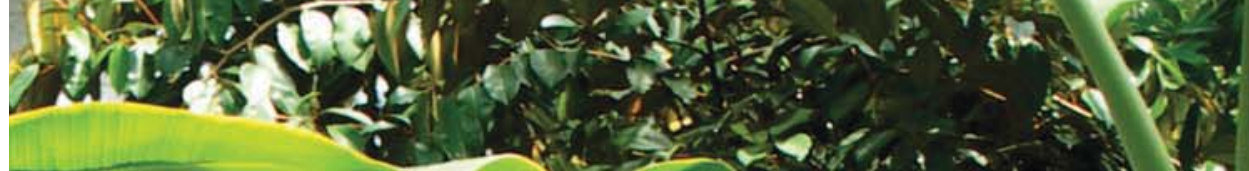
monos on a. 3 a

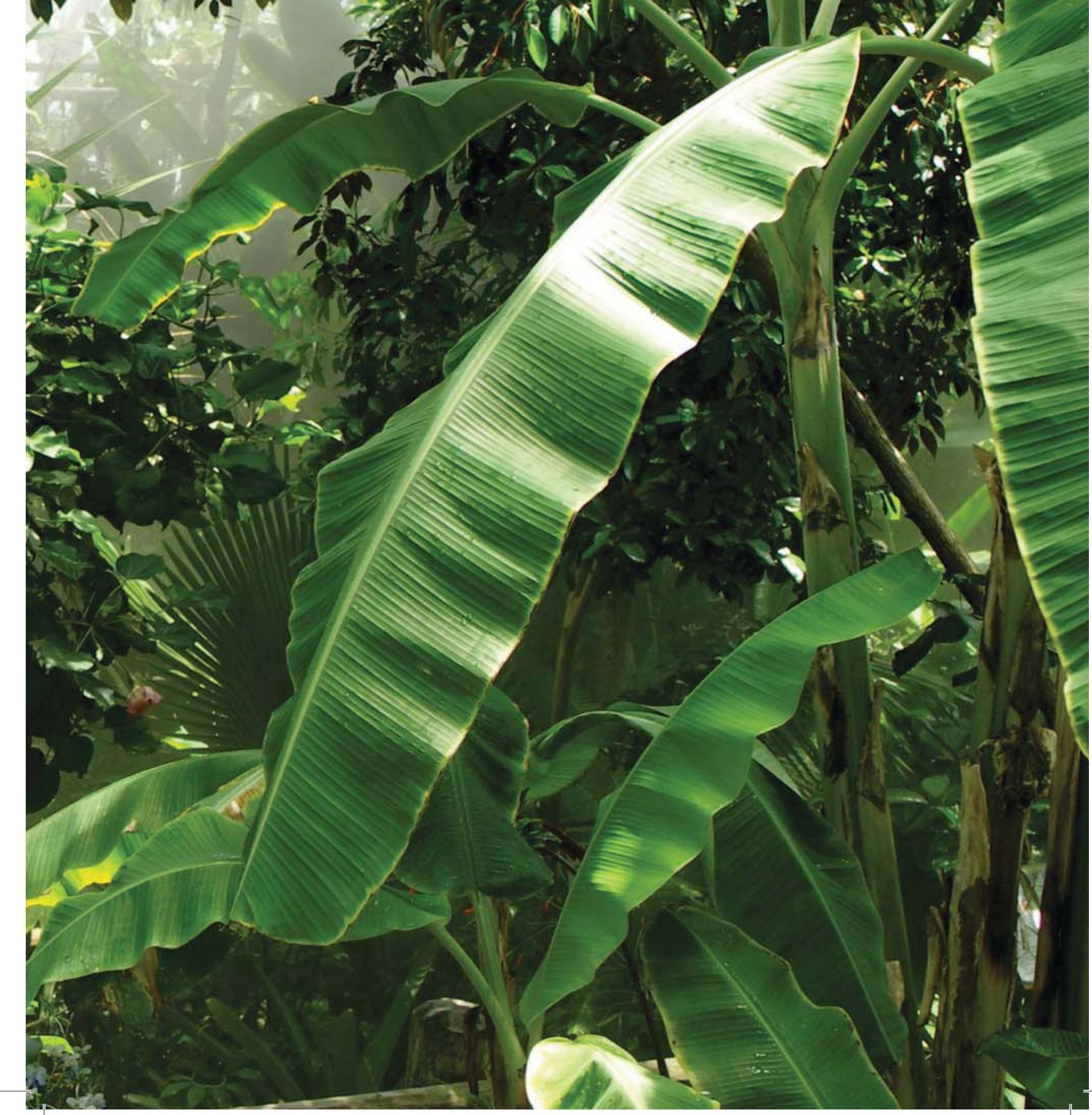




\title{
Múltiplos saberes da diversidade em rede: conexões interculturais no debate da inclusão digital na perspectiva dos povos da floresta
}

\author{
Multiple knowledge of network diversity: intercultural \\ connections in the debate over digital inclusion with \\ respect to the people of the forest
}

\begin{abstract}
Múltiples saberes de la diversidad en red: conexiones interculturales en la discusión de la inclusión digital en la perspectiva de los pueblos de la floresta
\end{abstract}

Ricardo Damasceno Moura, especialista em populações indígenas da Amazônia. Endereço: Av. José Bonifácio, Vila Joca n 17, apto 06 - São Braz. CEP: 66063-130 - Belém, PA. Telefone: (91) 91189582. E-mail: tecsocial.moura8@gmail.com.

\section{Resumo}

O artigo analisa a questão relativa à inclusão digital no espaço amazônico, enfocando as razões para uma inclusão digital/intercultural; os múltiplos saberes culturais existentes; a implementação das novas tecnologias da informação e do conhecimento, a partir da etnologia na cibercultura; além de buscar compreender essa nova inclusão digital pautada nos reais interesses dos povos e das populações tradicionais da Amazônia. Enfatiza as propostas de inclusão digital presentes na agenda de governo, com o objetivo de questionar a dificuldade de acesso por parte de populações ribeirinhas, quilombolas e indigenas, tendo em vista que as políticas públicas de inclusão digital não se estendem para essas populações. Com este estudo de caráter ensaístico, chegouse à conclusão de que ainda há muito a ser feito pelas populações tradicionais da Amazônia, a começar pelo reconhecimento de suas culturas e da conquista da cidadania.

Palavras-chave: Inclusão Intercultural e Digital. Etnologia e Cibercultura. Sustentabilidade. 


\section{Abstract}

The article analyzes the issue of digital inclusion in the Amazon region, focusing on the reasons for digital intercultural/inclusion, on existing multiple cultural knowledge, and on the implementation of New Technologies of Information and Knowledge from an ethnology in cyberculture perspective. It also seeks to understand this new digital inclusion as guided by the real interests of the peoples and the traditional populations of the Amazon. The article emphasizes the proposed digital inclusion on the agenda of government, with the aim of questioning the difficulty of access by riverine populations, maroons and indigenous, considering that the public policy of digital inclusion does not extend to these populations. This study of essayistic character concludes that there is still much to be done for the people of the Amazon, beginning with the recognition of their culture and their conquest of citizenship.

Keywords: Digital intercultural inclusion. Ethnology and cyberculture. Sustainability.

\section{Resumen}

El artículo analiza el tema de la inclusión digital en la región amazónica, con foco en las razones de la inclusión digital / intercultural, los múltiples saberes culturales existentes, la implementación de nuevas tecnologías de la información y del conocimiento, a partir de la etnología en la cibercultura, además de tratar de entender esta nueva inclusión digital basada en los verdaderos intereses de los pueblos y las poblaciones tradicionales de la Amazonia. El texto enfatiza las propuestas de inclusión digital presentes en la agenda de gobierno, con el objetivo de cuestionar la dificultad de acceso de las poblaciones ribereñas, quilombolas e indígenas, una vez que las políticas públicas de inclusión digital no incluyen estas poblaciones. Con este estudio de carácter ensayístico, se concluyó que aún hay mucho por hacer por los pueblos tradicionales de la Amazonia, empezando por el reconocimiento de su cultura y la conquista de la ciudadanía.

Palabras clave: Inclusión Intercultural y Digital. Etnología y la Cibercultura. Sostenibilidad. 


\section{Introdução}

Nos últimos anos, questões como a democratização do acesso às tecnologias de informação e comunicação, tendo a internet como principal ferramenta, introduziram reflexões importantes a cerca de novos referenciais sobre o reconhecimento das populações tradicionais da Amazônia.

O propósito deste trabalho é trazer alguma contribuição não apenas para as discussões que estão sendo travadas sobre a exclusão digital, mas, sobretudo, para as discussões cadentes que buscam uma inclusão específica e diferenciada em se tratando de populações tradicionais da Amazônia. Nesse sentido, a democratização das tecnologias digitais deve contemplar as inter-relações que coexistem na Amazônia, incluindo a análise dos determinantes do processo, o papel dos atores envolvidos e os deslocamentos atuais do conceito de inclusão digital.

Tomando-se como referência antropológica os aspectos regionais e culturais de cada comunidade, observam-se o aumento do poder das ações alternativas de inclusão intercultural/digital e o surgimento de um perfil de desenvolvimento, com ênfase na sustentabilidade socioambiental. Pensamos que as reflexões sobre as práticas sociais em um contexto que resultou em “inclusão” marginal e perversa envolvem uma necessária articulação com entidades que têm hoje um papel importante para a implementação de projetos e ações voltados à geração de trabalho e renda.

Vale ressaltar que criar um novo modelo democrático e participativo do que se passou a denominar de inclusão digital não é tarefa trivial, pois apresenta a possibilidade de analisar as transformações de culturas tradicionais sob o novo sistema eletrônico de comunicação, resultante de novas tecnologias de comunicação e informação.

Como em nenhum outro momento, as discussões sobre inclusão digital trouxeram para o âmbito acadêmico os mais diversos conceitos. Mas, ao se conceituar inclusão digital, não atentamos para 
se as definições são aquelas desejadas pelas populações tradicionais. Considera-se que as populações tradicionais devem ter o que dizer a respeito de como deveria ser a inclusão digital, uma inclusão capaz de levar à experiência de inclusão social, abrindo caminho para que os amazônidas ditem os rumos que querem dar ao seu futuro e ao do seu território.

Em meio à simbologia do espaço de vivência dessas populações, constroem-se os espaços da educação bilíngue e diferenciada como direito e política.

Essa educação, que é multidisciplinar e busca dimensionar o conhecimento das relações étnico-raciais na educação escolar indígena, favorece, principalmente, a compreensão da diversidade cultural a partir dos Parâmetros Curriculares Nacionais para a Educação Básica (BRASIL, 1997, p. 6), com uma proposta que se aproxima de

\begin{abstract}
conhecer e valorizar a pluralidade do patrimônio sociocultural brasileiro, bem como aspectos socioculturais de outros povos e nações, posicionando-se contra qualquer discriminação baseada em diferenças culturais, de classe social, de crenças, de sexo, de etnia ou outras características individuais e sociais.
\end{abstract}

Neste ínterim, a nova cibercultura ${ }^{1}$ vai se configurando; exige que se amplie uma cultura de mobilização para a criação de estratégias sociais/educacionais de qualidade nas diversas comunidades tradicionais. É um contexto em que a definição do que é inclusão tem seu ritmo dado pelo avanço da consciência coletiva como prática da conquista da cidadania brasileira.

1 Cibercultura é um termo utilizado na definição dos agenciamentos sociais das comunidades no espaço eletrônico virtual. Essas comunidades estão ampliando e popularizando a utilização da internet e de outras tecnologias de comunicação, possibilitando assim maior aproximação entre as pessoas de todo o mundo.

Refletir sobre a complexidade do processo de inclusão digital abre a oportunidade para compreender as dificuldades que surgem especialmente para antropólogos/as, etnólogos/as e pedagogos/as que discutem a valorização dos saberes tradicionais.

Interessa-nos aqui que a inclusão digital/intercultural esteja presente no crescimento das mídias indígenas, ampliando a possibilidade do empoderamento das questões nos aspectos ambientais, sociais e educacionais. 
Refletir sobre a inclusão digital de forma diferenciada é abrir novos campos para a construção de outras cidadanias, que se fazem presentes a partir da Tecnologia da Informação (TI), da defesa dos direitos indígenas e do intercâmbio de informações entrelaçadas nas redes.

O debate sobre a inclusão digital não tem a escola como único lócus de conhecimento, porém está nas universidades, nas organizações não governamentais e nas discussões de cientistas da educação sobre os impactos da sociedade em rede e suas relações com os saberes tradicionais.

Nesse cenário, as críticas às políticas de inclusão social reaparecem; são vistas como políticas universalistas, sem levar em consideração que a inclusão digital de populações vulneráveis não é um problema comum, pois demanda políticas específicas e macrossociais, ocasionando, dessa forma, um processo de inclusão digital que dá pouca importância para a estrutura das comunidades da Amazônia.

O ponto-chave para a inclusão social é a diversidade, mas, infelizmente, os programas de inclusão digital são incapazes de partilhar e acolher alternâncias para a efetivação de políticas de diversidade.

Interessa-nos aqui buscar outra visão da inclusão digital com ritmos diversos, com uma efetiva mudança em seus modelos de estruturação ditados pelas políticas públicas, não sendo para as populações ribeirinhas da Amazônia um caminho de adaptação às exigências de inserção na aldeia global, mas sim transformações no caráter de incluir os sujeitos, vinculando-os a um compromisso de inclusão social.

Este trabalho está dividido em três caminhos.

O primeiro consiste em uma introdução. O segundo aprofunda a discussão a respeito de uma nova inclusão digital; abordaremos o espaço da cibercultura e a sua relação com a Etnologia² como ciência da

2 Etnologia é o estudo (ou ciência que estuda) dos fatos e documentos levantados pela etnografia no âmbito da antropologia cultural e social, buscando uma apreciação analítica e comparativa das culturas. 
pluralidade humana, com vistas à compreensão das possibilidades de inclusão de povos e comunidades da Amazônia-de se disseminarem em redes -, propiciando interação digital entre culturas/saberes. 0 terceiro traz a discussão a respeito de uma inclusão digital/intercultural; uma concepção de inclusão digital respaldada na diversidade e nas relações concretas entre os povos da floresta, em oposição aos programas de inclusão digital que desconsideram os anseios e interesses das populações da Amazônia.

Se conseguirmos, ao menos, fornecer subsídios a mais para a reflexão da inclusão digital na Amazônia, acreditaremos ter atingido os objetivos a que nos propusemos.

\section{Inclusão digital e a busca por um acesso tecnológico respaldado nos reais interesses dos povos da Amazônia}

Um problema sempre suscitado quando se inicia um trabalho sobre inclusão digital é o da constante afirmação no campo acadêmico de que esse processo peca por não ter incorporado os direitos humanos, sociais e históricos de povos minoritários, omitindo os elementos de promoção de uma inclusão digital específica e diferenciada.

Tal problemática conduz à reflexão que, de fato, as conclusões sobre o que é inclusão digital não têm qualquer valor, pois se constituem em conceitos e práticas desvinculados dos reais interesses de populações ribeirinhas e tradicionais da Amazônia.

Nesse contexto, as populações tradicionais ainda têm pouca presença. Temos um ciberespaço de cerceamento da diversidade cultural e invisibilizador das culturas e cosmologias indígenas e de matriz africana; um espaço de formação e informação que não foi absorvido pelos conceitos de inclusão, a qual se encontra, meramente, no plano intelectual.

O que dificulta a inclusão do acesso de índios na cibercultura é a: 
implantado no Brasil, que até hoje ainda influencia programas sociais, através de um conteúdo ideológico que desconsidera a diversidade cultural das populações indígenas, caboclas e negras, entendendo-as como culturas pobres, e portanto, sem prioridade (ASSIS, 2006, p. 36).

A apropriação digital por meio de uma etnologia na cibercultura, apoiada na Tecnologia Social (TS)33, traz um novo conceito de diversidade, de etnodesenvolvimento e de cultura como repertório de práticas e reconhecimento da condição básica dos povos tradicionais.

A necessidade de abordar o tema do acesso às Novas Tecnologias de Informação e Comunicação (NTICs) pelos povos e pelas comunidades tradicionais da Amazônia decorre da percepção sobre o incipiente processo de reflexão acerca das práticas de democratização digital e das múltiplas possibilidades de, ao pensar a realidade plural da Amazônia, defini-la como intercultural/digital em um espaço em que se articulam natureza, técnica e cultura.

Necessário se faz, portanto, efetivamente incluí-las, mas uma inclusão que evidencie as possibilidades, potencialidades e vantagens que as Tecnologias de Informação e Comunicação (TIC) trazem para a diversidade cultural e para a emancipação das subjetividades e dos saberes.

A diversidade cultural tem a capacidade de "reinventar" um mundo rico e variado, que aumenta a gama de possibilidades e nutre as capacidades e os valores humanos, constituindo, assim, um dos principais motores do desenvolvimento sustentável das comunidades, dos povos e das nações (UNESCO, 2007)4.

Fica evidente que, dependendo do lugar, da organização social e da pedagogia própria de determinada população, diferentes serão as respostas para as políticas públicas de inclusão digital, demandando propostas de inclusão(ões) digital (is) diferenciada (s).

Há séculos se entende a Amazônia como um "circuito inferior", como territórios improdutivos, o que confirma que, quando o assunto é Amazônia, o grande destaque nos noticiários nacionais e internacionais
3 Considera-se tecnologia social todo o produto, método, processo ou técnica criado para solucionar algum tipo de problema social e que atenda aos quesitos de simplicidade, baixo custo, fácil aplicabilidade (e reaplicabilidade) e impacto social comprovado.

4 Diversidade cultural, citado no Plano da Secretaria de Economia Criativa, do Ministério da Cultura. 
vai para os alarmes referentes à situação de pobreza. Mas, ao contrário do que se supõe nos municípios encobertos pela floresta, temos territórios com potencialidades, força, capacidade e competência. Isso impõe um duplo desafio para as ciências tecnológicas e sociais. Por um lado, viabiliza o entendimento de que a tecnologia transforma a realidade social (mesmo diante da imprecisão do conceito de inclusão digital); por outro, cria a capacidade de geração de riqueza adaptada aos fenômenos culturais apresentados pelas comunidades tradicionais.

Diante das necessidades de um mundo cada vez mais globalizado, vemos que outra proposta de inclusão digital, quando apropriada pelos povos indígenas e direcionada para atender às suas necessidades atuais, pode ser um instrumento de fortalecimento das culturas e identidades indígenas e um possível canal de conquista da desejada cidadania. A perspectiva de trabalho de combate à exclusão social, a priori, tem que prever niveis de proteção que garantam o exercício da cidadania, possibilitando a autonomia de vida dos povos da floresta.

Ainda existe no Brasil a ideia errônea de inclusão digital como “modismo”, apoiada em ações isoladas e superficiais que trabalham na erradicação da barreira digital, resultando, dessa forma, em um distanciamento de ações pedagógicas que envolvem toda a comunidade. Outra proposta de inclusão digital que se defende neste trabalho visa o fortalecimento da sociedade civil, está menos em nível de política e relaciona-se com a prática do aprender, do ensinar e de promover mudanças juntos.

Essa inclusão social vista pelas populações da Amazônia é algo emancipador, não inviabilizando, dessa forma, a manutenção de sua(s) alteridade(s), suas tecnologias e inovações. Cada comunidade torna-se capaz de desenvolver estratégias próprias de comunicação sociocultural em rede e usufruir de bens culturais, sociais, tecnológicos e econômicos.

Para o trabalho com os povos e as comunidades tradicionais, trata-se menos de oferecer um pacote fechado de conhecimentos e 
mais de colocar a educação a serviço de uma comunidade que moldará o universo de conhecimento, de acordo com suas necessidades, seus momentos e a dinâmica concreta de seu desenvolvimento sustentável e coletivo.

A proposta educativa de Educação Escolar Indígena deverá ir além da educação multicultural. Seu principal desafio é articular-se com a Tecnologia de Informação (TI) ${ }^{5}$, propiciando o acesso a instrumentos tecnológicos, desde a aula convencional até os sistemas baratos e modernos de TV comunitária. As Novas Tecnologias de Informação e Comunicação (NTICs) podem ser utilizadas em uma concepção pedagógica em que o educador é mais um “parteiro” do potencial local do que propriamente fonte de saber.

Nas aldeias, novos movimentos surgem para defender as causas indígenas, os direitos humanos e a preservação ambiental: transformam a internet em uma ferramenta essencial para disseminar informações, organizar e mobilizar. As novas tecnologias alteram a natureza da comunidade em prol do coletivo.

No Brasil, o termo inclusão digital é muito recente e desconhecido para grande parte dos brasileiros que ocupam os espaços longínquos da Amazônia. Há um desconhecimento tanto em termos de concepção quanto em suas múltiplas formas de implementação.

Atualmente, o processo de inclusão digital pode ser definido como:

um conjunto de políticas públicas que está relacionada à aprendizagem necessária ao individuo para circular e interagir no mundo das mídias digitais, como consumidor e como produtor de seus conteúdos e processos. Assim, estabelece-se uma relação intrínseca entre acesso/ uso. É a partir do uso que as pessoas fazem das informações que se podem distinguir níveis ou tipos de inclusão digital (BAVA, 2004, p. 40).

Contudo, a discussão sobre a inclusão digital tem girado, basicamente, em torno de um de seus pilares, que é o acesso à utilização de equipamento, programas de computador e navegação. No entanto, as ações de democratização das tecnologias digitais vão mais
${ }^{5}$ É a área de conhecimento responsável por criar, administrar e manter a gestão da informação por meio de dispositivos e equipamentos para acesso, operação e armazenamento dos dados, de forma a gerar informações para a tomada de decisão. 
além. Sinalizam para dois objetivos fundamentais: um, de caráter de equiparação de oportunidades e de acesso; outro, de caráter formativo - relacionado à aprendizagem necessária para que atores e sujeitos sociais possam interagir no mundo das mídias digitais.

A educação para a multiculturalidade desenvolve competências e habilidades que permitem articular os diversos espaços de diversidades e conhecimentos por onde trafegam simbologias, saberes e culturas.

Contudo, não se vê uma sinalização do poder público no envolvimento das populações tradicionais no processo de apropriação das tecnologias; não se veem indígenas tecnólogos para a aplicação social de novas tecnologias em suas comunidades. Não se desenvolvem na Amazônia tecnologias associadas a saberes e conhecimentos sobre o meio ambiente.

Existe, portanto, pouco empenho das universidades no sentido da formação de pesquisadores indígenas, pois isso exige não somente a aplicação de novas tecnologias, mas a apropriação e ressignificação tecnológica em termos de empoderamento de povos vulnerabilizados.

Hoje em dia, o que se vêé que a exclusão social se dá já pela forma como as tecnologias digitais são pensadas e exercidas na academia: fica sempre na contramão da democratização, sem a necessidade de ser consolidada em diferentes espaços. Contudo, a universidade ainda se constitui em um espaço pouco democrático para o amplo acesso digital, pois, mesmo os conhecimentos nativos, quando transformados em uma linguagem científica, acabam se tornando incompreensíveis para as populações tradicionais.

A exclusão se dá duplamente, pois a linguagem científica acaba por borrar o acesso ao conhecimento científico e local; além disso, os problemas e dilemas enfrentados pela população da Amazônia não são reconhecidos como temas legítimos para a academia. Desse modo, não chega a se constituir uma comunidade científica forte e organizada em torno da pesquisa de soluções para os problemas das populações 
tradicionais. E, quando soluções são encontradas, elas não logram ser distribuídas de modo a causar um impacto significativo para a melhoria da qualidade de vida da população.

A instrumentalização tecnológica a partir das Tecnologias da Informação e Comunicação (TICS) não é apenas um direito: é também uma necessidade de povos e comunidades tradicionais da Amazônia e também um desejo da sociedade brasileira, na medida em que os povos indígenas administram hoje mais de 13\% do território nacional, sendo que na Amazônia legal esse percentual sobe para 23\%. Não se trata apenas de garantir o acesso, mas de dar condições de inclusão digital plena e diferenciada para que possam “trazer para a rede” seus anseios cadentes por políticas públicas de diversidade, possibilitando reconfigurações da inclusão na perspectiva dos excluídos.

\section{Inclusão intercultural/digital}

O conceito de inclusão intercultural/digital aplicado à inserção tecnológica na Amazônia demanda cada vez mais novos enfoques, que transcendem a mera aplicação dos conhecimentos científicos e tecnológicos disponíveis para as comunidades. Esse novo conceito se consubstancia na possibilidade de lidar com conexões entre diferentes etnias, propiciando entrelaçamentos em rede e compartilhamentos entre múltiplos saberes.

Considerando que o escopo da inclusão digital exige a atenção de todos os setores, a nova inclusão intercultural/digital visa um aprendizado de que ainda carecemos: encontrar meios criativos, de forma pública e democrática, para um processo diferenciado e sustentável de inclusão digital que alcance a todas as dimensões culturais de povos e comunidades da Amazônia.

Contudo, existem debates contrários a essa inclusão, que impedem ou dificultam uma discussão profunda sobre o processo de inclusão digital específico para grupos étnicos e com menos chances de serem incluídos digitalmente; mais do que isso, há debates que 
inibem ou tentam impedir a implementação de políticas públicas com base na diversidade.

Na Amazônia, temos uma grande lacuna de tecnologia de informação, sobretudo, nos territórios indígenas, mas ainda porque em diferentes instâncias políticas e institucionais do Brasil contemporâneo se perpetua uma atitude colonialista em relação aos povos indígenas e permanecem compreensões de invisibilidade e redutoras do índio, imagens estereotipadas que necessitam de profunda crítica e ruptura. Para Gates (1995, p. 50) essa situação se agrava "se não temos um sólido campo de discussão de como essa inclusão digital pode ser realizada”. No entanto, a viabilidade de um trabalho efetivo requer um conhecimento preciso dos povos e das comunidades que habitam esse território imerso na floresta.

Negligenciar a inclusão de múltiplas etnias ao acesso às TICs é destituí-las de sua condição de sujeitos, aprofundando a desigualdade e impedindo que atores sociais se estruturem e se organizem, originando novas formas de resistência coletiva contra a opressão.

Os “excluídos da floresta” não são apenas rejeitados física, geográfica ou materialmente, mas também o são por todas as riquezas de seus valores que não são reconhecidos, ou seja, há também uma exclusão cultural.

Daí a necessidade de uma inclusão intercultural/digital, um saber ainda em construção que demanda empenho para fortalecer a garantia do acesso às tecnologias por meio da consolidação de canais abertos à participação de uma pluralidade de atores em processos decisórios de interesse público.

\section{A etnologia na cibercultura}

A inserção de novas tecnologias nas comunidades tradicionais da Amazônia é um fenômeno recente e envolve relações entre coletividades distintas, com formas específicas de apropriação das 
TICs. Isso nos remete a pensar em uma etnologia na cibercultura que não trate tão somente da cultura material dos povos, mas, sobretudo, que estimule a interação entre grupos culturais nos ambientes digitais.

Erny (1982, p. 17) faz incursões por esse campo da etnologia ao afirmar que “[...] quando se ensina etnologia, nota-se, entretanto, que por vezes é difícil responder o que é efetivamente etnologia. Uma ciência não se define somente pelo assunto a que se dedica, mas também o ângulo em que o aborda e pretende trabalhar”.

A etnologia da Amazônia presta-se particularmente bem a uma reflexão sobre culturas e grupos sociais com sua forma própria/ específica de apropriação das TICs e inclusão de comunidades amazônicas na aldeia/digital/global: ela se interessa prioritariamente pelo que é diferente, privilegia o contato com a realidade humana, pretende levar a investigação até o nível inconsciente da vida social, sempre perseguiu um ideal de aproximação total, procura apreender as culturas tais como as percebem aqueles que são delas portadores e atinge logicamente a comparação (ERNY, 1982).

Para uma análise das populações tradicionais da Amazônia, a etnologia pode fornecer matéria para uma antropologia social ou cultural, ou mesmo filosófica, mais geral, indo além das diversidades das culturas, mas apoiando-se nela na procura de aprofundar uma análise crítica, tomando-se por objeto culturas específicas em toda sua extensão.

Nessa perspectiva, segundo Bauman (2005), para que haja de fato uma apropriação tecnológica ressignificante de povos tradicionais, ela deve ser implementada dentro de critérios que não neguem as suas raízes e nem as suas histórias. Uma inclusão capaz de trazer esses povos para a problemática de suas populações, propondo diálogos interculturais em rede sobre as preocupações convergentes da comunidade.

As etnias do Brasil nos programas sociais não foram consideradas uma prioridade, o que levou indígenas e ribeirinhos a se 
organizarem em associações para demandar a sua participação ou inclusão nas políticas de combate à exclusão digital. Por quejustamente as populações tradicionais não seriam incluídas? Por que teriam que ficar à margem do processo tecnológico? Segundo Lévy (1999, p. 20), a inclusão digital traz consigo o problema da questão da exclusão. Para ele, o crescimento do ciberespaço provoca uma exclusão social: “A cibercultura provoca exclusões? É evidentemente uma pergunta central em uma sociedade mundial na qual a exclusão (ou seja, a forma contemporânea, de injustiça social) é uma das principais doenças”.

Na sociedade em rede, tudo se interconecta: as pessoas, os espaços, as tecnologias. Surowiecki (2006) identifica esse processo como sabedoria das multidões, pois grupos diferentes conectados compartilham informações e resultados. Já Lévy (1998) fala em inteligência coletiva: é uma inteligência que, distribuída por toda parte, incessantemente valorizada e coordenada em tempo real, resulta em uma mobilização efetiva de grupos e movimentos que buscam não somente uma satisfação, mas o reconhecimento de suas culturas, identidades e aspirações (Ibidem).

É nesse contexto que a etnologia como ciência da diversidade e do particularismo torna-se imprescindivel para nos dar a ideia do processo de inserção tecnológica de populações tradicionais da Amazônia a partir de uma inclusão intercultural/digital que surja no âmbito dos espaços indígenas e quilombolas dos temas que nascem da diversidade e das inquietudes dos povos da floresta.

Destarte, é preciso considerar que as populações da Amazônia construíram uma organização baseada em princípios voltados para a conservação da natureza, ancestralidade, o uso coletivo da terra e as relações de parentescos, formando assim uma territorialidade diferenciada. Resistiram ao longo da história e constituíram organizações representativas de suas categorias, estabelecendo um processo de reivindicação política pautado na visibilidade e no reconhecimento dos direitos.

A democratização do acesso à tecnologia tem sido assumida em diversos graus pelos governos nacionais de turno, isto é, têm sido até 
agora medidas públicas ligadas a partidos políticos. Porém, iniciativas da área privada, da sociedade civil, de empresas transnacionais e organismos internacionais já têm criado algumas medidas de inclusão digital.

O atual plano de governo para a inclusão digital precisa conferir importância à democratização do acesso às TICs como política pública pautada por dois pressupostos: reconhecer que a exclusão digital amplia a miséria e dificulta o desenvolvimento humano e que hoje o direito à comunicação é sinônimo de direito à comunicação mediada por computador, tratando-se, portanto, de uma questão de cidadania.

Os programas de inclusão digital em nenhum instante de sua elaboração incluíram em sua pauta a diversidade como fenômeno ou conceito que se estende muito além do acesso. Para Silva et al. (1996), a diversidade amazônica diz respeito às variedades de grupos, etnias, indivíduos, condições socioeconômicas, trajetórias sociais, origens geográficas, deslocamentos territoriais, visões de mundo, práticas culturais, crenças, religiões, etc. Por isso, hoje é grande a dificuldade de se constituir políticas de inclusão digital nas comunidades da Amazônia.

Em meio a programas do governo brasileiro, a inclusão digital surge como medida ou programa pró-acesso/uso. É a marginalização de grandes camadas da população que, por carecerem das condições mínimas de bem-estar, não têm, pelo geral, um acesso mínimo assegurado às tecnologias de informação, que são elementos-chave para a formação integral do ser humano, no que diz respeito ao acesso e uso das informações. Porém, a erradicação da exclusão digital não aparece, nesse cenário, articulada com outras políticas de luta contra as diversas desigualdades sociais.

Para Sawaia et al. (2001), temos uma proposta não de inclusão, mas de inserção social perversa, pois a sociedade exclui para incluir, e essa transmutação é condição da ordem social desigual, o que implica o caráter ilusório da inclusão. Portanto, em lugar da inclusão, o que se tem é a dialética da inclusão/exclusão, principalmente, quando se pensa nas populações tradicionais. 
Em síntese, a exclusão é um processo complexo e multifacetado, uma configuração de dimensões materiais, políticas, relacionais e subjetivas. Não é uma coisa ou um estado; é um processo que envolve o homem por inteiro e suas relações com os outros.

De acordo com Foracchi (1982), o conceito de exclusão social é dinâmico, referindo-se tanto a processos quanto a situações consequentes. De forma mais clara que o conceito de pobreza, compreendido, muito frequentemente, como se referindo exclusivamente à renda, ele também estabelece a natureza multidimensional dos mecanismos por meio dos quais os indivíduos e grupos são excluídos das trocas sociais, das práticas componentes e dos direitos de integração social e identidade. Ele, ao mesmo tempo, engloba os campos de habitação, educação, saúde e acesso a serviços.

Na Amazônia, com relação à situação atual dos povos tradicionais, observa-se que as políticas econômicas acabam por provocar políticas de inclusão precária e marginal.

As reflexões e análises, infelizmente, não se produziram a partir de horizontes necessariamente críticos em relação ao cenário atual dessas comunidades. Entende-se que a compreensão dos ambientes cultural, étnico e social em que serão inseridas é condição necessária para que elas sejam eficazes e se convertam em ferramentas de mediação entre culturas e de transformação das realidades.

O espaço de uma etnologia na cibercultura alerta para as condições entre as possibilidades do reconhecimento do saber tradicional em rede, favorecendo a troca de conhecimentos e a efetiva participação pública de populações da Amazônia nas tomadas de decisão em prol da sustentabilidade e do meio ambiente.

Assim, a tecnologia provoca mudanças “ecológicas”: ela modifica totalmente as relações no ambiente em que é introduzida. O fundamental, portanto, é saber em que medida os novos meios/ tecnologias alteram a concepção sobre o que é o conhecimento e, no limite, sobre o que é a educação - não uma educação puramente técnica, 
pensada apenas como treinamento para o uso de equipamentos, mas uma educação que faça da própria tecnologia objeto de interrogação, a fim de que os sujeitos não sejam usados nem abusados por ela (POSTMAN, 2002).

Consideramos que um primeiro passo nessa direção é reconhecer que a inclusão que se vem realizando hoje termina por negar a diferença ou silenciá-la. Então, propõe-se - por meio de processo específico e diferenciado de inclusão digital - colocar ênfase na diferença e garantir, pelo uso da tecnologia, que diferentes identidades e interfaces culturais presentes em um determinado contexto indígena ou quilombola se expressem nos espaços em redes digitais.

Outro elemento importante para a inclusão digital é o processo de empoderamento de direitos, principalmente, orientando os atores sociais que, com o advento da globalização, têm menos poder na sociedade da informação e menores possibilidades de influir nas decisões políticas e nos processos coletivos. 0 empoderamento favorece sua organização e sua participação ativa na sociedade.

Por isso, o processo de inclusão digital é também uma ação afirmativa, concebida no sentido de desenvolver estratégias e metodologias de fortalecimento do poder de grupos vulnerabilizados para que eles possam lutar pela igualdade de condições de vida em sociedades marcadas por mecanismos estruturais de desigualdade e discriminação.

Outro aspecto fundamental da inclusão digital etnológica é a formação para uma cidadania, capaz de subsidiar os "povos excluídos" a reconhecer as assimetrias de poder, trabalhar os conflitos e promover reações solidárias.

Nessa direção, que efeitos têm hoje as políticas públicas de inclusão digital para o empoderamento de direitos e quais os desafios das populações tradicionais na medida em que elas cobram esforços para a promoção de um mundo social mais solidário e reconhecedor da diversidade? 
No entanto, defendemos uma perspectiva de democratização das tecnologias, que, por um lado, propõe o acesso aberto, livree interativo às TICs, de forma a acentuar a interculturalidade, por considerá-la a mais adequada para combater a exclusão digital; por outro lado, uma inclusão que ofereça um contexto novo e impressionante, em que se reforcem identidades e saberes na internet.

A inclusão digital em uma perspectiva intercultural objetiva promover uma educação para o reconhecimento do outro, para o diálogo entre os diferentes grupos sociais e culturais. Certamente, tem-se que levar em consideração que cada cultura tem suas raízes e que elas são históricas e dinâmicas.

Segundo Walsh (2001, p. 10-11), a interculturalidade é "um intercâmbio que se constrói entre pessoas, conhecimentos, saberes, práticas culturalmente diferentes, buscando desenvolver um novo sentido entre elas na sua diferença”.

Já Candau (2010, p. 16) reforça que "a interculturalidade orienta processos que têm por base o reconhecimento do direito e a luta contra todas as formas de discriminação e desigualdade social”. De acordo com as pesquisas de Fleuri (2000, p. 91):

a interculturaralidade refere-se a um complexo campo de debate entre as variadas concepções e propostas que enfrentam a questão da relação entre processos identitários socioculturais diferentes, focalizando especificamente a possibilidade de respeitar as diferenças e de integrálas em uma unidade que não as anule.

Repensar a inclusão digital/intercultural põe à frente um grande desafio de reconhecimento da cultura e fortalecimento dos conhecimentos tradicionais. Refere-se ainda à construção de conteúdos digitais e ao compartilhamento de saberes a partir de uma perspectiva política. Uma luta por reconhecimentos e direitos à cidadania que se dissemina também em redes. Os "povos da floresta” participam então dessas redes como populações dinâmicas, com capacidade de compreender e articular tecnologias, pactuando-as com os interesses comuns de cada grupo étnico. 
Para uma inclusão digital diferenciada e específica que restabeleça o respeito às diferenças, ampliando a significação do habitat de populações indígenas, há de se pensar, também, de forma geral, quais são os benefícios e as implicações da tecnologia nas relações sociais na Amazônia.

\section{Considerações finais}

O processo de redução da exclusão digital traz novas possibilidades para povos e comunidades tradicionais que foram historicamente objetos passivos de políticas indigenistas assimilacionistas e tutelares, silenciados em suas culturas e identidades, mas que agora buscam o reconhecimento pelas práticas pedagógicas que desenvolvem como sujeitos com cultura e conhecimento.

A inclusão intercultural/digital destinada a segmentos que, por séculos, viveram em condição de invisibilidade é também uma forma de ação reparadora, tendo em vista que se desenvolve entre grupos específicos que apresentam menores chances de serem incluídos digitalmente.

Uma das características mais importantes da democratização do acesso às tecnologias de informação e comunicação é o desenvolvimento de práticas que ensejam uma transformação nos comportamentos e na mentalidade da sociedade, sobretudo, das novas gerações que habitam a floresta, dando condições de refletirem sobre as desigualdades inerentes ao processo de inclusão na sociedade do conhecimento.

Algumas etnias começaram a se organizar para serem partícipes da chamada sociedade da informação, porém, em geral, têm tido um papel passivo, sendo receptoras de medidas governamentais ou privadas, o que poderia influir na demora para a expansão de programas de inclusão digital para elas.

Para uma efetiva inclusão digital pautada no conceito de diversidade e cidadania, faz-se necessária uma ação formativa, com 
a participação estadual, municipal e federal, reunindo a sociedade civil, as universidades e empresas para a formulação de políticas públicas voltadas à inclusão.

Dentro dessa perspectiva, espera-se que surjam novos debates para que possamos dividir experiências, trazer inéditas contribuições para o desenvolvimento social, além de assegurar uma nova tomada de pensamento. Nesse sentido, experiências concretas de apropriação social da tecnologia de informação e comunicação impulsionam metodologias em que se constroem os parâmetros, aliando os saberes das comunidades aos conhecimentos técnicos.

Recebido 15/09/2012 Aprovado 25/07/2013

\section{Referências bibliográficas}

ASSIS, E. Direitos indígenas num contexto interétnico: quando a democracia importa. 2006. 207 f. Tese (Doutorado em Ciência Política)Universidade Federal do Pará, Belém, 2006.

BAUMAN, Z. Identidade: entrevista a Benedetto Vecchi. Tradução Carlos Alberto Medeiros. Rio de Janeiro: Editora Jorge Zahar, 2005.

BAVA, S. C. Tecnologias sociais e políticas públicas. In: PAULO, A. de (Org.). Tecnologias Sociais: uma estratégia para o desenvolvimento. Rio de Janeiro: Fundação Banco do Brasil, 2004. p. 103-116.

BRASIL. Ministério da Educação e Cultura. Secretaria de Educação Fundamental. Parâmetros Curriculares Nacionais: pluralidade cultural, orientação sexual: Brasília, DF: MEC/SEF, 1997. Disponível em: <http:/ / mecsrvo4.mec.gov.br/sef/estrut2/pcn/pdflivro101.pdf>. Acesso em: 13 mar. 2013.

CANDAU, V. M. F. Multiculturalismo e educação: desafios para a prática pedagógica. In:CANDAU, V. M.; MOREIRA, A. F. (Orgs.). Multiculturalismo: 
diferenças culturais e práticas pedagógicas. Petrópolis, RJ: Vozes, 2010.

p. 13-37.

ERNY, P. Etnologia da Educação. Rio de Janeiro: Zahar, 1982.

FLEURI, R. M.; SOUZA, M. I. P. Entre os limites e limiares de culturas: educação na perspectiva intercultural. In: FLEURI, R. M. (Org.). Ensinar e aprender: sujeitos, saberes e pesquisa. Encontro Nacional de Didática e Prática de Ensino. Rio de Janeiro: DP\&A, 2000. p. 67-81.

FORACCHI, M. A participação social dos excluídos. São Paulo: Hucitec, 1982.

GATES, B. A Estrada do Futuro. Tradução de Beth Vieira. São Paulo: Editora Companhia das Letras, 1995.

LÉVY, P. A inteligência coletiva: por uma antropologia do ciberespaço. São Paulo: Record, 1998.

Cibercultura. São Paulo: Editora 34, 1999.

POSTMAN, N. O fim da Educação: redefinindo o valor da escola. Rio de Janeiro: Graphia, 2002.

SAWAIA, B.; et al. (Orgs.). As artimanhas da exclusão social: análise psicossocial e ética da desigualdade social. Rio de Janeiro: Vozes, 2001.

SILVA, L. H.; et al. (Org.). Novos mapas culturais, novas perspectivas educacionais. Porto Alegre: Editora Sulina, 1996.

SUROWIECKI, J. A sabedoria das multidões. Rio de Janeiro: Record, 2006.

UNESCO - Organização das Nações Unidas para a Educação, a Ciência e a Cultura. Convenção sobre a proteção e promoção da diversidade das expressões culturais. Paris: UNESCO, 2007.

WALSH, C. La educación intercultural en la Educación. Lima: Ministério da Educação, 2001. 


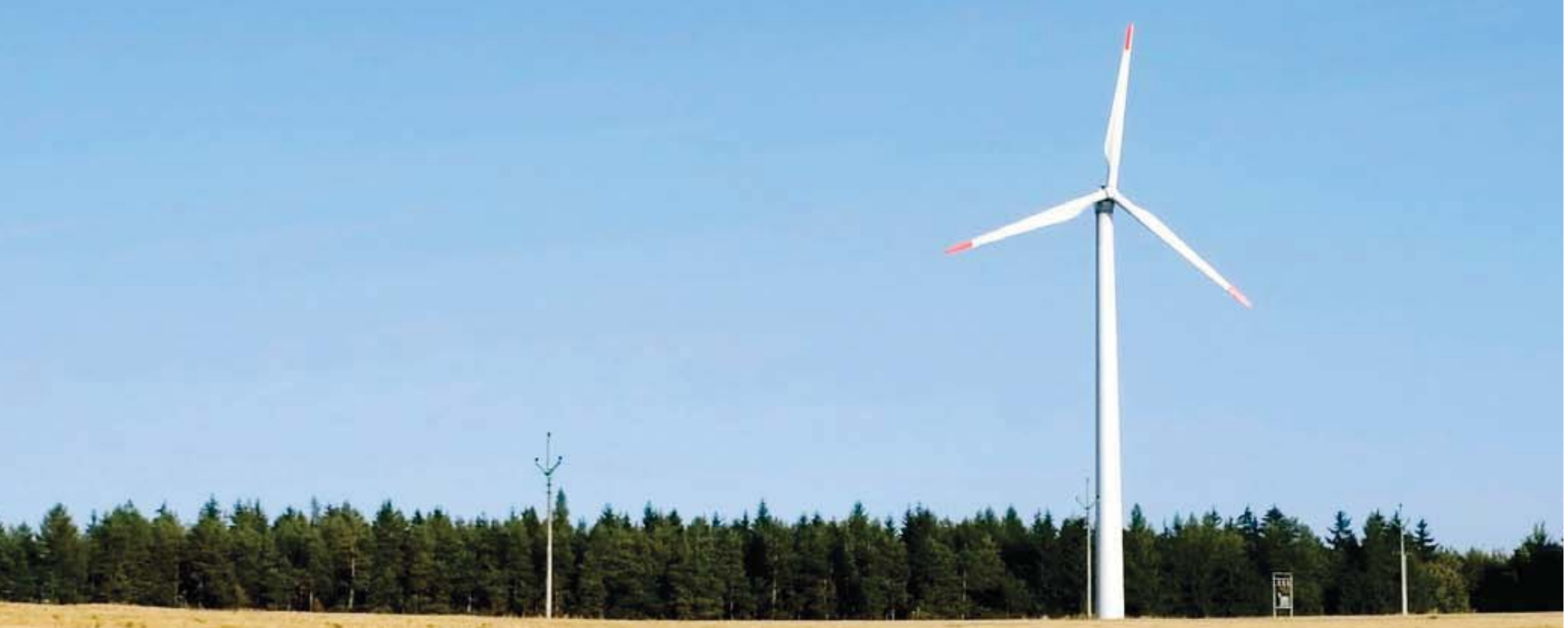

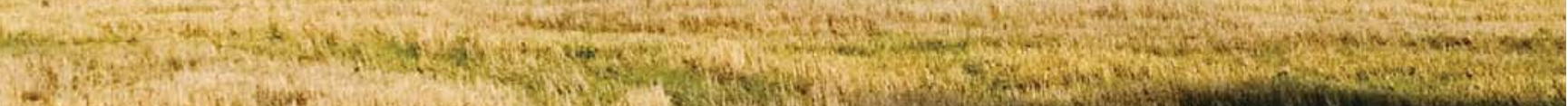

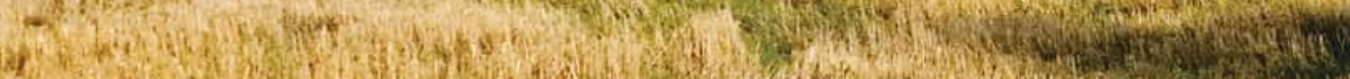

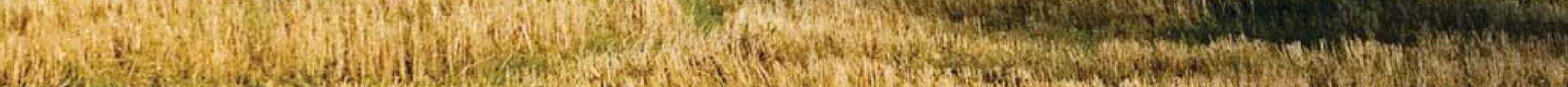

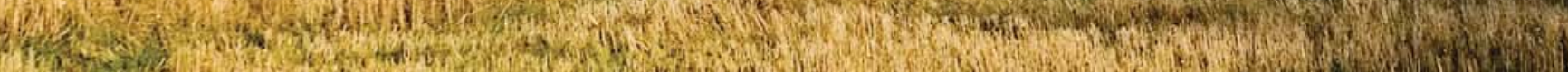

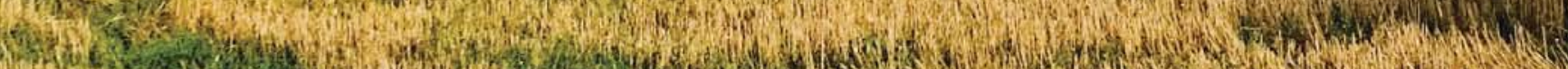

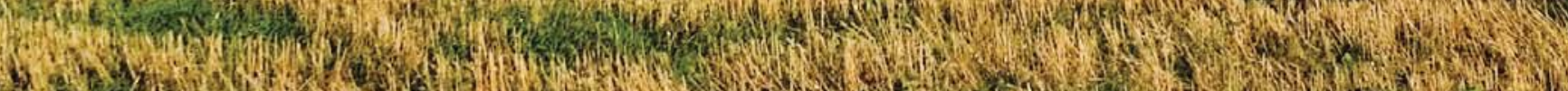

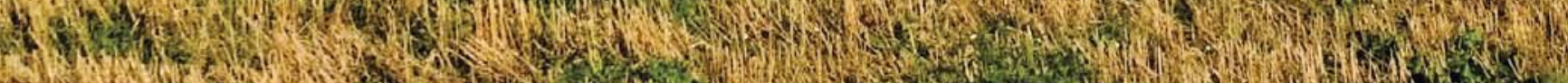

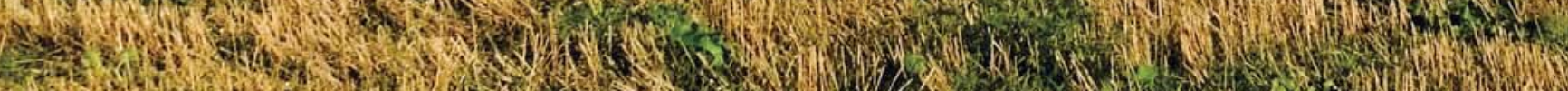

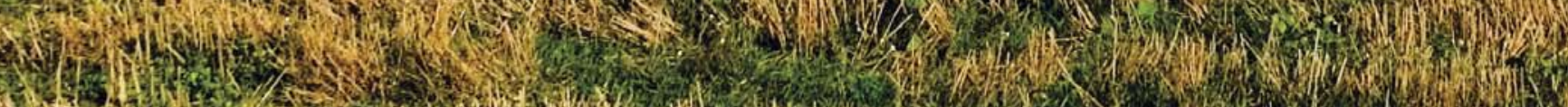

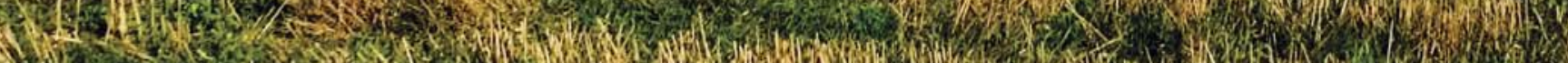

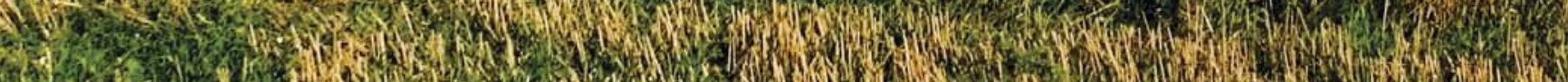

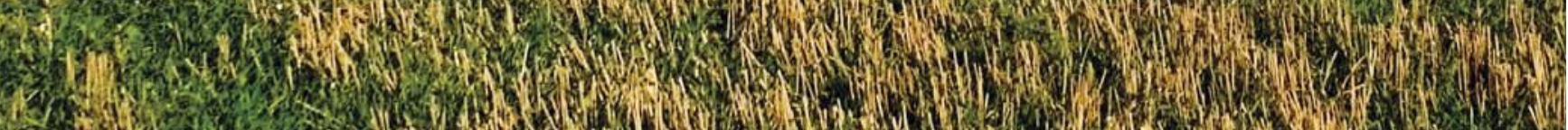

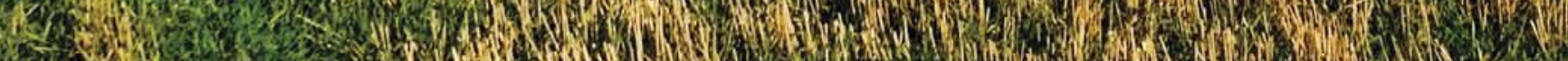

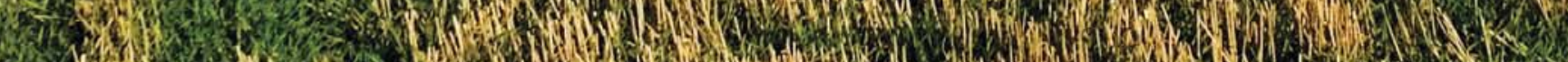

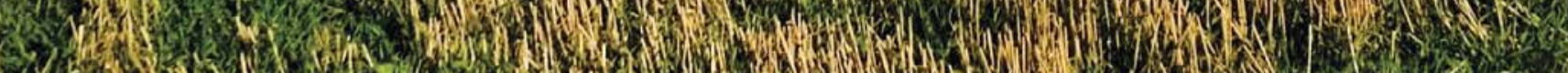

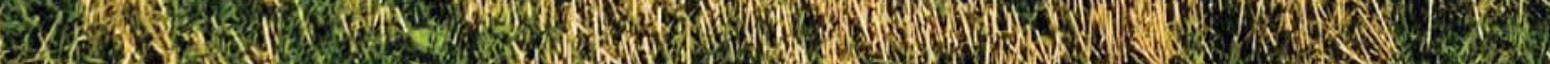

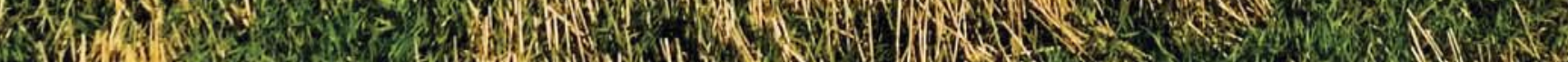

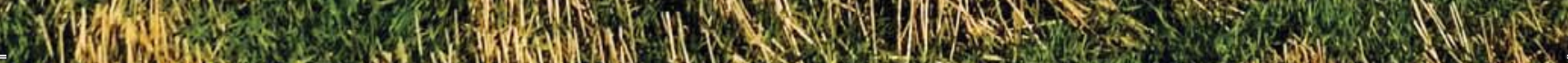

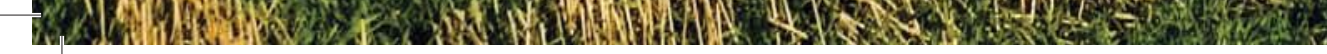




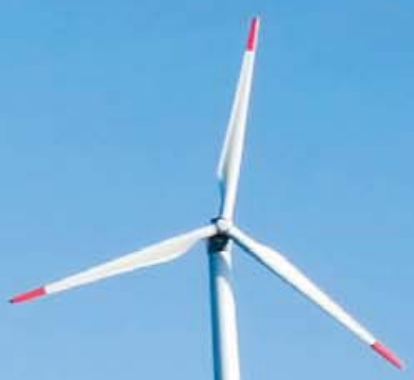

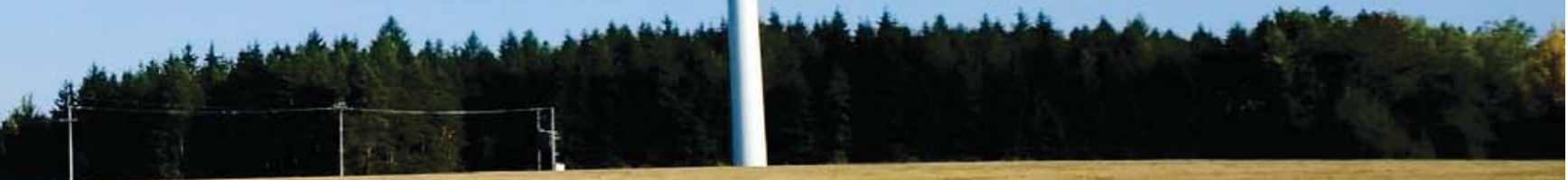

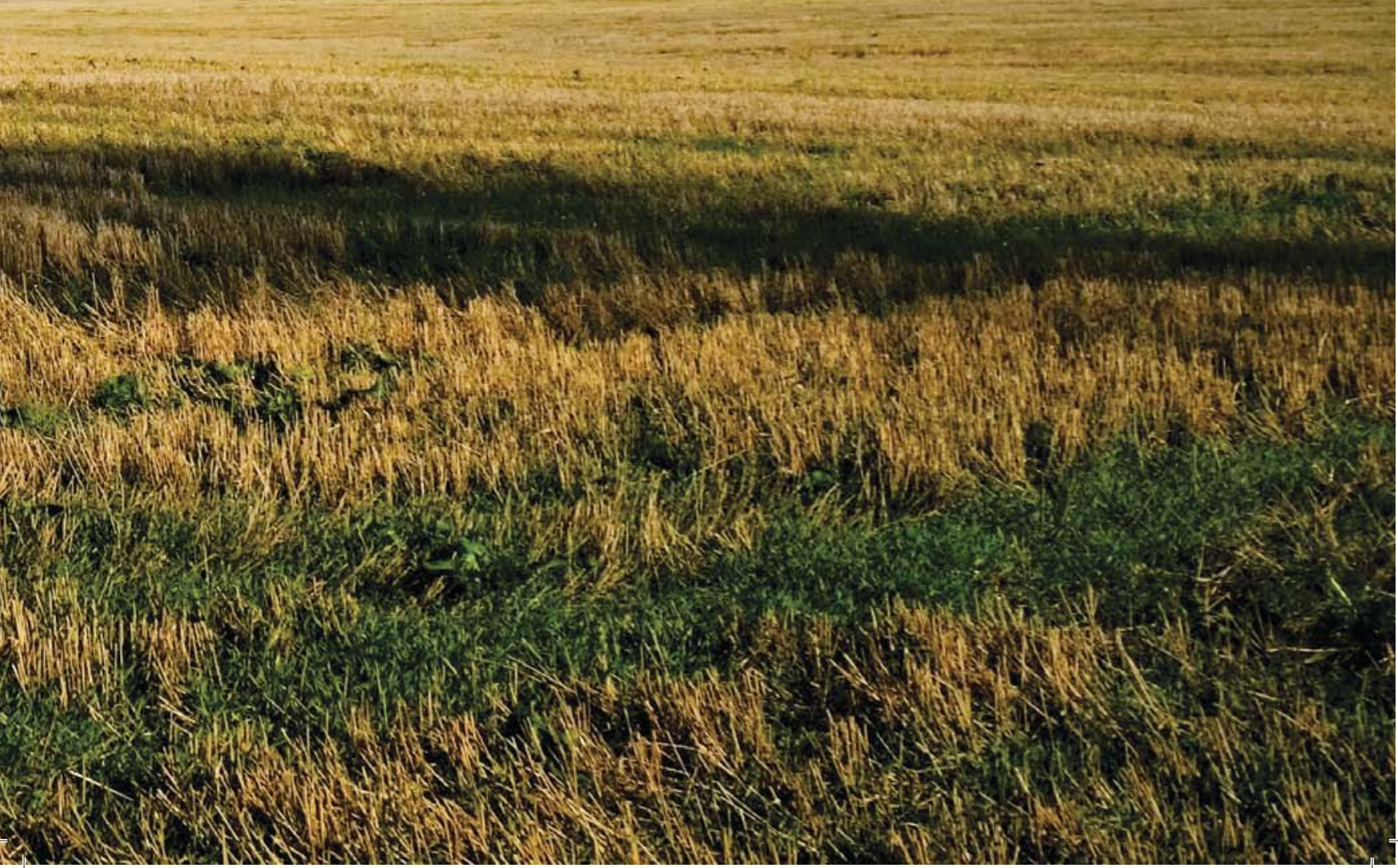


Desenvolvimento sustentável e algumas vulnerabilidades geradas pelo não atendimento de necessidades básicas

\section{Sustainable development and specific vulnerabilities generated by the lack of basic necessities}

\section{El desarrollo sostenible y algunas de las vulnerabilidades generadas por la falta de atención a las necesidades básicas}

Wilma de Assis, doutora em Meio Ambiente e Desenvolvimento pela Universidade Federal do Paraná (UFPR). Endereço: Rua Nova Iguaçu, 897 - Recreio. CEP: 28890-000 - Rio das Ostras, RJ. E-mail: wilmadeassis@hotmail.com.

Maria Elisa Zanella, doutora em Meio Ambiente e Desenvolvimento pela UFPR. Endereço: Rua Monsenhor Otávio de Castro, 677, apto 303 - Fástima. CEP: 60050-150 - Fortaleza, CE. E-mail: elisazv@terra.com.br.

\section{Resumo}

O tema deste artigo se insere no contexto atual de transição, ou de tentativas de transição, de um modelo de desenvolvimento considerado insustentável para outro, sustentável. Analisa essa transição pela presença de organizações internacionais atuando em prol da humanização do desenvolvimento e pela existência de novos indicadores de desenvolvimento. Tem por objetivo abordar as vulnerabilidades individuais/sociais possiveis de serem geradas pelo não atendimento de necessidades humanas. Utiliza como método a sobreposição dos conceitos de desenvolvimento, necessidades e vulnerabilidades, recorrendo a algumas disposições metodológicas da teoria da complexidade. Conclui sobre a importância de abordagens econômicas aproximarem-se da complexidade, utilizarem os novos 
indicadores de sustentabilidade e de valores humanos. Considera a proposição de que, quando a economia muda, o desenvolvimento muda. Quando o ser humano muda, a economia e o desenvolvimento também mudam.

Palavras-chave: Vulnerabilidades. Necessidades. Desenvolvimento. Sustentabilidade.

\section{Abstract}

This study was conducted within the framework of the transition, or attempted transition, from a model of development considered unsustainable to one characterized by sustainability. This transition is analyzed based on the presence of the international organizations that work towards the humanization of the development process and the existence of new indices of development. The principal objective is to identify the potential social or individual vulnerabilities generated by the lack of basic necessities. The study approaches this question through an overlap of the concepts of development, necessities, and vulnerabilities, drawing on a number of methodological procedures derived from Complexity Theory. The results of the study indicate the need for economic approaches to assimilate the complexity of the problem, using new indices of sustainability and human values. In particular, the study concludes that when the economy changes, the development process also changes. When human beings change, the economy and development also change.

Keywords: Vulnerabilities. Necessities. Development. Sustainability.

\section{Resumen}

El tema de este artículo es parte del contexto actual de transición, o de los intentos de transición, de un modelo de desarrollo considerado insostenible para otro, sostenible. Analiza esta transición por la presencia de organizaciones internacionales que trabajan por la 
humanización del desarrollo y por la existencia de nuevos indicadores de desarrollo. Su objetivo es abordar las vulnerabilidades individuales/ sociales que se pueden generar por no atender a las necesidades no humanas. Utiliza como método la superposición de los conceptos de desarrollo, necesidades y vulnerabilidades, recurriendo a algunas disposiciones metodológicas de la teoría de la complejidad. Concluye sobre la importancia de los enfoques económicos se acercaren a la complejidad, utilizaren los nuevos indicadores de sostenibilidad y de valores humanos. Considera la proposición que afirma que cuando la economía cambia, el desarrollo cambia. Cuando el hombre cambia, la economía y el desarrollo también cambian.

Palabras clave: Vulnerabilidades. Necesidades. Desarrollo. Sostenibilidad.

\section{Introdução}

A proposta de uma economia verde divulgada na Conferência das Nações Unidas (Rio+20) chama a atenção para a necessidade de a economia transformar-se para que o desenvolvimento siga um caminho sustentável. A economia verde é definida como aquela que resulta na melhoria do bem-estar humano e da igualdade social, ao mesmo tempo em que reduz significativamente os riscos ambientais e as limitações ecológicas (PNUD, 2012).

O objetivo proposto é o de abordar vulnerabilidades sociais/ individuais possíveis de serem geradas pelo não atendimento de necessidades básicas, amparado na perspectiva inter e transdisciplinar da Economia Ecológica (EE).

O método utilizado vem da teoria da complexidade, em que é realizada a sobreposição dos conceitos de desenvolvimento, necessidades e vulnerabilidades, com a presença de novos indicadores de desenvolvimento e das principais organizações internacionais.

Para a realização desse propósito, no campo do que se pode chamar de economia com enfoque humano, apoia-se na construção 
teórica das necessidades humanas vinda de Maslow (1975), idealizador da Pirâmide das Necessidades; de Max-Neef (1992), idealizador da Matriz da Felicidade; de De Masi (2001), entendendo ser o tempo livre uma importante necessidade humana. Apoia-se ainda em: Sen (2000; 2001), que ressalta a liberdade (como uma necessidade humana) ligada à igualdade como condição e meio para o desenvolvimento; Schumacher (1983), por ressaltar valores humanos; Furtado (1984; 1996), no sentido de diferenciar desenvolvimento de crescimento econômico; Bosi (2012), que registra em seu artigo sobre a reconstrução da história da economia e do humanismo o importante, mas não reconhecido, movimento Economia e Humanismo, fundado pelo frade Joseph-Louis Lebret, propondo o reconhecimento das necessidades básicas na consolidação das comunidades para a reivindicação da satisfação dessas necessidades e redefinindo o ser humano concreto nas relações com a economia, com a política e com o Estado.

A parte 1 é a introdutória, a 2 aborda algumas das principais Organizações Internacionais (OI) e novos indicadores de desenvolvimento. A parte 3 apresenta conceitos de vulnerabilidade e descreve alguns elementos introdutórios da formação dos desejos e das necessidades. A parte 4 contempla brevemente o tema economia a partir de conceitos gerais, passando para o campo da complexidade para a economia. Na parte 5, apresenta-se uma junção dos elementos de desenvolvimento, vulnerabilidades e necessidades humanas, obtendo-se um parâmetro para estudos sobre insustentabilidade atrelados ao não atendimento das necessidades. Encerra-se com as conclusões.

\section{Organizações internacionais (OI) e os novos indicadores de Desenvolvimento Humano (DH) e Ecologicamente Sustentável (DeS)}

Organizações Internacionais (OI) são constituídas por meio de tratados ou acordos com a finalidade de incentivar a permanente cooperação entre seus membros, a fim de atingir objetivos comuns, entre eles, o de desenvolvimento. Indicadores de desenvolvimento dependem do que se entende pelo termo e, para diferenciar da 
ideia de crescimento, é sempre importante diferenciar a ideia de Desenvolvimento Econômico (DE) como aumento do PIB e, portanto, de crescimento da ideia de Desenvolvimento Humano (DH) e Desenvolvimento (ecologicamente) Sustentável (DeS) como aumento da qualidade de vida e do bem-estar. Isso porque a visão econômica generalizada no mundo (acadêmico, político, empresarial e social) ainda é a de que o PIB é um indicador de desenvolvimento.

0 atendimento de necessidades humanas representa o respeito aos direitos humanos, e o atendimento desses direitos representa o $\mathrm{DH}$ e, por consequência, o DeS. DeS diz respeito às questões globais, uma vez que as dinâmicas dos ecossistemas não respeitam fronteiras territoriais criadas pelo homem. Além dessa condição global, o DeS não se limita aos cuidados apenas com o meio natural biofísico externo ao humano, mas diz respeito também às necessidades da natureza humana - entre elas, a de viver em um meio natural saudável. Sendo global, é evidente a importância da atuação das Ol como orientadoras, reguladoras ou mesmo controladoras de caminhos sobre o desenvolvimento em um mundo globalizado.

As Ol foram fundadas após as trágicas atrocidades ocorridas durante a $2^{\text {a }}$ Guerra Mundial, mas suas raízes antecedem esse período. Em 1789, houve a Declaração dos Direitos do Homem e do Cidadão, proclamada na França, demonstrando que a liberdade é uma necessidade humana. Passaram-se mais de 150 anos e ainda nessa primeira década do século XXI há países onde muitos dos direitos humanos não são respeitados.

Somente em 1945, com a Carta das Nações Unidas, assinada inicialmente por 51 Estados membros originais (atualmente, 193), povos de diferentes culturas exprimiram sua determinação em respeitar os direitos fundamentais das pessoas: a dignidade e o valor humano. Na sequência, abriu o espaço para ser lançada a Declaração Universal dos Direitos Humanos (em 1948, nos Estados Unidos).

Desse movimento surgiram as OI, sendo as mais relevantes para o presente estudo: A ONU (Organização das Nações Unidas), 
criada em 1945 com o objetivo de organizar as relações internacionais e assegurar a paz mundial diante de conflitos de ordens diversas, procurando representar a promessa de segurança às sociedades mundiais; a OIT (Organização Internacional do Trabalho), criada antes da ONU e acolhida por ela como sua primeira agência, com o objetivo de influenciar legislações trabalhistas com recomendações muitas vezes voltadas à diminuição da exploração do trabalho pelos interesses do mercado e tendo como pauta, na primeira década do século XXI, ainda em fase inicial de discussões, a redução da carga horária diária dos trabalhadores; a FAO (Organização das Nações Unidas para Agricultura e Alimentação), criada em 1945 objetivando negociar acordos, políticas e estratégias de erradicação da fome e da insegurança alimentar no mundo; envolve-se também com problemas de ordem ecológica na medida em queágua ealimentos são dependentes de um meio ambiente saudável; a UNESCO (Organização das Nações Unidas para Educação, Ciência e Cultura), criada em 1945 com o objetivo de contribuir para a paz por meio da educação, da ciência e da cultura, visando eliminar o analfabetismo; a OMS (Organização Mundial da Saúde), fundada em 1948, subordinada à ONU, tendo por objetivo acompanhar e fornecer orientações para o desenvolvimento do nível de saúde de todos os povos, definindo a saúde não apenas como ausência de doença, mas como o estado completo de bem-estar físico, mental e social; e a OCDE (Organização para a Cooperação e o Desenvolvimento Econômico), fundada em 1961 em substituição à OECE (Organização Europeia para a Cooperação Econômica), com ações voltadas ao contexto econômico e à área das políticas sociais de educação, saúde, emprego e renda, atuando com fóruns internacionais a fim de articular políticas públicas (entre os países mais ricos do mundo) e voltada ao pensamento econômico neoclássico, em que resultados do PIB representam desenvolvimento.

Outras organizações com abrangência internacional e de cunho não governamental surgiram ao longo da segunda metade do século XX com propósitos de colaborar com o DH, como a Anistia Internacional (Al) fundada em 1961, atuante na divulgação e defesa dos direitos humanos, e o Greenpeace, fundado em 1971, atuando internacionalmente em questões relacionadas à preservação do meio ambiente e do desenvolvimento sustentável. 
A década de 1990 foi atuante no sentido de ações voltadas aos direitos humanos e aos cuidados com o meio ambiente. Foi a década do surgimento de novos indicadores de desenvolvimento procurando complementar as limitações, principalmente, do principal indicador das atividades econômicas, o PIB (Produto Interno Bruto), criado na década de 1940.

Entre os novos indicadores, está o IDH (Índice de Desenvolvimento Humano), procurando medir a qualidade de vida, inicialmente, por meio dos seguintes fatores: educação, longevidade e renda per capita, indicando algumas vulnerabilidades sociais diante do não atendimento a esses três restritos fatores. Posteriormente surgiu o IS (Índice de Sustentabilidade), o mais divulgado, a Pegada Ecológica, criado em 1996, método pioneiro que se propôs a contabilizar os fluxos de matéria e energia de um sistema convertendo-os em área correspondente de terra ou água existentes na natureza. O IVH (Índice de Valores Humanos), lançado como um complemento do IDH, procura retratar de forma qualitativa as vivências da população em relação à saúde, educação e ao trabalho, aplicado em algumas regiões brasileiras com o objetivo de identificar como as pessoas percebem o respeito, a liberdade, a reciprocidade e a convivência na sociedade. 0 ponto de partida do IVH é a ideia de que os valores são formados a partir das experiências das pessoas, por isso, o índice tenta captar a percepção dos indivíduos sobre situações vivenciadas no dia a dia (PNUD, 2010).

\section{Vulnerabilidade}

Vulnerabilidades podem ser observadas pela via ambiental (envolvendo ecossistemas e outras dinâmicas da natureza externas ao humano) e pela via social e individual (envolvendo diretamente a natureza humana).

A vulnerabilidade ambiental corresponde à resposta do meio às ações humanas, variando conforme suas características naturais e antropogênicas, afetando diretamente a estabilidade do meio, bem como sua qualidade ambiental (SANTOS; CALDEYRO, 2007). A vulnerabilidade 
ambiental é também entendida como a suscetibilidade do ambiente ao impacto provocado pela antropização. Já a vulnerabilidade social é entendida como a suscetibilidade das sociedades pela escassez de recursos em geral, gerando áreas de risco ambiental, aumentando a insegurança sobre a vida e agravando o atendimento de mais uma das necessidades do ser humano que é a de sentir-se em segurança (TAGLIANI, 2002).

A vulnerabilidade social é normalmente definida diante da existência de três situações: a exposição social/individual ao risco (fontes geradoras de insegurança física e emocional); a incapacidade de reação (no sentido de impotência diante de um fato vivido ou prospectado); e a dificuldade de adaptação diante da concretização do risco (conforme as limitações adaptativas da natureza humana) (MOSER, 1983).

Da relação entre natureza e sociedade, ambas em situações de risco, forma-se o que conhecemos como cumulatividade de riscos, formando a vulnerabilidade socioambiental (MOSER, 1983; MARANDOLA; HOGAN, 2005).

\section{a. Formação dos desejos e das necessidades}

Muitas das necessidades e dos desejos humanos foram descritos nas mais antigas escrituras da história humana e posteriormente fizeram parte de debates filosóficos na antiga Grécia. Na sequência, a ciência realizou pesquisas, construiu conceitos, dividiu o tema em diferentes setores do conhecimento e, de certa forma, o conhecimento sobre a natureza humana ficou esquartejado.

Uma das formas de compreensão sobre a formação dos desejos é descrita por Lacan (apud DOR, 1989), no sentido de que o desejo adquire voz no inconsciente e, embora pareça ser individual, é revelado pelo outro por meio do discurso do outro, na medida em que o sujeito humano é um efeito da linguagem. Definir o desejo como desejo do outro foi, para Lacan, instituir um princípio explicativo para as transformações sociais e culturais. O desejo demonstra a ausência 
do objeto desejado ou indica a presença da percepção da falta, ou seja, da necessidade. Em uma sociedade, essa percepção ocorre de forma dinâmica e em cadeia e sempre está amparada pelo que, de início, poucos percebem, mas, na medida em que a nova percepção é transmitida aos outros, o grupo humano passa a ter desejos semelhantes e assim novas culturas são formadas.

O sistema cultural como um elemento formador dos desejos e das percepções é capaz de ocultar algumas necessidades e criar outras. Foi o que ocorreu com a mimetização cultural consumista iniciada no século passado, quando algumas necessidades humanas foram abafadas pelos interesses do mercado e outras foram criadas.

Conforme observações de Adorno (1995), no século XX o sentido legítimo da cultura foi transgredido, e a cultura passou a se subordinar às leis de equivalência do mercado, o que criou uma cultura da produção e do consumo a qualquer custo. Tudo virou produto. A civilização que deveria transcender regrediu e se tornou consumivel, mimetizada, a ponto de esquecer algumas das suas reais necessidades básicas para o seu bem-estar e, de certa forma, houve uma espécie de desumanização do humano.

Ativar o processo de humanização é ampliar o desenvolvimento das capacidades cognitivas individuais das pessoas. Como resultado desse processo, pode ser ampliada a percepção individual/social sobre necessidades, bem-estar e/ou qualidade de vida.

Na Conferência de Ottawa, realizada pela OMS em 1986, a expressão qualidade de vida, assim como de saúde, foi definida como um completo bem-estar físico, mental e social (OMS, 1986), de acordo com as necessidades humanas atingidas. No documento resultante dessa conferência, a Carta de Ottawa declara que são os indivíduos e grupos sociais quem devem saber identificar suas aspirações e satisfazer suas necessidades (Ibidem).

Uma das abordagens teóricas mais difundidas sobre necessidades humanas foi desenvolvida por Maslow (1975), em um 
sentido hierárquico de necessidades, obedecendo a uma escala de valores a serem transpostos. Na base estão as fisiológicas, seguidas das de segurança, sociais, de status e estima e de autorrealização. Esses cinco grupos de necessidades englobam três tipos de motivos: 1) os físicos, 2) os de interação com os outros e 3) os relacionamentos com o self(Ibidem). A prioridade dada para as necessidades fisiológicas, formando a base da pirâmide das necessidades, não pode ser muito questionada; entretanto, a ordem das demais pode ser discutivel se a análise se der a partir de uma visão da complexidade e, nesse sentido, elas relacionam-se como em rede e não em hierarquias piramidais.

As mais básicas, as físicas ou fisiológicas, responsáveis pelo bom funcionamento do corpo, são: as necessidades de alimentação (incluindo água); de ar; de excreção; da homeostase; de abrigo; e de descanso (além da energia solar).

As três primeiras necessidades (alimento, ar e excreção) explicam o corpo humano (com vida) como um sistema aberto que permanentemente troca matéria e energia com o ambiente externo. A homeostase, uma espécie de vontade própria da natureza, é "a habilidade de um indivíduo manter as condições internas constantes em face de um ambiente externo variante” (RICKLEFS, 1996, p. 145). 0 estado de equilíbrio das diversas funções e composições químicas do corpo, como a temperatura, o pulso, a pressão arterial, a taxa de açúcar no sangue, etc., depende da capacidade de resiliência do corpo. Essa capacidade descreve o montante de distúrbio que pode ser absorvido pelo corpo (ou pelos ecossistemas), assim como a velocidade do retorno ao estado de equilíbrio (uma vez eliminados os distúrbios), antes que ocorra uma mudança fundamental na sua estrutura ou que provoque os sintomas de doenças (ou os sérios desequilíbrios).

A necessidade de abrigar o corpo está relacionada à homeostase e à segurança. O corpo humano recebe influências da temperatura e trabalha para o alcance de um equilíbrio que o mantenha vivo. Segundo Mendonça, "o clima é um dos principais fatores a influenciar os diferentes tipos de adaptações do homem na superfície do planeta, podendo influenciá-lo positiva ou negativamente” e a sensibilidade humana ao clima, enquanto temperatura do ar, se muito elevada 
ou muito baixa, é também um dos elementos estimulantes da agressividade humana (MENDONÇA, 2001, p. 23). Além da relação do abrigo com o clima, podendo gerar vulnerabilidades individuais/sociais, a necessidade de abrigar o corpo envolve também a necessidade da segurança física diante dos perigos que possam o atingir. A insegurança ou a vulnerabilidade do corpo sem abrigo ou com abrigo inadequado pode provocar alterações psicológicas, interferindo no comportamento humano da mesma forma como ocorre a homeostase como defesa fisiológica do corpo humano diante da temperatura.

Dessa reação natural há efeitos ou estímulos no comportamento para a realização do bem-estar ou do conforto térmico. Sobre esse assunto, Ayoade (1996) considera que, na medida em que as condições climáticas diferem espacialmente e influenciam no metabolismo do corpo humano, surge uma questão já estudada, principalmente pelos climatólogos, no sentido das interfaces e complementaridades entre clima e sociedade, clima e comportamento, envolvendo a correlação clima e bem-estar ou clima e mal-estar. Segundo Ayoade:

\footnotetext{
Ainda que se reconheça que o aspecto climático seja apenas uma parcela do grande enfoque do bem-estar humano, a saúde humana, a energia e o conforto são afetados mais pelo clima do que por qualquer outro elemento do meio ambiente. O conforto fisiológico do homem é determinado, principalmente, pela temperatura, pelo vento e pela umidade (1996, p. 189-0).
}

A necessidade de descanso, no sentido físico, também desencadeia no corpo reações homeostáticas. A defesa do corpo diante do esgotamento físico é o sono, uma necessidade citada pela OMS como a terceira mais importante necessidade básica para a saúde, seguida da água e do alimento.

Outras descrições das necessidades humanas vêm de MaxNeef (1986) e Lebret (apud BOSI, 2012). Max-Neef (1986) salientou a necessidade de subsistência, de proteção, de compreensão, de participação, de lazer, de criação, de expressão da liberdade e da identidade, do exercício do afeto, do amor e do ócio, classificadas em duas categorias: a existencial e a axiológica. 
Lebret (apud BOSI, 2012) classificou as necessidades como pessoais e coletivas. Nas pessoais estariam as conhecidas pela biologia como básicas; quando não satisfeitas em seus limites máximos, promovem a morte. Chamou de comodidades domésticas os serviços de água, luz e aquecimento; e de comodidades externas os serviços principais de um bairro. Elencou também como necessidade um trabalho regular e uma vida cultural e social, incluindo na educação a leitura, o conhecimento histórico, político e religioso. Em uma segunda classe de necessidades pessoais, elencou a dignidade (incluindo o espaço para se receber os amigos) e o conforto psíquico e social do ser humano. Como necessidade cultural incluiu o domínio de uma arte e a capacidade de compreender uma obra literária. Quanto às necessidades pessoais ou terciárias, entendeu que os seres humanos devem ser capazes de desenvolver ao máximo as suas capacidades (Ibidem), para que ocorra o que podemos entender como desenvolvimento humano.

Conforme são as indicações dos estudos apresentados sobre as necessidades para a saúde e o bem-estar, o tempo livre e com qualidade é um elemento-chave. Lebret considerou o tempo livre para pensar, estudar, meditar, contemplar, criar obras de arte e orar, o que é travado pelo excesso de trabalho bruto ou burocrático e o aguilhão dos cuidados materiais (Ibidem). Nessa mesma linha está De Masi (2001) em seu livro “Economia do Ócio”, que tratou da necessidade de tempo para o ócio considerando que a sociedade já teria passado da fase industrial e estaria em uma fase pós-industrial. Nesta, o centro da economia deslocar-se-ia da produção de bens materiais para bens imateriais, ou seja, para uma economia que valorizasse novas ideias e analisasse melhor ou de forma mais complexa as necessidades humanas (DE MASI, 2001). Também Max-Neef inclui a necessidade de tempo ocioso para a realização de atividades da vida que estão além do que o mercado pode proporcionar.

Enquanto no passado o tempo livre, por existir naturalmente na vida das pessoas, não era considerado como uma necessidade, na medida em que o novo modelo industrial impôs mais atividades ao humano, ocupando mais o tempo de vida das pessoas, a própria sociedade industrial (chamada equivocadamente de desenvolvida) 
adotou culturalmente a ideia de que o tempo livre é algo negativo a ser desprezado, ligado a pessoas aposentadas, desempregadas ou desocupadas. Entretanto, tempo livre é necessário para a realização com liberdade das necessidades sensiveis, como de interação com os outros e os relacionamentos com o self (MASLOW, 1975); para o exercício do afeto, do lazer, da criação, da participação, da proteção e do próprio ócio (LEBRET apud BOSI, 2012), podendo o ócio ser apenas o deitar em uma rede e meditar (MAX-NEEF, 1992), realizar uma leitura, uma oração, estudos informais; em suma, para a realização da instrução (LEBRET apud BOSI, 2012).

Eibl-Eibesfeldt (1970), em “Amor e o Ódio”, concluiu que se há um instinto da agressividade inato no humano há também um forte impulso contrário e que as potencialidades do bem são biologicamente tão nossas como as do autoconhecimento. Sem o sentimento de amor, os sentimentos agressivos prevalecem e o oposto também é verdadeiro. Enquanto os sentimentos ligados ao amor são o cuidado com o outro, a amizade e a simpatia, os sentimentos que rompem ligações sentimentais são a ganância, a disputa e a agressividade. Tema também desenvolvido no século XVIII por Adam Smith em Teoria dos Sentimentos Morais (SMITH, 2002), quando desde o início da formação do funcionamento do sistema econômico já percebia a importância dos sentimentos de simpatia para o bem-estar social e dos sentimentos da ganância e do egoísmo como construtores do mal-estar.

Embora na condição humana coexistam os impulsos para o bem (paz, tranquilidade, amor) e para o mal (agressividade, ódio, elementos que geram insegurança), Eibl-Eibesfeldt (1970) conclui que a cultura é capaz de estimular, reprimir ou redirecionar tais impulsos. Considerou que a sociedade humana moderna perdeu muito dos significados primitivos da agressividade; entretanto, na base dos comportamentos, a condição biológica da espécie não desapareceu, pois as necessidades básicas não desapareceram. Afirma que a não possibilidade de liberar o impulso negativo acumulado (da insatisfação diante do não atendimento de necessidades biológicas) pode levar a comportamentos agressivos em busca da liberação desse impulso, o que amplia a vulnerabilidade individual/social. 
Ainda sobre a agressividade, Freud (1950 apud ElBLEIBESFELDT, 1970) entendeu que, embora não seja possível suprimi-la da condição humana, é possível neutralizá-la pela ativação de todas aquelas forças que atendam às necessidades básicas humanas e aquelas que estabeleçam as ligações sentimentais entre os seres humanos, ou seja, tudo aquilo que produz pontos comuns significativos entre homens estimula tais sentimentos de comunidade, e a estrutura da sociedade humana se assenta em grande parte sobre esses sentimentos (Ibidem).

\section{Economia}

A economia é o estudo da escassez para o atendimento das necessidades humanas. Surgiu com a denominação de economia política, como o ramo do conhecimento essencialmente voltado para a administração e o fortalecimento do Estado. A partir de Adam Smith, o foco da economia política passou do Estado para o indivíduo.

Smith e Hume (apud HEILBRONER, 1996) buscavam a racionalização do mundo social e acreditavam que a economia política deveria descobrir os princípios que fundamentariam a obtenção da felicidade humana - e isso se daria pelo estudo do homem e de suas motivações.

No final do século XIX, Marshall (1996) considerou cruciais os conceitos de riqueza e bem-estar social para a economia. Os pontos fundamentais dessa abordagem foram de que as necessidades e os desejos humanos são inúmeros e de várias espécies e as mudanças nos estágios culturais das sociedades organizadas definiriam as transformações dos desejos. Compreendeu que, de um lado, a economia seria um estudo da riqueza a partir do uso de recursos naturais e, de outro, seria o estudo do homem. No centro, estaria a atividade econômica com todas as relações entre produção e consumo, geração de empregos, circulação da renda, decisões de investimentos.

Diante da complexidade em se compreender a natureza humana e do esquartejamento do conhecimento, a economia limitou- 
se mais às relações internas do sistema econômico, como a velocidade da circulação da moeda, o aumento da produção, a geração de empregos e todos os intrincados cálculos que exigem as relações produção e consumo e a definem como economia neoclássica, mas deixando de lado o centro do estudo da natureza humana e a consideração de que o meio natural possui vida e uma lógica própria.

Essa compreensão foi mantida e continua na atualidade em livros de economia, com abordagens neoclássicas, a exemplo de Mankiw (2003), em que os dois polos das naturezas (humana e não humana) permanecem nas definições, mas na prática são apenas as engrenagens necessárias para que o sistema econômico mantenhase em funcionamento, e, quanto mais autômatos, melhor para a economia. Daí as profundas divergências entre a vertente neoclássica e a ecológica da economia, pois, na medida em que esses dois polos que mantêm o sistema econômico em funcionamento são compostos por elementos vivos, ao considerá-lo como tal em sua complexidade muitas das robustas teorias neoclássicas se esvaziam.

\section{a. A complexidade para a economia}

Não há uma teoria específica que trate da complexidade para a economia nem da economia como uma ciência complexa. Nesse sentido, o que ampara estudos sobre a complexidade para um desenvolvimento sustentável depende de compreender primeiramente a própria complexidade da vida.

Conforme descreveu Japiassu (1976; 1977), a busca em dissolver o reducionismo abriu espaços para o surgimento de uma epistemologia crítica sobre a responsabilidade social dos cientistas e dos teóricos na construção do conhecimento. Dessa busca surgiram a complexidade e as possibilidades de enfrentar problemas humanos complexos, como a difícil tarefa de transição de todo um modelo de desenvolvimento para outro, sobre a qual a economia chamada de verde pretende deixar a sua contribuição.

Morin (1995) observa que a própria ciência nos ensinou a separar e isolar as coisas a serem investigadas, pois não há como dar 
conta do todo, mas negar a complexidade pelas dificuldades que ela apresenta não resolve problemas complexos. Um exemplo dado por Morin (1995) remete-se diretamente à economia, ou seja, trata-se da ciência humana mais sofisticada no plano matemático e formal, mas incapaz de atuar sozinha sobre as várias crises que o sistema econômico apresenta de tempos em tempos.

Morin (1995) e Morin e Prigogine (1996), assim como outros cientistas que enfrentaram o problema da complexidade na ciência, entenderam que no interior das teorias há um núcleo obscuro que envolve interesses diversos, muitas vezes mais preocupado com a objetividade científica do que com a realidade complexa das coisas. Argumentaram que "a cientificidade é a parte emersa de um iceberg profundo de não cientificidade” (MORIN; PRIGOGINE, 1996, p. 18). A descoberta de que a ciência não é totalmente científica é, para Morin, uma grande descoberta científica que a maior parte dos cientistas ainda não percebeu.

Esse reconhecimento reforça a importância de pesquisas voltadas às racionalidades substantivas (SERVA, 1996) ou o que Morin e Prigogine (1996) chamam de racionalidade aberta, complementares às instrumentais; estas configuram-se como alternativas teóricometodológicas para uma nova economia, em que são revistas as condições de homo consumus e homo ecconumus, em um sentido de resgate do homo sapiens e podendo colocar a economia em uma condição de humana e ecológica.

Horkheimer (1976), embora considerado por alguns como polêmico, defendeu a junção das racionalidades, a instrumental e a subjetiva, e ainda postulou sobre a necessidade de ultrapassar o positivismo, no qual se buscam critérios de verdade apenas operacionais e de dominação e, dessa forma, incapazes de perceber outras racionalidades. Conforme argumentos de Horkheimer (1976), uma sociedade viva e crítica, de tempos em tempos, age a partir da ampliação da consciência sobre as resignações/vulnerabilidades sentidas e, assim, anuncia necessidades de mudança. Nessa perspectiva teórica, as mudanças projetadas para um novo modelo de 
desenvolvimento saem do campo do positivismo e entram no campo das complexidades.

A concepção da complexidade sugere o desafio e a motivação para pensar e é, antes de tudo, "o esforço para conceber um incontornável desafio que o real lança a nossa mente” (MORIN, 1999, p. 176). Um exemplo dado para se perceber a complexidade é de que "se tentamos pensar no fato de que somos seres ao mesmo tempo físicos, biológicos, sociais, culturais, psíquicos e espirituais, é evidente que a complexidade é aquilo que tenta conceber as articulações, a identidade e a diferença de todos os aspectos”; nesse sentido, a ambição da complexidade é "prestar contas das articulações despedaçadas pelos cortes entre disciplinas, entre categorias cognitivas e entre tipos de conhecimento”. A complexidade não é uma proposta que pretenda “dar todas as informações sobre um fenômeno estudado, mas respeitar suas diversas dimensões [...] este é um princípio de incompletude e de incerteza” (MORIN, 1999, p. 177).

É dentro dessa concepção que residea EE, como uma abordagem complexa, inter e transdisciplinar. Piaget (1970) foi o primeiro a tratar da expressão transdisciplinaridade; Nicolescu (1999) apresentou o Manifesto da Transdisciplinaridade e diversos outros estudos; e Morin (1995) desenvolveu a Teoria da Complexidade.

A relação de pesquisadores adeptos à linha da EE é extensa e em crescimento constante. Cavalvanti (2010) apresenta uma relação, classificando-os, na medida do possível, pelas linhas dos estudos desenvolvidos, e também apresenta uma listagem de nomes de economistas ecológicos organizada por Alier (2007), o que dá um amplo formato de referências bibliográficas da EE. Vale lembrar que todos têm como denominador comum a defesa de um modelo de desenvolvimento ecológico e socioeconômico sustentável.

A EE percebe o sistema econômico como um subsistema de um sistema ecológico maior e dedica-se às relações das leis da termodinâmica com a economia e com as lógicas de funcionamento dos sistemas naturais, destacando a dimensão e a dependência de cada um desses sistemas (GEORGESCU-ROEGEN, 1975). 
Além da relação do sistema econômico com os sistemas naturais não humanos, a EE abre espaços para se perceber a dimensão humana do sistema econômico, mas não mais como uma engrenagem a alimentá-lo, e sim como a sua razão de ser. Ao colocar o humano como superior ao econômico, invertem-se as lógicas do pensamento neoclássico, ou seja, não serão mais as coisas que exigirão determinados comportamentos e necessidades das pessoas, e sim as pessoas serão as definidoras das suas necessidades, de seus comportamentos e do comportamento do sistema econômico. Para isso, é essencial que pessoas tenham a percepção sobre suas reais necessidades, seus direitos e suas capacidades, e, dessa forma, sejam as legítimas autoras de um desenvolvimento sustentável, capazes de gerar qualidade e bem-estar às suas vidas.

De forma global, o fortalecimento do campo humano da EE vem recebendo apoio das ações das organizações internacionais na medida em que direitos humanos estão cada vez mais sendo divulgados e, com eles, ampliando-se a percepção sobre as reais necessidades humanas. Os importantes debates entre EE versus abordagens neoclássicas são crescentes na medida em que novos indicadores vêm demonstrando e confirmando a insustentabilidade socioambiental - e, com ela, as vulnerabilidades socioambientais.

Essas afirmações encontram amparo nas conclusões presentes na Agenda XXI (1992), que diz que o êxito de um desenvolvimento sustentável é dependente de que se modifiquem comportamentos e estilos de vida, que ocorram mudanças de valores, de preceitos culturais e de morais arraigados, da ampliação da percepção individual e social sobre desenvolvimento, em que a conduta humana se fundamenta.

A noção de desenvolvimento alheia ao pensamento neoclássico pode também ser amparada na descrição de Furtado (1984) ao afirmar que as sociedades são consideradas desenvolvidas na medida em que nelas o homem consegue satisfazer suas necessidades, manifestar suas aspirações e exercer seu gênio criador. Desenvolvimento é:

[...] um processo criativo, de invenção da História pelos homens, em contraste com o quadro mimético e repetitivo de que são prisioneiras as 
sociedades dependentes. [...] o desenvolvimento é menos o domínio da natureza e mais um processo de criação de valores, portanto, de avanço na racionalidade substantiva ou dos fins (FURTADO, 1984, p. 63).

Em outras definições de desenvolvimento também são evidentes as relações com o atendimento das necessidades da natureza humana. Entre elas, estão a de: Cavalcanti (2001), definindo desenvolvimento como a realização de certos objetivos de valor para o engrandecimento do ser humano a partir de uma visão integrada de variáveis ecológicas, econômicas e sociais, ao lado de aspectos biológicos, físicos, políticos, institucionais e culturais, sem esquecer anteparos éticos e filosóficos; Schumpeter (1997), ao entender que desenvolvimento é mudança, o novo, significando evolução, transformação; Sen (2000), ao identificar que desenvolvimento é o exercício da liberdade individual e das capacidades humanas e como um processo de expansão das liberdades substantivas das pessoas. As liberdades não são os fins primordiais do desenvolvimento, mas os meios principais. Também Furtado (1996) define desenvolvimento como menos o domínio da natureza e mais um processo de criação de valores, de avanço na racionalidade substantiva. Da mesma forma Schumacher (1983) observa que o desenvolvimento representa dar ao homem a oportunidade de utilizar e desenvolver suas faculdades, entre elas, a criatividade artística, em um aperfeiçoamento progressivo do bem-estar a partir da realização de novas capacidades e potencialidades verdadeiramente humanas.

Diante de tais definições, insustentável é tentar alcançar o DH e DS a partir do bom desempenho do PIB e excluindo o que os novos indicadores de IDH e, principalmente, o IVH podem demonstrar.

\section{A insustentabilidade e o não atendimento de necessidades}

A essência e o desafio do conceito de sustentabilidade ecológica são a manutenção de estoques físicos de capital natural (não degradado) e o atendimento das necessidades humanas ou a essência da insustentabilidade, o encontro da redução irreversivel dos estoques 
naturais com a ampliação das vulnerabilidades individuais/sociais. 0 não atendimento das reais necessidades humanas é um dos principais fatores das vulnerabilidades socioambientais (fonte geradora da insegurança), enquanto a corrida pelo atendimento de todas as necessidades criadas pela cultura consumista é observada como um dos motivos da insustentabilidade do modelo de desenvolvimento/ crescimento adotado na grande maioria dos países.

O acompanhamento da evolução das condições socioambientais do desenvolvimento depende dos dados dos novos indicadores já criados (IDH, IS, IVH), mas ainda em fase de implantação de mais variáveis e abrangência. Anualmente, são lançados relatórios diversos organizados pelas $\mathrm{Ol}$ a fim de registrar e divulgar as condições da vida global.

Dados globais relacionados à distribuição de alimentos, de água potável e de doenças que mais atingem as sociedades, ou mesmo dados sobre a violência, são algumas das informações que podem ser contrapostas às definições de necessidades humanas, vulnerabilidades e desenvolvimento.

Segundo dados da FAO (2011), aproximadamente 925 milhões de pessoas no mundo não têm acesso à alimentação necessária para serem consideradas saudáveis; a fome está na lista dos 10 maiores riscos de vida e é o que mais mata pessoas anualmente, mais do que a AIDS, a malária e a tuberculose juntas (OMS, 2012).

No Brasil, 40 milhões de pessoas convivem com a forma leve de insegurança alimentar, 14 milhões estão na situação moderada e 11 milhões passam pela privação de alimentos, considerada como grave insegurança alimentar (IBGE, 2012). No entanto, há um excesso do consumo de alimentos, gerando problemas de obesidade presentes em várias sociedades e o Brasil não escapa desse diagnóstico, além do excesso de desperdício de alimentos - cerca de 1,3 bilhões de toneladas de alimentos são perdidos, conforme mostra o relatório da ONU (FAO, 2011). 
Relatórios da ONU repetem diagnósticos declarando que mais de um bilhão de pessoas não têm acesso a uma quantidade mínima aceitável de água potável, e estima-se que em 2025 mais de cinco bilhões de pessoas estarão nessa estatística. No Brasil, de acordo com relatório elaborado pela Agência Nacional de Águas (ANA, 2012), apesar do aparente conforto em reservas hídricas, a distribuição espacial é desigual. Cerca de $80 \%$ da disponibilidade hídrica está na Amazônia, onde se encontra o menor contingente populacional, e 47\% das águas em áreas urbanas foram avaliadas como ruins ou péssimas, dado o baixo índice de coleta e tratamento de esgoto; constatou-se, ainda, que apenas $45,7 \%$ dos domicílios brasileiros possuem acesso à rede de esgoto. Dos 5.565 municípios brasileiros, mais da metade poderá ter déficit no abastecimento de água em 2015 pela falta de investimentos para a adequação dos sistemas produtores de água potável. Além de a água ser essencial para a manutenção da vida (humana e não humana), também é essencial para o setor industrial, gerador de empregos e renda, e, mesmo assim, nem mesmo medidas básicas de saneamento, de coleta e destino do lixo, estão resolvidas e ainda não há uma percepção social geral sobre esses serem os investimentos públicos mais primordiais.

Conforme relatório do Ministério das Cidades (2011), para o Brasil resolver apenas o problema relacionado ao saneamento básico será necessário investir R\$ 420,9 bilhões em medidas estruturais e estruturantes, porém, considerando-se que investimentos públicos anuais são divididos em vários segmentos e a prioridade de investimentos é um resultado da pressão social e da eficiência política, dependente da percepção individual e social das suas próprias necessidades, sem tal percepção não há a pressão social necessária e, nesse quadro, a perspectiva para a totalização desse investimento é de 20 anos.

A insônia foi diagnosticada pela OMS (2011) como o problema de saúde mais comum no mundo e uma série de diagnósticos apontam para alterações comportamentais e o aumento da agressividade quando o sono é prejudicado. As causas da insônia podem ser várias, mas a mais evidente e citada pela OMS é o estresse (divulgado em 
2008, também pela OMS, como a epidemia do século). A depressão, a poluição sonora, a fome, a falta de moradia digna, a falta de segurança e a falta de tempo também são fontes causadoras da insônia.

A necessidade de descanso é prejudicada pela cultura consumista estabelecida no século passado que impõe às pessoas mais o ter do que o ser. Essa falta de tempo para as atividades sensiveis, sociais, psicológicas ou apenas para o descanso mental (ócio) gera a insônia e o estresse.

Com o aumento populacional e a concentração de pessoas em centros urbanos, com jornadas de trabalho muitas vezes ultrapassando oito horas diárias, com a ineficiência da mobilidade urbana e dos serviços de transporte coletivo e diante da ineficiência do setor público e privado em atender às demandas pelos serviços sociais (bancários, de telefonia, de saúde e outros), o tempo para a prática da vida é reduzido. Nesse sentido, as filas de atendimento, filas para o transporte, filas diversas podem ser consideradas como algo insustentável para o bem-estar e para a qualidade de vida das pessoas, e esse também é um forte indicativo para definições de prioridades políticas para o desenvolvimento humano.

A agressividade e a violência no mundo atual são medidas de acordo com registros em delegacias e pelo tamanho da população carcerária, mas não são medidas pela falta de atendimento das necessidades humanas. O sistema carcerário brasileiro está entre os piores e mais desumanos do mundo (GRECCO, 2010), e, conforme análises do referido autor, há ainda uma cultura social de que presos não devem ter direitos humanos, o que de certa forma reforça o não atendimento das suas necessidades e amplia ainda mais o problema na medida em que eles retornam à sociedade.

\section{Conclusão}

No mundo globalizado, evidencia-se a importância das Ol como orientadoras, reguladoras ou mesmo controladoras de caminhos para 
o desenvolvimento, que deveria levar em conta as reais necessidades humanas e um ambiente saudável para viver com qualidade, com minimização das vulnerabilidades.

O sistema cultural como um elemento formador dos desejos e das percepções é capaz de ocultar algumas necessidades e criar outras, assim como aconteceu na atual cultura da produção e do consumo a qualquer custo, em que tudo é considerado mercadoria. Contudo, as reais necessidades vão além daquelas consideradas básicas, pois outras, como a compreensão, participação, o lazer, a criação, a expressão da liberdade e da identidade, o exercício do afeto, o amor e o ócio, ou seja, ter tempo para pensar, estudar, meditar, contemplar, criar obras de arte e orar, também se fazem necessárias para o bem-estar de todos.

Do ponto de vista da economia ecológica, não há como atingir o desenvolvimento sustentável a partir do pensamento neoclássico. Essa ciência, que naturalmente deveria ser interdisciplinar, ao ter sido enquadrada em moldes disciplinares e seus interesses reduzidos muito mais às dinâmicas mecânicas do funcionamento do mercado, acabou por não conseguir gerar um desenvolvimento com fisionomia humana e sustentável. A economia nos moldes neoclássicos, ao se debruçar na busca por um rigor matemático, elimina das suas abordagens tudo o que diz respeito à vida e às suas complexas relações e articulações. Assim, torna-se ineficiente a ponto de estar no centro do furacão chamado desenvolvimento insustentável. Com as suas simplificações, a cada resolução de um problema, cria outros a serem solucionados no futuro. Todo esse conhecimento é dotado de grande complexidade e por isso demanda outras abordagens para o seu entendimento e compreensão. A falta de percepção social sobre as consequências negativas do não atendimento às necessidades da natureza humana interfere na qualidade de vida de todos.

Recebido 20/09/2012

Aprovado 25/07/2013 


\section{Referências bibliográficas}

ADORNO, T. W. Educação e Emancipação. Rio de Janeiro: Paz e Terra, 1995.

AGENDA XXI. Conferência das Nações Unidas sobre Meio Ambiente e Desenvolvimento. Rio de Janeiro: 1992. 2. ed. Brasília: Senado Federal, 1997.

ALIER, J. M. Economia e Ecologia: questões fundamentais. Tradução Mauricio Waldman. São Paulo: Contexto, 2007.

ANA - Agência Nacional de Águas. Conjuntura dos recursos hídricos no Brasil: informe 2012. ed. especial. Brasília: ANA, 2012.

AYOADE, J. O. Introdução à Climatologia para os trópicos. 4. ed. Rio de Janeiro: Bertrand Brasil, 1996.

BOSI, A. Economia e humanismo. Estudos Avançados, São Paulo, v. 26, n. 75, maio/ago. 2012. Disponível em: <http://www.scielo.br/scielo. php?script=sci_arttext\&pid=S0103-40142012000200017\&Ing=pt\&nr m=iso\&tlng=en>. Acesso em: 10 ago. 2012.

CAVALCANTI, C. Pensamento econômico, saber ecológico tradicional e etnoeconomia: uma proposta introdutória de nova perspectiva disciplinar. Recife: Instituto de Pesquisas Sociais, Ed. Fundação Joaquim Nabuco, 2001.

Concepções da economia ecológica: suas relações com a economia dominante e a economia ambiental. Estudos Avançados, São Paulo, v. 24, n. 68, 2010.

DE MASI, D. A economia do ócio. Rio de Janeiro: Sextante. 2001.

DOR, J. Introdução à Leitura de Lacan, O Inconsciente Estruturado como Linguagem. Porto Alegre, RS: Artmed Editora, 1989. 
EIBL-EIBESFELDT, I. Amor e Ódio: História Natural dos Padrões Elementares do Comportamento. Lisboa: Livraria Bertrand, 1970.

FAO - Organização das Nações Unidas para Agricultura e Alimentação. Publicações. 2011. Disponivel em: <https://www.fao.org.br/ publicacoes.asp>. Acesso em: 03 ago. 2012.

FURTADO, C. Cultura e Desenvolvimento em época de crise. Rio de Janeiro: Paz e Terra, 1984.

O mito do desenvolvimento econômico. Rio de Janeiro: Paz e Terra, 1996.

GEORGESCU-ROEGEN, N. Energy and the economic myths. Southern Economic Journal, v. 41, n. 3, 1975.

GRECCO, R. Direitos Humanos e Sistema Prisional. TVLFG, 30 set. 2010. Disponivel em: <http://www.youtube.com/watch?v=JhpVSaavBB8>. Acesso em: 12 maio 2012.

HEILBRONER, R. L. A história do pensamento econômico. 6. ed. Coleção Os Economistas. São Paulo: Nova Cultural, 1996.

HORKHEIMER, M. Eclipse da razão. Rio de Janeiro: Labor, 1976.

IBGE - Instituto Brasileiro de Geografia e Estatística. Segurança Alimentar. Disponivelem:<http://www.ibge.gov.br/home/estatistica/ populacao/trabalhoerendimento/pnad2004/suplalimentar2004/>. Acesso em: 20 ago. 2012.

JAPIASSU, H. F. Interdisciplinaridade e patologia do saber. Rio de Janeiro: Imago, 1976.

Introdução ao pensamento epistemológico. 2. ed. Rio de Janeiro: Francisco Alves, 1977.

MANKIW, M. N. G. Introdução à Micro e à Macroeconomia. Rio de Janeiro: Campus, 2003. 
MANANDOLA, E.; HOGAN, D. J. Vulnerabilidade e riscos: entre Geografia e demografia. Revista Brasileira de Estudos de População, São Paulo, v. 22, n. 1, p. 29-53, 2005.

MARSHALL, A. Princípios de Economia. São Paulo: Nova Cultural, 1996.

MASLOW, A. H. Uma teoria da motivação humana. In: BALCÃO, Y.; CORDEIRO, L. L. (Orgs.). 0 comportamento humano na empresa. Rio de Janeiro: FGV, 1975. p. 337-366.

MAX-NEEF, M. Economía Descalza. Señales desde el mundo invisible. Tradução de Stela Lorca. Colección Pensamiento Descalzo. Montevideo: Nordam Comunidad, 1986.

. Chamar Desenvolvimento a um Suicídio Colectivo. A Rede para o Desenvolvimento Local, n. 7, p. 18-27, dez. 1992.

MENDONÇA, F. Clima e criminalidade: Ensaio analítico da correlação entre a temperatura do ar e a incidência de criminalidade urbana. Curitiba: UFPR, 2001.

MINISTÉRIO das Cidades. Panorama do saneamento básico no Brasil. v. 5. 2011. Disponivel em: <http://www.saneamentoweb.com.br/ sites/default/files/PANORAMA_Vol_1.pdf>. Acesso em: 08 jul. 2012.

MORIN, E. Introdução ao pensamento complexo. 2. ed. Lisboa: Instituto Piaget, 1995.

O Método Il: A vida da vida. 3. ed. Portugal: Publicações EuropaAmérica, LDA, 1999.

MORIN, E.; PRIGOGINE, I. A Sociedade em Busca de Valores. Lisboa: Instituto Piaget, 1996.

MOSER, A. 0 problema ecológico e suas implicações éticas. Petrópolis, RJ: Vozes, 1983. 
NICOLESCU, B. O Manfesto da Transdisciplinaridade. São Paulo: Triom, 1999.

OMS-Organização Mundial da Saúde. Carta de Ottawa. 1986. Disponível em: <http://www.mpba.mp.br/atuacao/cidadania/gesau/legislacao/ internacionais/carta_ottawa.pdf>. Acesso em: 28 dez. 2005.

World Health Statistics 2011. 2011. Disponivel em:

<http:/ / www.who.int/whosis/whostat/2011/en/index.html>. Acesso em: 01 ago. 2012.

O que você precisa saber sobre a fome em 2012. 2012. Disponivel em: <http://www.onu.org.br/o-que-voce-precisa-sabersobre-a-fome-em-2012/>. Acesso em: 01 ago. 2012.

PIAGET, J. Problemas gerais da investigação interdisciplinar e mecanismos comuns. Tradução de Maria Barros. Paris: Bertrand, 1970.

PNUD - Programa das Nações Unidas para o Desenvolvimento. Novo indicador do RDH retrata vivências no trabalho, na educação e na saúde. 2010. Disponivel em: <http://www.pnud.org.br/Noticia. aspx?id=2377>. Acesso em: 12 mar. 2012.

Rumo a uma economia verde. Caminhos para 0 Desenvolvimento Sustentável e a Erradicação da Pobreza. 2012. Disponível em: <http://www.pnuma.org.br/admin/publicacoes/ texto/1101-GREENECONOMY-synthesis_PT_online.pdf>. Acesso em: 28 ago. 2012.

RICKLEFS, R. A Economia da Natureza. 3. ed. Tradução de Cecília Bueno e Pedro P. de Lima e Silva. Rio de Janeiro: Guanabara, 1996.

SANTOS, R. F.; CALDEYRO, V. S. Vulnerabilidade Ambiental: desastres ambientais ou fenômenos induzidos?. In: SANTOS, R. F. (Org.). Vulnerabilidade Ambiental: desastres ambientais ou fenômenos induzidos? Brasília: MMA, 2007. 
SCHUMACHER, E. F. O negócio é ser pequeno: um estudo de economia que leva em conta as pessoas. 4. ed. Tradução Octávio Alves Velho. Rio de Janeiro: Zahar, 1983.

SCHUMPETER, J. A. Teoria do Desenvolvimento Econômico: uma investigação sobre lucros, capital, crédito, juro e o ciclo econômico. São Paulo: Nova Cultural, 1997.

SEN, A. Desenvolvimento como Liberdade. São Paulo: Cia das Letras, 2000.

Desigualdade reexaminada. Rio de Janeiro: Record, 2001.

SERVA, M. R. Racionalidade e Organizações: O fenômeno das organizações substantivas. São Paulo: Fundação Getúlio Vargas, 1996.

SMITH, A. Teoria dos Sentimentos Morais. 2. ed. São Paulo: Editora Martins Fontes, 2002.

TAGLIANI, C. R. A mineração na porção média da Planície Costeira do Rio Grande do Sul: estratégia para a gestão sob enfoque de Gerenciamento Costeiro Integrado. 2002. 252p. Tese (Doutorado em Geociências)Programa de Pós-Graduação em Geociências, Universidade Federal do Rio Grande do Sul, Porto Alegre, 2002. 


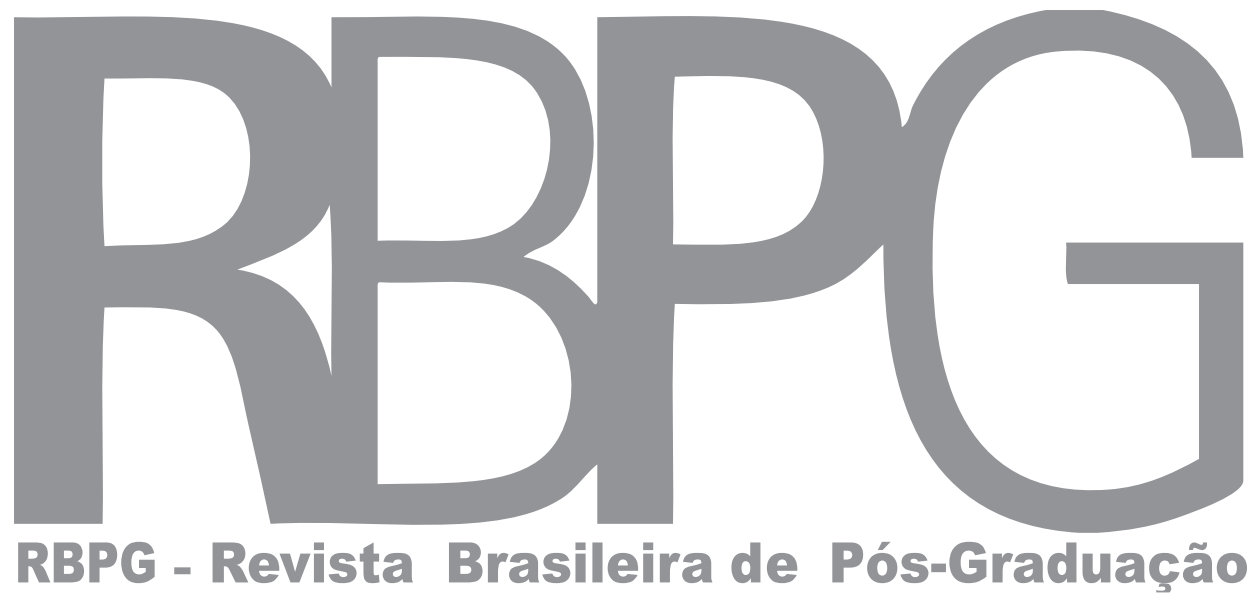




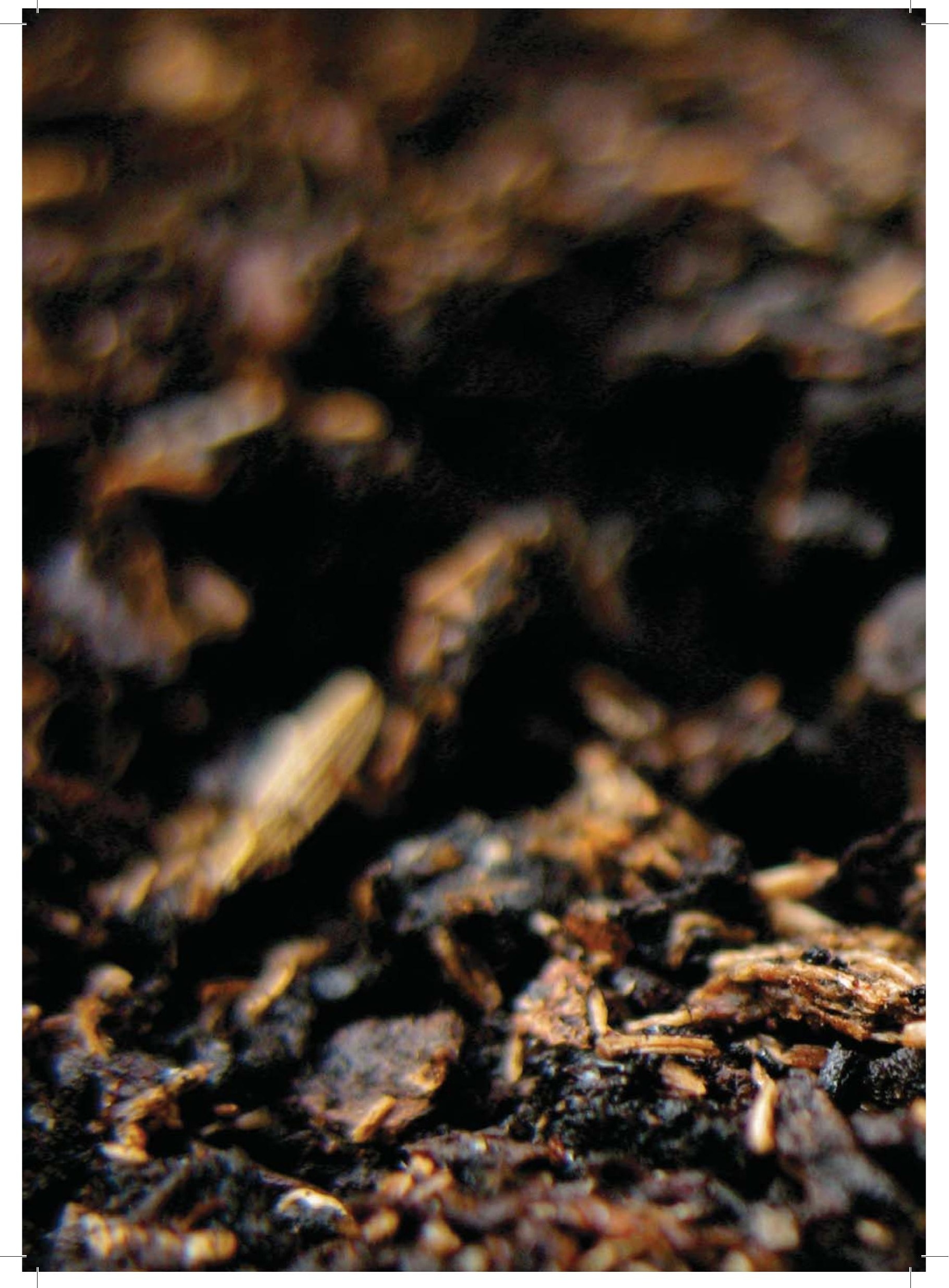




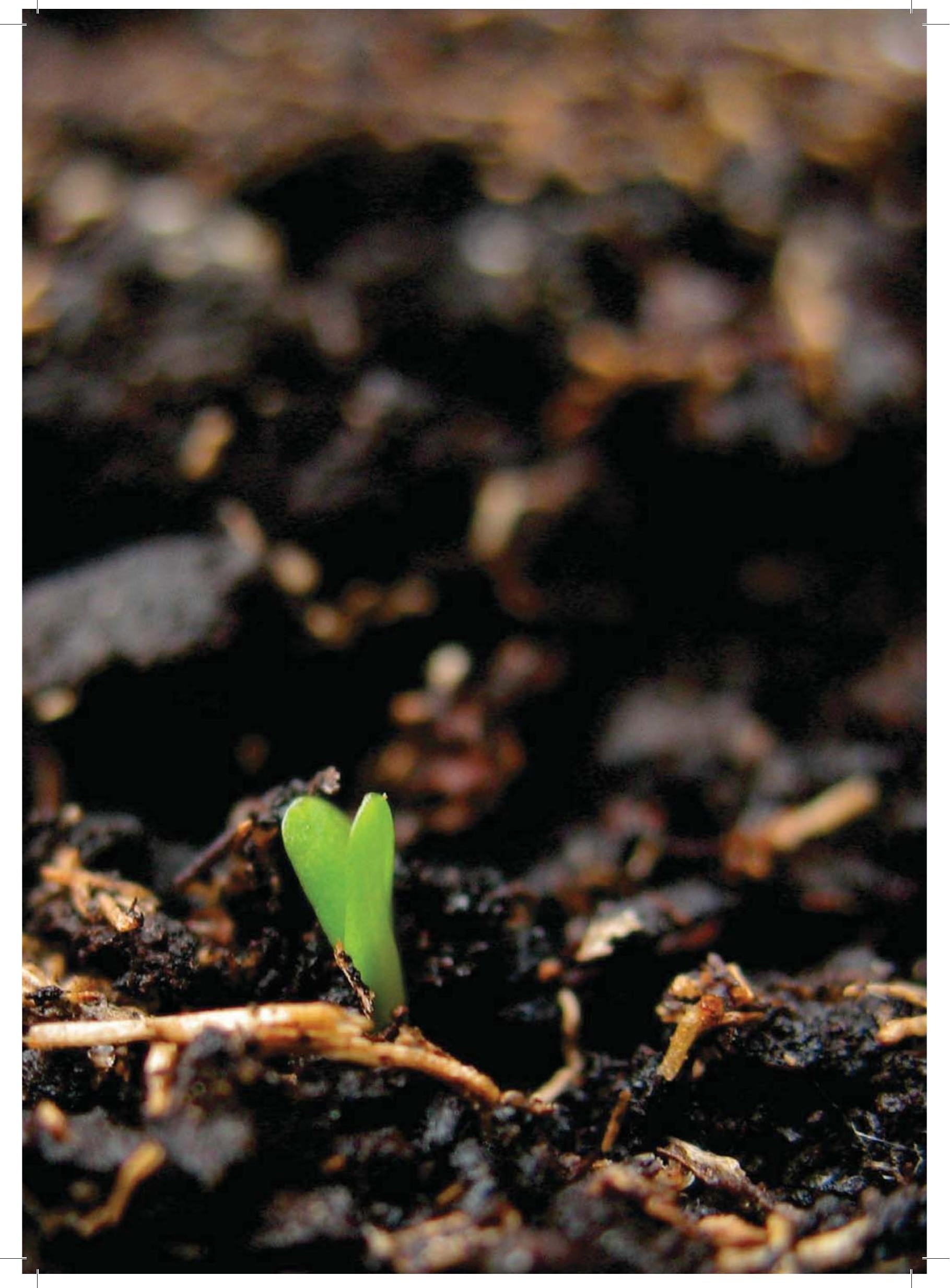




\section{A experiência do Prodema na pós-graduação brasileira: ciência para a sustentabilidade na UFC}

\section{The experience of PRODEMA in Brazilian graduate education: science for sustainability at UFC}

\section{La experiencia del PRODEMA en el posgrado brasileño: ciencia para la sostenibilidad en la UFC}

Laudemira Silva Rabelo, doutoranda e mestre em Desenvolvimento e Meio Ambiente junto ao Programa de Pós-Graduação em Desenvolvimento e Meio Ambiente (Prodema) da Universidade Federal do Ceará. Endereço: Centro de Ciências, bloco 902, Campus do Pici. CEP: 60455-970 - Fortaleza, CE. Telefone: (85) 3366-9781. Fax: (85) 3366-9466. E-mail: laudemira@yahoo.com.br.

Melca Silva Rabelo, doutoranda e mestre em Desenvolvimento e Meio Ambiente junto ao Prodema. Endereço: Centro de Ciências, bloco 902, Campus do Pici. CEP: 60455-970-Fortaleza, CE. Telefone: (85) 3366-9781. Fax:(85) 3366-9466. E-mail:msilvarabelo@yahoo. com.br.

George Satander Sá Freire, doutor em Geologia pela Universidade de Nantes, França, e professor associado IV da Universidade Federal do Ceará. Endereço: Centro de Ciências, bloco 902, Campus do Pici. CEP: 60455-970 - Fortaleza, CE. Telefone: (85) 3366-9781. Fax: (85) 3366-9466. E-mail: satanderfreire@gmail.com.

Vládia Ponto Vidal de Oliveira, doutora em Engenharia Agrícola pela Universidad de Almería, Espanha, e professora associada I da Universidade Federal do Ceará. Endereço: Centro de Ciências, bloco 902, Campus do Pici. CEP: 60455-970 - Fortaleza, CE. Telefone: (85) 3366-9781. Fax: (85) 3366-9466. E-mail: vladia.ufc@gmail.com.

Patrícia Verônica Pinheiro Sales Lima, doutora em Economia Aplicada pela Universidade de São Paulo (USP) e professora 
associada da Universidade Federal do Ceará. Endereço: Centro de Ciências, bloco 902, Campus do Pici. CEP:60455-970 - Fortaleza, CE. Telefone: (85) 3366-9781.Fax:(85) 3366-9466. E-mail:pvpslima@ gmail.com.

\section{Resumo}

A sustentabilidade insere-se em um contexto em que é necessário desvincular-se da visão disciplinar e adentrar na construção do saber interdisciplinar e complexo. A Rio + 20 trouxe à tona a urgência da mudança para um sistema econômico inclusivo denominado Economia Verde. Essa transformação irá demandar novos profissionais e cientistas que possam melhor transpor as barreiras para a real mudança. Dessa forma, o presente artigo tem como objetivo apresentar as contribuições do Programa de Pós-Graduação em Desenvolvimento e Meio Ambiente, da Universidade Federal do Ceará, na construção do saber interdisciplinar frente às questões relacionadas ao desenvolvimento sustentável no ensino de pós-graduação e na formação de profissionais aptos a contribuírem para a efetivação dos ideais propagados pela educação para a sustentabilidade.

Palavras-chave: Sustentabilidade. Pós-Graduação. Interdisciplinaridade. Prodema.

\section{Abstract}

Sustainability is inserted in a context in which it must be extricated from disciplinary vision and included into the construction of complex and interdisciplinary knowledge. The Rio +20 raised the urgency of moving to an inclusive economic system called Green Economy. This transformation will require new professionals and scientists that can better overcome barriers to real change. Thus, this paper aims to present the contributions of the Graduate Program in Environment and Development at the Federal University of Ceará (UFC) in the construction of interdisciplinary knowledge in the face of issues related 
to sustainable development arising in the context of graduate education and professional training.

Keywords: Sustainability, Graduate Study, Interdisciplinarity, PRODEMA.

\section{Resumen}

La sostenibilidad forma parte de un contexto en el que es necesario desvincularse de la visión disciplinaria y adentrar la construcción del conocimiento interdisciplinario y complejo. La cumbre Río + 20 planteó la urgencia de hacer un cambio hacia un sistema económico inclusivo llamado “Economía Verde”. Esta transformación requerirá de nuevos profesionales y científicos que puedan superar de una mejor forma los obstáculos para que haya un verdadero cambio. Por lo tanto, este trabajo tiene por objetivo presentar los aportes del Programa de Posgrado en Desarrollo y Medio Ambiente de la Universidad Federal de Ceará, en la construcción del conocimiento interdisciplinario frente a cuestiones relacionadas con el desarrollo sostenible en la enseñanza de posgrado y en la formación de profesionales capaces de contribuir a la realización de los ideales propagados por la educación para la sostenibilidad.

Palabras clave: Sostenibilidad. Posgrado. Interdisciplinariedad. PRODEMA.

\section{Introdução}

A complexidade dos problemas relacionados à sustentabilidade foge dos métodos positivistas e remete-se à interdisciplinaridade e ao pensamento sistêmico. Analisá-la perpassa pela necessidade de um conhecimento amplo da capacidade de sustentação da Terra e dos processos que possam prejudicar ou estimular a continuidade da vida. Configura-se imprescindivel uma nova forma de pensar que possibilite o conhecimento das propriedades sistêmicas ou emergentes dos sistemas que compõem a relação sociedade-natureza. 
A Rio+20 fomentou o debate sobre a transição para um modelo econômico inclusivo denominado Economia Verde, que irá demandar a construção de novos paradigmas. A sua aplicação exige que haja mudanças nos setores produtivos e na sociedade, surgindo, dessa forma, a necessidade de se inserir a questão do desenvolvimento sustentável nos currículos acadêmicos das universidades, locais tradicionais de formação de recursos humanos. Preparar o novo profissional e estimular a criação de ciência e tecnologia capaz de transpor as barreiras existentes para a efetivação da Economia Verde é o grande desafio da universidade. Tal desafio demanda urgência na implementação dos princípios inseridos na educação para o desenvolvimento sustentável.

Nesse contexto, fica clara, também, a urgente necessidade de formação de docentes conhecedores do arcabouço conceitual do Desenvolvimento Sustentável e aptos a incorporar mudanças nas disciplinas tradicionais. Essa é uma das propostas do Programa de Pós-Graduação em Desenvolvimento e Meio Ambiente (Prodema).

O presente artigo tem como objetivo apresentar as contribuições do Programa de Pós-Graduação em Desenvolvimento e Meio Ambiente, da Universidade Federal do Ceará, na construção do saber interdisciplinar frente às questões relacionadas ao desenvolvimento sustentável no ensino de pós-graduação e na formação de profissionais capazes de promoverem a efetivação dos ideais propagados pela educação para a sustentabilidade.

\section{Ensino superior para o desenvolvimento sustentável}

A importância da educação nas questões ambientais tem suas raízes na Declaração de Estocolmo, documento resultante da Cimeira da Terra, em 1972, que definiu o termo educação ambiental e o seu propósito de conscientização ecológica do cidadão comum. Dentre as suas diversas recomendações, foi estabelecido que a UNESCO ${ }^{1}$ e outras instituições internacionais competentes adotassem disposições

${ }_{1}^{1}$ United Nations Educational, Scientific and Cultural Organization. necessárias para a criação de um programa educativo internacional de educação interdisciplinar formal e não formal, relativo ao meio ambiente. 
Em 1975, foi criado o Programa Internacional de Educação Ambiental (Piea) com a finalidade de desenvolver o conhecimento e suscitar ações que permitissem contribuir para a gestão e proteção ambiental. Trabalho pioneiro, o Piea consolidou a preocupação crescente dos habitantes do planeta com as questões ambientais. Porém, nesse primeiro momento, teve melhor absorção na estrutura curricular dos ensinos fundamental e médio das escolas.

De acordo com as recomendações da Declaração de Estocolmo, o Pnuma² e a UNESCO realizaram o I Seminário sobre Universidade e Meio Ambiente para a América Latina e o Caribe, em Bogotá, Colômbia, no período de 28 de outubro a 01 de novembro de 1985. Foi a primeira tentativa de diagnosticar o grau de avanço dos programas ambientais no ensino superior e assim promover trocas de experiências, discussão de conceitos, orientações e incorporações de critérios sobre a dimensão ambiental nas práticas acadêmicas e investigativas. Em dezembro de 2002, a Assembleia Geral da ONU aprovou a Resolução 57 / 254, em que declarou o período de 2005-2014 como a Década das Nações Unidas da Educação para o Desenvolvimento Sustentável (DEDS).

A educação, que tem como objetivo despertar a consciência crítica sobre os problemas que afetam a relação sociedade-natureza, foi designada como fundamental para a efetivação da transição para o desenvolvimento sustentável. Integrar valores, atividades e princípios inerentes ao desenvolvimento sustentável em todas as formas de educação e contribuir para uma mudança de atitude, comportamentos e valores que possam garantir um futuro sustentável em termos sociais, ambientais e econômicos (UNESCO, 2007) é o objetivo audacioso da Década das Nações Unidas da Educação para o Desenvolvimento Sustentável, que não deve ser confundida com Educação Ambiental. "Educação para o desenvolvimento sustentável lida com a complexa fusão das questões relevantes a sociedade, ao meio ambiente e a economia, preparando pessoas para enfrentar e encontrar soluções para os problemas que ameaçam a sustentabilidade do planeta" (UNESCO, 2007, p. 6).

A base "recursos naturais" é prioritária para ambas, mas a Educação Ambiental enfatiza esse viés enfocando a administração
2 Programa das Nações Unidas para o Meio Ambiente, cuja sigla em inglês é UNEP (United Nations Environment Programme). 
desses recursos, seja pela conservação ou preservação ambiental. Enquanto a Educação para o Desenvolvimento Sustentável traz um contexto mais amplo dessa relação sociedade-natureza ao pontuar outros itens que também interagem com as perspectivas socioculturais e ambientais e as questões sociopolíticas e econômicas, como podem ser vistas no Quadro 1.

\section{Quadro 1. Aspectos tratados pela educação para o Desenvolvimento Sustentável}

\begin{tabular}{|c|c|c|}
\hline $\begin{array}{l}\text { Perspectivas } \\
\text { Socioculturais }\end{array}$ & $\begin{array}{l}\text { Perspectivas } \\
\text { Ambientais }\end{array}$ & $\begin{array}{l}\text { Perspectivas } \\
\text { Sociopolíticas e } \\
\text { Econômicas }\end{array}$ \\
\hline $\begin{array}{l}\text { - Direitos humanos } \\
\text { - Paz e Segurança } \\
\text { - Humana } \\
\text { - Igualdade de Gênero } \\
\text { - Diversidade Cultural } \\
\text { e Compreensão } \\
\text { Intercultural } \\
\text { - Saúde } \\
\text { - Governança }\end{array}$ & $\begin{array}{l}\text { - Recursos Naturais } \\
\text { (água, energia, } \\
\text { agricultura e } \\
\text { biodiversidade) } \\
\text { - Mudanças Climáticas } \\
\text { - Desenvolvimento } \\
\text { Rural } \\
\text { - Urbanização } \\
\text { Sustentável } \\
\text { - Prevenção e } \\
\text { Diminuição de } \\
\text { Desastres }\end{array}$ & $\begin{array}{l}\text { - Redução da Pobreza } \\
\text { - Responsabilidade das } \\
\text { Empresas } \\
\text { - Economia de } \\
\text { Mercado }\end{array}$ \\
\hline
\end{tabular}

Fonte: UNESCO $(2005 ; 2007)$.

Revisão é a palavra que solicita a educação. É o vetor para promover mudanças não somente nas suas várias dimensões - educação formal não formal ${ }^{4}$ e informal ${ }^{5}$-, mas também na sua capacidade de formar competências que incentivem os alunos não somente a buscarem, mas promoverem, uma sociedade sustentável. Para tal, a efetivação da Educação para o Desenvolvimento Sustentável (EDS) necessita conter determinadas características estruturais, entre elas:

3 Conteúdo com inclusa na educação de uma instituição de ensino.

Conteúdo com metodologia, mas fora de uma instituição de ensino.

${ }^{5} \mathrm{O}$ repasse dessa educação não é sistematizado, nem possui metodologia, como nas relações cotidianas. (TOZONI-REIS, 2004). a) Inserir, de forma interdisciplinar e holística, o Desenvolvimento Sustentável, que necessita perpassar de forma integrada por todo o currículo e não como disciplina à parte;

b) Compartilhar valores e princípios fundamentados pelo Desenvolvimento Sustentável;

c) Desenvolver o pensamento crítico e a capacidade de encontrar solução para os desafios em relação ao Desenvolvimento Sustentável; 
d) Utilizar uma multiplicidade de métodos pedagógicos e analíticos para se moldar o processo ao Desenvolvimento Sustentável;

e) Estimular o processo participativo de tomada de decisão;

f) Aplicar no cotidiano as experiências de aprendizagem para o Desenvolvimento Sustentável; e

g) Contextualizar os problemas locais e globais na busca pelo Desenvolvimento Sustentável (UNESCO, 2005).

O papel de capacitar pessoas, principalmente, para as necessidades do mercado de trabalho não resume o projeto de ensino das universidades. A ciência e a tecnologia merecem o seu destaque. Enquanto a ciência é capaz de fornecer meios para se entender o mundo e os limites do ser humano no planeta, a tecnologia proporciona ferramentas para mudanças, inclusive de paradigmas. E essas visões podem ser aplicadas nos cursos de pós-graduação, “[...] concebidos para treinar os responsáveis por decisões” (AGENDA 21 GLOBAL, 2012, cap. 36).

Uma compreensão científica de sustentabilidade, conjuntamente com novos métodos inter e transdisciplinares de avaliações, conduzirá a sociedade a um processo de transição para o desenvolvimento sustentável. Entretanto, se faz necessário fortalecer as capacidades científicas (Ibidem, cap. 35), para que possam responder às novas necessidades da sociedade, cada vez mais complexas. E se é por meio da educação superior que se tem acesso à ciência e à tecnologia, precisa-se então ser repensada a sua função, que tem sido modificada a depender da própria evolução da sociedade.

Com esse olhar surgiu a Parceria Global de Ensino Superior para a Sustentabilidade (GHESP), de que constam a Associação Internacional de Universidades, o Campus Copernicus, a UNESCO e a Associação da Universidade de Líderes para um Futuro Sustentável, que, em esforço conjunto, promovem uma melhor compreensão e aplicação da inserção do desenvolvimento sustentável nas universidades e nos institutos de ensino superior do desenvolvimento sustentável, por meio de uma abordagem interdisciplinar em seus currículos no ensino, na pesquisa e 
extensão, como resposta ao capítulo 36 da Agenda 21 Global (UNESCO, 2012).

O caminho para uma sociedade sustentável perpassa pela universidade, instituição que nem sempre teve o formato hoje conhecido, bem como não é unificada de forma global. Embora conste, na maioria das universidades, o tripé ensino, pesquisa e extensão, ela não surgiu com essa concepção estrutural e nem com a função social atual. Evoluiu com os anseios e as dificuldades dos seus diversos atores sociais e, hoje, necessita de mudanças, tais como a inserção da interdisciplinaridade na formação de seus profissionais, algo que os orientaria na compreensão desse novo mundo - mais complexo e dinâmico - e em proposições de soluções à insustentabilidade vigente.

\section{Das certezas disciplinares à busca interdisciplinar}

O advento, na França, da Universidade napoleônica - a Universidade Imperial - pela Lei de 10 de maio de 1806 aboliu a instituição universidade medieval e instituiu faculdades superiores compartimentadas, com importância à colação de grau e ao diploma. Seus novos membros, não mais jesuítas devotos a uma igreja e sim ao Estado, são obrigados, sob juramento, a obedecer aos estatutos e a sujeitar-se ao Imperador. A formação universitária passa a não ser mais em busca das certezas da ciência, e sim por uma formação profissional, cujo diploma é requisito para o exercício de uma profissão (ROSSATO, 1998).

A criação da Universidade de Berlim, em 1809, trouxe algo novo para o conceito de universidade moderna, ao incorporar a pesquisa como um instrumento, conjuntamente com o ensino, para se atingir o desenvolvimento da ciência. A valorização da pesquisa fez desse modelo de universidade uma corporação de cientistas, que gozavam de liberdade de expressão no exercício do ensino - ação complementar à pesquisa (Ibidem). Esse modelo de universidade abriu o caminho para a universidade contemporânea, exportando essa nova estrutura para diversas outras mundialmente, que também adotaram a pesquisa como prioridade e o ensino como seu complemento, ou simplesmente 
a inseriram, conjugando a tríade acadêmica - ensino, pesquisa e extensão.

A Revolução Industrial e o capitalismo influenciaram bastante a instituição universidade, ao solicitar cada vez mais conhecimentos úteis e de aplicação imediata. Nesse caminhar, modificou-se o cenário de autonomia da ciência, que se tornou porosa à política, deixando-se penetrar pela economia. Ao aceitar profissionalizar-se, passou a definirse como uma atividade orientada não tanto pelo desejo da verdade, mas pela capacidade de produção de resultados práticos imediatamente aplicáveis na esfera política, militar ou econômica. A instituição universidade moderna trouxe não somente a função formadora de indivíduos, mas também o local de pesquisa e a produção de novos conhecimentos prioritariamente para a sua região ou país. Percebe-se assim um novo olhar dado pelo Estado ao ensino superior, em especial à pesquisa.

O fato de integrar a produção científica aos processos produtivos, consequentemente, moldou um novo mundo e alavancou o progresso econômico (LEFF, 2000; 2002), inicialmente de forma local e, posteriormente, global, trazendo novas responsabilidades para a ciência, que anteriormente buscava apenas entender as causalidades das coisas. Assim, a ciência nas universidades inclui-se (ou deveria incluir-se) como área prioritária de qualquer país, percorrendo caminhos direcionados pelas necessidades governamentais e de mercado, por meio dos diversos editais que a fomentam.

Hoje, somos convidados a usar tudo o que a ciência constrói para facilitar a vida humana, reconhecendo, assim, nossa dependência da ciência com a política, com a economia ou com o cotidiano da vida. Se a ciência se modifica para a política, a economia ou para o nosso dia a dia, as universidades, ao longo de sua história, tentaram acompanhar essas transformações e aceitar novas abordagens dessa realidade, não mais vista apenas de forma disciplinar, por abranger cada vez mais problemas complexos. E, sendo os problemas ambientais discrepâncias entre o que o mundo é e o que deveria ser (GROOT, 1992), essa mesma ciência precisa ser capaz de promover a transição para a sustentabilidade - em direção 
a padrões de desenvolvimento que promovam o bem-estar humano ao mesmo tempo em que conservem a vida dos diversos ecossistemas.

O desenvolvimento sustentável, que tem como cenário a complexidade das inter-relações sociedade-natureza, demanda novos conhecimentos e novas formas de análises dessa realidade, diferente da racionalidade tecnológica e da fragmentação do conhecimento. O método científico, que norteia o modelo predominante da ciência moderna, fundamentado nos pressupostos positivistas, foi necessário para um conhecimento e avanço tecnológico especializado, mas deixou como legado uma cegueira disciplinar, advinda da fragmentação do saber e impotente diante de problemas acentuados ou gerados pelo progresso.

Assim, são duas as possíveis estratégias para a análise dos problemas ambientais. A primeira seria recorrer à especialização de cada disciplina de conhecimento e buscar soluções adequadas. Nesse olhar, escolher uma única disciplina, por mais promissora que seja, inviabiliza a sua correta análise, devido ao fato de a questão ambiental transitar pelas diversas áreas de conhecimento. A segunda seria trazer as várias disciplinas para uma convergência, algo concretizado pela interdisciplinaridade (BÜRGENMEIER, 2005).

A inserção da Educação para o Desenvolvimento Sustentável no ensino superior traz implícita a necessidade também dessa forma holística e interdisciplinar de ver o mundo, algo muitas vezes esquecido e controverso para as universidades.

\section{a. A interdisciplinaridade como categoria de reflexão à sustentabilidade}

O termo interdisciplinaridade tem seus primeiros relatos na década de 1930, como um atalho para pesquisas que cruzaram disciplinas, descritas no Social Science Research Council, existindo exemplos em pesquisas agrícolas na década de 1940 e experiências educativas nos anos de 1960 e 1970 (KLEIN, 1990). Mas foi com Jean William Fritz Piaget (1896-1980), defensor da abordagem interdisciplinar para a investigação epistemológica, no I Seminário Internacional sobre Pluri e Interdisciplinaridade, realizado na Universidade de Nice, na 
França, em 1970 (LEFF; MONTES, 1986), que a interdisciplinaridade ganhou força.

O movimento interdisciplinar iniciou-se na Europa no final da década de 1960, conjuntamente com a crise econômica e política do sistema capitalista na década de 1970; isto é, a crise do petróleo. Os movimentos de cunho político-cultural de oposição ao modelo taylorista/ fordista, a competitividade entre os países - organizados por blocos - e as mudanças tecnológicas que traziam uma nova realidade não eram mais compreendidos pelo modelo educacional vigente. Os movimentos estudantis, iniciados na França, Alemanha e Itália, exigiam modificações no estatuto das universidades, em oposição à alienação da academia frente às questões do cotidiano da sociedade e às organizações curriculares que privilegiavam excessivamente a especialização (KLEIN, 1990; FAZENDA, 1994; ALVARENGA; SOMMERMAN; ALVAREZ, 2005; ROHDE, 2005).

Nesse período, a competição acirrada forçou as empresas a se reestruturarem para intensificarem uma produção pautada em um modelo de gestão que não aceitava desperdício - surgia, dessa forma, o modelo de produção enxuta, que exigia qualidade total; e, para tal, necessitaria do comprometimento e da colaboração dos funcionários por meio da difusão de suas experiências e seus conhecimentos -, incentivando-se os trabalhos em equipe. Nesse novo modelo, a formação disciplinar não mais cabia, pois o profissional precisava combinar a flexibilidade da produção com a dos mercados, isto é, a multifuncionalidade que vinha como condição necessária para assegurar rentabilidade e produtividade (MANGINI; MIOTO, 2009).

Resposta à formação de um novo indivíduo capaz de integrar, colaborar com e coordenar uma postura mais flexível diante de um mundo em mudanças, a interdisciplinaridade teve em Georges Gusdorf (1912-2000) um grande incentivador dessa proposta, que a definiu como o resultado do diálogo entre especialistas e da interação afetiva entre as disciplinas. O sucesso da interdisciplinaridade dependeria do domínio aprofundado de cada uma das disciplinas participantes, para que se pudesse chegar à construção do todo, não anulando assim a 
disciplinaridade (ALVARENGA; SOMMERMAN; ALVAREZ, 2005; MINAYO, 1994).

O movimento interdisciplinar iniciava sua jornada influenciado tanto pelas demandas sociais, que viam no conhecimento especializado a ligação direta entre a racionalidade tecnológica e o comprometimento com a lógica de mercado, bem como pela própria evolução do discurso científico, isto é, por influências externas e internas ao pensamento científico (FOLLAN, 1995). A produção interdisciplinar era solicitada a adentrar o seu conhecimento na aplicação e no planejamento do desenvolvimento econômico, enquanto, ao mesmo tempo, fenômenos interdisciplinares não eram abarcados por objetos teóricos disciplinares - o real pertencia à ciência não como objeto isolado, mas como a reunião das partes de um todo. Pelo fato de os problemas de pesquisa do mundo real raramente surgirem ordenados em categorias disciplinares e muito menos suas soluções (REPKO, 2012), a interdisciplinaridade propõe-se como avanço do conhecimento para a resolução dos problemas do novo mundo, dentre eles os ambientais, originando-se assim as Ciências Ambientais (LEFF, 2002).

A relação sociedade-natureza tornou-se objeto de estudo das Ciências Ambientais (GROOT, 1992). Contudo, natureza e sociedade não são conceitos e nem objetos de nenhuma ciência, não constituindo termos de articulação científica (LEFF, 2002). Sua articulação darse-á por sua interação e seu efeito no mundo real, ao transformar ecossistemas; por exemplo, incorporar a natureza ao processo produtivo.

A problemática ambiental, acentuada nas últimas décadas com a crise da civilização, questiona a racionalidade econômica e a tecnologia dominante, em que ambos foram impulsionados por uma ciência positivista que priorizou o fracionamento do conhecimento em busca dos progressos científico, tecnológico e econômico. Hoje, essa mesma ciência é convidada a revisitar o seu legado e rever o modelo de progresso, que tem como fator limitante não somente a natureza, mas a própria sociedade que também é parte integrante desse sistema.

São diversas as razões para a existência da interdisciplinaridade, tais como a unidade da realidade, a intercepção ou a similitude de 
diferentes objetos teóricos, a conveniência de mais conhecimento como suporte de uma intervenção social, a consciência dos investigadores da existência de outros discursos “complementares” ao seu, a percepção de que “pequenas coisas” podem ser importantes para estar e agir e, principalmente, a criação de um ambiente social favorável à troca de saberes (POMBO, 2005).

A interdisciplinaridade tem-se intensificado nos últimos anos e está fundamentada em três áreas, com dinâmicas próprias: a) investigação científica; b) ensino-educação; e c) ação (LEFF, 2000; PIMENTA, 2008). Na investigação científica, surgem os fenômenos interdisciplinares, permeados por distintas lógicas de apreensão, que solicitam os diversos campos do saber para se gerar conhecimento, em que se ressalta como exemplo a interdisciplinaridade ambiental.

Assim, questões ambientais nos remetem necessariamente a um olhar interdisciplinar, por haver uma insuficiência do conhecimento fragmentado para o tratamento da complexidade ambiental, em que diferentes intervenções acontecem em escalas espaços-temporais também diferenciadas (PENA-VEJA; ALMEIDA, 1999). Contudo, nem todo agrupamento de pessoas de diferentes especializações pode ser considerado uma equipe interdisciplinar.

Para tal, interdisciplinaridade precisa ser conhecida conceitualmente a partir de algumas definições:

[...] é um método de pesquisa e de ensino suscetível de fazer com duas ou mais disciplinas interajam entre si. Esta interação pode ir da simples comunicação das idéias até a integração mútua dos conceitos, da epistemologia, da terminologia, da metodologia, dos procedimentos, dos dados e da organização da pesquisa (JAPIASSU, 2006, p. 109).

[...] qualquer forma de combinação entre duas ou mais disciplinas com vista à compreensão de um objecto a partir da confluência de pontos de vista diferentes e tendo como objectivo final a elaboração de uma síntese relativamente ao objecto comum. A interdisciplinaridade implica, portanto, alguma reorganização do processo de ensino / aprendizagem e supõe um trabalho continuado de cooperação dos professores envolvidos (POMBO; LEVY; GUIMARÃES, 1993, p. 13). 
Conceitualmente, um estudo interdisciplinar é um processo que responde a uma pergunta, resolve um problema ou é solução de um tema amplo ou complexo para ser tratado por uma única disciplina, baseandose em perspectivas disciplinares, mas sendo capaz de integrar os seus conhecimentos por meio de uma perspectiva mais abrangente. Pode ser acrescentado que, em pesquisas interdisciplinares, além da necessidade crítica e autocrítica, existe também uma visão integrada e propositada do problema. Estudos interdisciplinares dependem das disciplinas para as suas perspectivas, percepções, seus dados, conceitos, suas teorias e seus métodos no processo de desenvolvimento de uma compreensão interdisciplinar de um problema particular, mas não de uma classe de problemas semelhantes (REPKO, 2012).

Essas demandas geram adequações metodológicas, técnicas e de linguagens de cada disciplina em uma tarefa que se caracteriza por um processo dialético - quando traz contradições que caracterizam o esforço em inter-relacionar os saberes -, sistêmico - por obrigar uma análise dinâmica entre relações e complementos -, seletivo - ao buscar para cada problema suas categorias críticas - e interativo e aberto (REPKO, 2012).

Para aprofundar um pouco mais a abordagem, é necessário lembrar que nem todas as interdisciplinaridades são iguais. Se existem divergências sobre a definição, elas se refletem na finalidade de investigação e educação. Klein (1990) apresenta duas categorias de interdisciplinaridade: a) endógena, que se preocupa com a produção de novos conhecimentos; e b) exógena, que interroga as disciplinas sobre as demarcações que se aplicam à vida real e exige da universidade sua função social.

Paviani (2008) também apresenta a interdisciplinaridade instrumental como uma atividade de solução de problemas que podem ser projetados para atender às demandas da indústria e do governo, enquanto a interdisciplinaridade conceitual está preocupada com as questões teóricas, epistemológicas do conhecimento. No entanto, essas distinções apresentadas não são absolutas, por não ser a interdisciplinaridade um fenômeno homogêneo e uniforme, e sim com diversos níveis e graus de afetividade. 
A interdisciplinaridade pode ser trabalhada em um tema ou objeto de estudo, em que as disciplinas, duas ou mais, intencionalmente se relacionam, sem perderem suas características, mas somando-as para o conhecimento de uma forma mais abrangente e sistêmica. Contudo, a construção de um novo objeto científico a partir da colaboração de diversas disciplinas, e não apenas como o tratamento comum de uma temática, é um processo que se consumou em poucos casos na ciência e que não são generalizáveis a ponto de permitir depreender uma metodologia aplicável para produzir efeitos similares em outros campos do conhecimento e da pesquisa (LEFF, 2002).

Percebe-se que a interdisciplinaridade é também um resgate do ser humano com a síntese projetada do mundo real, precisando também de uma reflexão sobre as atitudes que se constituem como interdisciplinares, para que não ocorra desvio de sua prática (TRINDADE, 2008).

Embora a interdisciplinaridade tenha tido um crescimento dentro do pensamento científico, não existe a obrigatoriedade de seu uso em todos os objetos científicos analisados; isso porque também não existe a pretensão de substituir a disciplinaridade e a especificidade necessária em determinadas áreas da ciência, mas especificamente em sistemas complexos, dinâmicos e não-lineares, como são todos os envolvidos na questão ambiental, nos quais intervêm processos de diferentes racionalidades, ordens de materialidade e escalas-temporais (UNESCO/ UNEP, 1985).

A solução para a transição ao desenvolvimento sustentável não poderá advir apenas de uma gestão racional da natureza e dos riscos de mudanças globais. O conhecimento gerado pelo mundo tem contribuído para a permanência do modelo de desenvolvimento global. E se anteriormente para a ciência não cabiam os limites da natureza, o tempo da matéria e da história ou mesmo a diversidade, hoje, a complexidade reabre todas essas reflexões sobre o tempo no real, que se manifesta na irreversibilidade dos processos, agora distantes do equilíbrio e influenciados pelo ser cultural, o homem (MORIN, 2000). 
O novo ser precisa compreender a complexidade das inter-relações desse novo sistema - os mundos de vida. Isso porque mesmo que se consiga um elevado nível de capacidade crítica, nenhum sujeito individual conseguirá solucionar sozinho nenhuma crise. Esse esforço é sempre acumulativo e social, enquanto o conhecimento é relativo, parcial e incompleto (FOLLAN, 1995).

O desenvolvimento sustentável, como fenômeno complexo, solicita estudos interdisciplinares, holísticos e sistêmicos, adotados não apenas por pequenos grupos de cientistas desbravadores, para que se firme em longo prazo e possibilite integrações tanto locais como globais.

Nesse viés, os programas de pós-graduações no Brasil foram pioneiros ao inserirem a interdisciplinaridade no enfoque temático do meio ambiente, destacando-se, por cronologia, os seguintes cursos de pós-graduação brasileiros: Programa em Ciência Ambiental (Procam), originado em 1989, pela USP/São Paulo; o Programa em Meio Ambiente e Desenvolvimento (Made), originado em 1994, pela UFPR/Paraná; o Programa de Desenvolvimento Sustentável (CDS), da UnB/Brasília, criado em 1995; e o Programa de Pós-Graduação em Desenvolvimento e Meio Ambiente (Prodema), criado em 1996, em rede.

\section{Prodema UFC - experiência interdisciplinar}

O Programa de Pós-Graduação em Desenvolvimento e Meio Ambiente (Prodema), da Universidade Federal do Ceará, faz parte de uma rede de sete universidades concebidas para compreender e incorporar a complexidade do desenvolvimento sustentável nos estudos da região Nordeste do Brasil. Em 1996, o Prodema-Rede foi consolidado, inicialmente, com a participação de seis Instituições de Ensino Superior (IES); no entanto, como afirma Ramalho Filho (1999), sob pressões acadêmicas, as atividades nessas IES foram iniciadas localmente em períodos diferenciados - Universidade Federal de Sergipe (UFS); Universidade Federal do Ceará (UFC); Universidade Regional do Rio Grande do Norte (URRN), em 1995; Universidade Federal da Paraíba (UFPB); conjuntamente com a Universidade Estadual da 
Paraíba (UEPB) em 1996 e Universidade Federal de Alagoas (Ufal) em 1997.

No decorrer dos quase 18 anos do Prodema-Rede, os programas de pós-graduação foram incorporados, enquanto outros foram retirados. Em 2010, com o amadurecimento do curso de mestrado, foi criado o doutorado em Desenvolvimento e Meio Ambiente, que surgiu com uma nova estrutura organizacional - Associação Plena em Rede das Instituições -, incluindo uma coordenação geral, institucionalizada atualmente na UFC, e vários subprogramas a ela subordinados. Hoje, o Prodema-Rede é formado pelas seguintes IES: Universidade Federal do Piauí, Universidade Federal do Ceará, Universidade Federal do Rio Grande do Norte, Universidade Federal da Paraíba, Universidade Federal de Pernambuco, Universidade Federal de Sergipe e Universidade Estadual de Santa Cruz.

A proposta do Prodema-Rede caracteriza-se por conter quatro itens inovadores: a questão do desenvolvimento sustentável na pósgraduação e o caráter interdisciplinar, interinstitucional e intrarregional. A incorporação do conceito de desenvolvimento sustentável ao discurso acadêmico, com preocupações voltadas ao desenvolvimento de uma região historicamente fragilizada, trouxe a perspectiva de um planejamento para médio e longo prazos capaz de beneficiar as futuras gerações. Além disso, a interdisciplinaridade necessária para tal processo tende a quebrar o paradigma da departamentalização nas universidades, incentivando não somente a formação de grupos de pesquisa interdepartamentais, mas possibilitando que os docentes compreendam a importância da pesquisa interdisciplinar.

O caráter interinstitucional, por sua vez, fortalece o programa ao somar as melhores especializações de cada IES enquanto rede, diante de objetos de estudos comuns, abrangendo não somente o seu local, mas uma região, a partir da intrarregionalidade, o que possibilita estudos comparativos e uma maior abrangência de capacidades institucionais. 


\section{a. Contribuições do Prodema-UFC para a sustentabilidade}

O Prodema-UFC iniciou suas atividades com a entrada de sua primeira turma de mestrado em 1995 e com a efetiva participação de professores dos departamentos de Biologia, Economia Agrícola e Geografia dessa instituição. Outros departamentos também contribuíram com recursos humanos de qualidade ao longo do tempo, como foi o caso dos departamentos de Letras, Geologia, Solos, Química, Engenharia Agrícola, Medicina, Engenharia de Pesca e Economia Doméstica. Os departamentos citados são unidades de diferentes centros da Universidade Federal do Ceará: Centro de Ciências, Centro de Ciências Agrárias, Centro de Ciências da Saúde e Centro de Humanidades, o que já fortalece sua predisposição à interdisciplinaridade.

Desde a criação do Prodema até 2012, foram selecionados 287 estudantes, sendo contabilizadas 266 dissertações defendidas (Figura 1).

\begin{tabular}{|c|c|c|c|c|c|c|c|c|c|c|c|c|c|c|c|c|c|}
\hline \multicolumn{2}{|c|}{$\begin{array}{l}\text { Criação } \\
\text { Prodema- } \\
\text { UFC }\end{array}$} & \multirow{2}{*}{ 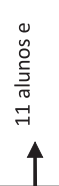 } & 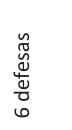 & 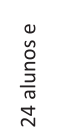 & 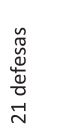 & $\begin{array}{l}0 \\
\tilde{O} \\
\stackrel{5}{J} \\
\frac{5}{\pi} \\
\stackrel{7}{7}\end{array}$ & 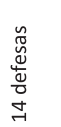 & 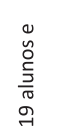 & 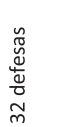 & 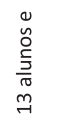 & 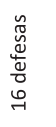 & $\begin{array}{l}0 \\
\tilde{0} \\
\stackrel{5}{5} \\
\frac{5}{\pi} \\
\stackrel{N}{N}\end{array}$ & 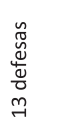 & $\begin{array}{l}0 \\
\tilde{o} \\
\stackrel{5}{5} \\
\frac{3}{\pi} \\
\stackrel{N}{ }\end{array}$ & 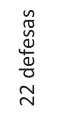 & \multirow{2}{*}{\multicolumn{2}{|c|}{ 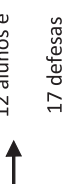 }} \\
\hline & 1997 & & 199 & 9 & 2001 & $T$ & 2003 & & 2005 & & 2007 & 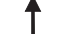 & 2009 & & 2011 & & \\
\hline 1995 & $\downarrow$ & 1998 & $\downarrow$ & 2000 & $\downarrow$ & 200 & $\downarrow$ & 2004 & $\downarrow$ & 2006 & $\downarrow$ & 2008 & 3 & 2010 & $\downarrow$ & 201 & \\
\hline 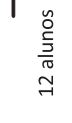 & 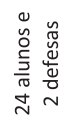 & & $\begin{array}{l}0 \\
\check{0} \\
\stackrel{5}{5} \\
\frac{5}{\pi} \\
\exists \\
\overrightarrow{7}\end{array}$ & 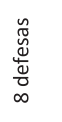 & $\begin{array}{l}0 \\
\tilde{O} \\
\stackrel{5}{N} \\
\stackrel{5}{N} \\
\vec{N}\end{array}$ & 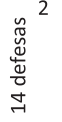 & $\begin{array}{l}0 \\
\tilde{0} \\
\stackrel{5}{5} \\
\frac{5}{\pi} \\
\stackrel{n}{N}\end{array}$ & 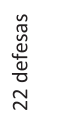 & $\begin{array}{l}0 \\
\tilde{0} \\
\frac{5}{5} \\
\frac{3}{\pi} \\
\end{array}$ & 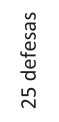 & $\begin{array}{l}0 \\
\tilde{0} \\
\stackrel{0}{5} \\
\frac{3}{\pi} \\
0 \\
0\end{array}$ & 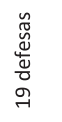 & 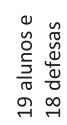 & & 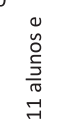 & 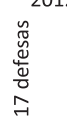 & \\
\hline & & & & & & & & & & & & & & & $\begin{array}{l}\text { riaçãa } \\
\text { Prod }\end{array}$ & & \\
\hline
\end{tabular}

Fonte: Dados do banco de dissertações da UFC, atualizado em julho de 2012.

Figura 1. Linha do Tempo Prodema-UFC

Diversos são os cursos de graduação de origem dos alunos, expondo-se assim a diversidade dos discentes do programa (Figura 2). Profissionais oriundos de 37 diferentes cursos, distribuídos em áreas mais ou menos associadas diretamente às questões ambientais, foram qualificados pelo Prodema-UFC, havendo destaque para os cursos de: Agronomia (24 alunos), Biologia (48 alunos), Direito (25 alunos), Engenharia de Pesca (28 alunos) e Geografia (72), contabilizados no 
período de 1995 a 2012. Com esse perfil, verificam-se quais as áreas que mais buscam a inserção da sustentabilidade na sua profissionalização.

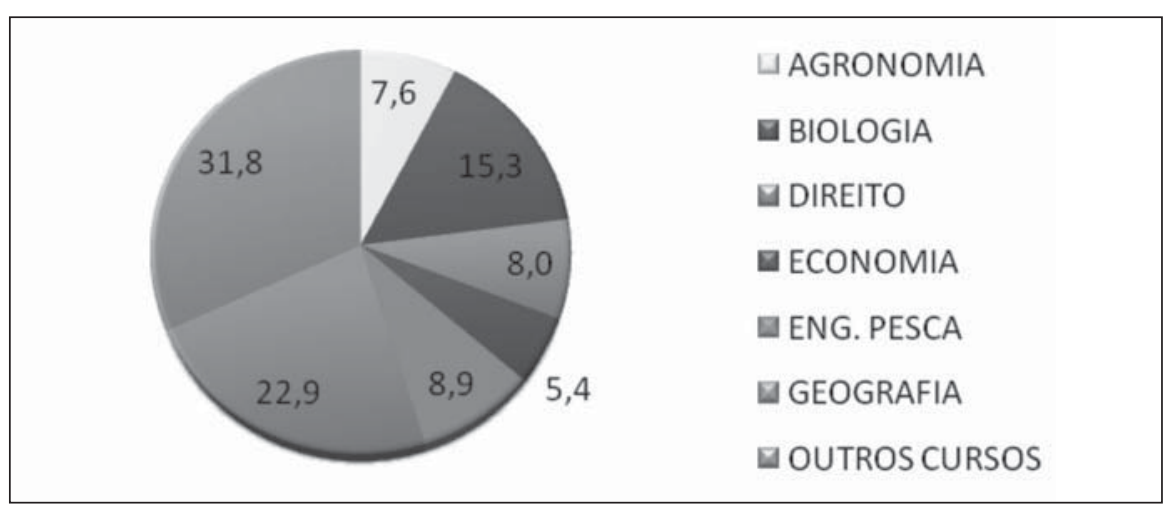

Fonte: Prodema-UFC, dados atualizados em junho de 2012

Figura 2. Distribuição relativa dos discentes selecionados para o mestrado no Prodema-UFC, segundo o curso de graduação, período 1995 a 2012 (\%)

Vale destacar que em 2004 foi criado o mestrado em Geografia; em 2008, o Programa de Ecologia e Recursos Naturais; e, em 2009, o doutorado em Geografia. E mesmo com essas novas pós-graduações na UFC, que inserem em suas especialidades um viés de sustentabilidade, a busca pela interdisciplinaridade trabalhada pelo Prodema-UFC cresceu. No ano de 2008, dos 20 alunos que entraram, 10 possuíam a graduação em Geografia e três em Biologia.

O conhecimento gerado pela interdisciplinaridade envolve uma subjetividade improvável de ser quantificada. No entanto, a categorização das 266 dissertações defendidas no período de 1997 a 2012, nas diferentes temáticas priorizadas pela Rio+20 - água, cidades sustentáveis, desastres naturais e mudanças climáticas, economia verde e inclusão social, energia sustentável, oceanos, segurança alimentar e agricultura orgânica -, apresenta a contribuição do programa na busca por um modelo mais sustentável para a região (Figura 3). As categorias desenvolvimento rural, formação de recursos humanos e gênero devemse à necessidade regional do programa. 


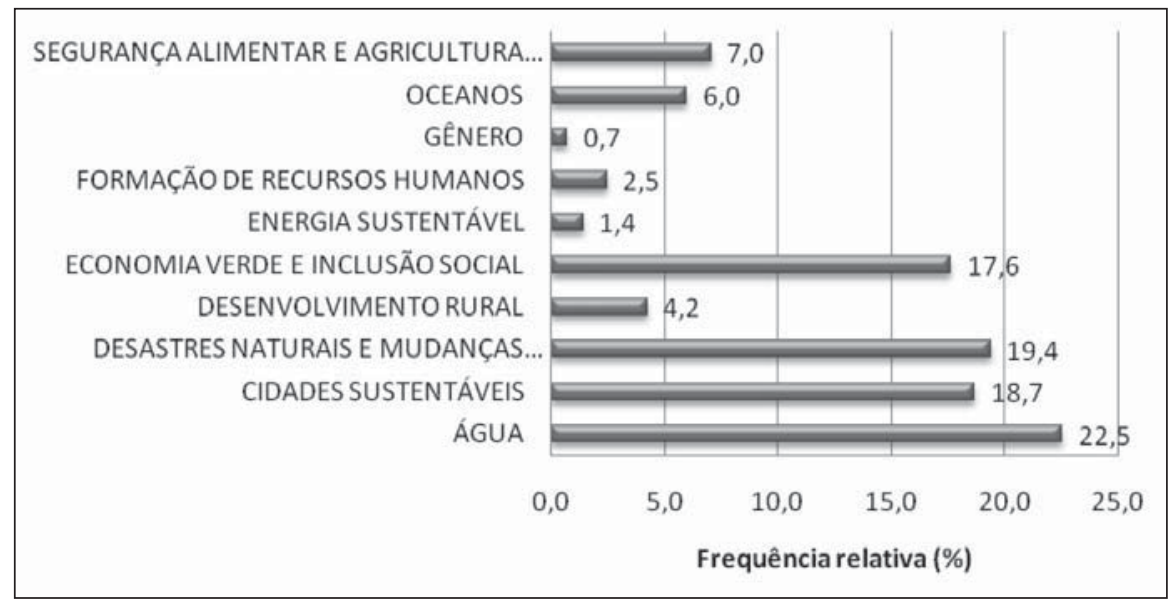

Fonte: Prodema-UFC, dados atualizados em junho de 2012.

\section{Figura 3. Distribuição relativa das dissertações defendidas no Prodema- UFC segundo as temáticas da Rio+20 (turmas de 1995 a 2010)}

Esses temas estão intimamente relacionados às vulnerabilidades socioeconômicas e ambientais do estado do Ceará, principal objeto de estudo do programa. A inserção do estado do Ceará no bioma caatinga solicita, para uma convivência com o semiárido, um conhecimento prévio científico que possa subsidiar as tomadas de decisões. Ao longo de sua história, as pesquisas desenvolvidas pelo Prodema-UFC priorizaram as seguintes categorias: água, cidades sustentáveis, desastres naturais e mudanças climáticas e economia verde e inclusão social; inerentes às preocupações locais, essas categorias também se inserem nas atenções globais, ao serem priorizadas na Rio+20. Embora muitas das temáticas trabalhadas pelos mestrandos possam ser incentivadas pelos grupos de pesquisas, liderados pelos docentes, outras já adentram o programa pela necessidade profissional do aluno. Percebe-se assim a contribuição do programa não somente em concretizar um estudo científico sobre objetos de pesquisa que possam inserir essa transição ao desenvolvimento sustentável, mas ao preparar também esse novo profissional, instigando-o criticamente a quebrar paradigmas.

\section{b. Evoluções e limites da interdisciplinaridade}

No Prodema-UFC, são percebidas três dimensões distintas que potencializam a interdisciplinaridade em um curso de pós-graduação: 
uma interação entre os discentes de diferentes formações, entre discentes e docentes e, finalmente, entre docentes.

Atualmente, o quadro de docentes do Prodema-UFC é composto por 24 professores, distribuídos em nove departamentos da Universidade Federal do Ceará: Biologia, Economia Doméstica, Economia Agrícola, Educação, Engenharia Agrícola, Geografia, Geologia, Medicina e Solos. Quanto aos discentes, considerando-se as turmas anuais de 1995 a 2012, são provenientes dos mais diversos cursos de graduação.

A interdisciplinaridade que nasce entre os conhecimentos dos discentes, por meio de suas especialidades, advindas de suas graduações, com os docentes e orientadores - com sua bagagem departamental - é uma das mais complexas. Nesse processo, é obvio que o trabalho acadêmico flui melhor quando a graduação do discente insere-se nas áreas abrangidas pelo departamento do orientador. Contudo, a interdisciplinaridade é mais bem vivenciada quando as áreas aparentam discordância, como, por exemplo, um docente biólogo com um orientador economista. A desconstrução do saber e as dúvidas sobre o objeto de estudo são redescobertas pelos pares, que, em geral, solicitam um terceiro membro - coorientador - para equilibrar o diálogo. Dessa experiência, o discente é quem obtém o melhor resultado interdisciplinar, por ser ele o recurso humano formado na pós-graduação. Embora os docentes também aprendam com as descobertas de seus alunos, um pós-graduado interdisciplinar absorverá melhor, sem preconceitos metodológicos, a fusão de novos olhares para velhos problemas do mundo.

O Prodema-Rede possui duas áreas consideradas no programa como básicas a serem interligadas - a Economia e a Ecologia - pelas suas disciplinas de tronco comum. No mestrado, são três as disciplinas, com ementas, programas e bibliografia básica iguais para a rede e ajustados, a depender das necessidades locais, pelos docentes responsáveis. Nesse formato, as disciplinas são trabalhadas localmente e ministradas geralmente com outro docente local. A função dessas disciplinas não é apenas o de repasse de conhecimentos, mas também a necessidade de uma construção crítica na perspectiva do desenvolvimento sustentável. 
No formato do doutorado, houve um avanço. Por ser institucionalizado perante a Capes, o formato rede possibilita um melhor diálogo entre os docentes e as disciplinas das diversas IES que compõem o Prodema-Rede. 0 tronco comum é formado por quatro disciplinas, em que três são as mesmas compartilhadas no mestrado e apenas uma é exclusiva do doutorado. Essa disciplina exclusiva é ministrada, anualmente, na IES escolhida para a aula magna do curso, sendo obrigatoriamente trabalhada por no mínimo dois docentes. Esse é um ponto importante a ser mais bem analisado: a interação interdisciplinar entre docentes.

A construção interdisciplinar do curso de mestrado forneceu subsídio ao curso de doutorado para se perceber a importância do "dividir para somar”, ao se ministrar uma disciplina a ser trabalhada em um viés interdisciplinar. Se em um curso local se buscava essa interdisciplinaridade entre departamentos, em um curso de rede interinstitucional a interdisciplinaridade vem também com a interdepartamentalização, influenciada pela cultura organizacional da IES de origem do docente.

O planejamento de uma disciplina nesse formato, quando trabalhada de forma local, se dá de forma presencial entre docentes de diferentes departamentos da mesma instituição e de acordo com a proximidade profissional. Porém, quando incorpora docentes de diferentes instituições, como no caso do doutorado, nem sempre existe a proximidade profissional, devido ao tamanho do Prodema-Rede em si. A inserção da interdisciplinaridade nesse formato traz alguns fatores limitantes, entre os quais a própria disciplinaridade dos docentes, além dos valores de formação educacional compartilhados pelas IES de origem desses docentes participantes. Contudo, em ambos os casos, existe dificuldade em encontrar docentes com formação holística e sistêmica.

Para os discentes, a interdisciplinaridade entre docentes de uma mesma instituição traz um novo olhar para a própria instituição, antes vista apenas de forma fechada em seus departamentos, haja vista que a interdisciplinaridade entre docentes de diferentes instituições traz uma riqueza imensurável para o aprendizado, principalmente quando trabalhada por docentes de áreas de conhecimento que aparentemente 
seriam antagônicas. O grande desafio no modelo de pós-graduação interinstitucional são os custos financeiros, principalmente relativos às disciplinas, que requerem o deslocamento físico dos discentes matriculados e respectivos docentes para uma das IES da rede.

O Prodema-UFC não está vinculado a nenhum departamento e não possui nenhum curso de graduação. Sua vinculação com a UFC é diretamente com a Pró-Reitoria de Pesquisa e Pós-Graduação. Esse fator permitia, em seu projeto inicial, que a filosofia do curso perpassasse por qualquer departamento. Contudo, diante de uma estrutura organizacional departamental, em que as alocações de recursos financeiros ou humanos assim também são distribuídos, os 18 anos de programa não foram suficientes para a construção de um espaço físico para o Prodema-UFC.

A não vinculação a um departamento também traz outras variáveis importantes a serem refletidas, principalmente diante da nova demanda pelos cursos de pós-graduação no Brasil, sejam eles inter ou disciplinares. De 1995 até o ano de 2010, houve um grande salto na quantidade de alunos que ingressaram nas universidades, inclusive na busca por um título de mestre ou doutor. Essa demanda também requisita uma maior dedicação do docente a seu departamento de origem. Se o ProdemaUFC não está ligado a nenhum departamento e não possui graduação acoplada, a dedicação de seus docentes tende a ser cada vez menor, diante das urgências departamentais no cumprimento de suas metas com a IES.

Além das disciplinas de tronco comum e das optativas, inserem-se, na estrutura curricular do Prodema-Rede, os seminários integradores, cuja proposta é fornecer um diálogo interdisciplinar entre discentes, docentes e convidados especiais acerca das pesquisas de dissertações e teses dos docentes. São três os números de seminários a constar na proposta, em que o II Seminário Integrador, para o mestrado, e o I Seminário de Tese, para o doutorado, ocorrem ambos em Rede, com a participação de todos os alunos matriculados nesse período, transformando-se em um evento científico regional de todas as IES associadas. Essa "babel acadêmica” possibilita, principalmente entre 
os discentes, o contato com os diversos trabalhos e, muitas vezes, o conhecimento de novas formas metodológicas de analisar objetos de estudos semelhantes.

A visibilidade do Prodema-Rede cresceu em número de alunos e de IES participantes. Hoje, existe a participação de alunos não somente da região Nordeste, mas de todo o Brasil, e, desde 2009, diversos alunos dos países de língua portuguesa, principalmente na UFC, estão internacionalizando o curso, o que torna o desafio interdisciplinar ainda maior, devido à inserção também da variável cultural, que faz parte desse processo.

\section{Conclusões}

A universidade, ao formar recursos humanos e gerar conhecimentos, pode contribuir para a transição do desenvolvimento sustentável, passando do embate teórico-conceitual para a busca de sua aplicabilidade. Precisa-se rever o real papel do ensino superior nessa jornada e habilitar as universidades a se tornarem modelos de práticas sustentáveis transformadoras, inserindo a sustentabilidade na arquitetura de suas instalações físicas, nos modelos de gestão e principalmente em seus currículos de ensino, pesquisa e extensão.

Uma IES que não insere em sua missão a prioridade no desenvolvimento sustentável não pode formar líderes em sustentabilidade ou fazer ciência para a sustentabilidade. Trazer novas respostas tecnológicas e socioeconômicas na resolução de problemas nas áreas de produção e desenvolvimento, entre eles, a transição para o desenvolvimento sustentável, é hoje responsabilidade social das universidades.

A interdisciplinaridade é o ponto de partida na abordagem necessária dessa transição. Adotada por um grupo de pesquisadores desbravadores do Prodema-Rede, desde a década de 1990, verificase, ao longo dessa jornada, que muito se aprendeu com a prática interdisciplinar, não se findando; pelo contrário, transformando-se, com novos e antigos desafios. 
O Prodema-Rede apresenta como diferencial e maior contribuição à experiência da interdisciplinaridade na pós-graduação, como tentativa de aprofundar o debate sobre um dos temas mais discutidos e complexos das últimas décadas, o Desenvolvimento Sustentável.

Ao reunir docentes e discentes com diferentes formações acadêmicas, o Prodema-UFC ultrapassou a expectativa de interdisciplinaridade e criou um ambiente favorável à quebra de paradigmas na formação de recursos humanos ao apontar, por meio de dissertações defendidas, mudanças possíveis nos setores produtivos e na sociedade.

Essa experiência vem contribuindo para inserir a questão do desenvolvimento sustentável nos currículos acadêmicos das universidades. No entanto, há, ainda, grandes desafios. Preparar o novo profissional de sustentabilidade e estimular a criação de ciência e tecnologia capazes de transpor as barreiras existentes para a efetivação da economia verde talvez seja o maior deles. Tal desafio demanda urgência na implementação dos princípios inseridos na Educação para a Sustentabilidade.

Recebido 25/11/2012 Aprovado 25/07/2013

\section{Referências bibliográficas}

AGENDA 21 GLOBAL. Conferência das Nações Unidas sobre Meio Ambiente e Desenvolvimento. Capítulo 36: promoção do ensino, da conscientização e do treinamento. Disponivel em: <http:/ / www.mma. gov.br/responsabilidade-socioambiental/agenda-21/agenda-21global/item/716>. Acesso em: 17 jun. 2012

ALVARENGA, A. T. de; SOMMERMAN, A.; ALVAREZ, A. M. de S. Congressos Internacionais sobre Transdisciplinaridade: reflexões sobre emergências e convergências de idéias e ideais na direção de uma nova ciência moderna. Saúde e Sociedade, São Paulo, v. 14, n. 3, set./dez. 2005. 
BÜRGENMEIER, B. Economia do Desenvolvimento Sustentável. Lisboa: Instituto Piaget, 2005.

FAZENDA, I. C. A. Interdisciplinaridade: História, teoria e pesquisa. Campinas, SP: Papirus, 1994.

FOLLAN, R. A. Interdisciplinaridade e Dialética: sobre um mal-entendido. In: FRIGOTTO, G. et al. Interdisciplinaridade: para além da filosofia do sujeito. Petrópolis, RJ: Vozes, 1995. p.127-141.

GROOT. H. T. de. Environmental science Theory. Concepts and methods in a one-world, problem-oriented paradigm. Centre for Environmental Studies. University of Leiden. Netherlands: Elsevier, 1992.

JAPIASSU, H. Dicionário Básico de Filosofia. 4 ed. atual. Rio de Janeiro: Jorge Zahar Ed., 2006.

KLEIN, J. T. Interdisciplinarity: history, theory and practice. Detroit, Michigan: Wayne State University Press, 1990.

LEFF, E. Complexidade, Interdisciplinaridade e Saber Ambiental. In: PHILIPPI JR, A. Interdisciplinaridade em Ciências Ambientais. São Paulo: Signus Editora, 2000. p. 19-51.

Epistemologia ambiental. São Paulo: Cortez, 2002.

LEFF, E.; MONTES, J. M. Los problemas del conocimiento y la perspectiva ambiental del desarrollo. Mexico: Siglo Veintiuno, 1986.

MANGINI, F. N. da R.; MIOTO, R. C. T. A interdisciplinaridade na sua interface com o mundo do trabalho. Revista Katálysis, Florianópolis, v. 12, n. 2, p. 207-215, dez. 2009.

MINAYO, M. C. S. Interdisciplinaridade: funcionalidade ou utopia? Saúde e Sociedade, v. 3, n. 2, p. 42-64, 1994.

MORIN, E. Os sete saberes necessários à educação do futuro. 2. ed. São Paulo: Cortez; Brasília, DF: UNESCO, 2000. 
PAVIANI, J. Interdisciplinaridade: conceitos e distinções. 2 ed. Caxias do Sul, RS: Edusc, 2008.

PENA-VEGA, A.; ALMEIDA, E. P. de. O pensar complexo: Edgar Morin e a crise da modernidade. Rio de Janeiro: Garamond, 1999.

PIMENTA, C. Contributos para a elaboração de uma tese interdisciplinar. Revista do Centro de Educação e Letras, v. 10, n. 1, p. 63-77, 2008.

POMBO, O. Interdisciplinaridade e integração dos saberes. Liine em Revista, v. 1, n. 1, p. 3-15, mar. 2005.

POMBO, O.; LEVY, T.; GUIMARÃES, H. A interdisciplinaridade: reflexão e experiência. 1. ed. Lisboa: Ed. Texto, 1993.

RAMALHO FILHO, R. A. Seminário Fundacional: Desenvolvimento e Meio Ambiente - Agenda 21 para o Nordeste do Brasil. Maceió: Prodema/ Ufal, 1999. 431p.

REPKO, A. F. Interdisciplinary research: process and theory. 2. ed. USA: Sage, 2012.

ROHDE, G. M. Epistemologia Ambiental: uma abordagem filosóficocientífica sobre a efetivação humana alopoiética da Terra e de seus arredores planetários. 2 ed. rev. e ampl. Porto Alegre: EDIPUCRS, 2005.

ROSSATO, R. Universidade: nove séculos de história. Passo Fundo: Ediupf, 1998.

TOZONI-REIS, M. F. C. Educação ambiental: natureza, razão e história. Campinas, SP: Autores Associados, 2004.

TRINDADE, D. F. Interdisciplinaridade: um novo olhar sobre as ciências. In: FAZENDA, I. 0 que é interdisciplinaridade? São Paulo: Cortez, 2008. p. 65-84. 
UNESCO. Década da Educação das Nações Unidas para um Desenvolvimento Sustentável, 2005-2014: documento final do esquema internacional de implementação. Brasília: UNESCO/ OREALC, 2005.

The UN Decade of Education for Sustainable Development (DESD 2005-2014). The First Two Years. Paris: UNESCO, 2007.

Global Higher Education for Sustainability Partnership (GHESP). 2012. Disponivel em: <http://portal.unesco.org/education/en/ev.phpURL_ID=34701\&URL_DO=DO_TOPIC\&URL_SECTION=201.html>. Acesso em: 05 set. 2012.

UNESCO/UNEP. Interdisciplinary Approaches in Environmental Education. Environmental Education Series 14. Paris: UNESCO/UNEP, 1985. 


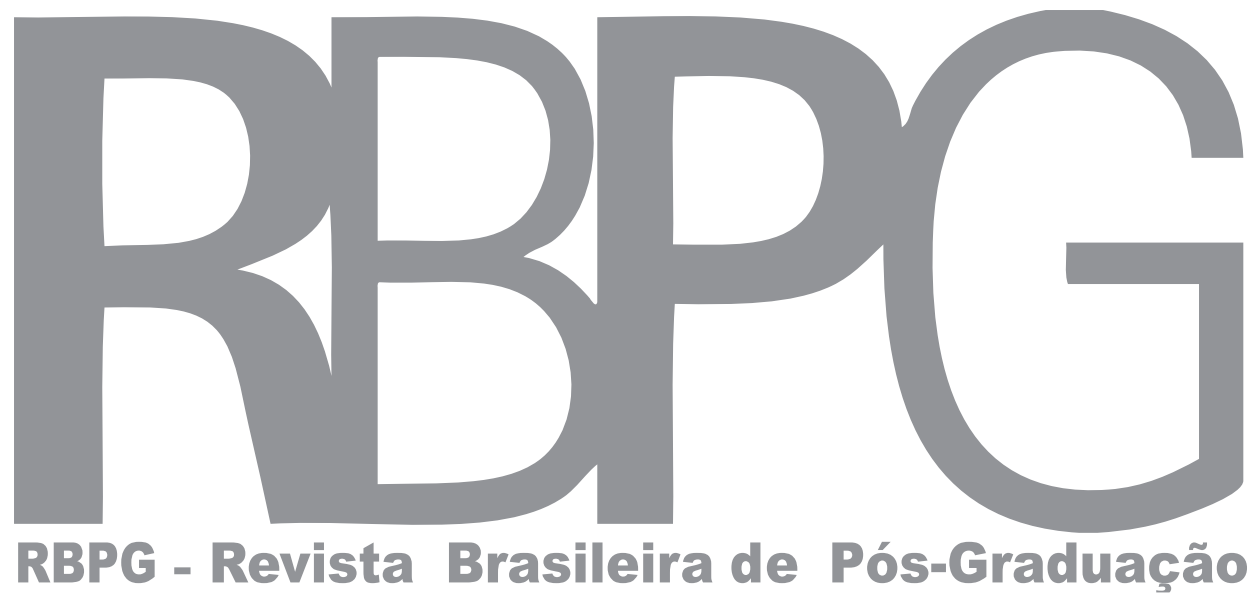




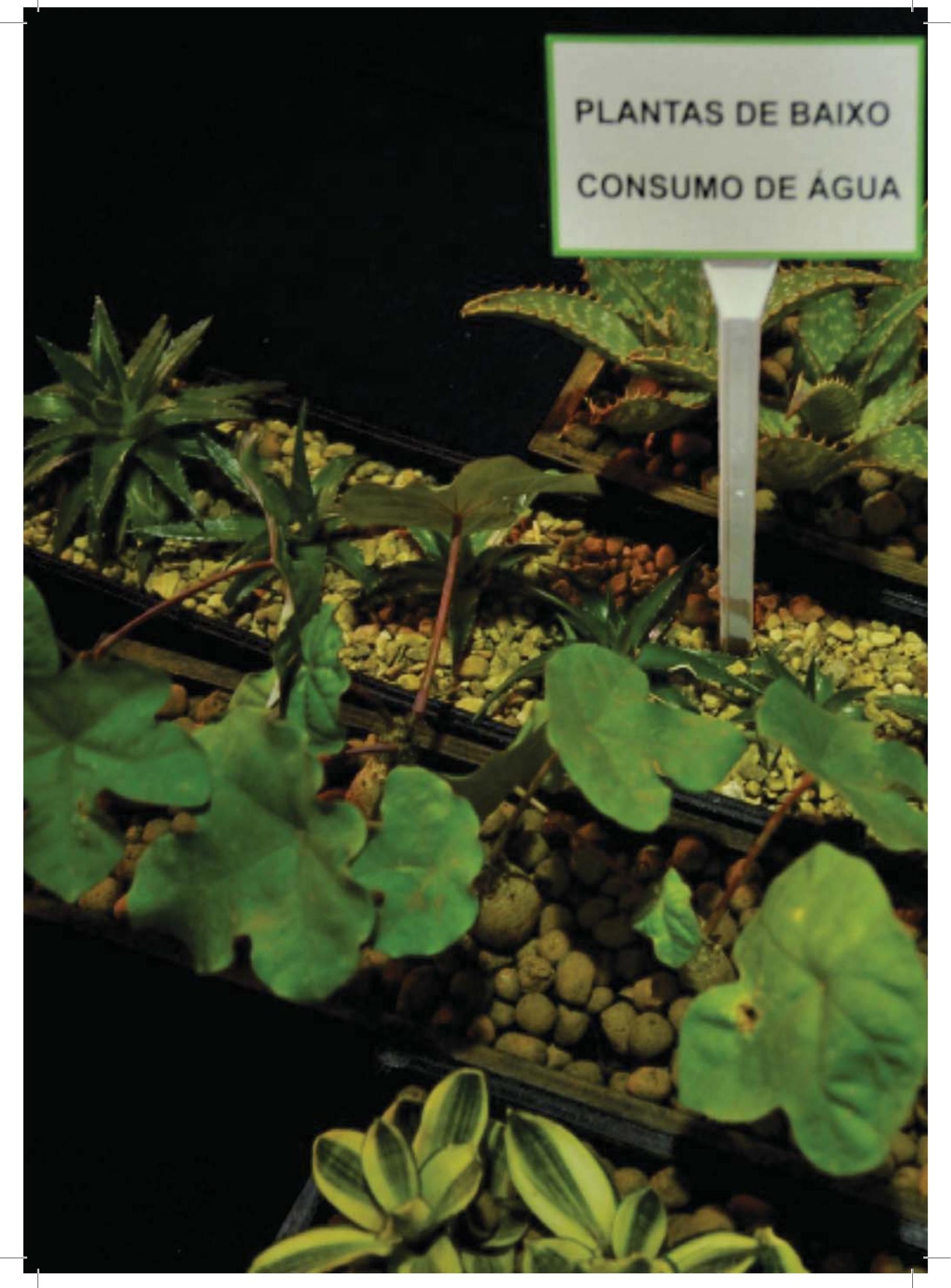




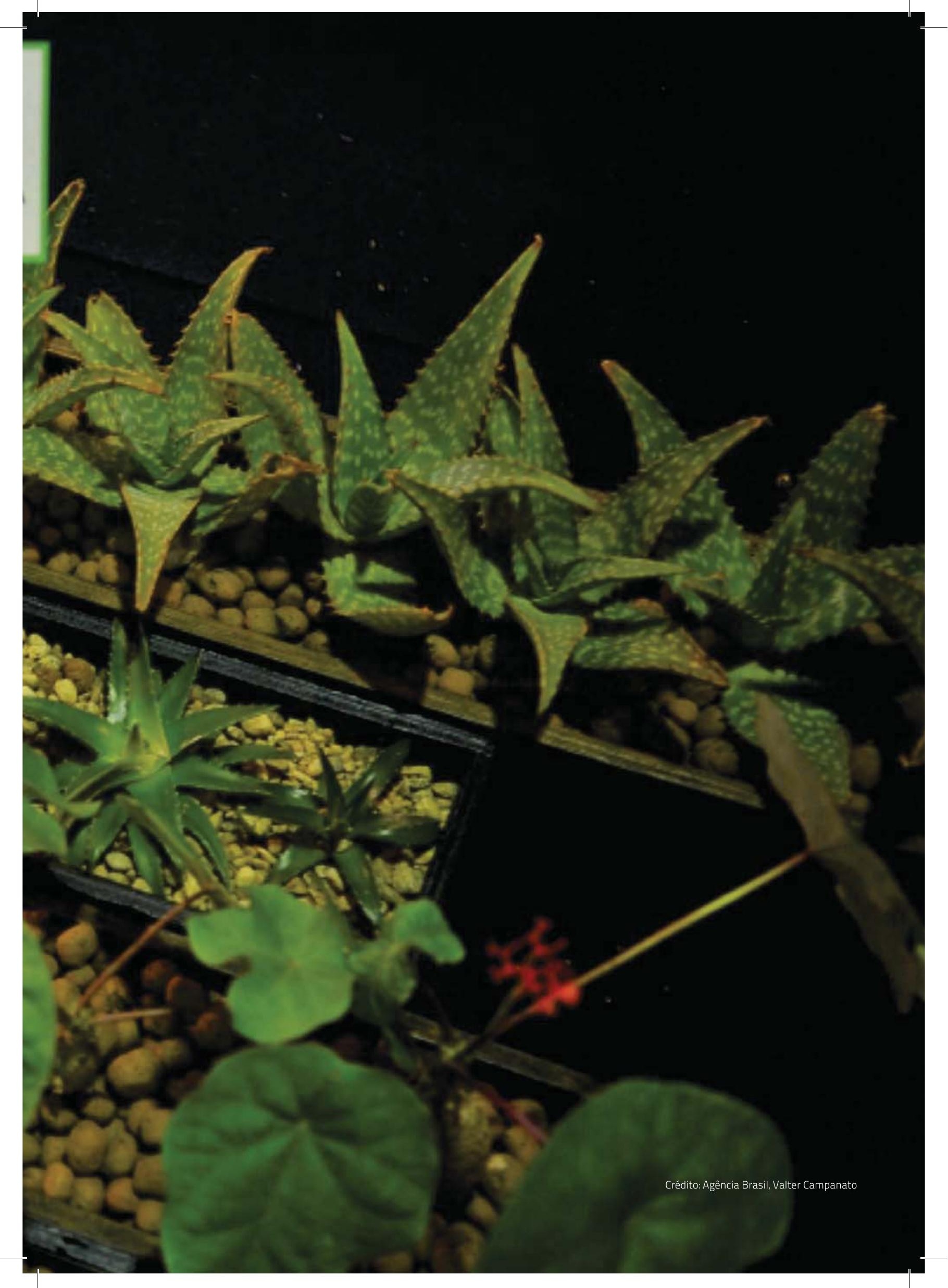


Sustentabilidade e interdisciplinaridade: inovações e desafios dos programas de pós-graduação em Ambiente e Sociedade. 0 caso do Centro de Desenvolvimento Sustentável da Universidade de Brasília

Sustainability and interdisciplinarity: innovations and challenges for graduate programs in Environment and Society. The case of the Center for Sustainable Development at the University of Brasilia

La sostenibilidad y la interdisciplinariedad: innovaciones $y$ retos de los programas de posgrado en Medio Ambiente y Sociedad. El caso del Centro para el Desarrollo Sostenible de la Universidad de Brasilia

Elimar Pinheiro do Nascimento, professor associado II do Centro de Desenvolvimento Sustentável da Universidade de Brasília (CDS/UnB). Endereço: Rua Espírito Santo, 14 - Vila Planalto. CEP: 70803-260 - Brasília, DF. E-mail: elimarcds@gmail.com.

Mauricio Amazonas, professor adjunto do Centro de Desenvolvimento Sustentável da Universidade de Brasília. Endereço: Centro de Desenvolvimento Sustentável (CDS), Universidade de Brasília. Campus Universitário Darcy Ribeiro. CEP: 70904-970 - Brasília, DF. Telefone: 3107-6000/ 6001. Fax: 3107-5972. E-mail:mauricioamazonas@uol.com.br.

Andréa Vilhena, doutoranda do CDS. Endereço: Centro de Desenvolvimento Sustentável (CDS), Universidade de Brasília. Campus Universitário Darcy Ribeiro. CEP: 70904-970 - Brasília, DF. Telefone: 3107-6000/ 6001. Fax: 3107-5972. E-mail: melvilhena@gmail.com. 


\section{Resumo}

Realizada pela ONU em 1992, a Conferência sobre Desenvolvimento e Meio Ambiente consagra a noção de Desenvolvimento Sustentável, nascida na década anterior. Três anos depois, surge o Centro de Desenvolvimento Sustentável da Universidade de Brasília (CDS/UnB), que antecede o boom dos programas de pósgraduação interdisciplinares e se insere no crescimento de programas voltados à relação entre ambiente e sociedade. 0 presente artigo reflete sobre algumas das inovações e desafios desse centro, que construiu sua identidade no binômio sustentabilidade e interdisciplinaridade. Portanto, aborda essas duas noções antes de adentrar a trajetória específica do centro em seus componentes de inovação e desafios. Como considerações finais, o artigo apresenta uma reflexão sobre o novo desenho do campo da sustentabilidade e os desafios para os programas de pós-graduação que lidam com o tema.

Palavras-chave: Sustentabilidade. Interdisciplinaridade. Pesquisa. Inovação.

\section{Abstract}

Held by the UN in 1992, the Conference on Environment and Development reinforces the concept of Sustainable Development, born in the preceding decade. Three years later the Center for Sustainable Development was established at the University of Brasilia (CDS/UNB), which has witnessed a boom of interdisciplinary graduate programs as part of a growing trend among other academic units dealing with the relationship between environment and society. This article reflects on some of the innovations and challenges faced by CDS, which proclaims its identity built on the binomial "sustainability and interdisciplinarity". It therefore addresses both notions before discussing the specific path of the Center with respect to its components of innovation and challenges. As concluding remarks, the article presents thoughts on the new design of the field of sustainability and on the challenges facing graduate programs that deal with this matter.

Keywords: Sustainability. Interdisciplinarity. Research. Innovation. 


\section{Resumen}

Realizada por las Naciones Unidas en 1992, la Conferencia sobre el Medio Ambiente y el Desarrollo consagra el concepto de desarrollo sostenible, nacido en la década anterior. Tres años más tarde nace el Centro para el Desarrollo Sostenible de la Universidad de Brasilia (CDS/ UNB), antes del boom de los programas de posgrado interdisciplinarios y se inserta en la ampliación del número de programas dirigidos a la relación entre el medio ambiente y la sociedad. Este artículo reflexiona sobre algunas de las innovaciones y los retos de este centro, que ha construido su identidad basada en el binomio sostenibilidad y interdisciplinariedad. Por lo tanto, se refiere a estos dos conceptos antes de tratar de la trayectoria específica del centro en sus componentes de innovación y retos. Como conclusión, el artículo presenta una reflexión sobre el nuevo diseño del campo de la sostenibilidad y los retos para los programas de posgrado que tienen que ver con el tema.

Palabras clave: Sostenibilidad. Interdisciplinariedad. Investigación. Innovación.

\section{Introdução}

O Desenvolvimento Sustentável tornou-se, há um quarto de século, uma referência ímpar no mundo político, empresarial e acadêmico. Governos e organismos multilaterais o escolheram como referência e parâmetro de suas ações, em face do crescimento da consciência ambiental de seus eleitores; empresas o elegeram como marca de sua atividade, em função das pressões dos consumidores; e a academia adotou a ideia criando revistas, programas de pesquisa e formação de alto nível. No terceiro setor, proliferam, atualmente, as organizações que lutam por um novo tipo de desenvolvimento, dedicadas à defesa do meio ambiente, ao combate aos impactos negativos do crescimento econômico e à promoção da igualdade socioambiental.

Movimentos simultâneos, mesmo tendo surgido em espaços diferentes, gradativamente se articulam em torno da tríplice consciência: 
da finitude dos recursos naturais, do esgotamento do modelo de desenvolvimento adotado no pós-guerra e da potencialidade de novas formas de produção do conhecimento. Embora fosse possivel notar a presença de sinais dessa consciência já nas décadas de 50 e 60, será nas duas décadas seguintes que ela assumirá configurações nítidas, disseminando-se na sociedade. Assim, no final do século XX e início do século XXI, dois conceitos ganham proeminência: sustentabilidade e interdisciplinaridade.

É nesse contexto que surge a proposta do Desenvolvimento Sustentável (DS), ainda nos anos 80, ocupando o lugar de sua antecessora, o Ecodesenvolvimento, embora mantendo suas três dimensões estruturais: econômica, social e ambiental. Essa formulação supõe que o Desenvolvimento Sustentável possa ser implantado na medida em que existam: ecoficiência econômica, equidade social e conservação ambiental.

A ideia do DS ganha concretude com os problemas causados pelo uso dos combustiveis fósseis em larga escala, pela dificuldade cada vez maior da coleta e destinação dos dejetos urbanos e pela interferência prejudicial do homem no ciclo natural do nitrogênio. Mas, também, pela escassez e perda de qualidade dos recursos hídricos, pelos riscos da disseminação da energia nuclear, pelo degelo das placas polares e pela elevação do nível do mar, pelo avanço da desertificação e pela perda constante da biodiversidade, entre outros. Assim, o debate teórico articula-se ao monitoramento do meio ambiente e à busca de soluções práticas: desmaterialização produtiva, energia renovável, economia verde, reciclagem e reuso de materiais, prolongamento do ciclo de vida dos produtos e descarbonização da economia, para citar algumas.

Na década da validação pela ONU da ideia de Desenvolvimento Sustentável, na Rio 92, surge o Centro de Desenvolvimento Sustentável da Universidade de Brasília, em 1995. O presente artigo reflete sobre os elementos inovadores de sua trajetória, fundamentada na sustentabilidade e na interdisciplinaridade. Inicialmente, aborda o campo da sustentabilidade em suas múltiplas conotações e, em 
seguida, a experiência da interdisciplinaridade para, depois, adentrar a trajetória específica do centro, destacando seus componentes inovadores e desafios e os obstáculos a serem vencidos. Conclui com uma reflexão sobre um possível futuro do campo da sustentabilidade e seus desafios.

\section{Desenvolvimento e sustentabilidade}

O período do afloramento da ordem burguesa e do pensamento iluminista no século XVIII, em conjunto com as revoluções Agrícola e Industrial inglesa, assistiu à constituição da ordem capitalista a partir da mercantilização da força de trabalho e da propriedade da terra. Nesse contexto, a ciência econômica desponta como um novo campo do conhecimento que, em harmonia com o naturalismo das ciências e do jusnaturalismo iluminista, considera o mundo econômico, assim como seus processos e suas leis, decorrente do mundo natural.

A economia política clássica, com Smith e Ricardo, ao direcionar seu foco de interesse para a vida econômica industrial e para o trabalho, como gerador de valor e riqueza, o faz preservando uma visão de naturalidade das leis econômicas, especialmente em sua relação com a terra. Nesse sentido, é notório o papel desempenhado por Malthus, ao ancorar sua análise das leis econômicas em leis populacionais e de rendimento da terra.

Aos poucos, no entanto, essa nova ciência assiste à cisão entre o mundo natural e o mundo econômico. A partir de Marx e seus sucessores, tornou-se mais e mais evidenciada a "natureza” do capitalismo como algo não natural, mas uma construção social capaz de subjugar e desfigurar o mundo natural. A revolução marginalista neoclássica também dá sua dose de contribuição para reduzir a compreensão da relação entre esses dois mundos, lançando a ciência econômica em um nível de abstração formal tal que acabou por reduzir a natureza a variáveis de equações matemáticas.

Será, contudo, com a II Revolução Industrial, no início do século XX, que efetivamente a ordem econômica se dissocia da ordem natural 
enquanto valor. Desde então, o novo paradigma sociotécnico apoiou-se na produção industrial em série e em massa (o fordismo) e no petróleo como fonte energética, possibilitando um crescimento econômico nunca antes visto. A expansão desse modelo de desenvolvimento aos países periféricos contribuiu para aumentar a assimetria e as desigualdades tanto entre os países como no interior deles (FURTADO, 1974). Ao mesmo tempo, produziu intensa destruição do meio ambiente.

Desde a bomba de Hiroshima, o perigo da dominação econômica, política, militar e de destruição ecológica se torna um só e adquire proporção universal. Não por outro motivo, a crítica social progressivamente construída e que desagua nos anos 60, como na contracultura ou no Maio de 68, é, ao mesmo tempo, crítica ao capitalismo, anti-imperialista, libertária, pacifista... e ecológica.

É nesse contexto que o ambientalismo adentra a agenda pública. Se até então os movimentos em defesa da natureza se caracterizavam mais por uma orientação preservacionista ou de proteção de ecossistemas e de espécies, a partir dos anos 60 o ambientalismo surge identificando a destruição da natureza como intrínseca ao modelo vigente de crescimento econômico. Obras como “A Primavera Silenciosa”, de Rachel Carson (1962), criticando os efeitos da Revolução Verde; “A Bomba Populacional”, de Paul Ehrlich (1968), indicando o perigo da explosão demográfica; e, especialmente, “Limites do Crescimento”, de Meadows et al. (1972), estabelecem o enunciado de uma ideia: a incompatibilidade entre o crescimento econômico e o equilíbrio ecológico. Ou seja, a ideia de uma insustentabilidade estrutural do sistema econômico. Ideia em seguida abordada de maneira distinta e mais consistentemente por Georgescu-Roegen (2012).

O mainstream econômico, em reação ao aflorar da questão ambiental, defende a compatibilidade entre crescimento econômico e recursos naturais e ambientais. Para isso, propõe a incorporação dos elementos naturais e ambientais no sistema de preços, de modo a não constituírem externalidades negativas e serem consideradas suas externalidades positivas. E acredita no potencial do progresso 
técnico em prover a maior eficiência no uso dos recursos naturais e a substituição do capital natural por outras formas de capital, argumento notabilizado por Robert Solow, em 1974, na American Economic Review, e que veio a constituir o que atualmente é conhecido por Sustentabilidade Fraca.

O período gestou ainda a “terceira via”. A ideia de Ecodesenvolvimento, lançada por Maurice Strong na reunião de Estocolmo de 1972 e desenvolvida conceitualmente por Ignacy Sachs (1986), buscou romper tanto com o ideal de crescimento econômico a qualquer custo, quanto com o ideal neomalthusiano de crescimento zero, advogando a necessária interdependência entre crescimento econômico e equilíbrio ecológico. Ao romper com a premissa, comum a ambas as posições antagônicas, de que o desenvolvimento e a preservação ambiental seriam intrinsecamente incompativeis (NOBRE; AMAZONAS, 2002), o Ecodesenvolvimento representa uma ruptura epistêmica e vislumbra um novo caminho para o desenvolvimento baseado no reencontro do mundo socioeconômico com o mundo natural.

A evolução desse processo culminou com a concepção da ideia do Desenvolvimento Sustentável, focado não em questões ecológicas, mas sim de justiça social. Como aparece no Relatório Brundtland, publicado em 1987, o DS é definido como aquele capaz de atender “às necessidades do presente sem comprometer a capacidade das gerações futuras para atender às suas necessidades” (CMMAD, 1991, p. 46).

Com essa definição, ampla e genérica, o conceito se consagra. Do ponto de vista epistêmico, estabelece um marco geral ético, a que os lados econômico e ecológico devem se subordinar. Do ponto de vista concreto e político, abre um guarda-chuva que abriga as mais diferentes correntes de pensamento e ações. Em ambos os casos, isso somente é possível na medida em que o termo mantém-se vago e generalista, permitindo serem-Ihe atribuídos os mais diferentes sentidos. Assim, sua fraqueza conceitual é justamente o que Ihe imprime força histórica e política, permitindo organizar abaixo e dentro de si o núcleo do debate contemporâneo (NOBRE; AMAZONAS, 2002). 
Desenvolvimento Sustentável se torna, portanto, um marco balizador das mais diversas agendas, um princípio paradigmático de valores, conceitos, políticas, instrumentos, técnicas e ações. Seu elevado nível de generalidade, associado à sua relevância social e política histórica, evidencia tanto a necessidade do desenvolvimento científico do conceito e da área do saber a ele associada, como também da formação humana para o fazer agir.

O enfrentamento dessa questão faz com que se abra um campo inovador para o pensamento científico. Mais do que o reconhecimento da existência de um novo campo do saber, a requerer tratamento disciplinar específico e se basear na integração interdisciplinar de outras áreas do saber, a questão do Desenvolvimento Sustentável coloca o quesito da interdisciplinaridade em seu mais amplo nível de requisito. O objeto de estudo a ser tratado interdisciplinarmente consiste tanto no desenvolvimento, ou seja, no processo dinâmico pelo qual a humanidade progride e prospera, com todas suas contradições, como nas relações interativas desse processo com a realidade que o sustenta e o limita, ou seja, a sustentabilidade. Desenvolvimento e sustentabilidade passam, assim, a requerer expertise interdisciplinar para sua compreensão e seu tratamento.

Desenvolvimento, mais do que mero crescimento econômico, consiste no processo dinâmico referido à capacidade de uma sociedade realizar com plenitude e liberdade seus potenciais e suas capacidades constitutivas. Embora seja um processo econômico, não se restringe apenas à dimensão econômica. É constituído pelas múltiplas dimensões sociais, políticas, institucionais, cognitivas (culturais, científicas, tecnológicas), espaciais-territoriais e temporais. No dizer de Furtado,

[...] o crescimento econômico, tal qual o conhecemos, vem se fundando na preservação dos privilégios das elites que satisfazem seu afã de modernização; já o desenvolvimento se caracteriza por seu projeto social subjacente. Dispor de recursos para investir está longe de ser condição suficiente para preparar um melhor futuro para a massa da população. Mas quando o projeto social prioriza a efetiva melhoria das condições de vida desta população, o crescimento se metamorfoseia em crescimento (2004, p. 484). 
Já a sustentabilidade deve ser entendida como um conceito mais amplo do que a manutenção de níveis de atividade dentro da capacidade de suporte de ecossistemas. Afinal, a ideia de sustentação não pode se restringir apenas a variáveis da dimensão ambiental ou ecológica, mas deve considerar todas as condições, naturais e humanas, que sustentam o processo de desenvolvimento. E, sendo este dinâmico e evolutivo, assim também se torna a sustentabilidade, vista em termos de como as condições de sustentação do processo de desenvolvimento são capazes (ou não) de se transformarem dinamicamente de modo a garantirem sua resiliência. Holling, um dos principais formuladores nessa perspectiva, ao desenvolver sua conceituação de dinâmica evolutiva de sistemas, mostra como

\footnotetext{
este processo pode servir para esclarecer o significado de “desenvolvimento sustentável”. Sustentabilidade é a capacidade para criar, testar e manter a capacidade adaptativa. Desenvolvimento é o processo de criar, testar, e manter oportunidade. 0 termo que combina os dois, desenvolvimento sustentável", portanto, refere-se ao objetivo de fomentar capacidades adaptativas e, simultaneamente, criar oportunidades. Portanto, não é um oxímoro, mas um termo que descreve uma parceria lógica (2001, p. 399).
}

Assim, a franca natureza interdisciplinar do objeto fenomênico definido como Desenvolvimento Sustentável coloca a enorme necessidade e o desafio do desenvolvimento científico e da formação humana interdisciplinar para tratá-lo.

\section{0 desafio da interdisciplinaridade}

Disciplina foi a forma como se organizou o conhecimento humano desde os gregos, com Platão (sec. III), Escola de Nalanda na Índia (sec. IV a.C.) e a Jãmi'at al-Qarawiyyin (sec. XIX a.C.)1', no mundo mulçumano, mais precisamente em Marrocos. Essa fragmentação do conhecimento disseminou-se nas universidades europeias a partir do século XI e consagrou-se com a universidade moderna criada por inspiração de Kant (sec. XVIII) e von Humboldt (sec. XIX). Criada para dar ordem e sistematização aos conhecimentos sobre a alma, o corpo

Aliás, criada por uma mulher, Fatima al-Fihri. 
humano e a natureza, imperou, soberana, durante cerca de dois séculos (SANTOS; ALMEIDA FILHO, 2012). Dessa forma, disciplina é entendida como categoria organizacional do conhecimento científico ou, ainda, a identidade social, profissional e epistemológica de diferentes corpos de saberes especializados (MORIN, 2003). Possui, pelo menos, duas características básicas. A primeira, lógica, refere-se a um corpo teórico unificado, intelegível; a segunda, funcional, possibilita organizar a diversidade dos objetos do conhecimento (PENA VEGA, 2008).

Tentativas de complementação, de superação ou, mesmo, de ruptura com a categoria disciplina levaram à formulação, há pouco mais de meio século, das ideias de interdisciplinaridade e de transdisciplinaridade. A noção da interdisciplinaridade tem como proposta ocupar o imenso vazio que separa as diferentes disciplinas. Já a transdisciplinaridade coloca-se em uma posição de ruptura e, assim, de superação do conhecimento disciplinar.

Organizar e trabalhar o conhecimento científico de maneira não disciplinar passa a ocorrer de forma mais sistemática a partir dos anos 60 e, sobretudo, 70, vide o trabalho de Piaget no seminário de 1972, na França; os trabalhos do Centro Nacional de Pesquisa Científica da França (CNRS); e os da UNESCO, no mundo inteiro (APOSTEL et al., 1972). As reflexões e iniciativas, nesse sentido, são particularmente férteis nas décadas seguintes, resultando em um incremento de programas de pós-graduação, de laboratórios de pesquisa, de publicações, mas, também, uma mudança na prática docente em todo o mundo.

Desde então, quatro movimentos centrais ocorreram no ambiente acadêmico:

1. uma crítica ferrenha ao conhecimento disciplinar, denunciando-o como reducionista e limitado, sem contato com a complexidade do mundo real (MORIN, 1973; 2005; MATURANA; VARELA, 1995);

2. novas práticas de pesquisa eensino decaráter interdisciplinar e, mais recentemente, transdisciplinar (PHILIPPI JR; SILVA NETO, 2011);

3. a inserção de temas transversais, inerentemente inter ou transdisciplinares, como mudanças climáticas, 
sustentabilidade e nanobiotecnologia, na estruturacurricular e de poder das instituições de ensino e de pesquisa aplicada (KLEIN, 1990);

4. reflexões sobre essas práticas para formular um corpo teórico propositivo (REPKO, 2008; RIBEIRO, 2010).

Embora haja quase um consenso que o conhecimento disciplinar é útil, e mesmo indispensável, percebe-se, também, que ele se mostra limitado para lidar com fenômenos, problemas e desafios novos, decorrentes da maior complexidade de nossas sociedades e capacidades de produzir informações (FAZENDA, 1994; LEIS, 2001; 2005). A interdisciplinaridade surge, então, como um convite à produção de novos conhecimentos, como uma interlocução com as diversas disciplinas. Como mostram Costa e Nascimento (2012), no estudo de práticas de referência em universidades do Brasil, Chile, da Alemanha e dos Estados Unidos, inúmeras são as possibilidades para a adoção de práticas interdisciplinares no seio das universidades.

A prática da interdisciplinaridade, em alguns casos, traz mais atores para o debate, pois a ampliação de perspectivas inclui novos olhares. Essa é uma concepção para além da coleção de disciplinas propriamente ditas, que promove o enlace entre o saber científico com o conhecimento popular e, assim, proporciona uma ampliação das visões de mundo (DUARTE et al., 2011).

Em parte, a crítica à organização do conhecimento em disciplinas estanques e a busca do exercício da interdisciplinaridade se devem a transformações recentes da sociedade. Primeiro, daquelas advindas de processos ocorridos nos anos 60, como a revolta estudantil de Maio de 68, a revolução feminista, o movimento dos hippies e a revolução cultural, que diversificaram a moralidade dos costumes, disseminaram o consumo de massa, reforçaram o individualismo, valorizaram a cultura do corpo e a apologia do prazer imediato (FREIRE, 2004), colocando, portanto, no centro de nossas preocupações a diversidade comportamental e cognitiva.

Interdisciplinarity is a central topic in the debate about the crisis and the future of the University. Although it is not a new issue, it remains highly relevant. Specialization divided the academic world into hundreds of 
isolated and self-centered fields over the last century. This process was supported and reinforced by the proliferation of specialized journals and by the institutional structure set up for the accreditation, evaluation, and funding of research projects and degree courses. In the wake of thisprocess, interdisciplinarity claims to integrate parts that seem to stay away from each other (BURSZTYN; DRUMMOND, 2013, p. 3).

Mas o novo campo de produção e transmissão do conhecimento emerge, sobretudo, com as mudanças que se iniciam nos anos 1970: a vitória do neoliberalismo, o apogeu da revolução científica-tecnológica (informática, comunicação, robótica) e o renascimento da globalização, que são a base das novas sociedades do conhecimento (UNESCO, 2005), em rede (CASTELLS, 1998) e do risco (BECK, 2001). A velocidade das transformações sociais e inovações chamam a atenção nesse processo.

Ainda nesse contexto, globalização e consciência ambiental ganham vigor nos anos 1980. A consciência ambiental global se amplia com a Conferência Internacional das Nações Unidas no Rio de Janeiro (ECO-92) e, em 1997, com o relatório do Intergovernmental Panel on Climate Change (IPCC).

Há, portanto, uma demanda empírica da sociedade para o desenvolvimento da interdisciplinaridade, assim como há também uma demanda epistemológica, que nasceu com a teoria dos sistemas, ainda no século XIX, mas se disseminou na segunda metade do século XX. E ganhou continuidade, mais recentemente, com a teoria da complexidade e a teoria do caos (PRIGOGINE; STERGERS, 1986; PRIGOGINE, 1996). Contribui, igualmente, para a expansão da interdisciplinaridade o excesso de especialização que o conhecimento disciplinar proporcionou e estimulou nos últimos 40 anos. Essa superespecialização tornou o diálogo difícil, mesmo no interior das disciplinas, e provocou efeitos nefastos, percebidos desde os anos 1960 (ILLICH, 2005).

Com isso, nos anos 80 e 90, sobretudo os programas de pósgraduação e de pesquisa multidisciplinares, interdisciplinares e mesmo transdisciplinares disseminaram-se no mundo inteiro. Um campo do conhecimento que se presta, de forma particular, à interdisciplinaridade 
é aquele que estuda as relações entre o homem e a natureza ou entre as ciências sociais e biológicas (ecológicas inclusive), devido à complexidade das relações envolvidas. Tal campo é denominado por Jolivet (1992) de Espaço do Humano.

Grande parte da criação e do desenvolvimento de programas de ensino e de pesquisa se faz na confluência entre o vivido e o téorico ou epistemológico. É no diálogo entre os dois que se constroem os novos conhecimentos e se desenvolvem as novas práticas pedagógicas. Tal diálogo possibilita evitar o monopólio de um ponto de vista único. Não existe “a” teoria da interdisciplinaridade ou da transdisciplinaridade. Tão pouco existe um paradigma dominante mundialmente e aceito consensualmente, mas proposições diversas provindas de autores distintos como Morin (2005), Maturama e Varela (1995), Leff (2002)...

As novas práticas pedagógicas exigem uma postura não dogmática em relação às teorias, aos conceitos, às escolas ou aos autores. Exigem a disposição de se romper fronteiras. A ousadia de se buscar o novo. De querer inventar e inovar. Afinal, as teorias são ideias que surgem da reflexão humana sobre o seu contexto e suas práticas. No campo da ciência, elas não são sagradas. São, sobretudo, mas não só, instrumentais e servem para produzir conhecimentos novos e consistentes dos pontos de vista empírico e argumentativo. E a possibilidade mais interessante que a interdisciplinaridade nos oferece, ao dispor de uma maior amplitude conceitual e instrumental, é a de enfrentar a inesgotável capacidade de perguntarmos mais e de modo mais qualificado.

\section{0 perfil do CDS²}

O Centro de Desenvolvimento Sustentável da Universidade de Brasília(CDS/UnB)éumespaçoacadêmico quevisaformarcompetências e produzir novos conhecimentos no campo da sustentabilidade. Sua missão é promover a ética da sustentabilidade por meio do diálogo entre saberes, da construção de novos conhecimentos e da formação de competências.

2 Este item e o seguinte foram inspirados em Drummond e Nascimento (2010a; 2010b). 
Criado em dezembro de 1995, sob inspiração do professor Cristovam Buarque, como um centro interdisciplinar subordinado diretamente ao reitor da Universidade de Brasília, é hoje reconhecido como uma unidade de ensino, pesquisa e extensão com ênfase na pósgraduação.

As atividades de ensino do CDS iniciaram-se, em 1996, com a criação do Programa de Pós-Graduação (PPG-CDS). Começou com um curso de doutorado e, em seguida, ampliou para cursos de mestrado, acadêmico e profissional, e de especialização em Desenvolvimento Sustentável. Cinco anos depois, foram criados mestrados interinstitucionais. Em 2009, o centro ampliou sua atuação acadêmica, criando com o departamento de Economia e os institutos de Química, Geociências e Biologia da UnB um curso de graduação em Ciências Ambientais. Em 2010, criou o Programa de Pós-Doutoramento em Desenvolvimento Sustentável. Em resumo, hoje o CDS está presente nas atividades docentes da graduação ao pós-doutoramento.

Um dos pioneiros na área de sustentabilidade, o PPG-CDS formou, até junho de 2013, cerca de 200 estudantes nos seus cursos de especialização, 495 mestres e 145 doutores. Além disso, concedeu seis certificados de pós-doutorado.

A seleção para ingresso nesses cursos sempre contou com forte concorrência, entre outras razões pelo reconhecimento acadêmico do CDS (com conceito 5 na Capes desde 2004), pelo crescimento da questão ambiental na sociedade brasileira, pelo surgimento de mercados de trabalho específicos que exigem pessoal de alta qualificação, pela escassez de cursos semelhantes no País e, finalmente, pela aceitação de candidatos formados em todas as áreas de saber. A localização do CDS na capital federal oferece, também, mais facilidades para atrair estudantes de todas as regiões brasileiras. Duas ações específicas têm contribuído para a grande procura do CDS pelos candidatos a mestrado e doutorado: o fluxo de alunos especiais nas disciplinas optativas e as Quartas Sustentáveis, ciclo de palestras aberto à participação do público em geral. 
Atualmente, o CDS e seu programa de pós-graduação possui 15 projetos de pesquisa em andamento, com participação de estudantes e pós-doutorandos. Esses projetos são desenvolvidos no âmbito de Redes, Laboratórios e Observatórios que se ocupam de mudanças climáticas, políticas púbicas, unidades de conservação, energias alternativas, sustentabilidade e inclusão social na construção civil e no turismo, na tecnologia social e complexidade. Algumas dessas unidades têm caráter internacional.

No terreno da consolidação cientítica da área de Sustentabilidade, o CDS lançou em 2010 a revista Sustentabilidade em Debate, que coordena e que vem adquirindo rápido reconhecimento em virtude da qualidade de seus artigos, de sua regularidade e de sua ampla circulação.

Depois de 12 anos funcionando fora do campus principal da UnB, o CDS mudou-se para lá em meados de 2008, embora ainda em instalações provisórias. Em 24 de outubro de 2012, o CDS inaugurou seu prédio próprio de $1.430 \mathrm{~m}^{2}$.

\section{Inovações e desafios acadêmicos}

O esforço na busca de uma solidez conceitual sobre as questões do desenvolvimento e da sustentabilidade e de uma prática interdisciplinar na formação de seus quadros e na produção de novos conhecimentos tem sido constante nos 16 anos de existência do CDS.

Na busca de tal êxito, a viabilização estratégica da construção interdisciplinar do tratamento da sustentabilidade pelo CDS ocorre nas seguintes fronteiras:

1) A estrutura e grade curricular de seu Programa de PósGraduação, nas diferentes modalidades;

2) As linhas de pesquisa, projetos de pesquisa e grupos de pesquisa;

3) As duas exigências fundamentais na docência e na pesquisa dos mestrandos e doutorandos: interdisciplinaridade e sustentabilidade; 
4) A formação e produção interdisciplinar do corpo docente e de pesquisadores;

5) A atuação na construção e sustentação do curso de graduação em Ciências Ambientais, em consórcio multidisciplinar e interdepartamental;

6) O arco de cooperações e parcerias nacionais e internacionais; e

7) A gestão estratégica e participativa do Centro.

O CDS, como citado anteriormente, tem dois programas, um acadêmico, com mestrado e doutorado, e outro profissional, com mestrado. Aqui vamos abordar, sobretudo, a experiência do programa de pós-graduação acadêmico, na medida em que ele tem mais tempo e, sobretudo, continuidade, o que será feito seguindo a ordem dos sete pontos acima referenciados.

\section{Grade curricular}

No que toca a estrutura e grade curricular, o programa acadêmico de pós-graduação do centro está estruturado, como de praxe, em disciplinas obrigatórias e optativas. No caso das primeiras, divide-se em dois eixos: um teórico, em torno da compreensão e do aprofundamento dos conceitos básicos de desenvolvimento e de sustentabilidade, a partir das teorias econômicas, sociais e de ciências naturais; e um segundo eixo de caráter normativo e instrumental, relativo à política e gestão em sustentabilidade e à elaboração do projeto de dissertação/tese, em que metodologicamente são trabalhados os fundamentos e os projetos de todos os alunos de modo a atenderem as exigências conceituais da temática e da interdisciplinaridade. No que se refere às disciplinas optativas, o aluno encontra um conjunto diverso de disciplinas, a maioria de caráter interdisciplinar, em torno da temática do Desenvolvimento Sustentável, que o aluno cursará conforme as necessidades postas por seu projeto de pesquisa.

Atualmente, o programa está em a sua terceira grade curricular, buscando avanços em relação às duas anteriores. Tal busca visa um 
maior equilíbrio em três frentes estratégicas. A primeira refere-se à forma de contemplar os conceitos básicos da formação, especialmente os de desenvolvimento e sustentabilidade. Embora seja claro no programa o entendimento de que tais conceitos são estruturantes, a forma de contemplá-los na grade não os efetiva rigorosamente. Diferentes perspectivas sobre o sentido do desenvolvimento e da sustentabilidade, assim como de suas implicações em temáticas específicas, produzem respostas, por vezes, que tendem a um almágama ou uma justaposição de conceitos e conhecimento. Em que pese a importância da pluralidade de visões para a sustentação e evolução de tal base epistêmica - fato que efetivamente se mostra virtuoso no CDS -, faz-se necessário contudo que tal construção se dê de forma sistemática para tornar-se mais efetiva. A segunda diz respeito à forma de enfatizar a indisciplinaridade, tendo sido contemplada distintintamente nas diversas grades curriculares. Na grade atual, prevalece a interdisciplinaridade no âmbito das ciências sociais (análise socioeconômica), havendo ainda um espaço necessário de ser pavimentado de maior interação interdisciplinar desse âmbito com o das ciências naturais e exatas. Finalmente, a terceira frente diz respeito à necessidade de avanço de um núcleo instrumental metodológico integrado. Se, por um lado, o CDS reúne acúmulo de vários anos no aprofundamento da temática epistêmica no campo da interdisciplinaridade e da complexidade, por outro lado, ainda se faz necessária sua extensão para o plano instrumental, produzindo uma oferta mais estruturada e integrada de metodologias qualitativas, quantitativas e mistas. Tais metodologias têm sido tratadas em iniciativas individualizadas e de forma não sistemática.

Embora não diga respeito especificiamente às práticas de interdisciplinaridade, uma atividade inovadora consistiu na criação recente de disciplina optativa voltada para a redação de textos científicos. O pré-requisito para a participação dos alunos é o de ter um texto escrito de sua autoria, preferencialmente com a co-autoria do seu orientador, que é trabalhado ao longo da disciplina. A aprovação na disciplina está atrelada não apenas ao desenvolvimento dos textos, em atividades individuais e coletivas, mas também à submissão a periódicos científicos bem qualificados. 


\section{Linhas, projetos e grupos de pesquisa}

No tocante à estruturação da pesquisa produzida pelo centro, ela se organiza em três campos de conhecimento associados às dimensões estruturantes do Desenvolvimento Sustentável enquanto episteme e enquanto campo de ação. Ignacy Sachs defende que o Desenvolvimento Sustentável deve ser compreendido a partir da sustentabilidade dos processos de desenvolvimento em cinco dimensões (SACHS, 1993); posteriormente, esse número foi ampliado para oito: econômica, social, ecológica, ambiental, cultural, política nacional, política internacional e territorial (SACHS, 2002). Nesse sentido, as três linhas de pesquisa do CDS constituem não caixas disciplinares ou subdisciplinares, mas sim campos da realidade em que a interface de conhecimento ocorre de forma transversal e integradora de diferentes áreas do saber. Assim, elegeram-se, a partir da capacidade historicamente acumulada pelo CDS, os seguintes campos como linhas de pesquisa:

1. Políticas públicas, cultura e sustentabilidade: Compreende o estudo do conjunto de atividades voltadas à formulação, implementação e avaliação de políticas que convergem para o desenvolvimento sustentável. Engloba igualmente a abordagem da dimensão cultural como componente indissociável da sustentabilidade;

2. Tecnologia, consumo e sustentabilidade: Visa o estudo das relações, no processo de desenvolvimento, entre as dimensões científica, tecnológica e de inovação com a sustentabilidade, considerando também o impacto dos novos padrões sociotécnicos produtivos sobre a sociedade e a natureza; e

3. Território, meio ambiente e sociedade: Trata de como as sociedades configuram os territórios e o meio ambiente e como as atividades e as condições de vida são afetadas por esse processo, em diferentes escalas e sob modos de regulação próprios.

O trabalho interdisciplinar se realiza, sobretudo, na pesquisa, estimulado pela docência. Por isso, o desenvolvimento das pesquisas em centros interdisplinares é objeto de atenção especial, devendo ser 
estreitamente articuladas com as dissertações e teses, assim como com as publicações.

Originalmente, o CDS foi marcado por uma grande profusão de pequenas pesquisas, por vezes sem relação entre si e com os objetos de estudo dos mestrandos e doutorandos. Um esforço bem sucedido tem sido realizado no sentido de agrupar as pesquisas e definir projetos de maior dimensão, assim como o de criar campos de articulação: laboratórios e observatórios, todos com a preocupação central da sustentabilidade e com marcas claras de interdisciplinaridades na composição do corpo de pesquisadores e na definição do objeto de pesquisa.

A pesquisa interdisciplinar é sempre um desafio. Aos poucos aprendemos que, para obter um caráter interdisciplinar inovador, os projetos de pesquisa devem estar articulados em um ambiente propício, como uma rede, um laboratório ou um observatório. Ao longo de sua trajetória, o CDS criou um conjunto desses espaços para abrigar seus projetos de pesquisa em condições mais favoráveis à interdisciplinaridade, articuladamente a outras unidades da UnB:

- Laboratório de Energia e Ambiente (LEA), integrado à Faculdade de Tecnologia;

- Laboratório de Ambiente Construído, Inclusão e Sustentabilidade (Lacis), em associação com a Faculdade de Arquitetura e Urbanismo;

- Laboratório de Unidade de Conservação e de Políticas Sociais Conexas (LUC-S), em franco diálogo com o Ibama e o ICMBio;

- Laboratório da Complexidade, associado ao Centro de Estudos Avançados e Multidisciplinares (Ceam);

- Laboratório de Estudos sobre a Sustentabilidade do Turismo (LETS), em parceria com o Centro de Excelência de Turismo;

- Laboratório de Tecnologia Social; e

- Rede Clima.

No entanto, a participação dos mestrandos e doutorandos nesses laboratórios e obervatórios tem sido parcial, na medida em que 
o ingresso no programa de pós-graduação não se faz por docente e/ ou laboratório. Apenas uma parte trabalha nesses grupos de pesquisa, o que em parte é compensado quando o estudante participa de um projeto em andamento.

Como forma de produzir maior consolidação das linhas, dos projetos e grupos de pesquisa, o CDS tem realizado mudanças em seu processo seletivo de modo a que os projetos dos alunos ingressantes encontrem mais sólida associação com os projetos em curso e/ou as linhas de atuação dos orientadores.

\section{As duas exigências fundamentais na docência e na pesquisa de mestrandos e doutorandos: interdisciplinaridade e sustentabilidade}

A experiência tem mostrado que as melhores teses e dissertações são aquelas em que os estudantes estão articulados a espaços de pesquisa (laboratórios ou observatórios), ingressam com orientadores definidos e adotam temas naturalmente vinculantes aos dois eixos do CDS: interdisciplinaridade e sustentabilidade.

Esses eixos, por sua vez, podem ser estimulados por práticas docentes formais e informais. Um dos bons resultados tem-se observado na adoção de disciplinas ministradas por dois professores de origem disciplinar distintas. E o mesmo se observa quando se aplica esse princípio na definição de orientação e coorientação. O seminário de integração também tem essa finalidade, demonstrando resultados favoráveis. Finalmente, a disciplina de metodologia e técnicas de pesquisa vem sendo desenhada para articular procedimentos das ciências sociais, biológicas, da terra e das engenharias.

Uma iniciativa de boa repercussão interna em termos de diálogos e interações interdisciplinares em torno da temática do DS constitui o Mesão, um fórum interno, no formato de seminários, debate de pesquisas e publicações produzidas por docentes e pesquisadores, voltado ao aprofundamento crítico deles. 


\section{Formação e produção interdisciplinar do corpo docente e de pesquisadores}

O CDS tem um corpo de professores e pesquisadores com formação em várias áreas do conhecimento, entre elas: agronomia, geologia, biologia, engenharias, geografia, sociologia, economia, ciência política e antropologia, no total de 51 profissionais. Eles estão distribuídos entre: professores doutores em regime de dedicação exclusiva (11), professores da UnB que participam do programa e de atividades de pesquisa (09), aposentados da UnB (3), pesquisadores colaboradores (10) e professores visitantes (2), além de profissionais em estágio de pós-doutoramento (8).

Com relação à formação dos quadros docentes e de pesquisadores do CDS, seu caráter interdisciplinar tem tido um cuidado especial na ampliação de seu corpo de professores e pesquisadores. Enquanto os docentes mais antigos ou de formação mais antiga fizeram a sua transição para a multi ou interdisciplinaridade no meio de suas carreiras e por iniciativa própria, os professores incorporados mais recentemente no PPG-CDS possuem formação em cursos multi e interdisciplinares. Assim, os novos professores navegaram ao longo de sua formação no âmbito de, pelo menos, duas disciplinas. Por exemplo, graduação em agronomia e doutorado em ciência política; graduação em agronomia e doutorado em economia; graduação em economia e doutorado em sociologia; e assim por diante.

\section{A experiência da graduação em Ciências Ambientais em consórcio multidisciplinar e interdepartamental}

A UnB implantou em 2009, no âmbito do Programa de Apoio a Planos de Reestruturação e Expansão das Universidades Federais (Reuni), o curso de graduação (bacharelado) em Ciências Ambientais, visando a formação de cientistas ambientais com conhecimento multidisciplinar científico de sistemas socioeconômicos e naturais, passível de aplicação no contexto de gestão pública ou privada e de políticas do meio ambiente. 
A característica interdisciplinar do curso de Ciências Ambientais se reflete em sua própria origem institucional multidisciplinar. Sua criação se deu por meio de um consórcio entre cinco diferentes unidades acadêmicas necessárias à composição multidisciplinar: Instituto de Ciências Biológicas (IB), Instituto de Geociências (IG), Instituto de Química (IQ), Departamento de Economia (Eco) e o Centro de Desenvolvimento Sustentável (CDS), além de outras unidades colaboradoras em disciplinas específicas, como o Instituto de Ciências Exatas, Instituto de Física e Instituto de Ciências Humanas.

O curso oferece formação conceitual básica nos quatro primeiros semestres, quando os estudantes cursam disciplinas introdutórias de Matemática, Física, Química, Geologia, Ecologia, Ciencias Sociais, Economia e Filososia. A partir do quinto semestre, os estudantes devem optar pelas disciplinas de uma das quatro áreas de especilização:

- Conservação e uso da biodiversidade;

- Manejo e conservação de recursos hídricos e solos;

- Planejamento ambiental; e

- Políticas de sustentabilidade.

Outro traço distintivo do curso é o de voltar-se a capacitar o aluno em atividade de extensão, desenvolvendo disciplinas obrigatórias específicas a tal finalidade.

Sendo o curso jovem, cuja primeira turma ainda não se formou, inúmeros esforços vêm sendo empreendidos pelos membros do consórcio na direção de aprimorar os conteúdos de sua grade curricular, especialmente no tocante a sua integração interdisciplinar, bem como na promoção de espaços inovadores de aplicação de tais conhecimentos em pesquisas e extensão.

\section{0 arco de cooperações e parcerias nacionais e internacionais}

A cooperação internacional é outra marca de origem do CDS, conservada e desenvolvida até hoje. Inicialmente, a cooperação se 
deu, sobretudo, com a França, em particular com o IRD (/nstitut de Recherche pour le Développement), o CIRAD (Centre de Coopération Internationale en Recherche Agronomique pour le Développement) e o IHEAL (Institut d’ Etudes sur I'Amerique Latine). Depois, ela passou a ser ampliada de forma a incluir outros países da América do Sul e Europa. A seguir, foram desenvolvidos projetos com o Canadá, a Índia e Indonésia. Com a Rede Lusófona de Cooperação entre programas e centros de estudos da sustentabilidade, a cooperação foi ampliada para países africanos de língua portuguesa. Dessa forma, hoje o CDS tem relações com instituições de mais de 30 países, e dessas atividades de cooperação participam sempre os mestrandos e doutorandos, alguns tendo realizado seus doutorados em cotutela.

Condizente com a valorização da internacionalização, que Santos e Almeida Filho chamam de a quarta dimensão da universidade (2012), o CDS inovou na adoção de uma avaliação de suas atividades com um corpo de pesquisadores e professores internacionais. Para compor essa avaliação, em 2005, foram convidados os professores Alfredo Pena Vega, da École des Hautes Études en Sciences Sociales, em Paris, na França; Manfred Nitsch, da Freie Universität Berlin (Latin American Institute); e Marc Lucotte, da Université de Montréal, no Canadá. A atividade que se desenvolveu durante uma semana contou com a presença de um representante da Capes, o professor Álvaro Prata, ex-reitor da UFSC.

Os avaliadores apresentaram várias sugestões, todas implementadas. Entre elas, há algumas mais gerais, como o planejamento estratégico, a internacionalização, a maior presença no diálogo com a sociedade e a construção da nova sede para propiciar melhores espaços de trabalho para os alunos. Já outras são mais concernentes ao objeto deste artigo, como aprofundar a aproximidade com o Departamento de Ecologia, fortalecer as Ciências Naturais, promover o contato com o pensamento complexo, refletir mais profundamente as práticas interdisciplinares na docência e na pesquisa.

A importância da internacionalização, no caso de programas de pós-graduação como o CDS, é incrementada por sua natureza e 
pelo próprio objeto central de estudo, a sustentabilidade. Não há como desenvolvê-la se não de forma global.

\section{A gestão estratégica e participativa do centro}

Há quase 10 anos, o CDS adota a prática do planejamento estratégico. A cada três anos, realiza uma oficina, normalmente em local externo, com a presença de professores, pesquisadores, estudantes e servidores, quando é feito um balanço de suas atividades, é discutida sua missão, assim como as ações prioritárias em função de uma visão de futuro e objetivos acolhidos, senão por todos, pelo menos pela maioria dos presentes. O primeiro plano foi 2005-2007; o segundo, 20082010; e o terceiro, 2011-2013. Uma síntese de cada plano é elaborada, reproduzida e distribuída para seu corpo docente e discente. Durante o período de vigência do plano, faz-se uma reunião de avaliação. Com isso, várias decisões estratégicas foram tomadas e implementadas, tais como a mudança para o campus e a construção de uma sede própria; o incremento das publicações, incluindo a participação do corpo discente; a ampliação do corpo docente de tempo integral; a participação na graduação e no pós-doutoramento; a expansão da internacionalização; a adoção de novas práticas pedagógicas; e a expansão para a região amazônica.

O desafio, porém, permanece em discernir no planejamento estratégico as medidas que deem maior robustez às práticas de docência e pesquisa interdisciplinares. Tudo indica que, nesse ponto, o centro tem ainda a avançar, autoavaliando suas experiências e implementando inovações. Nos últimos anos, a maior inovação ocorrida no centro fez-se à margem do programa acadêmico, com a criação de um mestrado profissional em gestão de terras indígenas, com metade dos alunos índios e a outra metade de não índios. Esses também participaram do corpo docente. Aparentemente, uma nova avaliação internacional parece ser um bom caminho. Outra frente a se avançar é o aprofundamento de fóruns internos de debate e avaliação. No que toca à produção docente e de pesquisadores, o Mesão, dados seus bons resultados, deve ser ampliado e intensificado. No que toca à 
produção discente, o CDS tem a proposta de implementar em caráter periódico e regular (semestral) seminários discentes, em que os pósgraduandos em fase de elaboração de suas teses e dissertações deverão apresentar a evolução de suas pesquisas para o conjunto da comunidade do CDS.

\section{A título de conclusão: desafios do novo campo da sustentabilidade}

No campo da sustentabilidade, ingressam aqueles que partilham de algumas ideias comuns, entre elas, a de que paira sobre nós uma ameaça. Ela pode ser definida de muitas maneiras, desde as mais estaparfúdias - ameaça de extinção do planeta -, passando pela pouco provável - extinção da vida - e por uma factível - extinção do gênero humano -, até a mais provável - ameaça às condições de vida do homem na Terra atualmente imperantes (NASCIMENTO, 2012).

De toda forma, a ameaça preocupa uma parte significativa da sociedade, que se movimenta em busca de soluções e que participa do debate de forma mais ou menos ativa. Segmentos sociais crescentes pressionam os governos na adoção de medidas que contribuam para a sustentabilidade.

Essa preocupação e essas pressões devem se manter por um bom tempo enquanto persistirem as perceções de que nos encontramos sob uma ameaça. A tendência mais provável, inclusive, é de que ela venha a crescer, pois os indícios, por enquanto, são nesse sentido: aumento dos gases de efeito estufa na atmosfera, crescimento do degelo e elevação do nível do mar, incremento da perda de biodiversidade e dos efeitos nefastos das alterações no ciclo de nitrogênio, expansão das áreas com escassez de recursos hídricos e infectadas por resíduos não tratados.

Se essa hipótese for verídica, deverá aumentar a demanda por profissionais compententes para propor medidas de sustentabilidade e por conhecimentos que reduzam os riscos, sem afetar a vida da humanidade. Sobretudo, porque a tensão entre a demanda por 
produtos e a ameaça ao meio ambiente tende a crescer com a ascensão de cerca de 120 milhões de pessoas/ano ao mercado de consumo, abandonando a linha de pobreza. Como alimentar, abrigar, vestir e proporcionar o acesso à saúde e à educação a esses novos contigentes populacionais sem aumentar o uso dos recursos naturais, ameaçando a sua reprodução?

Com isso, a demanda tende a crescer, sobretudo, no campo das soluções práticas e do monitoramento. E esses serão os dois aspectos mais prementes no futuro próximo para os programas de pós-graduação e institutos de pesquisa. No caso do Brasil, com uma mudança que já se anuncia na agenda ambiental: a sustentabilidade urbana tende a pesar cada vez mais, livrando-nos do monopólio da questão amazônica. Com isso, o bioma do cerrado, e talvez da caatinga, com a elevacão das temperaturas, começará a demandar mais atenção dos governos e da sociedade.

Por parte dos governos, a melhor forma para assegurar uma resposta competente será ajustar o foco de suas políticas de fomento nas áreas de conhecimento mais relevantes para o desenvolvimento sutentável do País. Tarefa nada fácil, tendo em vista que os diversos programas e planos, das duas últimas décadas, não têm conseguido atingir o alvo, prisioneiros de interesses corporativos já assentados ${ }^{3}$. 0 novo é sempre mais difícil de criar, sobretudo porque o velho conhece artimanhas.

O desafio é o fortalecimento das práticas de docência e pesquisa interdisciplinares, não apenas com a adoção de uma interdisciplinaridade fraca (no âmbito das Ciências Humanas, por exemplo). Afinal, os problemas relativos à sustentabilidade, especialmente aqueles concernentes à ameaça do crescimento da crise global, demandam esforços de diálogo entre todas as disciplinas. Portanto, exige o rompimento das fronteiras tanto disciplinares como nacionais.

Isso demanda uma reflexão em profundidade que não deveria, 
conjunto, preferencialmente promovida pela Capes. E, nesse processo de reflexão, seria interessante identificar os egressos dos programas: onde estão e o que fazem? Suas práticas refletema interdisciplinaridade? Afinal, o mais importante não são os discursos, mas as práticas; não apenas os desempenhos, mas os resultados. A avaliação de um programa de pós-graduação da natureza do CDS (e, como ele, existem outros no Brasil) não pode se restringir à sua produção científica; deve englobar, também, uma análise de seus egressos. Afinal, são centros e programas de produção do conhecimento, com quadro de profissionais diferenciados, cuja qualidade deveria se refletir sobretudo na capacidade de analisar e gerar soluções científicas e técnicas para os problemas de sustentabilidade.

Recebido 25/09/2012

Aprovado 25/07/2013

\section{Referências bibliográficas}

ALMEIDA, L. B. de. Inserção profissional dos ex-bolsistas de doutorado do CNPq e da CAPES dos programas em engenharia e ciência da computação no período de 1996-2006. 2012. Tese (Doutorado em Desenvolvimento Sustentável)- Centro de Desenvolvimento Sustentável, Universidade de Brasília, Brasília, 2012.

APOSTEL, L. et al. L'intesdisciplinarité: problèmes de l'enseignement et de rechercher dans les universités. Paris: Ceri/OCDE, 1972.

BECK, U. La société du risque. Sur la voie d'une autre modernité. Paris: Aubier, 2001.

BURSZTYN, M.; DRUMMOND, J. Sustainability science and the university: pitfalls and bridges to interdisciplinarity. Environmental Education Research, v. 19, n. 3, 2013. Disponível em: <http://dx.doi.org/10.1080/ 13504622.2013.780587>. Acesso em: 20 jun. 2013.

CARSON, R. Silent Spring. Boston: Houghton Mifflin, 1962. 
CASTELLS, M. L'ére de I'Information. La société en réseaux. v. 1. Paris: Fayard, 1998.

CMMAD - COMISSÃO MUNDIAL SOBRE MEIO AMBIENTE E DESENVOLVIMENTO. Nosso futuro comum. Relatório Brundtland. 2. ed. Rio de Janeiro: Editora da Fundação Getúlio Vargas, 1991.

COSTA, H. A. ; NASCIMENTO, E. P. do. Benchmarking Internacional de Práticas Interdisciplinares: o caso das Universidades. In: NASCIMENTO, E. P. do; PENA-VEGA, A. Novas dimensões da Universidade: sustentabilidade, interdisciplinaridade e inserção social. Rio de Janeiro: Garamond, 2012.

DRUMMOND, J. A.; NASCIMENTO, E. O Programa de Pós-graduação em Desenvolvimento Sustentável da Universidade de Brasília (1996-2009): desafios, impasses e conquistas. In: RIBEIRO, W. C. (Org.). Práticas Tessocioambientais na pós-graduação brasileira. São Paulo: Anna Blume, 2010a. p. 87-110.

A aventura da interdisciplinaridade. O Centro de Desevolvimento Sustentável da Universidade de Brasília (1995-2010). Brasília: Editorial Abaré, 2010b.

DUARTE, L. M. G. et al. Construção de campo interdisciplinar e a trajetória do Centro de Desenvolvimento Sustentável da UnB. In: PHILIPPI JR, A.; SILVA NETO, A. J. (Orgs). Interdisciplinaridade em ciência, tecnologia e inovação. Barurei, SP: Manole, 2011. p. 510-527.

EHRLICH, P. The population bomb. Califórnia: Stanford University, 1968.

FAZENDA, I. Interdisciplinaridade: história, teoria e pesquisa. Campinas: Papirus, 1994.

FREIRE, J. 0 vestígio e a aura: corpo e consumismo na moral do espetáculo. Rio de Janeiro: Garamond, 2004.

FURTADO, C. 0 mito do desenvolvimento econômico. Rio de Janeiro: Paz e Terra, 1974. 
Os desafios da nova geração. Revista de Economia Política, v. 24, n. 4, p. 96, out./dez. 2004.

GEORGESCU-ROEGEN, N. O decrescimento: entropia, ecologia e economia. São Paulo: Editora Senac São Paulo, 2012.

HOLLING, C. S. Understanding the Complexity of Economics. Ecological and Social Systems. Ecosystems, v. 4, n. 5, p. 290-405, ago. 2001.

ILLICH, I. CEuvres complètes. Paris: Fayard, 2005.

JOLLIVET, M. Sciences de la nature, sciences de la société: les passeurs de frontières. Paris: CNRS, 1992.

KLEIN, J. T. Interdisciplinarity: history, theory, and practice. Detroit: Wayne States University Press, 1990.

LEFF, E. Epistemologia Ambiental. 2. ed. São Paulo: Cortez Editora, 2002.

LEIS, H. R. Para uma reestruturação interdisciplinar das ciências sociais. Ambiente e Sociedade, n. 8, p. 1145-154, jan./jun. 2001. Sobre o conceito de interdisciplinaridade. Cadernos de Pesquisa Interdisciplinar em Ciências Humanas, n. 73, p. 2-23, ago. 2005.

MATURANA, H.; VARELA, I. El árbol del conocimento. Santiago, Chile: Editorial Universitaria, 1995.

MEADOWS, D. H.; et al. Limits to Growth. New York: Universe Books, 1972.

MORIN, E. Le paradigme perdu: la nature humaine. Paris: Seuil, 1973.

Educar para a era planetária. São Paulo: Cortez, 2003.

Introduction a la pensée complexe. Paris: Seuil, 2005. 
NASCIMENTO, E. P. do. Sustentabilidade: o campo de disputa de nosso destino civilizacional. In: LENA, P.; NASCIMENTO, E. P. do. Enfrentando os limites do crescimento: sustentabilidade, decrescimento e prosperidade. Rio de Janeiro: Garamond, 2012.

NOBRE, M.; AMAZONAS, M. Desenvolvimento Sustentável: a institucionalização de um conceito. Brasília: Ibama, 2002.

PENA VEGA, A. O despertar ecológico: Edgar Morin e a ecologia contemporânea. Rio de Janeiro: Garamond, 2008.

PHILIPPI JR., A.; SILVA NETO, A. A. (Orgs). Interdisciplinaridade em ciências ambientais. São Paulo: Signus, 2011.

PRIGOGINE, L. $\mathbf{O}$ fim das certezas: tempo e caos e as leis da natureza. São Paulo: Unesp, 1996.

PRIGOGINE, L.; STENGERS, I. La nouvelle alliance. Paris: Gallimard, 1986.

REPKO, A. F. Interdisciplinary reseach: process and theory. New York: Sage, 2008.

RIBEIRO, W. C. (Org.) Práticas socioambientais na pós-graduação brasileira. São Paulo: Anna Blume, 2010.

SACHS, I. Ecodesenvolvimento: crescer sem destruir. São Paulo: Vértice, 1986.

Estratégias de transição para o século XXI. In: BURSZTYN, M.

Para Pensar o Desenvolvimento Sustentável. São Paulo: Brasiliense, 1993. p. 29-56.

Caminhos para o Desenvolvimento Sustentável. Rio de Janeiro: Garamond, 2002.

SANTOS, F. S. e ALMEIDA FILHO, N. de. A quarta dimensão da Universidade. Brasília: Ed. da UnB, 2012. 
SOLOW, R. The economics of resources or the resources of economics.

The American Economic Review, v. 64, n. 2, 1974.

UNESCO - United Nations Educational, Scientific and Cultural Organization. Towards Knowledge Societies. World Repport. França: Unesco, 2005. 


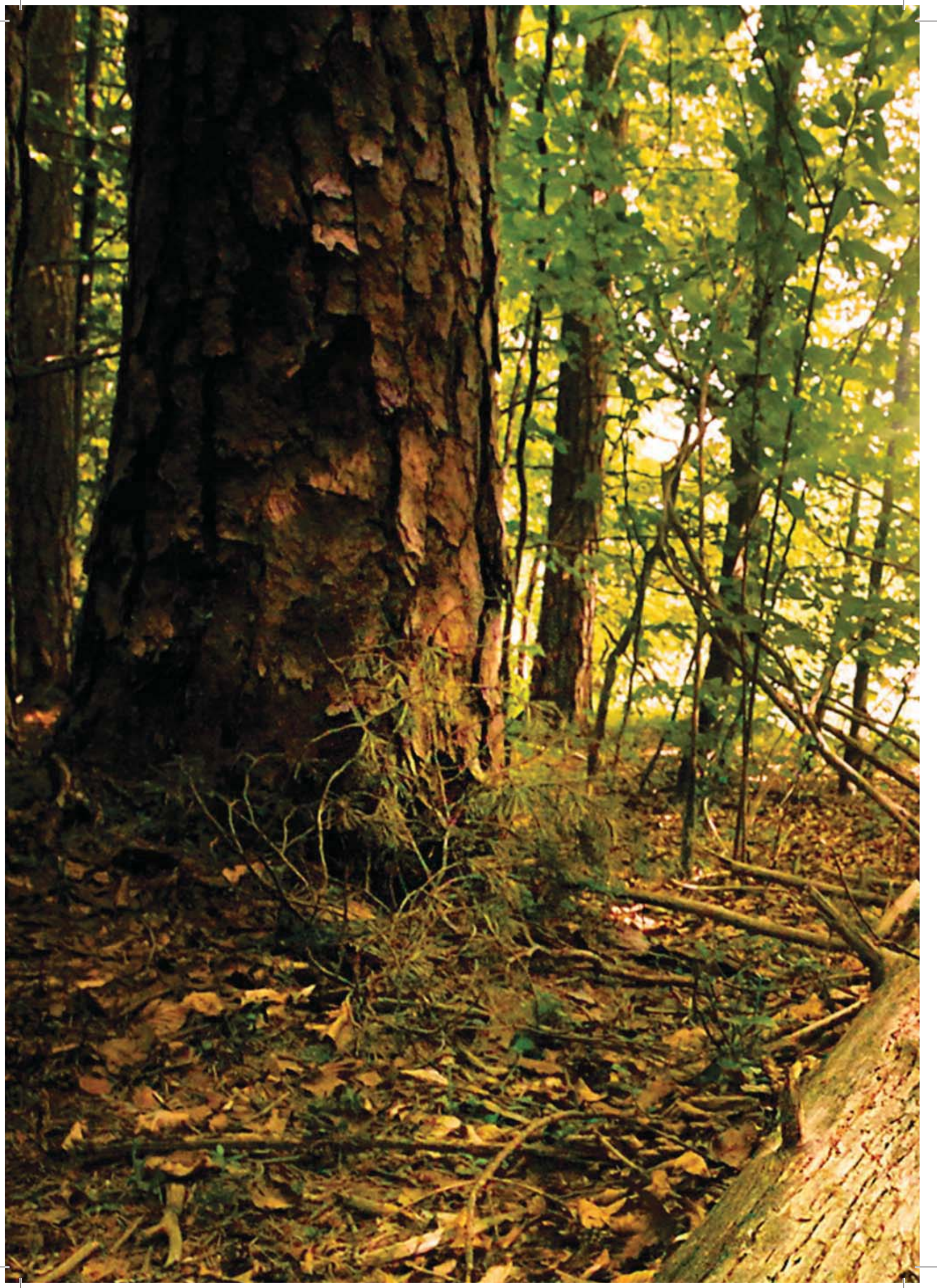




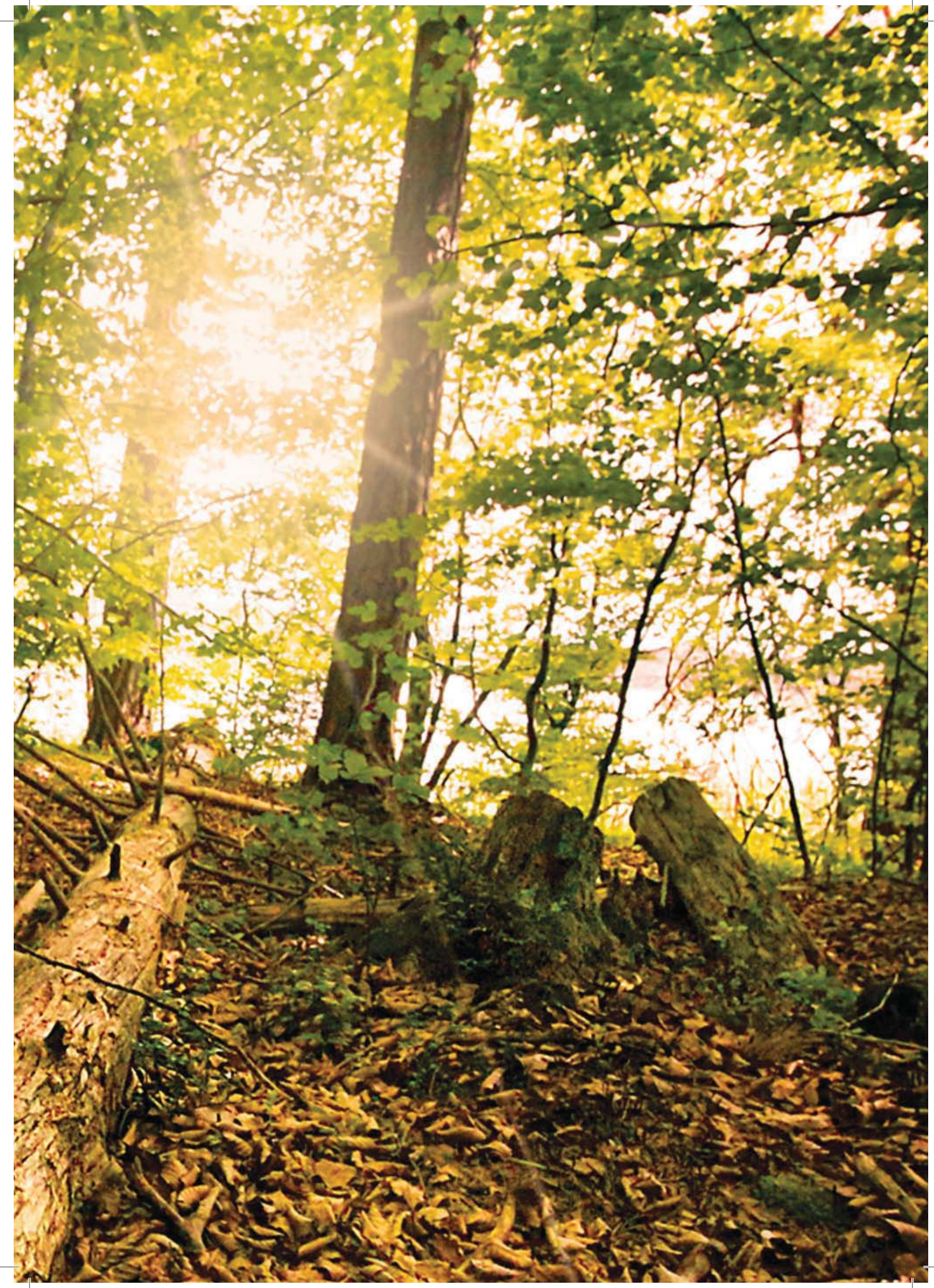


Comprometimento e alinhamento da pós-graduação da PUC-Rio com o desenvolvimento sustentável

\section{Commitment and alignment of the post-graduation education of Catholic University of Rio de Janeiro with the sustainable development}

\section{El compromiso y la alineación del posgrado de la PUC- Rio con el desarrollo sostenible}

Maurício Nogueira Frota, coordenador do Programa de PósGraduação em Metrologia da PUC-Rio. Endereço: Programa de Pós-Graduação em Metrologia (PósMQI/PUC-Rio) - Rua Marquês de São Vicente, 225 - Gávea. CEP: 22453-900 - Rio de Janeiro, RJ. Telefone: (21) 3527-1542/2053/ 9341-0659. E-mail:mfrota@ puc-rio.br.

Fabrício Casarejos Lopes Luiz, doutor em Física Experimental na área de Biofísica pela Pontifícia Universidade Católica do Rio de Janeiro (PUC-Rio) e pós-doutor em Metrologia na área de Qualidade, Inovação e Sustentabilidade (PósMQI/PUC-Rio). Endereço: Programa de Pós-Graduação em Metrologia (PósMQI/ PUC-Rio) - Rua Marquês de São Vicente, 225 - Gávea. CEP:22453900 - Rio de Janeiro, RJ. Telefone: (21) 3527-1542/2053. E-mail: casarejos@esp.puc-rio.br.

Resumo

Em sintonia com a temática "a pós-graduação e o desenvolvimento sustentável” desta edição da Revista Brasileira de Pós-Graduação, o artigo reflete o comprometimento da Pontifícia Universidade Católica do Rio de Janeiro (PUC-Rio) com o desenvolvimento sustentável. Destaca ações já empreendidas em resposta a recomendações das conferências das Nações Unidas sobre o meio ambiente e o desenvolvimento sustentável (1972, 1980, 
1992 e 2012) e do Colóquio Global de Reitores de Universidades (N. York University, 1987), do qual participaram reitores das principais universidades do mundo. Cônscia de sua responsabilidade, a PUCRio pautou o seu compromisso na ética ambiental voltada para a transformação da cultura antropocêntrica com vistas à integralização do ser humano pela preservação da biodiversidade e do meio ambiente. No contexto de uma ação integrada da universidade, discute a consolidação do pilar sustentabilidade no seu Programa de PósGraduação em Metrologia para Qualidade e Inovação.

Palavras-chave: Desenvolvimento Sustentável. Sustentabilidade. PósGraduação. Metrologia. Qualidade. Inovação.

\section{Abstract}

In line with the theme "post-graduate education and sustainable development" of this issue of the Brazilian Journal of PostGraduate Education, the article indicates the commitment of the Catholic University of Rio de Janeiro (PUC-Rio) to sustainable development. It highlights actions already taken in response to recommendations of the United Nations Conferences on the environment and sustainable development (1972, 80, 92 e 2012) and of the "Global Colloquium of University Chancellors" (New York University, 1987), attended by rectors of leading universities in the world. Aware of its responsibility, PUC-Rio oriented its commitment to environmental ethics toward the transformation of anthropocentric culture in order to better integrate the human being into processes of biodiversity and environmental preservation. In the context of an integrated action of the university, the article discusses the consolidation of the pillar sustainability in its Postgraduate Programme in Metrology for Quality and Innovation.

Keywords: Sustainable Development. Sustainability. Postgraduate Education. Metrology. Quality. Innovation.

\section{Resumen}

En consonancia con el tema "el posgrado y el desarrollo sostenible” de esta edición de la Revista Brasileña de Posgrado, este 
artículo refleja el compromiso de la PUC-Rio con el desarrollo sostenible. Se destacan medidas adoptadas en respuesta a las recomendaciones de las conferencias de las Naciones Unidas sobre el medio ambiente y el desarrollo sostenible (1972, 1980, 1992 y 2012) y del Coloquio Mundial de Rectores de Universidades (N. York University 1987), al que asistieron rectores de las principales universidades del mundo. Consciente de su responsabilidad, la PUC-Rio orientó su compromiso con la ética ambiental hacia la transformación de la cultura antropocéntrica con el fin de integrar el ser humano a la preservación de la biodiversidad y del medio ambiente. En el contexto de una acción integrada de la universidad, se analiza la consolidación del pilar de la sostenibilidad en su Programa de Posgrado en Metrología para la Calidad y la Innovación.

Palabras clave: Desarrollo Sostenible. Sostenibilidad. Posgrado. Metrología. Calidad. Innovación.

\section{O vocábulo sustentabilidade e os riscos da sua plurivalência}

Do ponto de vista linguístico, o étimo sustentar, de que se origina o termo sustentabilidade, provém de sustentare (sustinere), verbo latino que designa ações verbais de conteúdo similar. Figurativamente, amplia sua significação para expressar ideias contíguas (defender; afirmar categoricamente; alimentar; fazer subsistir; amparar) e tantas mais. Não obstante o conceito ser antigo - segurar por baixo; suportar; escorar; ajudar; auxiliar; servir; impedir um desequilíbrio ou queda; servir de barreira (LELLO, 1926; BOFF, 2012) -, sustentabilidade é um conceito que ganhou o mundo nos últimos anos para designar o bom uso das riquezas naturais do planeta (UNCSD/RIO+20, 2012).

Como se nota, o significado de seus congêneres não difere tanto um do outro. Chama a atenção, no entanto, a sua aplicação atual e insistente em teses acadêmicas e outras publicações científicas das mais diversas áreas do conhecimento, na mídia em geral, nas políticas públicas do mundo inteiro, nos discursos político-ideológicos, em propagandas e marketing tão díspares quanto alimento e automóvel. Dessa sobre-exposição do termo, aleatória em muitos dos casos, 
emergiu um sentido inusitado: o de perigo iminente contra a vida humana e o universo natural. Qual o perigo? O de que o planeta não consiga mais, por exaustão e fadiga de suas forças naturais e impotência para neutralizar os escombros resultantes da intervenção do homem na natureza, sustentar a vida lato sensu na Terra. Fala-se, desse modo, de dois termos mútuo-dependentes: habitat natural e preservação da vida, ou seja, meio ambiente e condição de vida, cujo fôlego cresce na proporção que a informação sobre esse processo devastador avança e atinge praticamente todos os extratos sociais. 0 pensamento contemporâneo elegeu, então, o substantivo sustentabilidade para arrimo de teses relativas à necessidade de alinhar o processo desenvolvimentista à manutenção das condições de vida no planeta (UNCSD/RIO+20, 2012). Ou seja, o de preservar o equilíbrio viável entre a necessidade de desenvolvimento e a preservação dos recursos naturais que garantam a sobrevivência do binômio desenvolvimento e condição de ótima qualidade de vida.

Do ponto de vista meramente filosófico, sustentabilidade pode ser compreendida como o meio de possibilitar um projeto civilizatório humano cujo fim último seria o alcance universal do equilíbrio entre o desenvolvimento e a preservação das fontes de vida futura. E, do ponto de vista pragmático, como estratégia para a consecução desse meio. A designação indiscriminada, e por vezes oportunista, do termo sustentável e de seus cognatos para referência de políticas desenvolvimentistas tão diversas quanto as sociais, culturais, econômicas ou mesmo religiosas acabou gerando uma polissemia que impede sua inteligibilidade universal, bem como os limites claros de práticas “sustentáveis” igualmente universais.

Embora a introdução do conceito de sustentabilidade seja comumente atribuída à Comissão Mundial sobre o Meio Ambiente e Desenvolvimento (BRUNDTLAND, 1987), já em 1560, na Saxônia (Alemanha), fazia-se menção à nachhaltigkeit para referir-se ao que hoje se entende por sustentabilidade. Na realidade, um movimento originado na preocupação com o uso intensivo dos recursos madeireiros e escasseamento das riquezas da floresta levou a uma visão nova de redirecionamento da exploração sustentável da floresta para que fosse 
“capaz de se manter e regenerar suas riquezas” (CARLOWITZ, 2000, p. 105), “permitindo às futuras gerações dispor das mesmas vantagens que a atual” (GROBER, 2003, p. 167).

Não obstante as questões e contradições que o conceito sustentabilidade ainda suscita no âmbito da investigação científica, reconhece-se, entretanto, a contribuição do Relatório Bruntdland para o seu entendimento:

Desenvolvimento sustentável: aquele que atende às necessidades das gerações atuais sem comprometer a capacidade das gerações futuras de atender às suas necessidades e aspirações (BRUNTDLAND, 1987, p. 54).

No contexto desse relatório, a definição encerra, essencialmente, dois conceitos-chave: (i) os conceitos de necessidades, em particular, as necessidades essenciais da pobreza universal, que deveria merecer prioridade absoluta; e (ii) a ideia de limitações impostas pelo estado de tecnologia e organização social sobre a capacidade de o ambiente atender a necessidades presentes e futuras. Foi dessa iniciativa da ONU que se reconheceu ser de interesse comum de todas as nações o estabelecimento de políticas comuns de desenvolvimento sustentável e de os problemas ambientais serem de natureza global.

Tal conceituação parece ter-se popularizado e se tornado jargão corrente no discurso oficial da sociedade contemporânea. Percebe-se aí uma atitude de aproximação aos princípios e critérios delineados no Relatório Bruntdland por instituições governamentais e não governamentais, que passaram a anunciar publicamente a adoção do Triple Bottom Line para modelo padrão de desenvolvimento, cuja base assenta-se em três pilares: o do economicamente viável, o do socialmente justo e o do ambientalmente correto (ELKINGTON, 1990).

A leitura do modelo de desenvolvimento padrão, compreendido no chamado Triple Bottom Line constante do Relatório Bruntdland, leva aos seguintes questionamentos: em que medida consegue-se definir e determinar as necessidades das gerações atuais e, sobretudo, das futuras gerações? Qual o grau de confiabilidade desse processo de definição e determinação? Quais os processos envolvidos na 
capacidade física do planeta em suprir tais necessidades? Quais os limites da capacidade-suporte dos recursos e serviços ecossistêmicos? Quais as grandezas físicas envolvidas nos processos fundamentais que mantêm a homeostase climática? Como se comportam tais processos? Como estabelecer limites e trajetórias desejáveis para os padrões de uso, operação e consumo de recursos e serviços ecossistêmicos? Como quantificar e qualificar fisicamente a regeneração/recomposição e a biodiversidade? Quais os critérios utilizáveis para a seleção das métricas e dos indicadores necessários para a correta avaliação do desenvolvimento? Como orientar um processo de inovação em condicionamento estável da habitabilidade do planeta e da prosperidade do projeto civilizatório? Como determinar o real impacto antrópico sobre a interconectividade física, química e biológica de toda a vida e processos existentes no planeta? Como elaborar estratégias efetivas em niveis local e global capazes de conferir adaptação às mudanças climáticas? E, considerando as questões anteriores, como mensurar, quantificar e qualificar com confiabilidade no modelo Triple Bottom Line o viável do econômico, o justo do social e o correto do ambiental? (MEADOWS; RANDERS; MEADOWS, 2004; IPCC, 2007).

Tais questionamentos indicam uma necessidade: a de se construir uma amálgama de conhecimentos capaz de compreender o sentido intrinsecamente complexo da sustentabilidade da vida e da qualidade de vida no planeta. Nesse contexto, um desafio inédito e uma ampla responsabilidade se mostram por inteiro para as sociedades: o de buscar soluções que permitam a construção de um modelo confiável e, portanto, verificável de desenvolvimento em bases sustentáveis.

\section{O papel das universidades com o desenvolvimento sustentável}

A universidade, classicamente entendida, define-se como centro de produção de conhecimento e saber. Produz conhecimento sem perder de vista o horizonte de sua aplicação direta na transformação do homem e da sociedade que, em verdade, são o seu fim e a razão mesma de sua existência. Nesse processo de transmissão do saber em que a interação social é condição essencial, a universidade educa 
no sentido original do termo. Ou seja: leva, conduz, orienta, nisso consistindo o peso real de sua responsabilidade quanto à formação do cabedal humano que dali evade para atuar e, em grande parte, liderar nas mais diversas frentes do tecido social, seja ele político, social ou religioso. Claro fica, no âmbito dessa compreensão, que o grau de interferência no desenvolvimento social remonta quase sempre ao embrião universitário, que inclui, incisivamente, no momento político atual, a questão da importância da sustentabilidade para a segurança das condições ótimas da vida presente e futura. Assim, se a razão do instituto universitário pode ser entendida no bojo da "assepsia" meramente científica, sua finalidade trai a singularidade desse caráter único por causa mesmo da sua finalidade - o homem e a vida - por onde permeia a noção de valor: o que vale e o que não vale; o que conta e o que desconta no âmbito da existência humana e de seu habitat. Essa noção de valor obriga, em última instância, à educação para uma ética solidária, bem como para o desenvolvimento de linguagens, símbolos, ferramentas científicas e tecnológicas adequadas a esse fim (LUKMAN; GLAVIC, 2007).

A promoção da importância da sustentabilidade na universidade pode e deve ser conseguida por meio da criação de programas acadêmicos de recorte “sustentável” determinado. Essencialmente, de parcerias e de redes cooperativas, de forma a consolidar uma cultura intra e extramuro universitário dessa disciplina voltada para o desenvolvimento sustentável, pois são as instituições universitárias que, pela sua vocação natural, promovem a sinergia ideal e espontânea entre docentes, discentes, funcionários e a sociedade, assim potencializando a elaboração de soluções inovadoras.

O reconhecimento mundial do papel das universidades na construção de saberes voltados ao desenvolvimento sustentável pode ser observado nos documentos oficiais dedicados a discutir a incorporação da sustentabilidade às instituições de ensino e pesquisa. Entre os quais, pode-se citar:

- A Declaração de Estocolmo (SOHN, 1973): primeira a explicitar a necessidade do ensino e da formação em educação ambiental;

- A Declaração de Tbilisi (THE TBILISI DECLARATION, 1977): veio reforçar a importância da educação ambiental na 
preservação e melhoria da biodiversidade e do meio ambiente;

- A Declaração de Talloires (THE TALLOIRES DECLARATION, 1990): enalteceu o papel de liderança da universidade na indução de uma consciência para o desenvolvimento ambientalmente sustentável; na criação de uma cultura institucional da sustentabilidade; na educação voltada para a cidadania ambientalmente responsável; na proposição de práticas de ecologia institucional; no engajamento das partes interessadas; e na colaboração construtiva destinada à expansão de abordagens interdisciplinares;

- A Declaração de Halifax (THE HALIFAX DECLARATION, 1991) e a Declaração de Kyoto (THE KYOTO DECLARATION, 1993): ambas propuseram um conjunto de ações para as universidades, tais como utilizar seus recursos intelectuais para incentivar a compreensão da sociedade acerca dos riscos dos impactos antrópicos e das alterações climáticas; enfatizar a responsabilidade da geração atual com a sustentabilidade e os danos pela inobservância à devida utilização dos recursos naturais e serviços ambientais; e ensinar e praticar princípios sustentáveis;

- As Declarações de Thessaloniki (THE THESSALONIKI DECLARATION, 1997) e de Swansea (THE SWANSEA DECLARATION, 1993): soaram o alerta de que a regressão da não sustentabilidade somente seria viável mediante a compugnação de todos os segmentos da sociedade contra as más práticas vigentes;

- A Carta de Copernicus (COPERNICUS GUIDELINES, 1993): compilou um conjunto de diretrizes estratégicas destinadas a facilitar a incorporação de temas sobre desenvolvimento sustentável e mudanças climáticas nas instituições de ensino superior europeias;

- A Declaração Mundial sobre o Ensino Superior para o Século XXI - visão e ação (WORLD, 1993): composta por 17 artigos, faz do ensino o pilar fundamental dos direitos humanos, da democracia, da paz mundial e da busca do desenvolvimento sustentável sua premissa maior; e 
- A Declaração de Luneburg (LUNEBURG DECLARATION, 2001): emanada da conferência sobre Higher Education for Sustainability: Towards the World Summit on Sustainable Development 2002, delineou um conjunto de critérios e princípios para a incorporação da sustentabilidade em instituições de ensino superior, precedendo os muitos outros documentos que a esse se seguiram.

Percebe-se que a extração de um denominador comum para a assimilação e adoção de medidas de proteção e desenvolvimento da sustentabilidade por parte de instituições tão distintas, embora complementares (e.g.: instituições de ensino, governos, associações e organizações sociais livres), teve importância fundamental na tomada definitiva de consciência desse problema que ameaça a vida qualificada lato sensu.

Dessa forma, e considerando as proposições e os resultados do UNED (United Nations Environment and Development) (capítulo 36 da AGENDA 21, 1995); do International Work Programme on Education, Public Awareness and Training for Sustainability, adotado pelas Nações Unidas (Commission on Sustainable Development, 1996); as conclusões da International Conference on Environment and Society (THESSALONIKI, 1997); as definições da World Conference on Higher Education (Paris, 1998); da World Conference on Science (Budapest, 1999); do World Education Forum (Education for All, Dakar, 2002); e reportando-se ainda aos avanços na formação de redes entre três associações acadêmicas que constituem a GHESP (Global Higher Education for Sustainability Partnership, que conta com o suporte inicial de mil faculdades e universidades comprometidas com a implementação de ações voltadas para o entendimento do desenvolvimento sustentável), foram sumarizadas as medidas concludentes de indiscutível relevância:

- assegurar a atualização e revisão do conceito científico sustentabilidade;

- priorizar o tema desenvolvimento sustentável no processo de formação continuada dos professores;

- prover a atualização formal e continuada de professores, 
lideranças e do público em geral em desenvolvimento sustentável;

- incentivar instituições de ensino a incluir nas suas atividades o exercício reflexivo sobre valores e normas afetas a desenvolvimento sustentável;

- elevar o grau de alerta e intensificar a compreensão da importância e relevância de uma avaliação tecnológica e dos riscos correlatos à não sustentabilidade;

- incentivar a criatividade para o desenvolvimento e a implementação de projetos direcionados à sustentabilidade em institutos de ensino superior e outros;

- atentar para a dimensão internacional do problema e incentivar a troca internacional em conhecimento ambiental;

- aumentar o foco no potencial desenvolvimentista e intensificar a formação de redes (enredamento) entre as instituições educacionais;

- fortalecer a integração entre treinamento e pesquisa, bem como a interação com os financiadores ao longo do processo de desenvolvimento; e

- pressionar governos de forma a assegurar que a educação em geral e a educação superior, em particular, estejam contempladas no programa de trabalho internacional (World Summit on Sustainable Development).

Por fim, cabe salientar a Declaração de Ubuntu (2002), que propôs uma aliança global entre todas as instituições em prol do ensino, da pesquisa e da cultura do desenvolvimento sustentável.

As discussões estabelecidas por essas declarações atestam o reconhecimento mundial do papel a ser desempenhado pelas universidades na construção de um modelo de desenvolvimento em bases sustentáveis, muito embora o desafio devencer a própria definição do conceito de sustentabilidade paire real e claro. Ou seja, a dificuldade de abranger concomitantemente diferentes culturas e grupos, cuja apreensão de termo condiciona-se a interferentes específicos, como cultura, visão própria do mundo, propósitos e interesses específicos. Portanto, materializar e operacionalizar os conceitos da chamada 
ciência da sustentabilidade é um desafio complexo a exigir a difícil (mas não impossível) sinergia entre os saberes, os cidadãos, as instituições e as sociedades.

\section{O papel da PUC-Rio na construção da sustentabilidade}

A Pontifícia Universidade Católica do Rio de Janeiro (PUCRio), reconhecidamente um campo de produção do saber, manteve, paralelamenteà sua missão imediata de gerare distribuir conhecimento, o alinhamento às teses humanistas de valorização do homem como ser comprometido com a espiritualidade imanente à edificação da vida lato sensu. Nesse sentido, sua conformidade com a ênfase atual no conceito sustentabilidade como via de reconstrução de um mundo futuro mais humano e, portanto, mais solidário sempre existiu na base fundamental de seu projeto educacional. Projeto diferenciado em que uma espécie de civismo cognoscitivo prevaleceu e prevalece sobre o pragmatismo puro das ciências e das tecnologias do conhecimento. Nela, o conceito sustentabilidade é quase inerente à sua finalidade, apenas sem, talvez, sua conformação em disciplina estanque e de destaque acadêmico.

A Pontifícia Universidade Católica do Rio de Janeiro foi instituída por deliberação do I Concílio Plenário Brasileiro como centro nacional de cultura católica, reconhecida pelo governo federal do Brasil nos termos do Decreto Lei $n^{\circ}$ 8.631, de 15 de janeiro de 1946, e oficializada canonicamente por Decreto da Sagrada Congregação dos Seminários e Universidades em 20 de janeiro de 1947. Constitui-se em instituição privada de caráter confessional, comunitário e filantrópico, sem fins lucrativos, dedicada ao ensino, à pesquisa e à extensão (PUC-RIO, 2012). Declarada de utilidade pública federal pelo Decreto $n^{\circ}$ 43.454, de 26 de março de 1958, a PUC-Rio, para o cumprimento de sua missão de servir ao Brasil e à comunidade universal por meio da busca da verdade, destina todos os seus recursos: (i) à promoção da cultura, nos planos intelectual, estético, moral e espiritual; (ii) ao desenvolvimento do ensino, da pesquisa e da extensão em uma visão de mundo pluralista do conhecimento; e (iii) à promoção do intercâmbio e da cooperação com instituições públicas e privadas, nacionais e 
estrangeiras, especialmente as de caráter educacional, científico e cultural, na intenção de emprestar universalidade ao sentido de sua missão.

Compassivo e cônscio de sua responsabilidade sobre as questões sensiveis da sustentabilidade, o atual reitor da PUC-Rio, Pe. Josafá Carlos de Siqueira S. J., fundou em 1999 o Núcleo Interdisciplinar de Meio Ambiente (Nima) com o objetivo de aglutinar em um lócus comum as competências multidisciplinares internas e estabelecer a desejável interação entre a universidade e a sociedade para o fomento de projetos socioambientais. Há 13 anos, o Nima vem realizando projetos em parceria com escolas, empresas, municípios e instituições nacionais e internacionais, conciliando a escala local à global. Na visão do reitor da universidade (SIQUEIRA, 2009), deve pautar o seu compromisso maior na ética ambiental voltada para a transformação da cultura antropocêntrica com vistas à integralização do ser humano pela preservação da biodiversidade e do meio ambiente, integrando o pensamento técnico-científico ao axiológico.

Submissa a tais objetivos e compromissos, a PUC-Rio mantém processo permanente de autoavaliação de desempenho em busca do aperfeiçoamento institucional continuado. Em resposta às recomendações do Colóquio Global de Reitores de Universidades, realizado em dezembro de 2007 por solicitação do secretário geral das Nações Unidas, a PUC-Rio abraçou o desafio de tornar-se uma universidade orientada para a promoção da sustentabilidade e para o desenvolvimento sustentável. Uma decisão com o propósito de transformar o campus em um grande laboratório que estimule o aluno e o professor a alterarem seus hábitos. A universidade, portanto, incorporou em sua missão a busca de soluções de garantia da sustentabilidade e de inovações que balizem a transição para uma economia verde $e$, consequentemente, venham mitigar os efeitos perversos das mudanças climáticas. Esse desafio, que exige esforços acadêmicos extraordinários, vem sendo enfrentado com determinação e constância (PUC-RIO/NIMA, 2009).

De forma a planejar, materializar e operacionalizar a sustentabilidade, a PUC-Rio criou, em 2009, uma agenda ambiental sob 
a coordenação e responsabilidade do Nima. Essa agenda ambiental, congregando naturalmente uma pluralidade de pensamentos e conhecimentos acerca do conceito sustentabilidade devido à multidisciplinaridade da sua composição, compreende um conjunto de práticas que permitem e estimulam a sustentabilidade e a qualidade de vida socioambiental no campus universitário. Estrutura-se em sete eixos temáticos: biodiversidade; água; energia; atmosfera; materiais; resíduos; e educação ambiental. Cada um dos eixos esclarece, na sua introdução, o posicionamento ético-ambiental assumido; um planejamento de execução; e um conjunto de objetivos de curto, médio e longo prazos (PUC-RIO/NIMA, 2012). Em seu quarto ano, desde sua implantação, já são percebidos resultados positivos. No GreenMetric World University Ranking 2011 - instrumento de classificação do comprometimento das universidades do mundo inteiro com a sustentabilidade-, a PUC-Rio ocupou a $66^{a}$ posição no ranking mundial entre 178 instituições avaliadas e a $1^{\text {a }}$ posição no ranking nacional (GREENMETRIC, 2012). Atualmente, a Agenda Ambiental PUC-Rio conta com a participação do grupo de pesquisa Universidade Sustentável, composto de professores de diversas unidades da instituição que acompanham o processo de implantação da agenda e orientam alunos de graduação e de pós-graduação na produção de monografias, dissertações e teses destinadas ao equacionamento de soluções concretas aos desafios impostos pela busca da sustentabilidade.

\section{Ações da pós-graduação em metrologia, qualidade, inovação e sustentabilidade}

O Programa de Pós-Graduação em Metrologia para Qualidade e Inovação (PósMQI/PUC-Rio), por meio de seu recém implantado pilar da sustentabilidade, tem sua origem em um esforço acadêmico conjunto dos departamentos do Centro Técnico Científico da Universidade. Beneficiando-se da intrínseca multidisciplinaridade de uma universidade global como a PUC-Rio, o PósMQl visa formar um profissional interdisciplinar, com características próprias, distintas das áreas que caracterizam a sua formação original. 
Aberto a profissionais de diversas formações profissionais, o PósMQI/PUC-Rio não objetiva especializar engenheiros, administradores, biólogos, físicos, químicos, mas capacitá-los de forma integral para atuar na interface da ciência das medições e dos saberes. A interdisciplinaridade refere-se tanto à convergência de duas ou mais áreas do conhecimento quanto à identificação e pesquisa de novos modos de relacionamento entre elas. O PósMQI atua em áreas do conhecimento que possam contribuir para o avanço da ciência, da arte e da tecnologia das medições e da instrumentação. Contribui para a difusão da qualidade em novos campos da atividade humana e para a criação e agregação de valor mediante dinâmicas de inovação tecnológica. Esse é um processo que se torna cada vez mais crítico na sociedade do conhecimento que se estrutura nesse início de século e que requer aceleração na transferência de conhecimentos de uma área para outra.

Com a consolidação da sua visão institucional, o PósMQl transcendeu o uso restringente da metrologia como instrumento de competitividade industrial e de melhoria de produtos e processos em disputa no mercado. Evoluiu para uma visão que expande a instrumentalização das medições rumo à equidade social, prosperidade econômica, valoração e preservação ambiental. No contexto de sua visão ampla da ciência, da qualidade (adequação ao uso), da competitividade, da tecnologia e da arte das medições, o PósMQ passou a promover o ensino e a pesquisa em metrologia segundo um modelo sistêmico voltado à sustentabilidade, modelo que alinha-se aos capítulos da Agenda 21 (1995), integrando as dimensões social, econômica, cultural e ambiental do desenvolvimento sustentável à sociedade industrial e a demais organizações. No contexto dessa nova lógica da qualidade e inovação orientadas para a sustentabilidade, o PósMQI formalizou junto à Capes a mudança de sua área de concentração, evoluindo de "metrologia para qualidade industrial” para “metrologia para qualidade e inovação”, enaltecendo a sustentabilidade em sua identidade institucional.

Ao assegurar uma formação sólida e interdisciplinar, o PósMQI/PUC-Rio capacita profissionais a fazer uso da ciência das 
medições e da instrumentação no dia a dia de suas atividades. Em particular, prepara profissionais para superar os desafios do mercado de trabalho em um mundo globalizado e, em grande medida, está atento à necessidade de internalização da noção de sustentabilidade e do desenvolvimento sustentável. Estimula, assim, a busca de soluções para problemas próprios de setores dinâmicos da economia e de segmentos relacionados à manutenção e melhoria da qualidade de vida, da biodiversidade e do acesso à cidadania. Em síntese, no cumprimento de sua missão institucional, o PósMQl objetiva: (i) formare qualificar profissionais interdisciplinares, inovadores, empreendedores e sensíveis às questões de competitividade e sustentabilidade; (ii) formar e qualificar profissionais para o ensino e a pesquisa, com o foco na qualidade, inovação e sustentabilidade; e (iii) desenvolver atividades de P\&D em setores promissores na geração de inovações tecnológicas e desenvolvimento sustentável.

Três são as linhas de pesquisa do Programa: instrumentação e medição (confiabilidade metrológica e inovação de técnicas e métodos de medição); gestão estratégica, inovação e sustentabilidade (modelos de gestão estratégica da inovação; fundamentos históricos, antropológicos e científicos do desenvolvimento sustentável; e mudanças climáticas); e redes inteligentes - smart grid -, voltadas às inovações tecnológicas da comunicação e informação associadas às redes inteligentes de energia.

Sustentabilidade é tema recorrente em todas essas linhas de pesquisa. Introduz uma nova realidade, criando novas perspectivas para evoluir e encontrar soluções práticas no contexto de um ambiente regido por inovações tecnológicas. Eficiência energética; eficiência estratégica e operacional; métricas de ecoeficiência; tecnologias de processamento de smart grid; fontes alternativas de energia; pegada ecológica; pegada de carbono; estratégia corporativa de carbono; mecanismos de desenvolvimento limpo; estratégias de adaptação e mitigação às mudanças climáticas; tarifas mais ajustadas e justas; e participação colaborativa dos consumidores são apenas algumas das questões-chave trabalhadas nessas linhas de pesquisa. As dimensões continentais do Brasil impõem desafios para superar a defasagem de 
infraestrutura ainda existente. Estabelece-se, assim, a interconexão dos sistemas e subsistemas, integrando o País e assegurando o acesso à energia e transmissão de informação, às condições básicas de vida e à cidadania para o desenvolvimento sustentável.

A grade curricular do PósMQl foi estruturada segundo as linhas de pesquisa do programa. A grade incorpora um conjunto de disciplinas optativas e eletivas que complementam as disciplinas obrigatórias, totalizando os 24 créditos acadêmicos requeridos pelo mestrado acadêmico stricto sensu. O PósMQl reestruturou sua missão e identidade, atualizando sua grade curricular e suas linhas de pesquisa com base no monitoramento permanente das demandas por capacitação profissional e pesquisas e nos desafios impostos pela missão PUC-Rio para tornar-se um modelo de universidade sustentável. A sustentabilidade foi introduzida na nova grade curricular por meio de disciplinas específicas. Entre elas, Metrologia para o Desenvolvimento Sustentável; Metrologia e Estratégia Corporativa de Carbono; Elaboração de Projetos e Relatórios em Sustentabilidade; Sistemas de Mensuração de Sustentabilidade; Gestão Estratégica da Inovação; Aprendizagem Organizacional e Cultura Metrológica; Normalização e Sistemas de Gestão; Regulação, Avaliação e Gestão de Riscos; Biometrologia, Medição Bioeletromagnética, Introdução às Redes Inteligentes de Energia; Infraestrutura de Redes Inteligentes de Energia; Regulação no Setor Energético; Eficiência Energética; e Cidades Inteligentes.

A estrutura da rede de pesquisa, conhecida pela articulação institucional e pelos sistemas de colaboração e cooperação entre pesquisadores e instituições, otimiza e proporciona a concreta realização do conhecimento interdisciplinar. Proporciona um marco analítico para a identificação e caracterização de novos e inovadores objetos de pesquisa. Torna-se crítica para a geração e agregação de valor, para a consolidação de vantagens competitivas, para a difusão da cidadania e para o entendimento da sustentabilidade. Ano após ano, o PósMQI se fortalece pelo esforço bem sucedido no investimento da articulação institucional interna, que congrega atores da própria universidade, e externa, por meio da colaboração e cooperação com centros de pesquisa 
e empresas do Brasil e do exterior. No âmbito externo, beneficia-se da sua capacidade de articulação para viabilizar o enriquecimento de sua produção intelectual, participação e representação em fóruns específicos, na execução de projetos e no registro de patentes. Ao longo dos últimos anos, o programa tem participado de projetos de P\&D desenvolvidos por organizações internacionais, entre os quais se incluem projetos de avaliação da infraestrutura nacional da qualidade (metrologia, normas, avaliação da conformidade) de países europeus e asiáticos e projetos de orientação a governos da América Latina na estruturação de seus sistemas regulatórios e de metrologia. Cada vez mais, o programa é procurado por candidatos ao mestrado de outros países (e.g.: o programa já graduou profissionais de Peru, Paraguai, Bolívia, Colômbia, Panamá, Costa Rica e Alemanha).

Como parte de sua estratégia, em 2010, o PósMQI constituiu um grupo de pesquisa (ECOMQI: Metrologia para o Desenvolvimento Sustentável) para atuar ativamente na interface da metrologia com as áreas da sustentabilidade. O grupo foi cadastrado no diretório de grupos de pesquisa do CNPq. O ECOMQI considera que o paradigma do desenvolvimento sustentável pressupõe a institucionalização da inovação e da sustentabilidade nos processos e nas condições políticas, culturais, sociais, técnicas, econômicas e ambientais. Considera a responsabilidade social em seu sentido lato, percebendo as estratégias de adaptação e mitigação às mudanças climáticas como estratégias inteligentes para consolidar a sustentabilidade e assegurar a melhoria da qualidade de vida. O ECOMQI prevê a articulação de políticas e projetos de interesse para o desenvolvimento do tema e a mobilização de competências existentes nos centros de pesquisa, universidades, empresas conscientes, órgãos públicos e de fomento, com vistas a criar sinergias mobilizadoras. Assim atuando, potencializa os esforços no sentido de articular o diálogo e organizar e estimular a promoção do desenvolvimento científico e tecnológico em bases sustentáveis.

No ano de 2011, o PósMQI inseriu-se oficialmente na agenda ambiental da Universidade, propondo um conjunto consistente de indicadores de sustentabilidade para a avaliação dos resultados da implantação da agenda, definidos pela análise dos conteúdos- 
chave expressos nas diretrizes de cada eixo temático (COSTA, 2012). Merecedor do segundo lugar do Prêmio da XV Mostra PUC: Iniciativas Sustentáveis - Sustentabilidade: um compromisso de todos. Categoria: Pós-Graduações, Dissertações e Teses.

No ano de 2012, um segundo trabalho avaliou o potencial do Departamento de Química da Universidade para adotar métodos de Química Analítica Verde, estabelecendo conformidade aos princípios de Química Verde internacionalmente aplicáveis (OLIVEIRA, 2012).

Em 2013, um terceiro trabalho propôs um conjunto de métricas para a valoração dos recursos e serviços ecossistêmicos da palmeira Euterpe edulis Martius (Juçara) na Floresta Atlântica Tropical (FERREIRA, 2013). Trabalho alinhado com as demandas estabelecidas pela Agenda Ambiental da PUC-Rio e pelo Programa Frente Pró-Juçara do estado do Rio de Janeiro (NIMA, 2013), a ser lançado em evento oficial no dia 3 de junho de 2013 na PUC-Rio com o plantio de mil mudas de Juçara no campus da universidade. Entre suas principais ações, cabe salientar que o programa Frente Pró-Juçara estabelece o plantio e o monitoramento de 10 milhões de mudas de Juçara em áreas degradadas de Floresta Atlântica no estado do Rio de Janeiro até 2016.

Atualmente, em colaboração com o Centre for Climate Change Impacts Adaptation \& Modeling (CCIAM) da Faculdade de Ciências da Universidade de Lisboa (FC-UL), o PósMQI ingressou no projeto de colaboração internacional da União Europeia Bottom-up Climate Adaptation Strategies towards a Sustainable Europe(BASE, 2013). Além disso, dois novos trabalhos de mestrado estão sendo desenvolvidos: um dedicado à formulação de métricas e indicadores de ecoeficiência em Estratégia Corporativa de Carbono; e o outro, à formulação de métricas para a análise da pegada de carbono de instituições de ensino superior, tendo como estudo de caso a PUC-Rio.

O PósMQl já possui forte inserção em atividades de P\&D voltadas diretamente à inovação e sustentabilidade nos setores de energia elétrica, petróleo e gás. Entre os projetos, destacam-se: (i) 
Projeto de P\&D Indústrias do Futuro e Tecnologias Emergentes, em parceria com o Centro de Gestão e Estudos Estratégicos, realizado no período de março de 2010 a setembro de 2011; (ii) Projeto de P\&D Produção Limpa: Química Sustentável, Tendências, Novos Negócios e Reciclagem, em parceria com o Centro de Gestão e Estudos Estratégicos (CGEE/MCT), realizado no período de julho de 2009 a fevereiro de 2011; (iii) Projeto de P\&D Light-Aneel P\&D 80/11, em andamento, intitulado Desenvolvimento Tecnológico e Inovação na Utilização de Tecnologia Fotovoltaica e sua Integração Inteligente com a Rede de Distribuição: uma Ação Voltada a Grandes Clientes da Light. Em parceria com a concessionária, o P\&D desenvolve um sistema inteligente acoplado a um sistema supervisório para a conversão fotovoltaica, incluindo monitoramento, controle e gerenciamento da energia solar. Assistido por sensores e equipamentos de aquisição de dados operando em tempo real e contínuo, um sistema fotovoltaico para a geração distribuída será instalado no Museu da Energia da Light, atendendo a demandas específicas de iluminação, integração com a rede e sensibilização do público do Museu para o uso de energias alternativas renováveis. Original na sua concepção, o P\&D incorpora a avaliação complementar da estratégia corporativa de carbono na utilização da energia fotovoltaica.

No âmbito de sua linha de pesquisa Gestão Estratégica, Inovação e Sustentabilidade, atualmente o PósMQI colabora com o Centre for Climate Change Impacts Adaptation \& Modeling (CCIAM) da Faculdade de Ciências da Universidade de Lisboa (FC-UL); com o Programa de Doutorado em Alterações Climáticas e Politicas de Desenvolvimento Sustentável da Universidade de Lisboa, Universidade Técnica de Lisboa e Universidade Nova de Lisboa; com o grupo de pesquisa interinstitucional Rede de Tecnologia da Juçara, que congrega pesquisadores de diversas instituições nacionais; e com os empreendimentos Light - Concessionária de Energia; Petrobrás - Energia; Amável - a Mata Atlântica Sustentável -; e CBPAK Embalagens Compostáveis. 


\section{Considerações finais}

A metrologia-considerada por especialistas como uma espécie de "tecnologia invisivel", cujos resultados nem sempre são facilmente perceptíveis - não necessariamente é compreendida pelos cidadãos comuns ou pelos governos, que, por falta de sensibilidade técnica, não percebem o resultado da sua ação no meio ambiente e o impacto econômico que resulta do uso adequado de sistemas de medição na redução de desperdícios e retrabalho e, principalmente, no seu papel estratégico na construção das modernas sociedades industriais. Ao longo dos anos, a importância da infraestrutura nacional de qualidade (i.e.: acesso a serviços confiáveis de metrologia, normalização e avaliação da conformidade) - um bem público do ponto de vista da teoria econômica - tem sido subestimada no desenvolvimento de políticas econômicas, em que o comércio é um componente essencial. Mas foi apenas uma década atrás que o International Committee of Weights and Measures (CIPM), apoiado pelos diretores dos institutos nacionais de metrologia (NMI) de 38 estados-membros da Convenção do Metro e por representantes de organizações internacionais de metrologia, acreditação e certificação (BIPM, OIML, llac e IAF), introduziu um regime global para estabelecer a equivalência global dos sistemas nacionais de metrologia. Criou-se, assim, a base para o Acordo de Reconhecimento Mútuo (CIPM-MRA), que estabelece o consenso para que medições possam ser intercomparadas. Esse é um passo fundamental para estabelecer consenso mundial de resultados de medições críticas e impactantes (e.g.: qualidade do ar, água, bem estar, pegadas de carbono) que fundamentam os tratados internacionais de manutenção dos recursos e serviços ecossistêmicos.

A busca da elaboração de um modelo de desenvolvimento em bases sustentáveis revela um conjunto de problemas estruturais e traz para as sociedades um desmedido desafio. Tal modelo de desenvolvimento deverá ser capaz de beneficiar esse fenômeno único que é a vida e contribuir para um projeto civilizatório lastreado em parâmetros de prosperidade, dignidade e bem estar, de tal sorte que permaneça para sempre assegurado o capital da vida, esse bem principal da Terra. A conquista da sustentabilidade irá exigir 
uma reforma da mentalidade cultural atual em que o desperdício, a depredação ambiental e o desrespeito às fontes finitas de preservação da natureza foram e estão violentadas avassaladoramente pela força gananciosa do homem, primitivo e incivilizado ainda. Deverá contar para isso com forças revolucionárias naturais da sociedade para que o salto qualitativo para a habitabilidade futura possa ser dado sem impactos negativos no estágio atual da vida social.

As universidades e os programas de pós-graduação cumprem um papel decisivo nessa reavaliação, já que a sustentabilidade não resulta da geração espontânea mecânica, mas da interferência do homem na transformação dos valores que se querem subsistindo à linha da existência. É preciso garantir a confiabilidade e a justa medida dos saberes e indicadores que regem as tomadas de decisão. É preciso compreender os comportamentos, as singularidades, os limites e as condições que regem os processos ecossistêmicos. É preciso qualificar e orientar a inovação para a manutenção das condições de habitabilidade do planeta. Uma vez compreendido o modo como a sustentabilidade se projeta na Terra, na vida e na sociedade, poder-seão formular hipóteses confiáveis para um modelo de desenvolvimento de base sustentável.

Partindo-se do pressuposto de que futuras tecnologias e inovações tecnológicas impulsionarão negócios e relacionamentos mais sustentáveis, propiciando às instituições novas opções de criação e agregação de valor, o desafio é descobrir de que maneira é possível atuar em ambientes cada vez mais complexos. E mais, de ser capaz de incorporar a visão da sustentabilidade social, econômica, ambiental e cultural em suas estratégias, seus processos e suas atividades. Nesse contexto, o PósMQI/PUC-Rio introduz um novo olhar à sua missão institucional e às pesquisas em metrologia, qualidade e inovação. Contribui para tal a interdisciplinaridade que é intrínseca à metrologia, não denotando uma simples justaposição de outras áreas do conhecimento ou aglutinação de esforços estanques desvinculados, mas uma busca de produção de novas e inovadoras soluções para a geração e agregação de novo valor - a sustentabilidade. 
Fundamentado em sua experiência nos últimos 16 anos e atento às novas demandas advindas de uma sociedade da inovação e da informação, o PósMQI/PUC-Rio continuará evoluindo. Suas ações se encaminharão no sentido de preencher um vazio existente na formação de profissionais com vocação interdisciplinar em metrologia e com sólidos conhecimentos complementares, que vão da tecnologia industrial básica à sustentabilidade. Isso sem perder de vista o desafio constante da extensão e o aprofundamento da qualidade, voltados para os interesses do meio acadêmico, do setor industrial e de serviços da sociedade brasileira em geral.

A atenção às inovações e aos novos conhecimentos gerados deve continuar balizando o processo de evolução do Programa de PósGraduação em Metrologia da PUC-Rio à luz do conceito de progresso científico de Dewey (1952, p. 271), para quem "todo gran avance de la ciencia se ha devido a una nueva audacia de la imaginación”. Trazendo para a cena de discussão a inconveniência de se considerar de forma estanque ciência e filosofia, Dewey argumenta que à filosofia cumpre refletir e apropriar-se dos resultados específicos dos conhecimentos gerados, transformando-os em ações práticas que favoreçam o homem. Em sentido convergente, propõe também o reordenamento dos conceitos de arte (estética) e ciência, esmaecendo por completo o entendimento diverso da natureza de cada uma delas: experimentação, inerente à ciência; e impressão, inerente à arte. Isso pelo fato de que em ambos os objetos da expressão/experimentação, os elementos constitutivos naturais e funcionais, permanecem os mesmos, em ambos variando a consequência que depende de valor na sua função de desvelar ou expressar a natureza íntima da natureza.

Não resta dúvida de que a criação de um mundo sustentável necessitará, antes de qualquer medida, da imaginação que crie métodos de convencimento antes de aplicar os conhecimentos e toda a ciência disponíveis para chamar a técnica a serviço de sua implementação.

A PUC-Rio está comprometida com a sustentabilidade. Participa ativamente, em escala global, do debate sobre a sustentabilidade. Definindo o tom, o reitor da universidade é autor de aproximadamente 
60 artigos científicos e 12 livros voltados para as temáticas da educação ambiental, ética socioambiental e espiritualidade ecológica. O seu recente livro Rio+20: Reflexões sobre a sustentabilidade ambiental (SIQUEIRA, 2012) discute a inquietação da sociedade global e regional sobre essa temática, que envolve aspectos econômicos, climáticos e éticos. Na visão do filósofo Danilo Marcondes, que apresenta o livro, o reitor da PUC-Rio

mostra a necessidade de superar a dicotomia entre o ser humano e a natureza, em uma visão integrada da realidade natural em que habitamos. É essa postura da ética do cuidar e da responsabilidade pelo que não é nosso, mas que consiste no meio ambiente que compartilhamos com todos os seres vivos e do qual somos parte integrante, que forma o pano de fundo dessas reflexões. Isso aponta para a adoção de uma racionalidade dialógica e integradora para além da racionalidade instrumental ainda dominante em uma visão da técnica como dominação e submissão da natureza (SIQUEIRA, 2012, prefaciais).

\section{Agradecimentos}

À Capes, pela bolsa de pós-doutoramento (PNPD 2007) concedida a um dos autores, assim contribuindo para a consolidação do pilar da sustentabilidade no Programa de Pós-Graduação em Metrologia para Qualidade, Inovação e Sustentabilidade da PUC-Rio. Ao professor Dr. Luiz Felipe Guanaes Rego, diretor do Núcleo Interdisciplinar de Meio Ambiente (Nima), pela oportunidade de participação do PósMQI na Agenda Ambiental da Universidade e pela criteriosa leitura crítica do texto.

Recebido 21/09/2012

Aprovado 25/07/2013 


\section{Referências bibliográficas}

AGENDA 21. Conferência das Nações Unidas sobre Meio Ambiente e Desenvolvimento. Brasília: Câmara dos Deputados, 1995.

BASE. Bottom-up Climate Adaptation Strategies towards a Sustainable Europe. Disponível em: < http://base-adaptation.eu>. Acesso em: 31 maio 2013.

BOFF, L. Sustentabilidade. O que é? O que não é? Rio de Janeiro: Editora Vozes, 2012.

BRUNTDLAND, G. H. Our common future. The World Commission on Environment and Development. New York: Oxford University Press, 1987.

CARLOWITZ, H. C. Sylvicultura Oeconomica. Anweisung zur wilden Baum-Zucht. Freiberg: Reprint der tu bergakademie, 2000.

COSTA, A. V. O. Indicadores de Sustentabilidade para Instituições de Ensino Superior: Uma Contribuição para a Agenda Ambiental PUCRio. 2012. Dissertação (Mestrado em Metrologia)- Programa de PósGraduação em Metrologia, Pontifícia Universidade Católica do Rio de Janeiro, Rio de Janeiro, 2012.

COPERNICUS GUIDELINES. The university chapter for sustainable development. 1993. Disponivel em: <http://www.iisd.org/educate/ declarat/coper.htm>. Acesso em: 29 ago. 2012.

DEWEY, J. La busca de la certeza: un estudio de la relación entre el conocimiento y la acción. Tradução Eugenio Ímaz. México/Buenos Aires: Fondo de Cultura Económica, 1952.

ELKINGTON, J. Cannibals with forks: The triple botton line of 21st Century Business. Journal of business ethics, v. 23, n. 2, p. 229-231, 1990. 
FERREIRA, L. Avaliação de sustentabilidade e captura de carbono na

Floresta Atlântica Tropical: formulação de métricas e estudo de caso da Euterpe edulis Martius. 2013. Dissertação (Mestrado em Metrologia)Programa de Pós-Graduação em Metrologia, Pontifícia Universidade Católica do Rio de Janeiro, Rio de Janeiro, 2013.

GREENMETRIC UI World Universities Ranking. Guidelines of UI GreenMetric World Universities Ranking 2011. 2012. Disponível em: <http://greenmetric.ui.ac.id>. Acesso em: 27 ago. 2011.

GROBER, U. Modewort mit tiefen Wurzeln: Kleine Begriffsgeschichte von 'sustainability' und 'Nachhaltigkeit'. In: ALTNER, G.; LEITSCHUHFECHT, H.; SIMONIS, U. E. Jahrbuch Ökologie 2003. München: Beck, 2002. p. 167-175.

IPCC. Climate Change: Synthesis Report. Fourth assessment report. An Assessment of the intergovernmental panel on the climate change. Published by the Intergovernmental Panel on Climate Change. Geneva: 2007. p. 44-5.

LELLO Universal. Dicionário Enciclopédico Luso-Brasileiro. v. 2. Portugal: Editora Lello e Irmãos Editores Porto, 1926. p. 1130.

LUKMAN, R. G.; GLAVIC, P. What are the key elements of a sustainable university? Clean Technologies and Environmental Policy, v. 9, p.103$114,2007$.

LUNEBURG DECLARATION on higher education for sustainable development. 2001. Disponível em: <http://portal.unesco.org/ education/en/files/37585/11038209883LuneburgDeclaration. pdf/ LuneburgDeclaration.pdf>. Acesso em: 29 ago. 2012.

MEADOWS, D.; RANDERS, J.; MEADOWS, D. Limits to Growth: The 30Year Update. Vermont: Chelsea Green Publishing Company, 2004.

NIMA - NÚCLEO INTERDISCIPLINAR DE MEIO AMBIENTE. Um fruto brasileiro. Disponivel em: <http://www.nima.puc-rio.br/index. php/pt/todas-as-notas/4115-lancamento-do-projeto-frente-projucara>. Acesso em: 30 maio 2013. 
OLIVEIRA, B. Química Analítica Verde: proposições para a Agenda Ambiental PUC-Rio. 2012. Dissertação (Mestrado em Metrologia)Programa de Pós-Graduação em Metrologia, Pontifícia Universidade Católica do Rio de Janeiro, Rio de Janeiro, 2012.

PUC-RIO - PONTIFÍCIA UNIVERSIDADE CATÓLICA DO RIO DE JANEIRO. Marco Referencial, Estatuto, Regimento, Constituição Apostólica, Ex Corde Ecclesiae. Rio de Janeiro: Editora LibraryThing, 2001.

PUC-RIO/NIMA - PONTIFÍCIA UNIVERSIDADE CATÓLICA DO RIO DE JANEIRO/NÚCLEO INTERDISCIPLINAR DE MEIO AMBIENTE. Agenda ambiental-PUC-Rio. Rio de Janeiro: PUC/Núcleo Interdisciplinar de Meio Ambiente, 2009. Disponível em: <http://www.nima.puc- rio.br>. Acesso em: 21 jan. 2012.

Sobre o NIMA. 2012. Disponivel em: <http://www.nima.pucrio.br>. Acesso em: 21 jan. 2012.

SIQUEIRA, J. C. Ética sócio ambiental. Rio de Janeiro: Editora PUC-Rio, 2009.

Rio $+\mathbf{2 0}$ - Reflexões sobre a sustentabilidade socioambiental. Rio de Janeiro: Editora PUC-Rio, 2012.

SOHN, L. B. The Stockholm Declaration on the human environment. Harvard International Law Journal, v. 14, n. 3, p. 423-515, 1973.

THE TBILISI DECLARATION. Intergovernmental Conference on Environmental Education. Final Report. USSR: 1977. Disponivel em: <http://unesdoc.unesco.org/images/0003/000327/032763eo.pdf>. Acesso em: 29 ago. 2012.

THE TALLOIRES DECLARATION. Association of University Leaders for a Sustainable Future. 1990. Disponivel em: <http://www.ulsf.org/ talloires_declaration.html>. Acesso em: 29 ago. 2012. 
THE HALIFAX DECLARATION. Creating a Common Future: University Action for Sustainable Development. 1991. Disponivel em: <www.iauaiu.net/content/rtf/sd_dhalifax.rtf>. Acesso em: 29 ago. 2012.

THE KYOTO DECLARATION. Ninth International Association of Universities Round. 1993. Disponivel em: <http://www.iisd.org/educate/ declarat/kyoto.htm>. Acesso em: 29 ago. 2012.

THE THESSALONIKI DECLARATION. International Conference Environment and Society: Education and Public Awareness for Sustainability. 1997. Disponível em: <http://resources.spaces3.com/f49d326a-5930-45cfa9ef-4d23a0670a6d.pdf>. Acesso em: 29 ago. 2012.

THE SWANSEA DECLARATION. Association of Commonwealth Universities' Fifteenth Quinquennial Conference. 1993. Disponivel em: <http://www.iisd.org/educate/declarat/swansea.htm>. Acesso em: 29 ago. 2012.

THE UBUNTU DECLARATION. Ubuntu Declaration on Education, Science and Technology for Sustainable Development. 2002. Disponível em: <http:/ / www.ias.unu.edu/sub_page.aspx?catID=108\&ddIID=304>. Acesso em: 29 ago. 2012.

UNCSD/RIO+20. The future we want. 2012. Disponivel em: <http:// www.rio20.gov.br>. Acesso em: 30 ago. 2012.

WORLD declaration on higher education for the twenty-first century: vision and action. 1993. Disponivel em: <http://www.unesco.org/ education/educprog/wche/declaration_eng.htm>. Acesso em: 29 ago. 2012. 


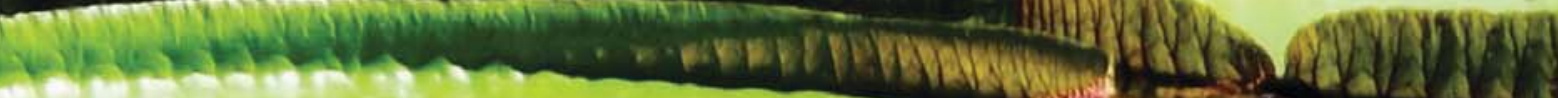

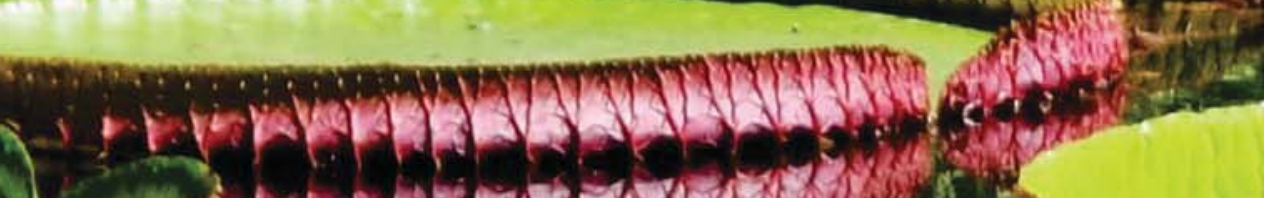
Tinj

197m

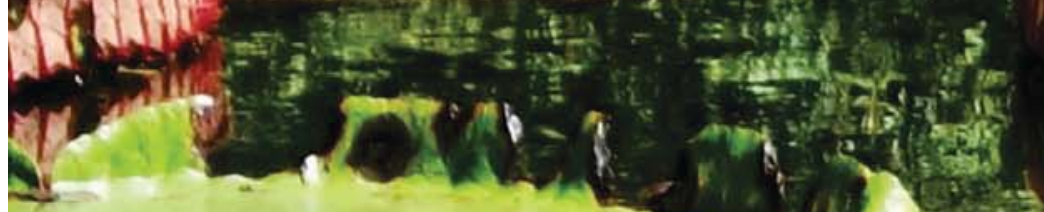

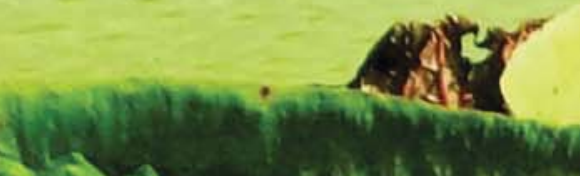

\section{atr}

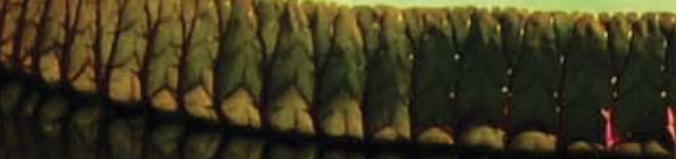

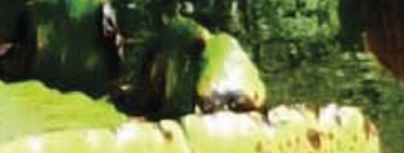

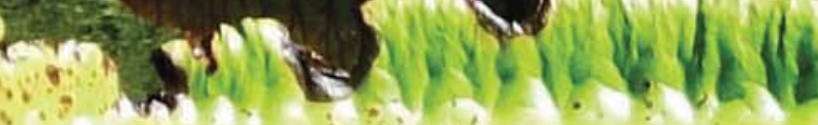
ofle

1972

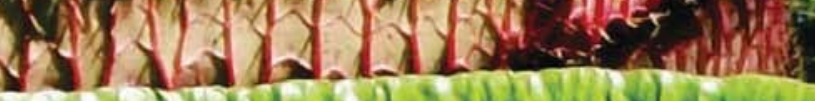

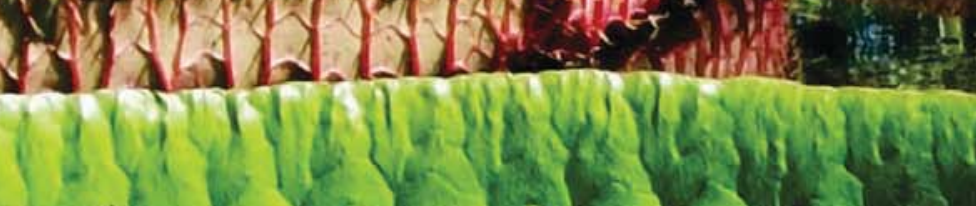

xit

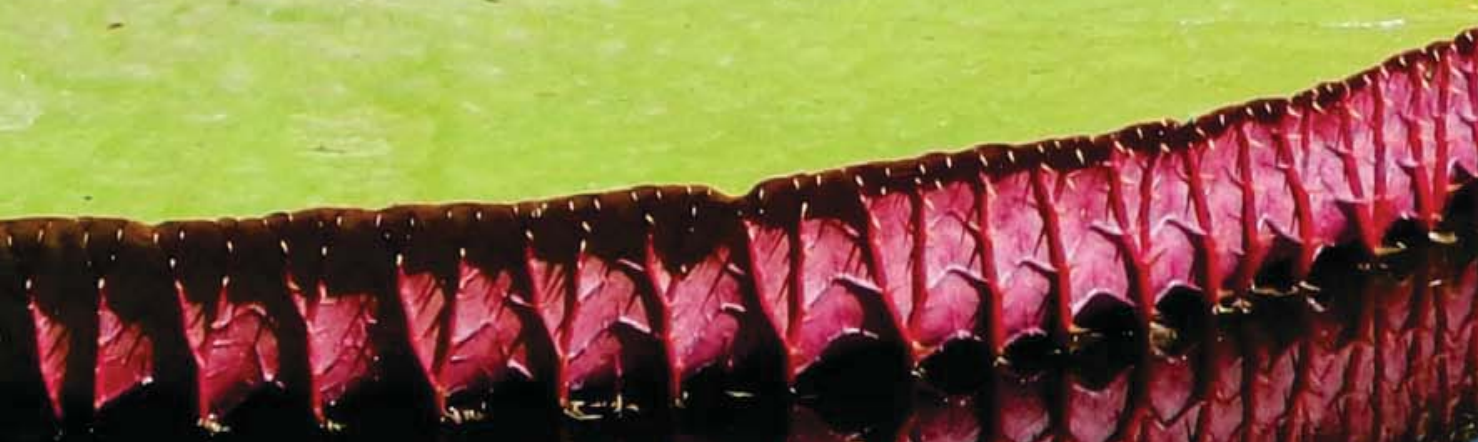

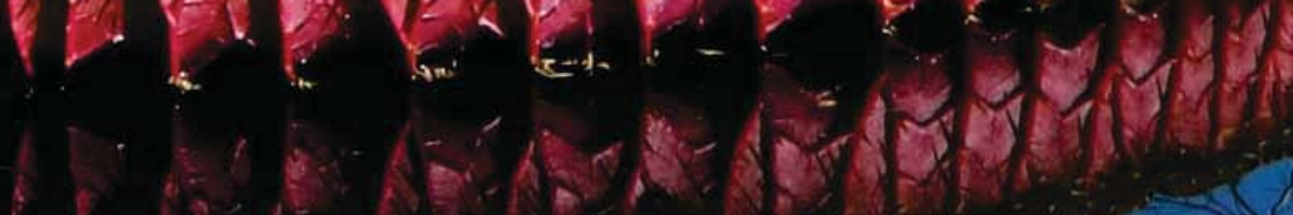




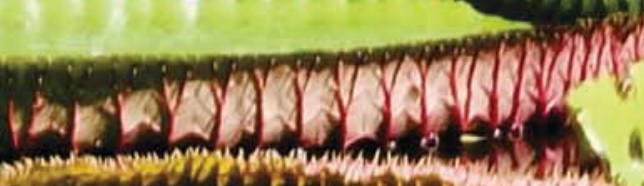

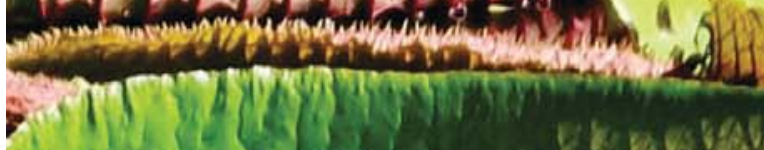

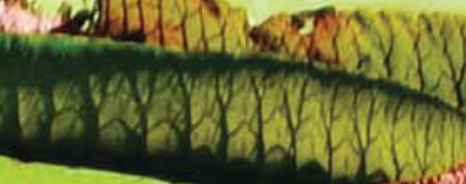

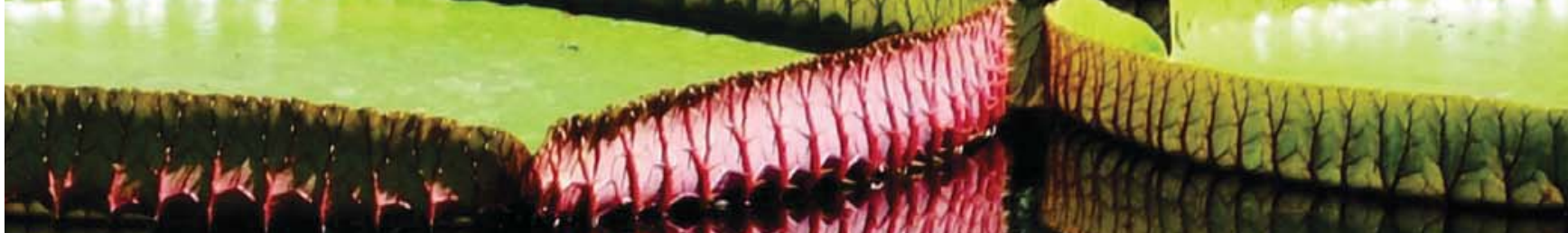

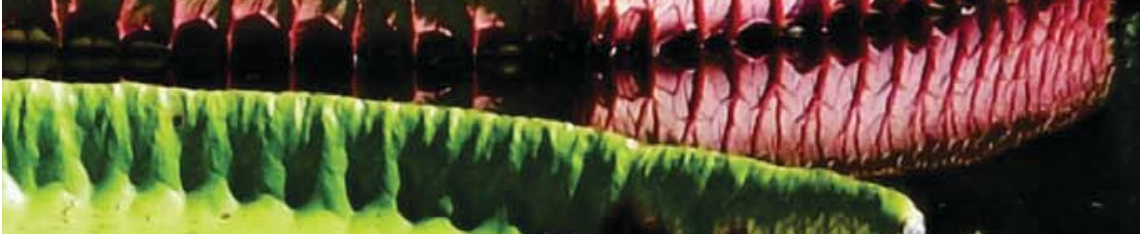
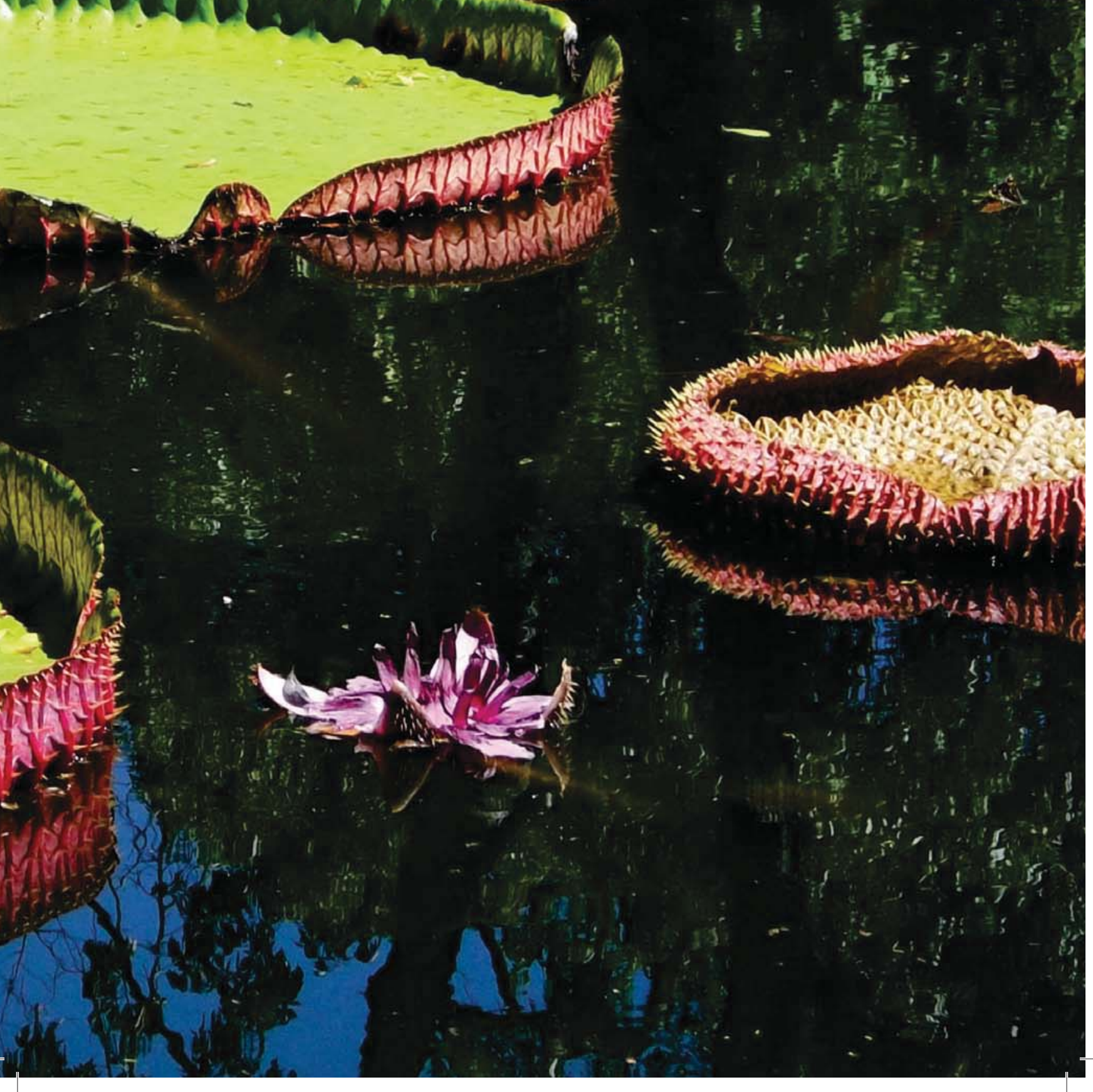
Aprendizagem colaborativa, transdisciplinaridade e gestão socioambiental na Amazônia: abordagens para a construção de conhecimento entre academia e sociedade

Collaborative learning, transdisciplinarity and socioenvironmental management in the Amazon: approaches to knowledge production between academia and society

El aprendizaje colaborativo, la transdisciplinariedad y la gestión socioambiental en la Amazonía: enfoques para la construcción del conocimiento entre la academia y la sociedad

Simone Athayde, PhD em Ecologia Interdisciplinar. Endereço: 381 Grinter Hall. CEP: 30611 - Gainesville, Florida, USA. Telefone: +1(352) 273-4729. E-mail: simonea@ufl.edu.

Wendy-Lin Bartels, PhD em Ecologia Interdisciplinar. Endereço: 102 NW Seminary Avenue. CEP: 32667 - Micanopy, Florida, USA. Telefone:+1(352) 352-222-2672. E-mail: wendylin@ufl.edu.

Robert Buschbacher, PhD em Ecologia. Endereço: School of Forest Resources and Conservation, PO Box 110760, University of Florida. CEP: 32608 - Gainesville, Florida, USA. Telefone:+1(352) 846-2831.E-mail: rbusch@ufl.edu.

Rosane Duarte Rosa Seluchinesk, doutora em Gestão Ambiental pelo Centro de Desenvolvimento Sustentável da Universidade de Brasília (CDS/UnB). Endereço: Rua E-4, 432 - Centro. CEP: 78580000 - Alta Floresta, MT. Telefone: (66) 3521-7643. E-mail: rosane. rosa@unemat.br. 


\section{Resumo}

Este artigo apresenta uma reflexão sobre duas experiências de formação de líderes para a gestão socioambiental colaborativa na Amazônia como contribuição à geração de abordagens para o fortalecimento da pós-graduação na construção de caminhos para o desenvolvimento sustentável. As abordagens inter e transdisciplinar aplicadas foram adaptadas de programas de pós-graduação e formação de lideranças da Universidade da Flórida. Essa abordagem, ainda em construção, tem como objetivo integrar teorias e métodos de sistemas socioecológicos complexos com conceitos e experiências de gestão participativa, bem como elementos da aprendizagem colaborativa e experiencial na educação de adultos. As lições aprendidas apontam para oportunidades e desafios na construção conjunta de conhecimento entre academia e sociedade como paradigma inovador de educação para a sustentabilidade na Amazônia, integrando perspectivas e conhecimentos de diferentes atores sociais.

Palavras-chave: Pós-Graduação na Amazônia. Aprendizagem Colaborativa. Sistemas Socioecológicos Complexos. Pesquisa Participativa. Desenvolvimento Sustentável. Transdisciplinaridade.

\section{Abstract}

This article focuses on two experiences of training leaders for collaborative social-environmental management in the Amazon as a contribution to the generation of approaches for strengthening graduate education for creating innovative paths for sustainable development. The inter and transdisciplinary approach applied was adapted from programs for graduate study and leadership training at the University of Florida. The approach seeks to integrate theories and methods of complex social-ecological systems with concepts and experiences of participatory management, as well as elements of collaborative and experiential learning for adult education. Lessons learned point to opportunities and challenges for the joint construction of knowledge between academia and society as an innovative paradigm of education for sustainability in the Amazon, 
integrating the perspectives and the knowledge of diverse social actors.

Keywords: Graduate Education in the Amazon. Collaborative Learning. Complex Social-Ecological Systems. Participatory Research. Sustainable Development. Transdisciplinarity.

\section{Resumen}

Este artículo presenta una reflexión sobre dos experiencias de formación de líderes para la gestión socioambiental colaborativa en la Amazonía como una contribución a la generación de enfoques para el fortalecimiento del posgrado en la construcción de caminos hacia el desarrollo sostenible. Los enfoques inter y transdisciplinario aplicados son una adaptación de los programas de posgrado y formación de liderazgos en la Universidad de Florida. Este enfoque, todavía en construcción, busca integrar teorías y métodos de sistemas socio-ecológicos complejos con los conceptos y las experiencias de gestión participativa, así como elementos de aprendizaje colaborativo y experiencial en la educación de adultos. Las lecciones aprendidas apuntan a oportunidades y desafíos para la construcción conjunta de conocimiento entre la academia y la sociedad como paradigma innovador de la educación para la sostenibilidad en la Amazonía, integrando perspectivas y conocimientos de diferentes actores sociales.

Palabras clave: Educación de Posgrado en la Amazonía. Aprendizaje Colaborativo. Sistemas Socio-Ecológicos Complejos. Investigación Participativa. Desarrollo Sostenible. Transdisciplinariedad.

\section{Introdução}

Nos últimos 20 anos, desde a primeira Conferência das Nações Unidas sobre Meio Ambiente e Desenvolvimento realizada no Rio de Janeiro em 1992 até a Conferência da Rio+20 em 2012, houve mudanças 
profundas na geração e transmissão do conhecimento científico voltado para o desenvolvimento sustentável. Transformações na ciência e na educação superior não estão isoladas de transformações da sociedade, dos meios de comunicação e de paradigmas do desenvolvimento. 0 próprio conceito de desenvolvimento sustentável tem sido alvo de transformações e sujeito a críticas e revisões. No entanto, a ênfase na interdisciplinaridade como ferramenta de análise e resolução compartilhada de problemas socioambientais, na qualidade de vida das gerações futuras e na integração entre as dimensões social, ecológica e econômica de forma multiescalar (do local para o global e vice-versa) tem sido mantida ao longo dessa trajetória (BRASIL, 2012). Este artigo apresenta uma contribuição para a construção de abordagens inter e transdisciplinares na educação de adultos, visando a capacitação de líderes para a gestão socioambiental colaborativa na Amazônia.

Na educação superior, a perspectiva do desenvolvimento sustentável subentende um processo de transformação do saber que se contrapõe à racionalidade científica baseada em modelos reducionistas e fragmentados, fomentando a construção de um conhecimento interdisciplinar e integrativo. A interdisciplinaridade pode ser entendida como um modo de conhecimento integrador de perspectivas disciplinares em busca de pontos de convergência e diálogo entre os referenciais teóricos e métodos das ciências, sem a fragmentação do fenômeno (FERNANDES; SAMPAIO, 2008). Para Piaget (1972), a interdisciplinaridade compreende o intercâmbio mútuo entre várias disciplinas, tendo como resultado um enriquecimento recíproco. Japiassú (1976) qualifica a interdisciplinaridade pela intensidade das trocas entre os especialistas e pelo grau de integração das disciplinas em um projeto comum. Compartilhar informações e perspectivas passa a ser algo necessário nesse processo em que não há como avançar sem o diálogo entre pesquisadores e enfoques disciplinares.

Na educação de pós-graduação brasileira, a interdisciplinaridade surge impulsionada pela necessidade de interligar saberes e ampliar a cooperação técnico-científica. Em 2008, a Capes redefiniu a Área Multidisciplinar criada em 1999 como Área Interdisciplinar (CAlnter). A existência da CAlnter induziu a proposição de cursos com visão 
interdisciplinar, acompanhando a tendência mundial de aumento de grupos de pesquisa e programas acadêmicos tratando de problemas complexos, que demandam filosofia e práticas interdisciplinares (BRASIL, 2012).

No final de 1980, o paradigma epistemológico da transdisciplinaridade foi estabelecido com mais força no mundo acadêmico, abrangendo formas de conhecimento que se situam além da ciência ocidental e das fronteiras teórico-metodológicas disciplinares (FREITAS; MORIN; NICOLESCU, 1994). A abordagem da transdisciplinaridade ainda é relativamente nova e contestada nos meios acadêmicos. Para alguns, ela significa um modo de construção do saber integrativo que vai além das disciplinas da ciência ocidental, pressupondo o diálogo, as trocas e a integração de saberes entre academia e sistemas de conhecimento de participantes não acadêmicos (TRESS; TRESS; FRY, 2005). Outros autores percebem a transdisciplinaridade como uma filosofia de compreensão do mundo que possibilita a transcendência das disciplinas, em que as ligações entre elas estariam situadas no interior de um sistema total, sem fronteiras estáveis (PIAGET, 1972; NICOLESCU, 2008).

Nos últimos vinte anos, apesar da proliferação de ONGs, políticas e projetos de pesquisa voltados ao desenvolvimento sustentável participativo e focados na escala local, envolvendo processos de construção de conhecimento inter e transdisciplinar, a síntese e o retorno de lições aprendidas e implicações dessas experiências para a prática da educação superior no Brasil ainda requerem esforços e recursos específicos. A relevância dessas experiências em termos de entendimento do processo de construção inter e transdisciplinar, das trajetórias do conhecimento socialmente construído e da possível inserção de modelos alternativos de educação e pesquisa no ensino formal precisa ser sintetizada e socializada (BRASIL, 2012).

Este artigo apresenta uma reflexão sobre dois cursos de formação de lideranças para a gestão colaborativa na Amazônia. Essas experiências situam-se na interface de conceitos e práticas do desenvolvimento participativo e sustentável, da abordagem sistêmica, 
inter e transdisciplinar para a compreensão das inter-relações entre ambiente e sociedade e da aprendizagem colaborativa na educação de adultos. Essas iniciativas foram desenvolvidas por meio de cooperação internacional e de parcerias com instituições de ensino superior da região amazônica, bem como com outras instituições. Por meio da análise e reflexão dessas experiências, visa-se contribuir para a geração de propostas inovadoras para a educação formal e informal na Amazônia, integrando academia e sociedade na construção de um desenvolvimento pluricultural, inclusivo e compartilhado.

\section{Histórico e unidades de análise}

O programa Formação de Lideranças para a Conservação da Amazônia (Amazon Conservation Leadership Initiative - ACLI), financiado pela Fundação Gordon \& Betty Moore, faz parte do Programa de Conservação e Desenvolvimento Tropical da Universidade da Flórida (TCD) O TCD visa fortalecer a educação universitária para a conservação e o desenvolvimento tropical e baseia-se na ação conjunta entre academia e profissionais da conservação; na integração entre disciplinas das ciências sociais e biológicas; e na integração entre teoria e prática (KAINER et al., 2006).

Em dezembro de 2007, foi organizado pelo ACLI em Manaus o workshop intitulado O Estado da Arte da Pós-Graduação na Região Amazônica em Áreas afins à Conservação da Biodiversidade e ao Desenvolvimento Sustentável. Nesse workshop, coordenadores de programas de pós-graduação de 14 universidades, pesquisadores da Universidade da Flórida e outros atores da Amazônia brasileira reconheceram a existência de limitações na capacidade dos PPGs (Programas de Pós-Graduação) no atendimento à demanda do setor no tema de conservação da biodiversidade e desenvolvimento sustentável, tanto no aspecto de geração de conhecimento quanto na formação profissional (ACLI, 2008). Uma das recomendações desse encontro foi para que os PPGs abordem com maior profundidade

ACLI: http://www.sfrc.ufl. edu/ACLI/; TCD: www.tcd ufl.edu. o tema interdisciplinar de conservação da biodiversidade e do desenvolvimento sustentável na Amazônia, destacando o 
estabelecimento de parcerias entre universidades, outras instituições e atores sociais.

O curso de formação de lideranças realizado em Alta Floresta, MT, em 2009, foi um seguimento a essa trajetória. A partir desse curso, foi formado um grupo de pessoas interessadas em aprender e trabalhar de forma colaborativa no estudo e na gestão de paisagens amazônicas. Foi criado o grupo de pesquisa do CNPq Água, Floresta e Gente, seguido pelo desenvolvimento de um segundo curso, dessa vez, formalizado como especialização lato sensu, com duração de dois anos.

As unidades de análise exploradas neste artigo são esses dois cursos de formação de lideranças para a gestão socioambiental na Amazônia realizados em Mato Grosso. O primeiro é a experiência de capacitação informal, denominado ao longo do artigo Curso de Alta Floresta. O segundo é o curso formal de especialização, denominado Curso de Cotriguaçu. O foco de análise é o processo de construção do conhecimento inter e transdisciplinar por meio da aprendizagem colaborativa entre grupos de participantes e entre eles e grupos de atores sociais da região amazônica.

\section{1) Curso informal de capacitação de lideranças (Curso de Alta Floresta)}

O curso Desenvolvendo Estratégias Colaborativas para a Gestão Socioambiental na Amazônia Brasileira foi realizado pela Universidade da Flórida em Alta Floresta em julho de 2009, com duração de 15 dias. Reuniu 19 participantes de sete universidades amazônicas (federais do Acre, Amapá, Amazonas, Pará, Rondônia e Tocantins e estadual do Mato Grosso), incluindo três coordenadores de programas de pós-graduação. O enfoque multidisciplinar e multi-institucional foi aperfeiçoado pela inclusão de representantes do governo estadual, do setor privado, do povo indígena Kaiabi e de ONGs no curso. O curso teve como objetivo instrumentalizar os participantes para enfrentar desafios ligados à gestão socioambiental na Amazônia, entendendo a diversidade de usos da terra, atores sociais e políticas públicas representados na região de estudo. 


\section{2) Curso de pós-graduação lato sensu (Curso de Cotriguaçu)}

O curso de especialização Gestão Colaborativa de Sistemas Sócio-Ecológicos Complexos na Amazônia Brasileira foi um desdobramento do curso de Alta Floresta, realizado graças a uma parceria entre a Universidade da Flórida e a Universidade do Estado do Mato Grosso (Unemat), com apoio da Prefeitura de Cotriguaçu, da Secretaria de Estado do Meio Ambiente do Mato Grosso (SemaMT) e do Instituto Centro de Vida (ICV). O curso enfocou a região de Cotriguaçu, MT, e teve duração de dois anos (2010 a 2012), com quatro módulos presenciais de, em média, 10 dias, além de atividades intermódulos. Os 23 participantes representaram diversas áreas disciplinares, instituições e experiências de gestão na Amazônia. Concomitantemente ao curso, foi executado o projeto de pesquisa Desenvolvendo um Modelo de Gestão Socioambiental Colaborativa em um Programa de Pagamento por Serviços Ambientais no Estado de Mato Grosso, com financiamento da Fundação de Amparo à Pesquisa do Estado de Mato Grosso (Fapemat).

\section{Abordagem teórico-metodológica}

Gibbons etal. (1994), no livro “A nova produção do conhecimento” (The new production of knowledge), descreveram a emergência de um outro modo de produção de conhecimento científico, distinto da produção convencional acadêmica, a que chamaram de modo 2 de geração de conhecimento, em oposição ao modo 1 ou à ciência convencional. Entre os paradigmas que fundamentam a transformação da produção de conhecimento defendida pelos autores estão o contexto de aplicação, a transdisciplinaridade, a heterogeneidade de locais e públicos envolvidos, a reflexividade, a responsabilidade social e o controle diferenciado de qualidade dessa produção.

No Brasil, na década de 1960, Paulo Freire apontava o diálogo entre saberes e a aprendizagem colaborativa como caminhos da educação para a liberdade e pregava a construção de conhecimento entre ciência e sociedade como uma prática político-social. Freire 
enfatizou a valorização dos conhecimentos locais, a construção do conhecimento a partir da realidade dos sujeitos e a quebra da distinção entre pesquisador e objeto de pesquisa para um modelo de aprendizagem colaborativa entre professor e aluno, pesquisador e pesquisado e, em última instância, ciência e sociedade (FREIRE, 1967; 1970; 1985). Em suas reflexões e práticas educativas, Freire já trazia elementos para um modo de construção de conhecimento pluriepistemológico, que transcende as fronteiras acadêmicas.

Na convergência entre a crise educacional e a crise do modelo convencional de desenvolvimento top-down (de cima para baixo), é que surgem, mais fortemente a partir dos anos 1980, as abordagens participativas para o desenvolvimento, que utilizam preceitos do modo 2 de produção de conhecimento (CHAMBERS, 1994). O conhecimento não é transferido do professor ao aluno ou do técnico ao ator social, mas gerado por meio de um processo de aprendizagem colaborativa, integrando referenciais teóricos e conhecimentos práticos, direcionado à resolução de problemas. Embora existam muitas abordagens, críticas e percepções sobre o desenvolvimento participativo, um dos preceitos dessa abordagem é o foco no direito à participação e na aprendizagem colaborativa, levando ao empoderamento de comunidades locais para tomar decisões de forma autônoma (Ibidem).

As transformações na educação, pesquisa e extensão reificadas no primeiro encontro da Rio 92 coincidiram com a abertura política no País, com o início da crise e conscientização ecológica, com a crise do conhecimento científico disciplinar, com a crise do modelo capitalista de desenvolvimento e, por fim, com a crise do colonialismo científico da ciência ocidental (SANTOS, 2009). Nesse cenário de transformações, a transdisciplinaridade surgiu como uma proposta de construção de conhecimento que transcende as disciplinas acadêmicas e possibilita a incorporação de uma pluralidade de epistemologias, acadêmicas e não acadêmicas, na análise de um problema comum.

É importante considerar que a transdisciplinaridade, entendida como modo de construção de conhecimento ou paradigma epistemológico, não necessariamente nos ensina como esse saber plural e multidimensional pode ser construído. Daí a importância 
de se buscar elementos pedagógicos e filosóficos para qualificar, sintetizar e compartilhar as experiências transdisciplinares. No caso dos dois cursos discutidos neste artigo (Alta Floresta e Cotriguaçu), foram realizadas experiências para conciliar abordagens sistêmicas interdisciplinares com elementos de aprendizagem colaborativa e experiencial na educação de adultos, integrando princípios de pesquisa e desenvolvimento participativo. A abordagem teórico-metodológica aplicada nos dois cursos é sintetizada na Figura 1. De acordo com essa abordagem, o conhecimento gerado no processo transdisciplinar deve ser reintegrado, tanto para o desenvolvimento científico, como para a resolução de problemas da sociedade.

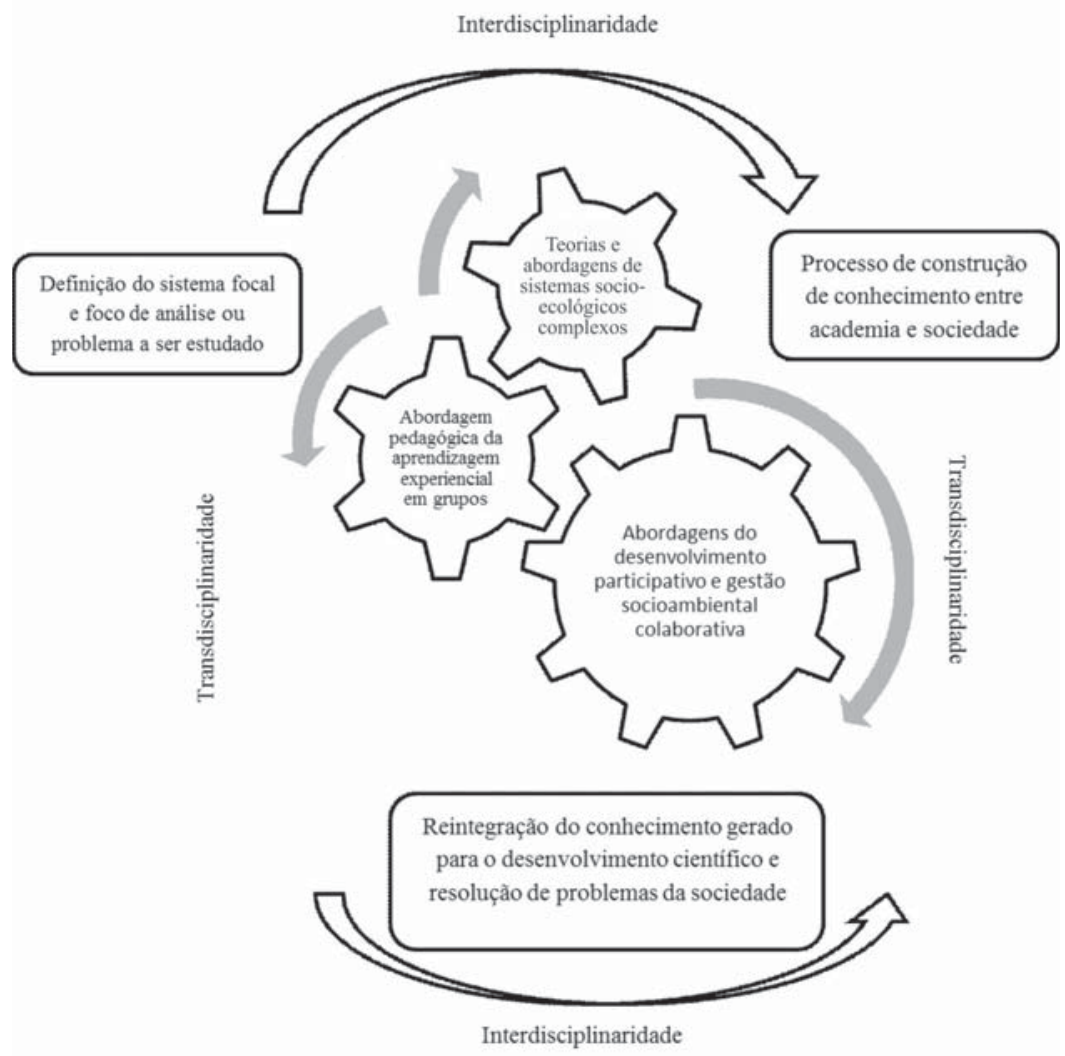

Obs.: 0 processo de construção do conhecimento inter e transdisciplinar ocorre com a integração de teorias e métodos de pesquisa e desenvolvimento participativo, da aprendizagem experiencial na educação de adultos e da abordagem de sistemas socioecológicos complexos.

Figura 1. Abordagem teórico-metodológica adotada nos cursos de formação de lideranças para a gestão colaborativa de sistemas socioecológicos na Amazônia 
Em ambas as experiências, foram aplicados métodos e ferramentas para a análise de sistemas socioecológicos complexos, adaptados de um manual para a avaliação da resiliência desenvolvido pelo grupo de cientistas denominado Aliança para a Resiliência (Resilience Alliance ${ }^{2}$ ). Esse grupo, um corpo teórico interdisciplinar para o estudo integrado das relações entre os sistemas ecológicos e sociais, desenvolveu a abordagem de sistemas socioecológicos (GUNDERSON; HOLLING, 2002). Nos dois cursos, foram aplicados elementos de avaliação da resiliência como arcabouço teórico de condução de análises e exercícios de pesquisa realizados entre os participantes e entre eles e atores sociais regionais. Como exemplo, uma etapa inicial na aplicação dessa metodologia envolve a análise da história do sistema, visando a identificação de fatores de mudança, levando ao entendimento de como o sistema se reorganiza e reage a perturbações. A resiliência pode ser traduzida como a capacidade de um sistema para absorver perturbações e reorganizar-se frente à mudança, mantendo funções, estrutura e mecanismos essenciais para sua existência (WALKER et al., 2004). O conceito de resiliência tem sido defendido como paradigma para a sustentabilidade por reconhecer o aspecto dinâmico e interativo dos sistemas socioecológicos, seus ciclos, suas reorganizações, escalas, interações e propriedades emergentes (FOLKE et al., 2002).

A pedagogia adotada nos cursos baseia-se na teoria e na prática do aprendizado experiencial, adaptada para a educação de adultos e integrada à formação de lideranças para o trabalho colaborativo (O'LEARY; BLOMGREN; CHOI, 2010). Alguns métodos para a formação de líderes foram adaptados do Instituto de Formação de Lideranças para o Manejo de Recursos Naturais da Universidade da Flórida ${ }^{3}$ (NRLI). Em oposição à liderança top-down ou hierárquica, em ambos os cursos visou-se a capacitação de líderes para colaboração, qualificados para resolver problemas complexos que requerem o entendimento interdisciplinar e a colaboração entre múltiplos atores. Foram desenvolvidas habilidades para gerir processos dinâmicos associados a disputas e conflitos na gestão de recursos naturais por atores sociais com interesses, conhecimentos e sistemas de manejo diferenciados (e muitas vezes incompatíveis). Os métodos foram aplicados visando propiciar aos participantes a possibilidade de ouvir as perspectivas dos

www.resalliance.org/index.php/resilience_assessment.

${ }^{3}$ http://nrli.ifas.ufl.edu/ 
atores e então refletir como um grupo sobre as implicações dessas visões. A busca de conceitos fechados não é o objetivo maior a ser atingido no processo educativo, e sim o compartilhamento de diversos entendimentos e experiências sobre conceitos e problemas, gerando novas ideias e formas de análise (FREIRE, 1985).

O desenvolvimento de competências específicas na formação de lideranças para o trabalho colaborativo ocorreu por meio da aplicação de ferramentas para o desenho de processos de facilitação para o diálogo e a aprendizagem em grupo entre o grupo de participantes e entre eles e atores sociais das regiões de Alta Floresta e Cotriguaçu. Dessa forma, os participantes foram preparados para o trabalho em equipe, exercitando a liderança colaborativa em suas atividades profissionais pela compreensão do funcionamento de grupos e redes (O'LEARY; BLOMGREN; CHOI, 2010).

A teoria do aprendizado experiencial aplicada nos cursos tem origem em abordagens da educação para a liberdade e psicologia da educação desenvolvidas por educadores e teóricos como Paulo Freire no Brasil e David Kolb nos Estados Unidos. Esse corpo teóricometodológico apresenta uma crítica à abordagem tradicional focada na transferência de conhecimento professor-aluno que, segundo os autores, limita a capacidade dos estudantes de se tornarem aprendizes independentes (FREIRE, 1967; KOLB, 1984). Por meio da incorporação do ciclo de aprendizagem experiencial ou vivencial proposto por Kolb (1984) no desenho e desenvolvimento dos cursos, o processo de aprendizado dos estudantes foi potencializado (Figura 2). 0 ciclo inicia-se proporcionando experiências concretas que desencadeiam observações e reflexões. Educandos traduzem suas reflexões em conceitos abstratos e começam a envisionar implicações para novas ações. Finalmente, a experimentação e o teste de novas ideias proporcionam experiências concretas que levam o sujeito a repetir o ciclo de aprendizagem (Ibidem). 


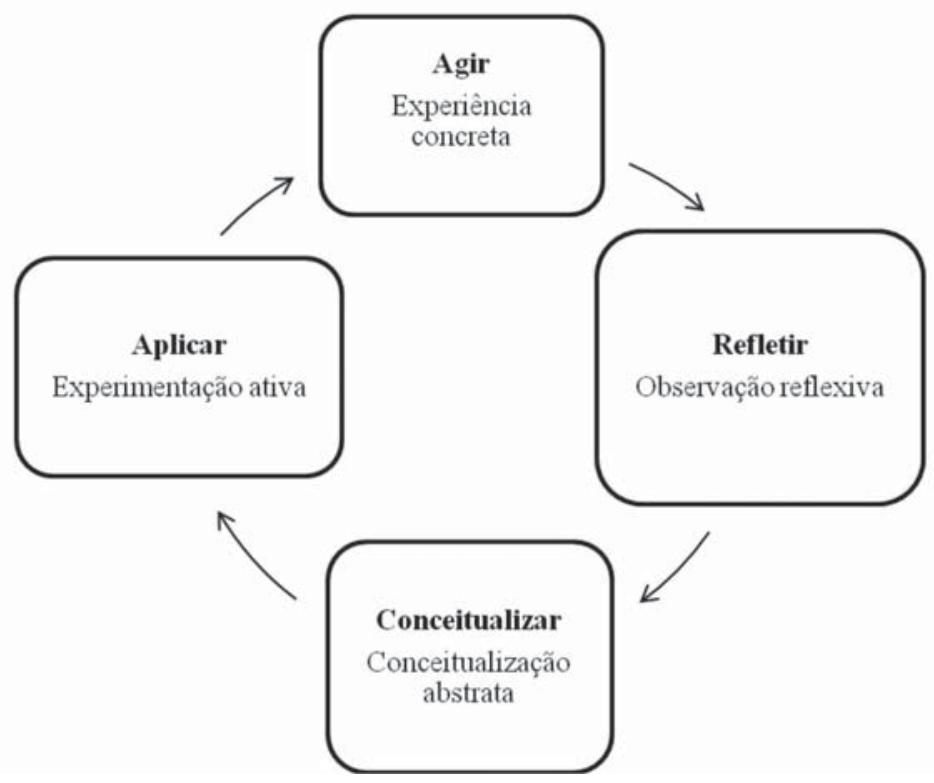

Obs.: O ciclo compreende quatro etapas, iniciando com uma ação ou experiência concreta, seguida por uma reflexão individual ou em grupo, seguida pela conceitualização ou revisão teórica da temática em análise e, por fim, da aplicação da aprendizagem experiencial, que é novamente vivenciada em futuras ações.

\section{Figura 2. Ciclo de aprendizagem experiencial de Kolb (1984)}

Na abordagem da aprendizagem experiencial, os participantes são incentivados a reconstruir a sua própria experiência, de forma que o aprendizado é visto como um processo, em oposição a um resultado ou produto. À medida que os participantes movem-se entre modos de pensar, sentir, refletir e agir, desavenças, diferenças e conflitos tornamse catalisadores no processo de aprendizagem (KOLB; KOLB, 2005).

Para possibilitar a construção do conhecimento inter e transdisciplinar, foram usadas ferramentas e dinâmicas de aprendizagem em grupo, diálogo facilitado, entrevistas e visitas a campo com atores sociais locais, palestras com especialistas, discussão de filmes, feira de experiências, painéis mistos (tipo mesa redonda) com atores sociais representando conhecimentos e perspectivas diferenciados, exercícios de cenários e discussão facilitada de leituras. Ferramentas e métodos como grupos de monitoramento, diálogo facilitado e reflexão individual e em grupo foram utilizados para assegurar a meta-aprendizagem e potencializar as trocas entre os saberes disciplinares e o conhecimento dos atores locais. Grupos de 
monitoramento foram formados entre os participantes para relembrar as atividades realizadas no dia ou período anterior, bem como para trazer elementos importantes sobre a dinâmica de aprendizagem do grupo e a condução das atividades. Esses grupos foram criativos no desenvolvimento de atividades e processos de reflexão (que também levam a quebrar o gelo e descontrair o grupo), documentados em um livreto contendo uma coletânea das dinâmicas realizadas no Curso de Cotriguaçu (ATHAYDE; BARTELS; BUSCHBACHER, 2011).

No curso de Alta Floresta, a abordagem para a participação dos atores e para a inclusão de suas perspectivas no entendimento do sistema socioambiental da região incluiu, em um primeiro momento, palestra técnica sobre setores econômicos, panoramas regionais e/ou políticas públicas. Em seguida, foram realizadas visitas a campo com entrevistas que permitiram conhecer melhor a diversidade de atores locais e as condições em que eles vivem. Os painéis de discussão propiciaram o diálogo com e entre atores, representando diversos setores produtivos e pontos de vista. No fim do curso, os participantes apresentaram as análises e os modelos de entendimento da realidade aos atores sociais.

O processo de avaliação foi desenvolvido de modo a propiciar uma reflexão contínua sobre as aprendizagens a nível individual e de grupo, por meio de ensaios de reflexão individuais e avaliações formais após e entre cada etapa presencial. Os participantes foram incentivados a manter um diário de aprendizagem, em que anotavam as principais aprendizagens durante as etapas presenciais.

\section{Estrutura dos cursos e lições aprendidas no Mato Grosso}

No primeiro curso em Alta Floresta, o planejamento e a coordenação das atividades foram desenvolvidos por um grupo de três coordenadores durante quatro meses. A familiaridade prévia desses indivíduos com a abordagem teórica e metodológica aplicada, bem como a experiência de pesquisa e trabalho na Amazônia, foram elementos-chave para o sucesso do curso. Já no curso de Cotriguaçu, realizado como continuidade ao de Alta Floresta, foram encontradas 
barreiras no processo de planejamento. Houve a tentativa de fazerse um planejamento participativo do curso com o envolvimento do grupo recém-formado em Alta Floresta. No entanto, dificuldades de distância, disponibilidade de tempo, agendas conflitantes e,sobretudo, a falta de esclarecimento suficiente de funções e papéis entre os participantes dificultou o processo de planejamento. Uma primeira lição aprendida foi que a fase de planejamento requereria muito mais tempo, dedicação e estratégia para ser realizada de forma participativa e compartilhada, possibilitando evitar conflitos que se seguiram. Enquanto o curso de Alta Floresta foi informal e de curta duração, o curso de Cotriguaçu foi formalizado como curso de pós-graduação lato sensu, o que dificultou a flexibilização de atividades e engessou alguns procedimentos administrativos necessários.

Nas duas experiências, para o processo de seleção dos participantes, levou-se em consideração a representatividade da diversidade de experiências, áreas disciplinares e instituições atuantes na Amazônia. Também foi estabelecido que houvesse representantes de comunidades locais com experiências e formações variadas. No curso de Alta Floresta, houve a participação de uma pessoa do setor de exploração florestal local e de um representante do povo indígena Kaiabi. No curso de Cotriguaçu, houve a participação de quatro representantes locais, um do setor de exploração florestal, um representante da Secretaria de Agricultura, uma representante da Sema-MT e uma representante do setor da produção pecuária. Essa diversidade de participantes atendeu a um dos princípios norteadores da abordagem, que busca potencializar o próprio grupo como espaço de aprendizagem para entendimento e manejo da diversidade social representada na região Amazônica.

No curso de Alta Floresta, foi dada ênfase para a análise de políticas públicas relevantes para o desenvolvimento sustentável na região e para como diferentes atores sociais representando setores socioeconômicos regionais participam das políticas em questão, entendem-nas e as afetam. O cerne do curso foi uma análise de três sistemas de uso da terra da região. No decorrer do curso, os estudos dos setores foram ficando mais complexos e mais aprofundados, 
complementando as análises e metodologias usadas nos subsistemas anteriores. O curso iniciou-se com o setor florestal focando de forma bem específica no potencial de reflorestamento com plantações de teca (Tectona grandis) como alternativa para o desafio da indústria em garantir uma oferta adequada de matéria-prima. Em um segundo momento, abordou-se o setor agrícola, examinando uma política pública específica do governo estadual denominada MT Legal, que implica a regularização e o licenciamento de propriedades rurais. 0 terceiro subsistema teve como foco de análise as áreas protegidas, inseridas no contexto do mosaico regional de diferentes usos da terra, incluindo unidades de conservação públicas e privadas e terras indígenas.

No curso de Cotriguaçu, os quatro módulos presenciais foram organizados de forma a proporcionar um entendimento progressivo da região como um sistema sócio-ecológico, abrangendo o seu contexto histórico, as atividades econômicas, o meio ambiente e os atores sociais que determinam a dinâmica da paisagem regional. Durante esses módulos, os participantes desenvolveram projetos em grupo, chamados de projetos demonstrativos, visando a aprendizagem e o teste da metodologia de avaliação da resiliência a partir do engajamento com grupos de atores sociais locais.

Em Cotriguaçu, diferentes atores interagem a partir de sistemas específicos de conhecimento, uso e gestão da terra. Em contraste com o curso de Alta Floresta, o curso de Cotriguaçu foi iniciado com uma pergunta ampla: "Como manter a viabilidade dos sistemas de gestão da terra e dos recursos naturais na região?”. Essa pergunta possibilitou aos participantes maior flexibilidade e abertura para ouvir os atores sobre suas expectativas, dificuldades e seus objetivos. Além do mais, dificultou a integração entre os atores e a existência de um fio condutor comum. Os participantes foram divididos por grupo de atores sociais presentes no município, além de um quarto grupo que aplicou a abordagem teórico-metodológica do curso junto a comunidades ribeirinhas em Rondônia e no Amazonas.

Os quatro grupos de trabalho organizados para o curso de Cotriguaçu foram: 
- Agricultura familiar, principalmente assentamentos rurais;

- Médios e grandes produtores rurais (setores de produção florestal e pecuária);

- Povos indígenas (povo indígena Rikbaktsa); e

- Populações tradicionais (ribeirinhos da região de Porto Velho, RO, e do baixo Rio Negro, AM).

Esses grupos foram mantidos até o final do curso, o que, por um lado, facilitou o aprofundamento da análise daquele grupo social, mas, por outro, limitou a troca e a interação entre os participantes. Apesar do esforço empreendido no sentido de criar atividades para a ligação e integração entre os grupos com a aplicação do exercício de avaliação da resiliência, eles acabaram ficando relativamente isolados. A integração da análise dos diferentes sistemas socioecologicos representados pelos grupos de atores que convivem na paisagem de Cotriguaçu acabou acontecendo somente no último módulo do curso, por meio da realização de um exercício de cenários. No primeiro módulo, criouse um grupo transversal de recursos hídricos, organizado por tema socioambiental em vez de por setor ou ator regional, como nos outros grupos. Foi uma experiência interessante, pois mostrou a importância da criação de variáveis e temas transversais de análise para possibilitar a ponte entre disciplinas, grupos de atores e contrastes entre os conhecimentos locais.

Entre as etapas presenciais, foram desenvolvidos projetos aplicados de pesquisa pelos participantes. Nesses projetos, os participantes realizaram pesquisa junto a grupos de atores sociais locais, sintetizados em monografias individuais de conclusão de curso. Os participantes desenvolveram pesquisas sobre a história regional, percepção ambiental, as políticas públicas para a conservação e o desenvolvimento na Amazônia, o uso e manejo de recursos naturais, as redes sociais e os sistemas produtivos em Cotriguaçu. Dois participantes desenvolveram pesquisas em outras regiões da Amazônia deslocamento forçado pela barragem de Jirau em Rondônia e dinâmica da pesca no Amazonas (grupo populações tradicionais) - e uma participante desenvolveu pesquisa sobre o conceito de colaboração como percebido pelo grupo de participantes. Para aprofundar os conhecimentos teóricos 
e acompanhar esses projetos aplicados, foram organizadas reuniões mensais a distância (via internet) entre as etapas presenciais, com a manutenção de uma página na internet para compartilhamento de bibliografia e outros documentos técnicos entre o grupo.

Um exemplo de conhecimento transdisciplinar trazido pela interação dos participantes do grupo indígena com representantes do povo Rikbaktsa foi a reflexão sobre o conceito de território. 0 grupo percebeu que, segundo a concepção Rikbaktsa, todas as áreas ancestralmente ocupadas por eles fazem parte de seu território, mesmo estando geograficamente separadas. Nesse caso, o foco de análise do grupo indígena na Terra Indígena Escondido, localizada no município de Cotriguaçu, teve que ser ajustado para incluir as outras áreas Rikbaktsa no Mato Grosso. Ou seja, a concepção Rikbaktsa de território parece transcender as fronteiras disciplinares ocidentais da geografia e da biofísica. Foi importante a abordagem do grupo indígena de ouvir e aproximar-se dos Rikbaktsa sem um referencial teórico ou uma pergunta de pesquisa fechados, possibilitando abertura à percepção de outras visões de mundo, nesse caso, diferenciadas da ciência ocidental.

É importante ressaltar que o trabalho de engajamento dos atores durante os dois cursos foi um exercício de aplicação do método. Em uma situação real de pesquisa participativa, a participação dos atores no planejamento e na execução da pesquisa aconteceria de forma mais profunda e em um horizonte de tempo adequado às especificidades dos atores e objetivos de pesquisa ou do processo em questão.

\section{Produtos e retorno de resultados para a população local}

Em ambas as experiências, houve eventos para a apresentação e devolução de resultados para a população local. Nesses eventos, os participantes se organizaram em grupos, criando atividades lúdicas para serem desenvolvidas com os visitantes. As diferentes fases de uma pesquisa participativa foram, dessa forma, exercitadas pelos participantes em seu ciclo completo: aproximação, trabalho conjunto 
com atores e compartilhamento de resultados de pesquisas (mesmo que em caráter preliminar), como abordagem filosófica de construção de conhecimento conjunto entre os participantes e grupos de atores sociais. Em Cotriguaçu, foi realizada a Feira de Conhecimentos de Cotriguaçu, que contou com a participação de moradores das áreas urbana e rural do município. Nesse evento, o grupo de participantes organizou atividades lúdicas com as crianças; a montagem de uma linha do tempo interativa contando a história do município junto com os moradores; uma exposição fotográfica sobre o Povo Rikbaktsa; e a exposição de pôsteres resultantes das monografias realizadas pelos participantes (Figura 3).

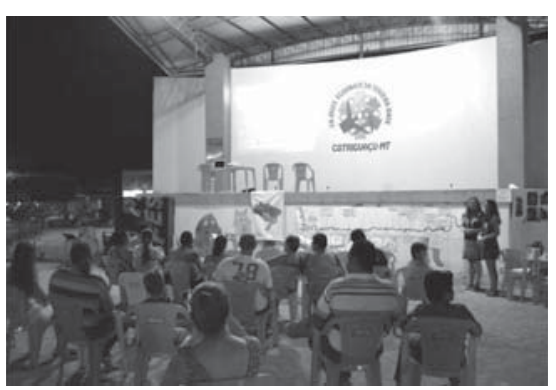

A

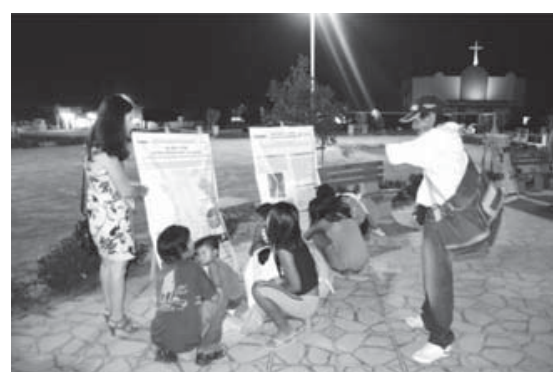

C

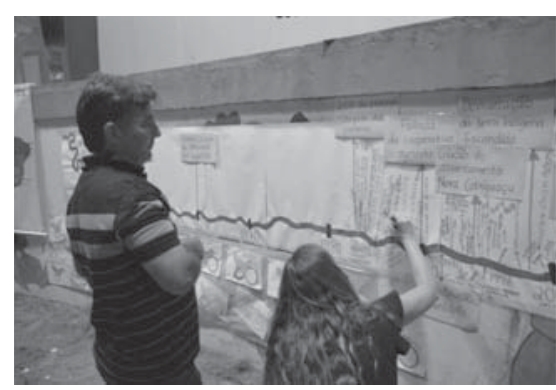

B

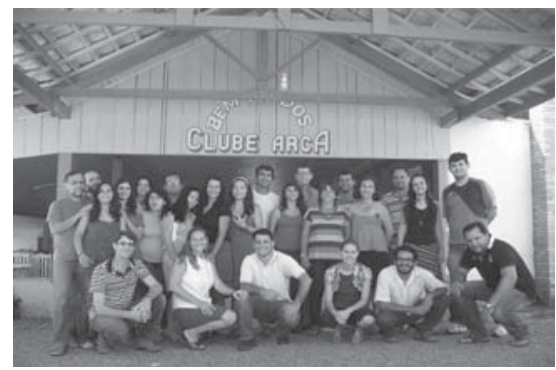

D

Fotos: Simone Athayde.

Figura 3. Curso de especialização lato sensu Gestão Colaborativa de Sistemas Socioecologicos Complexos na Amazônia Brasileira. A-C: Feira de Conhecimentos de Cotriguaçu, evento realizado na praça municipal. A. Projeção de slides e explicação dos resultados do curso para a população de Cotriguaçu. B. Construção de uma linha do tempo interativa com os visitantes, contando a história local. C. Exposição de pôsteres sobre as monografias dos participantes, com visita de representantes do povo indígena Rikbaktsa. D. Grupo de participantes, atores locais e professores do curso 
Os produtos elaborados pelos participantes do curso de Alta Floresta foram modelos preliminares da interação de variáveis socioambientais críticas em setores regionais-chave - manejo florestal, agropecuária e conservação - e cenários de possíveis futuros com e sem governança (BUSCHBACHER; ATHAYDE; BARTELS, 2010). No curso de Cotriguaçu, os produtos gerados foram monografias de conclusão de curso, relatórios de grupo e outros produtos em elaboração (livro para o público em geral e artigos científicos). Cabe ressaltar que os exercícios de pesquisa e as ferramentas de análise dos contextos regionais foram aplicados com o objetivo de desenvolver habilidades e aplicar a pedagogia da aprendizagem colaborativa, gerando subsídios para a gestão regional. No entanto, é necessário um esforço sistemático de examinar e revisar os resultados com os atores locais para uma descrição detalhada do sistema regional em ambos os casos.

Como indicador de sucesso, as atividades de adaptação e reaplicação dessas abordagens foram desenvolvidas pelos próprios participantes. Um curso de capacitação foi liderado por professores da Universidade Federal do Acre (Ufac) e por alguns participantes dos cursos de Alta Floresta e Cotriguaçu em 2010. Um novo curso de especialização está sendo implementado em Alta Floresta para técnicos das instituições ICV (Instituto Centro de Vida) e IOV (Instituto Ouro Verde). Princípios e aprendizagens dessa abordagem estão sendo aplicados no desenvolvimento de um Programa Internacional de Pesquisa Integrativa sobre Barragens Hidroelétricas na Amazônia, uma cooperação entre as universidades federal de Rondônia, do Tocantins e a estadual do Mato Grosso e a Universidade da Flórida.

\section{Reflexão: transdisciplinaridade, aprendizagem colaborativa e educação de adultos na Amazônia}

Os dois cursos trouxeram aprendizagens em diversos niveis e escalas, desde a escala pessoal ou individual, passando pela escala 
dos grupos de participantes, que levam essas experiências para suas instituições e para o sistema amazônico. Pode-se entendera construção do conhecimento transdisciplinar como um conjunto de escalas que se autoalimentam, como no conceito de panarquia, apresentado pelos cientistas que desenvolveram a abordagem dos sistemas socioecológicos complexos (GUNDERSON; HOLLING, 2002). Na Figura 4, é apresentado um diagrama ilustrativo dessa multidimensionalidade e das escalas de aprendizagens e conhecimentos trocados entre academia, atores sociais e instituições dentro do paradigma transdisciplinar.

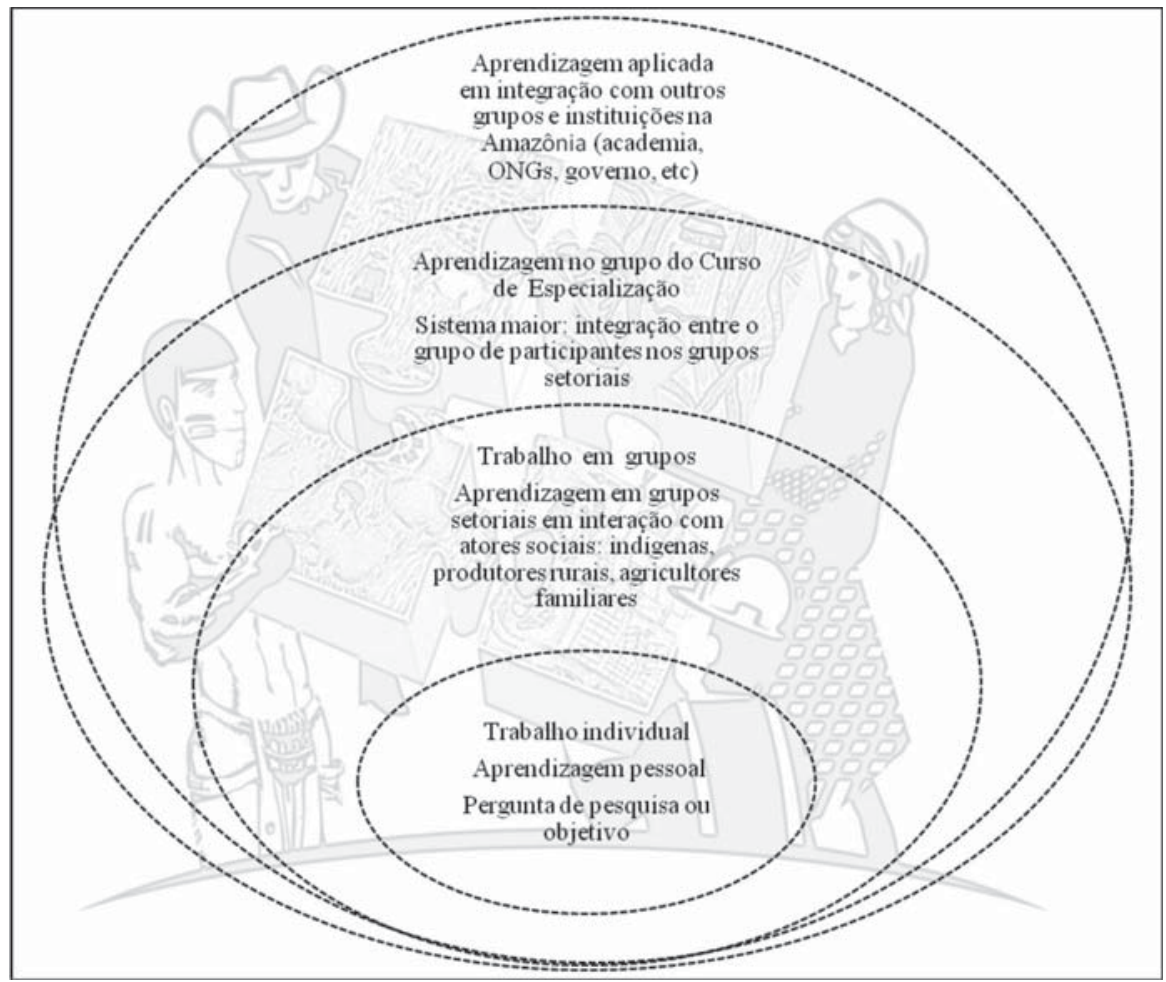

Obs.: As linhas tracejadas indicam a fluidez dos limites entre as escalas de aprendizagem. A figura de fundo representa grupos de atores sociais com diferentes sistemas de gestão dos recursos naturais na Amazônia.

Figura 4. Panarquia ou escalas de aprendizagem e construção do conhecimento transdisciplinar a partir do curso de especialização lato sensu em Cotriguaçu

Um aprendizado importante para a construção de abordagens inter e transdisciplinares em cursos de pós-graduação na Amazônia diz respeito à questão da representatividade disciplinar e da 
representatividade de perspectivas de atores sociais. Como frisaram Lele e Norgaard (2005), existem vários obstáculos para o fortalecimento e a valorização de abordagens interdisciplinares na academia. Entre eles, está o fato de que a interdisciplinaridade depende de processos cooperativos e/ou colaborativos entre profissionais que estejam dispostos a cruzar as fronteiras disciplinares. Assim, é mais fácil para acadêmicos de alguns campos disciplinares das ciências sociais trabalharem com acadêmicos das ciências biofísicas lou ciências naturais). Em geral, o trabalho interdisciplinar entre economistas e cientistas biofísicos é mais raro do que entre antropólogos e sociólogos trabalhando com biólogos e agrônomos, por exemplo. Nesses cursos, houve dificuldade em atrair profissionais das áreas econômica e jurídica. Assim, as análises interdisciplinares ficaram restritas às ciências sociais e humanas (principalmente antropologia, educação e desenvolvimento regional) e naturais (engenharia florestal, biologia e agronomia).

No curso de Alta Floresta, houve maior representatividade disciplinar nas análises de políticas públicas, que são temas interdisciplinares por natureza e demandam a integração de várias disciplinas para a sua compreensão. Em Cotriguaçu, como o foco de análise foi mais aberto, com a aplicação da metodologia de análise da resiliência a partir da perspectiva dos atores locais, foi dada ênfase a conteúdos das ciências sociais, em detrimento de análises ecológicas ou ambientais. A existência de temas transversais pode facilitar a construção dessas pontes, como no caso do grupo dos recursos hídricos formado no projeto demonstrativo do primeiro módulo presencial em Cotriguaçu.

O engajamento e a interação com atores sociais locais também não foi um processo fácil e natural. Em Cotriguaçu, o grupo enfrentou dificuldades em trabalhar com alguns grupos de atores sociais. A aproximação colaborativa com o povo indígena Rikbaktsa foi um processo lento e longo, difícil de ser realizado no horizonte temporal do curso. O contato e a realização de entrevistas com produtores rurais do setor florestal e da pecuária também foi complicado, mesmo contando com representantes locais entre o grupo de participantes. 
Assim, a compreensão dos atores, de suas identidades e seus objetivos de gestão ficou preliminar, mas o aprendizado sobre a multiplicidade de atores, identidades e conhecimentos representados na fronteira amazônica foi rico. Cabe ressaltar que o foco dos cursos foi o desenvolvimento de conhecimentos teóricos e habilidades para a análise de sistemas socioecológicos, e não havia a ambição de realizar pesquisas acadêmicas com rigor científico necessário a uma pesquisa de mestrado ou doutorado.

Outro aprendizado relaciona-se à questão da formação de lideranças e da gestão colaborativa do curso na experiência de Cotriguaçu, em comparação com Alta Floresta, onde já tinha-se um pacote pronto de conceitos, métodos, ferramentas e pedagogia. Se, por um lado, essa experiência de desenvolvimento colaborativo do curso foi importante no fortalecimento de lideranças e incentivo à criatividade entre os participantes, por outro, a falta de retroalimentação para processos colaborativos e a tensão entre liderar e deixar liderar foram fatores difíceis de manejar entre a equipe de coordenação e o grupo, traduzindo-se em conflitos e frustrações. Para futuros cursos, é preciso determinar previamente e com clareza o papel e as responsabilidades de cada participante no processo, bem como enfatizar o fechamento e a retroalimentação de aprendizagens sobre colaboração e produção inter e transdisciplinar de conhecimento.

É importante ressaltar que essa análise não defende a transdisciplinaridade, a aprendizagem colaborativa e a pesquisa participativa como única forma válida de praticar educação para adultos em processos de gestão de recursos naturais, com o envolvimento de múltiplos atores sociais. Não se tem a pretensão de apresentar essa abordagem como um preceito a ser cumprido, de caráter normativo. A combinação entre abordagens disciplinares em processos multi, inter e transdisciplinares deve ocorrer como se julgar mais apropriado para atingir objetivos educacionais ou de pesquisa. 


\section{Conclusão}

As abordagens da pesquisa participativa e da aprendizagem colaborativa, desenvolvidas nas experiências analisadas neste artigo, trazem elementos para integrar os atores sociais no processo de construção de conhecimento, ao mesmo tempo em que facilitam a aprendizagem mútua entre pesquisadores, técnicos e outros atores que interagem no sistema amazônico. O diálogo entre saberes, tanto na educação de pós-graduação como para além dos espaços acadêmicos, pode ser potencializado pela troca de experiências e pela consciência individual e coletiva do processo inter e transdisciplinar pelos participantes.

É enfatizada a importância da inclusão de profissionais de várias áreas disciplinares e experiências de gestão em processos educativos formais e informais abordando o desenvolvimento sustentável. No caso dos cursos realizados em Alta Floresta e Cotriguaçu, a inclusão de profissionais das áreas econômica, jurídica e política, entre outras, teria enriquecido as análises realizadas e a experiência interdisciplinar. Outro alerta diz respeito à definição e concordância prévia de funções a serem desempenhadas por educadores e pesquisadores em processos educativos que envolvem grupos multidisciplinares trabalhando de forma colaborativa. Sugerimos que o processo de avaliação de cursos de formação deve ser planejado de forma a possibilitar o acompanhamento, a sistematização e o compartilhamento do processo de aprendizagem individual e em grupo, bem como o entendimento dos impactos dessa aprendizagem na vida profissional dos participantes. O registro, a análise e a retroalimentação da aprendizagem de grupos multidisciplinares é um grande desafio para o avanço da educação formal e informal na Amazônia.

A educação de pós-graduação no Brasil pode ser fortalecida em diversos níveis e espaços de construção de conhecimento, visando um alcance maior dos objetivos de formação de líderes para a gestão socioambiental colaborativa. É recomendada a coordenação de esforços entre universidades e outras instituições para integrar capacitação formal e informal com processos de pesquisa e extensão e projetos de 
desenvolvimento local, aplicando abordagens inter e transdisciplinares em ligação com atores locais e regionais. Outra sugestão é a criação de disciplinas comuns entre universidades e programas de pósgraduação, com etapas presenciais complementadas por educação a distância. É importante dar ênfase para a cooperação técnico-científica nacional e internacional no fortalecimento da pós-graduação no País, por meio da criação de programas e redes de cooperação internacional e intercâmbio acadêmico.

Propostas educativas que levem em conta o caráter multidimensional, pluricultural e multiescalar da produção e aplicação do conhecimento inter e transdisciplinar podem criar plataformas para a transformação da sociedade rumo à sustentabilidade em um momento de crescente vulnerabilidade socioambiental e econômica pós-Rio+20.

Recebido 25/11/2012

Aprovado 05/08/2013

\section{Referências bibliográficas}

ACLI - Amazon Conservation Leadership Initiative. Relatório do Workshop: 0 Estado da Arte da Pós-Graduação na Região Amazônica em Áreas afins à Conservação da Biodiversidade e ao Desenvolvimento Sustentável. Gainesville, 2008. Disponível em: http://www.sfrc.ufl. edu/acli/Amazon_Workshop.htm. Acesso em: 10 dez. 2012.

ATHAYDE, S. F.; BARTELS, W.; BUSCHBACHER, B. A Caixa de Dinâmicas do Beija-flor: Ferramentas e Dinâmicas para Aprendizagem em Grupo (versão preliminar). Cotriguaçu, 2011. Disponivel em: http://ufdc.ufl. edu/IR00000674/00001. Acesso em: 10 dez. 2012.

BRASIL. Ministério da Educação. Coordenação de Aperfeiçoamento de Pessoal de Nível Superior - Capes. Contribuição da pós-graduação brasileira para o desenvolvimento sustentável: CAPES na Rio +20. Brasília: Capes, 2012. 194 p. 
BUSCHBACHER, R.; ATHAYDE, S. F.; BARTELS, W. (Orgs). Entendendo a fronteira amazônica como um sistema complexo. E-book (versão preliminar). Gainesville: Tropical Conversation and Development Program (TCD), Center for Latin American Studies, University of Florida, 2010.

CHAMBERS, R. The Origins and Practice of Participatory Rural Appraisal. World Development, v. 22, n. 7, p. 953-969, 1994.

FERNANDES, V.; SAMPAIO, C. A. C. Problemática ambiental ou problemática socioambiental? A natureza da relação sociedade/meio ambiente. Revista Desenvolvimento e Meio Ambiente, n. 18, p. 87-94, jul./dez. 2008.

FOLKE, C; i et al. Resilience and Sustainable Development: Building Adaptive Capacity in a World of Transformations. Ambio, v. 31, n. 5, p. 437-440, 2002.

FREIRE, P. Educação como prática da liberdade. Rio de Janeiro: Paz e Terra, 1967.

Pedagogia do oprimido. Rio de Janeiro: Paz e Terra, 1970.

Por uma pedagogia da pergunta. 3. ed. Rio de Janeiro: Paz e Terra, 1985.

FREITAS, L.; MORIN, E.; NICOLESCU, B. Charter of Transdisciplinarity. In: WORLD CONGRESS OF TRANDISCIPLINARITY, 1., Portugal, nov. 1994. Disponível em: <http://ciret-transdisciplinarity.org/chart.php>. Acesso em: 23 nov. 2012.

GIBBONS, M.; et al. The New Production of Knowledge: The Dynamics of Science and Research in Contemporary Societies. London: SAGE, 1994.

GUNDERSON, L. H.; HOLLING, C. S. (Eds.) Panarchy. Understanding Transformations in Human and Natural Systems. Washington: Island Press, 2002. 
JAPIASSÚ, H. Interdisciplinaridade e patologia do saber. Rio de Janeiro: Imago, 1976.

KAINER, K.; et al. A Graduate Education Framework for Tropical Conservation and Development. Conservation Biology, v. 20, n. 1, p. 3-13, 2006.

KOLB, D. A. Experiential learning: Experience as the source of learning and development. New Jersey: Prentice-Hall, 1984.

KOLB, A. Y.; KOLB, D. A. Learning Styles and Learning Spaces: A Review of the Multidisciplinary Application of Experiential Learning Theory in Higher Education. Working Paper 5/05, Department of Organizational Behavior, Weatherhead School of Management, Case Western Reserve University, 2005.

LELE, S.; NORGAARD, R. B. Practicing Interdisciplinarity. Special Roundtable Section. Bioscience, v. 55, n. 11, p. 967-975, 2005.

NICOLESCU, B. (Ed.) Transdisciplinarity: Theory and practice. New Jersey: Hampton Press, 2008.

O'LEARY, R.; BLOMGREN, L. B.; CHOI, Y. Teaching Collaborative Leadership: Ideas and Lessons for the Field. JPAE, v. 16, n. 4, p. 565 592, 2010.

PIAGET, J. Psychology and Epistemology: Towards a Theory of Knowledge. Harmondsworth: Penguin, 1972.

SANTOS, B. S. Para além do Pensamento Abissal: Das linhas globais a uma ecologia de saberes. In: SANTOS, B. S.; MENESES, M. P. (Orgs.). Epistemologias do Sul. Coimbra: Editora Almedina, 2009. p. 23-71.

TRESS, B.; TRESS, G.; FRY, G. Integrative studies on rural landscapes: policy expectations and research practice. Landscape and Urban Planning, v. 70, n. 1/2, p. 177-191, 2005. 
Athayde et al / Aprendizagem colaborativa, transdisciplinaridade e gestão socioambiental na Amazônia: abordagens para a construção de

WALKER, B.; et al. Resilience, adaptability and transformability in social ecological systems. Ecology and Society, v. 9, n. 2, art. 5, 2004. Disponivel em:<http://www.ecologyandsociety.org/vol9/iss2/art5/>. Acesso em: 10 dez. 2012. 


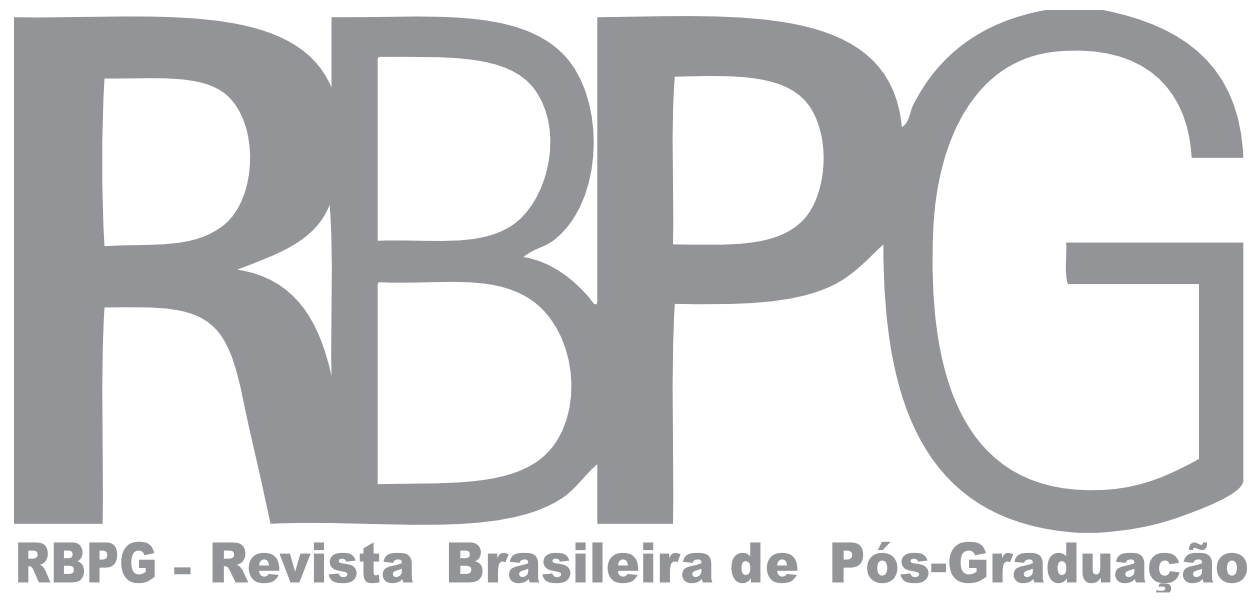




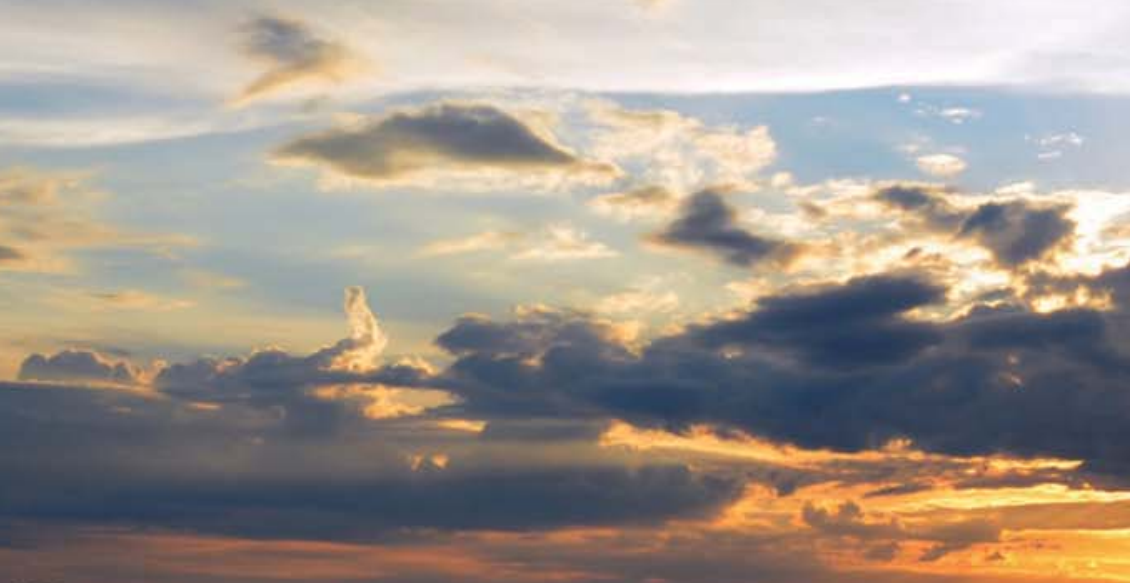

tercos

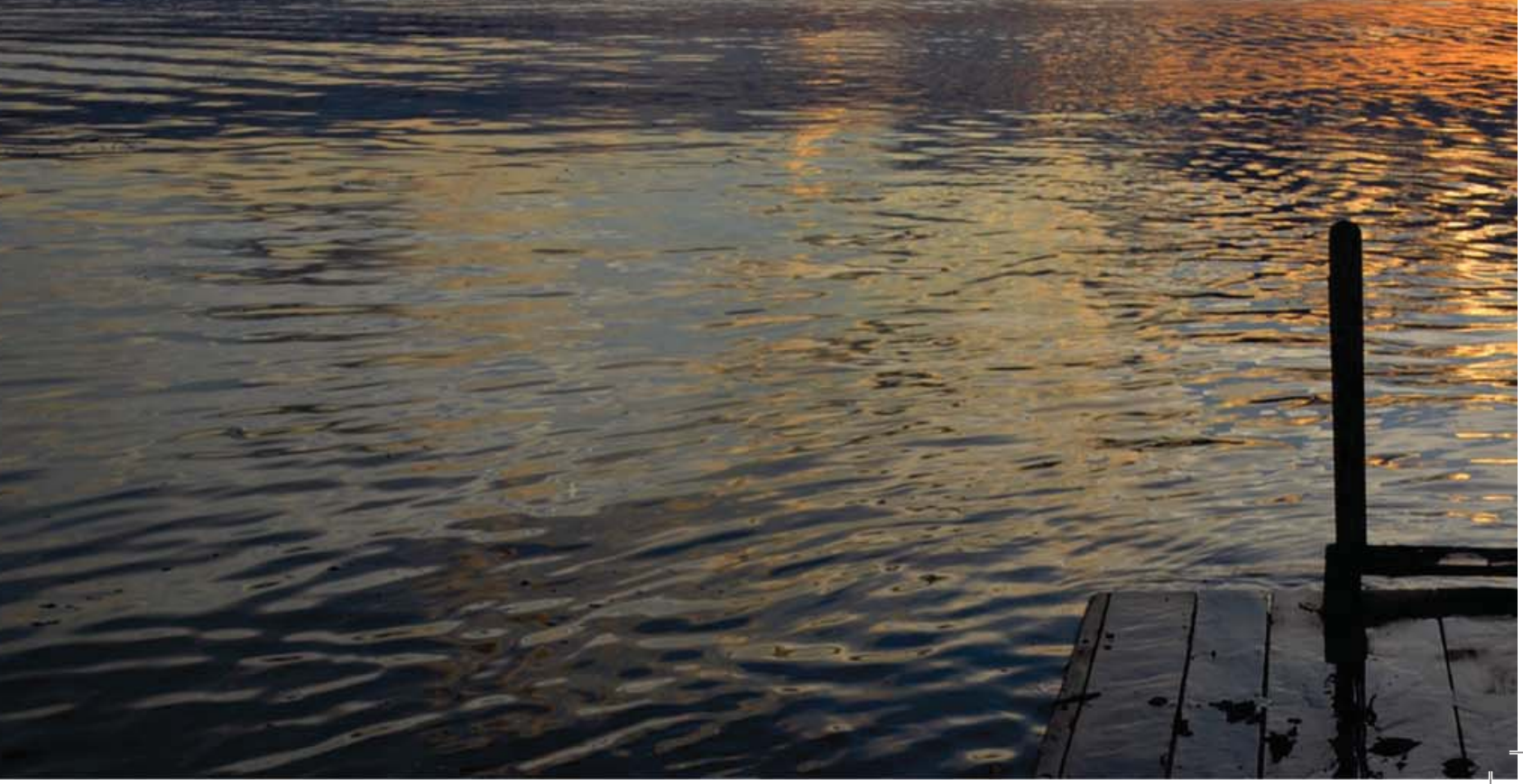



A pós-graduação e a sustentabilidade do abastecimento de comunidades ribeirinhas na Amazônia por meio de água de chuva: da concepção à ação

Graduate programs and the sustainability of water supply through rainwater in the riverine communities of the Amazon: from conception to action

El posgrado y la sostenibilidad del abastecimiento de comunidades ribereñas en la Amazonía por medio del agua de la lluvia: de la concepción a la acción

Nircele da Silva Leal Veloso, mestre em Gestão de Recursos Naturais e Desenvolvimento Local na Amazônia pela Universidade Federal do Pará. Endereço: Av. Almirante Barroso, no 1155 Marco. CEP: 66093-020 - Belém, Pará. Telefone: (91) 8829-7674. E-mail: nircele@ig.com.br.

Cristiane da Costa Gonçalves, mestre em Engenharia Civil pela Universidade Federal do Pará. Endereço: Campus do Guamá, Numa, Augusto Correa, nº 01 - Guamá. CEP: 66075-110 - Belém, Pará. Telefone: (91) 3201-7652. E-mail: ccg@ufpa.br.

Ronaldo Lopes Rodrigues Mendes, doutor em Desenvolvimento Socioambiental pela Universidade Federal do Pará. Endereço: Campus do Guamá, Numa, Augusto Correa, nº 01 - Guamá. CEP: 66075-110 - Belém, Pará. Telefone: (91) 3201-7652. E-mail: rmendes@ufpa.br.

Mário Vasconcellos Sobrinho, PhD em Estudos do Desenvolvimento pela University of Wales Swansea (Reino Unido). Endereço: Campus do Guamá, Numa, Augusto Correa, nº 01 - Guamá. CEP: 66075-110 - Belém, Pará. Telefone: (91) 32017652.E-mail:mariovasc@ufpa.br. 
Tony Carlos Dias da Costa, doutor em Geociência pela Universidade Federal do Pará. Endereço: Campus do Guamá, Numa, Augusto Correa, nº 01 - Guamá. CEP: 66075-110 - Belém, Pará. Telefone: (91) 3201-8063. E-mail: tony@ufpa.br.

Dênio Ramam de Carvalho Oliveira, doutor em Estruturas pela Universidade de Brasília. Endereço: Campus do Guamá, Numa, Augusto Correa, nº 01 - Guamá. CEP: 66075-110 - Belém, Pará. Telefone: (91) 3201-8063. E-mail: denio@ufpa.br.

\section{Resumo}

Apesar de a Amazônia ser rica em recursos hídricos, sua população tem dificuldade no acesso à água potável. 0 abastecimento de água nas ilhas de Belém (PA) é deficitário. Alternativas locais que garantam o acesso à água em quantidade e qualidade adequadas são grandes desafios. O objetivo deste artigo é apresentar uma experiência integradora de dois programas de pós-graduação na implementação de alternativas de aproveitamento da água de chuva para fins potáveis a fim de contribuir com a sustentabilidade do abastecimento local. A caracterização socioeconômica e o diagnóstico do abastecimento de água subsidiaram a implantação dos sistemas. Verificou-se a sustentabilidade por meio da aceitabilidade e do acesso ao sistema, dos impactos financeiros e dos padrões qualitativos da água. De forma geral, são modelos positivos de abastecimento de água para populações ribeirinhas da Amazônia.

Palavras-chave: Água da Chuva. Abastecimento de Água. Desenvolvimento Local. Belém. Amazônia.

\section{Abstract}

In spite of the fact that the Amazon is rich in water resources, its population has difficulty in gaining access to drinking water. The water supply in the islands of Belém (PA) is deficient. Local 
alternatives that guarantee access to water in adequate quantity and quality represent major challenges. The objective of this paper is to present an experience of integrating two graduate programs in the implementation of alternative rainwater use for potable purposes in order to contribute to the sustainability of the local supply. The socioeconomic characterization and diagnosis of water supported the deployment of the systems. Sustainability was verified by considering the acceptability of and the access to the system, as well as the financial impacts of the water quality standards. In general, the adopted models are positive with respect to the provision of water supply to the riverine populations of the Amazon.

Keywords: Rainwater. Water Supply. Local Development. Belém. Amazon.

\section{Resumen}

A pesar de la Amazonía ser rica en recursos hídricos, su población tiene dificultades en el acceso al agua potable. El abastecimiento de agua en las islas de Belém (PA) es deficiente. Alternativas locales que garanticen el acceso al agua en cantidad y calidad adecuadas son los principales retos. El objetivo de este trabajo es presentar una experiencia de integración de dos programas de posgrado en la puesta en práctica de alternativas para el aprovechamiento del agua de la Iluvia como agua potable con el fin de contribuir a la sostenibilidad del abastecimiento local. La caracterización socioeconómica y el diagnóstico del abastecimiento de agua apoyaron la implementación de los sistemas. Se verificó la sostenibilidad por medio de la aceptabilidad y del acceso al sistema, de los impactos financieros y de las normas de calidad del agua. En general, son modelos positivos del abastecimiento de agua para las poblaciones ribereñas de la Amazonía.

Palabras clave: Agua de Lluvia. Abastecimiento de Agua. Desarrollo Local. Belém. Amazonía. 


\section{Introdução}

A água é elencada como uma das necessidades básicas do ser

humano. É, também, um recurso natural de significância econômica, social, ambiental e, no caso da Amazônia, cultural e de reprodução social. A água é um grande condicionante ao desenvolvimento sustentável e, por esse motivo, um dos grandes desafios brasileiros, uma vez que o Brasil, apesar de possuir $12 \%$ dos recursos hídricos superficiais, possui adversidades quanto à distribuição e qualidade.

Os dados da Organização das Nações Unidas indicam que, segundo os aspectos hídricos, o mundo alcançou o Objetivo de Desenvolvimento do Milênio (ODM) antes do planejado, já em 2010. Entretanto, 1,2 bilhão de pessoas ainda sofre por falta de acesso à água tratada (ONU, 2010).

Existem localidades inseridas na Amazônia, área notoriamente reconhecida por ser a maior reserva hídrica do planeta, que, ironicamente, são reféns da escassez de água potável. Segundo a Agência Nacional das Águas (ANA, 2011), cerca de 70\% da população da região Norte é desprovida de acesso à água tratada. Giatti e Cutolo (2012), ao analisarem o crescimento do PIB per capita nos estados da Amazônia Legal e o acesso à água e ao esgoto proveniente de rede em domicílios no período de 2002 a 2009, afirmaram que o Pará apresentou pouco avanço dos serviços de oferta de água e saneamento.

Com aproximadamente mil habitantes, as ilhas Grande e Murutucu, localizadas na porção sul de Belém, não dispõem de sistema de abastecimento de água. A demanda por esse recurso vem sendo suprida de forma inadequada. Sem alternativas, muitos ribeirinhos compram água ou extraem-na de poços com qualidade duvidosa. Há o consumo direto do manancial, que apresenta altos índices de degradação, o que gera riscos de doenças, complicando ainda mais a situação dos serviços de saúde, que, por sua vez, já são precários (VELOSO, 2012).

Diante desse cenário, a Universidade Federal do Pará (UFPA), a partir da interação entre dois programas de pós-graduação - Programa 
de Pós-Graduação em Gestão de Recursos Naturais e Desenvolvimento Local na Amazônia (PPGEDAM), do Núcleo de Meio Ambiente (Numa), mestrado de modalidade profissional; e Programa de Pós-Graduação em Engenharia Civil (PPGEC), do Instituto de Tecnologia (Itec), mestrado acadêmico -, vem desenvolvendo pesquisas aplicadas empenhadas a buscar modelos de abastecimento alternativos que garantam acesso à água de qualidade em comunidades ribeirinhas do estado e, particularmente, de Belém.

A aliança entre um mestrado profissional e um acadêmico tem se mostrado útil no exercício de uma das funções que a universidade assume, que é a de contribuir para o desenvolvimento do território onde ela está inserida, seja em espectro regional, seja em nível comunitário. Adicionalmente, a união entre os dois mestrados tem se apresentado como uma prática da interdisciplinaridade, uma vez que ambos os programas advêm de diferentes áreas de conhecimento. A multi e interdisciplinaridade que a temática de gestão dos recursos hídricos exige têm possibilitado que os programas compartilhem metodologias e efetivem trocas teóricas que colaboram com o avanço das fronteiras da ciência e da tecnologia, medida preconizada no Plano Nacional de Pós-Graduação - PNPG 2011-2020 (BRASIL, 2010).

A aproximação entre os dois programas de pós-graduação culminou na implantação de sistemas de aproveitamento da água de chuva nas ilhas Grande e Murutucu. O uso da água de chuva consiste em uma tecnologia social de abastecimento de água que utiliza os telhados da casa para coletar o recurso das precipitações pluviométricas em reservatório próprio e daí a distribui, por via da gravidade, sem a necessidade do consumo de energia elétrica.

Como Belém apresenta altos índices pluviométricos, cerca de 2.800 mm por ano (INMET, 2011), acredita-se que essa modalidade é uma alternativa de abastecimento de água potável diante da degradação dos mananciais superficiais, principalmente junto aos centros urbanos. De fato, as intensas chuvas que ocorrem em Belém favorecem essa modalidade de captação, que pode suprir completamente a demanda de consumo. O manejo da água da chuva 
é uma forma de gestão de recurso hídrico que pode contribuir com o equacionamento dos conflitos e das pendências de ordem econômica, social e ambiental vivenciados pelas populações que vivem à beira dos rios, os chamados ribeirinhos, uma vez que a maioria das ilhas de Belém não apresenta significativas intervenções do poder público em favor do abastecimento de água.

\section{A concepção}

O PPGEDAM foi implantado em 2007 com o propósito de capacitar profissionais para atuar em órgãos públicos e privados como agentes de desenvolvimento e de gestão ambiental. O PPGEDAM é fruto da experiência do Núcleo de Meio Ambiente da UFPA, que tem atuado precipuamente na formação de profissionais para atuarem no âmbito da gestão das unidades de conservação ambiental de uso sustentável e dos múltiplos territórios que configuram a região amazônica, especialmente comunidades, municípios, microrregiões e bacias hidrográficas. O entendimento da necessidade de gestão apropriada dos recursos naturais com vistas ao desenvolvimento da região sob a perspectiva de sua diversidade direcionou a proposta do programa na busca de alternativas de desenvolvimento para o nivel local. Nesse contexto, o PPGEDAM busca, também, capacitar profissionais para a transferência de tecnologia em seu duplo sentido, ou seja, da academia para as coletividades e das coletividades para a academia, e para a gestão do uso e aproveitamento dos recursos naturais para o nível local.

O desenho geral do programa segue as linhas estabelecidas pela Capes para os mestrados profissionais. O PPGEDAM tem entre seus pressupostos básicos: o entendimento de que o desenvolvimento sustentável deve pautar-se na gestão apropriada dos recursos naturais e ser um processo endógeno de mudança que leve à melhoria da qualidade de vida das coletividades locais, com respeito a suas culturas e seus valores; o desenvolvimento local é produto da relação dinâmica de todos os seus atores sociais, que envolvem organizações locais e governamentais e comunidades atuando sob a concepção da 
governança; e a universidade, enquanto produtora de conhecimentos, é um importante ator social para dar suporte à construção de uma nova sociedade.

Diante dos pressupostos assumidos, o programa tem entre seus objetivos: discutir métodos e modelos de gestão ambiental para o uso e aproveitamento de recursos naturais; e instrumentalizar seus participantes para atuarem de modo inovador na elaboração de programas, projetos, metodologias, processos e produtos que possam ser viabilizados para atender as demandas das coletividades locais.

O PPGEC, por sua vez, também tem como princípio o desenvolvimento sustentável e a preservação ambiental da região. 0 programa tem entre suas áreas de concentração os recursos hídricos e o saneamento ambiental e sistemas de infraestrutura urbana. 0 objetivo dessa linha de pesquisa é desenvolver estudos avançados relativos à Engenharia de Recursos Hídricos, com ênfase em estudos dos recursos hídricos no aspecto quantitativo e qualitativo, sua ocorrência, propagação, distribuição e utilização, em busca do aperfeiçoamento de diversos usos da água, de modo a assegurar, à atual e às futuras gerações, elevado padrão de qualidade e utilização racional e integrada, com vistas ao desenvolvimento sustentável e à prevenção e defesa contra fenômenos hidrológicos críticos ou devido ao uso inadequado de recursos naturais.

Enquanto o PPGEC se concentra nos aspectos construtivos de propagação, distribuição e utilização para uso e aproveitamento dos recursos hídricos, o PPGEDAM se concentra na forma como as novas tecnologias podem ser implantadas, apropriadas e gerenciadas em nível das comunidades locais. A complementaridade dos programas ocorre na medida em que cada um com seu objeto desenvolve pesquisas voltadas à aplicabilidade e ao atendimento de demandas sociais e ambientais de comunidades já identificadas pelo poder público como carentes, mas que ainda não foram contempladas em determinadas políticas públicas de sustentabilidade local. Se pelo PPGEC o público para a formação pós-graduada é de engenheiros e afins, no PPGEDAM o público advém de áreas interdisciplinares e são 
qualificados para conceber estudos integrados que contribuam e/ou promovam o desenvolvimento local e comunitário.

\section{Pressupostos para a sustentabilidade do abastecimento em comunidades rurais da Amazônia}

Como pressupostos para alcançar seus objetivos, este trabalho assume como elemento básico que os sistemas de abastecimento de água de populações humanas devem ser sustentáveis. Isto é entendido como: devem satisfazer as necessidades dos usuários em todas as suas fases, desde sua concepção até seu uso e manutenção.

Como apresentado por Mendes (2005), Fenzl, Mendes e Fernandes (2010), Mendes e Fenzl (2011) e Mendes et al. (2012), os sistemas de abastecimento são sistemas sociais abertos e que, por sua natureza, tanto alteram como são alterados por seu entorno. Para essa visão sistêmica, o abastecimento de água está vinculado ao bem-estar nutricional, habitacional e material das sociedades. Tais condições são garantidas pelos fluxos contínuos de energia e matéria do ambiente natural, conforme Figura 1.

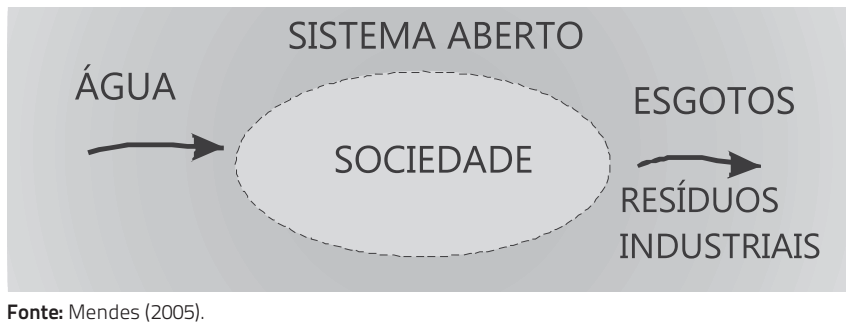

Figura 1. Representação da interação do sistema social e da entrada e saída de água

Portanto, fazem parte dos sistemas de abastecimento, além da água e da estrutura física, os usuários (e as formas de uso da água), o meio que os cerca e ainda aspectos financeiros para sua instalação e manutenção. Assim sendo, para a sustentabilidade de um sistema de abastecimento, todos esses elementos devem ser considerados. A sustentabilidade do sistema de abastecimento é traduzida pela 
satisfação do usuário em termos de: a) facilidade no acesso à água; b) quantidade que atenda ao consumo; c) qualidade dentro dos padrões de potabilidade; e d) preço adequado às suas possibilidades de pagamento (MENDES, 2005). Todos esses elementos são considerados neste trabalho.

\section{A ação: as pesquisas e a metodologia de aplicação}

Em 2012, duas dissertações de mestrado foram concluídas no âmbito dos programas de pós-graduação da UFPA, uma no PPGEC e outra no PPGEDAM, ambas com foco na implantação de sistemas de aproveitamento de recursos pluviais como alternativa de abastecimento de água nas ilhas Grande e Murutucu: Aproveitamento de águas pluviais para abastecimento em área rural na Amazônia. Estudo de caso: ilhas Grande e Murutucu, Belém-PA e Água de chuva e desenvolvimento local: o caso do abastecimento das ilhas de Belém. A primeira teve como objetivo desenvolver modelos de Sistema de Abastecimento de Água da Chuva (Saac) para atendimento de comunidades ribeirinhas; a segunda, por sua vez, objetivou avaliar a viabilidade do aproveitamento sustentável da água da chuva para fins potáveis de abastecimento nas ilhas Grande e Murutucu.

De cunho interdisciplinar, os trabalhos buscam a aplicabilidade social da ciência e a integração entre estudos de dois programas de pós-graduação. Os Saacs foram desenvolvidos e implantados tomando como base os diagnósticos socioeconômicos e estudos de percepção resultantes das investigações realizadas pelas dissertações de mestrado.

O recorte espacial dos estudos faz parte do município de Belém / PA, mais especificamente sua região insular, formada por ilhas com características rurais. As ilhas Grande (1 $\left.{ }^{\circ} 29^{\prime} 23.32^{\prime \prime} \mathrm{S} / 48^{\circ} 24^{\prime} 18.39^{\prime \prime} 0\right)$ e Murutucu ( $1^{\circ} 29^{\prime} 27.80^{\prime \prime} \mathrm{S} / 4^{\circ} 24^{\prime} 40.18^{\prime \prime}$ ) estão localizadas ao longo do rio Guamá, na porção sul do município, dispostas geograficamente uma em frente à outra, separadas pelo rio Bijoró e distantes cerca de $12 \mathrm{~km}$ da área urbana da capital paraense, conforme demonstra a 
Figura 2. As duas apresentam uma área de 1.789,81 ha e compõem um universo de 39 ilhas que Belém possui sob sua jurisdição, que representam 65\% do total da superfície municipal (BELÉM, 2012).

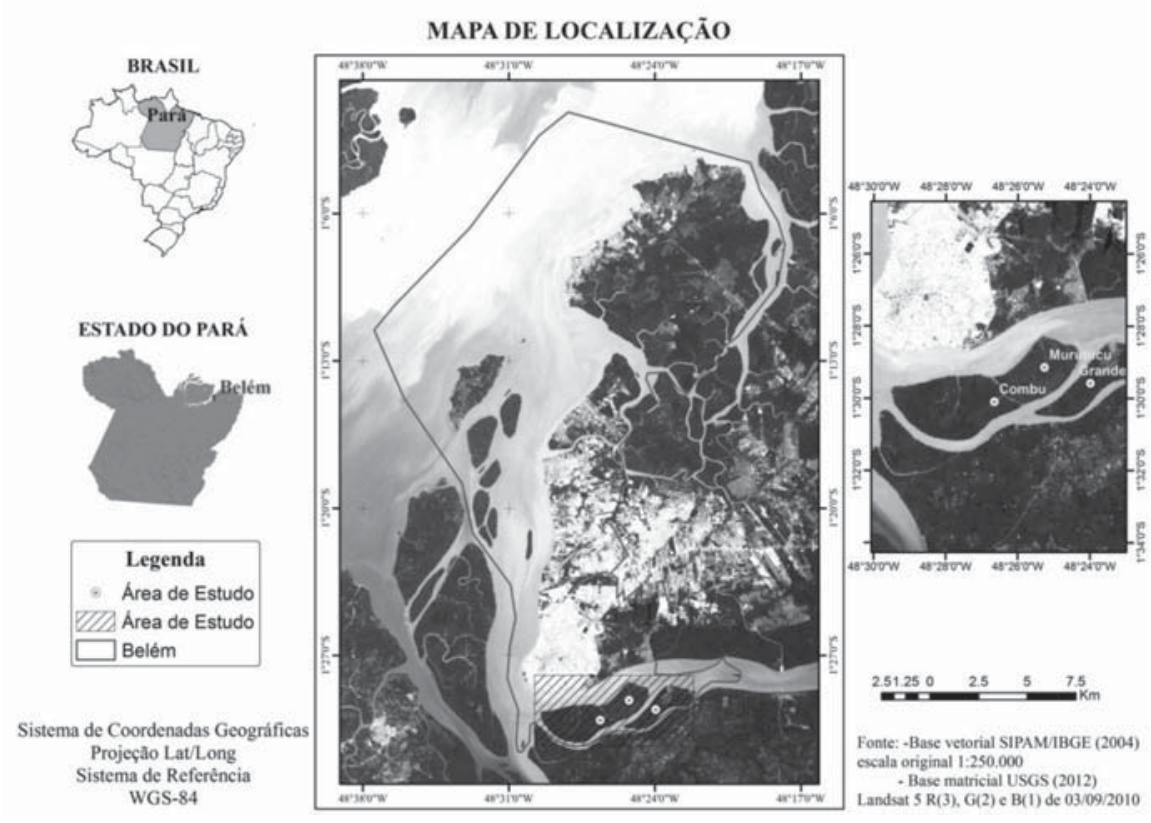

Fonte: Guimarães (2012)

\section{Figura 2. Mapa de localização da área de estudo}

Os estudos forneceram subsídios para o dimensionamento do sistema de captação e manejo da água de chuva em ambas as ilhas. Tais subsídios emergiram a partir da construção do perfil socioeconômico dos moradores e do diagnóstico do abastecimento para fins potáveis. Em consequência, foram implantados dois protótipos e investigados os impactos oriundos da utilização do modelo no desenvolvimento local, por via do monitoramento da eficiência dos sistemas a partir da qualidade da água e do acompanhamento dos usuários.

As primeiras visitas de campo, ocorridas entre março e abril de 2011, foram fundamentais para a visualização das condições locais de saneamento e para a sondagem da aceitabilidade da água da chuva. A partir dessas visitas, verificou-se que a llha Grande já possuía experiências de abastecimento com água da chuva, o que demonstrou 
predisposição da comunidade em receber o modelo proposto. A determinação das moradias que receberiam os protótipos se deu a partir de três fatores: interesse do morador em possuir o sistema, número de usuários e área dos telhados. Em função do último fator, houve medições das dimensões dos telhados das moradias.

A elaboração e o dimensionamento do projeto foram concebidos de acordo com os parâmetros: área de contribuição, índices pluviométricos críticos da localidade, demanda dos usuários. A definição da disponibilidade de água foi adquirida a partir da série histórica de chuva obtida do último manual das normas climatológicas do Instituto Nacional de Meteorologia (INMET, 2011), do período de 1961 a 1990¹, da estação Belém, número 82191. A demanda per capita considerada no dimensionamento foi calculada por meio da média do consumo diário em atividades de beber e cozinhar durante três dias consecutivos. A demanda calculada correspondeu a 5l/dia/hab. Para o volume total, utilizou-se o número de usuários dos sistemas, 19 na llha Grande (cinco famílias) e 14 na Ilha Murutucu (três famílias).

Os sistemas são compostos por calha, condutores, dispositivos de autolimpeza, reservatório de acumulação, filtro de areia e reservatório de água tratada. O dimensionamento dos Saacs foi baseado na NBR 10844 (ABNT, 1989), que versa sobre as instalações prediais de águas pluviais. O cálculo do reservatório baseou-se no método Rippl contido na NBR 15527 (ABNT, 2007).

Com o objetivo de garantir os padrões de potabilidade exigidos na Portaria $n^{\circ}$ 2.914/2011 do Ministério da Saúde (BRASIL, 2011), foram desenvolvidos filtros de areia com os mesmos princípios dos filtros tradicionais.

Na Ilha Grande, o modelo apresenta quatro reservatórios de autolimpeza, dois filtros, caixa d'água superior de 500 e inferior de 310l. O sistema edificado na Ilha Murutucu, de menor porte, conta com dois reservatórios de autolimpeza, um filtro e duas caixas d'água de 310l, conforme as Figuras 3a e 3b.

'Esse período é o último ciclo disponibilizado pelo Inmet. Ressalta-se que os padrões climatológicos normais são calculados para períodos consecutivos de 30 anos. Não estão disponiveis dados históricos de 1991 aos dias atuais. 


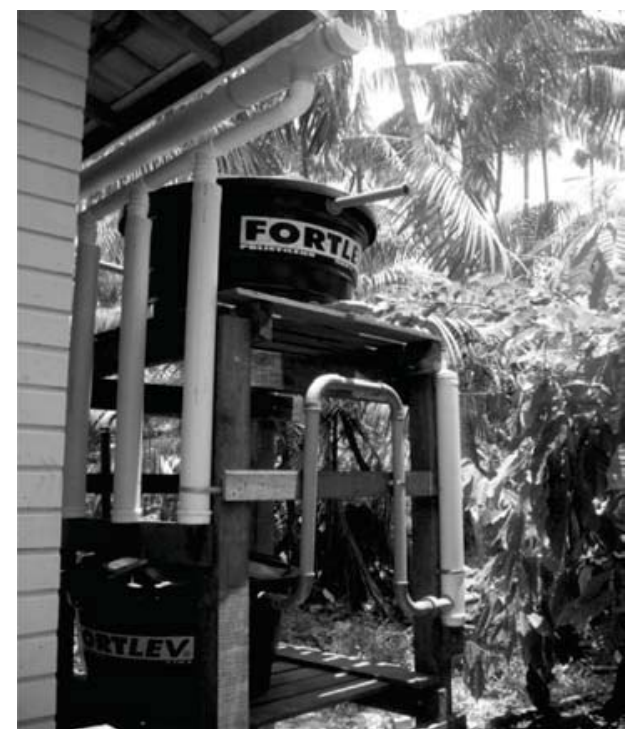

Fonte: Veloso (2012)

Figura 3a. Sistema instalado em Ilha Grande

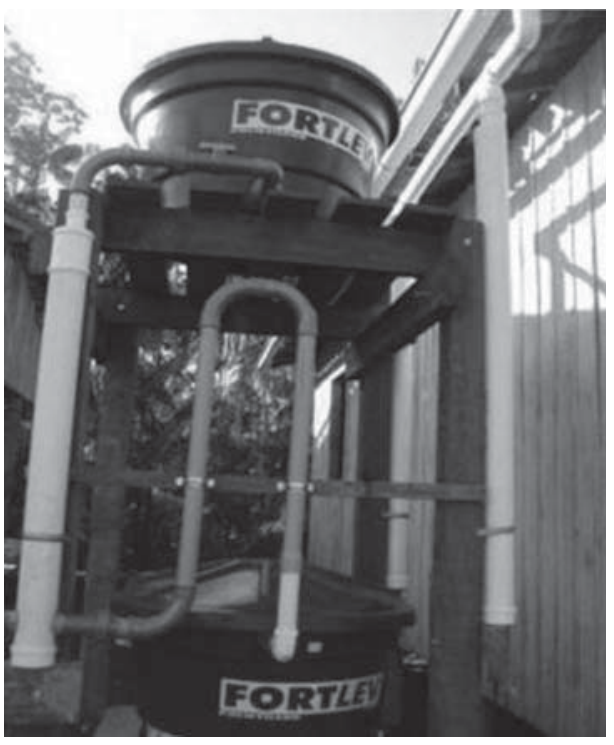

Fonte: Gonçalves (2012)

Figura 3b. Sistema instalado em Ilha Murutucu

O formulário aplicado possuía questões relacionadas: aos aspectos socioeconômicos, ao diagnóstico do abastecimento da população, às formas de tratamento da água, à aceitação da água de 
chuva, ao interesse em possuir o Saac, aos aspectos físico-construtivos das moradias, ao conhecimento do sistema de aproveitamento, à ciência das condições sanitárias, à acessibilidade e partilha do modelo, entre outras.

Foram visitados 201 domicílios. Esse total corresponde a 79\% das moradias da Ilha Grande e cerca de 88\% de Murutucu. Após a coleta, o trato estatístico dos dados se deu pelo Statistical Package for the Social Sciences (SPSS Data Editor versão 13.0).

As iniciativas de educação sanitária e ambiental foram concretizadas a partir de encontro com os moradores na Escola de São José na Ilha Grande com a participação de duas agentes de saúde que trabalham na comunidade.

O acompanhamento e monitoramento dos Saacs ocorreram por meio de análises físico-química e bacteriológica ao longo do sistema de coleta, tratamento e armazenamento, especificamente nas calhas e nos reservatórios de autolimpeza e de acomodação (após a filtração). Também foram analisadas amostras coletadas direto da atmosfera.

Foram realizadas 15 análises da qualidade da água ao longo dos meses de janeiro e abril de 2012. A preservação das amostras e a metodologia analítica das análises físico-químicas e bacteriológicas da água coletada foram feitas de acordo com Standard Methods for the Examination of Water and Wastewater (APHA; AWWA; WPCF, 1980). As análises das amostras fisico-químicas foram realizadas pelo Laboratório de Multi-Usuário de Tratabilidade de Águas e as das amostras bacteriológicas pelo Laboratório de Microbiologia no Instituto de Ciências Biológicas, ambos da Universidade Federal do Pará.

O entendimento dos impactos gerados foi realizado após a leitura geral do contexto. Os resultados quantitativos e qualitativos da pesquisa serviram de referência para apontar os reflexos na sustentabilidade dos Saacs e o alcance do desenvolvimento local. As proposições buscam subsidiar a gestão do abastecimento de água em regiões de ilhas. 


\section{Os resultados das pesquisas, da integração entre os programas de pós-graduação e do desenvolvimento comunitário}

Esta seção se concentra em mostrar os resultados das pesquisas, da integração entre o PPGEDAM e PPGEC e da contribuição dos Saacs para o desenvolvimento comunitário. Inicialmente, serão tecidos comentários sobre a caracterização socioeconômica dos moradores das ilhas e do diagnóstico do abastecimento de água nas ilhas. Apresenta-se, também, a avaliação da sustentabilidade dos sistemas segundos três critérios: (1) aceitabilidade e acesso ao sistema proposto; (2) análise financeira e impactos na renda dos moradores; e (3) avaliação dos padrões qualitativos da água. Tais comentários representam as conexões entre as dissertações.

\section{Perfil socioeconômico dos moradores e diagnóstico do abastecimento para fins potáveis}

Para a caracterização do contexto social dos ribeirinhos das ilhas, foram levantadas informações sobre o tamanho da população, a estratificação por gênero, o número de pessoas por residência, seus respectivos niveis de escolaridade e, ainda, a renda familiar.

A llha Grande é composta por 89 domicílios que comportam 288 pessoas, sendo 53,1\% do sexo masculino. A llha Murutucu, por sua vez, possui 149 domicílios e uma população de 529 pessoas, com predominância, também, de homens, que correspondem a 52,1\% do total da população da ilha. Destaque-se que em ambas as ilhas há um percentual significativo de crianças (moradores com menos de 12 anos de idade): 33\% na Ilha Grande e 32\% na Ilha Murucutu. Os dados levantados indicaram que as residências possuem 3,23 e 3,55 pessoas por residência nas ilhas Grande e Murucutu, respectivamente. Esse perfil da população das ilhas demonstrou o quanto um Saac podia contribuir para a melhoria da qualidade de vida das populações locais.

Em termos de estudos, os resultados das pesquisas demonstraram que os moradores das duas ilhas possuem baixo nível de escolaridade. De fato, 10,7\% e 9,8\% dos moradores das ilhas Grande e Murucutu, respectivamente, nunca frequentaram a escola; e 33,6\% da primeira ilha e $30 \%$ segunda sequer completaram a $4^{\text {a }}$ série do 
ensino fundamental. Destaque-se que esses números representam a população da faixa etária de 21 a 50 anos de idade.

Das famílias entrevistadas, 60\% de seus integrantes praticam atividade remunerada. Vale elucidar que a composição da renda em áreas rurais não pode ser vista apenas com a renda declarada. Por se tratar de populações de regiões insulares com dinâmicas econômicas próprias, as pessoas residentes possuem atividades peculiares na garantia do sustento da família, tais como o extrativismo vegetal e animal. O exercício dessas atividades se constitui em importante parcela da renda das famílias, teoricamente não contabilizada pelos moradores. Na verdade, há uma dificuldade real em mensurar a efetiva renda familiar mensal. O objetivo do levantamento da renda das famílias foi aferir se a população possuía sustentabilidade financeira para implementar e manter o sistema de aproveitamento da água da chuva. Por esse motivo, utilizou-se a faixa de ganho apenas como indicadores de renda, conforme Tabela 1.

Tabela 1. Renda mensal familiar por ilha

\begin{tabular}{|l|c|c|c|c|}
\hline \multirow{2}{*}{\multicolumn{1}{|c|}{ Renda Familiar }} & \multicolumn{2}{c|}{ Ilha Grande } & \multicolumn{2}{c|}{ Iha Murutucu } \\
\cline { 2 - 5 } & $\begin{array}{c}\text { Percentual } \\
\text { (\%) }\end{array}$ & $\begin{array}{c}\text { Percentual } \\
\text { acumulado }\end{array}$ & $\begin{array}{c}\text { Percentual } \\
\text { (\%) }\end{array}$ & $\begin{array}{c}\text { Percentual } \\
\text { acumulado }\end{array}$ \\
\hline Menos de 1SM & 44,3 & 44,3 & 65,6 & 65,6 \\
\hline Entre 1 e 1,5 SM & 35,7 & 80,0 & 21,4 & 87,0 \\
\hline Entre 2 e 3 SM & 14,3 & 94,3 & 6,1 & 93,1 \\
\hline Acima de 3 SM & 4,3 & 98,6 & 4,6 & 97,7 \\
\hline NS/NR & 1,4 & 100,0 & 2,3 & 100,0 \\
\hline Total & 100,0 & & 100,0 & \\
\hline
\end{tabular}

SM: salário mínimo (R\$545,00, em 2011).

Fonte: Veloso (2012).

Em Ilha Grande, verificou-se que 80\% da população anunciou ganhos mensais de até 1,5 salário mínimo. Já em Ilha Murutucu, cerca de dois terços dos moradores recebem menos de um salário mínimo. Os dados revelam que os moradores de ambas as ilhas possuem dificuldades em manter a sustentabilidade financeira do sistema.

Para o diagnóstico das categorias de abastecimento de água, foram levantados dados sobre a origem da água consumida, o tipo de 
tratamento da água realizado pelos moradores, a percepção que os moradores detinham sobre a qualidade da água consumida e, também, os dados que refletissem as condições de saúde dos moradores quanto ao aspecto de doenças de veiculação hídrica.

A investigação revelou que as formas de obtenção da água para satisfazer as necessidades potáveis dos moradores, no que tange às atividades de beber e cozinhar, foram: consumo direto do rio, retirada manualmente ou por meio de equipamento de recalque (bomba), compra de água mineral, extração de água em poço na própria propriedade ou na casa de vizinhos, coleta em lugares próximos, como a sede urbana de Belém ou o município de Acará, e, por fim, a compra de água.

Segundo os moradores, a compra de água é praticada em duas modalidades: pelo pagamento de $\mathrm{R} \$ 2,00$ a cada 20 litros de água a um barqueiro que entrega de porta em porta os recipientes ou ainda pelo pagamento de $\mathrm{R} \$ 3,00$ mensais às associações de moradores de quatro localidades pertencentes ao município de Acará: Itancuã, Guajará, Boa Vista e Santa Maria, que cobram tal taxa para a liberação, a moradores externos, da retirada de água dos poços localizados nas comunidades.

A Figura 4 apresenta os percentuais por categorias de abastecimento praticadas nas ilhas.

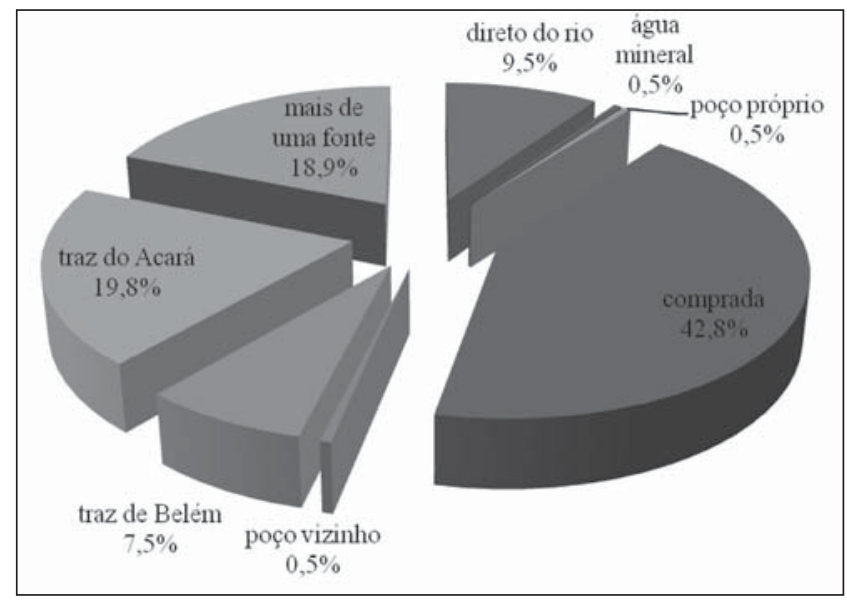

Fonte: Veloso (2012)

Figura 4. Modalidades de abastecimento praticadas nas ilhas 
Conforme a figura, as modalidades que mais se destacam são a compra de água e a coleta do recurso em comunidades localizadas em Acará. Constata-se, ainda, que $10 \%$ da população consome tão somente a água do rio. Ao analisar o uso da água do rio, concomitantemente a outras categorias, na ocasião em que os ribeirinhos declaram a utilização de mais de uma fonte, esse percentual dobra; ou seja, 20\% das famílias consomem de alguma forma água do manancial para fins potáveis, seja exclusivamente ou combinada a outra modalidade. Esse quadro demonstra a carência de acesso à água por parte dos moradores das ilhas pesquisadas, uma vez que, com exceção da compra de água mineral, as categorias não possuem origem segura quanto aos critérios qualitativos.

As pesquisas revelaram que 44,3\% da população entrevistada da Ilha Grande não realiza qualquer tipo de tratamento na água ingerida, ou seja, são moradores que, independentemente da origem da água (mineral, comprada, trazida de Acará ou Belém ou extraída de poços vizinhos), não fornecem nenhum tipo de tratamento diferenciado para a água que utilizam para beber e cozinhar. 0 restante, 55,7\%, declarou realizar um ou mais de um tipo de tratamento na água reservada para esses fins. Já na Ilha Murutucu, das 131 famílias entrevistadas, 39 não realizavam qualquer tratamento na água (29,8\%). O alto número de famílias que não empregam nenhum tratamento da água consumida em ambas as ilhas indica uma situação preocupante em termos de impacto na saúde dos moradores em função do provável consumo de água contaminada.

Com o intuito de relacionar a influência do nível de escolaridade da população no tratamento fornecido àágua, realizou-se o cruzamento estatístico das informações, demonstrado na Tabela 2. A partir dele, é possível verificar que, paradoxalmente ao esperado, a parcela da população que, teoricamente, teve menos a acesso à educação retrata um comportamento mais salutar no que se refere aos cuidados com o tratamento da água. Parte significativa das pessoas que possuem maior nível de escolaridade (ensino fundamental completo, ensino médio incompleto e até pós-graduados) não dispensa o devido tratamento à água que consome. Isso chama a atenção para a necessidade da ação 
dos agentes de saúde na educação sanitária relacionada ao uso da água.

Tabela 2. Relação entre escolaridade da população e tratamento fornecido à água

\begin{tabular}{|c|c|c|}
\hline \multirow{2}{*}{ Escolaridade } & \multicolumn{2}{|c|}{ Tratamento } \\
\hline & Sim & Não \\
\hline Nunca foi à escola & $69,6 \%$ & $30,4 \%$ \\
\hline Ensino fundamental até a $4^{\mathrm{a}}$ série incompleto & $76,2 \%$ & $23,8 \%$ \\
\hline Ensino fundamental até a $4^{\mathrm{a}}$ série completo & $73,9 \%$ & $26,1 \%$ \\
\hline Ensino fundamental de $5^{a}$ a $8^{a}$ série incompleto & $59,3 \%$ & $40,7 \%$ \\
\hline Ensino fundamental completo & $28,6 \%$ & $71,4 \%$ \\
\hline Ensino médio incompleto & $43,7 \%$ & $56,3 \%$ \\
\hline Ensino médio completo & $63,6 \%$ & $36,4 \%$ \\
\hline Ensino superior completo & $66,7 \%$ & $33,3 \%$ \\
\hline Pós-graduado & $0,0 \%$ & $100,0 \%$ \\
\hline Total & $65,2 \%$ & $34,8 \%$ \\
\hline
\end{tabular}

Fonte: Veloso (2012)

As opções dos tipos de tratamento da água enfatizados na pesquisa foram: fervura, coagem, adição de hipoclorito ou sulfato de alumínio, exposição aos raios ultravioleta por radiação solar (Sodis), bem como a combinação de mais de uma dessas formas de tratamento. 0 perfil do tipo de tratamento realizado pelas famílias da Ilha Grande é expresso nas Figuras 5a e 5b. A partir dele, é possivel, mais claramente, identificar a realidade vivenciada pelos moradores das ilhas, destacando que a forma mais usual de tratamento da água foi o uso de hipoclorito. 


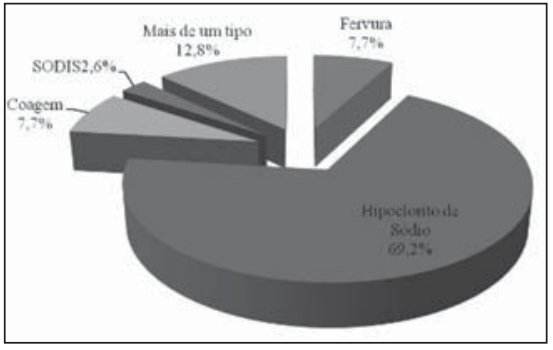

Fonte: Veloso (2012)

\section{Figura 5a. Caracterização do tipo de tratamento da água na Ilha Grande}

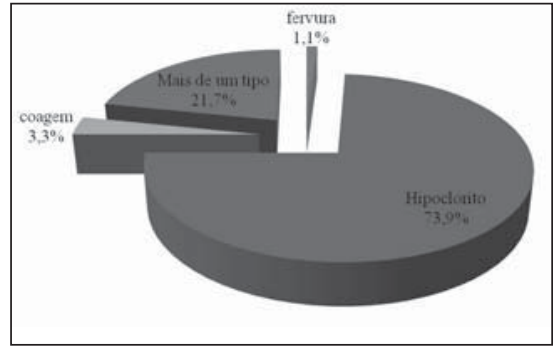

Figura 5b. Caracterização do tipo de tratamento da água na Ilha Murutucu

De fato, a caracterização do tipo de tratamento que cada ilha pratica revelou coincidências quanto ao uso de hipoclorito de sódio. Tal fato pode ocorrer em virtude do fácil acesso ao insumo, haja vista a distribuição periódica da solução pelos agentes de saúde locais. Tal situação se configura como um forte indicador de eficiência institucional do município de Belém, no que concerne ao rateio da substância em localidades insulares.

Na Ilha Grande, as pesquisas apontaram que $41,4 \%$ dos moradores entrevistados admitiram que algum membro da família foi acometido, nos últimos seis meses, por doenças que se manifestaram na forma de sintomas típicos de doenças de veiculação hídrica: dor de barriga, diarreia, urina escura, coceira. Desse total, 75\% afirmaram que as ocorrências se deram de uma a três vezes nos últimos seis meses.

Nesse tocante, na llha Murutucu, 39,7\% informaram que algum membro da casa apresentou, nos últimos seis meses, algum dos sintomas característicos de doenças de veiculação pela água. Desse total, cerca de $70 \%$ afirmaram que os indícios se deram em até três vezes nos últimos seis meses. Destaque-se que $21,1 \%$ dos pesquisados declararam que doenças com sintomas característicos de uso de água contaminada ocorreram sete ou mais vezes nos membros de suas respectivas famílias.

Existem, porém, controvérsias nessas informações. A ocorrência dos sintomas se opõe ao que dizem $70 \%$ das pessoas 
entrevistadas na Ilha Murutucu, no que se refere ao tratamento da água. De qualquer forma, pode-se inferir que o tratamento realizado está inadequado ou insuficiente². As indagações que vêm à baila são: como pode haver tantos casos de doenças em famílias que dizem tratar a água consumida? Por que o tratamento da água com hipoclorito não está sendo eficaz?

\section{A sustentabilidade dos Saacs nas ilhas Grande e Murutucu}

A análise da sustentabilidade dos Saacs considerou a aceitabilidade e o acesso ao sistema proposto, a avaliação financeira dos sistemas, os impactos na renda dos moradores e o acompanhamento dos padrões qualitativos da água. Esses aspectos foram considerados pelas pesquisas como fatores fundamentais para o sucesso do modelo de abastecimento no que se concerne à gestão e sustentabilidade.

No que se refere à aceitabilidade, as pesquisas revelaram que $61,4 \%$ dos moradores da Ilha Grande se posicionam a favor do consumo da água da chuva; já na llha Murutucu, constatou-se que $50,4 \%$ dos entrevistados declararam que consomem ou consumiriam a água captada dessa forma. 0 número de pessoas que aceitam o uso da água da chuva para fins potáveis representou a maioria em ambas as ilhas. 0 índice de aceitabilidade na Ilha Grande foi maior, o que pode ser explicado pela experiência de boa parte dos moradores, em especial daqueles que possuíam o sistema. Ao investigar o motivo da não aceitação do consumo da água oriunda das precipitações pluviométricas, as respostas mais frequentes foram o desagrado pelo sabor $(38,9 \%)$, pela cor $(14,4 \%)$ e pelo cheiro $(7,8 \%)$.

A análise do acesso percebida pelos moradores é entendida como a capacidade que a modalidade de abastecimento tem de ser ou se tornar facilmente acessivel quanto aos aspectos de disponibilidade pelo fornecimento contínuo, tempo de captação do recurso e pela

${ }^{2}$ Isso mostra a necessidade de análise dos dados dos agentes comunitários de saúde e dos postos de saúde locais. Infelizmente, esses dados não estão disponiveis. praticidade nos procedimentos de coleta. Na visão de $31,4 \%$ dos moradores da Ilha Grande, o aproveitamento da água pluvial é a maneira mais acessível de garantir água potável para a realidade local. A segunda forma mais citada para a captação de água potável foi a 
retirada do recurso hídrico diretamente do rio com o auxílio de uma bomba e posterior tratamento $(28,6 \%)$.

Na Ilha Murutucu houve uma leitura diferenciada da acessibilidade à água potável. Os moradores consideraram ser mais fácil a captação por meio de bomba da água do rio e posterior tratamento (41,2\%). Alternativas também se evidenciaram como: contar com um sistema de aproveitamento da água da chuva $(26,7 \%)$, continuar comprando água sem procedência definida (14,5\%) ou a obtenção do recurso por conta própria de alguma localidade próxima $(7,6 \%)$.

A análise de tais resultados, combinada com a observação de campo, ajuda na compreensão do contexto local quanto à questão da acessibilidade do abastecimento de água. Em relatos, os moradores das ilhas temem que o volume das precipitações pluviométricas no período do verão amazônico não satisfaça a totalidade da demanda potável e, por isso, não a consideram como a opção mais sustentável quanto à quantidade.

Quanto às famílias atendidas pelos sistemas de abastecimento de água de chuva, o acesso direto é iminente, posto que a instalação dos Saacs possibilitou o fornecimento de água em suas torneiras. Os moradores não mais se preocupam em carregar pesados recipientes por dezenas ou centenas de metros.

Para a avaliação da sustentabilidade financeira dos Saacs, foi necessário investigar o contexto local e estimar os impactos da implantação do modelo proposto para o aproveitamento da água da chuva na renda mensal da população. O foco do exame foram as análises de custo do sistema e seus impactos financeiros nas famílias.

De acordo com Gonçalves (2012), o valor total do sistema na Ilha Grande foi de R\$ 2.110,58. Na Ilha Murutucu, o valor do sistema ficou em R\$1.638,88. Como apresentado anteriormente, a renda mensal mais frequente em ambas as ilhas corresponde a menos de um salário mínimo. Pelos custos que o modelo requer, torna-se incompatível, em aquisição com o pagamento imediato, o custeio individual do sistema proposto.

Constatou-se que $86,4 \%$ dos ribeirinhos interessados no sistema são a favor da sua partilha com outras famílias e 52,6\% dos entrevistados interessados no sistema já possuem reservatório em casa, o que reduziria os custos, conforme May (2004). Outra forma de buscar redução de custo do sistema pelo seu compartilhamento é a sua instalação em espaços coletivos como escolas, centros comunitários, igrejas, associações, 
entre outros. Tal ação é uma alternativa que deve ser considerada para o abastecimento coletivo.

Para a determinação do consumo potável, adotou-se como demanda para o dimensionamento do sistema a quantidade de 5 litros/morador/dia (GONÇALVES, 2012). Partindo dessa estimativa, uma família, da classe de renda supracitada, com quatro integrantes, responderá por um consumo total diário de 20 litros, o que representa por mês uma necessidade de 600 litros. Como o preço de compra praticado equivale a $\mathrm{R} \$ 2,00$ por 20 litros, ter-se-á um gasto de $\mathrm{R} \$$ 60,0/mês com água. Esse total representa 11\% do salário mínimo, praticado no período investigado. Trata-se, portanto, de um percentual considerável da renda que vem sendo destinado à aquisição de um recurso que não possui qualidade comprovada.

Em uma situação hipotética em que os moradores das ilhas comprariam água todos os dias do ano para suprir a mesma demanda de água utilizada no dimensionamento dos sistemas (951/dia na Ilha Grande, com 19 usuários, e 70l/dia na Ilha Murutucu, com 14 usuários), verificou-se que os gastos são bem maiores que o custo com a instalação dos Saacs. A Tabela 3 ilustra as características do exemplo formulado.

Tabela 3. Custos diário, mensal e anual com água, considerando a vazão de projeto do sistema, em cada ilha

\begin{tabular}{|c|c|c|c|c|c|c|}
\hline Local & $\begin{array}{c}\text { Demanda } \\
\text { de água } \\
\text { I/dia }\end{array}$ & $\begin{array}{c}\mathbf{N}^{\circ} \text { de } \\
\text { usuários } \\
\text { atendidos }\end{array}$ & $\begin{array}{c}\text { Gastos } \\
\text { diários } \\
\text { com } \\
\text { compra } \\
\text { de água } \\
\mathbf{( R} \$ \mathbf{)}\end{array}$ & $\begin{array}{c}\text { Gasto } \\
\text { mensal } \\
\text { com } \\
\text { compra } \\
\text { de água } \\
\mathbf{( R} \$ \mathbf{)}\end{array}$ & $\begin{array}{c}\text { Gasto } \\
\text { anual } \\
\text { com } \\
\text { compra } \\
\text { de água } \\
\mathbf{( R} \$ \mathbf{)}\end{array}$ & $\begin{array}{c}\text { Custo } \\
\text { com a } \\
\text { instalação } \\
\text { do sistema } \\
\mathbf{( R} \$ \mathbf{)}\end{array}$ \\
\hline $\begin{array}{c}\text { IIha } \\
\text { Grande }\end{array}$ & 95 & 19 & 9,50 & 285,00 & $3.467,50$ & $2.110,58$ \\
\hline $\begin{array}{c}\text { Ilha } \\
\text { Murutucu }\end{array}$ & 70 & 14 & 7,00 & 210,00 & $2.555,50$ & $1.638,88$ \\
\hline
\end{tabular}

Fonte: Gonçalves (2012)

Se os moradores se reunissem e poupassem dinheiro por um ano, além de instalarem os sistemas, teriam um saldo de $\mathrm{R} \$ 1.356,92$ 
na Ilha Grande e R\$ 916,62 na Ilha Murutucu, em relação ao dinheiro gasto com a compra de água no período de 12 meses. Os moradores da Ilha Grande que gastam R\$285,00/mês com a compra de água poderiam instalar o Saac em apenas 7,4 meses; e os moradores da llha Murutucu, em 7,8 meses. Obviamente que, considerando o contexto, o melhor mesmo seria uma solução institucional, em que o poder público doasse ou financiasse os Saacs.

No que se refere à sustentabilidade quanto à qualidade da água, as pesquisas se direcionaram para análises físico-químicas e bacteriológicas das amostras de água da chuva (coletada diretamente da atmosfera) e de diversos pontos dos sistemas (calha, descarte, reservatório superior e reservatório inferior). Os parâmetros físicoquímicos averiguados foram: cor aparente, turbidez, temperatura e $\mathrm{pH}$. E os biológicos: coliformes totais e Escherichia Coli.

A temperatura da água da chuva, coletada diretamente da atmosfera, variou na faixa de 18,5 a $23,4^{\circ} \mathrm{C}$, com média de $20,8^{\circ} \mathrm{C}$. A Tabela 4 exibe a caracterização da água da chuva dos sistemas, abordando as principais informações dos valores de temperatura, como máximo, mínimo, média, desvio padrão e coeficiente de variação.

Tabela 4. Máximo, mínimo, média, desvio padrão e coeficiente de variação da temperatura, em ${ }^{\circ} \mathrm{C}$, nos sistemas das ilhas

\begin{tabular}{|l|c|c|c|c|c|c|c|c|}
\hline & \multicolumn{3}{|c|}{$\begin{array}{r}\text { Temperatura, em }{ }^{\circ} \text { C, no sistema da } \\
\text { Ilha Grande }\end{array}$} & \multicolumn{4}{c|}{$\begin{array}{c}\text { Temperatura, em }{ }^{\circ} \text { C, no sistema da Ilha } \\
\text { Murutucu }\end{array}$} \\
\hline Pontos & Calha & Descarte & $\begin{array}{c}\text { Reserv. } \\
\text { superior }\end{array}$ & $\begin{array}{c}\text { Reserv. } \\
\text { inferior }\end{array}$ & Calha & Descarte & $\begin{array}{c}\text { Reserv. } \\
\text { superior }\end{array}$ & $\begin{array}{c}\text { Reserv. } \\
\text { inferior }\end{array}$ \\
\hline Máximo & 25,3 & 25,2 & 25 & 25,1 & 24,5 & 24,9 & 24,7 & 24,5 \\
\hline Mínimo & 18,1 & 18,3 & 18 & 17,3 & 18,1 & 18,5 & 18,1 & 17,8 \\
\hline Média & 21,77 & 21,57 & 21,59 & 21,59 & 21,35 & 21,49 & 21,49 & 21,75 \\
\hline DP & 2,35 & 2,35 & 2,39 & 2,58 & 2,15 & 2,1 & 2,26 & 2,13 \\
\hline CV & 0,11 & 0,11 & 0,11 & 0,12 & 0,1 & 0,1 & 0,11 & 0,1 \\
\hline
\end{tabular}

Fonte: Gonçalves (2012). 
$\mathrm{O} \mathrm{pH}$ das amostras de água de chuva coletadas sem passar pelos telhados, ou seja, direto da atmosfera, apresentou-se ácido, em que o valor mínimo encontrado foi de 3,9 e o máximo de 6,6. No entanto, em $53,33 \%$ das amostras analisadas, o pH se manteve acima de 5,0. A Figura 6 ilustra os valores de $\mathrm{pH}$ nos quatro pontos analisados no sistema da Ilha Grande (sistema 1) e no sistema da Ilha Murutucu (sistema 2), consecutivamente, promovendo a visualização das relações entre dados dos pontos mostrados.

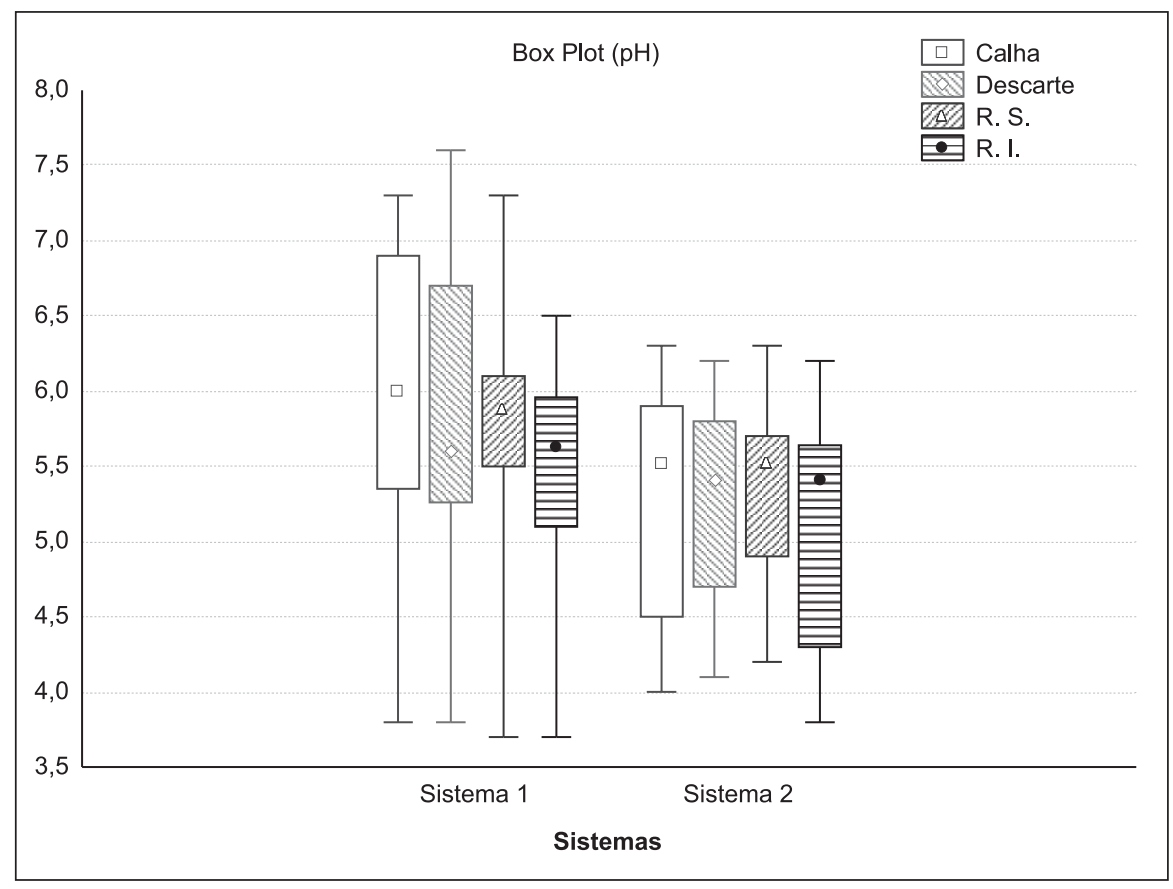

Fonte: Gonçalves (2012).

Figura 6. Box plot do parâmetro pH nos sistemas

Em 92,86\% das amostras de água coletadas diretamente da atmosfera, a cor aparente apresentou valores iguais ou menores a 15 U.C, de acordo com o padrão estipulado pela Portaria n 2914/2011 do Ministério da Saúde. A Figura 7 ilustra os valores de cor aparente nos quatro pontos analisados nos sistemas. 


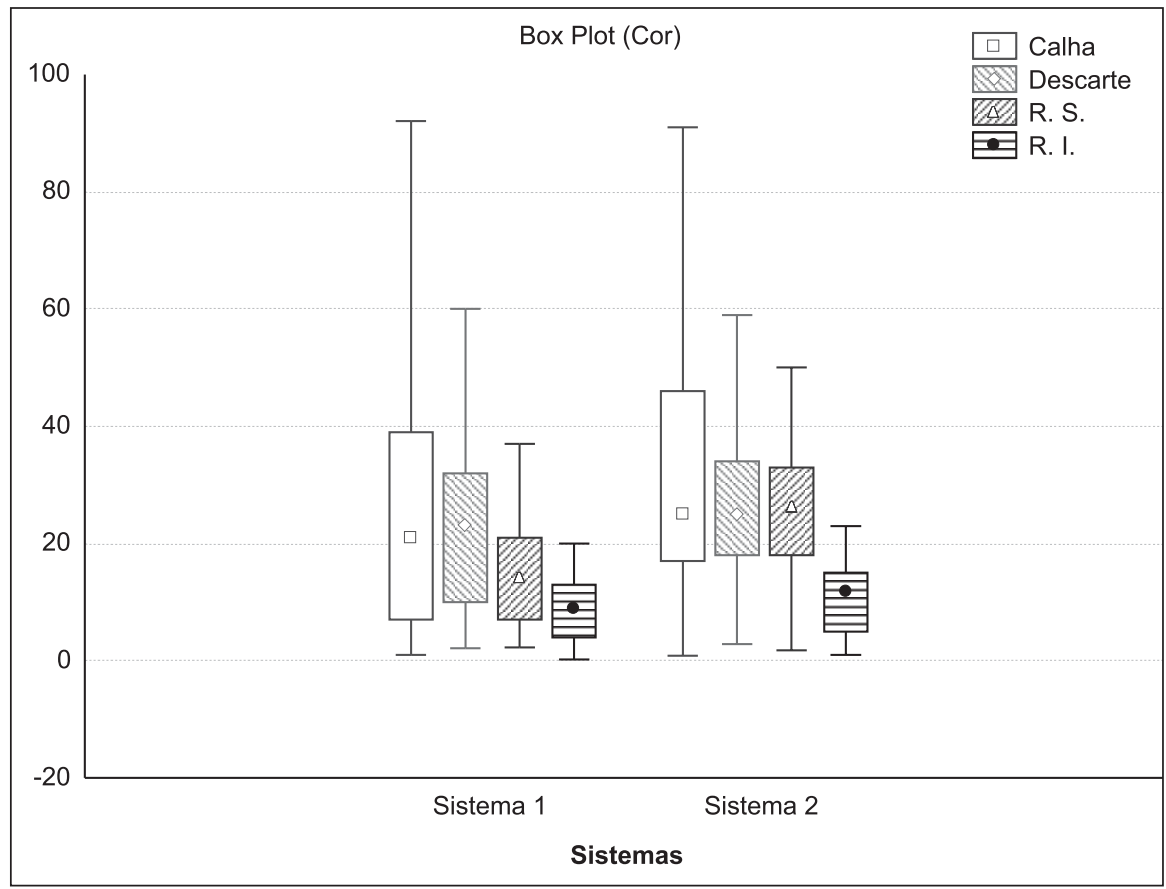

Fonte: Gonçalves (2012).

\section{Figura 7. Box plot do parâmetro cor, em U.C, nos sistemas}

O filtro proposto neste trabalho não se enquadra nem em filtração rápida, nem em filtração lenta; ainda assim, os valores de turbidez serão avaliados de acordo com o VMP para filtração lenta, ou seja, 1 UT, conforme Portaria nº 2914/2011 do Ministério da Saúde.

A água coletada direto da atmosfera apresentou $73,33 \%$ das amostras abaixo do valor preconizado no normativo, sendo o valor mínimo de 0 UT, o máximo de 3,26 UT e a média de 0,9 UT. Na Figura 8, são apresentados os dados de turbidez em ambos os sistemas. 


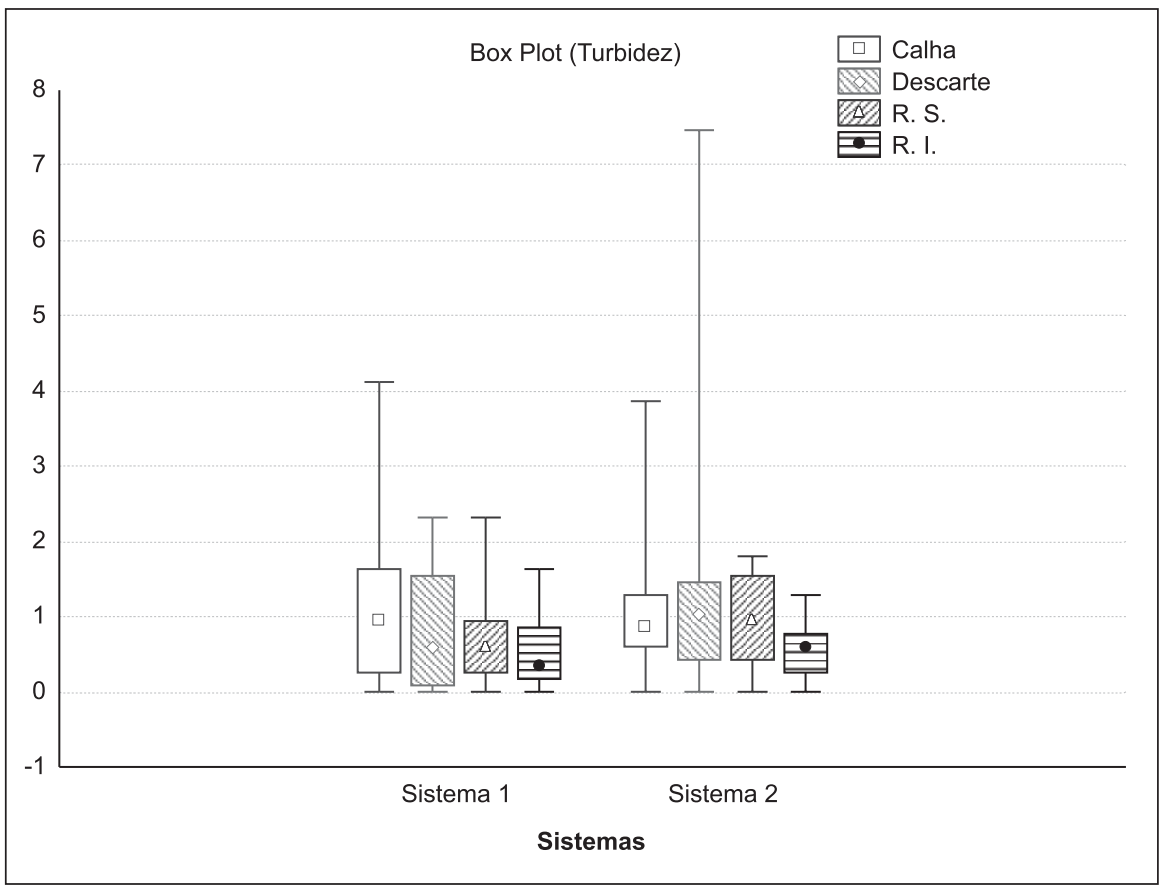

Fonte: Gonçalves (2012)

Figura 8. Box plot do parâmetro turbidez, em UT, nos sistemas

Os Saacs mostraram eficiência na remoção da turbidez nos dois sistemas; entretanto, nos primeiros pontos dos sistemas, foram detectados valores elevados. A turbidez na calha do sistema 1 variou entre 0 UT e 4,12 UT; no sistema 2, entre 0 e 3,86 UT. No descarte, o valor máximo caiu quase pela metade no sistema 1 (2,32 UT). 0 sistema 2 não se comportou da mesma forma: houve aumento de turbidez (7,47 UT), que pode ser atribuído às condições desse telhado, em que as impurezas passam pela calha e posteriormente se depositam nos descartes. Os reservatórios superiores, nos dois sistemas, apresentam menor turbidez em relação ao ponto anterior, e, no último ponto de coleta dos sistemas (reservatório inferior ou pós-filtro), houve remoção de quase toda turbidez, sendo identificada apenas uma campanha em cada sistema com turbidez acima de 1,0 UT. O comportamento da turbidez em todos os pontos dos sistemas pode ser visualizado na Tabela 5. A eficiência do filtro na remoção da turbidez em ambos os sistemas foi de $93,33 \%$. 
Tabela 5. Mínimo, máximo e média da turbidez, em UT, nos sistemas

\begin{tabular}{|l|c|c|c|c|c|c|c|c|c|c|c|c|}
\hline \multicolumn{1}{|c|}{ Ponto } & \multicolumn{3}{|c|}{ Calha } & \multicolumn{3}{c|}{ Descarte } & \multicolumn{3}{c|}{ Reserv. superior } & \multicolumn{3}{c|}{ Reserv. inferior } \\
\hline Medida & Min. & Max & Med. & Min. & Max. & Med. & Min. & Max & Med. & Min. & Max. & Med. \\
\hline I. Grande & 0 & 4,12 & 1,28 & 0 & 2,32 & 0,85 & 0 & 2,32 & 0,66 & 0 & 1,63 & 0,47 \\
\hline I. Murutucu & 0 & 3,86 & 1,04 & 0 & 7,47 & 1,38 & 0 & 1,8 & 1,01 & 0 & 1,29 & 0,5 \\
\hline
\end{tabular}

Fonte: Gonçalves (2012).

Entre as 14 amostras de água coletadas diretamente da atmosfera, 13 apresentaram coliformes totais; e sete, E. coli. Para explicar essa situação, trabalha-se com duas hipóteses: a provável contaminação da água durante o processo de coleta, visto que o recipiente ficava exposto ao tempo em torno de 30 a 40 minutos; ou a existência naturalmente na atmosfera.

A Tabela 6 exibe os resultados da qualidade bacteriológica das 15 campanhas realizadas nos pontos dos sistemas. Todas as amostras das calhas, dos descartes e reservatórios superiores apresentaram coliformes totais nos dois sistemas. No reservatório inferior, em 14 campanhas no sistema 1 e em 15 campanhas no sistema 2, identificaram-se coliformes totais.

Tabela 6. Resultado da presença de coliformes totais e $E$. coli nos sistemas

\begin{tabular}{|l|c|c|c|c|c|c|c|c|}
\hline \multirow{2}{*}{ Parâmetro } & \multicolumn{2}{|c|}{$\begin{array}{c}\text { No de amostras contendo micro-organismos em cada } \\
\text { ponto de coleta do sistema 1 (ilha Grande) }\end{array}$} & \multicolumn{2}{|c|}{$\begin{array}{c}\text { No de amostras contendo micro-organismos em cada } \\
\text { ponto de coleta do sistema 2 (ilha Murutucu) }\end{array}$} \\
\cline { 2 - 9 } & Calha & Descarte & $\begin{array}{c}\text { Reserv. } \\
\text { sup. }\end{array}$ & $\begin{array}{c}\text { Reserv. } \\
\text { inf. }\end{array}$ & Calha & Descarte & $\begin{array}{c}\text { Reserv. } \\
\text { sup. }\end{array}$ & $\begin{array}{c}\text { Reserv. } \\
\text { inf. }\end{array}$ \\
\hline $\begin{array}{l}\text { Coliformes } \\
\text { totais }\end{array}$ & 15 & 15 & 15 & 14 & 15 & 15 & 15 & 15 \\
\hline E. Coli & 15 & 15 & 14 & 6 & 15 & 15 & 13 & 12 \\
\hline
\end{tabular}

Fonte: Modificado de Gonçalves (2012).

Identificou-se a presença de E.coli em todas as amostras da calha, do descarte e reservatório superior, com exceção de uma amostra que atestou negativa para E.colino reservatório superior do sistema 2. No reservatório inferior, seis campanhas no sistema 1 e 12 campanhas no sistema 2 atestaram presença de coliformes. Pode-se inferir que o filtro de areia proposto tem pouca eficiência na remoção de $E$. coli. 
De forma geral, os parâmetros físico-químicos estão dentro dos padrões de potabilidade. No entanto, a bacteriologia ainda demonstra a necessidade de melhoria, revelando então a necessidade de desinfecção da água, que, por enquanto, tem sido realizada com a adição de hipoclorito de sódio pelos próprios usuários.

\section{Conclusões}

Como verificado, a interação entre os dois programas de pósgraduação se apresentou como uma forma de complementariedade de conhecimentos para responder a uma demanda científica e social específica da realidade amazônica.

No contexto dos estudos, o aproveitamento das águas pluviais se relaciona com o desenvolvimento local sustentável das ilhas de Belém por representar uma possibilidade de ação integrada nas comunidades em prol da satisfação de água potável. A sustentabilidade do sistema buscou avaliar aspectos relacionados à quantidade, ao acesso, custo e à qualidade da água oferecida pelos Saacs.

Os sistemas se mostraram viáveis em termos de quantidade, acesso facilitado e custo e com grandes possibilidades de aquisição. No entanto, em termos de qualidade da água, ainda espera-se uma melhora, em especial com a introdução da desinfecção mais eficiente que o uso do hipoclorito de sódio.

De uma forma geral, as contribuições do PPGEDAM e do PPGEC demonstram que a gestão da água da chuva satisfaz as necessidades locais, estabelece o manejo racional do recurso hídrico, diminui os riscos à saúde humana e facilita o acesso à água potável. Isso contribui para o desenvolvimento humano e a melhora das condições de vida das comunidades ribeirinhas e certamente pode ser usado como modelo para outras populações amazônicas em condições semelhantes. 


\section{Agradecimentos}

Ao CNPq, à Fapespa e à Capes pelo apoio financeiro, que deu condições para o desenvolvimento destas pesquisas. E também ao PPCEC-Itec-UFPa e ao PPGEDAM-NumaMA-UFPa por todo o apoio acadêmico-técnico-científico.

Recebido 25/11/2012

Aprovado 25/07/2013

\section{Referências bibliográficas}

ABNT - ASSOCIAÇÃO BRASILEIRA DE NORMAS TÉCNICAS. NBR 10844: Instalações Prediais de Águas Pluviais - Procedimento. Rio de Janeiro: ABNT, 1989. 13p.

NBR 15527. Água da chuva - Aproveitamento de coberturas em áreas urbanas para fins não potáveis - Requisitos. Rio de Janeiro: ABNT, 2007. 12p.

ANA - Agência Nacional de Águas. Atlas Brasil: abastecimento urbano de água: panorama nacional. Brasília: Engecorps; Cobrape, 2010. Disponivel em: <http://arquivos.ana.gov.br/institucional/sge/ CEDOC/Catalogo/2011/AtlasBrasil-AbastecimentoUrbanodeAguaPanoramaNacionalv1.pdf>. Acesso em: 29 mai. 2012.

APHA; AWWA; WPCF. Standard Methods for the Examination of Water Wastewater. Washington, D.C.: APHA, AWWA, WPCF, 1980.

BELÉM. Secretaria Municipal de Coordenação Geral do Planejamento e Gestão. Anuário Estatístico do Município de Belém. Belém: Prefeitura Municipal de Belém, 2012.

BRASIL. Ministério da Educação. Coordenação de Aperfeiçoamento de Pessoal de Nível Superior. Plano Nacional de Pós-Graduação - PNPG 2011-2020. Brasília: Capes, 2010. 
2011. Dispõe sobre os procedimentos de controle e de vigilância da qualidade da água para consumo humano e seu padrão de potabilidade. Diário Oficial da República Federativa do Brasil, Poder Executivo, Brasília, DF, 14 dez., 2011. Seção 1, p. 39.

FENZL, N.; MENDES, R. L. R; FERNANDES, L. L. A sustentabilidade do sistema de abastecimento de água: da captação ao consumo de água em Belém. Belém: Numa/Ufpa, 2010.

GIATTI, L. L.; CUTOLO, S. A. Acesso à água para consumo humano e aspectos de saúde pública na Amazônia Legal. Ambiente \& Sociedade, v. 15, n. 1, p. 93-109, 2012.

GONÇALVES,C.C. Aproveitamento deáguas pluviais para abastecimento em área rural na Amazônia. Estudo de caso: ilhas Grande e Murutucú, Belém-PA. 2012. Dissertação (Mestrado em Engenharia Civil)-Instituto de Tecnologia, Universidade Federal do Pará, Belém.

GUIMARÃES, U. Mapa de localização das ilhas Combu, Grande e Murutucu. Belém, 2012.

INMET - Instituto Nacional de Meteorologia. Padrões climatológicos normais (1961 - 1990). Disponível em: http://www.inmet.gov.br/ html/observacoes.php. Acesso em: 12 ago. 2011.

MAY, S. Estudo da viabilidade do aproveitamento de água de chuva para consumo não potável em edificações. 2004. Dissertação (Mestrado em Engenharia de Construção Civil e Urbana)- Escola Politécnica, Universidade de São Paulo, São Paulo. Disponível em: < www.teses. usp.br/teses/disponiveis/3/3146/tde-02082004-122332/>. Acesso em: 24 jan. 2011.

MENDES, R. L. R Indicadores de sustentabilidade do uso doméstico da água. 2005. Tese (Doutorado em Desenvolvimento Socioambiental)Núcleo de Altos Estudos Amazônicos, Universidade Federal do Pará, Belém. 
MENDES, R. L. R.; et al. Desenvolvimento de indicadores para o sistema de abastecimento público de água de Belém-PA. Papers do NAEA, v. 1, n. 301, p. 1-20, 2012.

MENDES, R. L. R.; FENZL, N. Indicator System For Domestic Water Supply In Belém, Pará, Brazil. In: HENSEL, O.; SELBACH, J. F.; BILIBIO, C. (Orgs.). Sustainable water management in the tropics and subtropics and case studys in Brazil. Jaguarão: Fundação Universidade Federal do Pampa, Unikassel, PGCult/Ufma, 2011. p. 953-974.

ONU - Organização das Nações Unidas. Sick Water - the central role of Wastewater Management. Arendal: PNUMA/ONU-HABITAT, 2010. Disponivel em: <http://www.unep.org/pdf/SickWater_screen.pdf>. Acesso em: 07 jan. 2012.

VELOSO, N. S. L. Água da chuva e desenvolvimento local: o caso do abastecimento das ilhas de Belém. 2012. Dissertação (Mestrado em Gestão de Recursos Naturais e Desenvolvimento Local na Amazônia)Núcleo de Meio Ambiente, Universidade Federal do Pará, Belém. 


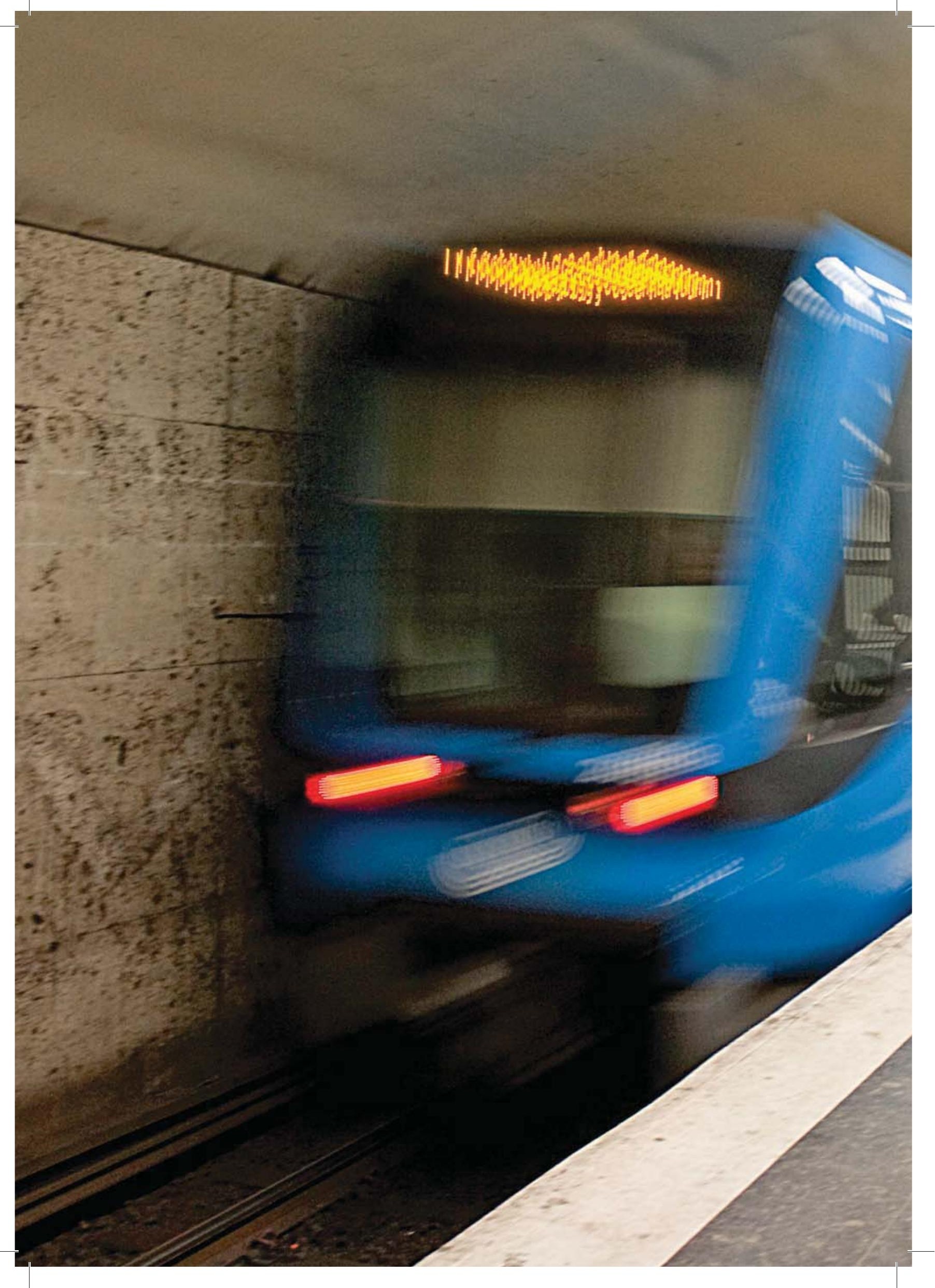




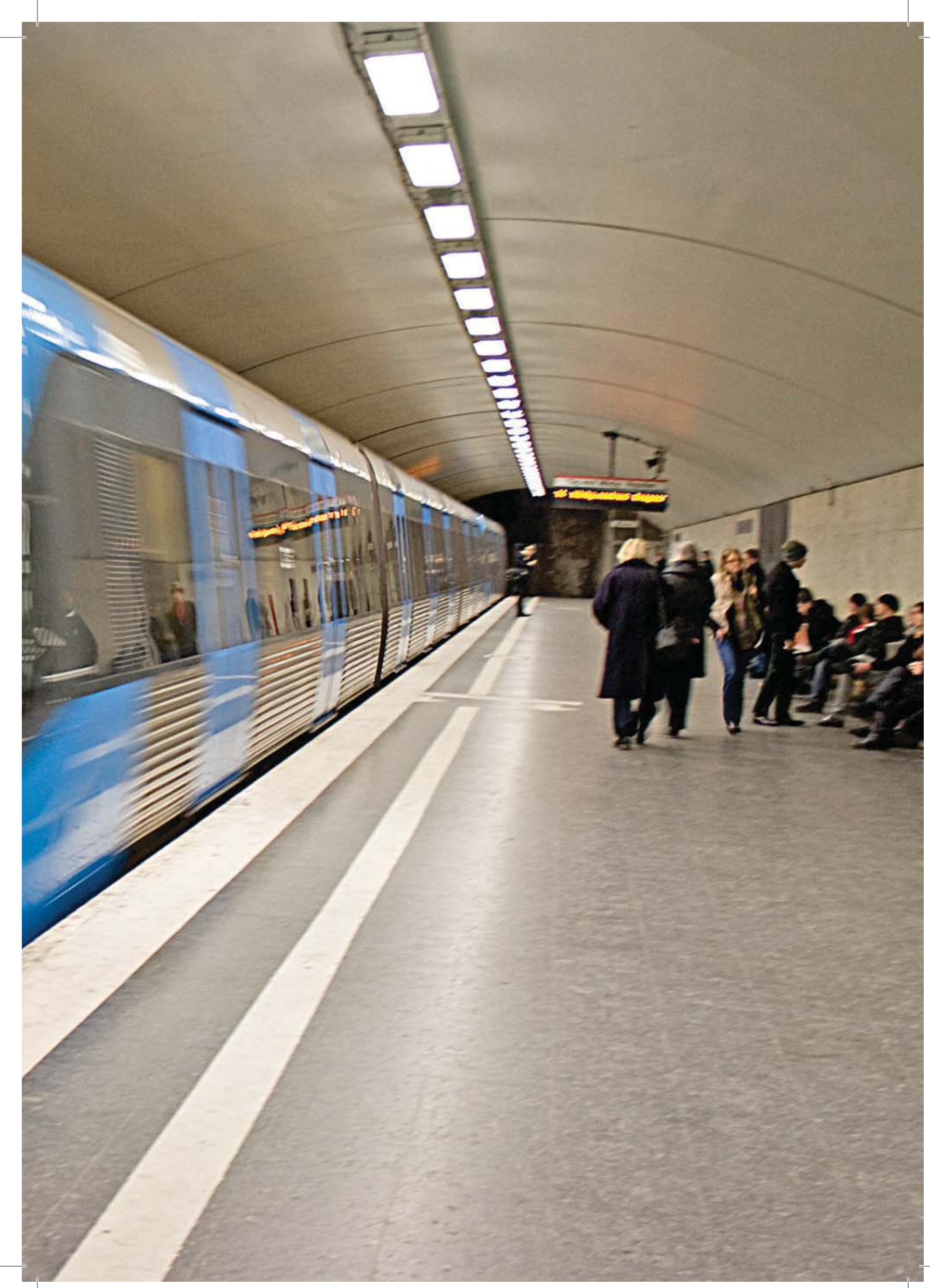


Inovação e sustentabilidade na indústria da construção: um exercício de ensino no PPG-FAU/UnB

Innovation and sustainability in the construction industry: a teaching exercise at the PPG / FAU-UnB (Graduate Program in Architecture and Urbanism UnB)

Innovación y sostenibilidad en la industria de la construcción: un ejercicio de enseñanza en el PPGFAU/UnB (Programa de Posgrado en Arquitectura y Urbanismo)

Raquel Naves Blumenschein, doutora em Desenvolvimento Sustentável pela Universidade de Brasília e professora adjunta 2 da Universidade de Brasília. Endereço: Campus Universitário Darcy Ribeiro - Asa Norte, Instituto de Ciências Sociais - ICC Norte, Faculdade de Arquitetura e Urbanismo - FAU/UnB, Gleba A - Mezanino. LACIS. Caixa Postal 04431. CEP: 70904-070 - Brasília, DF. Telefone: (61) 3107-7482/ 8135-1822. E-mail: raquelblum@ terra.com.br.

Katia Broeto Miller, doutoranda em Arquitetura e Urbanismo pela Universidade de Brasília. Endereço: Campus Universitário Darcy Ribeiro - Asa Norte, Instituto de Ciências Sociais - ICC - Norte, Faculdade de Arquitetura e Urbanismo - FAU/UnB, Gleba A Mezanino. LACIS. Caixa Postal 04431. CEP: 70904-070 - Brasília, DF. Telefone: (61) 3273-7655. E-mail: miller.katiab@gmail.com.

Maria Vitoria Ferrari Tomé, doutora em Agronomia - Solos e Nutrição de Plantas pela Universidade Federal de Viçosa e professora adjunta 1 da Universidade de Brasília. Endereço: Campus Universitário Darcy Ribeiro - Asa Norte, Instituto de Ciências Sociais - ICC - Norte, Faculdade de Arquitetura e Urbanismo - FAU/UnB, Gleba A - Mezanino. LACIS. Caixa Postal 04431. CEP: 70904-070 - Brasília, DF. Telefone: (61) 3032-7590/ 8118-5125. E-mail:vitferrari@unb.br. 


\section{Resumo}

Este artigo apresenta os resultados do desenvolvimento da ferramenta Cais (Concepção e Análise em Inovação e Sustentabilidade) para a estruturação do raciocínio e análise de projetos, concebida e utilizada na disciplina Estudos Especiais em Tecnologia 1: Inovação e Sustentabilidade na Indústria da Construção (PPG-FAU/UnB). O método utilizado foi dividido em fundamentação, concepção, análise e teste de aplicabilidade. $\mathrm{O}$ uso do Cais potencializou a estruturação e delimitação das pesquisas, permitiu analisar as contribuições em inovação e sustentabilidade das pesquisas no contexto da CPIC e identificar caminhos para a difusão dos resultados das pesquisas. Essa ferramenta pode ser um instrumento de avaliação, alavancagem e incentivo para projetos que gerem resultados em sinergia com a inovação e sustentabilidade da indústria da construção.

Palavras-chave: Estruturação e Difusão de Pesquisas. Inovação. Sustentabilidade. Indústria da Construção.

\section{Abstract}

This paper presents results about the development of the tool CAIS (Conception and Analysis in Innovation and Sustainability) for thought structuring and project analysis, designed and used in the course "Specials Studies in Technology 1: Innovation and Sustainability in Construction Industry" (PPG-FAU/UnB). The method used was divided into theoretical framework, conception, analyses, and applicable tests. The use of this tool improved research organization and delimitation, and it allowed for the analysis of the contributions to innovation and sustainability of research in the PCCI context, as well as the identification of patterns for the communication of research results. This tool can serve as a device of evaluating, leveraging, and encouraging projects that generate results in synergy with innovation and sustainability in the construction industry.

Keywords: Research Organization and Diffusion. Innovation. Sustainability. Construction Industry. 


\section{Resumen}

En este artículo se presentan los resultados del desarrollo de la herramienta CAIS (Diseño y Análisis en Innovación y Sostenibilidad) para estructurar el raciocinio y el análisis de proyectos, creada y utilizada en la asignatura Estudios Especiales en Tecnología 1: Innovación y Sostenibilidad en la Industria de la Construcción (PPGFAU/UnB). El método utilizado se dividió en: fundamentación, diseño, análisis y pruebas de aplicabilidad. El uso de la CAIS fortaleció la estructuración y delimitación de las investigaciones, permitió analizar las contribuciones en innovación y sostenibilidad de las investigaciones en el contexto de la CPIC e identificar vías para la difusión de los resultados de las investigaciones. Esta herramienta puede ser un instrumento de evaluación, estímulo y motivación para proyectos que generen resultados en sinergia con la innovación y sostenibilidad de la industria de la construcción.

Palabras clave: Estructuración y Difusión de Investigaciones. Innovación. Sostenibilidad. Industria de la Construcción.

\section{Introdução}

A cadeia produtiva da indústria da construção (CPIC) integra as atividades necessárias para a produção do ambiente construído, que é o seu principal produto, na forma de edificações, espaços e infraestruturas urbanas. A CPIC pode ser conceituada como o conjunto de atividades que se articulam de maneira progressiva, integrando os insumos básicos, a inteligência de projeto e construção, até o produto final (BLUMENSCHEIN, 2004).

Ao aplicar esse conceitoà indústria da construção, Blumenschein (2004) considera três grupos industriais básicos, que representam os principais elos da CPIC:

a. Indústrias de suprimentos, que produzem materiais, insumos e componentes;

b. Indústrias de processos (ou principal), que produzem edificações e obras de engenharia pesada; e 
c. Indústria auxiliar, que agrega arquitetos, consultores, projetistas, entre outros profissionais que oferecem a inteligência de projeto, planejamento e produção.

Essa cadeia, que representa um importante vetor de desenvolvimento econômico e social, também causa impactos negativos ao meio ambiente, desde a construção à operação dos seus principais produtos. Em 2011, o Produto Interno Bruto (PIB) setorial da CPIC foi de $\mathrm{R} \$ 170,94$ bilhões, o que corresponde a 5,35\% do PIB brasileiro (SINDUSCON-SP, 2011).

Apesar da importância econômica da CPIC, impactos ambientais negativos são gerados em todo o ciclo de vida do ambiente construído, desde a ocupação da terra até a demolição e o descarte de edifícios ou obras de infraestrutura, passando pela extração da matéria-prima, pelo beneficiamento dos insumos, pela produção de componentes e derivados, pelo transporte, processo construtivo e pela fase de uso e operação do produto final (BLUMENSCHEIN, 2004).

A CPIC consome $40 \%$ da matéria-prima e da energia, 17\% da água potável no mundo e é responsável por 40\% do volume dos resíduos sólidos gerados no mundo. O Programa das Nações Unidas para o Meio Ambiente (UNEP, sigla em inglês) (2012), em seu terceiro relatório de diferenças de emissões entre o esperado e o real, aponta o setor da construção com um aumento de mais de 70\% na emissão anual de gases de efeito estufa nas últimas quatro décadas.

Em cidades brasileiras de médio e grande porte, as taxas de geração de resíduos sólidos da construção e demolição podem variar de 400 a 700 kg/hab.ano. Esses impactos são agravados pela alta demanda no País por habitação e infraestrutura. O déficit habitacional brasileiro é de 7,9 milhões de habitações, e o governo federal tem como uma das metas do bicentenário da independência zerar esse déficit habitacional até 2022 (TRUSTY; MEIL, 2000; OLIVEIRA; OLIVEIRA; FERREIRA, 2008; IPEA, 2011; SAE, 2010).

Além disso, o lançamento do Programa de Aceleração do Crescimento (PAC) e a realização dos eventos internacionais que serão 
sediados no País, como a Copa do Mundo de 2014 e as Olimpíadas em 2016, demandam obras de infraestrutura e edificações de grande porte. Prover toda a infraestrutura necessária para sediar esses eventos de grande visibilidade internacional e atender às metas do PAC é um desafio que exige a aceleração de mudança de paradigmas tecnológicos, para que processos e produtos da CPIC atendam a critérios de sustentabilidade.

Segundo Blumenschein (2004), um paradigma tecnológico estabelece-se ao longo de um processo de acumulação de aprendizados, dependendo, portanto, do conhecimento e de informações acumulados ao longo dos vários processos de produção, representados por um conjunto de exemplares adquiridos. Dosi (1988, p. 224) afirma que paradigma tecnológico “define contextualmente as necessidades a serem preenchidas, os princípios científicos utilizados para a tarefa e o material tecnológico a ser usado”.

A aceleração da mudança de paradigmas na direção de processos e produtos da CPIC mais sustentáveis torna-se urgente ao considerar os desafios colocados para o século XXI, que, segundo a Unep (2007), incluem: mudança climática; desastres e conflitos; manejo de ecossistema; governança do meio ambiente; substâncias perigosas; e eficiência do uso de recursos naturais. Há, portanto, uma enorme demanda para o desenvolvimento e a pesquisa de conhecimentos que contribuam com a mudança de paradigmas tecnológicos na CPIC.

Na última década, registra-se um aumento significativo de pesquisas focadas na sustentabilidade do ambiente construído, em seus processos produtivos e produtos. Levantamento da produção técnico-científica com o tema Sustentabilidade do Ambiente Construído, feito no sítio do banco internacional de teses, dissertações e artigos Science Direct, demonstra um aumento de 1859\% no número de publicações entre 1994 e 2012 (Figura 1). 


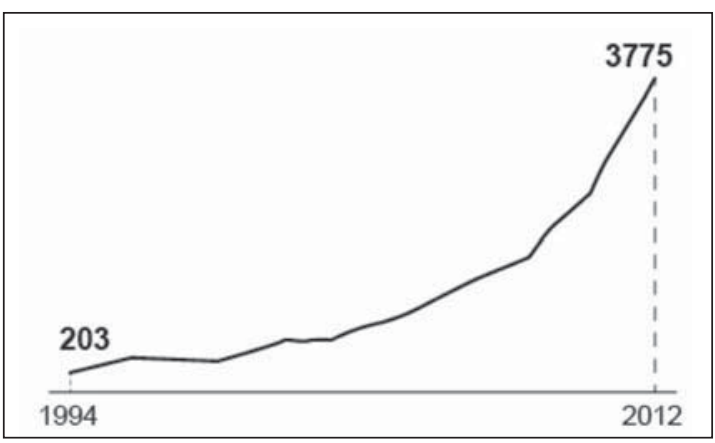

Figura 1. Levantamento das produções técnico-científicas sobre Sustentabilidade no Ambiente Construído no Science Direct

Entre os obstáculos encontrados no desenvolvimento de pesquisas, citam-se as dificuldades dos alunos de pós-graduação em definir os escopos e as interfaces dos seus temas de estudo; o distanciamento entre as necessidades reais da CPIC no processo de mudança de seu paradigma tecnológico para atender a sociedade e às pesquisas desenvolvidas na academia; a falta de definição de estratégias de disseminação de soluções inovadoras geradas em programas de pós-graduação; e as deficiências na definição de objetivos e métodos e na integração das pesquisas propostas pelos alunos às linhas de pesquisa desenvolvidas pelos orientadores.

Entre as dificuldades de integração, cita-se a falta de visão sistêmica na concepção e no desenvolvimento das pesquisas. É imprescindivel compreender o contexto em que a pesquisa ocorre, considerando sua função acadêmica, as implicações sociais e econômicas e a elaboração de projetos, incluindo a concepção de estratégias para a disseminação do conhecimento gerado.

Este artigo tem o objetivo de apresentar os resultados parciais do desenvolvimento da ferramenta Cais (Concepção e Análise em Inovação e Sustentabilidade), que auxilia na estruturação do raciocínio e análise de projetos de pesquisa por alunos e orientadores. Essa ferramenta foi concebida e vem sendo utilizada e aprimorada no âmbito do Programa de Pós-Graduação da Faculdade de Arquitetura e Urbanismo da Universidade de Brasília (PPGFAU/UnB), na disciplina Estudos Especiais em Tecnologia 1: Inovação e Sustentabilidade na Indústria da Construção. 


\section{Metodologia}

Para o desenvolvimento e a aplicação da ferramenta Cais, foram cumpridas três etapas:

Etapa 01 - Fundamentação: foram selecionados conteúdos que auxiliariam os alunos no desenvolvimento e na aplicação da ferramenta. Os conteúdos incluem conceitos da CPIC, construção sustentável, pensamento sistêmico e teoria de inovação aplicada à indústria da construção.

Etapa 02 - Concepção da ferramenta: a partir da introdução dos conceitos definidos na etapa anterior, identificaram-se os itens e critérios que deveriam compor a ferramenta a ser construída.

Etapa 03-Teste e análise da ferramenta proposta: a ferramenta foi analisada e aplicada nas pesquisas pelos alunos da disciplina nos semestres 02/2011 e 01/2012 e revisada de acordo com os resultados dessas análises.

\section{a. Fundamentação}

A definição de escopos de pesquisa e procedimentos metodológicos na produção de conhecimentos que contribuam para a mudança de paradigmas na CPIC exige a compreensão dos conceitos de sustentabilidade e de construção sustentável e do processo de inovação da cadeia produtiva da indústria da construção.

\section{a.1 Sustentabilidade na CPIC}

O processo de construção tem considerado como fatores competitivos o triângulo custo-qualidade-prazo (BLUMENSCHEIN, 2004), mas a complexidade da cadeia, os impactos ambientais negativos e sua interferência no meio ambiente têm forçado uma mudança nesse enfoque, passando a considerar fatores ambientais também como relevantes. 
Consequentemente, os princípios que norteiam as decisões tomadas na adoção de tecnologias da construção precisam estar fundamentados no conceito de sustentabilidade, que considera: os objetivos da conservação, que visam manter os processos ecológicos e assegurar a utilização sustentável das espécies e dos ecossistemas, defendendo o compromisso com a manutenção da vida (OFQPC, 1992); as variáveis ambientais, que não são opostas e nem paralelas aos processos industriais, fazendo parte do todo (HAWKEN et al., 1999); e os princípios de durabilidade, racionalização e gerência de cadeia integrada (HENDRIKS, 2000) e a responsabilidade ambiental e social (MACHADO FILHO, 2002).

Segundo Blumenschein (2004), três grandes grupos de paradigmas tecnológicos são relevantes para o exercício de aplicação de diretrizes fundamentadas nas raízes da sustentabilidade:

(i) O primeiro grupo refere-se aos que influenciam e determinam as decisões na fase de projeto, têm impacto na eficiência da operação da edificação e incluem o processo de elaboração do projeto. Essas decisões devem ser fundamentadas em diretrizes como: (a) a integração com a paisagem e/ou contexto arquitetônico, com atenção especial ao respeito das escalas; (b) a aplicação de princípios passivos de projeto, valorizando a iluminação e ventilação natural e aumentando a capacidade de adaptação aos efeitos das mudanças climáticas; (c) a padronização de dimensões, elementos e componentes, aumentando a flexibilidade no uso; (d) a redução de emissões de gases de efeito estufa, pelo compromisso com os critérios de especificação, norteados pela avaliação do ciclo de vida de produtos; (e) a racionalização de recursos; (f) a utilização de tecnologias de reciclagem de água; (g) a eficiência energética, priorizando decisões de projeto que minimizem o consumo de energia operacional e reduzam o consumo de energia, enquanto mantêm níveis de iluminação adequados e que ofereçam maior flexibilidade de controle de iluminação das áreas ocupadas; (h) e o exercício do projeto simultâneo, que assegura a compatibilização de projetos e linguagens técnicas, reduzindo perdas e aumentando eficiências entre a integração das soluções. 
(ii) O segundo grupo relaciona-se à fase do processo construtivo e fundamenta-se na gestão da qualidade, no cumprimento da responsabilidade ambiental e social e no conceito de processo construtivo como processo de reciclagem. Envolve: (a) a gestão eficiente e responsável do processo construtivo; (b) a reciclagem de materiais e resíduos; (c) o projeto preventivo (aplicado tanto a edifícios quanto a elementos e componentes); (d) a compra responsável de materiais e serviços; (e) e a responsabilidade social. O exercício contínuo da gestão da qualidade assegura que sistemas e procedimentos são introduzidos ao longo do processo como um todo, particularmente, por meio da implantação de sistemas e programas de qualidade, como, por exemplo, ISO ou PBQP-H. Consequentemente, há menos erros, menos retrabalhos, menos desperdícios, mais qualidade, mais durabilidade e menos manutenção, implicando a menor utilização de recursos naturais.

O conceito do processo construtivo visto como processo de reciclagem implica a reinserção de resíduos gerados em obras, como agregados reciclados, reintroduzidos no processo de produção. 0 cumprimento da responsabilidade ambiental e social assegura que custos não são transferidos indevidamente e há que comprometimento da empresa com seus funcionários e com a comunidade e sociedade.

(iii) Oterceiro grupo refere-seà fase de extração e processamento de matéria-prima, incluindo o fornecimento de materiais, elementos e componentes que alimentam o processo construtivo. Além do mais, ele envolve a necessidade da aplicação do conceito de gerenciamento em cadeia integrada, que visa o gerenciamento do ciclo de vida de produtos, considerando aspectos ambientais, sociais e econômicos, com base no princípio de redução do uso de fontes de energia fóssil e uso máximo de fontes de energia; além do balanceamento do processo de renovação de ecossistemas. Incorpora ainda o conceito de durabilidade, que assume que materiais são extraídos e processados, aplicados e demolidos, com a preocupação constante de permanecerem úteis e com qualidade.

A sustentabilidade da construção está relacionada à durabilidade dos materiais empregados e sua capacidade de resistir 
às intempéries sem perder suas funções originais (HENDRIKS, 2000). Blumenschein (2004) ainda afirma que a durabilidade de uma edificação sustentável está relacionada à qualidade do processo construtivo e aos materiais empregados. Hendriks (2000) aborda a flexibilidade da edificação como premissa importante para a sua sustentabilidade, e Romero (2001) resgata esse conceito e associa a durabilidade da construção à capacidade que ela possui em adaptar-se às diversas funções e se estabelecer como elemento de identidade visual de um lugar.

A partir da revisão das fases do processo construtivo e dos conceitos de sustentabilidade da CPIC dos autores anteriormente citados, foi elaborado um quadro analítico (Quadro 1), construído relacionando os autores, seus conceitos e as fases do processo construtivo com níveis de influência alta, média ou baixa, evidenciando que a construção sustentável é um conceito que abrange desde a tomada de decisão até o desmonte da construção.

No conceito de construções atentas ao meio ambiente concebido por Rovers (2001), por exemplo, existe uma influência alta nas etapas de decisão e desmonte da edificação e uma influência média nas etapas de projeto, construção e uso, pois esse conceito foca nas escolhas feitas no processo que antecede a concepção do edifício, que devem considerar o uso de materiais com potencial de destinação adequada na etapa de desmonte. 
Quadro 1. Relação entre os autores, os conceitos e as fases do processo construtivo - níveis de influência (alta, média e baixa)

\begin{tabular}{|c|c|c|c|c|c|c|}
\hline \multicolumn{7}{|c|}{ Fases do processo construtivo } \\
\hline Autor & Conceito & Decisão & Projeto & Construção & Uso & Desmonte \\
\hline \multirow[t]{3}{*}{$\begin{array}{l}\text { Rovers } \\
(2001)\end{array}$} & $\begin{array}{l}\text { Construções } \\
\text { atentas ao meio } \\
\text { ambiente }\end{array}$ & Alta & Média & Média & Média & Alta \\
\hline & $\begin{array}{l}\text { Construções } \\
\text { sustentáveis }\end{array}$ & Média & Média & Alta & Baixa & Baixa \\
\hline & Vida sustentável & Alta & Baixa & Baixa & Baixa & Média \\
\hline $\begin{array}{l}\text { Hendriks } \\
(2000)\end{array}$ & $\begin{array}{l}\text { Flexibilidade e } \\
\text { durabilidade }\end{array}$ & Alta & Média & Média & Baixa & Alta \\
\hline \multirow[t]{2}{*}{$\begin{array}{l}\text { Romero } \\
\text { (2001) }\end{array}$} & $\begin{array}{l}\text { Durabilidade } \\
\text { e adaptação } \\
\text { bioclimática }\end{array}$ & Alta & Média & Média & Baixa & Baixa \\
\hline & $\begin{array}{l}\text { Identidade } \\
\text { visual }\end{array}$ & Alta & Alta & Baixa & Baixa & Baixa \\
\hline
\end{tabular}

\section{b. Inovação na CPIC}

O estudo dos vetores que podem provocar mudanças nos paradigmas tecnológicos da CPIC, em uma trajetória tecnológica sustentável, está diretamente vinculado às pesquisas do processo de inovação e dos modelos de evolução tecnológica aplicados ao contexto da CPIC (BLUMENSCHEIN, 2004).

Apesar de os estudos de aplicação de modelos para a análise de mudanças tecnológicas e inovação oferecerem ferramentas relevantes ao estudo de inovação e mudanças na CPIC, nenhum se aplica integralmente ao seu contexto, particularmente, no Brasil. Primeiro, por se referirem a indústrias manufatureiras ou a indústrias de tecnologia avançada (de pesquisa intensa) e por serem, em sua maioria, estudos estrangeiros. Segundo, pelas características do produto final da construção, que define peculiaridades em seu processo (TURIN, 1968; IVE; GROAK; 1986). Além disso, o número de participantes no processo construtivo reforça a relevância da dimensão social em qualquer análise (BOWLEY, 1966; IVE; GROAK, 1986; TURIN, 1968). Terceiro, por estar inserido em um País que se caracteriza por realidades antagônicas e instituições desintegradas. 
Segundo Schumpeter (1949), inovação é o emprego de recursos existentes em diferentes maneiras ou, ainda, o desenvolvimento de novas combinações de fatores de produção. O conceito de novas maneiras de combinação inclui:

“[...] (a) a introdução de um novo produto; (b) a introdução de novo método de produção; (c) a abertura de um novo mercado; (d) a conquista de uma nova fonte de fornecimento de materiais ou produtos manufaturados; (e) o desenvolvimento de novas formas de organização de qualquer indústria, como por exemplo, a queda ou criação de uma posição de monopólio” (SCHUMPETER, 1939, p. 66 apud BLUMENSCHEIN, 2004, p. 29).

Freeman e Lundvall (1988), Dosi (1988), Viotti (1997) e Capra (2002) avançam nos conceitos de inovação, e Freeman (1995) difere a inovação schumpeteriana da inovação incremental. A inovação schumpeteriana envolve mudanças na organização de produção e mercados e implica, primeiramente, a introdução de um novo produto, processo ou forma de organização "inteiramente nova”. A mudança incremental, por sua vez, refere-se à introdução de melhorias em produtos, processos ou organização da produção sem ocasionar mudanças industriais (FREEMAN; LUNDVALL, 1988).

O Manual de Oslo, ao definir procedimentos metodológicos para analisar e avaliar a inovação, complementa esse conceito, introduzindo a ideia de inovação como a concepção e implantação de mudanças significativas no produto, processo, marketing ou na organização da empresa com o propósito de melhorar os resultados (OCDE, 2005).

\section{b.1 Vetores de influência da CPIC}

Blumenschein (2004) salienta a importância de identificar as forças responsáveis pelo surgimento das inovações e demonstrar com mais profundidade as relações entre os diferentes atores e vetores de influência. Nesse contexto, faz-se necessário identificar os potenciais vetores capazes de influenciar o passo de mudança de paradigmas tecnológicos na CPIC. 
A identificação dos vetores leva à integração de fatores técnicos, econômicos, organizacionais, institucionais e políticos, dependendo do contexto regional ou da cadeia em questão, destacandose o papel das políticas públicas e a relevância da integração de agentes coordenadores da indústria (CIB, 1999 apud BLUMENSCHEIN, 2004).

Considerando a crise ambiental no contexto da CPIC, é fundamental a incorporação e internalização de um paradigma tecnológico mais compatível com as necessidades de preservação dos ecossistemas e o uso sustentável de matérias-primas. Nesse sentido, os instrumentos de gestão ambiental passam a ter um importante papel como vetor de mudança em processos produtivos.

Ainda segundo, Blumenschein (2004), os vetores que influenciam inovações no contexto da CPIC incluem desde aqueles colocados pela teoria schumpeteriana, quanto os desenvolvidos pelos novos schumpeterianos:

A) Mercado e Demanda: A busca para ganhar mercados é uma força propulsora de novos produtos e processos, tanto na cadeia de insumos, quanto na cadeia de processos. Ao atender a necessidades específicas de clientes, têm-se introduzido novos produtos na indústria da construção;

B) Tecnologia e P\&D: o produto final da CPIC tem sido radicalmente modificado pela inserção de tecnologias, como computadores, componentes modulares, técnicas de gerenciamento, robôs, novos materiais, métodos modernos de construção, entre outros;

C) Produção: a integração entre os construtores e os fabricantes potencializa a introdução da grande maioria das inovações na CPIC, pois "quem usa e aplica, aprende e melhora” (SLAUGTHER, 1993 apud. BLUMENSCHEIN, 2004, p. 107);

D) Empreendedor (líder): os líderes conduzem o processo de mudança no processo de produção do ambiente construído e têm potencializado o surgimento de trabalhos relevantes;

E) SNI - Sistema Nacional de Inovação: O SNI integra instituições e instrumentos estruturados e trabalhados 
para suprir deficiências e fortalecer capacidades de inovação de indústrias. O conceito de SNI, definido por Freeman como "a rede de instituições no setor público e privado cujas atividades e interações iniciam, importam, modificam ou difundem inovações” (apud VIOTTI, 1997, p. 23), disponibiliza uma ferramenta indispensável na estruturação da análise e no estudo de instituições nacionais e suas relações no suporte à capacidade e habilidade de desenvolvimento tecnológico de nações e indústrias;

F) SNA - Sistema Nacional de Aprendizado: O processo de inovação, em países com industrialização tardia, caracterizase principalmente pela absorção e pelas melhorias, ou seja, difusão e mudanças incrementais; portanto, o foco é um aprendizado contínuo. Essa peculiaridade levou Viotti (1997) a propor uma ferramenta diferenciada. No lugar de Sistema Nacional de Inovação, a proposta mais adequada, segundo ele, é aplicar o conceito de Sistema Nacional de Aprendizado (SNA), principalmente, para analisar o processo de inovação em países como, por exemplo, o Brasil e a Coreia. Segundo Viotti (1997), um sistema de aprendizado está diretamente ligado aos padrões de educação e treinamento, de aquisição de tecnologia, dos recursos comprometidos com o aprendizado tecnológico e dos resultados nacionais em disseminar tecnologia;

G) Instrumentos de Política Ambiental: 0 objetivo de acelerar a absorção de tecnologias que minimizem os impactos causados pelacadeiaCPIC no meio ambientetorna necessária a identificação de instrumentos de política ambiental que vêm sendo usados para a introdução de mudanças compativeis com a preservação do meio ambiente. A teoria de inovação econômica tende a considerar três argumentos no que tange à introdução de inovações compatíveis com as necessidades de preservação do meio ambiente: inovações sustentáveis são induzidas por modificações em preços por meio de taxas ou subsídios, pelo estabelecimento de padrões ambientais ou por regulamentações e códigos que encorajem ou inibam a inovação (OECD, 2005). Três 
grupos de instrumentos de política ambiental vêm sendo usados: sistema de informação, regulamentação direta e instrumentos econômicos (FIORINO, 1995; CAMPOS; CORREA, 1998). Essa taxionomia também é apresentada dividindo os instrumentos em coercitivos (comando e controle), persuasivos e incitativos (econômicos) (BURSZTYN, 1994); e

H) Redes - Plataformas de integração de agentes, ações e instrumentos: As redes permitem o compartilhamento de recursos, competências e responsabilidades, com valores e objetivos compartilhados e interconexão de informações. Os atores que compõem essas redes devem ter objetivos comuns e estar conscientes da importância do trabalho conjunto, compartilhando responsabilidades, ações e recursos, pois cada ponto dessas redes é um centro em potencial (MCTI, 2011a). Segundo Blumenschein (2004), a sobrevivência de uma rede depende do compartilhamento de significados, que passam a permear todos os seus níveis e passam a funcionar como um fio condutor no processo de interação das partes. Esses significados têm raízes nas crenças, nos objetivos, valores e nas necessidades comuns dos atores envolvidos. Johnson (2010) oferece uma abordagem que enfatiza a complexidade da interconexão dos vetores que influenciam o surgimento de inovações. Ao apresentar sua analogia usando os bancos de corais e os castores, como engenheiros de ecossistemas que fortalecem e promovem a sobrevivência de organismos, confirma a importância das redes colaborativas.

\section{b. 2 A inovação na CPIC no Brasil}

Segundo a Antac (2011), o Brasil possui infraestrutura em Pesquisa e Desenvolvimento (P\&D) instalada na área de Tecnologia do Ambiente Construído. Uma pesquisa realizada no portal de inovação do Ministério da Ciência, Tecnologia e Inovação (MCTI) com a palavrachave “construção civil” aponta 10.276 especialistas nessa área (MCTI, 2011b). 
O país possui 42 centros de pós-graduação na área do ambiente construído com nível de formação de mestrado profissional, mestrado e doutorado, espacializados conforme a Figura 2 (ANTAC, 2011).

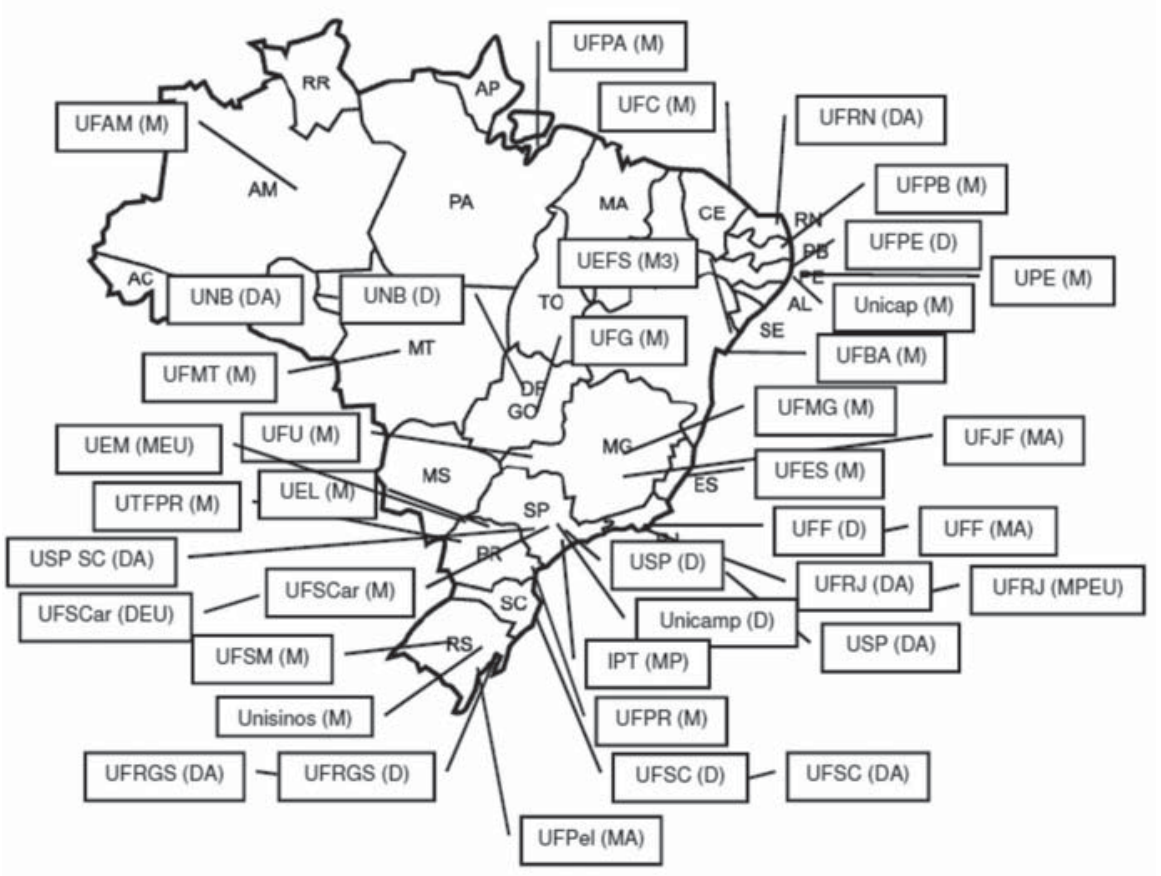

Fonte: Antac, 2011.

Figura 2. Principais centros de pós-graduação em engenharia civil, construção e tecnologia da arquitetura (letra A) e em engenharia urbana (letras EU) no País e niveis de formação (mestrado profissional - MP, mestrado - M e mestrado e doutorado - D)

Um dos marcos da inovação no Brasil foi a sanção da Lei 10.793, Lei da Inovação, em 2004, que se refere à necessidade de dispor de ferramentas legais e eficientes que contribuam para um cenário favorável ao desenvolvimento científico e tecnológico e ao incentivo à inovação (BRASIL, 2004). A criação de uma cultura de inovação baseiase na constatação de que a produção de conhecimento e a inovação tecnológica ditam crescentemente as políticas de desenvolvimento dos países (MCTI, 2011C).

Esse marco regulatório está organizado em torno de três vertentes: constituição de ambiente propício às parcerias estratégicas 
entre as universidades, os institutos tecnológicos e as empresas; estímulo à participação de instituições de ciência e tecnologia no processo de inovação; e incentivo à inovação na empresa, conforme os capítulos II, III e IV da Lei 10.793 (BRASIL, 2004).

Entre os principais vetores de influência presentes na Lei 10.793, identifica-se a integração de diferentes agentes na criação de redes de pesquisa e no compartilhamento de responsabilidades e recursos no desenvolvimento e na difusão de inovações, por meio da celebração de contratos ou convênios entre entes da administração pública ou com o setor privado. No artigo $3^{\circ}$, parágrafo único, é previsto que o fomento à pesquisa “[...] poderá contemplar as redes e os projetos internacionais de pesquisa tecnológica, bem como ações de empreendedorismo tecnológico e de criação de ambientes de inovação, inclusive incubadoras e parques tecnológicos” (BRASIL, 2004).

As vertentes e os processos produtivos da CPIC devem ser vistos de forma integrada, com entendimento de sua complexidade e do papel de cada um dos agentes envolvidos nesse processo. Considerando essa premissa, o conceito de redes de cooperação na CPIC envolve os agentes pertencentes aos setores produtivos (público, pesquisa e terceiro setor) e sua aplicabilidade, além de se revelar como indutor de mudança de paradigmas (BLUMENSCHEIN; TOMÉ, 2011).

\section{b. 3 Concepção da ferramenta}

Tendo como fundamentação os conceitos apresentados anteriormente, definiram-se os critérios e itens norteadores para a construção da ferramenta proposta.

Os critérios foram definidos a partir: da compreensão sistêmica do conceito de construção sustentável; do conceito de inovação, do seu ciclo e dos vetores com potencial de acelerar o seu passo; e do reconhecimento da importância de se conceber uma estratégia que assegure a difusão dos conhecimentos gerados a partir de pesquisas de pós-graduação. 

2):

A) Bloco 1: Propõe a caracterização da pesquisa em si e auxilia na visualização do tema da pesquisa, estruturando a justificativa do projeto, a hipótese, os objetivos geral e específicos e os resultados esperados. Estabelece de forma concisa o arcabouço de toda pesquisa científica que norteará o aluno ao longo de todo o processo de investigação;

B) Bloco 2: É composto pelo exercício de cinco questões que contextualizam a pesquisa, sendo que a primeira pergunta levanta o segmento da CPIC no qual a pesquisa se insere (cadeia de suprimentos, cadeia auxiliar ou cadeia principal). A segunda pergunta aborda o tipo de inovação trazido pela pesquisa (processo, produto, marketing ou organizacional). A terceira questão identifica as demandas e necessidades supridas pelo desenvolvimento da pesquisa. A quarta questão define os princípios científicos; a última pergunta define a solução tecnológica proposta ou a ser buscada. Ressalta-se que a primeira questão foi inserida considerando-se a caracterização da CPIC feita por Blumenschein (2004); e a segunda, pelas classificações de inovação feita por Schumpeter (1949) e pelo Manual de Oslo (OECD, 2005). A terceira questão foi inserida para ressaltar a importância da pesquisa e sua relevância para o mercado. $E$ as duas últimas questões foram fundamentadas pela Teoria da Inovação;

C) Bloco 3: Propõe um levantamento dos agentes, das ações e dos instrumentos e a relação desses agentes com a pesquisa, por meio da formação de uma rede de cooperação em que são definidas as responsabilidades de cada agente no processo produtivo. A inserção dessa matriz de identificação baseou-se no modelo de inovação aplicado por Blumenschein (2004). Nessa matriz, são identificadas as interfaces entre os agentes e os impactos relativos a essas interfaces. As ações dividem-se conforme o ciclo de desenvolvimento da inovação trazido por cada uma das pesquisas: concepção, desenvolvimento, teste, 
demonstração e difusão. Os instrumentos dividem-se em técnicos, legais e econômicos (BURSZTYN, 1994) e devem ser identificados conforme a interação entre agente e ação;

D) Bloco 4: Composto por quatro questões que analisam a pesquisa conforme os conceitos da teoria da inovação. As questões identificam os vetores de influência para a emergência e difusão da inovação proposta; as barreiras que impedem a difusão dessa inovação, podendo ser classificada como cultural, técnica ou financeira; as dimensões ambiental, econômica, social e cultural, conforme classificação feita por Sachs (2008); e as possíveis contribuições da pesquisa para a mudança do paradigma tecnológico na CPIC; e

E) Bloco 5: É a fase conclusiva da ferramenta e propõe a identificação das contribuições da pesquisa para a inovação e sustentabilidade no contexto da CPIC. Considera-se que o usuário da ferramenta precisará responder as questões anteriores para justificar quais são as contribuições.

\section{a. Análise e aplicação da ferramenta}

A ferramenta foi analisada e aplicada por 14 alunos dos semestres 02/2011 e 01/2012 da disciplina EET1: Inovação e Sustentabilidade na Indústria da Construção, no âmbito do PPG-FAU/ UnB, e revisada de acordo com o resultado dessa análise. Após a elaboração e aplicação da primeira versão da ferramenta, observou-se que faltavam algumas questões e que outras precisavam ser revisadas (Quadro 2).

Dessa forma, foram feitos ajustes, inserindo-se alternativas com questões objetivas nos itens 1 e 2 do segundo bloco, identificando quais são as cadeias que compõem a CPIC e os tipos de inovação. As questões 3, 4 e 5 do segundo bloco se tornaram mais específicas quanto ao objeto de questionamento. No bloco 3, foi sugerido um texto introdutório para explicar a interface entre os agentes e o uso dos termos parcial, integral e inexistente, para a interface, e os termos fraco, médio e forte para o impacto. 
No quarto bloco, inseriram-se outras dimensões da sustentabilidade. Além disso, devem-se considerar os graus de influência dessas dimensões nas pesquisas. Foi inserida mais uma questão nesse bloco que aborda as áreas de contribuição da pesquisa, considerando-se os impactos ambientais causados pela CPIC; e foi sugerido pelos alunos que uma alternativa fique em aberto para permitir complementações. No bloco 5, enfatizou-se, na apresentação da pergunta, a necessidade da coerência entre a conclusão e as respostas anteriormente apresentadas.

Foi sugerido ainda que a ferramenta Cais seja acompanhada de um glossário que facilite o entendimento dos termos, bem como o preenchimento da ferramenta. A ferramenta final está disponível no Quadro 2.

\section{Quadro 2. Ferramenta Cais}

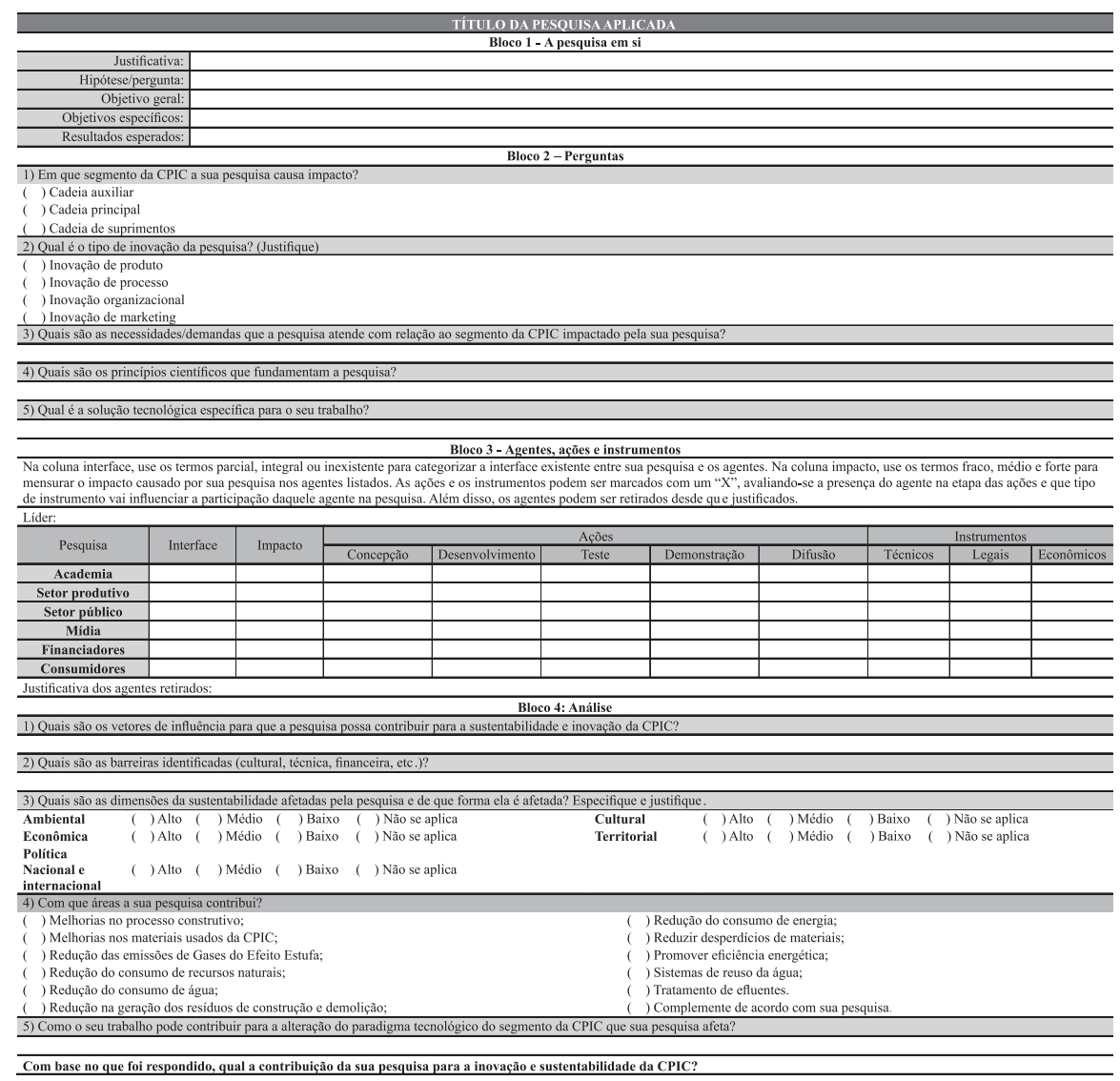




\section{b. Resultados}

Dos 14 alunos que aplicaram a ferramenta Cais, seis já estavam em estágio mais avançado na definição das suas pesquisas, quatro já tinham tema, mas não haviam aprofundado nos objetivos e na metodologia, e quatro não sabiam ainda o que pesquisar.

A ferramenta foi avaliada com base nas análises dos resultados apresentados por cada aluno em trabalho escrito e no seminário. Essa avaliação permitiu identificar as contribuições para a pesquisa com a utilização da ferramenta e as dificuldades em aplicá-la. O resultado da avaliação está apresentado no Quadro 3.

\section{Quadro 3. Avaliação sobre a utilização da ferramenta}

\begin{tabular}{|c|c|}
\hline Item avaliado & Resultado \\
\hline $\begin{array}{l}\text { Contribuiu para fortalecer a visão sistêmica da cadeia produtiva } \\
\text { da indústria da construção }\end{array}$ & $80 \%$ \\
\hline Contribuiu com a definição do escopo da pesquisa & $80 \%$ \\
\hline $\begin{array}{l}\text { Contribuiu na construção dos procedimentos metodológicos } \\
\text { para o desenvolvimento da pesquisa proposta }\end{array}$ & $60 \%$ \\
\hline $\begin{array}{l}\text { Permitiu situar melhor o tema de pesquisa com a realidade do } \\
\text { processo produtivo do ambiente construído }\end{array}$ & $80 \%$ \\
\hline $\begin{array}{l}\text { Permitiu identificar a contribuição da pesquisa para a } \\
\text { sustentabilidade da cadeia produtiva da indústria da construção }\end{array}$ & $100 \%$ \\
\hline $\begin{array}{l}\text { Foram identificadas estratégias de difusão efetivas dos } \\
\text { resultados de pesquisa }\end{array}$ & $60 \%$ \\
\hline $\begin{array}{l}\text { Nas estratégias identificadas para a difusão dos resultados } \\
\text { de pesquisa foi considerada a integração de agentes do setor } \\
\text { público, privado, da academia e do terceiro setor }\end{array}$ & $80 \%$ \\
\hline $\begin{array}{l}\text { Apresentou dificuldades nas respostas colocadas pela } \\
\text { ferramenta sem conhecimento do referencial teórico, seria } \\
\text { muito difícil responder às perguntas colocadas pela ferramenta }\end{array}$ & $100 \%$ \\
\hline $\begin{array}{l}\text { Considerou a objetividade das perguntas adequada às } \\
\text { respostas demandadas }\end{array}$ & $80 \%$ \\
\hline Considerou adequada a estrutura de preenchimento & $75 \%$ \\
\hline $\begin{array}{l}\text { Consideraram o nível de importância da ferramenta para o } \\
\text { desenvolvimento da pesquisa acima de oito em uma escala de } \\
\text { o a } 10\end{array}$ & $100 \%$ \\
\hline Julgaram as perguntas adequadas e respondidas com facilidade & $60 \%$ \\
\hline
\end{tabular}


Constatou-se que os 14 alunos que utilizaram a ferramenta conseguiram analisar as contribuições em inovação e sustentabilidade da pesquisa no contexto da CPIC. Considera-se como premissa que o conhecimento dos conceitos que fundamentaram a concepção da ferramenta apresentada neste artigo se faz necessário para respostas mais coerentes e consistentes, principalmente, devido ao grau de complexidade da CPIC.

Os alunos que estavam em nivel inicial de desenvolvimento de suas pesquisas apresentaram maior dificuldade de preenchimento, principalmente, pela falta do conhecimento específico, das teorias e dos termos relacionados à pesquisa. Apesar disso, o preenchimento da ferramenta permitiu que esses alunos avançassem na limitação e visualização de suas pesquisas.

Além disso, as pesquisas analisadas possuem focos diferentes: produto e processo. Constatou-se que as pesquisas relacionadas à inovação em produtos foram preenchidas com maior facilidade que as pesquisas que envolviam inovações em processos.

A maior parte dos alunos conseguiu desenvolver habilidades relacionadas à visão sistêmica, metodologia científica, aos princípios de inovação e conceitos de sustentabilidade. Foi possível constatar que apenas $60 \%$ dos alunos conseguiram identificar estratégias de difusão de suas pesquisas, o que demonstra uma deficiência grave para a disseminação dos resultados das pesquisas para fora dos limites das universidades pelos programas de pós-graduação.

A análise da ferramenta Cais aplicada aos projetos de pesquisa demonstrou que $75 \%$ das pesquisas estão no segmento da cadeia auxiliar dentro da CPIC, sendo que essas três pesquisas estão relacionadas aos três segmentos da CPIC. Todos os projetos de pesquisas estão relacionados à inovação de processos e 50\% deles também estão relacionados à inovação de produtos.

Quanto às dimensões da sustentabilidade consideradas na ferramenta, todas as pesquisas têm sinergia com a dimensão ambiental, 
mas, nas dimensões territorial e política nacional e internacional, somente $12 \%$ das pesquisas contribuíram. As dimensões econômica, social e cultural também tiverem expressiva sinergia, acima de $75 \%$ cada uma.

Nas áreas temáticas da CPIC definidas na ferramenta e que os alunos deveriam assinalar conforme o tema e a afinidade de sua pesquisa, $87,5 \%$ dos projetos de pesquisa contribuem para questões relacionadas às melhorias dos processos construtivos e do desempenho dos materiais usados na CPIC, mas somente 25\% das pesquisas contribuem para a redução do consumo de água, o reuso da água e tratamento de efluentes. Na área temática energia, 37,5\% das pesquisas contribuem para a redução no consumo de energia e da eficiência energética. Quanto à redução na geração de resíduos de construção e demolição, 50\% das pesquisas têm sinergia, 62,5\% contribuem para a redução dos Gases de Efeito Estufa e 75\% estão relacionadas à redução do consumo de recursos naturais e desperdício de materiais (Figuras 3A e 3B). Não foi identificada nenhuma pesquisa com foco na análise do processo de inovação da $\mathrm{CPCl}$, visando definir estratégias de aceleração da mudança de paradigmas.

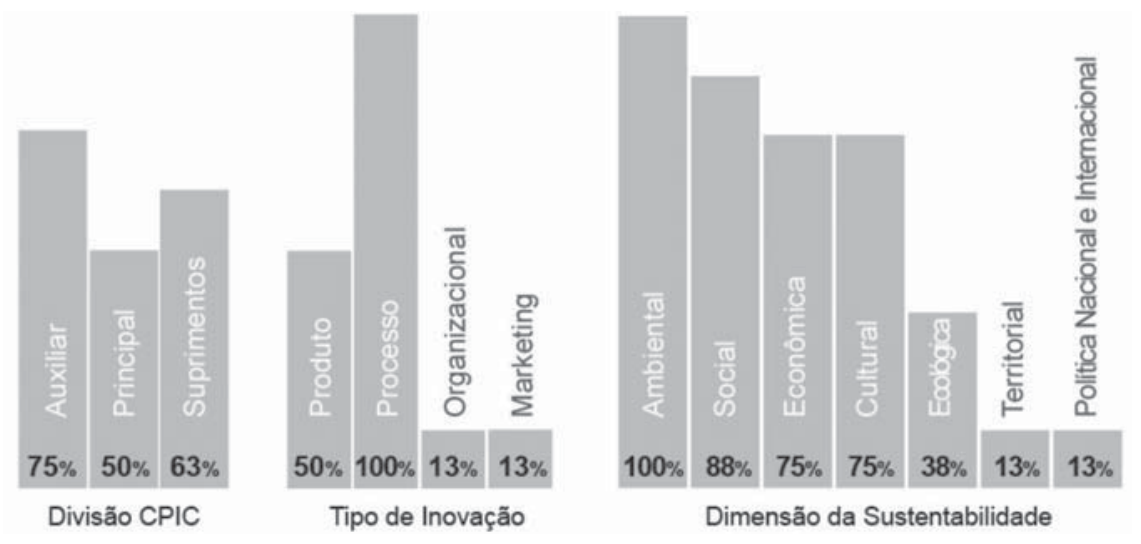

Figura 3A. Análise dos resultados das pesquisas dos alunos após aplicação da ferramenta Cais 


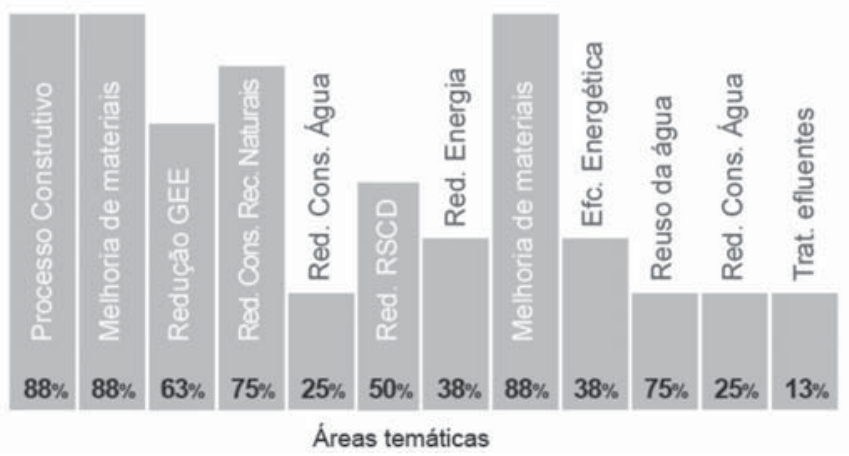

\section{Figura 3B. Análise dos resultados das pesquisas dos alunos após aplicação da ferramenta Cais}

Com base nas estatísticas geradas, observa-se que o foco das pesquisas precisa ser ampliado para os outros segmentos, como cadeia principal e de suprimentos da CPIC e inovação organizacional e de marketing. Observa-se ainda a necessidade da ampliação das contribuições das pesquisas para outras dimensões da sustentabilidade além da ambiental, econômica e social, abordando também as dimensões territorial, ecológica, cultural e de política internacional e nacional, atuando em um nível mais estratégico.

Os temas relacionados à água estão pouco explorados pelas pesquisas, seguido da temática energia e resíduos da construção e demolição. Entretanto, o tema processos construtivos possui grande relevância nas pesquisas analisadas, visto que é uma temática abrangente e que envolve áreas correlacionadas.

\section{c. Considerações finais}

Este artigo possui conclusões relacionadas a diferentes niveis de interação da ferramenta, do método e das pesquisas dos alunos. Dessa forma, as considerações finais foram divididas em quatro blocos: considerações sobre o método didático usado e a aplicação da ferramenta, considerações sobre a estrutura e o conteúdo da ferramenta, considerações sobre as pesquisas delimitadas pelos alunos e contribuições sobre trabalhos futuros. 
Quanto ao método didático usado e à aplicação da ferramenta Cais aos projetos de pesquisa, observa-se que o método didático utilizado na disciplina EET1: Inovação e Sustentabilidade na Indústria da Construção, por meio da ferramenta e das aulas expositivas, auxiliou os alunos a delimitar suas pesquisas e estruturar os projetos de pesquisa, bem como iniciar o desenho da estratégia de difusão dos resultados de suas pesquisas.

A ferramenta Cais contribui para estruturar o raciocínio da pesquisa, pois auxilia o pesquisador a fundamentar o seu trabalho de forma mais consistente, permitindo que princípios científicos sustentem e mantenham o foco da investigação. Além disso, oferece a oportunidade de exercitar uma visão sistêmica da sua pesquisa e da sua inserção no contexto da CPIC e conscientiza da importância de identificar estratégias de difusão.

Por meio da aplicação da ferramenta, foi possível observar que ela é um método útil para auxiliar os alunos e orientadores na estruturação de pesquisas com foco em inovação, sustentabilidade e estratégias de disseminação.

Outra contribuição importante foi a oportunidade de participação, por parte dos alunos, da metodologia de desenvolvimento da ferramenta, oferecendo uma experiência que poderá auxiliar no desenvolvimento de outras análises que tenham como objetivo a produção de ferramentas similares.

Observa-se ainda que a ferramenta desenvolvida contribui para que a comunidade acadêmica a utilize como instrumento de avaliação, alavancagem e incentivo, gerando resultados em sinergia com a inovação e sustentabilidade da CPIC de forma a atender as demandas do setor produtivo e público por meio das pesquisas desenvolvidas na academia.

Quanto ao conteúdo e à estrutura da ferramenta, observa-se que os pontos levantados nos cinco blocos de perguntas são objetivos e constroem um raciocínio gradual e contínuo que termina com a resposta 
ao questionamento quanto à contribuição da pesquisa em inovação e sustentabilidade. Entretanto, a estrutura da ferramenta precisa ser lapidada para que as dúvidas quanto ao tipo de preenchimento estejam adequadas, tais como legendas de termos que devem ser usados, se a opção deve ser preenchida com um “X” ou com texto, se é possível retirar ou inserir opções, entre outros. Faz-se necessário introduzir a identificação de inovação incremental, complementando a pergunta 2 do Bloco 2, que levanta o tipo e a inovação.

Quanto às pesquisas delimitadas pelos alunos, observa-se que a aplicação da ferramenta Cais foi mais fácil para alunos que já tinham iniciado suas pesquisas, mas que precisavam de auxílio para visualizar com mais clareza as etapas do projeto. Os projetos relacionados a inovações de produtos foram mais rapidamente preenchidos que as inovações ligadas a serviços e processos, visto que projetos de produtos costumam ser mais tangíveis, se comparados a serviços e processos.

Outro ponto importante é que todos os pesquisadores conseguiram identificar as contribuições de suas pesquisas para a inovação e sustentabilidade no contexto da CPIC. Por meio da aplicação da ferramenta Cais, disseminaram-se os conceitos de inovação e sustentabilidade aplicados à CPIC, fortalecendo a compreensão de que não é possível pensar em inovação sem considerar o conceito de sustentabilidade, já que são critérios conexos e intrínsecos ao desenvolvimento econômico, social e ambiental.

A ferramenta Cais é, sobretudo, qualitativa e está em fase de desenvolvimento. Para trabalhos futuros, acredita-se que a aplicação da ferramenta por alunos de outras turmas do PPG-FAU pode contribuir para o aperfeiçoamento da ferramenta, bem como para a inserção de mecanismos de quantificação para medir o grau de sustentabilidade e inovação de cada uma das pesquisas, tendo em vista a redução na subjetividade da análise.

Outra complementação que deve ser feita à ferramenta é a inserção de um glossário anexo que torne a tarefa de preenchimento mais clara, fácil e autônoma para os alunos. Observa-se ainda a 
necessidade de criar um questionário que sistematize a avaliação da ferramenta Cais pelos alunos, atribuindo pontuações a critérios selecionados e relacionados com o conteúdo, a estrutura, objetividade e o grau de importância da ferramenta para a delimitação e definição de projetos de pesquisa.

Essa ferramenta também pode ser adaptada para outras áreas de pesquisa, em que a carência por projetos em inovação e sustentabilidade pode ser amenizada com a inserção de um mecanismo de estruturação do raciocínio e da análise de projetos de pesquisa, como a ferramenta Cais.

\section{Agradecimentos}

Agradecemos aos alunos Ana Maria Curi, Carla Andreia Ferreira, Catarina Sombrio, Clarissa Belle Pimentel Félix Silva, Kátia Miller, Laura Restrepo, Leila Bueno de Oliveira, Marcelo Albuquerque Lima, Maria Aparecida Furtado de Resende, Osvaldo Telmo Melgares Lobo, Patricia da Silva Fiuza Pina, Renata Maciel e Rolzelin Rocco de Sá Coutinho pela participação na avaliação e aplicação da ferramenta proposta.

Recebido 25/11/2012

Aprovado 25/07/2013

\section{Referências bibliográficas}

ANTAC - AGÊNCIA NACIONAL DE TRANSPORTES AQUAVIÁRIOS. Ciência, Tecnologia e Inovação e a Indústria da Construção Civil: Elementos para a formulação de uma política para o setor. Porto Alegre: Antac, 2011.

TRUSTY, W. P.; MEIL, J. K. Building as Products: Issues and Challenges for LCA. In: INTERNATIONAL CONFERENCE ON LIFE CYCLE ASSESSMENT: TOOLS FOR SUSTAINABILITY, 1., 2000, Arlington, Virginia.

BLUMENSCHEIN, R. N. A Sustentabilidade na Cadeia Produtiva da Indústria da Construção. 2004. 264f. Tese (Doutorado em Política 
e Gestão Ambiental)- Centro de Desenvolvimento Sustentável, Universidade de Brasília, Brasília, 2004.

BLUMENSCHEIN, R. N.; TOMÉ, M. V. D. F. Inovação e Sustentabilidade. Sustentabilidade em Debate, Brasília, v. 2, p. 149-163, 2011.

BOWLEY, M. The british building industry: four studies in response and resistance to change. Cambridge: University Press, 1966.

BRASIL. Lei da Inovação. Lei n ${ }^{\circ}$ 10.973, de 2 de Dezembro de 2004. Disponivel em: <http://www.planalta.gov.br/ccivil_03/_ato20042006/2004/Lei/L10.973.htm>. Acesso em: 02 dez. 2011.

BURSZTYN, M. A. A. Gestão ambiental: instrumentos e práticas. Brasília: IBAMA, 1994.

CAPRA, F. As conexões ocultas. São Paulo: Editora Cultrix, 2002.

CAMPOS, L. B.; CORRÊA, G. A. Comércio e Meio Ambiente: Atuação Diplomática Brasileira em Relação ao Selo Verde. Brasília: Instituto Rio Branco; Fundação Alexandre Gusmão; Centro de Estudos Estratégicos, 1998.

FIORINO, D. J. Making environmental policy. London: University of California Press, 1995.

FREEMAN, C. The national system of innovation in historical perspective. Cambridge Journal of Economics, England, v. 19, n. 1, p. 5-22, fev. 1995.

FREEMAN, C.; LUNDVALL, B. A. Small countries facing the technological revolution. London: Pinter Publishers Limited, 1988.

HAWKEN, P. et. al. Capitalismo natural. São Paulo: Cultrix, 1999.

HENDRIKS, C. F. Durable and sustainable construction materials. The Netherlands: Aeneas Technical Publishers, 2000. 
IPEA - INSTITUTO DE PESQUISA ECONÔMICA APLICADA. Comunicados do IPEA: O planejamento de habitações de interesse social no Brasil: desafios e perspectivas, n. 118. Brasília: IPEA, 2011.

IVE, G.; GROAK, S. Economics and Technological Change: Some implications for the study of the building industry. Habitat International, Great Britain, v.10, n. 4, p.115-132, 1986.

JOHNSON, S. Where Good Ideas Come From: the Natural History of Innovation. Londres: Penguim Books, 2010.

MACHADO FILHO, C. A. P. Responsabilidade social corporativa e a criação de valor para as organizações: um estudo multicasos. 2002. Tese (Doutorado em Administração)- Faculdade de Economia, Administração e Contabilidade, Universidade de São Paulo, São Paulo, 2002.

MCTI - Ministério da Ciência, Tecnologia e Inovação. Redes de Pesquisa. 2011a. Documento Interno.

Portal da Inovação. 2011b. Disponível em: < http:/ / www.portalinovacao.mct.gov.br/pi/\#/pi/buscas / \$Wydjb25zdHJ1w6fDo28g>. Acessado em: 14 dez. 2011.

Marco legal da inovação. 2011c. Disponível em: <http:/ /www. mct.gov.br/index.php/content/view/8477.html>. Acesso em: 02 dez. 2011.

OCDE - ORGANIZAÇÃO PARA A COOPERAÇÃO E DESENVOLVIMENTO ECONÔMICO. Manual de Oslo: Diretrizes para Coleta e Interpretação de Dados sobre Inovação. 3. ed. Paris: OCDE, 2005.

OFQPC - OFFICE OF THE QUEENSLAND PARLIAMENTARY COUNSEL. Nature Conservation Act. Queensland: AustLII, 1992.

OLIVEIRA, P. E. S.; OLIVEIRA, J. T. R.; FERREIRA, S. R. M. Avaliação do Desempenho do Concreto com uso de Agregado de Resíduos 
de Construção e Demolição - RCD. In: CONGRESSO BRASILEIRO DO CONCRETO, 50., 2008, Salvador. Anais... Salvador: Ibracon, 2008. p. 5058.

ROMERO, M. A. A arquitetura bioclimática do espaço urbano. Brasília: Editora Universidade de Brasília, 2001.

ROVERS, R. Sustainable building an international overview of current and future activities. In: INTERNATIONAL CONFERENCE ON PASSIVE AND LOW ENERGY ARCHITECTURE, 18., Florianópolis. Anais... Florianópolis: PLEA, 2001. p. 27-35.

SACHS, I. Caminhos para o desenvolvimento sustentável. 3. ed. Rio de Janeiro: Garamond, 2008.

SAE - Secretaria de Assuntos Estratégicos. Presidência da República Federativa do Brasil. Brasil 2022. Brasília: SAE, 2010

SCHUMPETER, J. A. The theory of economic development. Cambridge, Massachusetts: Harvard University Press, 1949.

SINDUSCON-SP - Sindicato da Indústria da Construção no estado de São Paulo. Construção Civil: Desempenho em 2011 e perspectivas para 2012. 2011. Disponivel em: <http://www.sindusconsp.com.br/ downloads/ imprensa/2011/ coletiva.pdf>. Acesso em: 14 jun. 2012.

TURIN, D. A. Building as a process. London: Trans. Bartlett Society 6, 1967-68.

UNEP - United Nations Environment Programme. The Emissions Gap Report 2012. Nairobi: United Nations Environment Programme, 2012.

VIOTTI, E. B. Passive and active national learning systems. 1997. 311f. Tese (Doutorado em Filosofia)- The Graduate Faculty of Political and Social Science, New School for Social Research, New York, EUA, 1997. 


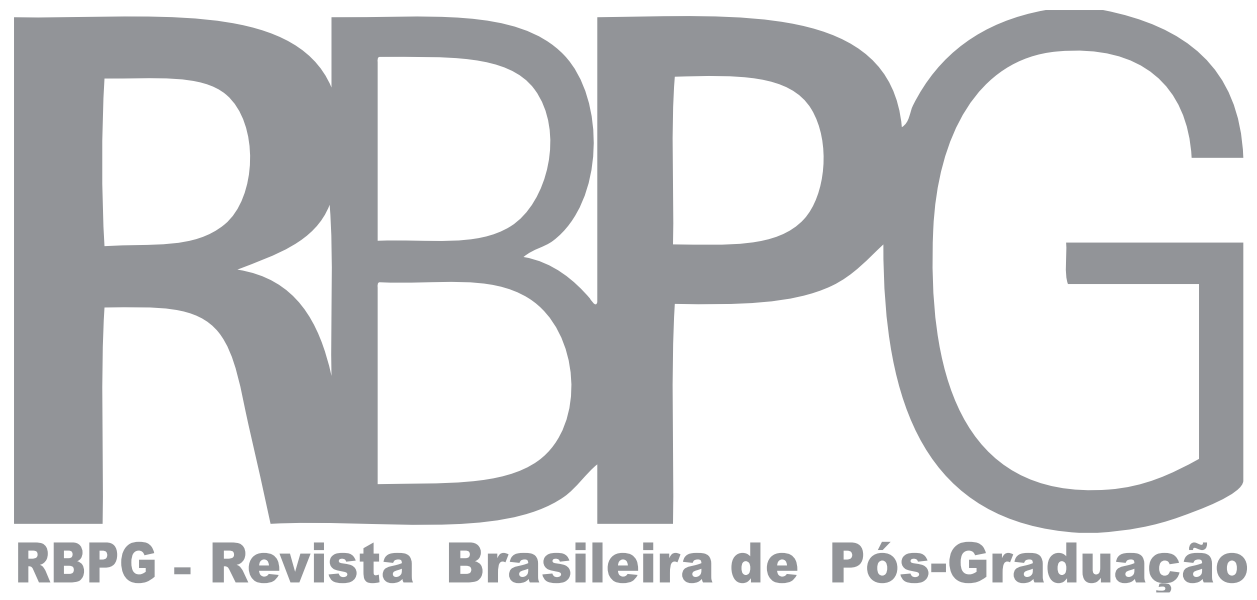




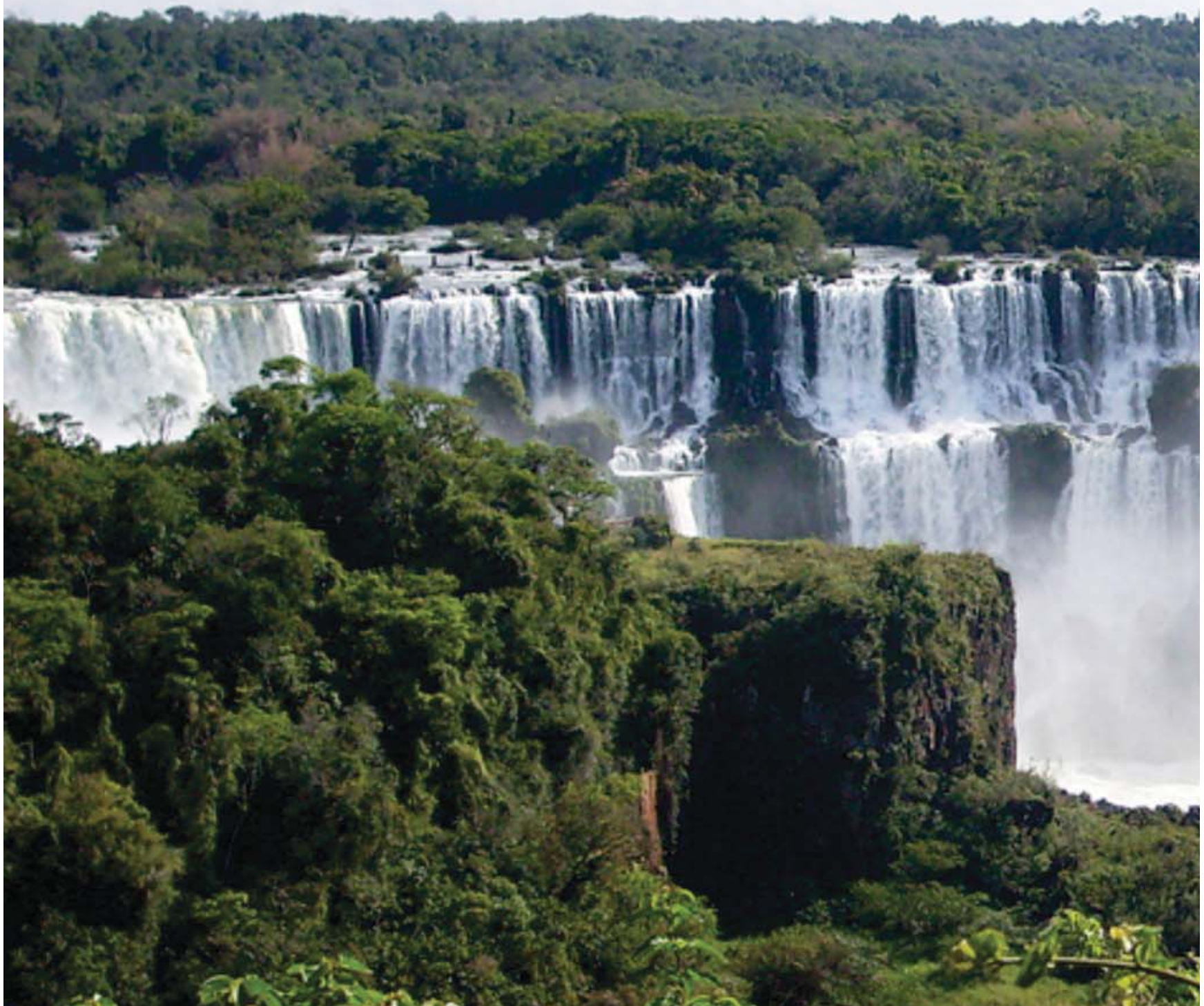

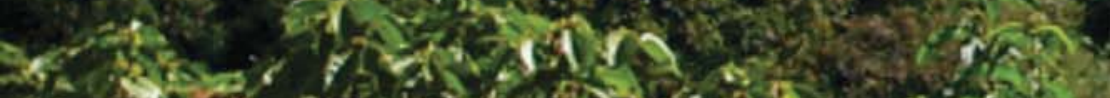
1.9.

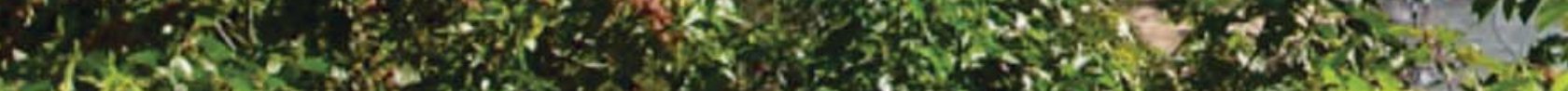

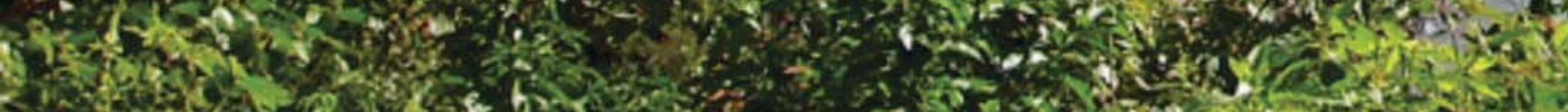

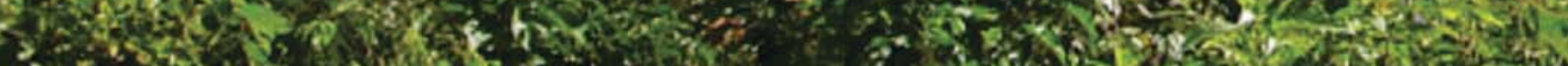

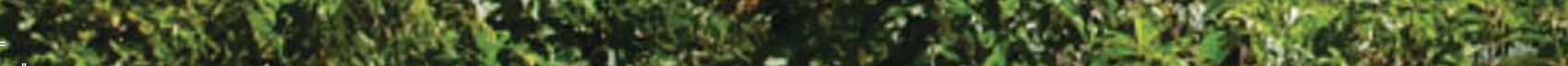




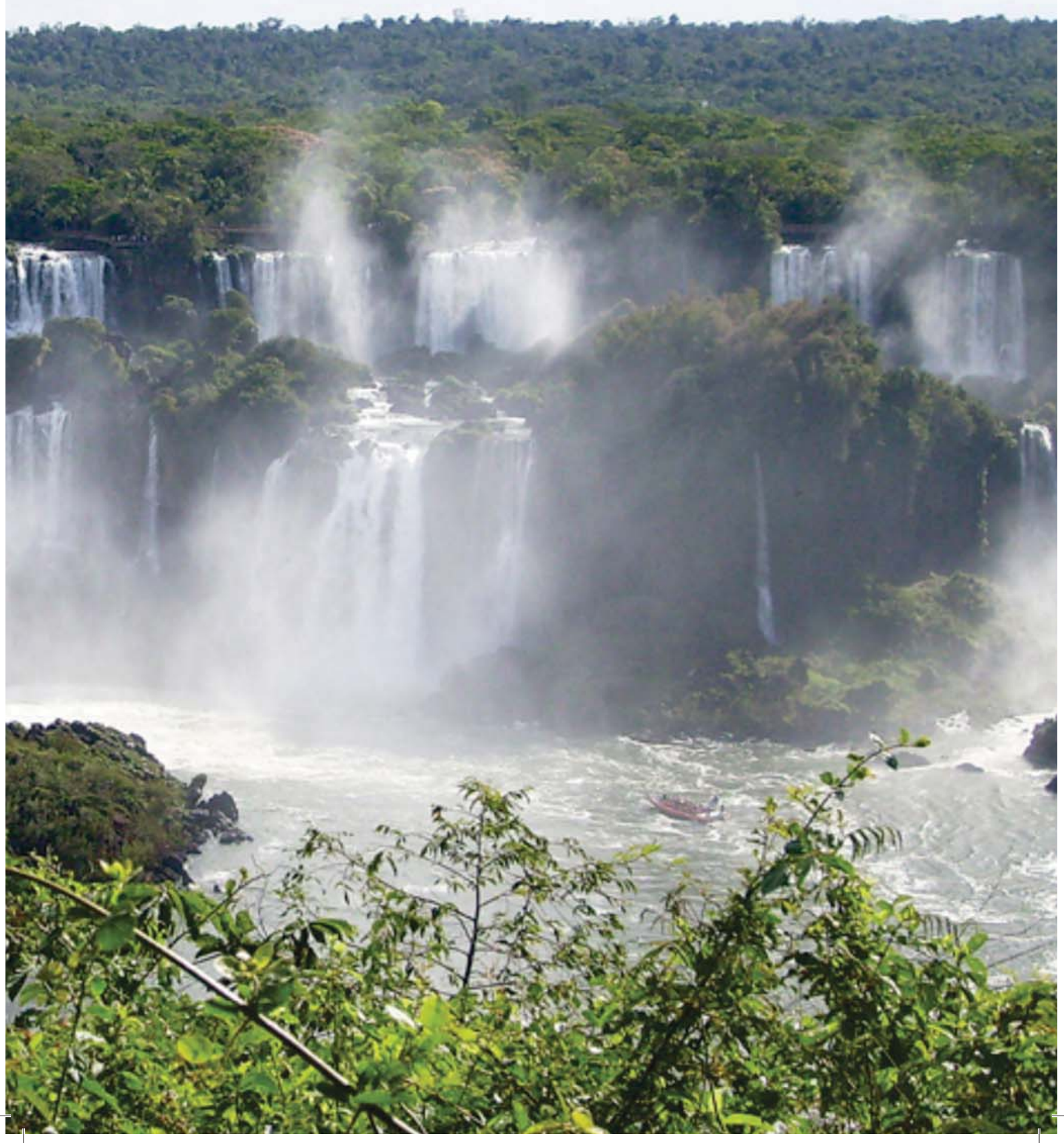


Legislação e política ambiental no Brasil: as possibilidades do desenvolvimento sustentável e os riscos do retrocesso ambiental

\section{Legislation and environmental policy in Brazil: the possibilities of sustainable development and the risks of environmental retrocession}

\section{Legislación y política ambiental en Brasil: las posibilidades del desarrollo sostenible y los riesgos del retroceso ambiental}

Rodrigo Machado Vilani, doutor em Ciências pela Universidade do Estado do Rio de Janeiro. Endereço: Universidade Candido Mendes - Mestrado Profissional em Planejamento Regional e Gestão de Cidades. Avenida Anita Peçanha, 100 - Parque São Caetano. CEP: 28030-335 - Campos dos Goytacazes, RJ. Telefone: (21)8187-6834.E-mail: r_vilani@yahoo.com.br.

\section{Resumo}

O presente artigo tem por objetivo analisar a apropriação do ideal de desenvolvimento sustentável pelas principais leis ambientais federais brasileiras. Criticado por ser amplo e vago, o conceito de desenvolvimento sustentável, reforçado durante a Rio+20, encerra um compromisso de equilíbrio intrageracional e equidade intergeracional, também firmado pela Constituição Federal. Assim sendo, importa reconhecer os rumos dados pela legislação para definir a compatibilidade entre aspectos sociais, ambientais e econômicos. Optou-se pela pesquisa qualitativa, bibliográfica e normativa para circunscrever o alcance conceitual da expressão e de sua delimitação constitucional, com o respectivo desdobramento na legislação e na política federal. Recomendações gerais e específicas são propostas a título de contribuir para a adequação das normas em vigor e das políticas públicas como forma de assegurar os direitos das futuras gerações. 
Palavras-chave: Desenvolvimento Sustentável. Legislação Ambiental. Políticas Públicas. Futuras Gerações.

\section{Abstract}

The aim of this study is to analyze the appropriation of the sustainable development ideal through the principal Brazilian environmental regulations. Criticized for being broad and vague, the concept of sustainable development, which was strengthened during the Rio+20, contains a commitment to intragenerational balance and intergenerational equity and was also outlined within the Federal Constitution. It is important to recognize the directions given under the legislation in order to define the compatibility of social, environmental and economic dimensions. We opted for research of a qualitative, bibliographic and normative nature, in order to circumscribe the conceptual aspects and constitutional limitations of the term, taking into account developments with respect to legislation and federal policy. We conclude with general and specific considerations in order to contribute to the adequacy of the current norms and public policies designed to ensure the rights of future generations.

Keywords: Sustainable Development. Environmental Legislation. Public Policies. Future Generations.

\section{Resumen}

Este artículo tiene como objetivo analizar la apropiación del ideal de desarrollo sostenible por las principales leyes ambientales federales brasileñas. Criticado por ser amplio y vago, el concepto de desarrollo sostenible, reforzado durante la cumbre Rio+20, contiene un compromiso de equilibrio intrageneracional y equidad intergeneracional, también firmado por la Constitución Federal. Por lo tanto, es importante reconocer la dirección dada por la legislación para definir la compatibilidad entre los aspectos sociales, ambientales y económicos. Se optó por la investigación cualitativa, bibliográfica y 
normativa para circunscribir el alcance conceptual de la expresión y su delimitación constitucional, con su despliegue en la legislación y en la política federal. Se proponen recomendaciones generales y específicas para contribuir a la adecuación de las normas vigentes y de las políticas públicas con el fin de garantizar los derechos de las generaciones futuras.

Palabras clave: Desarrollo Sostenible. Derecho Ambiental. Políticas Públicas. Generaciones Futuras.

\section{Introdução}

Em 1987, o Relatório Brundtland trazia a concepção mais difundida e até hoje aceita de desenvolvimento sustentável. Cinco anos mais tarde, o planeta aguardava os resultados da Conferência das Nações Unidas para o Meio Ambiente e o Desenvolvimento, a Rio-92. Agora, a Rio+20 teve por desafio confirmar os princípios estabelecidos. No momento em que os esforços políticos se voltam para a definição de alternativas para superar a atual crise econômica mundial, a preocupação das Ciências Jurídicas foi balizada para evitar o retrocesso em matéria ambiental' ${ }^{1}$.

Em relação ao Brasil, neste trabalho, procura-se atentar para duas questões consideradas fundamentais. Primeiramente, se as políticas públicas se coadunam com um modelo de desenvolvimento que se proponha sustentável. Em um segundo momento, qual o risco de um retrocesso ambiental, em razão dessas políticas estarem orientadas por uma racionalidade meramente econômica.

Analisaremos essas questões sob a ótica das contribuições a serem propostas pelas ciências, em uma perspectiva multidisciplinar, especificamente no que toca à legislação e às políticas ambientais no Brasil.

Primeiramente, é necessário apontar a origem da expressão desenvolvimento sustentável. Veiga (2006, p. 190) indica ter sido empregada "pela primeira vez em agosto de 1979, no Simpósio das

\footnotetext{
As discussões iniciadas pelo jurista francês Michel Prieur têm orientado o debate nacional, inclusive com a publicação pela Comissão de Meio Ambiente, Defesa do Consumidor e Fiscalização e Controle do Senado Federal do livro "O princípio da proibição de retrocesso ambiental” (BRASIL, 2012) entre os esforços para fortalecer os debates durante a Rio+20.
} 
Nações Unidas sobre as Inter-relações entre Recursos, Ambiente e Desenvolvimento, realizado em Estocolmo, e no qual W. Burger apresentou um texto intitulado $A$ busca de padrões sustentáveis de desenvolvimento”. Já parte da literatura (ROMEIRO, 2003; LEIS, 1999) aponta o surgimento do termo a partir do ecodesenvolvimento, cunhado na década de 1970 como proposta alternativa ao crescimento meramente econômico e que teve em Ignacy Sachs seu principal teórico. Há, ainda, indicação de que tenha surgido em 1983, durante Assembleia Geral da ONU, que dava início às discussões que culminariam, três anos mais tarde, no Relatório Nosso Futuro Comum (OSORIO; LOBATO; CASTILLO, 2005). Enfim, o único consenso em relação ao surgimento do termo desenvolvimento sustentável é que apenas em 1987, por meio do Relatório Nosso Futuro Comum ou Relatório Brundtland, em homenagem à presidente da Comissão Mundial sobre Meio Ambiente e Desenvolvimento, Gro Harlem Brundtland, cunhou-se o conceito, hoje utilizado mundialmente. “Desenvolvimento sustentável é o desenvolvimento que alcança as necessidades do presente sem comprometer a habilidade das gerações futuras de atender suas próprias necessidades” (UNITED NATIONS, 2008).

Apesar da crescente literatura sobre desenvolvimento sustentável, não se chegou a uma conceituação doutrinária consensual; pelo contrário, são apontadas críticas ao seu caráter meramente teórico, vago e muito amplo, ou seja, com pouca orientação prática (FARZIN, 2002; LENZI, 2006), lacuna que se aplica, também, às Ciências Jurídicas, segundo adverte Pepe (2002).

A amplitude do conceito, classificado de polissêmico por Jatobá, Cidade e Vargas (2009), acaba por permitir sua apropriação por diversos atores e em defesa de diferentes interesses, característica que acabou por banalizar a sustentabilidade, aprofundando a distância entre o discurso e a eficácia de políticas ambientais, conforme advertem Fonseca e Bursztyn (2009).

Longe de qualquer consenso em se tratando da temática ambiental, ainda que estejamos distantes quase quatro décadas daquela primeira discussão global e pouco mais de duas décadas do 
estabelecimento do marco conceitual do desenvolvimento sustentável (Relatório Nosso Futuro Comum ou Relatório Brundtland, produzido em 1987 pela Comissão Mundial de Meio Ambiente e Desenvolvimento da Organização das Nações Unidas - ONU), os esforços atuais ainda se voltam para a construção de um modelo multigovernamental, multissetorial e multidisciplinar para tratar do tema.

Assim, como problemática central do trabalho, destacamos a possibilidadepolítico-jurídicadeseefetivaromodelodedesenvolvimento sustentável em contraponto a interesses imediatistas, concentradores, predatórios e historicamente arraigados na estrutura de poder do País, inclusive como forma de evitar o retrocesso ambiental das políticas nacionais.

Para tanto, o trabalho visa analisar a apropriação do ideal de desenvolvimento sustentável pelas principais leis ambientais federais brasileiras e sua materialização em políticas públicas nacionais, discutidas a partir dos eixos estruturantes do documento final gerado na Rio+20.

Optamos pela pesquisa qualitativa, bibliográfica e documental, que se estrutura a partir da revisão de abordagens teóricas lançadas sobre o ideal de desenvolvimento sustentável e da perspectiva jurídica, dimensionada sob o enfoque dado pela Constituição Federal de 1988, para, então, analisar o arcabouço jurídico ambiental e sua aplicação por meio de políticas públicas implementadas pelo governo federal.

Três aspectos precisam ser destacados em relação às limitações da pesquisa. Primeiramente, em relação ao conceito estruturante do trabalho. Importante destacar que a multiplicidade de conceitos de desenvolvimento sustentável configura um desafio a qualquer abordagem sobre o tema, pela própria impossibilidade de uma amostragem abrangente em razão do escopo e espaço determinados. Em segundo lugar, a abordagem referente às políticas públicas é problemática devido ao conjunto de fatores institucionais, estruturais e conjunturais do atual cenário nacional. Logo, é preciso ter em mente o recorte proposto para a abordagem de políticas nacionais relacionadas 
ao documento final da Rio+20, analisadas sem um aprofundamento quantitativo. Por fim, a terceira limitação da pesquisa relaciona-se à impossibilidade de se generalizar a análise proposta para as políticas públicas de maneira geral, ainda que seja possivel extrapolar suas implicações sobre o modelo de desenvolvimento do País como um todo.

O trabalho, além dessa introdução, apresenta os aspectos conceituais de desenvolvimento sustentável. Em seguida, analisa o ordenamento jurídico brasileiro, a partir da Constituição Federal e das principais normas federais que tratam da matéria ambiental. Diagnosticado o modelo jurídico de sustentabilidade, é realizada uma análise de políticas públicas, especificamente no tocante à apropriação do ideal de sustentabilidade, teórico e jurídico. Por fim, são apresentadas propostas gerais e específicas para contribuir com o debate acadêmico acerca das contribuições científicas para o aprimoramento das políticas públicas em relação à equidade intra e intergeracional.

\section{Aspectos conceituais do desenvolvimento sustentável}

Partiremos da constatação de Veiga (2006, p. 165) referente à conceituação científica de sustentabilidade. O autor afirma que "a sustentabilidade não é, e nunca será, uma noção de natureza precisa, discreta, analítica ou aritmética, como qualquer positivista gostaria que fosse”. Nos dizeres de Carneiro (2005, p. 27), o termo é uma expressão perfeita da "dominância da onda geral de 'aconceitualidade' dos anos de 1990”.

É preciso, nesse sentido, esclarecer que a perspectiva ora adotada não desconhece as críticas relacionadas à possibilidade de existência de um modelo de sustentabilidade sob o manto das "relações capitalistas" que, efetivamente, "não condizem com um modelo de desenvolvimento sustentável” (FOLADORI, 2001, p. 210). Especialmente no que tange a recursos exauríveis, essa noção se acentua. O fato de ser intrínseco ao capital destruir suas próprias condições naturais de reprodução corresponde à chamada segunda 
contradição do capitalismo (MINGIONE, 1993; CARNEIRO, 2005; MONTIBELLER FILHO, 2004; FOLADORI, 2001). Essa característica, entretanto, não nos impede de admitir que a reestruturação do sistema de produção e consumo possa ser realizada (MINGIONE, 1993), o que, por sua vez, não implica reconhecer facilidade nesse processo de transição do imediatismo para uma visão de longo prazo.

Assim sendo, ainda que sejam evidentes as "tensões e ambigüidades” (LEIS, 1999, p. 156) do conceito de desenvolvimento sustentável, procuramos extrapolar, dentro dos limites deste trabalho, as críticas sobre a impossibilidade de um desenvolvimento capitalista sustentável para contribuir com a construção de um modelo, ainda que teórico, passível de suprir o "silêncio conceitual” (CARNEIRO, 2005, p. 32) existente, in casu, entre a produção capitalista e a sua base material de recursos energéticos. Essa assertiva se aplica, por exemplo, ao entendimento de Goldstein (2002) sobre o desenvolvimento sustentável como sendo "uma abordagem sistemática de alcançar o desenvolvimento humano de forma a sustentar os recursos planetários, baseada no reconhecimento de que o consumo humano extrapola a capacidade de suporte do planeta”.

Isso porque o conceito formulado pressupõe a existência de um desenvolvimento humano equânime, sem esclarecer o tempo de sustentação dos recursos e mesmo a forma de consumo a que se refere. Em escritos atuais, Sachs (2002, p. 35) aponta o Brasil como um dos países capazes de empreender os "três pilares do desenvolvimento sustentável”, quais sejam: "relevância social, prudência ecológica e viabilidade econômica”. A tríade apontada sinaliza a multiplicidade de atores envolvidos e a complexidade da discussão - elementos que conduzem a uma diversidade de apropriações do termo sustentabilidade. Nas palavras de Montibeller Filho (2004, p. 58), essa variação se deve à "existência de apropriações diferenciadas [...] por grupos sociais de interesse”. Fato que nos alinha com o pensamento de Limonad (2004, p. 5) de que a sustentabilidade é "socialmente criada e integra o corpo de representações hegemônicas do espaço na contemporaneidade”. 
Não se pode prescindir da discussão social, mesmo que ela se faça apenas superficialmente, visto que a complexidade nos remete à observação de Acselrad (2001) em relação ao nascedouro das duas problemáticas, o que, nas palavras do autor, implica reconhecer que a “raiz da degradação do meio ambiente” é “a mesma da desigualdade social” (ACSELRAD, 2001, p. 34) e, apesar de “ecologicamente interligado, o mundo é socialmente fragmentado”, devido à preponderância da "desigualdade ao acesso e uso da base material da existência” (RIBEIRO, 2003, p. 405). Desse modo,

[...] para os muitos mundos em que se divide o planeta pela desigualdade social entre classes e regiões, a questão da pressão agregada sobre os recursos ambientais é atravessada pelas temáticas da desigualdade distributiva, da dependência financeira, da desigualdade no controle dos mecanismos de comércio e dos fluxos de tecnologia. Tais mecanismos se originam na desigual correlação de forças econômicas e políticas que regulam o acesso de classes e países à base material do desenvolvimento. Dessa desigualdade nascem e, ao mesmo tempo, circularmente, a ela alimentam (ACSELRAD, 2001, p. 34).

Concomitante à ideia de muitos mundos, apontada por Acselrad (2001), caminha a noção de múltiplos "meios ambientes (o meio ambiente dos grandes projetos, o meio ambiente das empresas poluidoras ou não, o meio ambiente urbano das grandes cidades, o meio ambiente das unidades de conservação etc.)" (MACHADO, 2000, p. 17, grifos do autor). Essa diversidade de apropriações impede a formação de um modelo único de sustentabilidade capaz de percolar as diferentes esferas governamentais e alcançar satisfatoriamente os inúmeros interesses e atores envolvidos.

Apontados, ainda que brevemente, os elementos constitutivos do modelo de desenvolvimento sustentável, passamos à verificação de alguns conceitos aplicados a essa expressão. Primeiramente, apresentamos definição constante do Dicionário de Meio Ambiente e Desenvolvimento Sustentável, segundo o qual a expressão a que nos referimos (desenvolvimento sustentável) se configura como o que fornece benefícios econômicos, sociais e ambientais de longo prazo em atenção às necessidades das gerações presentes e futuras (GILPIN, 1996). 
No Dicionário Brasileiro de Ciências Ambientais (LIMA-E-SILVA et al., 1999, p. 76), é identificado como a "forma de desenvolvimento econômico que não tem como paradigma o crescimento, mas a melhoria da qualidade de vida; que não caminha em direção ao esgotamento dos recursos naturais”. Encontramos, sob conceituação semelhante, no Dicionário de Economia do Século XXI (SANDRONI, 2007, p. 243), desenvolvimento sustentável como aquele que "se refere ao desenvolvimento de uma empresa, ramo industrial, região ou país, e que seu processo não esgota os recursos naturais que consome nem danifica o meio ambiente de forma a comprometer o desenvolvimento dessa atividade no futuro”.

Podemos, portanto, por meio do desenvolvimento sustentável, antecipar as necessidades ou o que poderia ser aceito como qualidade de vida para as futuras gerações?

Entendemos que não, pois, exatamente como explica Montibeller Filho (2004), o conceito aqui em pauta está de fato ainda em elaboração. E mais, não encerra em si a noção de finalidade, mas, na verdade, de meio ou processo para a obtenção de qualidade de vida ou existência digna. Conceitos que, portanto, requerem revisão de acordo com o momento histórico e o contexto social. Essa é a direção para a que voltamos nossos esforços: da contribuição científica para o fortalecimento das premissas da sustentabilidade no âmbito da política nacional de forma a assegurar os direitos das presentes e futuras gerações.

E, tomando por base os critérios de sustentabilidade sugeridos por Sachs (2002), chegaremos à mesma ideia de construção constante, histórica, na medida em que acompanha o movimento social e cultural e as alternâncias impensáveis do mercado, transfiguradoras da ordem econômica, como a crise econômica mundial do segundo semestre de 2008. A multiplicidade de atores e interesses desvela um abismo entre os discursos público e privado e a realidade brasileira e mesmo global nos dias atuais, fato que nos leva a concordar com a seguinte afirmação de Sachs (2002, p. 55): a “História nos pregou uma peça cruel. O desenvolvimento sustentável é, evidentemente, incompatível com o jogo sem restrições das forças do mercado”. 
Isso porque a forma de exploração dos recursos naturais, baseada em sua suposta de inesgotabilidade, "indica a limitação do mercado como mecanismo regulador do manejo” desses recursos. No mesmo sentido, “a intervenção do Estado não tem significado uma alternativa eficaz na proteção do meio ambiente e dos recursos naturais” (GÓMEZ, 2001, p. 101-102).

\title{
Pelo exposto, concordamos que
}

\begin{abstract}
Pensar a sustentabilidade em uma sociedade tão diversa e desigual como a brasileira requer, além de uma revolução da eficiência e da suficiência, equacioná-la impreterivelmente à diversidade cultural, à democratização do acesso aos recursos naturais e à distribuição dos riscos da produção industrial (ZHOURI; LASCHEFSKI; PEREIRA, 2005, p. 18).
\end{abstract}

A realidade nacional releva a importância de implantação de um modelo de desenvolvimento que se proponha sustentável, na medida em que ele “defende que o ambiente não é um sistema em separado dos sistemas sociais e econômicos, e que o crescimento econômico, a justiça social e a sustentabilidade de longo prazo são objetivos que se fortalecem mutuamente, numa relação de cooperação” (WENCESLAU; ANTEZANA; CALMON, 2012, p. 592).

Nesse cenário, tomando o momento atual em que o Brasil reafirmou compromissos ambientais não cumpridos, em que se investe em empreendimentos de significativos impactos socioambientais, permanentes e de longo prazo, como os provenientes de grandes hidrelétricas e combustiveis fósseis, a crise econômica mundial pode ser o argumento necessário para uma estagnação com a temática ambiental, visto que o processo histórico em que se dá a gênese de tal problemática tem como uma de suas premissas a "expansão do modo de produção capitalista” (LEFF, 2002, p. 62). Como forma de ordenar o modelo econômico, eminentemente expansionista, procuramos, a partir do referencial teórico analisado, debruçar-nos sobre o modelo de desenvolvimento definido pela Constituição Federal, como forma de encontrar as diretrizes para a definição de uma proposta de desenvolvimento sustentável que compatibilize os interesses econômicos, as necessidades da população, presente e futura, e a capacidade de suporte do meio ambiente. 


\section{Qual o futuro que queremos?}

"O futuro que queremos" é o documento final da Conferência das Nações Unidas sobre Desenvolvimento Sustentável, realizada em junho de 2012 no Rio de Janeiro (Rio+20). Longe de se firmarem como um compromisso objetivo para a mudança no paradigma mundial de produção capitalista, as exortações encontradas ao longo de todo o texto são apenas, em sua maioria, reafirmações de princípios estabelecidos durante os 40 anos de discussão ambiental, contados da Conferência de Estocolmo em 1972.

Conforme destaca Goldemberg (2012), o texto se apoia em reafirmar, reconhecer, encorajar, entre outras palavras, sem estabelecer qualquer plano de ação específico para tornar o desenvolvimento sustentável uma realidade.

Wenceslau, Antezana e Calmon (2012, p. 597) corroboram esse entendimento ao afirmarem que o "documento não contesta a estrutura da economia capitalista, porém declara na abertura que erradicar a pobreza é o maior desafio para o mundo e pré-condição para o desenvolvimento sustentável”.

Os autores reconhecem o mérito de uma "abordagem holística e integrada do desenvolvimento sustentável, onde o crescimento econômico, a proteção ambiental e a justiça distributiva podem ocorrer simultaneamente" (Ibidem). Contudo, criticam o fato de, "no decorrer do documento, os aspectos econômicos [ganharem] uma força comparativamente superior aos aspectos ambientais em senso estrito e aos aspectos sociais, como se o ambiental se subordinasse ao econômico" (Ibidem).

A construção de um arcabouço institucional específico para o desenvolvimento sustentável é amplamente discutida no documento. A tradução de políticas de desenvolvimento sustentável em ações concretas no nível nacional é particularmente ressaltada no parágrafo 97 de "O futuro que queremos": Reconhecemos a importância da dimensão regional do desenvolvimento sustentável. Estruturas 
regionais podem complementar e facilitar a tradução efetiva de políticas de desenvolvimento sustentável em ação concreta no nível nacional (UNITED NATIONS, 2012).

Dessa forma, não há clareza em relação a responsabilidades, ações, metas ou objetivos para se alcançar o futuro harmonioso, equilibrado ecologicamente, socialmente justo, igualitário, distributivo e acessível economicamente, idealizado em mais um debate multilateral destituído de responsáveis e obrigações exigíveis.

A mesma linha de apresentação é apresentada no parágrafo 101, em que se destaca genericamente a necessidade de planejamento e de um processo decisório coerentes e integrados nos níveis nacional, subnacional e local (UNITED NATIONS, 2012).

Ainda assim, visto que as políticas públicas, a legislação e a regulamentação são instrumentos destacados ao longo de todo o documento, consideramos fundamental a análise do arcabouço jurídico nacional para verificar a adequação da estrutura normativa ambiental em vigor com uma proposta de futuro que se proponha sustentável.

E, por esse foco de análise, concordamos que:

A realização da Conferência das Nações Unidas sobre Desenvolvimento Sustentável, conhecida como Rio+20 é uma oportunidade para identificação e negociação de soluções para enfrentar os desafios nos últimos anos: econômico, pela crise financeira enfrentada pelos países desenvolvidos e ameaça o crescimento dos países em desenvolvimento; social, uma vez que a garantia de empregos e acesso às necessidades básicas ainda não atinge grande parte da população mundial; e proteção do meio ambiente, pelas pressões sobre os recursos naturais e consequências resultantes da mudança do clima (BRASIL, 2012, p. 177).

Contudo, aguardar meramente um acordo universal de ações nos conduzirá a novas conferências improdutivas, devendo as ações para o desenvolvimento sustentável serem implementadas nacionalmente para que seu somatório contribua para a longevidade planetária, respeitadas as condições e aptidões regionais e de cada país. 


\section{Desenvolvimento sustentável e ordenamento jurídico brasileiro}

Apesar das dificuldades conceituais discutidas, é possivel caminhar para um modelo de sustentabilidade calcado nas especificidades e aptidões nacionais e regionais, e, talvez, esse seja o melhor caminho para que a soma das sustentabilidades construa um projeto planetário perene e igualitário. Nesse sentido, partiremos das contribuições do Direito Ambiental, aqui entendido como o "complexo de princípios e normas reguladoras das atividades humanas que, direta ou indiretamente, possam afetar a sanidade do ambiente em sua dimensão global, visando à sua sustentabilidade para as presentes e futuras gerações” (MILARÉ, 2000, p. 93).

Antes de prosseguirmos, consideramos fundamental ressaltar o viés desse ramo da Ciência Jurídica, envolto que está pela exigência multidisciplinar da questão ambiental, classificado por Machado (1999, p. 127) como instrumento hábil para interligar os diversos temas ambientais, tais como água, atmosfera, solo, fauna, flora, biodiversidade, "com a argamassa da identidade dos instrumentos jurídicos de prevenção e de reparação, de informação, de monitoramento e de participação”.

Destarte, procura-se construir uma visão jurídica sistematizadora da questão ambiental, consoante a perspectiva do autor, para contribuir com os esforços existentes para regular o desequilíbrio entre o uso atual e a garantia de condições ambientais suficientes para atender às necessidades das futuras gerações. Essa contribuição vai ao encontro das dimensões da sustentabilidade e possui amparo em sede constitucional.

O direito das futuras gerações é baseado no princípio da equidade intergeracional. Sua concepção deu-se no Direito Internacional, ramo em que a Teoria da Equidade Intergeracional foi concebida, tendo por finalidade assegurar que cada geração receba o planeta em fideicomisso para as futuras gerações, segundo explicação de Carvalho (2005). Sua positivação, no âmbito do Direito Ambiental brasileiro, deu-se por meio do artigo 225, in fine, da Constituição 
Federal, adotando por premissa a concepção de distribuição justa dos recursos naturais, tanto sob a perspectiva da qualidade ambiental como do estoque de recursos das presentes para as futuras gerações.

Estamos, assim, diante de uma relação fundada sobre a dimensão temporal (KISS; SHELTON, 2007): passado, presente e futuro. A partir da reflexão de Carneiro (2003) sobre o tema, extrapolamos a proposta do autor por entender que às gerações presentes se impõe a "obrigação especial, enquanto tutores ou curadores do planeta" (KISS; SHELTON, 2007, p. 106) de preservar e aprimorar as condições ambientais, herdadas das gerações passadas, objetivando assegurar o direito ao ambiente ecologicamente equilibrado para as gerações futuras.

Definida a linha interpretativa e sua justificativa, passaremos ao delineamento do aspecto central, consoante a proposta deste estudo, intrínseco ao conceito de desenvolvimento sustentável: a equidade intergeracional. Em primeiro plano, apresentamos breve esclarecimento quanto ao aspecto ético envolvido na questão intergeracional (TRINDADE, 1993, p. 218, grifo do autor): “a dimensão temporal de longo prazo, desvendada pelo próprio termo humanidade, a abranger tanto as gerações presentes quanto as futuras, e a revelar o vínculo com o âmbito dos direitos humanos (a busca da sobrevivência)”.

Essa premissa ética entre gerações constitui requisito basilar para a posteridade de um planeta habitável para todas as formas de vida, ou ainda, consoante análise de Milaré (2000, p. 106), acerca do princípio do direito ao desenvolvimento sustentável:

O princípio aqui preconizado infere-se da necessidade de um duplo ordenamento - e, por conseguinte, de um duplo direito - com profundas raízes no Direito Natural e no Direito Positivo: o direito do ser humano de desenvolver-se e realizar as suas potencialidades, quer individual quer socialmente, e o direito de assegurar aos seus pósteros as mesmas condições favoráveis. Neste princípio, talvez mais do que em outros, surge tão evidente a reciprocidade entre direito e dever, porquanto desenvolver-se e usufruir de um planeta plenamente habitável não é apenas direito, é dever precípuo das pessoas e da sociedade. Direito e dever como contrapartidas inquestionáveis. 
Em relação ao preceito do desenvolvimento, é necessário, dentro dos contornos dados ao tema pelo Direito Ambiental, ressaltar, primeiramente, adotando um critério meramente cronológico, a contribuição da Política Nacional do Meio Ambiente (PNMA), instituída pela Lei ${ }^{\circ}$ 6.938, de 31 de agosto de 1981, ao elencar entre seus objetivos, no artigo $4^{\circ}$, incisos I e VI, a "compatibilização do desenvolvimento econômico-social com a preservação da qualidade do meio ambiente e do equilíbrio ecológico” (BRASIL, 1981) e a utilização racional e disponibilidade permanente dos recursos ambientais (Ibidem). Ainda que não se possa vislumbrar um claro conceito de desenvolvimento sustentável, duas premissas são facilmente destacáveis: a) equilíbrio entre econômico e ambiental; e b) a temporalidade encerrada na ideia de permanência do estoque de recursos naturais. Em um segundo momento, com a promulgação da Constituição Federal, supriramse as lacunas deixadas pela PNMA ao delimitar as linhas mestras do desenvolvimento sustentável a ser praticado e promovido pelas políticas nacionais. Nesse sentido, a partir de uma análise sistêmica da Constituição Federal, ou seja, pela interpretação do texto normativo constitucional no seu todo (GRAU, 2003), entendemos ter sido adotado como modelo para o desenvolvimento nacional aquele qualificado doutrinariamente como sustentável. O desenvolvimento no Brasil está, portanto, fundado sobre os seguintes pilares: a) desenvolvimento nacional (art. $3^{\circ}, \mathrm{II}, \mathrm{CF} / 88$ ); b) redução das desigualdades regionais e sociais (art. $3^{\circ}$, III, CF/88); c) ordem econômica com vistas a assegurar a todos existência digna em consonância com a preservação ambiental (art. 170, caput c/c VI, CF/88); d) meio ambiente ecologicamente equilibrado (art. 225, caput, CF/88); e) responsabilidade intergeracional (art. 225, caput).

Entre os dispositivos infraconstitucionais que incorporam expressamente o modelo constitucional, destacamos, primeiramente, o artigo $2^{\circ}$, inciso I do Estatuto da Cidade(Lei 10.257/2001), que estabelece a "garantia do direito a cidades sustentáveis, entendido como o direito à terra urbana, à moradia, ao saneamento ambiental, à infraestrutura urbana, ao transporte e aos serviços públicos, ao trabalho e ao lazer, para as presentes e futuras gerações” (BRASIL, 2001). Em diversos dispositivos do Sistema Nacional de Unidades de Conservação (Lei 
9.985/2000), apresenta-se a preocupação com o uso sustentável dos recursos naturais e o manejo desses espaços protegidos. “A concepção do meio ambiente em sua totalidade, considerando a interdependência entre o meio natural, o socioeconômico e o cultural, sob o enfoque da sustentabilidade” configura princípio básico da Política Nacional de Educação Ambiental - Lei 9.795/1999 (BRASIL, 1999). O uso racional dos recursos hídricos com vistas ao desenvolvimento sustentável também possui amparo legal (Lei 9.433/1997). Desenvolvimento e padrões sustentáveis de produção estão previstos na Política Nacional de Resíduos Sólidos (Lei 12.305/2010). A Política Nacional de Saneamento Básico (Lei 11.445/2010) apresenta o desenvolvimento sustentável entre suas diretrizes gerais de ações para a salubridade rural e urbana.

Desse resumido panorama legal, a nosso ver, o ordenamento jurídico, em plena vigência no Brasil, baseia-se no duplo imperativo ético da sustentabilidade ambiental, firmado por Veiga (2006, p. 171) sobre uma "solidariedade sincrônica com a geração atual e [outra] diacrônica com as gerações futuras”, ainda que careça de um detalhamento na determinação e especificação das ações, metas e dos objetivos para se alcançar a sustentabilidade proposta de maneira vaga em seus diversos e dispersos diplomas.

Por isso, ao balizarmos, pela Constituição Federal, o conceito de desenvolvimento sustentável a ser adotado neste trabalho, procuramos dar ao tema a sua máxima aplicação, visto sua obrigatoriedade estar positivada em sede constitucional. Isso porque, por imperativo do "princípio da supremacia das normas constitucionais, é certo que a interpretação destas normas repercute indiscutivelmente em todo o ordenamento jurídico” (FERREIRA, 2008, p. 37).

A sustentabilidade no uso dos recursos naturais deve ser encarada, nessa ótica, como modelo de desenvolvimento capaz de assegurar condições dignas à sobrevivência das futuras gerações humanas e de todas as demais formas de vida. Sob essa perspectiva, Derani (2001, p. 242) enfatiza a preponderância do qualitativo sobre o quantitativo: “Desenvolvimento econômico no Estado Brasileiro, 
subentende um aquecimento da atividade econômica dentro de uma política de uso sustentável dos recursos naturais objetivando um aumentado de qualidade de vida que não se reduz a um aumento do poder de consumo".

Dessa forma, o cotidiano cenário de exploração exclusivamente econômica dos recursos naturais, de pobreza generalizada e de desigualdades sociais, traços destacados do atual quadro de injustiça ambiental, está em patente dissonância com os objetivos constitucionais da República Federativa do Brasil.

Para ilustrar esse cenário, no próximo item serão analisados alguns exemplos de políticas públicas implementadas pelo governo federal, além de dispositivos legais, soba perspectiva da transversalidade da temática ambiental e da aplicação do desenvolvimento sustentável como modelo para se superar essas iniquidades persistentes na sociedade brasileira.

\section{Políticas públicas: aplicação do desenvolvimento sustentável pelo Estado}

Adotaremos a concepção de políticas públicas encontrada em Vieira e Bredariol (1998, p. 98), ou seja, “mediações políticoinstitucionais das inter-relações entre os diversos atores presentes no processo histórico-social em suas múltiplas dimensões”.

Em relação às políticas ambientais, os diversos atores estão envolvidos em uma "cadeia de agentes sociais, cujos elos vão desde o Estado e os agentes públicos, a academia e os cientistas, os setores econômicos, os meios de comunicação até a sociedade civil organizada e a população em geral” (SIQUEIRA, 2008, p. 425-426).

A descentralização político-administrativa promovida pela Constituição Federal fortaleceu o processo de autonomia ambiental de estados e municípios, consubstanciando a estrutura do Sistema Nacional de Meio Ambiente (Sisnama) prevista na PNMA. Contudo, o 
recorte para as políticas federais, aqui proposto, tem por finalidade contribuir para a superação de uma dificuldade estrutural relacionada às “diversidades culturais, econômicas e ambientais dos Estados e municípios, [o que implica na necessidade de se manter um] grau de centralidade do governo federal [...] para a manutenção e a articulação do SISNAMA” (SCARDUA; BURSZTYN, 2003, p. 205).

Políticas ambientais, sob a perspectiva da sustentabilidade, devem enfrentar a questão da troca ecologicamente desigual, conceito que, segundo Montibeller Filho (2004, p. 129), engloba “o problema de que os preços praticados no mercado não levam em conta o desgaste ambiental (degradação do meio; exaustão de recurso) havido no local da produção da mercadoria”.

Essa carência estrutural do mercado torna-se mais aguda ao tratarmos de gerações futuras; em outras palavras, um grupo vulnerável e sem possibilidade de participar do processo decisório presente na defesa de seus direitos potenciais. Avulta-se como uma das alternativas para a delimitação dos interesses econômicos o princípio da equidade intergeracional, por meio de que se propõe a adoção do pressuposto intertemporal de distributividade, encerrado no conceito de sustentabilidade (GOMES, 1999, p. 44):

A idéia de desenvolvimento sustentado também está relacionada à de riqueza constante, no sentido de que cada geração deve deixar para a próxima pelo menos o mesmo nível de riqueza, considerada como a disponibilidade de recursos naturais, de meio ambiente e de ativos produtivos.

Apesar da clareza inerente à "incidência do fator temporal no domínio da proteção ambiental”, Trindade (1993, p. 55) ressalta as profundas lacunas políticas e jurídicas no trato da matéria. Ao defender a preocupação temporal, o autor assevera "o estudo da proteção de vítimas potenciais ou prospectivas" como "uma real necessidade e não uma especulação teórico-acadêmica” (Ibidem).

Diante dessa preocupação, pontuaremos em relação a políticas instituídas no âmbito do governo federal, escolhidas aleatoriamente 
na tentativa de abarcar o amplo espectro das necessidades humanas, consoante estrutura do documento final da Rio+20, como energia, habitação e saneamento. Entendemos que, das políticas analisadas, é possível, dentro do limite de espaço da presente reflexão, discutir algumas das questões e áreas prioritárias definidas pelo "O futuro que queremos”, tais como: água e saneamento (parágrafo 119 e ss.); energia (parágrafo 125 e ss.); cidades sustentáveis e assentamentos humanos (parágrafo 134 e ss.); e saúde e população (parágrafo 138 e ss.).

O Programa de Aceleração do Crescimento (PAC) é apresentado em seu site oficial como "um novo conceito em investimento [da ordem de R\$ 503,9 bilhões] em infra-estrutura” (BRASIL, 2008). O PAC engloba um conjunto de políticas econômicas voltado para o incremento dos setores produtivos, com previsão de investimento nas áreas de saneamento, habitação, transporte, energia e recursos hídricos. Os objetivos apresentados pelo PAC, lançado em 28 de janeiro de 2007, para a área de investimentos em Geração e Transmissão de Energia Elétrica são "garantir a segurança do suprimento e a modicidade tarifária da energia elétrica” (BRASIL, 2008).

A previsão de investimento consolidado em petróleo, gás natural e combustíveis renováveis do PAC para a infraestrutura energética ( $R \$$ 196,4 bilhões), no período 2007-2010, distorce qualquer perspectiva de que se proponha sustentável. Isso porque as ações específicas quanto a petróleo ( $R \$ 93,4$ bilhões), refino, transporte, petroquímica ( $R \$ 45,2$ bilhões) e gás natural ( $R \$ 40,4$ bilhões) correspondem a cerca de $91 \%$ do total de investimentos, enquanto combustíveis renováveis ( $R \$ 17,4$ bilhões) compõem o restante para o setor. ${ }^{2}$ A diversificação da matriz energética escapa à pauta oficial, logo, não é possivel se falar em uma visão de longo prazo dentro da linha de planejamento adotada, calcada prioritariamente sobre recursos esgotáveis.

O PAC 2, por sua vez, tem como finalidade evitar a ocorrência de novos apagões e, para tanto, afirma priorizar alternativas sustentáveis para a geração de energia, citando como medidas a adoção de um “modelo de usinas hidrelétricas inspirado nas plataformas de petróleo,
2 Em outubro de 2010 segundo dados oficiais do governo federal (BRASIL, 2010a), para as ações previstas no PAC para o período 2007-2010, por valor, $49 \%$ foram concluídas e $50 \%$ estavam em obras. "Pelo critério de quantidade, $61 \%$ das ações do eixo de Energia acompanhadas desde 2007 foram concluídas, $28 \%$ estão em obras, $6 \%$ em licitação e $5 \%$ em projeto ou licenciamento." (Ibidem, p. 98). 
que reduz o impacto ao meio ambiente durante a construção e a operação” (BRASIL, 2010b, p. 8) e de “medidas de promoção da eficiência energética, que tem como objetivo a economia de energia, a redução da emissão de gases de efeito estufa” (Ibidem, p. 9).

Paradoxalmente, o PAC 2 determina a meta de consolidar o Brasil como “um dos países com a matriz energética mais limpa”, por meio de investimentos em agroenergia, com destaque para os biocombustíveis e o etanol, ao mesmo tempo em que acelera o processo de exploração das reservas do pré-sal, com investimentos em pesquisas exploratórias, perfuração de poços e construção de plataformas (Ibidem).

Contudo, do total de $\mathrm{R} \$ 1.088,5$ bilhões previstos para a área de energia, somados os períodos 2011-2014 e pós-2014 (designação adotada pelo PAC2), R\$ 875,1 bilhões são para petróleo e gás natural, enquanto o eixo de combustiveis renováveis receberá $\mathrm{R} \$ 1$ bilhão.

Temos, portanto, que a linha traçada no segmento energético pelo PAC2 mantém a concentração de investimentos em energia fóssil da ordem de 80,3\% para a área de petróleo e gás natural contra 0,1\% para combustiveis renováveis, adiando, por prazo indeterminado, a propalada e necessária diversificação da matriz energética brasileira.

A falta de uma perspectiva integradora e de longo prazo nas políticas públicas também está refletida no Programa Minha Casa Minha Vida (PMCMV), estruturado pelo e para o mercado imobiliário em descompasso com o planejamento urbano local, e, assim sendo, sem qualquer relação com o objetivo de construção de cidades sustentáveis. Não desconhecemos a importância da habitação, particularmente aquela direcionada à população de baixa renda:

No entanto, embora se refira à necessidade de inserção da moradia a ser construída no meio urbano, o pacote não garante essa condição devido aos agentes que estão envolvidos em sua formulação e operação. 0 governo federal formulou a proposta em parceria com as 11 maiores empresas - construtoras e incorporadoras - promotoras de moradia. Avanços conceituais sobre o tema da habitação social, tanto no que se 
refere à legislação urbanística, quanto ao que se refere aos projetos arquitetônicos, não são incorporados à sua operação. Analisando a proposta do PMCMV tendo como referência o que foi a experiência da política habitacional do Regime Militar - período de maior construção de moradias no país - foi possível prever o que a experiência recente já mostra: o impacto negativo sobre as cidades devido à localização inadequada de grandes conjuntos habitacionais e ao aumento do preço da terra e dos imóveis (MARICATO, 2011, p. 68).

O crescimento desordenado das cidades implica ainda um processo de expansão antrópica comumente desarticulado da capacidade de suporte de seu entorno, levando a mazelas humanas características das grandes cidades no Brasil, traduzidas por Maricato (2001, p. 22) como tragédia urbana brasileira, marcada por "enchentes, desmoronamentos, poluição dos recursos hídricos, poluição do ar, impermeabilidade da superfície do solo, desmatamento, congestionamento habitacional, reincidência de epidemias, violência etc.”.

Nesse cenário, aspectos relacionados ao saneamento merecem ser ilustrados. A Organização Pan-Americana de Saúde (OPS, 2000) relaciona o processo acelerado de urbanização, marcado pela periferização de moradias informais, entre os fatores complicadores para a melhoria dos serviços de saneamento (Ibidem). Como consequência, temos a contaminação de lagos e rios pelo lançamento de efluentes sanitários sem tratamento nos corpos hídricos (Ibidem). Fecha-se o ciclo a partir da identificação da água como uma das principais vias de risco para a saúde (Ibidem), tanto pelo consumo direto, recreacional ou pela contaminação dos alimentos durante o cultivo e a preparação, por exemplo (Ibidem).

Outra questão intrínseca ao modelo de desenvolvimento industrial-urbano é a "recrudescência das antigas infecções e o surgimento de novas - a emergência, reemergência e 'permanência' das doenças infecciosas" (IANNI, 2005, p. 78; no mesmo sentido: MACHADO et al., 2009; MACHADO; MIAGOSTOVICH; VILANI, 2012).

Apesar das consequências socioambientais, 
atualmente são investidos entre $\mathrm{R} \$ 7$ bilhões e $\mathrm{R} \$ 8$ bilhões por ano em saneamento no Brasil, quantia inferior à necessária para atingir as metas do governo até 2030 - investimento de $\mathrm{R} \$ 420$ milhões pelos próximos 18 anos, o que corresponde a cerca de $\mathrm{R} \$ 20$ bilhões por ano, de acordo com estimativas feitas pelo Ministério das Cidades.

Mesmo com o aumento dos recursos para saneamento básico nos últimos anos, principalmente por causa do PAC, a maioria dos projetos não sai do papel. Um levantamento divulgado no início de abril deste ano pelo Trata Brasil, sobre as 114 principais obras de saneamento da primeira fase do programa, mostra que apenas $7 \%$ delas estão prontas. Entre as demais, 32\% estavam paralisadas e 23\% atrasadas (ABDALA, 2012).

Para analisar esse descompasso entre o plano legislativo e a realidade concreta em matéria ambiental, é preciso, dentro dos limites desse trabalho, destacar a fragmentação e o isolamento da política ambiental no processo decisório nacional. Sob essa perspectiva, quatro aspectos são fundamentais para harmonizar a prática política e o sistema jurídico-ambiental:

- Fortalecimento institucional e efetiva integração do Sisnama;

- Transversalidade da questão ambiental na elaboração das políticas setoriais;

- Adoção da perspectiva de longo prazo no planejamento público; e

- Participação social.

Apesar dos avanços na estrutura protetiva ambiental, admitese aqui que a fragilidade das instituições democráticas no Brasil, discutidas por Frey (2000), traduz-se também nas políticas ambientais, conforme destacado na leitura proposta.

A priorização de alguns setores da economia em desfavor da atenção primária aos princípios de proteção ambiental configura-se, conforme O'Donnell (1991 apud FREY, 2000), em um reflexo do processo decisório em favor de elites dominantes, que caracteriza, ao lado da fraqueza institucional, as democracias delegativas. 
Como forma de fortalecimento político-institucional e de garantia do direito fundamental da pessoa humana, tem se discutido, especialmente a partir da Rio+20, a aplicação do princípio do não retrocesso ecológico. Tal princípio, também denominado princípio da proibição do retrocesso ambiental, possui “conteúdo impeditivo [que] torna possivel brecar planos políticos que enfraqueçam os direitos fundamentais” (ALMEIDA, 2007, p. 123).

Tomando por base o direito ao meio ambiente ecologicamente equilibrado, assegurado a todos pela Constituição Federal em seu artigo 225, caput, pode-se afirmar que:

\footnotetext{
Dito de outro modo, a Constituição não tem somente a tarefa de apontar para o futuro. Tem, igualmente a relevante função de proteger os direitos já conquistados. Desse modo, mediante a utilização da principiologia constitucional (explícita ou implícita), é possivel combater alterações feitas por maiorias políticas eventuais, que legislando na contramão da programaticidade constitucional, retiram (ou tentam retirar) conquistas da sociedade (STRECK, 2003, p. 53).
}

Logo, enquanto direito fundamental da pessoa humana, o direito ao meio ambiente ecologicamente equilibrado está resguardado contra eventuais intervenções políticas que possam esvaziar seu conteúdo protetivo. Destarte, o arcabouço jurídico de proteção ao ambiente encontra-se fortalecido e deve alcançar os diferentes temas que compõem o espectro ambiental (solo, atmosfera, fauna, flora, biodiversidade, recursos hídricos, etc.).

Almeida (2007, p. 119) ressalva a ausência de ampla aplicação do princípio e o define como aquele caracterizado "pela impossibilidade de redução dos direitos sociais amparados na Constituição, garantindo ao cidadão o acúmulo de patrimônio jurídico”.

No tocante à sustentabilidade, o legislador constituinte, no artigo 225, impõe ao poder público e à coletividade a preservação do meio ambiente sob o prisma da justiça intergeracional. Assim sendo, cabe à geração legar às gerações futuras "condições ambientais idênticas ou melhores do que aquelas recebidas das gerações 
passadas, estando a geração vivente, portanto, vedada a alterar em termos negativos as condições ecológicas, até por força do princípio da proibição do retrocesso socioambiental e do dever (do Estado e dos particulares) de melhoria progressiva da qualidade ambientap" (SARLET; FENSTERSEIFER, 2012, p. 159, grifos dos autores).

Dessa forma, as políticas públicas discutidas neste trabalho, sob a perspectiva proposta, configuram um retrocesso na esfera de proteção ambiental e uma violação à justiça intergeracional. Impõese, portanto, reconhecer a aplicação do princípio do não retrocesso ecológico diante da constatação de que o modelo de desenvolvimento em execução desconsidera a dimensão ambiental, priorizando o imediatismo a partir de uma anacrônica racionalidade econômica e, portanto, em flagrante descompasso com os princípios e objetivos constitucionais e da legislação ambiental em vigor.

\section{Considerações finais}

Analisados os aspectos teóricos e jurídicos do desenvolvimento sustentável, a nosso ver, há compatibilidadeentre a definição doutrinária e a construção conceitual realizada a partir da Constituição Federal para a qualificação de sustentável da proposta de desenvolvimento nacional. Isso porque, estruturalmente, as duas visões assentam-se sobre aspectos econômicos, sociais, ambientais e intergeracionais, tomando a dimensão temporal como fundamental para a perspectiva de longo prazo, inerente à ideia de desenvolvimento sustentável.

Portanto, o modelo de desenvolvimento nacional sustentável tem por pressupostos elementares a sensibilidade ecológica, a ética intergeracional, a justiça social e a participação cidadã (no sentido de pertencimento e defesa da República Federativa do Brasil).

Ainda que esses elementos possam ser considerados incompatíveis com a ordem econômica vigente, como os exemplos ilustraram, acreditamos que meramente aceitar ou criticar a postura imediatista do capitalismo por si só não contribui para a necessária 
inversão de paradigma em favor da sustentabilidade. Por isso, partimos da viabilidade de incorporação da diretriz constitucional apresentada por meio da especificação do modelo de desenvolvimento nacional sustentável como elemento harmonizador entre a legislação ambiental e as políticas públicas.

Assim, voltamos nossa análise para a legislação infraconstitucional e algumas políticas públicas federais tomadas como exemplo ilustrativo do modelo de ações governamentais em curso e sua compatibilidade com o ideal de sustentabilidade constitucional.

Dessa forma, foi possível identificar que, ainda que o arcabouço jurídico brasileiro aponte para o futuro, discorrendo em vários dispositivos sobre o desenvolvimento sustentável, consideramos que o modelo de planejamento público adotado em sede federal é insustentável, visto encontrar-se calcado sobre a preponderância de aspectos econômicos e de curtíssimo prazo.

A necessidade de amadurecimento institucional e o aumento da participação e do horizonte temporal no processo decisório são algumas questões que podem e devem ser enfrentadas pelos pesquisadores das diversas áreas do conhecimento, em um processo integrador e democrático.

A preocupação em explicitar o desenvolvimento sustentável nos dispositivos legais nacionais, pelos próprios questionamentos conceituais apontados, não pode pretender ser suficiente para a adequação das ações, dos programas e das práticas, públicos ou privados, no País. A delimitação do conceito deve se dar a partir de regulamentação específica com limites, padrões e normas que vinculem as atividades causadoras de impactos ambientais.

Crises econômicas mundiais não podem obscurecer os esforços políticos e contornar os desígnios constitucionais de proteção do direito ao meio ambiente ecologicamente equilibrado para as presentes e futuras gerações em favor de ações pontuais e sem planejamento adequado para uma revisão estrutural e estruturante das instituições nacionais. 
Dessa forma, podemos pensar na possibilidade político-jurídica do desenvolvimento nacional sustentável como modelo democrático, participativo e integrador como alternativa a interesses imediatistas e particulares em prol de uma sociedade justa, um ambiente equilibrado e uma ordem econômica distributiva.

Diante dessas observações, a pesquisa pretendeu contribuir e estimular novas discussões para o fortalecimento da efetividade da legislação ambiental no combate às formas de exclusão ambiental presente e futura, vista como a "impossibilidade de gozar dos benefícios ambientais, de ter acesso ao poder e aos processos decisórios” (CAVEDON; VIEIRA, 2008, p. 183).

Julgamos, por fim, imprescindivel o direcionamento das pesquisas acadêmicas no sentido de suprir as lacunas jurídicas e político-institucionais de tradução do desenvolvimento sustentável em ações governamentais concretas, como medida de um Estado Democrático de Direito pautado na sustentabilidade planetária e na existência digna das presentes e futuras gerações.

Recebido 25/11/2012

Aprovado 01/08/2013

\section{Referências bibliográficas}

ABDALA, V. Situação do saneamento no Brasil é dramática e não condiz com crescimento econômico do país, diz especialista. Agência Brasil, Brasília, 01 maio 2012. Disponível em: <http://agenciabrasil. ebc.com.br/noticia/2012-05-01/situacao-do-saneamento-no-brasile-dramatica-e-nao-condiz-com-crescimento-economico-do-paisdiz-espec>. Acesso em: 22 nov. 2012.

ACSELRAD, H. Sentidos da sustentabilidade humana. In: (Org.).

A duração das cidades: sustentabilidade e risco nas políticas urbanas. Rio de Janeiro: DP\&A, 2001. p. 27-55. 
ALMEIDA, D. C. A fundamentalidade dos direitos sociais e o princípio da proibição de retrocesso. Inclusão Social, Brasília, v. 2, n. 1, p. 118-124, mar. 2007.

BRASIL. Lei $\mathbf{n}^{\circ} \mathbf{6 . 9 3 8}$, de 31 de agosto de 1981. Disponivel em: <http:/ / www.planalto.gov.br/ccivil_03/leis/I6938.htm>. Acesso em: 24 set. 2013.

Lei n $^{\circ}$ 9.795, de 27 de abril de 1999. Disponivel em: <http:/ / www.planalto.gov.br/ccivil_03/leis//9795.htm>. Acesso em: 24 set. 2013.

Lei $\mathbf{n}^{\circ}$ 10.257, de 10 de julho de 2001. Disponível em: <http:/ / www.planalto.gov.br/ccivil_03/leis/leis_2001/|10257.htm>.

Acesso em: 24 set. 2013.

Programa de Aceleração do Crescimento. 2008. Disponível em: <http://www.brasil.gov.br/pac/>. Acesso em: 01 jan. 2008.

Balanço completo do PAC - 4 anos (2007-2010). Brasília, dez./2010a. Disponível em: <http://www.pac.gov.br/sobre-o-pac/ publicacoesnacionais>. Acesso em: 24 jul. 2013.

PAC 2. Brasília, 29 mar. 2010b. Disponível em: <http://www. brasil.gov.br/pac/pac-2/>. Acesso em: 13 abr. 2010.

Senado Federal. 0 princípio da proibição de retrocesso ambiental. Brasília: CMA, 2012.

CARNEIRO, E. J. Política ambiental e a ideologia do desenvolvimento sustentável. In: ZHOURI, A.; LASCHEFSKI, K.; PEREIRA, D. B. (Orgs). A insustentável leveza da política ambiental: desenvolvimento e conflitos socioambientais. Belo Horizonte: Autêntica, 2005. p. 27-47.

CARNEIRO, R. Direito ambiental: uma abordagem econômica. Rio de Janeiro: Forense, 2003. 
CARVALHO, E. F. Meio ambiente \& direitos humanos. Curitiba: Juruá, 2005.

CAVEDON, F. S.; VIEIRA, R. S. Socioambientalismo e justiça ambiental como novas perspectivas para o direito ambiental: contribuições para a construção de um “direito da sustentabilidade”. Revista Brasileira de Direito Ambiental, São Paulo, n. 13, p. 173-197, jan./mar. 2008.

DERANI, C. Direito ambiental econômico. São Paulo: Max Limonad, 2001.

FARZIN, Y. H. Can an exhaustible resource economy be sustainable? Social Science Research Network, n. 47, jun. 2002. Disponível em: <http://papers.ssrn.com/sol3/papers.cfm?abstract_id=317933>. Acesso em: 02 dez. 2008.

FERREIRA, R. M. Direito ambiental e a interpretação da Constituição brasileira de 1988: um critério democrático. Revista Brasileira de Direito Ambiental, São Paulo, n. 16, p. 33-40, out./dez. 2008.

FOLADORI, G. Limites do desenvolvimento sustentável. Campinas: Unicamp, 2001.

FONSECA, I.; BURSZTYN, M. A banalização da sustentabilidade: reflexões sobre governança ambiental em escala local. Sociedade e Estado, Brasília, v. 24, n. 1, p. 17-46, jan./abr. 2009.

FREY, K. Políticas públicas: um debate conceitual e reflexões referentes à prática da análise de políticas públicas no Brasil. Planejamento e Políticas Públicas, Brasília, v. 21, p. 211-259, 2000.

GILPIN, A. Dictionary of environment and sustainable development. Chichester: John Wiley \& Sons, 1996.

GOLDEMBERG, J. Rio+20 e o futuro que queremos. Política Democrática, Brasília, n. 32, p. 11-14, 2012. 
GOLDSTEIN, B. D. Sustainable development. Encyclopedia of Public Health. 2002. Disponível em: <http://www.encyclopedia.com>. Acesso em: 25 mar. 2009.

GOMES, H. M. As relações sociedade/natureza e a valoração econômica da natureza: o caso da mata do Estado - Cabedelo-PB. 1999. $123 f$. Dissertação (Mestrado em Meio Ambiente e Desenvolvimento)-Centro de Ciências Exatas e da Natureza, Universidade Federal da Paraíba, João Pessoa, 1999.

GÓMEZ, W. H. Desenvolvimento sustentável, agricultura e capitalismo. In: BECKER, D. F. (Org). Desenvolvimento sustentável: necessidade e/ ou possibilidade? Santa Cruz do Sul: Edunisc, 2001. p. 95-116.

GRAU, E. R. A ordem econômica na Constituição de 1988. São Paulo: Malheiros, 2003.

IANNI, A. M. Z. Biodiversidade e Saúde Pública: questões para uma nova abordagem. Saúde e Sociedade, v. 14, n. 2, p. 77-88, 2005.

JATOBÁ, S. U. S.; CIDADE, L. U. C.; VARGAS, G. M. Ecologismo, ambientalismo e ecologia política: diferentes visões da sustentabilidade e do território. Sociedade e Estado, Brasília, v. 24, n. 1, p. 47-87, jan./ abr. 2009.

KISS, A.; SHELTON, D. Guide to international environmental law. Leiden: Martinus Nijhoff, 2007.

LEFF. E. Epistemologia ambiental. São Paulo: Cortez, 2002.

LEIS, H. R. A modernidade insustentável: as críticas do ambientalismo à sociedade contemporânea. Petrópolis: Vozes; Santa Catarina: UFSC, 1999.

LENZI, C. L. Sociologia ambiental: risco e sustentabilidade na modernidade. Bauru: Edusc, 2006. 
LIMA-E-SILVA, P. P. et al. Dicionário brasileiro de ciências ambientais. Rio de Janeiro: Thex, 1999.

LIMONAD, E. Questões ambientais contemporâneas, uma contribuição ao debate. In: ENCONTRO DA ASSOCIAÇÃO NACIONAL DE PÓSGRADUAÇÃO E PESQUISA EM AMBIENTE E SOCIEDADE, 2., 2004, Indaiatuba. Anais... Indaiatuba: ANPPAS, 2004. p. 1-11.

MACHADO, P. A. L. Direito ambiental brasileiro. São Paulo: Malheiros, 1999.

MACHADO, C. J. S. A questão ambiental brasileira: uma análise sociológica do processo de formação do arcabouço jurídico-institucional. Revista de Estudos Ambientais, Blumenau, v. 2, n. 2-3, p. 5-20, 2000.

MACHADO, C. J. S. et al. Recomendações para elaboração e consolidação de uma estratégia nacional de prevenção e controle das espécies exóticas no Brasil. Ciência e Cultura, Campinas, v. 61, n. 1, p. 42-45, 2009.

MACHADO, C. J. S.; MIAGOSTOVICH, M. P.; VILANI, R. M. Colaboração entre sociologia e virologia ambiental para a implementação de políticas públicas nacionais. In: MACHADO, C. J. S. (Org.). Ciências, políticas públicas e sociedade sustentável. Rio de Janeiro: E-papers, 2012. p. 191-241.

MARICATO, E. Brasil, cidades: alternativas para a crise urbana. Petrópolis: Vozes, 2001.

0 impasse da política urbana no Brasil. Petrópolis: Vozes, 2011.

MILARÉ, É. Direito do ambiente. São Paulo: RT, 2000.

MINGIONE, E. The second contradiction of capitalism. Capitalism, Nature, Socialism, v. 4, n. 14, p. 85-92, jun. 1993. 
MONTIBELLER FILHO, G. 0 mito do desenvolvimento sustentável: meio ambiente e custos sociais no moderno sistema produtor de mercadorias. Florianópolis: UFSC, 2004.

ORGANIZACIÓN PANAMERICANA DE LA SALUD. La salud y el ambiente en el desarrollo sostenible. Washington: OPS, 2000.

OSORIO, L. A. R.; LOBATO, M. O.; CASTILLO, X. A. Debates on sustainable development: towards a holistic view of reality. Environment, Development and Sustainability, v. 7, n. 4, p. 501-518, dez. 2005.

PEPE, V. Lo sviluppo sostenibile tra diritto internazionale e diritto interno. Rev. Giur. Ambiente, n. 2, p. 209-243, 2002.

RIBEIRO, W. C. Em busca da qualidade de vida. In: PINSKY, J.; PINSKY, C. B. (Orgs.). História da cidadania. São Paulo: Contexto, 2003. p. 399-417.

ROMEIRO, A. R. Economia ou economia política da sustentabilidade. In: MAY, P. H.; LUSTOSA, M. C.; VINHA, V. (Orgs.). Economia do meio ambiente. Rio de Janeiro: Elsevier, 2003. p. 1-29.

SACHS, I. Caminhos para o desenvolvimento sustentável. Rio de Janeiro: Garamond, 2002.

SANDRONI, P. Dicionário de economia do século XXI. Rio de Janeiro: Record, 2007.

SARLET, I. W.; FENSTERSEIFER, T. F. Notas sobre a proibição de retrocesso em material (socio) ambiental. In: SENADO FEDERAL. 0 princípio da proibição de retrocesso ambiental. Brasília: CMA, 2012. p. 121-206.

SCARDUA, F. P; BURSZTYN, M. A. A. Descentralização da política ambiental no Brasil. Sociedade e Estado, Brasília, v. 18, n. 1/2, p. 257$290,2003$. 
SIQUEIRA, L. C. Política ambiental para quem? Ambiente \& Sociedade, Campinas, v. XI, n. 2, p. 425-437, 2008.

STRECK, L. L. Hermenêutica jurídica e(m) crise: uma exploração hermenêutica da construção do Direito. Porto Alegre: Livraria do Advogado, 2003.

TRINDADE, A. A. C. Direitos humanos e meio ambiente: paralelo dos sistemas de proteção ambiental. Porto Alegre: Sergio Antonio Fabris, 1993.

UNITED NATIONS. Our Common Future. Chapter 2: towards sustainable development. Disponível em: http://www.un-documents.net/ocf-02. htm. Acesso em: 24 nov. 2008.

The future we want. 2012. Disponivel em: <http://www. un.org/en/sustainablefuture/>. Acesso em: 24 set. 2013.

VEIGA, J. E. Desenvolvimento sustentável: o desafio do século XXI. Rio de Janeiro: Garamond, 2006.

VIEIRA, L.; BREDARIOL, C. Cidadania e política ambiental. Rio de Janeiro: Record, 1998.

WENCESLAU, J.; ANTEZANA, N. L.; CALMON, P. P. Políticas da Terra: existe um novo discurso ambiental pós Rio +20? Cad. EBAPE, Rio de Janeiro, v. 10, n. 3, p. 584-604, 2012.

ZHOURI, A.; LASCHEFSKI, K.; PEREIRA, D. B. Desenvolvimento, sustentabilidade e conflitos socioambientais. In: _-_-_-_. (Orgs). A insustentável leveza da política ambiental: desenvolvimento e conflitos socioambientais. Belo Horizonte: Autêntica, 2005. p. 11-24. 


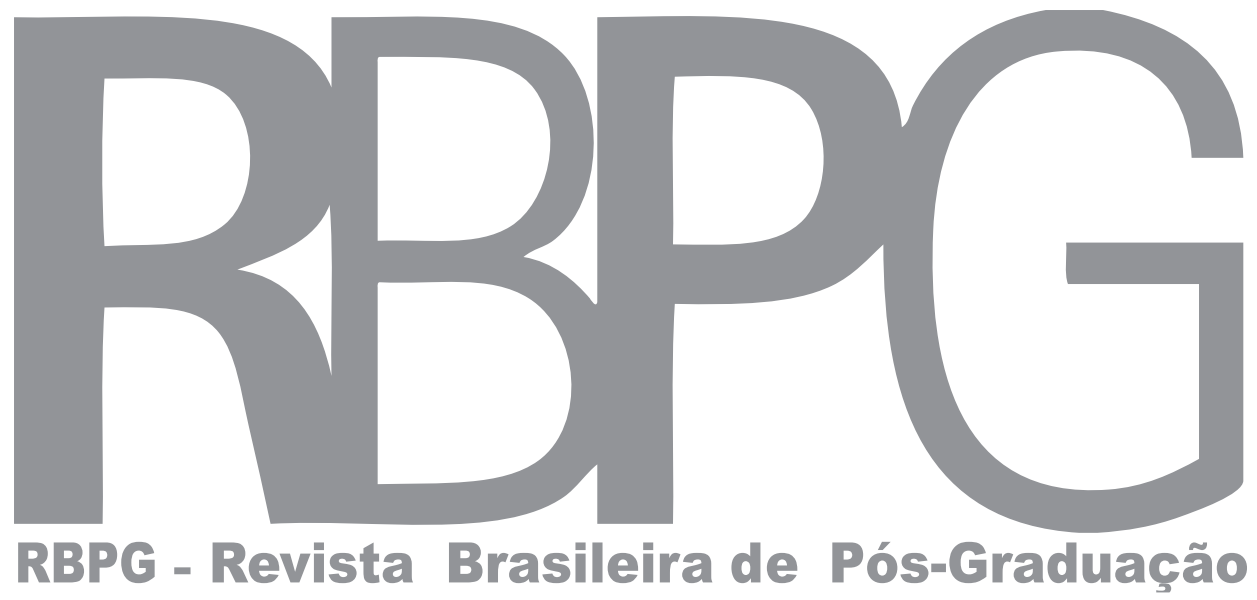




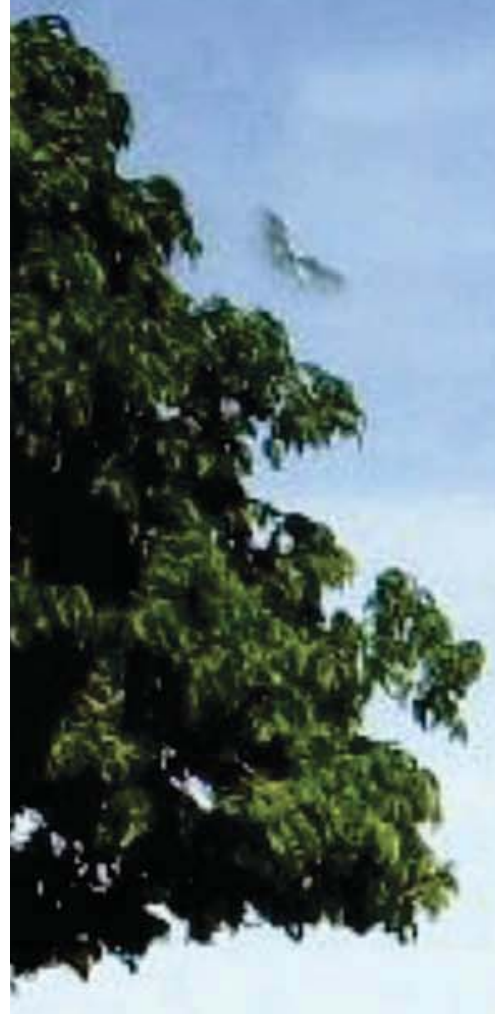




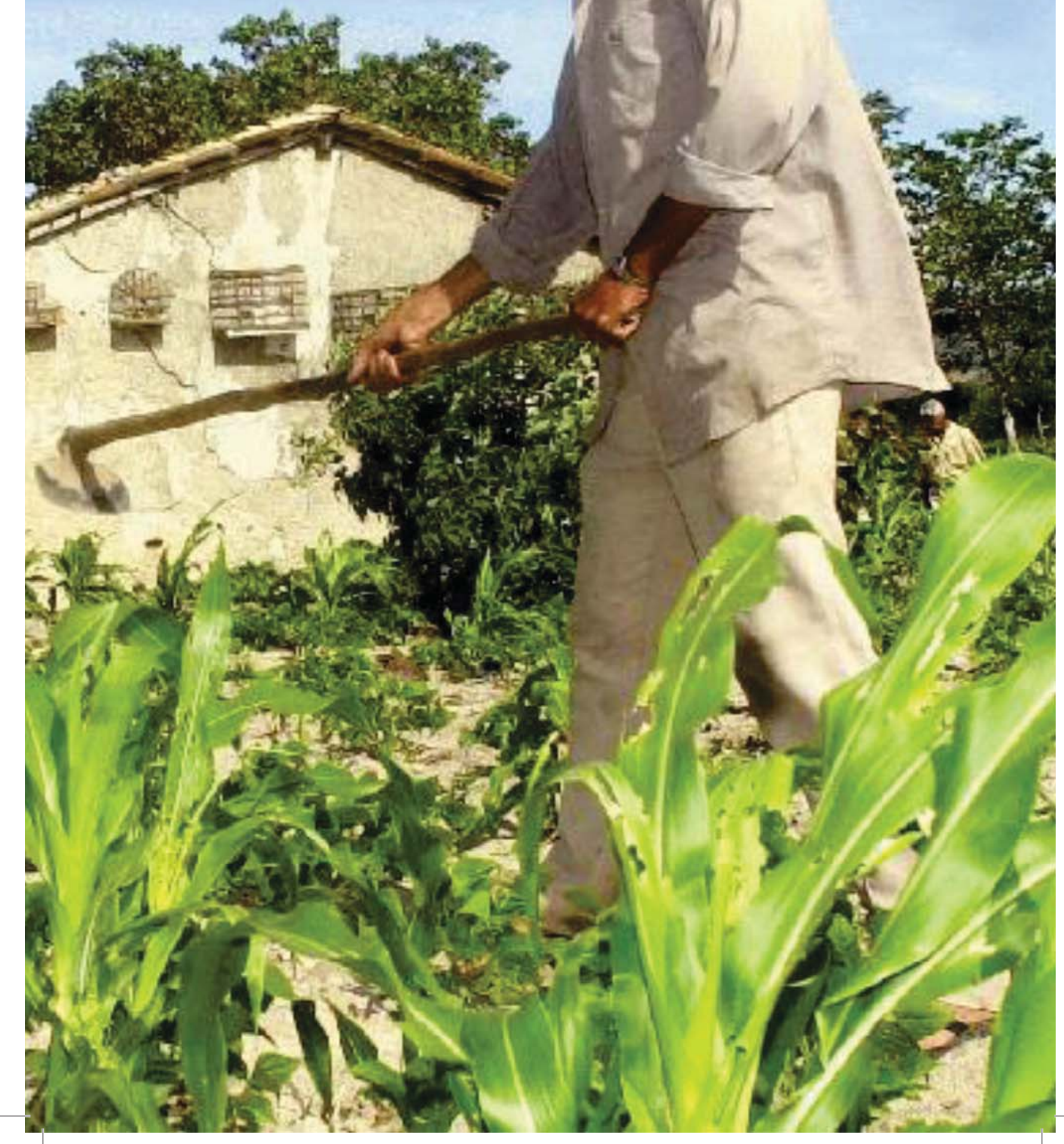




\section{As políticas públicas para a agricultura familiar brasileira em clima semiárido: do combate à convivência}

\section{The public policies for Brazilian family farming in semiarid climate: from drought combat to daily living in such climate}

\section{Las políticas públicas para la agricultura familiar brasileña en clima semiárido: del combate a la convivencia}

Daniel Alves Campelo, mestre em Gestão do Desenvolvimento Local Sustentável pela Faculdade de Ciências da Administração de Pernambuco da Universidade de Pernambuco (FCAP/UPE). Endereço: Rua Major Armando de Souza Melo, 42, apto 702B Boa Viagem. CEP: 51030-180 - Recife, PE. Telefone: (81) 92964261/3301-1355. E-mail: danicampelo@gmail.com.

\section{Resumo}

O trabalho apresenta as políticas públicas direcionadas para as famílias agricultoras, fundamentalmente aquelas que vivem em regiões de clima semiárido, tendo como objetivo geral apresentar as ideologias das políticas públicas de combate à seca, realizadas no início do século XX, comparando-as com as políticas de convivência com o clima semiárido, que trazem uma nova configuração de estratégia para a sustentabilidade do desenvolvimento local. Para tanto, apresentouse a importância das políticas públicas para a pequena agricultura e promoção do desenvolvimento sustentável, tendo como cenário principal o ciclo das secas, no período compreendido entre 1900 e 1970, bem como as mudanças de paradigmas nos modelos de produção da agricultura familiar, desde os modelos convencionais, transitando pelo período que ficou conhecido como revolução verde, até a agroecologia.

Palavras-chave: Políticas Públicas. Agricultura Familiar. Semiárido. 


\section{Abstract}

This work presents the public policies that focus on family agriculture, particularly on that undertaken in the semiarid region. The objective of the article is to analyze the public policy ideologies undergirding the 'battle against the drought' of the early XX century and compare them to the coexistence policies of the semiarid climate that represent a new strategy for local sustainable development. Therefore, the importance of the public policies during the drought cycle between 1900 to 1970 for small-scale agriculture and the promotion of sustainable development are presented. Also discussed are the paradigm changes that occurred in the models of family agriculture production, considering both conventional models and those adopted throughout the period of the so-called green revolution and agroecology.

Keywords: Public Policies. Family Agriculture. Semiarid.

\section{Resumen}

El trabajo presenta las políticas públicas dirigidas a la agricultura familiar, fundamentalmente aquellas que viven en regiones de clima semiárido, con el objetivo general de presentar las ideologías de las políticas públicas de combate a la sequía, celebradas a principios del siglo XX, comparándolas con las políticas de convivencia con el clima semiárido, que traen una nueva configuración de estrategia para la sostenibilidad del desarrollo local. Para ello, se mostró la importancia de las políticas públicas para la agricultura en pequeña escala y la promoción del desarrollo sostenible, teniendo como escenario principal el ciclo de las sequías, en el periodo comprendido entre 1900 y 1970, así como los cambios de paradigmas en los modelos de producción de la agricultura familiar, desde los modelos convencionales, en el periodo que se conoció como la revolución verde, hasta la agroecología.

Palabras clave: Políticas Públicas. Agricultura Familiar. Semiárido. 


\section{Introdução}

Com o intuito de aprofundar a discussão sobre a importância da agricultura familiar, das políticas públicas para a promoção do desenvolvimento sustentável na região semiárida e do acesso a essas políticas por parte dos agricultores familiares, este trabalho visa mostrar a importância da agricultura familiar na produção agrícola nacional, quais são as principais políticas existentes para esses agricultores e a mudança de paradigma nas políticas públicas para os agricultores familiares na região semiárida.

Para tanto, observou-se o papel da agricultura familiar na produção agrícola e do Estado, tendo como fundamento as políticas públicas voltadas para agricultura familiar em regiões de clima semiárido que estejam em acordo com a realidade local, identificando sua importância e a evolução histórica dessas políticas.

Para efetivar o objetivo proposto, em um primeiro momento, apresenta-se a importância da agricultura familiar para a produção agrícola nacional. Em seguida, destaca-se a importância das políticas públicas para a agricultura familiar e apontam-se quais são essas políticas, levando em conta que um dos grandes desafios é identificálas. Após admitir a existência dessas políticas direcionadas para as famílias agricultoras, chama-se a atenção para a relevância delas e também se comenta o acesso por parte das famílias agricultoras.

Em seguida, o trabalho faz uma abordagem histórica dos ciclos da seca e das políticas existentes de combate à seca; por fim, aborda a mudança de paradigma e a transição para a agroecologia, apontando para uma nova ideologia de convivência com o clima semiárido.

Em função dessas transformações conceituais, acreditamos que o resultado deste trabalho se torna relevante ao apresentar para sociedade a importância de sua participação. Pois, considerando a atuação efetiva do Estado com ações específicas para a agricultura familiar, é preciso que a sociedade se aproprie dessas informações e sirva como um catalisador, para que as políticas cheguem efetivamente às famílias agricultoras. 
Nas considerações finais, aborda-se a percepção de que ainda não há uma estratégia que seja um modelo para solucionar o problema da agricultura familiar. Destaca-se, nesse processo, a importância da participação do Estado na promoção do desenvolvimento sustentável da agricultura familiar, por meio de políticas de fomento à população rural, e ainda o fato de que as ideologias, baseadas em estratégias de governo, vão se modificando, buscando atender a complexidade da região semiárida, apresentando uma crescente e sustentada evolução das políticas públicas para a agricultura familiar.

\section{A importância da agricultura familiar e das políticas públicas}

A agricultura familiar tem relevante papel na produção agrícola brasileira. Segundo o Censo Agropecuário 2006 (IBGE, 2006), a agricultura familiar, em algumas culturas, é responsável por mais da metade da produção nacional brasileira, como é o caso da mandioca, com $87 \%$ da produção nacional; do feijão, em que a agricultura familiar é responsável por $70 \%$ da produção nacional; e leite, com 58\% da produção nacional. Merece destaque ainda o milho, com 46\%; e o café, com 38\%. Na pecuária, a agricultura familiar também tem importância significativa. Ainda de acordo com o Censo Agropecuário 2006, a agricultura familiar detém 59\% do plantel de suínos, 50\% do plantel de aves e 30\% dos bovinos.

Para este trabalho consideraram-se as definições de agricultura familiar tal qual o critério adotado em um estudo realizado pela FAO/Incra (2000), que chamou de agricultura familiar basicamente os estabelecimentos em que a direção dos trabalhos era exercida pelos produtores e o trabalho familiar era superior ao contratado. As duas características deveriam ser atendidas simultaneamente.

Dados esses relevantes aspectos, é preciso atenção para a discussão das perspectivas estruturais do Estado, que seria, junto com as grandes empresas, o único promotor do desenvolvimento, apresentando notadamente um fortalecimento da atividade econômica local. Isso garantiria à agricultura familiar ${ }^{1}$ fundamental importância na produção agrícola nacional. Nota-se, nesse breve contexto, a importância do poder público e de sua relação com a sociedade civil (MOURA, 1998).

De acordo com Teixeira (2002), as políticas públicas traduzem a forma de exercer poder político, e, como o poder é uma relação social que envolve vários atores, são necessárias, para que as 
políticas públicas sejam legítimas e eficazes, mediações sociais e institucionais.

Diante da necessidade de promoção e regulação dos aspectos referentes às relações socioeconômicas, para combater o desequilíbrio imposto pelo capitalismo, as políticas públicas devem investir em áreas estratégicas, capazes de promover o desenvolvimento econômico e o bem estar social (TEIXEIRA, 2002).

De acordo com Toledo (2002), com a separação entre o Estado e a economia e, ainda, com a tentativa de despolitizar as relações econômicas e sociais, o liberalismo, movimento social que predominou até a década de 1970, entra em decadência. A partir daí, ganhou espaço o neoliberalismo.

Teixeira (2002, p. 4) observa nesse período a falência do Estado protetor e ainda o agravamento da crise social. O neoliberalismo propõe uma reformulação estrutural nas políticas públicas, a redução dos gastos sociais, pois responsabiliza a política do intervencionismo como principal responsável pelo estagnacionismo. 0 autor afirma sobre as políticas públicas:

\footnotetext{
A globalização torna o processo de formulação de políticas públicas mais complexo, por estarem em jogo, agora, em cada país, interesses internacionais representados por forças sociais com um forte poder de interferência nas decisões quando essas não são diretamente ditadas por organismos multilaterais.
}

A partir daí, dado o elo entre sociedade e Estado, como promotor das políticas públicas, observou-se que o pensamento único neoliberal, reforçado pela necessidade de ajustar as políticas, no final da década de 70, principalmente aquelas criadas pelo esgotamento da fase chamada substituição de importações, atropelou o crescimento com equidade (SANTOS, 2007).

Com o avanço do neoliberalismo no Brasil e no mundo, o socialismo havia sido colocado como uma forma de organização da sociedade cada vez mais sem futuro e perspectiva. Esse cenário 
indicava o avanço da globalização, a partir da lógica da subordinação da agricultura ao capital financeiro e industrial (MOURA, 2011).

Porém, aponta Santos (2007), o início da década de 80 indica um descenso dessa ortodoxia neoliberal. Nesse processo de mudança na relação do Estado com a sociedade, as políticas púbicas voltadas para a agricultura familiar passaram também por diversas transformações conceituais, incluindo, nos dias atuais, a participação da sociedade na formação dessas políticas.

No Brasil, as políticas formuladas para a agricultura familiar foram de ordem agrícola ou agrária. Denardi (2001) destaca que as políticas agrárias foram quase inexistentes no Brasil.

Já as políticas agrícolas foram, de fato, as políticas públicas voltadas para a agricultura, incluindo a produção familiar, nas últimas quatro décadas. Teixeira (2002, p. 10), fundamentado na Lei de Política Agrícola ( $n^{\circ} 8.171$, de 17.01.91), define a política agrícola da seguinte forma:

[...] do ponto de vista formal, define os princípios fundamentais, objetivos e competências institucionais, prevê recursos, estabelece ações e instrumentos. A lei enfatiza a questão econômica (produtividade, incremento à produção, regularidade de abastecimento), enquanto a Constituição tem por referência a função social da propriedade. Equiparar estas duas dimensões, em nossa estrutura agrária, significa uma opção pelo produtivismo e pela tecnificação, independente de seus impactos sociais e ambientais.

São às políticas agrícolas que a agricultura familiar está submetida. De acordo com o Censo Agropecuário 2006 (IBGE, 2006), no Brasil, 84,4\% dos estabelecimentos são familiares, responsáveis por 38\% do Valor Bruto da Produção (VBP). Embora tenham grande participação na produção nacional, esses agricultores familiares ocupam apenas uma área de 80,25 milhões de hectares, ou seja, 24,3\% da área ocupada pelos estabelecimentos agropecuários brasileiros.

Isso reforça a importância da agricultura familiar brasileira e a necessidade de políticas que promovam o desenvolvimento da 
agricultura familiar e a melhoria na qualidade de vida da população rural, sem descartar a importância da preservação do meio ambiente.

No que concerne às políticas agrícolas, apresentam-se alguns avanços, principalmente graças à luta dos trabalhadores rurais. Porém, para realizar a reforma agrária de forma justa e eficiente, ainda persistem obstáculos burocráticos, jurídicos, econômicos, políticos e, inclusive, constitucionais (TEIXEIRA, 2002).

A reforma agrária não deve limitar-se apenas a dar terra para quem não a tem, mas, além disso, a aumentar a propriedade dos agricultores familiares de pequenas propriedades, que, devido à falta de espaço para a gestão da terra, promovem práticas agrícolas que causam impactos negativos no meio ambiente (PÁDUA, 2004).

Outro grande problema, como alerta Teixeira (2002), é que o trabalho escravo ainda é uma realidade; além disso, não há desapropriação de pequenas e médias propriedades para a distribuição de terras. A função social da propriedade é definida muito mais em termos econômicos do que em termos sociais e ambientais, que são tratados de maneira superficial.

Merecem atenção especial essas áreas de pequenas propriedades, cuja produção agrícola é de base familiar e, em grande parte, estão situadas em região de clima semiárido (além das dificuldades já encontradas pela agricultura familiar, ainda encontra no clima um grande opositor).

Sendo o clima um fator fundamental para a produção agrícola, desenvolver a agricultura com alimentos de qualidade, resultando em uma melhora na saúde da população e na expansão da biodiversidade, é um aspecto que deve ser considerado. Diante do cenário apresentado do meio rural e das políticas públicas desenvolvidas, tanto no âmbito nacional, quanto no local, é inegável que é preciso pensar a agricultura familiar em uma perspectiva sustentável.

O desenvolvimento sustentável ${ }^{2}$ na agricultura depende sobremaneira das práticas adotadas pelos agricultores, principalmente,
${ }^{2}$ A definição mais conhecida de desenvolvimento sustentável é a do Relatório de Brundtland, que afirma que, para que haja desenvolvimento sustentável, é preciso atender às necessidades do presente sem comprometer a capacidade das gerações futuras de suprir suas próprias necessidades. 
das práticas utilizadas pelos agricultores familiares, uma vez observada sua importância para a produção nacional. Os altos rendimentos e a lucratividade têm impulsionado a inovação na agricultura nos últimos 40 ou 50 anos, porém uma série de efeitos colaterais ambientalmente negativos tem-se apresentado (GLIESSMAN, 2000).

Ainda de acordo com Gliessman (2000), nos primeiros um ou dois anos de transição, os produtores apresentam uma redução de rendimento e lucro; no entanto, a maioria daqueles que persistem acabam tendo, devido à conversão, benefícios econômicos e ecológicos. Nessa perspectiva, diversos fatores estão encorajando os produtores para a conversão: custo crescente da energia, baixa margem de lucro das práticas convencionais, desenvolvimento de novas práticas como opção viável, aumento da consciência ambiental e novos e mais consistentes mercados cultivados e processados de forma alternativa.

Nessa perspectiva de sustentabilidade na agricultura, segundo Altieri (2012), há cinco pontos que explicam a importância da agricultura familiar para o desenvolvimento sustentável: a pequena produção é a chave para a segurança alimentar mundial, pois terá muito mais impacto na disponibilidade de alimentos em nível local; é mais produtiva, pois conserva mais os recursos naturais do que a monocultura; propriedades diversificadas representam modelo de sustentabilidade; ela representa um santuário de agrobiodiversidade, livre de Organismos Geneticamente Modificados (OGMs); e as pequenas propriedades rurais resfriam o clima (menos emissão de gases de efeito estufa).

Diante dessa preocupação com a promoção de uma agricultura preocupada com os aspectos ambientais, hoje as políticas públicas voltadas para a agricultura familiar em clima semiárido têm como princípio a convivência com o clima semiárido, mas não foi sempre assim. Sobre essa nova concepção de promover política em clima semiárido, trataremos mais adiante. A verdade é que as primeiras políticas promovidas pelo governo federal voltadas para a agricultura familiar eram conhecidas como políticas de combate à seca. 
É nessa relação do Estado com a sociedade e a economia, com tanta desigualdade e discrepantes ideologias políticas, que a agricultura de base familiar se consolidou em áreas de clima semiárido, em condição de pobreza e necessidade de políticas públicas de fomento. Observam-se a seguir as principais políticas públicas voltadas para a agricultura familiar, no período que compreende o início do século passado até os dias atuais.

\section{Os ciclos da seca no semiárido e as políticas de combate à seca}

No Brasil, segundo o Programa das Nações Unidas para o Desenvolvimento (Pnud) ${ }^{3}$, milhões de pessoas enfrentam um problema crônico de falta de água, vivendo no chamado polígono das secas. De acordo com o relatório final do estudo realizado pelo Grupo de Trabalho Interministerial (GTI), divulgado pelo Ministério da Integração Nacional, o semiárido é formado por 1.133 municípios, em uma área total de $969.589,4 \mathrm{~km}^{2}$ (BRASIL, 2005).

Nessa região, de tempos em tempos, as grandes estiagens agravaram as dificuldades já encontradas pela população, deixando-a, principalmente nesse período, mais dependente das intervenções do Estado, sobretudo das políticas que atenuassem a difícil condição imposta pelo clima e que fossem capazes de promover alternativas de emprego e renda para a agricultura familiar.

No período que se estende de 1915 até o início dos anos 2000, a região do polígono das secas enfrentou oito períodos de secas bastante marcantes. Porém, antes desse período, ainda no final do século XIX, as secas passaram a ser vistas como um problema importante para o governo brasileiro. As primeiras ações realizadas com a perspectiva de atenuar o impacto dos períodos secos foram as construções do açude do Cedro, no Ceará, e do açude de Poços, na Paraíba (VILAR FILHO, 2001).

Para Batista Filho (2001 apud CAMPELO; HAMASAKI, 2011), era necessário eliminar a indústria da seca, mas isso só seria
${ }^{3}$ Por definição, o Programa das Nações Unidas para o Desenvolvimento (Pnud) é a rede de desenvolvimento global da Organização das Nações Unidas. O Pnud faz parcerias com pessoas em todas as instâncias da sociedade para ajudar na construção de nações que possam resistir a crises sustentando e conduzindo um crescimento capaz de melhorar a qualidade de vida para todos. 
possível se fossem contornadas as limitações existentes, realizando transformações de ordem social e melhorando a qualidade de vida da população; além disso, era necessário que fosse feita uma reforma agrária que garantisse uma maior proporção de renda produzida na agricultura e pecuária ao produtor rural.

O que se observou, como se apresenta a seguir, é que as políticas públicas acompanharam os ciclos da seca, obedecendo inicialmente à ideologia de combate à seca, remetendo à ideia de transclimação, supondo-se a condição de mudar o clima (VILAR FILHO, 2001).

Ainda para Vilar Filho (2001), em 1908 foi criada a Inspetoria de Obras Contra as Secas (IOCS, que passou a se chamar IFOCS e, depois, DNOCS), primeira instituição cujo objetivo era cuidar das secas do Nordeste. Nesse período, o Nordeste sofreu a seca isolada de 1915, que ficou conhecida no Sertão do Cariri, na Paraíba, como "fome de 15", pois a seca agravara os problemas encontrados nos anos de 1913 e 1914, quando toda a lavoura temporária foi perdida devido ao excesso de água que atingiu a região naquele período.

A IOCS sofreu com a escassez de verbas nos seus 10 anos de existência, o que impedia o plano de ações daquele órgão. Essa situação motivou a apresentação de uma proposta para a criação de um fundo de irrigação para financiar obras no Nordeste (SILVA, 2006).

Já sob a denominação de Inspetoria Federal de Obras Contra as Secas (IFOCS, denominação alterada por meio do Decreto $n^{\circ} 13.687$, de 1919), a seca, mais uma vez, castigava o Nordeste, dessa vez no ano de 1919. A instituição, que até então nada fizera, foi ativada (VILAR FILHO, 2001).

Vilar Filho (2001) ainda destaca a seca de 42/43. Ela motivou, em 1949, pelo DNOCS, a criação do fundo especial das secas, que reservava 3\% da renda tributária da União para a realização de obras no semiárido. Sobre a utilização do fundo, que apresentava novas prioridades, Silva (2006, p. 52) afirma: “[...] deveria destinar um quinto da verba para socorro às populações atingidas pela seca lobras de 
emergência e serviços de assistência) e o restante para empréstimo aos produtores rurais”.

Em 1958, ano da segunda grande seca dos anos 1950 (a primeira foi em 1952), foi criado o Grupo de Trabalho para o Desenvolvimento do Nordeste (GTDN), responsável por diagnosticar a realidade e propor políticas públicas (SILVA, 2006). De acordo com Campelo e Hamasaki (2011), até1959 o DNOCS era o principal órgão governamental a executar obras, principalmente de infraestrutura. A criação da Superintendência de Desenvolvimento do Nordeste (Sudene), responsável pelo desenvolvimento regional e por seu planejamento, nos seus primeiros dias, fez surgir uma forte divergência com o DNOCS, causando prejuízos entre as instituições e o Nordeste. Campelo e Hamasaki (2011, p. 16) ainda destacam:

\begin{abstract}
Foram feitas diversas críticas ao modelo a partir dos anos 70 devido ao paternalismo e à inadequação da escolha da clientela a que se destinavam os perímetros irrigados. Porém o cenário criado não teve suas origens no Departamento, e sim, no Grupo Executivo de Irrigação e Desenvolvimento Agrário (GEIDA) criado em 1968 pelo Ministério do Interior, e era responsável pela formulação das políticas. A SUDENE ficava responsável pela supervisão e coordenação e a SUVALE (hoje CODEVASF), DNOCS e DNOS, pela execução, operação e manutenção dos projetos.
\end{abstract}

Nesse período, difundida internacionalmente, a revolução verde ${ }^{4}$ acabou substituindo, por meio de um pacote tecnológico, as formas tradicionais e locais de agricultura. Embora pregasse um aumento do nível de produção e renda por unidade de área e capital empregado, havia grande discussão sobre o futuro da agricultura brasileira, dados os resultados sociais e, sobretudo, ambientais (PÁDUA, 2004).

Em 1970, ano da seca isolada, que também fez parte do ciclo da seca, a Sudene enfraqueceu-se quando passou a ser subordinada ao Ministério do Planejamento, deixando de fazer planos trienais de desenvolvimento. Nesse período, foi criado o PIN/Proterra, que exauriu ainda mais a Sudene (BATISTA FILHO, 2001 apud CAMPELO; HAMASAKI, 2011).

\footnotetext{
${ }^{4}$ Neste trabalho, entendese revolução verde conforme definição de Campelo e Hamasaki (2011), como sendo políticas agrícolas voltadas ao crescimento da produção agrícola, utilizando o melhoramento genético de sementes, uso de fertilizantes e agrotóxicos e a mecanização.
} 
Mas, antes disso, a partir de 1964, já visando essa modernização agrícola, os gestores de políticas públicas procuraram criar uma nova estrutura institucional para a política agrícola brasileira. Nessa perspectiva, destacam-se: o Sistema Nacional de Crédito Rural (SNCR), que proporcionava aos agricultores linhas de crédito acessiveis e baratas, sendo a principal linha de crédito entre as décadas de 70 e 80; as Políticas de Garantia de Preço Mínimo (PGPM), que garantiam um preço mínimo de venda para os produtores e eram realizadas por meio do programa Aquisição do Governo Federal (AGF) e Empréstimo do Governo Federal (EGF). O primeiro eram compras feitas pelo governo federal de produtos com preço prefixados e o segundo era uma linha de crédito especial de comercialização, que tinha o propósito de financiar a estocagem (GREMAUD; VASCONCELLOS; TONETO JÚNIOR, 2009).

Ao longo dos anos 70 e 80, diversos programas e projetos de governo foram implantados com foco na agricultura familiar e no ambiente semiárido. $O$ que se percebe é que, na medida em que os anos avançavam, mudavam-se também os objetivos e as características dos programas e projetos. 0 Quadro 1 apresenta 12 programas e projetos que foram lançados pelo governo federal, a partir da década de 70.

\section{Quadro 1. Programas especiais de desenvolvimento com incidência no semiárido (anos 1970 e 1980)}

\begin{tabular}{|c|c|c|}
\hline Ano & Programa/Projeto & Objetivo e características \\
\hline 1971 & PIN/Proterra & $\begin{array}{l}\text { Promover a colonização na Amazônia e no } \\
\text { Nordeste }\end{array}$ \\
\hline 1971 & Provale & Incentivo à irrigação no Vale do São Francisco \\
\hline 1974 & Polonordeste & $\begin{array}{l}\text { Apoiar polos de desenvolvimento integrado } \\
\text { no Nordeste }\end{array}$ \\
\hline 1974 & Pdan & $\begin{array}{l}\text { Programa ligado ao Polonordeste com o } \\
\text { objetivo de desenvolver a agroindústria no } \\
\text { Nordeste }\end{array}$ \\
\hline 1976 & Projeto Sertanejo & $\begin{array}{l}\text { Apoiar pequenos e médios produtores rurais } \\
\text { no Nordeste }\end{array}$ \\
\hline 1979 & Prohidro & $\begin{array}{l}\text { Fornecer água para atividades agrícolas } \\
\text { irrigadas }\end{array}$ \\
\hline 1981 & Provárzeas & $\begin{array}{l}\text { Apoiar a produção de alimentos básicos em } \\
\text { áreas de várzeas }\end{array}$ \\
\hline
\end{tabular}




\begin{tabular}{|c|c|c|}
\hline Ano & Programa/Projeto & Objetivo e características \\
\hline 1983 & Projeto Nordeste & $\begin{array}{l}\text { Reestruturar e integrar os projetos de } \\
\text { desenvolvimento do Nordeste }\end{array}$ \\
\hline 1983 & Papp & $\begin{array}{l}\text { Apoiar o pequeno produtor rural por meio } \\
\text { de infraestrutura, irrigação, crédito rural, } \\
\text { comercialização, assistência técnica e } \\
\text { extensão, pesquisa e acesso à terra }\end{array}$ \\
\hline 1986 & Projeto São Vicente & $\begin{array}{l}\text { Oferecer suporte técnico e financeiro a } \\
\text { pequenos produtores rurais nordestinos }\end{array}$ \\
\hline 1986 & Proine & Promover a irrigação no Nordeste \\
\hline 1988 & Projeto Padre Cícero & $\begin{array}{l}\text { Ampliar o número de reservatórios de água } \\
\text { no interior do Nordeste, incentivando a } \\
\text { convivência com a seca }\end{array}$ \\
\hline
\end{tabular}

Fonte: Andrade (1984 apud SILVA 2006); BURSZTYN (1985 apud SILVA 2006); CARVALHO (1988 apud SILVA 2006); VILLA (2000 apud SILVA 2006).

Segundo Campelo e Hamasaki (2011), no final dos anos 70, as principais políticas de combate à seca esgotaram-se com o fim da revolução verde. Embora na agricultura ainda existam práticas acentuadas de um modelo produtivista brutal, como o uso de agrotóxicos, sementes modificadas e fertilizantes químicos, a revolução verde, como um paradigma ideológico, sustentado pelas políticas públicas voltadas para a agricultura familiar, que implantava esses pacotes tecnológicos, está praticamente extinta. A partir daí, é importante observar mais atentamente as políticas públicas mais atuais de convivência com o semiárido, que acompanharam a transição dos métodos convencionais de produção para a agroecologia.

Nas linhas seguintes, tenta-se resgatar os principais fatores que marcaram a transformação da agricultura familiar, observando paralelamente as políticas públicas de convivência com o semiárido, entendendo a relação dessas políticas com a mudança das antigas práticas convencionais de produção para a agroecologia.

\section{A transformação da agricultura familiar e as políticas de convivência com o semiárido}

Na metade do século $X X$, houve um aumento significativo da população urbana do Brasil. Assim, o País sofreu um processo de 
“desruralização”. No contexto histórico do País, nesse período, houve um crescimento, além da população urbana, da industrialização, o que supõe uma estrutura agrária concentrada e desigual (PÁDUA, 2004).

A transformação da agricultura familiar, aliada a uma nova perspectiva de desenvolvimento rural, tomou força a partir da década de 70. Foi nas três últimas décadas antes do século XX que se podem perceber as grandes mudanças na agricultura familiar e, consequentemente, nas políticas públicas direcionadas para essa atividade.

De acordo com Jalfim (2011), a lógica do desenvolvimento preconizado pelo Estado, baseada no combate à seca, perdurou por centenas de anos. Mais do que a lógica equivocada sobre a ecologia, trazia no seu bojo uma perversa forma de dominação social e política das oligarquias. Ainda de acordo com o autor (Ibidem, p. 72):

Essa dominação era alicerçada na dependência socioeconômica das famílias agricultoras através do tripé: concentração fundiária; precário acesso à água, notadamente relacionado à solução hidráulica, que não atendiam à demanda difusa por água; e políticas públicas clientelistas, simbolizadas pelo uso do caminhão-pipa.

Assim, a agroecologia surgia como um novo paradigma na agricultura familiar. Muito embora o agronegócio estivesse fortemente presente na agricultura familiar, a agroecologia provocava uma verdadeira mudança na agricultura de base familiar, assim como afirma Pádua (2004, p. 212):

Para implementar este paradigma, que tem sido chamado de agroecologia, a agricultura familiar vem sendo revalorizada e reconhecida por muitos especialistas como um espaço privilegiado. Essa aposta é, em primeiro lugar, conceitual. A ideia básica é de que a agroecologia não pode ser implementada a partir de pacotes tecnológicos, requerendo, ao contrário, um tratamento específico no contexto de cada propriedade.

Sobre este novo modelo, Diniz e Piraux (2011) afirmam que é justamente a partir dos anos de 1970 que começa o movimento de modernização agrícola em grande escala, dirigido especialmente pelo 
Estado. Isso reforça sobremaneiraqueo Estado não sóacompanhouessa transformação; foi muito além. Ele foi responsável pelo fortalecimento da agricultura familiar e estimulador do desenvolvimento rural.

Para Jalfim (2011), uma convergência entre iniciativas nacionais, a partir da década de 80, como o Projeto de Tecnologias Alternativas (PTA), tentava romper com o modelo de combate à seca, dando início a uma longa caminhada capaz de substituir a velha política por um modelo que integrasse as dimensões ecológicas, técnicas, culturais e socioeconômicas.

Nessa perspectiva, a Articulação no Semiárido Brasileiro (ASA) desenvolveu algumas tecnologias sociais ${ }^{5}$ que são simples, baratas e de domínio de agricultores e agricultoras. Inicialmente, em 2003, a ASA implantou o Programa Um Milhão de Cisternas (P1MC), cujo objetivo era beneficiar cerca de cinco milhões de pessoas em toda a região semiárida com água potável para beber e cozinhar, por meio das cisternas de placas. Hoje, a ASA conta com mais sete tecnologias sociais, por meio do Programa Uma Terra e Duas Águas (P1+2), desenvolvidas especialmente para captar água para a produção de alimentos: cisterna-calçadão, cisterna-enxurrada, barragem subterrânea, barreiro trincheira, barraginha, tanque de pedra e bomba d'água popular (ASA, 2013).

Quanto às políticas públicas voltadas para a agricultura familiar em clima semiárido, Campelo e Hamasaki $(2011$, p. 3) afirmam:

[...] devido a grandes períodos de estiagens e seca, aumentam as dificuldades de produção. Para o agricultor familiar poder produzir nessa região, é necessária uma política pública de fomento, seja por parte do governo, seja por parte de uma ONG (Organização NãoGovernamental), ou seja, é preciso colocar em prática uma Assessoria Técnica Permanente, de ação contínua e holística, focada na demanda, objetivo e interesse das famílias; e ainda, apoiar a agricultura familiar para promoção da segurança hídrica e alimentar; apoiar a produção e comercialização; possibilitar aos agricultores familiares acesso aos mercados locais, institucionais, justo e orgânico, como meio de agregar valor à produção e aumentar a renda dos agricultores familiares.

\footnotetext{
5 Segundo a Rede de Tecnologias Sociais (RTS), do Ministério da Ciência, Tecnologia e Inovação, a tecnologia social é o conjunto de atividades relacionadas a estudos, planejamento, ensino, pesquisa, extensão e desenvolvimento de produtos, técnicas ou metodologias reaplicáveis, que representem soluções para o desenvolvimento social e melhoria das condições de vida da população.
} 
É nessa perspectiva que se destacam as principais políticas públicas atuais, do governo federal, de apoio à agricultura familiar, alicerçadas na ideologia de convivência com o clima semiárido. Incialmente, pode-se destacar a Política de Assistência Técnica e Extensão Rural para a Agricultura Familiar e Reforma Agrária (Pnater).

Dadas as carências particulares da agricultura familiar, a Pnater, instituída com a Lei n 12.188, de 11 de janeiro de 2010, veio valorizara lógica de produção e reprodução social, suas dinâmicas e experiências, conforme seus objetivos, principalmente aqueles intrinsecamente relacionados com um modelo de agricultura sustentável (BRITO, 2011).

Ainda para Brito (2011 apud BRASIL 2010, p. 23), sobre os investimentos voltados para a agricultura familiar:

[...] as iniciativas são melhor traduzidas em números quando se verifica que, de 2003 a 2009, o investimento em Assistência Técnica e Extensão Rural (ATER) para a AF subiu de $\mathrm{R} \$ 46$ milhões para $\mathrm{R} \$ 428$ milhões ao ano, que, somados com o apoio aos assentados da reforma agrária, o valor chega a $\mathrm{R} \$ 626$ milhões só na safra 2009/2010, com um total de 24 mil técnicos).

Além da Pnater, merece grande destaque o Programa Nacional de Fortalecimento da Agricultura Familiar (Pronaf). Esse programa oferece diversas linhas de crédito para o agricultor familiar. Segundo a Secretaria da Agricultura Familiar (BRASIL, 2012):

O Programa Nacional de Fortalecimento da Agricultura Familiar (Pronaf) financia projetos individuais ou coletivos, que gerem renda aos agricultores familiares e assentados da reforma agrária. O programa possui as mais baixas taxas de juros dos financiamentos rurais, além das menores taxas de inadimplência entre os sistemas de crédito do País.

Os agentes financeiros que operam o Pronaf compõem o Sistema Nacional de Crédito Rural (SNCR), que, conforme apresentado anteriormente, era principal linha de crédito nas décadas de 70 e 80, e são agrupados em básicos (Banco do Brasil, Banco do Nordeste e Banco da Amazônia) e vinculados (BNDES, Bancoob, Bansicredi e associados à Febraban). 
De acordo com Denardi (2001), o Pronaf proporcionou uma política pública diferenciada para a agricultura familiar. No entanto, o Pronaf é um campo de disputa de duas forças. De um lado, o Ministério do Desenvolvimento Agrário, que vê o programa como uma efetiva política de desenvolvimento rural; do outro, os ministérios da Fazenda e da Agricultura, Pecuária e Abastecimento, que veem o Pronaf apenas como uma política social compensatória.

Segundo o Instituto de Pesquisa Econômica Aplicada (IPEA, 2012), houve um grande avanço no montante de crédito aplicado pelo Pronaf, beneficiando diretamente a agricultura familiar. No ano agrícola de 1998/1999, houve um montante de crédito rural na ordem de R\$ 1.263.133.634,16, realizados por meio de 174.286 contratos. Passados 12 anos, no ano agrícola de 2010/2011, o montante aplicado foi $809,2 \%$ superior, quando comparado com o ano agrícola de 1998/1999, atingindo um montante de $\mathrm{R} \$ 11.484 .067 .137,86$.

De acordo com o Ministério do Desenvolvimento Agrário (BRASIL, 2013), o valor destinado ao crédito rural é recorde. Segundo o Plano Safra, apresentado pelo MDA para o ano agrícola de 2012/2013, os agricultores e as agricultoras terão à disposição $\mathrm{R} \$ 18$ bilhões para as linhas de custeio, investimento e comercialização do Pronaf.

Nesse sentido, o que tem se visto é um aumento crescente do acesso ao crédito, porém, o reflexo disso de forma qualitativa ainda é muito baixo. Para atender a esse aumento e facilitar o acesso ao crédito, o Pronaf trabalha com algumas linhas de créditos divididas por categorias, conforme se apresenta a seguir:

\section{Quadro 2. Linhas de crédito do Pronaf}

\begin{tabular}{|l|l|}
\hline Linhas de Crédito & Descrição \\
\hline Custeio & $\begin{array}{l}\text { Destina-se ao financiamento das atividades } \\
\text { agropecuárias e de beneficiamento ou industrialização } \\
\text { e comercialização de produção própria ou de terceiros } \\
\text { agricultores familiares enquadrados no Pronaf. }\end{array}$ \\
\hline Investimento & $\begin{array}{l}\text { Destinado ao financiamento da implantação, ampliação } \\
\text { ou modernização da infraestrutura de produção e } \\
\text { serviços, agropecuários ou não agropecuários, no } \\
\text { estabelecimento rural ou em áreas comunitárias rurais } \\
\text { próximas. }\end{array}$ \\
\hline
\end{tabular}




\begin{tabular}{|c|c|}
\hline Linhas de Crédito & Descrição \\
\hline $\begin{array}{l}\text { Pronaf } \\
\text { Agroindústria }\end{array}$ & $\begin{array}{l}\text { Linha para o financiamento de investimentos, inclusive } \\
\text { em infraestrutura, que visam o beneficiamento, o } \\
\text { processamento e a comercialização da produção } \\
\text { agropecuária e não agropecuária de produtos florestais } \\
\text { e do extrativismo ou de produtos artesanais, além da } \\
\text { exploração de turismo rural. }\end{array}$ \\
\hline $\begin{array}{l}\text { Pronaf } \\
\text { Agroecologia }\end{array}$ & $\begin{array}{l}\text { Linha para o financiamento de investimentos dos } \\
\text { sistemas de produção agroecológicos ou orgânicos, } \\
\text { incluindo-se os custos relativos à implantação e } \\
\text { manutenção do empreendimento. }\end{array}$ \\
\hline Pronaf Eco & $\begin{array}{l}\text { Linha para o financiamento de investimentos em } \\
\text { técnicas que minimizem o impacto da atividade rural } \\
\text { no meio ambiente, bem como permitam ao agricultor } \\
\text { melhor convivio com o bioma em que sua propriedade } \\
\text { está inserida. }\end{array}$ \\
\hline Pronaf Floresta & $\begin{array}{l}\text { Financiamento de investimentos em projetos para } \\
\text { sistemas agroflorestais; exploração extrativista } \\
\text { ecologicamente sustentável; plano de manejo florestal; } \\
\text { recomposição e manutenção de áreas de preservação } \\
\text { permanente; e reserva legal e recuperação de áreas } \\
\text { degradadas. }\end{array}$ \\
\hline Pronaf Semiárido & $\begin{array}{l}\text { Linha para o financiamento de investimentos em } \\
\text { projetos de convivência com o semiárido, focados } \\
\text { na sustentabilidade dos agroecossistemas, } \\
\text { priorizando infraestrutura hídrica e implantação, } \\
\text { ampliação, recuperação ou modernização das demais } \\
\text { infraestruturas, inclusive daquelas relacionadas com } \\
\text { projetos de produção e serviços agropecuários e não } \\
\text { agropecuários, de acordo com a realidade das famílias } \\
\text { agricultoras da região semiárida. }\end{array}$ \\
\hline Pronaf Mulher & $\begin{array}{l}\text { Linha para o financiamento de investimentos de } \\
\text { propostas de crédito da mulher agricultora. }\end{array}$ \\
\hline Pronaf Jovem & $\begin{array}{l}\text { Financiamento de investimentos de propostas de } \\
\text { crédito de jovens agricultores e agricultoras. }\end{array}$ \\
\hline $\begin{array}{l}\text { Pronaf Custeio e } \\
\text { Comercialização } \\
\text { de Agroindústrias } \\
\text { Familiares }\end{array}$ & $\begin{array}{l}\text { Destinada aos agricultores e suas cooperativas ou } \\
\text { associações para que financiem as necessidades de } \\
\text { custeio do beneficiamento e da industrialização da } \\
\text { produção própria e/ou de terceiros. }\end{array}$ \\
\hline $\begin{array}{l}\text { Pronaf Cota- } \\
\text { Parte }\end{array}$ & $\begin{array}{l}\text { Financiamento de investimentos para a integralização } \\
\text { de cotas-partes dos agricultores familiares filiados } \\
\text { a cooperativas de produção ou para a aplicação em } \\
\text { capital de giro, custeio ou investimento. }\end{array}$ \\
\hline
\end{tabular}




\begin{tabular}{|l|l|}
\hline Linhas de Crédito & Descrição \\
\hline Microcrédito & $\begin{array}{l}\text { Destinado aos agricultores de mais baixa renda, } \\
\text { permite o financiamento das atividades agropecuárias } \\
\text { e não agropecuárias, podendo os créditos cobrir } \\
\text { qualquer demanda que possa gerar renda para a } \\
\text { família atendida. Crédito para agricultores familiares } \\
\text { enquadrados no Grupo B e agricultoras integrantes } \\
\text { das unidades familiares de produção enquadradas nos } \\
\text { Grupos A ou A/C. }\end{array}$ \\
\hline $\begin{array}{l}\text { Pronaf Mais } \\
\text { Alimentos }\end{array}$ & $\begin{array}{l}\text { Financiamento de propostas ou projetos de } \\
\text { investimento para a produção associados a açafrão, } \\
\text { arroz, café, centeio, feijão, mandioca, milho, sorgo, } \\
\text { trigo, erva-mate, apicultura, aquicultura, avicultura, } \\
\text { bovinocultura de corte, bovinocultura de leite, } \\
\text { caprinocultura, fruticultura, olericultura, ovinocultura, } \\
\text { pesca e suinocultura. }\end{array}$ \\
\hline
\end{tabular}

Fonte: Secretaria da Agricultura Familiar (BRASIL, 2012).

Ao longo das últimas três décadas, houve um crescimento sustentado por meio da contratação de créditos do Pronaf. Esse crescimento foi percebido não apenas pelo volume de recursos contratados, como também pelo número de beneficiários que acessaram o crédito. De acordo com a própria Secretaria da Agricultura Familiar, em 1999/2000, o Pronaf abrangia 3.403 municípios, passando para 5.379 em 2007/2008, um crescimento de 58\% em relação a 1999/2000.

Além da Pnater e do Pronaf, destaca-se também o Programa de Aquisição de Alimentos (PAA), outra grande política pública direcionada para a agricultura familiar, cuja ideologia está alicerçada na estratégia de convivência com o semiárido.

Segundo a Secretaria de Agricultura Familiar, o PAA foi criado em 2003 e seu objetivo principal é colaborar com o enfrentamento da fome e da pobreza no Brasil; ao mesmo tempo, fortalecer a agricultura familiar. Para tanto, o governo federal utiliza mecanismos que favorecem a aquisição direta de produtos de agricultores familiares ou de suas organizações, estimulando os processos de agregação de valor à produção. 
De acordo com o Ministério do Desenvolvimento Agrário (BRASIL, 2010), de 2003 a 2009, o PAA beneficiou 764 mil famílias de agricultores, gerando uma renda média anual, por família, de $\mathrm{R} \$ 3,9$ mil. Nesse período, as compras do PAA totalizaram um montante de $\mathrm{R} \$ 2,7$ bilhões. Para tanto, foram adquiridos 2,5 milhões de toneladas de alimentos, beneficiando 7,5 milhões de consumidores por ano.

O PAA vai muito além do que simplesmente viabilizar a comercialização dos alimentos. O programa representa uma garantia de mercado para a agricultura familiar, e, nesse contexto, o governo federal apresenta duas importantes preocupações: enfrentar o problema social e promover a inclusão social no meio rural, fortalecendo a principal atividade econômica.

Para ir além da ponte entre a produção e o combate à fome, o governo federal realiza a aquisição de alimentos, conforme as modalidades apresentadas no Quadro 3:

\section{Quadro 3. Modalidade dos PAA}

\begin{tabular}{|l|l|}
\hline Modalidade & Ação \\
\hline $\begin{array}{l}\text { Compra direta da } \\
\text { agricultura familiar }\end{array}$ & $\begin{array}{l}\text { Voltada à aquisição de produtos em situação de baixa } \\
\text { de preço ou em função da necessidade de atender às } \\
\text { demandas de alimentos de populações em condições } \\
\text { de insegurança alimentar. }\end{array}$ \\
\hline $\begin{array}{l}\text { Apoio à formação } \\
\text { de estoques pela } \\
\text { agricultura familiar }\end{array}$ & $\begin{array}{l}\text { Disponibiliza recursos para que as organizações da } \\
\text { agricultura familiar somem estoques de produtos } \\
\text { para posterior comercialização, em melhores } \\
\text { condições de mercado. }\end{array}$ \\
\hline $\begin{array}{l}\text { Compra com } \\
\text { doação simultânea } \\
\text { ou compra direta } \\
\text { local }\end{array}$ & $\begin{array}{l}\text { Responsável pela doação de produtos adquiridos } \\
\text { da agricultura familiar a pessoas em situação de } \\
\text { insegurança alimentar e nutricional. }\end{array}$ \\
\hline PAA Leite & $\begin{array}{l}\text { Assegura a distribuição gratuita de leite em ações } \\
\text { de combate à fome e à desnutrição de cidadãos que } \\
\text { estejam em situação de vulnerabilidade social ou } \\
\text { em estado de insegurança alimentar e nutricional. } \\
\text { Atende aos estados do Nordeste. }\end{array}$ \\
\hline
\end{tabular}

Fonte: Ministério do Desenvolvimento Agrário (BRASIL, 2010). Modificado pelo autor. 
O governo federal apresenta ainda outros programas voltados para a agricultura familiar, como o Programa Nacional do Biodiesel, que incentiva as unidades produtoras de biodiesel. No ano de 2008, a indústria comprou $\mathrm{R} \$ 230$ milhões em oleaginosas da agricultura familiar, passando para $\mathrm{R} \$ 600$ milhões em 2009 (BRASIL, 2010).

Outro importante programa é o Seguro da Agricultura Familiar (Seaf), que, segundo o Ministério do Desenvolvimento Agrário (BRASIL, 2010), amparou 500 mil famílias. O seguro é ativado toda vez que houver perda maior que $30 \%$ da lavoura ou a receita for menor do que $70 \%$ da receita esperada.

Todos esses programas realizados pelo governo federal ratificam a força da agricultura familiar e a importância de atender às demandas desses produtores. A transformação da agricultura e sua modernização requereram dos gestores políticas públicas mais dinâmicas que atendessem às diferentes necessidades sazonais e regionais.

\section{Considerações finais}

Todas essas políticas acompanharam a transformação da agricultura familiar no Brasil. Percebe-se que ainda não há uma estratégia que seja um modelo para solucionar o problema da agricultura familiar. $\mathrm{O}$ que se tem é que as políticas continuam acompanhando as mudanças e as diferentes demandas da agricultura familiar; além disso, estão consoante as demais políticas sociais, fundamentalmente de combate à pobreza extrema e à dinâmica da economia nacional.

Assim, a participação do Estado na promoção do desenvolvimento sustentável da agricultura familiar, por meio de políticas de fomento à população rural, mostra-se essencial. Não há como pensar no desenvolvimento da agricultura familiar sem a intervenção do Estado, tendo em vista toda a carência da região e os limites impostos pelo clima. 
Do combate à seca à convivência com o clima semiárido, mostra que as ideologias, baseadas em estratégias de governo, vão se modificando, buscando atender à complexidade da região semiárida, às necessidades dos agricultores familiares e à própria burocracia das políticas públicas. Porém, o que se vê é uma crescente e sustentada evolução das políticas públicas para a agricultura familiar.

Recebido 01/10/2012

Aprovado 25/07/2013

\section{Referências bibliográficas}

ALTIERI, M. Agroecologia: bases científicas para uma agricultura sustentável. 3. ed. Ver. ampl. São Paulo, Rio de Janeiro: Expressão Popular, AS-PTA, 2012.

ASA - Articulação no Semiárido Brasileiro. Tecnologias Sociais. Disponivel em: <http://www.asabrasil.org.br/Portal/Informacoes. asp?COD_MENU=1151>. Acesso em: 03 jun. 2013.

BRASIL. Ministério da Integração Nacional. Relatório Final do Grupo de Trabalho Interministerial para delimitação do semi-árido nordestino e do Polígono das Secas. Brasília: 2005. Disponível em: <http://www. cpatsa.embrapa.br/public_eletronica/downloads/OPB1839.pdf>. Acesso em: 03 jun. 2013.

Ministério do Desenvolvimento Agrário. Um novo Brasil rural. Brasília, DF: 2010. Disponivel em: <http://portal.mda.gov.br/portal/ publicacoes/download_orig_file?pageflip_id=4405346>. Acesso em: 03 jun. 2013.

Secretaria de Agricultura Familiar. Crédito Rural. Disponível em < http:/ / www.mda.gov.br/portal/saf/programas/pronaf>. Acesso em: 25 jul. 2012. 
em: <http://www.mda.gov.br/plano-safra/xowiki/recursos>. Acesso em: 04 jun. 2013.

BRITO, J. A. G. de. Agricultura familiar e sustentável: um estudo de caso da Associação Vanguarda, do Município de Cabo de Santo Agostinho. 2011. Dissertação (Mestrado em Gestão do Desenvolvimento Local Sustentável)-Faculdade de Ciências da Administração de Pernambuco, Universidade de Pernambuco, Recife.

CAMPELO, D. A.; HAMASAKI, C.S. Políticas públicas e ações sustentáveis no semiárido pernambucano: fortalecimento da pequena agricultura familiar. Revista da Ciência da Administração, v. 4, p. 1-34, dez. 2011.

DENARDI, R. A. Agricultura familiar e políticas públicas: alguns dilemas e desafios para o desenvolvimento rural sustentável. Agroecologia e Desenvolvimento Rural Sustentável, Porto Alegre, v. 2, n. 3, jul./set. 2001.

DINIZ, P. C. O.; PIRAUX, M. Agroecologia e convivência com semiárido: breves notas de uma longa trajetória de diálogos e interfaces. In: LIMA, J. R. T. de (Org.). Agroecologia e Movimentos Sociais. Recife: Editora Bagaço, 2011.

FAO/INCRA. Novo Retrato da Agricultura Familiar - O Brasil Redescoberto. Brasília: Projeto de Cooperação Técnica, 2000.

GLIESSMAN, S. R. Agroecologia: processos ecológicos em agricultura sustentável. Porto Alegre: Ed. Universidade/UFRGS, 2000.

GREMAUD, A. P.; VASCONCELLOS, M. A. S.; TONETO JÚNIOR, R. Economia Brasileira Contemporânea. São Paulo: Atlas, 2009.

IBGE-Instituto Brasileiro de Geografia e Estatística. Censo Agropecuário 2006. ISSN 0103-6157. Rio de Janeiro: IBGE, 2006.

IPEA - Instituto de Pesquisa Econômica Aplicada. Políticas sociais: acompanhamento e análise. 20. ed. Brasília: Ipea, 2012. 
JALFIM, F. Notas sobre a caminhada da agroecologia no semiárido pernambucano. In: LIMA, J. R. T. de (Org.). Agroecologia e Movimentos Sociais. Recife: Editora Bagaço, 2011.

MOURA, A. Contribuições do SERTA para a Agroecologia no Estado de Pernambuco. In: LIMA, J. R. T. de (Org.). Agroecologia e Movimentos Sociais. Recife: Editora Bagaço, 2011.

MOURA, S. A gestão do desenvolvimento local: estratégias e possibilidades de financiamento. Organizações \& Sociedade, Salvador, v. 5, n. 12, maio/ago. 1998.

PÁDUA, J. A. Agricultura Sustentável. In: CAMARGO, A.; CAPOBIANCO, J. P. R.; OLIVEIRA, J. A. P. de. (Orgs.). Meio ambiente Brasil: avanços e obstáculos pós Rio-92. 2. ed. São Paulo: FGV, Instituto Socioambiental e Estação Liberdade, 2004. p. 200-219. Parte II.

SANTOS, T. dos. Em busca de uma nova aliança política para o desenvolvimento. In: MARTINS, P. E. M.; PIERANTI, O. P. (Orgs.). Estado e Gestão Pública: visões do Brasil contemporâneo. Reimpressão. São Paulo: Editora FGV, 2007.

SILVA, R. M. A. da. Entre o combate à seca e a convivência com - semiárido: transições paradigmáticas e sustentabilidade do desenvolvimento. 2006. Tese (Doutorado em Desenvolvimento Sustentável)- Centro de Desenvolvimento Sustentável, Universidade de Brasília, Brasília. 298 p.

TEIXEIRA, E. C. O papel das políticas públicas no desenvolvimento local e na transformação da realidade. Salvador, Bahia: AATR, 2002.

TOLEDO, E. de la G. Neoliberalismo e Estado. In: LAURELL, A. C. (Org.). Estado e Políticas Sociais no Neoliberalismo. Trad. Rodrigo Leon Contrera. 3. ed. São Paulo: Cortez, 2002.

VILAR FILHO, M. D. Secas e Ciclos - Sinopse Analítica. In: FILHO, M. B. (Org.). Viabilização do Semi-Árido do Nordeste. Recife: Imip, 2011. p. $52-58$. 


\section{Siglas, termos e expressões}

\begin{tabular}{|c|c|}
\hline Abrabe & Associação Brasileira de Bebidas \\
\hline ANCEFN & $\begin{array}{l}\text { Academia Nacional de Ciencias Exactas, Fisicas y } \\
\text { Naturales (Argentina) }\end{array}$ \\
\hline Andifes & $\begin{array}{l}\text { Associação Nacional dos Dirigentes das Instituições } \\
\text { Federais de Ensino Superior }\end{array}$ \\
\hline AUIP & $\begin{array}{l}\text { Associação Universitária Iberoamericana de Pós- } \\
\text { Graduação }\end{array}$ \\
\hline BAM & $\begin{array}{l}\text { Instituto Federal de Pesquisas e Testes de Materiais } \\
\text { (Alemanha) }\end{array}$ \\
\hline CAp/Uerj & Instituto de Aplicação Fernando Rodrigues da Silveira \\
\hline Capes & $\begin{array}{l}\text { Coordenação de Aperfeiçoamento de Pessoal de Nivel } \\
\text { Superior }\end{array}$ \\
\hline CGEE & Centro de Gestão de Estudos Estratégicos \\
\hline CIB & $\begin{array}{l}\text { International Council for Research and Innovation in } \\
\text { Building and Construction }\end{array}$ \\
\hline Cieps & Centros Integrados de Educação Pública \\
\hline CNE & Conselho Nacional de Educação \\
\hline CNPq & $\begin{array}{l}\text { Conselho Nacional de Desenvolvimento Científico e } \\
\text { Tecnológico }\end{array}$ \\
\hline COFECUB & $\begin{array}{l}\text { Comitê Francês de Avaliação da Cooperação } \\
\text { Universitária com o Brasil }\end{array}$ \\
\hline Conaes & Comissão Nacional de Avaliação da Educação Superioı \\
\hline CONICET & $\begin{array}{l}\text { Conselho Nacional de Pesquisas Científicas e Técnicas } \\
\text { (Argentina) }\end{array}$ \\
\hline Coppe/UFRJ & $\begin{array}{l}\text { Instituto Alberto Luiz Coimbra de Pós-Graduação e } \\
\text { Pesquisa de Engenharia }\end{array}$ \\
\hline DED & Departamento de Educação \\
\hline DO & Denominação de Origem \\
\hline Embrapa & Empresa Brasileira ded Pesquisa Agropecuária \\
\hline ENBT & Escola Nacional de Botânica Tropical \\
\hline EHESS & Escola de Altos Estudos em Ciências Sociais (França) \\
\hline EPGE & Escola de Pós-Graduação em Economia \\
\hline ERC & European Research Council \\
\hline Esal & Escola Super \\
\hline
\end{tabular}




$\begin{array}{ll}\text { ESDI/Uerj } & \text { Escola Superior de Desenho Industrial } \\ \text { Fapergs } & \text { Fundação de Amparo à Pesquisa do Estado do Rio } \\ & \text { Grande do Sul } \\ \text { Faperj } & \text { Fundação Carlos Chagas Filho de Amparo à Pesquisa } \\ & \text { do Estado do Rio de Janeiro } \\ \text { Fapesc } & \text { Fundação de Amparo à Pesquisa do Estado de Santa } \\ & \text { Catarina } \\ \text { Fapesp } & \text { Fundação de Amparo à Pesquisa do Estado de São } \\ \text { FCT } & \text { Paulo } \\ \text { FEBF/Uerj } & \text { Fundação para a Ciência e a Tecnologia } \\ \text { FGV } & \text { Faculdade de Educação da Baixada Fluminense } \\ \text { Fiocruz } & \text { Fundação Getúlio Vargas } \\ \text { Fiperj } & \text { Fundação Oswaldo Cruz de Pesca do Estado do Rio de Janeiro } \\ \text { FMUSP } & \text { Faculdade de Medicina da USP } \\ \text { Fundaj } & \text { Fundação Joaquim Nabuco } \\ \text { Funpar } & \text { Fundação da Universidade Federal do Paraná } \\ \text { FURB } & \text { Universidade Regional de Blumenau } \\ \text { Gestec/Uneb } & \text { Mestrado Profissional em Gestão e Tecnologias } \\ & \text { Aplicadas à Educação } \\ \text { IBGE } & \text { Instituto Brasileiro de Geografia e Estatística } \\ \text { IBICT } & \text { Instituto Brasileiro de Informação em Ciência e } \\ \text { Ifpe } & \text { Tecnologia } \\ \text { IBMEC } & \text { Instituto Brasileiro de Mercado de Capitais } \\ \text { Ibri } & \text { Instituto Brasileiro de Relações Internacionais } \\ \text { IBYME } & \text { Instituto de Biología y Medicina Experimental } \\ \text { ICBA } & \text { Instituto Cultural Brasil Alemanha } \\ \text { ICSU } & \text { Conselho Internacional para a Ciência } \\ \text { ICTs } & \text { Institutos de Ciência e Tecnologia } \\ \text { IDCC } & \text { Instituto de Direito Constitucional e Cidadania } \\ \text { IDP } & \text { Instituto Brasiliense de Direito Público } \\ \text { IEN } & \text { Instituto de Engenharia Nuclear } \\ \text { IESALC } & \text { Instituto Internacional para la Educación Superior en } \\ & \text { América Latina y e/ Caribe } \\ \text { Instututi Federal de Educação, Ciência e Tecnologia } \\ \text { IFParnambucano }\end{array}$




\begin{tabular}{|c|c|}
\hline IGs & Indicações Geográficas \\
\hline IMA & Instituto Machado de Assis \\
\hline Imea & Instituto Mercosul de Estudos Avançados \\
\hline Impa & Instituto Nacional de Matemática Pura e Aplicada \\
\hline Inep & Instituto Nacional de Educação Profissional \\
\hline Inmetro & $\begin{array}{l}\text { Instituto Nacional de Metrologia Qualidade e } \\
\text { Tecnologia }\end{array}$ \\
\hline Inova & Agência de Inovação da Unicamp \\
\hline Inpa & Instituto Nacional de Pesquisas da Amazônia \\
\hline Inpe & Instituto Nacional de Pesquisas Espaciais \\
\hline Inpi & Instituto Nacional da Propriedade Industrial \\
\hline Insa & Instituto Nacional do Semiárido \\
\hline IP & Indicação de Procedência \\
\hline Ipen & Instituto de Pesquisas Energéticas e Nucleares \\
\hline IPT & Instituto de Pesquisas Tecnológicas \\
\hline ISPJAE & $\begin{array}{l}\text { Instituto Superior Politécnico "José Antonio } \\
\text { Echeverría" }\end{array}$ \\
\hline lussi & União Internacional para Estudo dos Insetos Sociais \\
\hline IVIC & Instituto Venezuelano de Investigações Científicas \\
\hline JBRJ & Jardim Botânico do Rio de Janeiro \\
\hline Lamel & Laboratório Multidisciplinar de Estudos da Linguagem \\
\hline LIPD & Laboratório de Investigação da Prática Docente \\
\hline LNA & Laboratório Nacional de Astrofísica \\
\hline LPI & Lei da Propriedade Industrial \\
\hline MAST & Museu de Astronomia e Ciências Afins \\
\hline Mackenzie & Universidaded Presbiteriana Mackenzie \\
\hline MBA & Master Business Administration \\
\hline MES & Ministério da Educação Superior de Cuba \\
\hline MP & Mestrado Profissional \\
\hline MPE & Mestrado Profissional em Educação \\
\hline MRE & Ministério das Relações Exteriores \\
\hline NASA & Agência Aeroespacial Norte-Americana \\
\hline NIT & Núcleo de Inovação Tecnológica \\
\hline OEA & Organização dos Estados Americanos \\
\hline ONG ASAS & Grupo de Assistência Solidária e Ação Social \\
\hline ONU & Organização das Nações Unidas \\
\hline PB & Português Brasileiro \\
\hline PE & Português Europeu \\
\hline
\end{tabular}




\begin{tabular}{|c|c|}
\hline PI & Propriedade Intelectual \\
\hline Pintec & Pesquisa de Inovação \\
\hline PLE & Português como Língua Estrangeira \\
\hline Pnud & Programa das Nações Unidas para o Desenvolvimento \\
\hline PPGDL & $\begin{array}{l}\text { Programa de Pós-Graduação Interdisciplinar em } \\
\text { Desenvolvimento Local }\end{array}$ \\
\hline Profletras & Programa de Mestrado Profissional em Letras \\
\hline Profmat & $\begin{array}{l}\text { Programa de Mestrado Profissional em Matemática } \\
\text { em Rede Nacional }\end{array}$ \\
\hline PUB/PR & Pontifícia Universidade Católica do Paraná \\
\hline PUC-Rio & Pontifícia Universidade Católica do Rio de Janeiro \\
\hline PUCRS & Pontifícia Universidade Católica do Rio Grande do Sul \\
\hline RBPI & Revista Brasileira de Política Internacional \\
\hline RPI & Revista da Propriedade Industrial \\
\hline RTDC & Revista Trimestral de Direito Civil \\
\hline Sebrae/PE & Serviço de Apoio às Micro e Pequenas Empresas \\
\hline Sanepar & Companhia de Saneamento do Paraná \\
\hline TCM & Trabalho de Conclusão do Mestrado \\
\hline TRIPs & Trade-Related Aspects of Intellectual Property Rights \\
\hline TWAS & $\begin{array}{l}\text { Academia de Ciências para o Mundo em } \\
\text { Desenvolvimento }\end{array}$ \\
\hline UAB & Sistema Universidade Aberta do Brasil \\
\hline UCLA & Universidade da Califórnia \\
\hline UCSal & Universidade Católica de Salvador \\
\hline UCP & Universidade Católica de Petrópolis \\
\hline UCS & Universidade de Caxias do Sul \\
\hline Uem & Universidade Estadual de Maringá \\
\hline Uerj & Universidade do Estado do Rio de Janeiro \\
\hline UFABC & Universidade Federal do ABC \\
\hline Ufba & Universidade Federal da Bahia \\
\hline UFC & Universidade Federal do Ceará \\
\hline UFCG & Universidade Federal de Campina Grande \\
\hline UFF & Universidade Federal Fluminense \\
\hline UFFS & Universidade Federal da Fronteira Sul \\
\hline UFG & Universidade Federal de Goiás \\
\hline UFLA & Universidade Federal de Lavras \\
\hline UFMG & Universidade Federal de Minas de Gerais \\
\hline UFPB & Universidade Federal da Paraíba \\
\hline
\end{tabular}




\begin{tabular}{|c|c|}
\hline UFPE & Universidade Federal de Pernambuco \\
\hline UFPR & Universidade Federal do Paraná \\
\hline UFRGS & Universidade Federal do Rio Grande do Sul \\
\hline UFRN & Universidade Federal do Rio Grabnde do Norte \\
\hline UFRJ & Universidade Federal do Rio de Janeiro \\
\hline UFRR & Universidade Federal de Roraima \\
\hline UFS & Universidade Federal de Sergipe \\
\hline UFSC & Universidade Federal de Santa Catarina \\
\hline Ufscar & Universidade Federal de São Carlos \\
\hline UFTM & Universidade Federal de Mato Grosso \\
\hline UFU & Universidade Federal de Uberlândia \\
\hline UFV & Universidade Federal de Viçosa \\
\hline Unam & Universidade Nacional Autônoma do México \\
\hline UnB & Universidade de Brasília \\
\hline Uneb & Universidade do Estado da Bahia \\
\hline Unesc & Universidade do Extremo Sul Catarinense \\
\hline UniCEUB & Centro Universitário de Brasília \\
\hline UNESCO & $\begin{array}{l}\text { Organização das Nações Unidas para a Educação, a } \\
\text { Ciência e a Cultura }\end{array}$ \\
\hline Unicuritiba & Centro Universitário Curitiba \\
\hline Unesp & Universidade Estadual Paulista \\
\hline Unicamp & Universidade de Campinas \\
\hline Unifae & Centro Universitário Franciscano do Paraná \\
\hline Unifesp & Universidade Federal de São Paulo \\
\hline Unila & Universidade Federal da Integração Latino-Americana \\
\hline Unilegis & Universidade do Legislativo Brasileiro \\
\hline Uninove & Universidade Nove de Julho \\
\hline Unisuam & Centro Universitário Augusto Motta \\
\hline Unir & Universidade Federal de Rondônia \\
\hline Univali & Universidade do Vale do Itajaí \\
\hline Univille & Universidade da Região de Joinville \\
\hline UNU & Universidade das Nações Unidas \\
\hline UP & Universidade Positivo \\
\hline USP & Universidade de São Paulo \\
\hline
\end{tabular}




\section{Conselho Editorial}

\section{Editora}

\section{Daniella Maria Barandier Toscano}

Doutoranda em Relações Internacionais pela Universidade de Brasília (UnB), é analista em Ciência e Tecnologia da Coordenação de Aperfeiçoamento de Pessoal de Nível Superior (Capes).

\section{Membros do Conselho}

\section{Ana Lúcia Gazzola}

PhD em Letras (Literatura Comparada) pela Universidade da Carolina do Norte, Chapel Hill, Estados Unidos, 1978. Pós-doutorado pela Universidade de Duke, 1994. Reitora da UFMG, 2002 a 2006. Presidente da Associação Nacional dos Dirigentes das Instituições Federais de Ensino Superior (Andifes), na gestão 2004/2005. Diretora do Instituto Internacional de Educação Superior para a América Latina e o Caribe (lesalc), da Unesco, de 2006 a 2008. Professora emérita da UFMG. Atualmente, é secretária de Estado de Educação de Minas Gerais.

\section{Carlos Ivan Simonsen Leal}

Presidente da Fundação Getúlio Vargas desde 2000. Possui graduação em Engenharia Civil pela Escola de Engenharia da Universidade Federal do Rio de Janeiro (UFRJ), 1980, e em Economia Matemática pelo Instituto de Matemática Pura e Aplicada (Impa), 1982. Doutorado em Economia pela Universidade de Princeton, Estados Unidos, 1986. Professor da Escola de Pós-Graduação em Economia (EPGE) da Fundação Getúlio Vargas, 1986. Diretor do FGV Business, 1992 a 1994. Diretor geral da EPGE, 1994 a 1997. Vice-presidente da FGV, 1997 a 2000. Foi condecorado, em 2002, com o título de Grão Cruz da Ordem Nacional do Mérito Científico, concedida pela Presidência da República, por suas contribuições à ciência e à tecnologia.

\section{Carlos Roberto Jamil Cury}

Doutor em Educação pela Pontifícia Universidade Católica de São Paulo, 1979. Pós-doutorado pela Faculdade de Direito da Universidade de São Paulo, 1994; pela Sorbonne (Paris IV), 1995; e pela Escola de Altos Estudos em Ciências Sociais (EHESS), França, 1999. Professor emérito da UFMG. Professor adjunto da Pontifícia Universidade Católica de Minas Gerais. Foi presidente da Capes, membro do Conselho Nacional de Educação e pró-reitor adjunto de pesquisa da UFMG.

\section{César Zucco}

Licenciado em Química pela FURB, 1974. Mestrado em Físico-Química pela UFSC, 1979. Doutorado em Química Orgânica pela Universidade de Glasgow, Escócia, 1982. Pós-doutorado em Físico-Química Orgânica pela Universidade da Califórnia, Santa Bárbara, 1988 a 1989. Professor titular do Departamento de Química da UFSC. Coordenador do Programa de PósGraduação em Química da UFSC. Próreitor de Pesquisa e Pós-Graduação da UFSC. Membro e coordenador do CA/CNPq 


\section{Conselho Editorial}

de Química e membro da Comissão de Avaliação dos Programas de Pós-Graduação de Química (Capes). Presidente da Sociedade Brasileira de Química e diretor de Pesquisa Científica e Tecnológica da Fapesc.

\section{Eloi de Souza Garcia}

Doutorado em Biologia Molecular pela Escola Paulista de Medicina, atual Universidade Federal de São Paulo, 1978. Pós-doutorado pelo Laboratório de Doenças Parasitárias, Estados Unidos, 1979 a 1980, e pelo Instituto Max-Planck de Bioquímica, Munique, Alemanha, 1985 a 1988. Vice-presidente, de 1991 a 1996, e presidente da Fundação Oswaldo Cruz, de 1997 a 2001. Presidente do Joint Coordenating Board do Task Force on Operation Research on Chagas Disease da Organização Mundial da Saúde, Genebra, 1995 a 1997. Subsecretário do Ministério de
Ciência e Tecnologia, 2001 a 2002. Diretor do Instituto Brasileiro para Informação em Ciência e Tecnologia (IBICT), 2002. Assessor da presidência e vice-diretor da Diretoria de Programas do Inmetro.

\section{Robert Evan Verhine}

PhD em Educação pela Universitat Hamburg. Atualmente, professor associado III e PróReitor de Ensino de Pós-Graduação da Universidade Federal da Bahia (Ufba). Representante da área de Educação junto à Capes, de 2005 a 2007, e presidente do Comitê Assessor para a Área de Educação do CNPq, 1998. Pró-reitor de Pesquisa e Pós-Graduação da Ufba (1995-1998). Membro do Comitê Multidisciplinar da Articulação do CNPq, 2005 a 2007. Membro do Comitê Editorial do CNPq, 2007 a 2010. 


\section{Comitê Científico}

\section{Abílio Afonso Baeta Neves}

Doutorado em Ciência Política pela Westfälische Wilhelms-Universität, Münster, Alemanha, 1981. Diretor presidente e científico da Fundação de Amparo à Pesquisa do Estado do Rio Grande do Sul (Fapergs), 1987 a 1990. Presidente do Instituto Cultural Brasil Alemanha (ICBA). Pró-reitor de Pesquisa e Pós-Graduação da UFRGS, 1988 a 1992. Presidente do Fórum Nacional de Pró-Reitores de Pesquisa e PósGraduação, 1991. Secretário de Educação Superior do Ministério da Educação, 1996 a 2000. Presidente da Fundação Coordenação de Aperfeiçoamento de Pessoal de Nível Superior (Capes), 1995 a 2002. Coordenador do Diálogo Brasil-Alemanha (Diálogo entre Sociedades Civis).

\section{Adalberto Luis Val}

Recebeu em 2004 a Ordem Nacional do Mérito Científico na classe Comendador. Em 2005, foi eleito membro titular da Academia Brasileira de Ciências. Em maio de 2006, assumiu a direção do Instituto Nacional de Pesquisas da Amazônia. Em 2007, foi eleito conselheiro da Sociedade Brasileira para o Progresso da Ciência e vice-presidente da Academia Brasileira de Ciências para a Região Norte. Em 2008, recebeu a Grande Ordem do Mérito Legislativo do estado do Amazonas. Possui mais de 100 trabalhos publicados em importantes periódicos internacionais. Orientou mais de uma centena de estudantes, desde a iniciação científica até o pós-doutorado.

\section{Amado Luiz Cervo}

Doutorado em História pela Universidade de Strasbourg, 1970. Oficial da Ordem de Rio Branco, 1992. Chefe do Departamento de História da Universidade de Brasília (UnB), 1995 a 1997. Atualmente, é professor titular da UnB, emérito, e professor do Instituto Rio Branco, do Ministério das Relações Exteriores (MRE). Tem experiência na área de História, com ênfase em História das Relações Internacionais. Atua principalmente nos seguintes temas: Relações Internacionais Contemporâneas e Política Exterior do Brasil.

\section{Antônio Carlos Moraes Lessa}

Professor associado II e coordenador de Pós-Graduação do Instituto de Relações Internacionais da Universidade de Brasília (UnB). Doutorado em História (área de concentração de História das Relações Internacionais) pela Universidade de Brasília, 2000. Estudos pós-doutorais pela Université de Strasbourg, França, 2008 a 2009. Editor da Revista Brasileira de Política Internacional (RBPI) e do Meridiano 47 - Boletim de Análise de Conjuntura em Relações Internacionais.

\section{Benamy Turkienicz}

PhD pela Arkitektur S. da Chalmers University of Technology, 1982. Professor titular da Faculdade de Arquitetura, do Programa de Pesquisa e Pós-Graduação em Arquitetura e do Programa de PósGraduação em Design da Universidade 


\section{Comitê Científico}

Federal do Rio Grande do Sul. Professor convidado do mestrado em Urbanismo do Programa Master Erasmus Mundus (Comunidade Europeia). Coordenador do Núcleo de Tecnologia Urbana da UFRGS, que congrega laboratórios de pesquisa da UFRGS e UFSC em diferentes áreas do conhecimento (Arquitetura, Ciências da Computação, Conforto Ambiental, Design, Ecologia, Engenharia Hidráulica, Geotecnia, Sistemas de Tráfego e Transportes e Urbanismo).

\section{Boaventura de Sousa Santos}

Doutorado em Sociologia do Direito pela Universidade de Yale (1973). Professor Catedrático da Faculdade de Economia da Universidade de Coimbra, Distinguished Legal Scholar da Universidade de Wisconsin-Madison e Global Legal Scholar da Universidade de Warwick. É também diretor do Centro de Estudos Sociais da Universidade de Coimbra. Coordena projetos no European Research Council (ERC), na União Europeia, Bélgica, e na Fundação para a Ciência e a Tecnologia (FCT), em Portugal. Foi coordenador de projetos no Ministério dos Negócios Estrangeiros em Portugal e no Ministério da Justiça no Brasil.

\section{Eduardo H. Charreau}

Presidente da Academia Nacional de Ciências Exatas, Físicas e Naturais da Argentina. Professor titular de Bioquímica na Escola de Ciências da Universidade de Buenos Aires. Diretor do Instituto de Biologia e Medicina Experimental (IBYME-CONICET). É membro da Academia de Ciências para o Mundo em Desenvolvimento (TWAS), da Academia Nacional de Medicina da Argentina e da Academia de Ciências Médicas de Córdoba. Desenvolveu seu pós-doutorado no Fogarty International Center do National Institutes of Health, nos Estados Unidos. Foi professor instrutor, assistente, associado e titular do Departamento de Bioquímica da Universidade de Buenos Aires, entre 1960 e 2006. Foi presidente do Conselho Nacional de Pesquisa da Argentina (CONICET), de 2002 a 2008.

\section{Fabio Rubio Scarano}

PhD em Ecologia pela Universidade de Saint Andrews, Escócia, 1992. Realizou estágios pós-doutorais no Jardim Botânico do Rio de Janeiro, 1992, na Universidade Tecnológica de Darmstadt, Alemanha, 2002, e na Universidade de Minnesota, Estados Unidos, 2003. Diretor de Pesquisas Científicas do Jardim Botânico do Rio de Janeiro, 2007 a 2009. É professor associado da Universidade Federal do Rio de Janeiro desde 1993, coordenador da área de Ecologia na Capes desde 2005 e diretor executivo da Conservação Internacional do Brasil.

\section{Hebe Vessuri}

PhD em Antropologia Social pela Universidade de Oxford, Reino Unido. Recebeu, em 2006, 0 Prêmio Nacional de Ciências da Venezuela. Pesquisadora emérita do Programa Nacional de Promoção do Pesquisador. Editora geral da revista Educación Superior y Sociedad da UNESCO/IESALC. Preside o Conselho 


\section{Comitê Científico}

de Governo da Universidade das Nações Unidas (UNU), Tóquio. Integra o Comitê de Pacificação e de Revisão Científica do Conselho Mundial da Ciência (ICSU) e o Comitê de Ética da Ciência da Unesco. Atualmente, dirige o Departamento de Estudos da Ciência do Instituto Venezuelano de Investigações Científicas (IVIC), Caracas.

\section{Heitor Gurgulino de Souza}

Bacharelado e licenciatura em Matemática pela Universidade Presbiteriana Mackenzie (1950), especialização em Física Nuclear pela Kansas University (1957), especialização em Física Nuclear - Laboratório Van de Graaff - pela Universidade de São Paulo (1959). Foi reitor da Universidade do Legislativo Brasileiro (Unilegis); da Universidade das Nações Unidas (UNU), da Organização das Nações Unidas (ONU); e da Universidade de São Carlos (Ufscar). Foi ainda professor de Física na Ufscar; chefe de unidade de Ensino e Pesquisa na Organização dos Estados Americanos (OEA); e professor titular na Universidade Estadual Paulista (Unesp, Rio Claro).

\section{Helgio Henrique Casses Trindade}

Doutor em Ciência Política pelo Institut d’Etudes Politiques de Paris, Université de Paris I, Panthéon-Sorbonne, 1971. Professor titular aposentado de Ciência Política da Universidade Federal do Rio Grande do Sul (UFRGS). Foi reitor da UFRGS e presidente da Comissão Nacional de Avaliação (Conaes); conselheiro da Câmara de Educação Superior do Conselho Nacional de Educação (CNE) e membro da Academia Brasileira de Ciências; e reitor da Universidade Federal da Integração Latino-Americana (Unila).

\section{Jair de Jesus Mari}

Possui graduação em Medicina pela Fundação Universitária do ABC, 1977. Doutor em Epidemiologia Psiquiátrica pela Universidade de Londres, 1986. Defendeu a Livre Docência no Departamento de Psiquiatria da Unifesp em 1995. Professor titular do Departamento de Psiquiatria da Universidade Federal de São Paulo. Professor honorário do Instituto de Psiquiatria, do King's College, Universidade de Londres. É o atual coordenador do Programa de PósGraduação do Departamento de Psiquiatria da Unifesp e coordenador do Instituto do Milênio do CNPq Saúde Mental e Violência. Atua principalmente nos seguintes temas: esquizofrenia, epidemiologia psiquiátrica, violência, cienciometria, avaliação de serviços de saúde mental, transtornos psiquiátricos na atenção primária e revisão sistemática.

\section{Jesús Julio Castro Lamas}

Doutor em Ciências Técnicas, Cuba, 1987. Professor titular do Instituto Superior Politécnico “José Antonio Echeverría” (ISPJAE) desde 1985. Diretor de Educação da Pós-Graduação do Ministério da Educação Superior de Cuba e do Escritório Regional da Associação Universitária Ibero-Americana de Pós-Graduação para o Caribe e a América Central (AUIP), desde janeiro de 2000. Vicereitor do ISPJAE, 1997 a 1999. Diretor de Relações Internacionais do ISPJAE, 1993 


\section{Comitê Científico}

a 1997. Diretor do Instituto de Geofísica e Astronomia, 1987 a 1989. Chefe do Departamento de Matemática do ISPJAE, 1978 a 1986. Especialista do Programa das Nações Unidas para o Desenvolvimento (Pnud) em Moçambique, 1991 a 1992, e membro do Comitê Internacional do Programa Alban (Bolsas de Estudo de Alto Nível para a América Latina), da Comissão Europeia, 2001 a 2007.

\section{Liovando Marciano da Costa}

Possui graduação em Agronomia pela Universidade Federal de Viçosa, 1971. Mestre em Fitotecnia (Produção Vegetal) pela Universidade Federal de Viçosa, 1973. Doutor em Soil Science, University of Missouri System, 1979. Pró-reitor de Pesquisa e Pós-Graduação da UFV de 1998 a 2000. Coordenador de Ciências Agrárias I da Capes por dois mandatos, de 1997 a 2001. De agosto 2006 a novembro de 2008 , foi diretor do novo Campus UFV de Rio Paranaíba, onde foram criados os cursos de Agronomia, Administração, Ciência de Alimentos e Sistemas de Informação. Coordenador Geral da Central de Experimentação Pesquisa e Extensão do Triângulo Mineiro em Capinópolis, Minas Gerais, de 2005 a 2008. Atualmente, é professor titular da Universidade Federal de Viçosa.

\section{Lourival Domingos Possani Postay}

Doutorado em Biofísica na Faculté des Sciences D'Orsay, da Université Paris, França (1970). Pesquisa na Rockefeller University, em Nova lorque, Estados Unidos (1971-1973); bolsista da Fundação Alexander Humboldt no Max Planck Institute de Dortmund, na Alemanha (1980-1982); professor associado do Baylor College of Medicine, em Houston, Estados Unidos (1986-1987). Pesquisador internacional da Fundação Howard Hughes Medical Institute, nos Estados Unidos (1991-2001). Pesquisador emérito do Instituto de Biotecnologia na Universidad Nacional Autónoma de México (19742012), membro da Academia de Ciencias de América Latina (1999) e Doutor Honoris Causa pela Universidade de Debrecen, na Hungria (2005).

\section{Luiz Edson Fachin}

Graduação em Direito pela Universidade Federal do Paraná (1980) e mestrado e doutorado em Direito pela Pontifícia Universidade Católica de São Paulo (1986 e 1991, respectivamente). Pós-doutorado no Canadá. Pesquisador convidado do Instituto Max Planck, em Hamburgo, na Alemanha. Professor visitante do King's College, em Londres. É professor titular de Direito Civil da Faculdade de Direito da UFPR; advogado; e membro de corpo editorial da Revista: de Derecho Comparado (Buenos Aires, Argentina); do Instituto de Direito Constitucional e Cidadania (IDCC); Crítica Jurídica (UNAM, México); Júris, da Faculdade de Direito da Fundação Armando Alvares Penteado (SP); Trimestral de Direito Civil (RTDC, Rio de Janeiro); e Brasileira de Direito Civil Constitucional e Relações de Consumo. 


\section{Comitê Científico}

\section{Pedro Dolabella Portella}

Doutor em Ciências dos Materiais e Engenharia pela Universidade de Erlangen-Nuremberg, 1984. Professor assistente da Pontifícia Universidade Católica do Rio de Janeiro (PUC-Rio), 1984 a 1987. Pesquisador do Instituto Federal de Pesquisas de Materiais e Teste (BAM), 1987 a 1992. Atualmente, é chefe do Departamento de Engenharia de Materiais do BAM e membro do Conselho Editorial do Praktische Metallographie and Journal of Failure Analysis and Prevention.

\section{Pierre Jaisson}

Doutorado em Ciências Naturais pela Universidade Pierre-et-Marie Curie, Paris 6, França, 1975. Reitor da Universidade Paris 13, 1982 a 1987. Presidente da União Internacional para Estudo dos Insetos Sociais (lussi), 1990 a 1994. Fundador e presidente do Programa Ecos de Colaboração Científica entre a França e seis países da América hispanófona, 1992 a 2001. Presidente do Grupo de Consultores Científicos do Programa Alfa (América Latina Formação Acadêmica), da Comissão Europeia, 2000 a 2005. Vice-reitor de Pesquisa e PósGraduação da Universidade Paris 13, 2003 a 2008. Professor titular de Etologia da Universidade Paris 13. Presidente do Cofecub desde 2006. Recebeu, em 2001, o grão de Oficial da Ordem Nacional da Legião de Honra.

\section{Thomas Maack}

Formou-se em Medicina pela Faculdade de Medicina da Universidade de São Paulo, 1961. Doutor em Medicina (Nefrologia) pela Escola Paulista de Medicina, 1980. É professor titular nos departamentos de Fisiologia e Medicina da Weill Medical College of Cornell University, Nova York, Estados Unidos, e professor emérito da FMUSP. Membro da Academia Brasileira de Ciências. As suas áreas principais de pesquisa são: transporte e metabolismo renal de proteínas e polipeptídeos e biologia dos peptídeos natriuréticos e seus receptores. Em sua bibliografia, constam mais de 100 artigos originais - que receberam mais de 7 mil citações na literatura científica.

\section{Vahan Agopyan}

Doutorado em Engenharia Civil pela University of London King's College, 1982. Diretor da Escola Politécnica da USP. Diretor presidente do IPT. Coordenador de Ciência e Tecnologia da Secretaria do Desenvolvimento do estado de São Paulo. Atualmente, é professor titular de Materiais e Componentes de Construção Civil da Escola Politécnica da Universidade de São Paulo; pró-reitor de Pós-Graduação da USP; vice-presidente do CIB (International Council for Research and Innovation in Building and Construction); membro do Conselho Superior da Fundação de Amparo à Pesquisa do Estado de São Paulo (Fapesp); presidente do Conselho de Superior do Instituto de Pesquisas Energéticas e Nucleares (Ipen). 


\section{Comissão de análise e julgamento de artigos sobre a pós-graduação e o desenvolvimento sustentável}

\section{Arlindo Philippi Junior}

Coordenador da Comissão de análise e julgamento de artigos sobre a pós-graduação e o desenvolvimento sustentável. Doutor em Saúde Pública e livre docente em Política e Gestão Ambiental pela Universidade de São Paulo. É professor titular da Universidade de São Paulo, pesquisador da Fapesp e do CNPq. Exerce atualmente a função de próreitor adjunto de Pós-Graduação da USP e presidente da Comissão de Pós-Graduação da Faculdade de Saúde Pública.

\section{Jose Carlos Barbieri}

Doutor em Administração pela Fundação Getúlio Vargas de São Paulo, Escola de Administração de Empresas de São Paulo (FGV/Eaesp). É professor adjunto do Departamento de Administração da Produção e Operações da Escola da FGV/ Eaesp e desenvolve pesquisas nas áreas de gestão ambiental e da inovação.

\section{Maria do Carmo Martins Sobral}

Coordenadora da Comissão de análise e julgamento de artigos sobre a pósgraduação e o desenvolvimento sustentável. Doutora em Planejamento Ambiental pela Universidade Técnica de Berlim, Alemanha, e com pós-doutorado no Instituto de Tecnologia Ambiental da mesma universidade. Professora do Departamento de Engenharia Civil da Universidade Federal de Pernambuco (UFPE) e membro do Conselho TécnicoCientífico de Ensino Superior (CTC-ES) da Capes como coordenadora da Área de
Ciências Ambientais da Capes.

\section{Maria do Socorro Bezerra de Araújo}

Doutora em Agronomia (Solos e Nutrição de Plantas) pela Universidade Federal de Viçosa e com pós-doutorado pela School of Environmental Sciences, University of Guelph, Canadá. É professora da Universidade Federal de Pernambuco, editora-chefe da Revista Brasileira de Geografia Física, coordenadora do curso de doutorado do Programa de Pós-Graduação em Desenvolvimento e Meio Ambiente e líder do grupo de pesquisa Geoambiental.

\section{Patricia de Sá Freire}

Doutora em Engenharia e Gestão do Conhecimento pela Universidade Federal de Santa Catariana (UFSC). É professora da Universidade do Extremo Sul Catarinense (Unesc) e membro do Instituto de Gestão de Mudanças Estratégicas e Pessoas (IGMEP). Entre suas linhas de pesquisa estão a sustentabilidade e a inovação organizacional.

\section{Ricardo Ojima}

Doutor em Demografia pela Universidade Estadual de Campinas (Unicamp), com pós-doutorado no Núcleo de Estudos de População (Nepo/Unicamp). É professor da Universidade Federal do Rio Grande do Norte (UFRN) e desenvolve pesquisas acerca dos temas: urbanização, mobilidade espacial da população, teoria demográfica e mudanças ambientais. 


\section{Wanda Maria Risso Günther}

DoutoradoemSaúdePública pela Universidade de São Paulo. É professora da Faculdade de Saúde Pública da USP, coordenadora do Programa de Mestrado Profissional Ambiente, Saúde e Sustentabilidade da USP e coordenadora do Laboratório de Mudanças Climáticas da FSP/USP e do Programa USP Recicla-FSP/USP. Atua nos temas: saneamento ambiental, resíduos sólidos, gestão ambiental, saúde ambiental, políticas públicas e educação ambiental. 


\section{Pareceristas ad hoc}

Ademir Antonio Cazzella (UFSC)

Adriana Marques Rossetto (UFSC)

Alexandre Biz (UFPR)

Alexandre de Oliveira e Aguiar (Uninove)

Alfredo Homma (Embrapa)

Ana Lúcia Britto (UFRJ)

Andrea Vieira Zanella (UFSC)

Antoninho Caron (FAE)

Antonio Ribeiro de Almeida Junior (USP)

Carlos Ricardo Rossetto (Univali)

Cláudio José de Araújo Mota (UFRJ)

Cleverson Vitorio Andreoli (Sanepar)

Clóvis Cavalcanti (Fundaj)

Danilo Marcondes de Souza Filho (PUC-Rio)

Deise Luiza da Silva Ferraz (UFMG)

Doris Sayago (UnB)

Edvania Torres Aguiar Gomes (UFPe)

Elaine Nolasco (UnB)

Emanuel Maia (Unir)

Fernando S. P. Sant'Anna (UFSC)

Gilberto Montibeller (Unesc)

Gilda Collet Bruna (Mackenzie)

Gilmar Sidnei Erzinger (Univille)

Gilson Lima (UFPe)

Hilka Vier Machado (UEM)

Hugo Vieira (IFPB)

João Eustáquio de Lima (UFV)

Joel Souto-Maior (UFPB)

Jorge Tenório (USP)

José Edmilson de Souza-Lima (UniCuritiba)

José Henrique de Faria (UFPR)

José Salatiel Pires (UFSCAR)

Klaus Frey (UFABC)

Leila da Costa Ferreira (Unicamp)

Luiz Panhoca (UFPR)

Marcelo D. Varella (UniCEUB)
Marcia Ribeiro (UFCG)

Marco Aurélio da Silva Carvalho Filho (UP)

Marcos José Salgado Vital (UFRR)

Maria Camerina Maroja Limeira (UFPB)

Maria Geralda de Almeida (UFG)

Maria José Nascimento Soares (UFS)

Marialva Tomio Dreher (Furb)

Maurício Dziedzic (UP)

Michèle Sato (UFTM)

Nemésio Salvador (UFSCAR)

Noemia Bohn (Furb)

Patrícia Lizi de Oliveira Maggi (UP)

Paulo Opuszka (UniCuritiba)

Paulo Roberto Janissek (UP)

Pedro Roberto Jacobi (USP)

Rafael Rodrigo Mueller (Unesc)

Rainer Randolph (UFRJ)

Renata $\mathrm{M}^{\text {a }}$ Caminha Mendes de O. Carvalho (IFPE)

Roberto Lamberts (UFSC)

Roberto Pacheco (UFSC)

Selma Simões de Castro (UFG)

Sérgio Roberto Martins (UFFS)

Sergio Amadeu da Silveira (UFABC)

Sergio Augustin (UCS)

Severino Soares Agra Filho (Ufba)

Silvio Figueiredo (UFPa)

Sonia Valle Walter Borges de Oliveira (USP)

Sylmara Lopes F. Gonçalves Dias (USP)

Valter Lúcio de Pádua (UFMG)

Victor Novick (UCP)

Vladimir Passos de Freitas (PUC/PR)

Wagner Costa Ribeiro (USP)

Washington Sousa (UFRN)

William Rauen (UP) 


\section{MINISTÉRIO DA EDUCAÇ̃̃O \\ COORDENAÇÃO DE APERFEIÇOAMENTO DE PESSOAL DE NÍVEL SUPERIOR - CAPES}

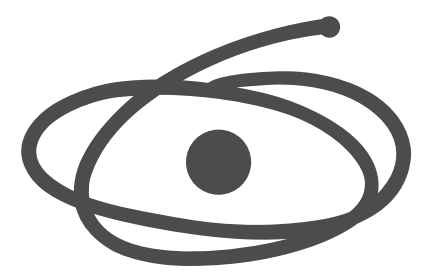

C A P E S

Portaria $n^{\circ}$ 56, de 9 de maio de 2013.

O PRESIDENTE DA COORDENAÇÃO DE APERFEIÇOAMENTO DE PESSOAL DE NIVEL SUPERIOR - CAPES, no uso das atribuições que the são conferidas pelo Estatuto aprovado pelo Decreto $n^{\circ}$ - 7.692, de 2 de março de 2012, resolve:

Art. $1^{\circ}$ Designar para compor a Comissão de análise e julgamento de artigos sobre a pós-graduação e o desenvolvimento sustentável que serão publicados pela Capes na Revista Brasileira de Pós-Graduação (RBPG), os seguintes professores:

a) Arlindo Philippi Junior, Universidade de São Paulo (coordenador);

b) Maria do Carmo Martins Sobral, Universidade Federal de Pernambuco (coordenadora);

c) Jose Carlos Barbieri, Fundação Getúlio Vargas/São Paulo;

d) Maria do Socorro Bezerra de Araújo, Universidade Federal de Pernambuco;

e) Patricia de Sá Freire, Universidade do Extremo Sul Catarinense;

f) Ricardo Ojima, Universidade Federal do Rio Grande do Norte;

g) Wanda Maria Risso Günther, Universidade de São Paulo.

Parágrafo único. A Comissão terá a assessoria técnica da seguinte servidora da Capes:

a) Daniella Maria Barandier Toscano

Art. $2^{\circ}$ - Esta portaria entra em vigor na data de sua assinatura.

JORGE ALMEIDA GUIMARÃES

PUBLICADA NO DOU DE 13/05/13 SEÇÃO 2 PÁG. 11 


\section{Normas para Colaborações}

1. A Revista Brasileira de Pós-Graduação (RBPG) é voltada à divulgação de estudos, experiências e debates sobre a pós-graduação. Nos termos de seu regulamento, a RBPG publica contribuições inéditas de autores brasileiros e estrangeiros em forma de estudos e pesquisas de caráter acadêmico-científico (Estudos), opiniões (Debates) e experiências inovadoras (Experiências) relativos à educação superior, ciência e tecnologia e cooperação internacional que tenham como foco a pós-graduação, seus programas e desafios.

2. Editada pela Capes, a Revista Brasileira de Pós-Graduação não traduz o pensamento de qualquer entidade governamental, acolhendo trabalhos que permitam a comunidade ampliar o debate e partilhar experiências sobre as questões atuais e os desafios da pós-graduação.

3. O envio espontâneo de qualquer colaboração implica automaticamente a cessão dos direitos autorais a Capes.

4. A publicação de artigos não é remunerada, sendo permitida sua reprodução total ou parcial, desde que citada a fonte.

5. Os artigos assinados serão de responsabilidade exclusiva de seus autores, não refletindo, necessariamente, a opinião da Capes.

6. A critério do Conselho Editorial poderão ser aceitas e publicadas colaborações em língua estrangeira.

7. Serão remetidos a cada autor 5 (cinco) exemplares da edição, em que for publicada sua colaboração.

\section{Envio de colaborações}

8. As colaborações para as seções Estudos, Debates e Experiências devem ser enviadas para a Capes, para o e-mail rbpg@capes.gov.br, sob a forma de documento anexado à mensagem, respeitadas as orientações de apresentação e formatação fixadas, contendo obrigatoriamente: 
- Mensagem: a) título do trabalho; b) indicação de seção (Estudos, Debates ou Experiências); c) dados pessoais e acadêmicos do autor ou autores (nome, endereço para correspondência, telefone, endereço eletrônico, mais alta titulação acadêmica, instituição de vinculação e área de atuação) na ordem a figurar na publicação;

- Documento a ser anexado, sem menção de autoria e em formato Word: a) título do trabalho em português, inglês e espanhol; b) resumo em até 10 (dez) linhas e 3 a 6 palavras-chave, formadas por expressões de no máximo 3 termos; c) "abstract" em até 10 (dez) linhas e 3 a 6 "keywords" formadas por expressões de no máximo 3 termos; d) "resumen” em até 10 (dez) linhas e 3 a 6 "palabras clave” formadas por expressões de no máximo 3 termos; e) texto do artigo ou matéria, incluindo notas e referências, tabelas, quadros e gráficos quando utilizados, com a formatação estabelecida.

9. Não serão aceitas colaborações que não atendam às normas fixadas.

10. Os textos destinados às seções Estudos e Experiências devem ser digitados em fonte Times News Roman, corpo 12, espaço simples, e não podem exceder 50 mil caracteres, incluindo os espaços e consideradas as referências bibliográficas, citações ou notas, quadros, gráficos, mapas, etc. Os textos a serem publicados na seção Debates devem obedecer ao limite de 35 mil caracteres, considerados os espaços e demais inserções. Títulos e subtítulos devem ter mesma fonte e estar em negrito.

11. Os quadros, gráficos, tabelas, mapas e imagens devem ser numerados e titulados, apresentar indicação das fontes correspondentes e estar em preto e branco.

12. Todas as referências bibliográficas devem obedecer às normas atualizadas da ABNT (Associação Brasileira de Normas Técnicas), de acordo com os exemplos abaixo:

\section{Para livros:}

TERRA, J.C.C. Gestão do conhecimento: o grande desafio empresarial - uma abordagem baseada na aprendizagem e na criatividade. São Paulo: Negócio Editora, 2000.

Obs.: o título de livro ou de artigos pode ser em itálico. 


\section{Para artigos:}

MARTINS, R.P.; ARAUJO-LIMA, C. O desenvolvimento da Ecologia no Brasil. Infocapes, v. 8, n. 2, 2000, p. 81-85.

\section{Para teses acadêmicas:}

VASCONCELOS, M. C. L. Cooperação universidade/empresa na pós-graduação: contribuição para a aprendizagem, a gestão do conhecimento e a inovação na indústria mineira. Tese de doutorado. Escola de Ciência da Informação, 2000, Universidade Federal de Minas Gerais.

\section{Para documentos eletrônicos:}

VARGAS, R. T. Reflexões sobre a integração universidade-empresa estudo de caso: mestrado profissionalizante. Disponível em:

<http:www.geocities.com/anpgbr/mestp.html>.

Acesso em: 30 set. 2001.

13. As menções a autores, no corpo do texto, devem subordinar-se à forma: autor (data) ou (AUTOR, data).

\section{Exemplo: Fischer (2002); (PEREIRA e FONSECA, 1997, p. 120).}

14. As notas de rodapé devem ser exclusivamente explicativas e numeradas, ter no máximo 3 linhas, com fonte Times News Roman, corpo 10, espaço simples. As notas com mais de 3 linhas deverão ser apresentadas ao fim do texto, antes das referências bibliográficas, com a numeração de sequência “i”.

15. As referências bibliográficas devem conter exclusivamente os autores e os textos citados no trabalho e ser apresentadas ao final do texto, em ordem alfabética.

\section{Seleção de matérias}

16. As colaborações para as seções Estudos, Debates e Experiências serão submetidas a, pelo menos, dois membros do Comitê Científico da revista ou colaboradores ad hoc por eles indicados, sem identificação do autor. 
17. Se a matéria for aceita para publicação, a revista permitese introduzir ajustes de formatação. Modificações de estrutura ou de conteúdo, sugeridas pelos pareceristas, somente serão incorporadas mediante concordância dos autores.

18. Artigos aprovados com restrições serão encaminhados para reformulação por parte dos autores. Nesses casos, a comissão editorial se reserva o direito de recusar o artigo, caso as alterações neles introduzidas não atendam às solicitações feitas pelos pareceristas.

19. O autor deve ser comunicado do recebimento da sua colaboração no prazo de até oito dias. 